25 BiAS - Bible in Africa Studies

Exploring Religion in Africa 4

Ezra Chitando, Masiiwa Ragies Gunda \& Lovemore Togarasei (Eds.)

\title{
RELIGION AND DEVELOPMENT IN AFRICA
}

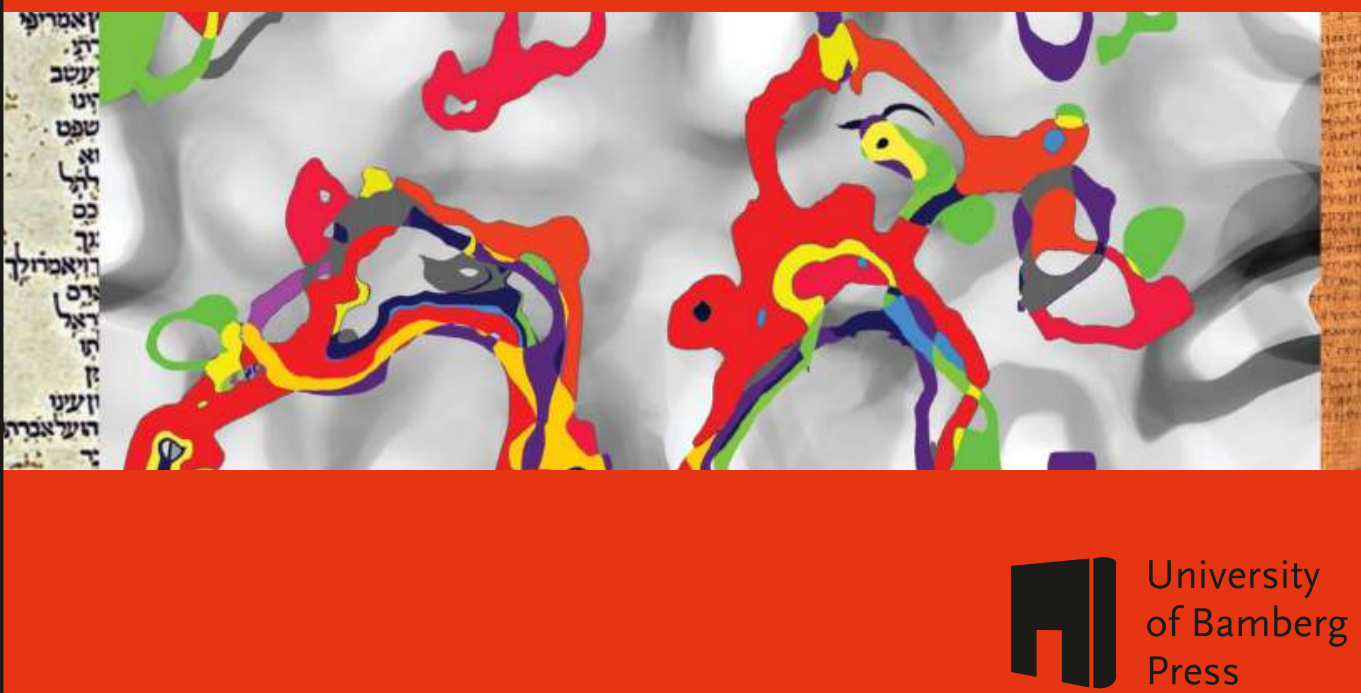


25 Bible in Africa Studies

Études sur la Bible en Afrique

Bibel-in-Afrika-Studien

Exploring Religion in Africa 4 
Bible in Africa Studies

Études sur la Bible en Afrique

Bibel-in-Afrika-Studien

Volume 25

edited by

Joachim Kügler, Lovemore Togarasei, Masiiwa R. Gunda

In cooperation with

Ezra Chitando and Nisbert Taringa ( $(\dagger)$

Exploring Religion in Africa 4

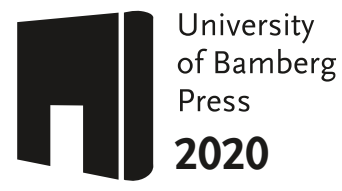




\section{Religion and Development in Africa}

edited by

Ezra Chitando, Masiiwa Ragies Gunda

\& Lovemore Togarasei

In cooperation with

Joachim Kügler

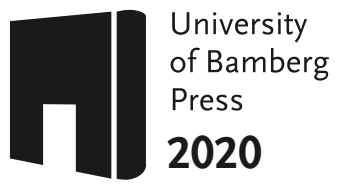


Bibliographische Information der Deutschen Nationalbibliothek

Die Deutsche Nationalbibliothek verzeichnet diese Publikation in der Deutschen Nationalbibliographie; detaillierte bibliographische Informationen sind im Internet über http://dnb.d-nb.de abrufbar.

Gedruckt mit Unterstützung von

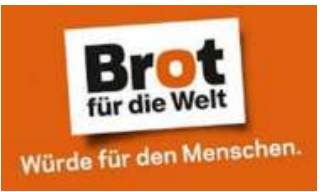

Dieses Werk ist als freie Onlineversion über das Forschungsinformationssystem (FIS; https://fis.uni-bamberg.de) der Universität Bamberg erreichbar. Das Werk - ausgenommen Cover und Zitate - steht unter der CC-Lizenz CCBY.

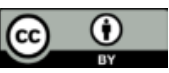

Lizenzvertrag: Creative Commons Namensnennung 4.0

http://creativecommons.org/licenses/by/4.0

Herstellung und Druck: docupoint Magdeburg Umschlaggestaltung: University of Bamberg Press Umschlaggraphik und Deco-Graphiken: (c) Joachim Kügler Text-Formatierung: Irene Loch, Joachim Kügler

(C) University of Bamberg Press, Bamberg 2020

http://www.uni-bamberg.de/ubp

ISSN: $2190-4944$

ISBN: 978-3-86309-735-6 (Druckausgabe) eISBN: 978-3-86309-736-3 (Online-Ausgabe)

URN: urn:nbn:de:bvb:473-irb-477591

DOI: http://dx.doi.org/10.20378/irb-47759 


\title{
Dedication
}

\author{
In \\ Memory of \\ Our Founding ERA Co-editor \\ And Beloved Colleague \\ Nisbert T. Taringa \\ $11^{\text {th }}$ May $1964-10^{\text {th }}$ January 2020 \\ He left us much too early! \\ $\dashv$ R.I.P. ト
}




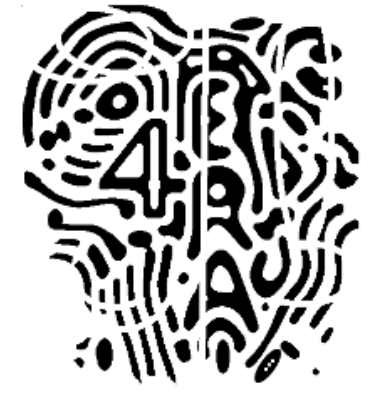




\section{ACKNOWLEDGEMENTS}

This volume emerged out of the three editors' engagement with development in Africa on both academic and practical fronts. Ezra Chitando is particularly grateful to colleagues within the World Council of Churches (WCC) Ecumenical HIV \& AIDS Initiatives and Advocacy (EHAIA) for ongoing reflections on religion and development.

The editors acknowledge the commitment of the contributors who persevered to see the project to its logical conclusion.

We are grateful to Prof. Dr. Joachim Kügler for providing a conducive environment and platform at the University of Bamberg for debating the role the Bible and religion play in Africa.

Support from the Alexander von Humboldt Foundation enabled the editors to work on the project during research stays in Germany and is hereby saluted.

We dedicate this volume to the memory of our late colleague Prof Dr Nisbert Taringa, a founding co-editor and important author of the BiAS series including the subseries ERA. With his volume Towards an African-Christian Environmental Ethic (BiAS 13), he was a pioneer to bring the topic of religion, ecology and development into our series. We will always be grateful for his support and all his creative contributions! 


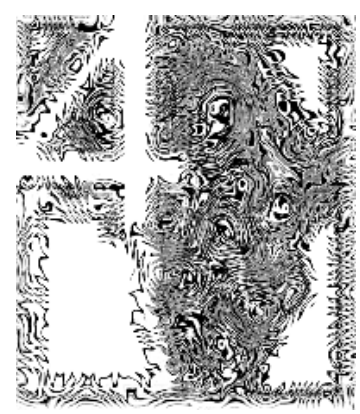




\section{TABLE OF CONTENTS}

Introduction: Religion and Development in Africa......................................... 13

Ezra Chitando, Masiiwa R. Gunda a Lovemore Togarasei

Rethinking Development in Africa and the Role of Religion

Masiiwa Ragies Gunda

Religion and Development in Africa - A Critical Analysis

Chammah J. Kaunda a Sokfa France John

Religion and Development in Sub-Saharan Africa

Tarisayi Andrea Chimuka

Gender in Religion and Development Research.

Loreen Maseno

Youth, Religion, and Development in Africa

Susan Mbula Kilonzo

Sacralization of the Humanitarian Space: Faith Based Organizations,

Mission-Aid and Development in Africa

Hassan J. Ndzovu

Africa's Muslim Non-Governmental Organizations:

Competitive Charities, Altruistic Allies?

Muhammed Haron

Religion's Contribution to Development: The Case of African Hindus

in Chana

Abamfo Ofori Atiemo

Sowing the Seeds of Dhamma - Buddhism and Development in Africa 185

Elizabeth Pulane Motswapong

Religion and Economic Justice: Jewish Migrants and the

Making of Zambia 203

Lilian C. Siwila, Nelly Mwale, Chita Joseph Chita

Navigating Imbusa in Public Spheres: Bemba Married Women,

Work and Agency

Mutale Mulenga Kaunda 
The Interplay Between Religion and Development in Ghana Samuel Awuah-Nyamekye

Religion and Development in Uganda

Andrew David Omona a Uzziah Maate Kiriaghe

Religion and Civic Participation in Post-Colonial Kenya Julius Gathogo

Religion and Development in Swaziland 305

Sonene Nyawo

Church-State Relations and the Political-Economy of Land and Development in Rhodesia

Petronella Munhenzva

Sustainable Peace and Development:

Peace Building by the Ecumenical Church Leaders Forum

Lindiwe Princess Maseko

The Seventh-day Adventist Church and Development in Northern Zimbabwe.

Blessing Nyahuma

Implications of the Wisdom Stored in Shona Oral Literature for

Sustainable Economic Development in Zimbabwe

Beatrice Taringa

The Potential of Ubuntu Values for a

Sustainable Ethic of the Environment and Development

Nisbert T. Taringa (i')

The Bible as a Resource for Development in Africa:

Ten Considerations for Liberating Readings 401

Ezra Chitando

"Liberating the Word" - One African Feminist Reading of Matt 23

Musa W. Dube

Resurrection as 'Corrective' Creation 445

Lovemore Togarasei a Sidney K. Berman 
Biblical Texts, Ecology, and Sustainable Development ..

Francis Machingura Q Ishanesu Gusha

The Bible, Sexuality Challenges and the Development Agenda

Canisius Mwandayi

Notes on Authors and Editors

491

The BiAS book series at University of Bamberg Press. 499 


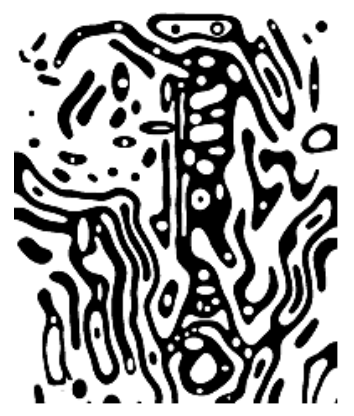




\title{
Introduction: Religion and Development in Africa
}

\author{
Ezra Chitando, Masiiwa R. Gunda Q Lovemore Togarasei
}

\section{Development?}

What is development? Who defines it? On top of which mountain can anyone stand and proclaim one community/country "developed", while characterising another community/country as "un/under-developed"? What, if any, is the relationship between religion and development in Africa? Does religion contribute to development or underdevelopment in Africa? These and related questions elicit quite charged reactions in African studies, development studies, political science and related fields. Africa's own history, including the memory of marginalisation, slavery and exploitation by global powers ensures that virtually every discussion on development is characterised by a lot of emotions and conflicting views. This is because the majority of the citizens of Africa continue to struggle to access the basics in life.

The inspirational stories of Africa's billionaires (Bishop 2017) do not silence the groans of pain and exclusion by the majority of its citizens. However, the debates do not end at the definitional stage. They continue in relation to the causes and proposed ways forward. If, for example, it is conceded that Africa is not yet at the stage of development that the continent would want to be at, how do we account for this reality? Put bluntly, who or what is responsible for Africa's current position in relation to development? Is this down to a single factor, or must we explore multiple reasons for Africa's current status? What must Africa do in order to place itself on a more positive growth trajectory? What is the role, if any, of external players in Africa's ongoing quest for self-improvement in the different areas of life, including the economic, social, political, spiritual and others? In particular, what is the place of religion in such a scheme? Is religion a help or a hindrance to development (Mtata 2013) in Africa? If we understand holistic community development to be the "betterment of people groups in all areas of life" (Mbogo 2015: 159), what is the role of religion in this quest? We bring out the turn to religion here because there is a growing consensus that religion (and the values it brings), is critical to the search for sustainable development. Thus: 
The world's religious traditions, despite their profound differences, all coalesce around a multi-religious vision of "shared well-being." Such a vision puts the dignity of the human being at the center of the common good. Such a vision puts the golden rule, to treat others as they would be treated, as the guiding moral precept. Such a vision enjoins us to help the poor, the hungry, and the suffering, for they have the greatest needs, and possess the same human dignity as everybody else. And such a vision, finally, must recognize that moral virtues are not simply inherited, or present, or lackingthese virtues are cultivated by societies that hold the dignity of the individual as the highest purpose. If we are silent in the face of suffering, we are degrading our own virtues (Annett et al 2017:2).

\section{Religion and Development in Africa: Setting the Context}

Whereas the field of religion and development has been gaining a lot of scholarly attention, particularly among some scholars in Europe and North America (see for example, the chapter by Kaunda in this volume, Tomalin 2018; Bompani 2018; Feener and Fountain 2018; Hassan 2017; Swart \& Nell 2016; Deneulin \& Rakodi 2011; and Haynes 2007), (we as) African scholars have not been as actively involved. Equally, there has been the realisation that there is need to study the impact of religion, even in societies that have at some point in their history instituted and actively enforced policies that do not promote religion, such as China (Xinping et al 2018). Thus:

From the mid-1990s development organizations are increasingly aware of the important role that culture and religion (as part of culture) may play for enhancing economic development. This awareness is noticeable in various reports by the World Bank and the activities of the World Faiths Development Dialogue (de Jong 2008:2).

In order to place the discourse on religion and development globally into its proper context, it is important to acknowledge that after many years in which religion was exiled from the development discourse, it has found its way back forcefully. This is both a result of the realisation that particularly faith-based organisations (FBOs) have been actively involved in the response to HIV \& AIDS since the 1990s (Cochrane, Schmid \& Cutts 2011; Kurian 2016), and that globally, religion has reasserted itself in the public sphere/space (Habermas 2006). Of course, as many scholars operating within the global South would contend, religion has never left the public space in the first instance! For example, such a towering figure in African politics as Nelson Mandela, was influenced by his spirituality 
(Cruywagen 2016). Further, religion remains important as a frame of reference in Africa and will remain critical to the continent's development (Ellis \& Ter Haar 2004).

Among others, scholars such as (in no particular order) Kathrine Marshall and Marisa Van Saanen (2007), Gerrie ter Haar (2011), Emma Tomalin (2013 and 2015), Barbara Bompani (2010), Kate Meagher (2009), Erica Bornstein (2003) and Carole Rakodi (2013) have contributed towards clarifying the interface between religion and development. They have challenged the notion that religion is of no consequence to the discourse and practice of development. It is striking to note that these are women scholars of religion. While more space is required to reflect on how this gender dimension might have shaped each one of these scholars' interest in the theme, we can surmise that women scholars are less interested in religion as a system and have been keen to focus on the practical expression of religion. This has seen more women scholars taking a lead in reflections on religion and development.

The growing awareness of the significance of religion to development has seen a number of publications addressing the theme of religion in international development. However, the discourse is still framed in the context of the global North assisting Africa to develop. Thus, for example, Hoffstaedter (2011) has reflected on Australian faith-based organisations, while Solhjell (2012) has examined the place of faith and religion in Norwegian development aid. This theme has been taken up by the German Federal Ministry for Economic Cooperation and Development (BMZ) (2016) who have sought to capture the voices of different religions on sustainable development. This theme has also been pursued by the Swedish Council for Mission (Odén 2016), as well as by Le Moigne \& Juul Petersen (2016) in relation to Denmark's development cooperation. Shifting the reflections to the United States of America (USA), Heist \& Cnaan (2016) have examined the literature on faith-based organizations and international development. We are convinced that the role of religion in international development requires further reflection than we can undertake in this section.

Overall, however, Africa does not feature prominently in discourses on religion and development. This is consistent with the continued marginalisation of Africa in global/human affairs. A small incident in Europe/North America receives consistent coverage from the 'global' media networks, while a massive disaster in Africa, for example, does not even get a passing reference. It would appear that the world still struggles to 
accept that Africa is, in fact, part of the world. In the specific case of religion and development, however, the fact that the fledgling discipline has been dominated by Western scholars has meant that data from Africa is/are often absent. Thus:

Closely related to methodological challenges, the geographical and other coverage of empirical studies varies significantly. The literature has addressed developed nations, especially Western democracies, to a much greater extent than developing countries. With a few exceptions (such as HIV and gender in relation to religion), research on religion has focused far more on traditions that are dominant in the Western world, such as mainstream Christianity and Islam than on other traditions. There are almost no studies on small fundamentalist, but increasingly influential, groups such as the Jehovah's Witnesses, evangelists, and born-again Christians. In terms of methods, experimental studies are mainly conducted with (sic) Western students and thus draw on largely unrepresentative subject pools (Basedau, Gobien \& Prediger 2017:36).

It is, therefore, important for (us as) African scholars to take up research and publication on religion and development in Africa. The cautionary note sounded by Oduyoye \& Kanyoro (1992:1) to African women, namely, that "as long as men and foreign researchers remain the authorities on culture, rituals, and religion, African women will continue to be spoken of as if they were dead," applies to all African scholars of religion. As long as foreign researchers remain the authorities on religion and development in Africa, (we) Africans will continue to be spoken of as if they (we) were dead. Thus, (we) African scholars of religion have the responsibility of researching, publishing and teaching on religion and development.

\section{Who Speaks on Africa and for Africa? Facing Africa's Development Challenges Realistically}

The massive Routledge Handbook of African Development (Binns, Linch \& Nel 2018) carries reflections mostly by "friends of Africa" and a few by African scholars. Similarly, in volumes on religion and development (see for example, Tomalin 2015 and Clarke 2013), African voices are barely audible. The dominant challenge is that there seems to be a widely held assumption that African scholars' expertise is limited to African Traditional Religions (in Africa and the Diaspora). Thus, African scholars tend to be overlooked in discourses on religion and development (as well as many/all 
other themes!). Alternatively, when there is a conscious decision to include African scholars in discussions that involve Africa, often it is (nonblack) South African scholars who tend to be preferred.

The political question, therefore, is: who speaks on and for Africa? Thus, "Who has the locus standi, and who, as a scholar, has the right to pronounce on Africa's development? How is our perspective affected by the way in which we are situated as 'insiders' and 'outsiders?'” (Beckman \& Adeoti 2006:2). These are abiding questions and Zimbabwe's former president, the late Robert G. Mugabe, gained massive popularity across Africa (and the global South), by consistently demanding that (we) Africans must be allowed to speak for ourselves.

Whereas radical African scholars are well within their rights for proposing that "development" in Africa be measured using different indices, we are more cautious in our approach. We, Africans, do deserve the good things in life: good health, low infant mortality rate, long life, prosperity, freedom from disease and stress, security, harmonious relations among humans, including with the created order, and others. After all, the concept of salvation in African Traditional Religions is this-worldly and the salvific goods sought after are predominantly material (Maimela 1985). Whereas there is merit to celebrate the fact that "poor" Africans are often classified amongst the world's happiest citizens, we contend that it is possible to retain the happiness alongside achieving an improved quality of life. The notion of there being a contradiction between the pursuit of happiness and human flourishing is a false dilemma, we contend. We are aware, for example, that Bhutan has challenged the emphasis on growth-based economic development by coining Gross National Happiness (GNH) as the key factor (Yangka et al 2018). We concede that Africa could glean insights from such an approach, while ensuring that the basics in life for all citizens are met.

The Africa Capacity Building Foundation has identified some of the major challenges that the continent is facing. These include sustainable development, human development and poverty reduction; HIV \& AIDS; governance; conflict prevention and management, and post-conflict reconstruction; human capital flight; private sector development; revitalising universities and research institutions; regional cooperation and integration; trade flow and trade negotiation; resource flow to Africa; external debt burden; information revolution and scientific and technological progress; as well as globalization (Sako \& Igiogio 2002:3-14). 


\section{Critiques and Divergent Readings of Development in Africa}

'Development' is not an innocent or universally accepted term; it has many dimensions (Alkire 2010), although we have utilised it liberally in this chapter. It is laden with historical, ideological, political, racial and other assumptions. Mawere (2017) questions the reliance on theories of development from the global North and challenges African scholars to generate more contextually sensitive approaches to development. Various chapters in this volume revisit the applicability of the concept of development that is often used by different actors on the continent and beyond. In particular, politicians, non-governmental organisations (NGOs) personnel and representatives of multilateral institutions have made 'development' central to their discourses.

However, the concept has attracted considerable criticism. Thus, there have been critiques of the emphasis on economic development at the expense of other dimensions of development (Mbogo 2015), as well as determined efforts to highlight the abiding influence of neo-colonialism (Langan 2018). Others have sought to expose the negative consequences of aid (Moyo 2009) and an interrogation of why Africa is poor (Mbetwa 2018). Writing on religion and development, Conradie (2016), a South African scholar, proposes an abandonment of the term and proposes that it be replaced by the concept of maturation.

On his part, Matunhu (2011) provides an informative critique of modernization and dependency theories, alongside showing how these have failed to catapult the continent on to the next level. Obeng-Doom (2013:170) challenges the dominant approaches to measuring economic development in Africa. For him, African people, “...live a purposeful and happy life." Similarly, contributors to the volume, Globalization and Sustainable Development in Africa (House-Soremekun \& Falola 2011), challenge the celebration of globalization. They contend that globalization is not bringing glad tidings to Africa, but that it has deepened Africa's exclusion and exploitation. This has generated considerable debate over the dependency theory (Kufakurinani et al 2019).

There are also debates over the financing of sustainable development in Africa (Efobi \& Asongu 2018), the contribution of innovation and regional integration to Africa's development (Oloruntoba \& Muchie 2019), as well as the role and status of indigenous knowledge systems in Africa's development (Mawere 2014). While global financial institutions have invested in promoting "good governance and poverty reduction," Adejumobi (2006) has exposed the assumptions behind such approaches and calls for 
a fundamental transformation of the skewed global economic system. Writing with particular reference to South Africa, Du Toit (2018) has called for the decolonising of development within the FBO sector. She maintains that the FBO sector is still dominated by white people.

Other African intellectuals critique the focus on poverty, pain, disease and death in narratives on and images of Africa. This is what the Nigerian author and activist Chimamanda Ngozi Adichie (2009) characterised as, "the danger of a single story." The "single story" in discourses on development in Africa is of Africa as a desperately poor, diseased and dying continent. It has not helped that the HIV \& AIDS epidemic has been so devastating on the continent. Africa is then projected as a hopeless continent characterized by never ending strife, crazy and blood thirsty dictators, corrupt and inefficient systems and so on. These images are worsened by some Western donor agencies that are keen to generate support by circulating images of African children in dire circumstances. However, this

...presents Africa as in effect infantilised and requiring the assistance from the West. Indeed, it is this focus that feeds perceptions of Africans as passive, needy, unable, or indeed, unwilling to help themselves. Implicit in the understanding of these images is the sense of Africans as inferior or as... 'under-developed' (Young 2012:19).

Running through these contributions by African intellectuals is the conviction that "development" in Africa must be "home grown," (Obijiofor 2001), that is, Africa must rely on ideas and finances from within the continent and resist formulations from beyond the continent, and that the continent has adequate resources to launch on its own, independent and sovereign development trajectory. There is also a painful struggle against stereotypes of Africa as 'under-developed.' Although we find many of these ideas appealing at the level of ideology and political correctness, but, as indicated above, we remain wary of the subtle suggestion that there is a sense in which Africans are "differently human." Further, while acknowledging the bias in the images of Africa, there is an urgent need for us as Africans to practically demonstrate our commitment to the dignity of all citizens by ensuring that they are treated with dignity and respect, even before we demand the same from "outsiders. " Issues such as upholding the full rights of children and women, refraining from abusing rural citizens for political gain, respecting pedestrians in African urban spaces, eliminating corporal punishment and others must be addressed as a matter of urgency. 
As we have indicated above, we are persuaded that "development" in Africa should deliver the good things in life that all humans in other parts of the world desire and yearn for: a high quality of life, postponement of death, leading full and fulfilling lives, freedom from oppression, disease and hunger, having functional and efficient systems, generating and deploying technology for ease of living and other processes. African people's lives, and capabilities must be enabled to flourish, without threats to their security (Chitando \& Tarusarira 2019). Thus, Africa's challenges with development have as much to do with what others have done to us, as they have to do with what we have done and are doing to ourselves.

\section{Religion and Development in Africa by African Scholars: Mapping the Terrain of an Emerging Field}

African scholars of religion have largely been absent from critiques of development in general, or reflections on religion and development in particular (as stated in an earlier section). It would, however, be misleading to suggest that African scholars have not been researching, publishing and teaching on religion and development at all. In fact, African scholars have been publishing on the theme, approaching it from diverse angles. An early intervention by Van Nierkerk (Jr) (1986) drew attention to the important role of religion in development in Africa. Although not an African, Petersen (1989) edited a volume that focused on religion, development and African identity and carried essays by some African scholars. Phiri, Ross \& Cox (1996) edited a volume on Christianity, development, peace and reconstruction, with particular focus on Africa. Since then, there has been a steady rise in reflections on religion and development in Africa. It is not possible to exhaust these reflections within the context of this introduction. Agbiji \& Swart (2015) explored the influence of religion in the struggle against poverty and corruption in Africa, more broadly understood, while the journal, HTS Theological Studies dedicated a volume $(72,4,2016)$ to reflections on religion and development in Africa. Further, a number of scholars have provided valuable descriptions of or reflections on religion and development within particular national contexts. Some of the countries covered include Tanzania (Mhina 2007), Ghana (AmengaEtego 2011 and Awuah-Nyamkye 2012), Nigeria (Ogbonnaya 2012), Zambia (Mwale 2013), South Africa (Atiemo 2017) and Botswana (Mangope 2007). 
A longer narrative is required in order to do justice to the contributions of African scholars to the discourse on religion and development. For the purposes of this chapter, we deemed it strategic to mention the contributions through making references to some of the major themes that have been pursued by various African scholars. It should be noted, however, that there is considerable overlap among the different themes. For example, although the themes of advocacy and gender can be separated at the conceptual level, in practice a lot of the advocacy done by religious groups in Africa has been around the issue of women's rights. Further, each one of these themes merits a separate study if we are to do justice to it. Therefore, our descriptions below should be regarded as exploratory or indicative of the major issues in religion and development in Africa, but not an exhaustive analysis of each theme.

Some of the key themes that have dominated reflections on religion and development in Africa include reflections on the theology of development (Mutongu 2016), the contribution of religion to specific African countries, for example, Nigeria (Ikechi-Ekpendu, Audu \& Ekpendu 2016), biblical studies and corruption in Africa (Abogunrin 2007), as well as the contributions by African scholars to the African-American and African collaborative publishing project, Religion and Poverty (Paris 2009).

One of the major themes in publications on religion and development in Africa is the focus on faith-based organisations (FBOs). In particular, FBOs became quite popular for their role in responding to HIV \& AIDS in Africa. It is not possible to undertake an exhaustive analysis of the role of FBOs in responding to HIV and other issues (particularly health) within the confines of this chapter. However, we would like to underscore the point that FBOs have been critical to the overall response to the epidemic in Africa, having been a challenge/stumbling block in the early years (Togarasei, Mmolai \& Nkomazana 2011; Okaalet 2002). This is one theme that has received considerable attention from African scholars. Apart from examining the role of FBOs in relation to HIV \& AIDS, other scholars have reviewed the contributions of FBOs to development in specific countries (Olarinmoye 2012; Odumosu, Olaniyi \& Alonge 2009; and Magezi 2017), or within a specific sector, such as the quest for social justice (Aguti 2017).

Alongside the theme of FBOs and development, African scholars have also invested in reflecting on religion, gender and development. Although the Circle of Concerned African Women Theologians (hereafter, the Circle) has not used the term development frequently in its publications, 
there is merit in regarding its work as being situated in the discourse on religion and development. Thus, by exposing harmful religio-cultural practices that prevent women and girls from expressing themselves fully and maximizing on their capabilities, Circle publications seek to mobilise faith communities to become more proactive in supporting women and girls (see for example, Maponda 2016 and Labeodan 2016).

Other themes in the broad field of religion and development in Africa include governance (Jere \& Magezi 2018), advocacy (Tinkasiimire 2013 and Simbi 2013), the environment and climate change (Ottuh 2018), human rights (Nyangweso 2016), peace building (Musana 2013; Opongo \& Kaulemu 2014) and Pentecostalism, particularly the prosperity gospel or message (see for example, some chapters in Togarasei 2018; Wariboko 2012, Obadare 2016 and Mapuranga 2018). There have been divergent views regarding the capacity of the teachings on prosperity in African Pentecostalism to propel development in Africa. Some scholars are sceptical, while others have become more optimistic that the Pentecostal message of prosperity does have potential to galvanise Africans towards higher productivity.

Whereas the Christian missionary enterprise has been critiqued by many African intellectuals, there are others, such as Nkomazana (1998), who contend that there were some individuals who had the right motivation. The role of churches in poverty alleviation (Ayiemba et al 2015 and Sekhaulelo 2014) has also attracted the attention of some African scholars.

Although more themes could be explored, we are hopeful that the examples provided above do capture some of the more salient themes in the discourse on religion and development. We observe that the dominant focus has been on Christianity/churches/church-affiliated FBOs or FBOs that were inspired by churches. Thus, one would be forgiven for imagining that all or most of the development work done by religions in Africa has been from the perspective of Christianity. Although some scholars do focus on Islam and development (Sounaye 2012), or religions that tend to receive less attention, such as Rastafari (Sibanda 2012), the bulk of the literature is on Christianity (and, to a less extent, Islam). While this volume has sought to address this imbalance by including chapters on other religions, we do concede that Christianity continues to dominate in subSaharan Africa.

Second, we have noted that there are multiple and diverse definitions of development that have been deployed by scholars. Thus, for some, development includes interventions that are meant to alleviate poverty, while 
for others it can be seen in investing in human capital and setting up infrastructure. Others approach development from the perspective of the values that religions instil in their adherents. These include the ethic of hard work and honesty that enable transparency and good governance.

Third, there is an uneven spread in terms of the countries covered. The impact of colonial policies and attitudes towards religious studies is felt in terms of scholarship on religion and development in Africa. Scholars from the Anglophone regions of the continent have tended to be more visible, with Nigeria, Ghana, Kenya and South Africa enjoying greater coverage. In addition, countries such as Uganda, Zimbabwe and Botswana have also been covered. This reflects the status of religious studies as an academic discipline in these countries (Chitando 2008). Thus, there is less work on religion and development in the Lusophone countries, as well as French-speaking Central and North Africa.

Fourth, unlike in the global North where it has been the established scholars or development practitioners who have contributed to the emerging field, in Africa it is mainly the younger researchers who are making the contribution. Older scholars have largely been seized with the perennial issue of religion and culture. The presence of younger scholars within the field in Africa, however, is a promising sign that the field can be expanded and strengthened, going forward.

Fifth, there is an emerging interest in the positive role of African Traditional/Indigenous Religions in the quest for development (see, among others, Alolo 2007). Whereas the dominant approach by missionaries and some arm-chair anthropologists as well as colonialists was to condemn African Traditional/Indigenous Religions, some African scholars have sought to reflect on the positive contribution of the same to development. Thus, scholars have been keen to demonstrate how African Traditional/Indigenous Religions are not retrogressive but rather progressive and making contributions to sustainable development.

\section{A Note on the Ambivalence of Religion in the Context of Development in Africa}

It is tempting to be overly celebratory and positive when reflecting on religion and development in Africa. Given the fact that religion has been neglected in studies on development in Africa, it is understandable that the "discovery" of religion often results in scholars concentrating on the positive contributions of religion to development. Indeed, we concede that 
this current volume is dominated by the optimistic perspective. However, it is critical to acknowledge that "...religion works in Africa for good and for ill and that understanding its functioning is essential to harnessing and benefiting from its potential" (Orobator 2018:xix).

Religious diversity in Africa, particularly the rush for souls between Christianity and Islam, has caused some governments in Africa to shift resources from development to security (Negussie 2018:3). Thus, it is important for scholars to be more cautious when reflecting on the interface between religion and development in Africa. Whereas there has been a worrying neglect of religion in discourses of development in Africa, the danger is real that the pendulum could swing to the other extreme of overrating the role of religion in development in Africa. Thus:

It is now widely accepted that the spread of religion could be a double-edged sword. On the one hand, it could facilitate economic development through the concomitant process of evangelism, religious liberty, mass education, mass printing, and support to civil society organizations, which in turn contribute to the entrenchment of democratic institutions and the rule of law. On the other hand, religious intransigence or polarization could undermine development by side-lining the importance of secular (western) education and also by promoting a culture of violence and terrorism (Kodila-Tedika \& Agbor 2013:2).

There is the danger of religion being appropriated and deployed to cause terror, alongside the ideological/political manipulation of religion (Kaunda 2018). Religion has also been implicated in cases of violence against women (Batchelor 2013), against children (Togarasei 2014), against people with disability (Kabue, Amanze \& Landman 2016), as well as against sexual minorities (Chitando \& Van Klinken 2016; Gunda 2010) in Africa (and, for the avoidance of doubt, just about everywhere else). Religion, we admit, has not always been good news to people on the margins. Throughout history, there have been moments where those with power have interpreted sacred texts and traditions to entrench themselves, while intensifying the marginalisation of others. On his part, the President of Rwanda at the time of writing, Paul Kagame, was reported as having ordered the closing down of a sizeable number of churches and mosques, insisting that there were too many and that their leaders did not have the necessary training (Kiunguyu 2018). Consequently, he felt that having too many religious institutions was inimical to development.

It is, therefore, critical to be always mindful of the "ambivalence of the Sacred" (Appleby 2000), namely, the capacity of religion to work for both progressive causes, as well as for retrogressive ones. Reflecting on the 
churches in Lesotho, Letsie (2015) highlights how the Roman Catholic Church and the Lesotho Evangelical Church were previously part of the political upheavals in the country, before contributing towards the quest for peace and healing. Similarly, while Boko Haram has offered a particular reading of Islam in its terror campaign in northern Nigeria, Muslim clerics are a critical factor in mobilising against this terrorist group. By providing an alternative (and, in our eyes, correct) reading of Islam, the Muslim clerics are vital in the battle for hearts and minds (Olojo 2017).

Overall, we concede that religion has not always been good news for people in Africa (and elsewhere). Therefore, our focus on religion and development should not be read as suggesting that we are willing to overlook the divisive and negative role of religion in African society. We readily acknowledge the "anti-development" capacity in religion but are convinced that there is need to invest more on its "pro-development" dimensions within this volume.

\section{Chapters in this Volume}

The chapters in this book are arranged thematically, with the first five chapters making conceptual reflections on religion and development. In the opening chapter, Masiiwa R. Gunda provides a reflection on the notion of development in the context of Africa, with special focus on Zimbabwe. Using Christianity, but with the hope that what applies to Christianity is also applicable to other religious traditions, Gunda strives to answer the following questions: What is development? What is the role of religion in the quest for development? Can religion contribute positively to the development of African societies?

In Chapter 2, Chammah J. Kaunda and Sokfa F. John critically review selected literature on religion and development in Africa. They examine the religious features and coverage of this literature, as well as the conception and coverage of development. In Chapter 3, Tarisayi A. Chimuka continues with the conceptual reflections on religion and development by examining the role of religion in development. Responding to the mischievious attitude displayed mostly by politicians that religion is a private and personal affair, Chimuka looks at both the positive and negative contributions of religion to development. In Chapter 4, Loreen Maseno reflects on the intersections of religion and development with a special focus on gender inquiries. She seeks to establish what feminist 
epistemology and methodology can contribute toward religion and development research. The conceptual reflections chapters then end with Chapter 5 in which Susan M. Kilonzo discusses religion and youth participation in Africa. Looking at both the negative and positive contributions of religion to development, Kilonzo examines how the youth are affected. Chapters 6-11 address the theme of religion and development with reference to specific religious traditions found in Africa, particularly those less referred to in discourses on religion and development. In Chapter 6 Hassan J. Ndzovu reflects on the rise and institutionalization of an independent civil society reflected in the massive spread of FBOs since the 1980s and ranging from Christian FBOs to Islamic oriented FBOs. The chapter focuses on the interface of religion and development networks, raising broader questions about how religious institutions balance between the two notions of mission and aid while offering services and undertaking development. Chapter 7 by Muhammed Haron addresses Muslim NGOs. Like Ndzovu, Haron questions whether Muslim NGOs (and their Christian counterparts) are intently mission oriented or whether they are purely humanitarian agencies that complement one another as they purport to be. In Chapter 8 Abamfo A. Atiemo discusses Hindus' contribution to development in Ghana. He argues that Hindu philosophical tenets such as rta, kama, artha, karma, and samsara can be developed to support socioeconomic developmental efforts of societies where religion still plays a role in development. Still focusing on specific religious traditions, in Chapter 9, Elizabeth P. Motswapong focuses on the possible contributions of Buddhism in Africa. Identifying meditation's ability to address the social challenges faced by an average African on a day to day basis, Motswapong also points out the developments effected by Buddhism, for instance, addressing the issue of water shortages, poverty and other challenges. Closing the chapters on the contributions of specific religious traditions are chapters addressing religion and development in Zambia. In Chapter 10, Lilian Siwila, Nelly Mwale and Chita Joseph Chita reflect on the role of Jewish migrants in the economic development of Zambia in the period between 1900 and the 1960s. In Chapter 11, Mutale M. Kaunda discusses how Bemba women navigate imbusa in public/social spheres as she answers the question, "How do married Bemba career women engage with the traditional cultural curriculum of marriage (amafunde yambusa) in their daily lives at home and workplace?"

The next 7 chapters focus on national coverages of religion and development. In Chapter 12 Samuel Awuah-Nyamekye presents study 
findings from Ghana, unearthing how religion and development have been faring in terms of the country's efforts to achieve development for its people. Chapter 13, by Andrew D. Omona and Uzziah Maate Kiriaghe, discusses religion and development in Uganda. Using theories of modernization, dependency and globalization, the chapter locates the importance of religion in the modernization of Uganda through discouraging dependency and taking the citizenry to match what is taking place around the globe. In Chapter 14, Julius Gathogo uses the story of Reverend Thomas Kuto Kalume, the first Kenyan African clergy to win a political seat in post-colonial Kenya, to illustrate the broad interface between religion and civic engagement. In Chapter 15, Sonene Nyawo investigates religion and development in the teaching of Religious Education in Swaziland (now eSwatini). She concludes that when considering the Swaziland educational context, there is an interface between the Christian religion and development, to an extent that Christianity has continued to have a pervasive influence on the education system down the generations.

Petronella Munhenzva argues that religion and politics have always had a close relationship by looking at the role of the church in the 1969 Land Tenure Act in Rhodesia (now Zimbabwe) in Chapter 16. In Chapter 17, Lindiwe P. Maseko explores the true identity of sustainable peace and development by focusing on the connection between the peace building work of a Christian organisation (the ECLF) and the SDGs Zaka district in Zimbabwe. In Chapter 18, Blessing Nyahuma investigates the interface of the theory of development and religion, focusing on its modern conceptualization. The chapter, which is on the VaDoma people of northern Zimbabwe, treats the subject of faith and development, interaction with national politics, setbacks in church politics and concludes by noting prospects and promises of FBOs in Zimbabwe.

The last set of chapters engage oral and scriptural literatures and how they promote or hinder development in Africa. In Chapter 19, Beatrice Taringa uses the conceptual framework of indigenous knowledge systems (IKS) to explore, through interviews and critical content and discourse analyses, the implications of the wisdom bestowed in selected Shona oral literature for sustainable economic development in Zimbabwe. The chapter discusses the potential of Shona wisdom in the form of idioms, taboos and proverbs to achieve sustainable economic development among the Shona in Zimbabwe. In Chapter 20, Nisbert T. Taringa makes a similar use of indigenous knowledge systems for sustainable development proposing the African philosophy of Ubuntu for environmental conservation. Ezra 
Chitando's Chapter 21 acknowledges the problems of biblical interpretation for promoting development and so sets out ten considerations to promote liberating readings of the Bible in the quest for development in Africa. In Chapter 22, Musa W. Dube rereads Matt 23 for liberation using an African feminist methodology. In Chapter 23, Lovemore Togarasei and Sidney Berman consider how Christian beliefs such as resurrection can be deployed in addressing some ecological problems that Africa is facing. Francis Machingura and Ishanesu Gusha, in Chapter 24, reread Matt 21:18-22 in the light of sustainable development and environmental theology. The book closes with Chapter 25 in which Canisius Mwandayi looks at the Bible and its use in a Zimbabwe tertiary institution to discuss the implications of sexual experimentation to the development agenda of a nation.

\section{Conclusion}

Religion and development have become an important theme in the study of religion and in development practice. Whereas the field has been dominated by scholars from the global North, African scholars have been making notable contributions. We are hopeful that this volume extends reflections on religion and development by African scholars and avails further data on this key theme.

\section{References}

Adejumobi, Said. 2006. 'Governance and Poverty Reduction in Africa: A Critique of the Poverty Reduction Strategy Papers (PRSPs),' Being a Paper Presented to the “InterRegional Conference on Social Policy and Welfare Regimes in Comparative Perspectives" organised by the College of Liberal Univ. of Texas, Centre for Latin American Social Policy, Apr. 20-22, 2006.

Adichie, Chimamanda N. 2009. “The Danger of a Single Story,” Youtube.com, TED, 07 Oct. Acc. 08/03/2019.

Agbiji, Obaji M. \& Ignatius Swart. 2015. "Religion and Social Transformation in Africa: A Critical and Appreciative Perspective," Scriptura 114(1), 1-20.

Aguti, Sarah. 2017. 'Promotion of Social Justice by Faith Based Organisations among Marginalised Communities in Uganda,' Master in Diakonia and Christian Social Practice, VID Specialised Univ., Oslo, Norway. 
Alkire, Sabine. 2010. "Human Development, Definitions, Critiques, and Related Concepts: Background Paper for the 2010 Human Development Report," OPHI Working Paper No. 36, Oxford Poverty \& Human Development Initiative (OPHI) Oxford Department of International Development Queen Elizabeth House (QEH), Univ. of Oxford.

Alolo, Namawu A. 2007. African Traditional Religion and Concepts of Development: A Background Paper. Working Paper 17. Birmingham, UK: International Development Department, Univ. of Birmingham.

Amenga-Etego, Rosemary M. 2011. Mending the broken pieces: indigenous religion and sustainable rural development in northern Ghana. Trenton, NJ; London: Africa World Pr.

Annett, Anthony et al. 2017. "A Multi-Religious Consensus on the Ethics of Sustainable Development: Reflections of the Ethics in Action Initiative," G 20 Insights. Available at: https://www.g20-insights.org/wp-content/uploads/2017/05/A-Multi-ReligiousConsensus-on-the-Ethics-of-Sustainable-Development. -Reflections-of-the-Ethics-inAction-Initiative.pdf, acc. 01/03/2019.

Atiemo, Abamfo O. 2017. “In Need of a New Lens: An African Christian Scholar's Religious Critique of Western European Attitude toward Religion and Development in Africa," Religious Studies and Theology 24, 250-273.

Awuah-Nyamekye, Samuel. 2012. "Religion and Development: African Traditional Religion's Perspective," Religious Studies and Theology 3(1), 75-90.

Ayiemba, Joshua O. et al. 2015. "The Mandate of the Christian Church in Poverty Alleviation: The Case of the Anglican Church of Kenya (ACK) in Maseno and Winam Divisions of Kisumu District, Kenya," International Research Journal of Arts and Social Science 4(2), 43-54.

Basedau, Matthias, Simone Gibeon \& Sebastian Prediger. 2017. “The Ambivalent Role of Religion for Sustainable Development: A Review of the Empirical Evidence," GIGA Working Paper 297. www.giga-hamburg.de/workingpapers, acc. 17/02/2019.

Batchelor, Valli B. 2013. Ed., When Pastors Prey: Overcoming Clergy Sexual Abuse of Women. Geneva: World Student Christian Federation/World Council of Churches.

Beckman, Björn \& Gbemisola Adeoti. 2006. "Predicament and Response: An Introduction," in Björn Beckman \& Gbemisola Adeoti, eds., Intellectuals and African Development: Pretension and Resistance in African Politics. Dakar: CODESRIA.

Binns, Tony, Kenneth Linch \& Etienne Nel. 2018. Eds., The Routledge Handbook of African Development. London: Routledge.

Bishop, Chris. 2017. Africa's Billionaires: Inspirational stories from the continent's wealthiest people. Cape Town: Penguin Books.

Bompani, Barbara. 2018. 'Religion and Development: Tracing the Trajectories of an Evolving Sub-discipline' Progress in Development Studies. Available at: www.research.ed.ac. uk/portal/files/77724051/Bompani_PDS_2018_ReligionAnd Development.pdf, acc. 17/02/2019.

Bompani, Barbara. 2010. "Religion and Development from Below: Independent Christianity in South Africa," Journal of Religion in Africa 40(3), 307-330. 
Bornstein, Erica. 2003. The Spirit of Development: Protestant NGOs, Morality, and Economics in Zimbabwe. New York: Routledge.

Chitando, Ezra. 2008. "Sub-Saharan Africa," in Gregory Alles, ed., Religious Studies: A Global View. New York: Routledge.

Chitando, Ezra \& Joram Tarusarira. 2019. "Introduction,” in Ezra Chitando \& Joram Tarusarira, eds., Religion and Human Security in Africa. London: Routledge.

Chitando, Ezra \& Adriaan Van Klinken. 2016. Eds., Christianity and Controversies over Homosexuality in Contemporary Africa. London: Routledge.

Clarke, Matthew. 2013. Ed., Handbook of Research on Development and Religion. Northampton, MA: Edward Elgar Publ.

Cochrane, James R., Barbara Schmid \& Teresa Cutts. 2011. Eds., When Religion and Health Align: Mobilising Health Assets for Transformation. Pietermaritzburg: Cluster.

Conradie, Ernst M. 2016, 'Why cannot the term development just be dropped altogether? Some reflections on the concept of maturation as alternative to development discourse, HTS Teologiese Studies/Theological Studies 72(4), a3415. http://dx. doi.org/10. 4102/hts. v72i4. 3415.

Crywagen, Dennis. 2016. The Spiritual Mandela: Faith and Religion in the Life of South Africa's Great Statesman. Cape Town: Zebra Pr.

Deneulin, Séverine \& Carole Rakodi. 2011. "Revisiting Religion: Development Studies Thirty Years On,” World Development 39(1), 45-54.

De Jong, Eelke. 2008. "Religious Values and Economic Growth: A review and assessment of recent studies," NiCE Working Paper 08-111, Institute for Management Research Radboud Univ. Nijmegen, Netherlands.

Du Toit, Nadine Bowers. 2018. "Decolonising Development: Re-claiming Biko and a Black Theology of Liberation within the Context of Faith Based Organisations in South Africa," Missionalia 46(1), 24-35.

Ellis, Stephen \& Gerrie Ter Haar. 2004. 'Religion and Development in Africa,' available at: https://openaccess. leidenuniv.nl/bitstream/handle/1887/12909/ASC071342346-174-01.pdf?sequence=1, acc. 10/03/2019.

Efobi, Uchenna R. \& Simplice Asongu. 2018. Eds., Financing Sustainable Development in Africa. Cham, Switzerland: Palgrave Macmillan.

Feener, R. Michael \& Philip Fountain. 2018. "Religion in the Age of Development," Religions 9, 382; doi:10. 3390/rel9120382.

German Federal Ministry for Economic Cooperation and Development (BMZ). 2016. Voices from Religions on Sustainable Development. Bonn: German Federal Ministry for Economic Cooperation and Development (BMZ).

Gunda, Masiiwa R. 2010. The Bible and Homosexuality in Zimbabwe. Bamberg: UBP

Habermas, Jürgen. 2006. "Religion in the Public Sphere," European Journal of Philosophy 14(1), 1-25.

Haynes, Jeffrey. 2007. Religion and Development: Conflict or Cooperation? New York: Palgrave Macmillan.

Hassan, Ruby. 2017. Religion and Development in the Global South. Cham, Switzerland: Palgrave Macmillan. 
Heist, Dan \& Ram A. Cnaan. 2016. "Faith-Based Development Work: A Review," Religions 7(19); doi:10. 3390/rel7030019.

Hoffstaedter, Gerhard. 2011. Religion and Development: Australian Faith-Based Organisations. ACFID Research in Development Series Report No. 3. Australian Capital Territory (ACT): Australian Council for International Development.

House-Soremekun, Bessie \& Toyin Falola. 2011. Eds., Globalization and Sustainable Development in Africa. New York: Univ. of Rochester Pr.

HTS Theological Studies. 2016. "Special Collection: Engaging Development, Contributions to a critical theological and religious debate," 72(4).

Ikechi-Ekpendu, Chioma, Sunday D. Audu \& Ikechi C. Ekpendu. 2016. “An Evaluation of the Role of Religion in the Development of Nigeria," Developing Country Studies 6(10), 82-87.

Jere, Qeko \& Vhumani Magezi. 2018, "Pastoral Letters and the Church in the public square: An assessment of the role of Pastoral Letters in influencing democratic processes in Malawi," Verbum et Ecclesia 39(1), a1844. https://doi.org/10. 4102/ve. v39i1. 1844.

Kabue, Samuel, James Amanze \& Christina Landman. 2016. Eds., Disability in Africa: Resource Book for Theology and Religious Studies. Nairobi: Acton.

Kaunda, Chammah J. 2018. The Nation That Fears God Prospers: A Critique of Zambian Pentecostal Theopolitical Imaginations. Minneapolis: Fortress Pr.

Kiunguyu, Kylie. 2018. "Pres Kagame Cracks Down on Churches and Mosques to Better Regulate the Religious Sector," available at: https://thisisafrica. me/kagame-closechurches-mosques/ (acc. 09/03/2019).

Kodila-Tedika, Oasis \& Julius Agbor. 2013. "Religious Diversity and Economic Development in Sub-Saharan Africa: So Far So Good," Munich Personal RePEc Archive. Available at: https://mpra. ub. uni-muenchen.de/46305/, acc. 01/03/2019.

Kufakurinani, Ushehwedu et al. 2019. Eds., Dialogues on Dependency. Volume 1 On Dependency. Harare: Univ. of Zimbabwe Publ.

Kurian, Manoj. 2016. Passion and Compassion: The Ecumenical Journey with HIV. Geneva: World Council of Churches.

Labeodan, Helen A. 2016. "Revisiting the legacy of the Circle of Concerned African Women Theologians today: A lesson in strength and perseverance," Verbum et Ecclesia 37(2), a1586. http://dx. doi.org/10. 4102/ve. v37i2. 1586

Langan, Mark. 2018. Neo-Colonialism and the 'Poverty' of Development in Africa. Cham, Switzerland: Palgrave Macmillan.

Le Moigne, Jannie \& Marie Juul Petersen. 2016. Donor Engagement with Religion and Faith-Based Organisations. Copenhagen: Danish Network on Religion and Development.

Letsie, Tlohang. 2015. "The Role of Christian Churches in Political Conflict in Lesotho," African Security Review 24(1), 75-88.

Magezi, Vhumani. 2017. “Making Community Development at Grassroots Reality: Church Driven Development Approach in Zimbabwe's Context of Severe Poverty', In die Skriflig 51(1), a2263. https://doi.org/10. 4102/ids. v51i1. 2263. 
Maimela, Simon S. 1985. "Salvation in African Traditional Religions," Missionalia 13(2), 63-72.

Mangope, Herman. 2007. "The Role of Religion: Particular Reference to Christianity in Botswana," Boleswa Occasional Papers in Theology and Religion 2(4), 43-50.

Maponda, Anastasie M. 2016, 'The impact of the Circle of Concerned African Women Theologians: French zone on church and African theology issues', Verbum et Ecclesia 37(2), a1597. http://dx. doi.org/10. 4102/ve. v37i2. 1597.

Mapuranga, Tapiwa P. 2018. Ed., Powered by Faith: Pentecostal Businesswomen in Harare. Eugene, Oregon: Resource.

Marshall, Kathrine \& Marisa Van Saanen. 2007. Development and Faith: Where Mind, Heart, and Soul Work Together. Washington, DC: World Bank.

Matunhu, J. 2011. "A Critique of Modernization and Dependency Theories in Africa: Critical Assessment," African Journal of History and Culture 3(5), 65-72.

Mawere, Munyaradzi. 2014. Culture, Indigenous Knowledge and Development in Africa: Reviving Interconnections for Sustainable Development. Bamenda, Cameroon: Langaa RPCIG.

Mawere, Munyaradzi. 2017. Theorising Development in Africa: Towards Building an African Framework of Development. Bamenda, Cameroon: Langaa RPCIG.

Mbetwa, Choolwe. 2018. Why Africa is Poor. Chingola, Zambia: Merina.

Mbogo, Rosemary W. 2015. "Historical Factors for the Church's Involvement in Holistic Community Development in East Africa," Developing Country Studies 5(21), 169-176.

Meagher, Kate. 2009. “Trading on Faith: Religious Movements and Informal Economic Governance in Nigeria," The Journal of Modern African Studies 47(3), 397-423.

Mhina, Amos. 2007. Religions and Development in Tanzania: a preliminary literature review. Working Paper. Birmingham, UK: Univ. of Birmingham.

Moyo, Dambisa. 2009. Dead AID: Why Aid is not working and how there is another way for Africa. London: Penguin Books.

Mtata, Kenneth. Ed. 2013. Religion: Help or Hindrance to Development? Leipzig: EVA.

Musana, Paddy. 2013. Ed., Peacebuilding in East Africa: Exploring the Role of the Churches. Nairobi: Paulines.

Mutongu, Zablon B. 2016. Theology of Development: The Integral Mission of Model of GodCentred Development. Second edition. Nairobi: Empiris Creative Communication.

Mwale, Nelly. 2013. "Religion and Development in Zambia: The Role of the Roman Catholic Church in the Political Development of Zambia: 1890-1964," Alternation Special Edition 11, 110-133.

Negussie, Siyum. 2018. "Why Africa Remains Underdeveloped Despite its Potential? Which Theory can Help Africa to Develop?” Open Access Biostatics \& Bioinformation 1(2). OABB. 000506. 2018. DOI: 10. 31031/OABB. 2018. 01.000506.

Nkomazana, Fidelis. 1998. "Livingstone's Ideas of Christianity, Commerce and Civilisation," PULA: Botswana Journal of African Studies 12 (1 \& 2), 44-57.

Nyangweso, Mary. 2017. "Religion, Human Rights, and the African Widow," Peace Human Rights Governance 1(3), 365-391. 
Obadare, Ebenezer. 2016. “"Raising righteous billionaires”: The prosperity gospel reconsidered', HTS Teologiese Studies/Theological Studies 72(4), a3571. http://dx. doi.org/10. 4102/hts. v72i4. 3571.

Obeng-Doom, Franklin. 2013. “Africa's Failed Development Trajectory: A Critique," African Review of Economics and Finance 4(2), 151-175.

Obijiofor, Levi M. 2001. “The Future of Africa Lies in Home-grown Solutions," in Olugbenga Adesida \& Arunma Oteh, eds., African Voices, African Visions. Uppsala: The Nordic Africa Institute.

Odén, Robert. 2016. For Better or Worse: The Role of Religion in Development Cooperation. Bromma, Sweden: Swedish Council of Mission.

Odumosu, Olankule, Rasheed Olaniyi \& Sunday Alonge. 2009. "Mapping the Activities of Faith-based Organisations in Development in Nigeria." Religions and Development Paper No. 38. Birmingham: International Development Programme, Univ. of Birmingham.

Oduyoye, Mercy A., \& Musimbi R. A. Kanyoro. 1992. "Introduction,” in Mercy A. Oduyoye \& Musimbi R. Kanyoro, eds., The Will to Arise: Women, Tradition, and the Church in Africa. Maryknoll, NY: Orbis Books.

Ogbonnaya, Joseph. 2012, "Religion and Sustainable Development in Africa: The Case of Nigeria," International Journal of African Catholicism 3(2), 1-22.

Okaalet, Peter. 2002. "The Role of Faith Based Organizations in the Fight against HIV/AIDS in Africa," Transformation: An International Journal of Holistic Mission Studies 19(4), 274-278.

Olarinmoye, Omobolaji O. 2012. "Faith-Based Organizations and Development: Prospects and Constraints," Transformation: An International Journal of Holistic Mission Studies 29(1), 1-14.

Olojo, Akinola E. 2017. "Resistance through Islamic Clerics against Boko Haram in northern Nigeria," African Security Review 26(3), 308-324.

Oloruntoba, Samuel O. \& Mamo Muchie. 2019. Eds., Innovation, Regional Integration, and Development in Africa: Rethinking Theories, Institutions, and Policies. Cham, Switzerland: Springer.

Opongo, Elias O. \& David Kaulemu. 2014. Eds., Catholic Church Leaders in Peace Building in Africa. Nairobi: Paulines.

Orobator, Agbonkhianmeghe E. 2018. Religion and Faith in Africa: Confessions of an Animist. Maryknoll, New York: Orbis Books.

Ottuh, John A. 2018. "Climate Destabilization in a Religious World: The Role of Religion in Addressing Climate Change in Nigeria," UJAH 19(1), 69-89.

Paris, Peter J. 2009. Ed., Religion and Poverty: Pan-African Perspectives. Durham, NC: Duke Univ. Pr.

Petersen, Kirsten Holst. 1987. Ed., Religion, Development and African Identity. Uppsala: Scandinavian Institute of African Studies.

Phiri, Isabel A., Kenneth R. Ross \& James L. Cox. 1996. Ed., The Role of Christianity in Development, Peace and Reconstruction: Southern Perspectives. Nairobi: All Africa Conference of Churches. 
Rakodi, Carole. 2013. Ed., Religion, Religious Organisations and Development: Scrutinising Religious Perceptions and Organisations. London: Routledge.

Sako, Soumana \& Genevesi Igiogio. 2002. "Africa: Major Development Challenges \& Their Capacity Building Dimensions.” Occasional Paper No. 1 Harare: Africa Capacity Building Foundation.

Sekhaulelo, Motshine A. 2014. "Reformed Churches in South Africa's Strategies for Poverty Reduction in Urban Communities," In die Skriflig 48(1), Art. \#1788, 10 pages.

Sibanda, Fortune. 2012. “The Impact of Rastafari Ecological Ethic in Zimbabwe: A Contemporary Discourse,” The Journal of Pan African Studies 5(2), 59-76.

Simbi, Grace Y. 2013. 'The Role of Faith Based Organisations in Policy Advocacy: A Case Study of the Pietermaritzburg Agency for Community Social Action (PACSA),' A dissertation submitted in partial fulfilment of the requirements for the degree of Master of Social Science in Policy and Development Studies in the School of Social Sciences, College of Humanities at the Univ. of KwaZulu-Natal, Pietermaritzburg.

Solhjell, Torstein. 2012. 'Religion in Development: How is the role and meaning of religion in development interpreted by organization staff and local participants of Norwegian development aid?' Masters Thesis, MF Norwegian School of Theology, Oslo.

Sounaye, Abdoulaye. 2012. “Doing Development the Islamic Way in Niger," Bulletin de l'APAD 33, 20 pages.

Swart, Ignatius \& Elsabė Nell. 2016. "Religion and Development: The Rise of a Bibliography," HHTS Teologiese Studies/Theological Studies 72(4), a3862. http://dx. doi.org/10. 4102/hts. v72i4. 3862.

Ter Haar, Gerrie. 2011. Ed., Religion and Development: Ways of Transforming the World. New York: Colombia Univ. Pr.

Tinkasiimire, Therese. 2013. "An Ethical Reflection on Religion as the Voice of the Voiceless in the emerging new World Order in Africa," International Journal of Sciences: Basic and Applied Research (IJSBAR) 7(1), 62-74.

Togarasei, Lovemore. 2018. Ed., Aspects of Pentecostal Christianity in Zimbabwe. Cham, Switzerland: Springer.

Togarasei, Lovemore \& Joachim Kügler. 2014. The Bible and Children in Africa. Bamberg: UBP

Togarasei, Lovemore, Sana K. Mmolai \& Fidelis Nkomazana. 2011. Eds., The Faith Sector and HIV/AIDS in Botswana: Responses and Challenges. Newcastle upon Tyne: Cambridge Scholars Pr.

Tomalin, Emma. 2013. Religions and Development. London: Routledge.

Tomalin, Emma. 2015. Ed., Handbook of Religions and Development. London: Routledge. Tomalin, Emma. 2018. "Religions, Poverty Reduction and Global Development Institutions,” Palgrave Communications 4:132 | DOI: 10. 1057/s41599-018-0167-8.

Van Nierkerk, A. S. (Jr) 1986. “African Religion and Development,” Development Southern Africa 3(1), 50-66. 
Wariboko, Nimi. 2012. "Pentecostal Paradigms of National Economic Prosperity in Africa," in Katherine Attanasi \& Amos Yong, eds., Pentecostalism and Prosperity: The Socio-Economies of the Global Charismatic Movement. New York: Palgrave Macmillan. Xinping, Zhuo et al. 2018. Eds., Toward a Shared Sustainable Future: The Role of Religion, Values and Ethics. Nanjing: Amity Foundation.

Yangka, Dorji et al. 2018. "Sustainability in an Emerging Nation: The Bhutan Case Study,” Sustainability 10, 1622; doi:10. 3390/su10051622.

Young, Orna. 2012. African Images and their Impact on Public Perceptions: What are the Human Rights Implications? Research Commissioned by the African and Caribbean Support Organisation Northern Ireland (ACSONI). Belfast: ACSONI. 


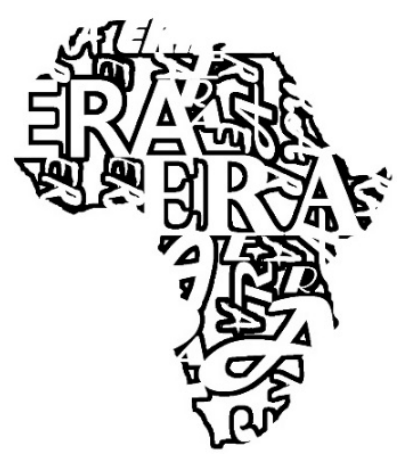




\title{
Rethinking Development in Africa and the Role of Religion
}

\author{
Masiiwa Ragies Gunda
}

\section{Introduction}

Zimbabwe has been described as having been the "breadbasket" of Africa at independence in 1980, that gradually deteriorated to becoming the "basket case" of Africa by 2002 after the Fast Track Land Reform Programme. Zimbabwe moved from a society that could feed itself and others to a society that begged others for food, including those it once fed, like Zambia. The case of Zimbabwe could be presented as the case of Africa, a continent with great potential, yet, struggling to realise that potential, thereby, remaining in the doldrums of underdevelopment. According to Adam Smirzai (2005:1), "The low standard of living of the mass of the population in developing countries is singled out as the key issue in development. " The connection between the low standard of living and development is an interesting one, one that we will seek to interrogate further in this chapter. This connection of development and low standards of living was directly deriving from the western ideas of development as an offshoot of secularism and secularization. Thus, "The rise of modern discourse on religion and the European secular state was cotemporaneous with the spread of Western imperialism" (Fountain 2013:13). In the European construction of the development discourse, development was only possible where religion was side-lined and replaced by secularism. It is critical that the notion of development be interrogated and defined for easy access to the implications it carries when applied to describe the state of the economies and human life on the African continent. Further, it is also vital to draw critical linkages that exist between the notion of development and religion, a critical component of life on the continent. The question of religion and development is very important for consideration because, while religion permeates the life of an African person, yet, the emergence of the development discourse seemingly saw no value in religion when it came to development. Haynes (2007:1) avers that;

After World War II, most Western governments and development agencies saw religion as part of the development problem, not as a potential aspect 
of its resolution. More recently, this negative consensus about religion has fractured, partly as a result of the widespread failure of secular development trajectories to achieve widespread poverty reduction or reductions of inequality and injustice in the developing world.

The mistrust and suspicion cast over religion in the post-World War II era meant that the emerging field of development studies would have no place for positive engagement with religion. If religion were to feature, it was only to show how problematic and anti-development it was. Thus, "It cannot be denied that one of the basic foundations for development studies precisely lies in ethical concerns about persistent poverty and marginalization of poor countries and the exclusion of poor people upon decolonization" (Ruben 2011:225). What is disturbing in this emergent field was its failure to recognize the centrality of religion to the lives of the poor people, that religion was the power of life for most of the poor people. While development may have benefited from the privatisation of religion in Europe, the development discourse which side-lines religion failed to appreciate the pre-colonial understanding of development by African societies and even failed to appreciate the early stages of western-influenced development projects among colonised African societies, which was mostly driven by missionary organisations and faith communities (Marshall \& Keough 2004, Fountain 2013, Boender et al 2011). There is a movement towards appreciating the positive contributions of religion to development, not least, what Laurence Iannaccone (1990) called 'religious capital', "to denote the resources generated from religious participation" (Wong 2013:176).

This chapter seeks to engage with the notion of development in the context of Africa, with special focus on Zimbabwe. What is development? What is the role of religion in the quest for development? Can religion contribute positively to the development of African societies? I will begin by attempting a definition of both development and religion to clarify how these concepts are understood when used in this chapter. Some of the issues to be addressed in this chapter will range from the articulation of the uneasy relationship between development and religion, then an investigation on the breadth and width of development within Africa: what should it look like? Can development in Africa be understood and confined to the parameters of development in the West? I will also investigate the potential role of religion in fostering development in Africa. I will end by drawing some concluding observations on development and religion in Africa. 
I must acknowledge that this chapter is written from a predominantly Christian background owing to the Zimbabwean background, however, it is my hope that the assertions and findings in this chapter can be translated to cover other religious traditions effectively.

\section{Defining Development and Religion}

In this section, the aim is to define development and religion so that there is clarity as to how we will use these terms in this exposition. Beginning from dictionary understanding, the word "development" in English connotes such ideas as "unfolding," "growth," "the fuller working out of the details of anything" and "bringing out the potential that is latent in something (as in the case of an image that is latent within the chemicals coating a piece of old fashioned film that must be "developed" in order to be revealed)" (Harriss 2014:37). This understanding of development is important because it associates development with growth and by implication development entails realising the full potential of something. A plant is fully developed when it becomes fruitful because then it has realised its full potential. According to Lorenzo G. Bellu (2011:2);

In general terms, "development" means an "event constituting a new stage in a changing situation" or the process of change per se. If not qualified, "development" is implicitly intended as something positive or desirable. When referring to a society or to a socioeconomic system, "development" usually means improvement, either in the general situation of the system, or in some of its constituent elements. Development may occur due to some deliberate action carried out by single agents or by some authority pre-ordered to achieve improvement, to favourable circumstances in both.

In the African context, therefore, we can understand development as the progress that is made or expected for African nation-states, which would see them adopting Western technologies to improve productivity as well as innovating on new ways of increasing productivity. The understanding of development in this way also implies that development would improve the living standards of citizens, providing employment, transport infrastructure that makes it easier to move from point $A$ to point $B$, availing health infrastructure that will improve the health and well-being of the citizens.

All these ideas are relevant to the concept of development that has informed so much public policy over the last half-century and more, both in the "core" of industrialized countries and in the "periphery" of the erstwhile colonies that came to be described as the "less developed countries" (LDCs) or the 
"Third World. " This concept, too, embraces ideas of "change" but also of "progress" - an idea which, in European thought, goes back to the philosophers of the Enlightenment, who found in it a rational basis for ethical judgment" (Hariss 2014:37).

While economic development is sometimes mistaken for development, itself a residue of the Enlightenment thinking and Western imperialism, it is becoming an acknowledged fact that economic development is one aspect of development. Among the leading scholars who have acknowledged the broad nature of development is Amartya Sen (1999), who has argued for an even broader concept of development focusing on the concept of freedom. He sees development as an integrated process of expansion of substantive freedoms or the deliberate process of removing obstacles and unfreedoms...Thus, "Among the most important of these freedoms are freedom from famine and malnutrition, freedom from poverty, access to health care and freedom from premature mortality" (Smirzai 2005:8). This understanding of development places human beings at the centre of development; development is meaningless unless it improves the livelihoods of citizens in a particular community or society.

The centrality of human beings and not simply economic productivity is the reason why most development scholars, with minor variations, identify almost similar development goals, such as "reduction of poverty, increased economic welfare, improved health and education, and increased political and social freedom. Development can then be defined as a movement in the direction of these developmental goals" (Smirzai 2005:9). A nation-state must come up with policies that will help it attain these goals for its citizens. Achieving these goals will make a society or country "developed" and a society that is making progress towards these goals is, therefore, "developing" - it is in the process but has not yet arrived. Instead of limiting development to economic development, development is better understood in terms of human development;

The concept of 'human development' can be understood in various ways. Politically and economically, human development is concerned with stability, security and the relative prosperity of citizens. Socially, it relates to literacy, education, social relationships and, more vaguely, 'the quality of life'. Morally, it involves development of conscience, moral awareness, and will and capacity to act according to societal and cultural knowledge of what is judged to be right - and in the developing world this overlaps considerably with religious and spiritual dimensions of life. Finally, psychologically, human development is to do with mental health, self-esteem, success in significant relationships, and happiness (Haynes 2007:4). 
Once development is understood in terms of human development, we get closer to the concept of sustainable development. Sustainable development is defined "as development that meets the needs of the present without compromising the ability of future generations to meet their own needs" (UN General Assembly 1987:43). This commitment to the present and the future is something that is interesting because it is also present in religion. At no point must a society seek to have all luxuries and funding such luxuries by taking resources for today and tomorrow, thereby making it impossible for future generations to enjoy similar success and development luxuries.

Having defined development above, it is important to now define religion. It is widely acknowledged by scholars of religion that religion defies definition. This is influenced by the divergencies that exist between various religions, yet, it must be accepted that definitions have been proffered by scholars and from these definitions;

Two approaches to religion have dominated academic debate (Cavanaugh 2009). Substantivist definitions posit that all religions share something in common and attempt to identify that content. A frequent substantivist definition, be it explicit or implicit, is what Fitzgerald (2003:5-6) derisively refers to as the 'alleged common-sense' variety of 'belief in gods or the supernatural.'" Functionalists, in contrast, propose that religion should be identified according to what it does, rather than through the identification of commonalities. Following Durkheim's (1965) famous formulation - religion is society's self-worship which binds a community together - functionalists tend to view religion as ritualistic acts of communal unification (Fountain 2013:11-12).

Assuming these two approaches as the dominant ways of approaching religion, it implies that we can either define religion as an entity that is shared across cultures and continents. Being such a widely shared entity, defining it must focus on the shared traits of religion. It is also possible to understand religion as it occurs in specific contexts, in the lives of believers and others under the influence of believers. Looked at from this perspective, religion can be defined by what it does and not what the religion of Zimbabwe shares with religion elsewhere. What is the function or role of religion in the Zimbabwean society? This is not to say either approach is right and the other wrong. Instead, both approaches bring important insights into the quest to understand religion. This will be important because it allows us to envision that which moulds religion that can contribute towards the development agenda and at the same time, we can also envision what religion can do to advocate for development. When 
considering the role of religion in development, there are questions on the meaning of religion that are pertinent;

Do you think religion is static (unvarying rules or holy texts to which people relate in a certain way) or dynamic (dependent on time, place and how people interpret it)? Do you think mainly in terms of personal interpretation (individual pastoral spiritual care) or do you see it as a political and social power that extends over the social and political domain? And what, in your opinion, is most influenced by religion: the individual conscience or the collective community? (Boender et al 2011:15).

Religion in Zimbabwe permeates both the private and public spheres, in ways that make it impossible to make these spheres exclusive of each other. Religion influences individuals to pursue a particular path in life and at the same time, it is also the glue that binds an entire community to follow a similar path. Religion is the basis upon which social trust is built in many communities, especially, among African communities. Through religion there are "emotional linkages between people, their identity-seeking behaviour and the key role of shared partnership relationships" (Ruben 2011:234). Indeed, while it influences the individual, it equally joins the individual to the group. Severine Deneulin \& Masooda Bano (2009:60) put it as follows: "Religion is not a set of private beliefs which may or may not instrumentally affect people's attitudes; it contains its own norms and values, which define the boundaries of the different social spheres and determine the way they function. "Whether the adherents believe in a god, as do most Zimbabweans, or not, religions are systems of organising society through the demarcation of that which is permissible and that which is not. Religion is pervasive and far reaching both in the private and public domains. This is why;

[T] hose who were predicting the death of religion were proved dramatically wrong. Religion has shown great resilience, as evidenced by the major religious revivals across the globe, be they in the Muslim world, the Americas, Africa or Eastern Europe. In the industrialised world, many policy-makers and opinion-leaders do not shy away either from dismissing scientific evidence (with reference to the theory of evolution or climate change for example) or from making decisions based on beliefs and ideology rather than on evidence-based information (Carbonnier 2013:1).

With religion defying secularism in the developed and developing worlds, it is imperative that religion must be taken as a serious resource and partner in development planning and execution of development agenda and policies. "The lack of attention to religion and faith in development research and policy thus stands in stark contrast to the paramount role 
played by religion in the daily lives of individuals and communities, particularly in the most active field of international development cooperation, the developing world" (Carbonnier 2013:2). If development is to be sustainable and attainable in predominantly religious communities, such as Zimbabwe, religion has to be seriously considered for what it is and for what it offers.

In this chapter, therefore, we understand development to mean the growth of society to a stage where it can guarantee education, health, wellbeing, employment and other opportunities and food to its citizens. Religion is understood as a system of organising society based on a set of norms and values that are used to guide the individual and the group creating a shared value system. Religion is the glue that binds several individuals together to create a community that has a shared goal and values.

\section{Religion and Development: An uneasy Relationship}

That we are speaking about development and religion is actually seen as a confirmation of the rebounding of religion. For a long time, development has always been understood as precluding religion, alternatively, the dominant discourse of development beginning as far back as the Enlightenment period in Europe did not believe religion could contribute to the development of society. Instead, from the Enlightenment onwards, secularism had replaced religion and "secular views of growth-based development became the dominant discourse, and studies on the role of religion in development only received marginal attention" (Ruben 2011:226). The thinking then seemed to suggest that if a society chose religion as opposed to secularism, such a society would not develop because development was seen as the benefit of secularism. Fountain (2013:9) writes that "a pervasive secular-religious dichotomy is implicit within this conceptualisation, constructing development as located within the secular domain, set apart from religion." This section tries to briefly outline the uneasy relationship between religion and development, trying in the process to note the contextual bases for the relationship that ensued for such a long time. According to Ruben (2011:229);

In the early years of development studies, the major paradigm was based on modernization theory that has been subsequently expanded with 'basic needs' and 'political economy' thinking. While attention was very much focused on the leading function of the state in steering development processes, the role of religion became marginalized to the personal domain." 
The thinking that led to the marginalization of religion in development discourses was influenced by the "prophecies" predicting that religion would soon die out. It was implied that development would kill religion, as if religion was one of the backward aspects of human life and societies that societies had to grow out of. As Carbonnier (2013:1) observed:

Sociologists have long predicted that the influence and role of religion(s) would wane in 'modern' societies. In Auguste Comte's positivist vision, religion is somewhat constructed as an obstacle to progress. Max Weber famously posited that the rationalisation process associated with modernisation would lead to the 'disenchantment of the world', whereby the search for truths and meanings come to rest on scientific investigation rather than religious beliefs, myths and magic.

With this kind of thinking, the relationship of development and religion was cast as of "either .... or", societies had to choose either development or religion. It was suggested that it was impossible to have development while retaining religion. In expressing the view of religion from the early dominant views and discourses on development, Fountain $(2013: 13,20)$ is instructive;

This creation of a 'secular sphere' of facts and rationality became the authoritative, legitimate location of politics, economics, military violence and objective science, all newly liberated from religious interference. Academic discourse about religion is directly implicated in the rise of secular regimes of knowledge.... This association of 'secular' with inclusiveness and impartiality is reinforced by Flanigan's rejection of the involvement of 'houses of worship' or local religious leaders in relief distribution due to their exclusionary potential.

Flanigan builds upon a hegemonic secular liberal tradition in international development that in turn derives from the Enlightenment zeal for binary purifications, wherein religious commitment is understood as deviating from the 'neutral' and morally superior norm of secularism. As such, Flanigan represents a dominant voice in secular development study and practice which views (a generic, universal and homogeneous) 'religion' with deep suspicion, if not outright hostility.

Religion has been mistrusted and fought by development activists, especially, with its association with religiously motivated violence in Middle Ages Europe and in the aftermath of 9/11 in the United States of America. Haynes (2007:218) argues that religion's 'exclusivist truth claims' give it an 'absolute and unconditional' character which tends toward 'totalitarian characteristics', including a propensity for 'intolerance, over-zealous proselytisation and religious fragmentation' (Haynes 2007:79). Also, “[e]xclusion, hatred and conflict, conditions that worsen poverty, have often been 
historically associated with religion. Secondly, benefits are not always evenly distributed within religious organisations" (Wong 2013:175) hence religion had to be side-lined in development. It was assumed that religion and religious communities are by nature exclusivist since they claim possession of the ultimate truth and path to salvation, they could not be trusted to champion an agenda that would benefit everyone, including those who do not share in the goals and values of that religious community. Thus "[t]hese dangers are not seen as apparent for secular actors", while "normal religion [was regarded] as private, interior, mystical and entirely marginal" (Fountain 2013:16-17, 22). As Fountain observes;

Among the reasons provided by the authors for this separation are (a) the historical institutional separation of Church and state, which continues to be influential, and (b) the fact that the 'two worlds' are 'propelled by a divergent set of impulses' with religious leaders primarily concerned with 'spiritual well-being', whereas development actors are interested in 'the material' and 'technical, hard-nosed economic and financial approaches' (Fountain 2013:15-16).

Even though the dominant view has been one of mistrust and rejection, it is also true that for some time there have been others who have had a different perspective and understanding of the relationship between development and religion. To begin with, "the current stage of development is sharply marked by a strong increase in violent conflicts, mostly originating from struggles regarding the control of resources and power" (Ruben 2011:231). This is telling in that whereas it was assumed religion was the source of conflicts, the current cases clearly show that a secularismbased development agenda has failed to stem development conflict in many communities. The failure of the secular development agenda to push societies into development led to a reappraisal of the role of religion in development: was there a way of reconciling these two previously separate entities?

The reason for seeking reconciliation is said to be a growing sense among development workers that development is more complex than initially imagined, and that successful development outcomes must pay attention to motivations, institutions and grassroots realities. Similarly, 'religious leaders' are presented as beginning to understand that they must look beyond 'religious well-being' to also foster 'community and temporal well-being'. This centripetal movement ensures that the 'walls' separating religion from development are beginning to 'crumble' (Fountain 2013:16). 
While this realisation has been celebrated, we must be quick to realise that it was not totally out of good faith. Religion was being invited to join development on the terms of the secular development agenda and activists. It appears that the secular values were not being challenged and reframed, rather the agenda and values were cast in stone and religion was supposed to acknowledge them as such and find gaps that it could contribute towards. It is, therefore, not surprising "that when it comes to religion, the dominant question of development experts has been: How can religion fit into our priorities?" (Fountain 2013:24). According to Jones \& Petersen (2011:1292), the interest in religion came more from the development industry, particularly the big multilateral and bilateral donors, than from universities and research organisations. Following the 9/11 attacks on the World Trade Center in New York and the ensuing 'war on terror', various governments proactively re-engaged with religion in their development strategies. In this context;

[T]he approach to religion is decidedly utilitarian, with the authors situated as advisors for mainstream development actors. The question of 'partnering' with religious NGOs is adjudicated according to the requirements of the mainstream development industry. This helps clarify as to whose religion, and therefore also whose 'our', is being addressed - that constructed by, and for, Western development organisations and their interests (Fountain 2013:24).

In Africa, as in many other developing countries, this secular development agenda did not succeed, as initially expected. It appears that failure to realise and appreciate the important position and function of religion contributed to the apparent failure of secularism-based development. For starters, in Zimbabwe, Africa and many other places;

Many development organisations stem from missionary work. These organisations, which operated mostly in colonies at the time, were traditionally accustomed to take religion into consideration. However, since the second half of the 20th century development cooperation has focused much less on religion. This has to do with the secularisation theory, i. e., the assumption that religion would lose its meaning in the public domain due to modernisation. The expectation was that - influenced by rationalism, science and technology - people would abandon religion over time, both in the Western world and in developing countries (Boender et al 2011:8).

In other words, religion was at the heart of the initial development agenda in Zimbabwe, especially when one considers the involvement of missionary organisations in entrenching and promoting health and education among the colonised masses. Thus "[i]n developing countries, religion 
[was and] is still heavily interwoven with public and political life, says American development professional Scott Thomas. Consequently, no one can privatise religion. He believes that the secularisation theory cannot possibly act as a model for developing countries" (Boender et al 2011:8). Religion had always been a leading sponsor of development; isolating and excluding it from development could only engender a sense of resistance among believers. Haynes (2007:1) argues that, "primarily concerned with the holistic human development dimension, visions of development from faith perspectives differ significantly from those expressed historically by secular development organisations, which often appear to be singularly concerned with 'economic development' to the exclusion of other aspects of development" (Haynes 2007:1). The realisation of the importance of religion in most developing countries, must have been playing on the mind of Ineke Bakker (2005), General Secretary of the Council of Churches in The Netherlands, when she intimated;

If you do not take into account religion and its dynamics, if you do not have sensitivity towards religious devotion, you simply cannot understand the mechanisms and strategies of the social movements nor the motives of the people who are your partners in development.

Religion has to be one of the resources and partners of development agencies in any attempts at fostering sustainable development among developing countries. It is a misunderstanding of religion to assume that religions only concern themselves with spiritual issues because all religions concern themselves with both spiritual and material things. The relationship between development and religion in dominant development discourses is unhealthy for development, which is holistic and much more than merely economic growth, as initially thought. Even though religion has of late been involved in development work and agenda, it is important that it becomes more than merely an invited guest to becoming a policy developer and an integral insider in the development agenda setting and execution.

\section{Re-thinking Development in Africa}

Now that we have tried to define development, religion and also highlighted the relationship between these two, it is now pertinent that we focus on development in Africa. How should we conceive development in Africa? The bulk of the continent is generally classified in the class of poor 
and developing societies and this classification has been based on "traditional views on poverty ... focused on low level of income or lack of material resources as major underlying causes for poor people being unable to satisfy their minimum living requirements" (Ruben 2011:228). Most African countries have abundant natural resources, yet, their income levels have remained very low. Therefore, "[g]oing back to the idea of development in the sense of 'to realize the potential that is latent in something,' we may understand international development as meaning the creation of conditions that make it possible for people to realize their potential as human beings, or to live full human lives that they value" (Harriss 2014:39). If development means creating the conditions for people to realize their full potential, it can also be argued that Africa is developing, meaning it is in the process of establishing the conditions for the realisation of the full potential of its citizens. Many people in Africa are far from realising their full potential owing to a number of obstacles, among them, lack of appropriate educational infrastructure, lack of health infrastructure, lack of employment opportunities.

If Africa in general or Zimbabwe in particular is to be a developed society, it must guarantee appropriate education to its citizens and by this we mean, schools must be equipped with all the necessary resources that will lead to the production of graduates that are appropriately equipped to function in their communities. The education system in Zimbabwe, while lauded across the continent and even beyond, has been a failure in this regard because it was structured in the model of a caste-system, where the poor have schools poorly equipped while the rich have schools that are adequately equipped. By implication, the education system that discriminates people according to class (and race in colonial times) cannot be an education that is appropriate for a developed country. Education must provide a fair and equal opportunity to all students irrespective of whether they have a poor or rich background. Similarly, the health sector must also provide infrastructure, in the form of clinics and hospitals that would make all human life important instead of a system that discriminates against the poor. This is where the poor have access to clinics and hospitals that are poorly equipped with staff and medication always in short supply. The reality of hospitals for the rich and hospitals for the poor is an indication of the failure of society to guarantee health and wellbeing to all citizens. Inappropriately educated workforce and unhealthy workforce will lead to less productivity for the society at large, making development a pipe dream. These elements are central to what Africa and Zimbabwe 
should aspire for as a developing continent and country. Consequently, there is need to eradicate these anomalies and create conditions that encourage and promote excelling by all citizens.

Development in Africa should be conceived of in terms of four dimensions of development, which are only here articulated separately even though in practice these are inseparably connected in African communities. To begin with, Africa is crying out for "Economic development: i. e., improvement of the way endowments and goods and services are used within (or by) the system to generate new goods and services in order to provide additional consumption and/or investment possibilities to the members of the system" (Bellu 2011:3). This has been the major focus of international development aid in most African countries, where the focus is on increasing productivity and consumption of goods. In the case of Zimbabwe, there has not been any meaningful production of goods and services, meaning that there is need for more resources to be invested in these economic endeavours. One of the major drawbacks to economic development is the lack of appropriately trained and equipped human resources. This leads us to consider the second kind of development that Africa is crying out for, that is, "Human development: people-centred development, where the focus is put on the improvement of the various dimensions affecting the well-being of individuals and their relationships with the society (health, education, entitlements, capabilities, empowerment etc" (Bellu 2011:3). Human development could be the most important aspect of development because of the way it affects other forms of development. Human beings are at the centre of development and unless they are appropriately equipped, all other aspects of development will suffer. Economic development cannot be achieved unless there are the persons to drive the growth of the economy. However, for people to drive economic growth, they must be properly trained and must be healthy so that they can execute their duties and tasks efficiently and positively. These two aspects of development have not received as much attention on the continent, as they should, hence the lack of economic growth is not surprising.

One of the major challenges the African continent has been grappling with is a result of the imperialistic looting of resources on the continent without regard to sustainability and future generations. Europe and the Americas and lately, China, have been treating Africa as the place where raw materials are looted for the development of their own societies. Africa is crying out for "Sustainable development: development which considers 
the long-term perspectives of the socio-economic system, to ensure that improvements occurring in the short term will not be detrimental to the future status or development potential of the system, i.e. development will be 'sustainable' on environmental, social, financial and other grounds" (Bellu 2011:3). Many natural raw materials were looted without the creation of an alternative source of livelihood for the communities and future generations across the African continent. It is suggested that where finite natural resources are being exploited, sustainable development must insist on responsible use of such resources while at the same time opening up opportunities in the beneficiation industries and other downstream industries to sustain the communities even when the natural resources have run out. Africa has experienced only the exploitation of resources without other industries being established to prepare for, when the resources run out. According to Bellu (2011:5):

The concept of "sustainable development" was first introduced by Brundtland (1987), who defines development as "sustainable" if it "meets the needs of the present without compromising the ability of future generations to meet their own needs". Sustainable development implies minimising the use of exhaustible resources, or at least, ensuring that revenues obtained from them are used to create a constant flow of income across generations, and making an appropriate use of renewable resources."

Finally, African countries aspire to achieving "Territorial development: development of a specific region (space) achievable by exploiting the specific socio-economic, environmental and institutional potential of the area, and its relationships with external subjects" (Bellu 2011:3). Development must never be piecemeal, as is the case currently in Zimbabwe and Africa in general where, as in the case of Harare, there are leafy suburbs where one could conclude the citizens and society are developed, yet, when one goes to southern and eastern suburbs, it becomes apparent that it is not the entire territory that is developed, but just some small spaces in Harare. Development demands that the continent and also the countries work towards establishing infrastructure that allows for the development of the entire territory as opposed to a system that only seeks to develop the areas of origin of political elites and captains of industry.

Common among all these dimensions of development is the desire to eliminate poverty and the marginalizations that come with being poor, meaning development begins and ends with the situation of the human being. Development that celebrates machinery and innovation and not 
what it does to positively impact on the lives of human beings is not development at all. Machinery is development if it can demonstrate that it will improve the lives of human beings, which is why certain innovations are difficult to accept as development; for example, the continued innovations in military war machinery, whose goal is to eliminate and not necessarily to improve human life. Development also entails eliminating exclusionary systems that seek to exclude and deprive others from the comfort of belonging because there cannot be human wellbeing where a human being is being excluded from belonging to social networks (Ruben 2011:228). If these are the concerns of development, there is no way one can speak of development in Africa without involving and including or maybe even being led by religion. "The activities that development centres on, such as education, healthcare and advocacy, influence the way people see themselves as belonging to a religious community" (Boender 2011:15). The participation of human beings in structures of economic development - either production or consumption - is dependent on their religious or faith background. Religious backgrounds are, therefore, critical determinants when deciding on development policy and execution of the same.

\section{The Role of Religion in Development in Africa}

If, as argued above, development is supposed to be a process of growth that sees society guaranteeing education, employment, health and wellbeing, then religion ought to have a critical role to play, especially in African societies where religion is growing rapidly, not waning. The role of religion in development should be sought in its nature and in its function in society. As a system of organizing society, where society faces the dangers posed by deprivation, vulnerability and poverty;

Religion could offer significant protective devices against such risks, but more importantly might enable people to take risks and thus act as a real transformative force. The latter option requires collective action that is usually based on a set of 'shared identities' that provide a common 'sense of belonging'. Especially under conditions of (post)conflict and insecurity, there is emerging importance attached to religion as a constructive force for (re-)establishing trust at different levels of societal interaction (Ruben 2011:226).

Religion includes individuals into a family and community, and with the capitalist industrialised economic system where individuals have had to leave their families in search of employment, religion has accommodated 
such individuals into a tightly knit unit. The sense of belonging that is engendered into individuals by religion allows individuals to take risks, especially in the area of investment and income generating projects because the community is not only a social and faith community but a ready market for products produced by members of the community. Further, because of shared values that determine who belongs and who does not, it is also possible for religion to regulate the activities that members engage in. For example, faith communities that will value protecting the environment, will be better prepared to protect the environment as members share in these values.

Nowhere does the unifying factor of religion manifest itself more clearly than in the case of the Johanne Marange Apostles in Zimbabwe, who for a long time have been involved in running battles with the government when it comes to compulsory immunization programmes of the government. While it is easy to understand the government programmes, the government as an agent of development has failed to understand the values and norms of this religious group. Instead of engagement and dialogue, government has often tried to force the community to participate in the programmes and the community has responded by resisting the programmes. While the response of this community may be negative, it shows the power of religion in engendering a unified position and identity. The Johanne Masowe Apostles shunned working for colonial institutions and as a religious community, they adopted self-employment as a response to colonial employment, they became successful entrepreneurs, famously known as the "Korsten basket makers" (Dillon-Malone 1978). Religion can significantly contribute to development because by its nature, religion thrives on collectivity, something that development needs to succeed.

It does this by creating a community as well as formulating values and norms that bind together members of the community so that it is easier to establish common goals and aspirations in faith communities. While this has a negative side to it, as noted by other scholars who are scared of the potential to exclude, this is only because some development agents are keen to come up with "one-size-fits-all" policies that would disregard the peculiarities of religious communities. We, therefore, agree with Fountain (2013:26) when he writes;

The key challenge for scholars, therefore, is, regardless of theoretical approach, to ground research on 'religion and development' in in-depth, detailed explorations of particular cases. Essentialist religion is best countered 
through studies that privilege 'richness, texture and detail' above abstract generalisation.

The generalisations of religion have tended to privilege the religions of development agents and activists at the expense of the religions of the people for whom development programmes are designed. The problem is that once the target community perceives the privileging of the religion of the development agents, resistance sets in and development is stalled. In the case of religion in Africa, some of my lasting images of ecumenism emerge in the grassroots where communities know when to go beyond the faith boundaries to address communal challenges. Development programmes must, of necessity, acquaint themselves with the specifics of the religions of the communities within which they are to be executed and make use of the resources embedded in the nature of such religions.

While religions are thought of as communities that are prone to excluding outsiders, that is actually a simplistic re-presentation of religion and a misunderstanding of the essence of religion. Faith communities create a community that must be clearly identifiable from other communities. This then creates a system of interaction with other communities that are so similarly constituted and will address the use of resources by members. These are values that are critical for the success of development programmes hence development agents need to involve religion to tap into these values. According to Ruben (2011:232);

Social values and relationships can constitute either bonding ties, bridging networks or linkages amongst (groups) of people. Bonding ties are based on homogeneous values that permit internal exchange and offer local protection against outsiders. Bridging networks are more externally oriented and permit regional cooperation and exchange amongst heterogeneous groups based on reciprocity. Finally, linking is strongly oriented towards the capacity to leverage resources and information from people beyond the community, recognizing that different social strata maintain a hierarchy where power, social status and wealth are accessed by different groups.

In Zimbabwe, as is the case on the African continent, it is not at all surprising that religion should be involved in development programmes because, religious groups and institutions have been in the forefront of the development discourse since the colonial times. Thus,

Given that the origins of development assistance trace back to missionary ventures and religiously inspired initiatives during the colonial era, this [the marginalization of religion in development programmes] is something of a surprise. Today, faith-based organisations remain highly prominent actors in the aid industry. The Christian organisation World Vision International, 
for instance, has the largest budget among humanitarian and development aid non-governmental organisations (NGOs) (Carbonnier 2013:1).

Also, Ruben (2011:232) articulates this reality, when writing;

At the interface between religion and development, similar binding, bridging and linking networks can be distinguished. At the local level, faith-based institutions play a critical role in providing communities access to basic services. Missionary churches and NGOs proved to be highly efficient development brokers, still delivering up to $40 \%$ of basic health care provision in large parts of sub-Saharan Africa. Their closeness to poor households in remote communities, their long-term relationships with the civic cause and strong identification with the demands of the poor make faith-based organizations highly reliable partners for grassroots-oriented development cooperation.

The reality in Zimbabwe is that the church is where government is not sometimes! The people identify with the church more than they do with the government owing to the proximity of the church to the people. If development is about improving the livelihoods of persons, then religion is better equipped to deliver development to the grassroots. For development to gain momentum, there is need for trust and social cohesion and these are among the central functions of religion in society. "In this context, religious values play an important role, since they can provide moral imperative for people to become engaged into shared commitments" (Ruben 2011:231). Religious commitment breeds trust amongst believers and that can help in creating a platform for the success of development programmes whose success is dependent on the trust existing between the community and the development partners as well as within the community itself. Without trust that others are as committed as I am committed, no one will invest much into a programme. Religion can help breed trust. Religions are sometimes accused of propagating messages that discourage persons from engaging in hard work, yet the reality in religions across the African continent, appears to be that religions do encourage their members to engage in hard work and to take risks in order to increase their earnings. As Togarasei (2011) argues, Pentecostal churches are among the most adventurous Christian groups when it comes to empowerment of members because they promote a spirit of entrepreneurship ranging from small income generating projects, such as selling sweets to much bigger projects that employ tens of employees. This realisation appears to confirm the theory of Max Weber on the centrality of the "protestant ethic" in the rise of capitalism, through the understanding of 
human work as their calling for the development of society according to God's plan (Hasan 2017:4).

To sum up this section, it must be acknowledged that the role of religion in development is associated with the notion of religious capital. The notion of religious capital bears significant relevance to poverty reduction due to, as argued by Finke (2003), the transferability of religious capital to other forms of capital. In other words, religious capital is a valuable asset that, when strategically invested, could bring social and economic advancement to individuals (Stark \& Finke 2000). There are linkages between religious capital and other forms of capital, such as human, social and financial capital and religious capital, like other forms of capital, can pass to other generations (Wong 2013:176). Religious capital emerges from the participation that one does in a particular faith community, which can then open up a market for their products or open up opportunities for access to financing from other members of the community, opportunities that would have been inaccessible if they were outsiders. The importance of religious capital must not be underestimated, especially when it comes to development programmes in a society.

\section{Conclusion}

In conclusion, it is important to reiterate that development is the process by which societies achieve wellbeing for all their citizens, seen in the availability of appropriate educational infrastructure and health infrastructure which will translate into economic growth. The earlier reduction of development to refer to economic growth only cannot be sustained in African communities and this obsession with economic growth led to the adoption of "so-called 'social indicators': life expectancy, literacy, levels of education, infant mortality, availability of telephones, hospital beds, licensed doctors, availability of calories, and so forth" (Smirzai 2005:7). When looked at closely, these social indicators point to the necessity of involving religion in development programmes because not only does religion possess the resources of making these social indicators achievable, in Africa, religion has for more than a century been involved in attempting to achieve these goals. Religion does not have to become secular in order to be involved in development, it has enough resources without sacrificing its nature and values and norms that can be key resources in development 
discourses. Religion in Africa is neither private nor public, it is both private and public, hence, it is essential if development agents are to succeed when working with African communities.

\section{References}

Bakker, Ineke. 2005 “Opening Speech” at Religion: A Source for Human Rights and Development Cooperation, Soesterberg, The Netherlands, Sept..

Bellu, Lorenzo G. 2011. “Development and Development Paradigms: A (Reasoned) Review of Prevailing” Visions, EASYPOL Module 102, available online: www.fao.org/easypol acc. 18 July 2018.

Boender, Welmoet et al, 2011. Religion and Development: Practitioner's Guide, Utrecht: Kenniscentrum Religie en Ontwikkeling. Available online: www.religion-anddevelopment.nl acc. 2 July 2018.

Carbonnier, Gilles. 2013. "Religion and Development: Reconsidering Secularism as the Norm”, Carbonnier, Gilles (et al), International Development Policy: Religion and Development, New York: Palgrave Macmillan, 1 - 5.

Cavanaugh, W. 2009. The Myth of Religious Violence: Secular Ideology and the Roots of Modern Conflict, Oxford: Oxford Univ. Pr.

Dillon-Malone, Clive M. SJ, 1978. The Korsten Basketmakers: A Study of the Masowe Apostles, an Indigenous African Religious Movement, Manchester: Manchester Univ. Pr.

Emas, Rachel. 2015. “The Concept of Sustainable Development: Definition and Defining Principles”, Brieffor GSDR.

Finke, R. 2003. “Spiritual Capital: Definitions, Applications and New Frontiers”, paper prepared for the Spiritual Capital Planning Meeting, 9-10 Oct., Fairfax: George Mason Univ.,Enterprise Institute. Online: http://spirituality.metanexus.metanexus. org/archive/spiritualcapitalresearchprogram/pdf/finke.pdf acc. on 23 July 2018.

Fitzgerald, T. 2003. The Ideology of Religious Studies, New York: Oxford Univ. Pr.

Fountain, Philip2013. "The Myth of Religious NGOs: Development Studies and the Return of Religion”, Carbonnier, Gilles (et al), International Development Policy: Religion and Development, New York: Palgrave Macmillan, 9-30.

Harriss, John. 2014. “Development Theory”, in Bruce Currie-Alder, Ravi Kanbur, David Malone \& Rohinton Medhora (eds), International Development: Ideas, Experience and Prospects. Oxford/New York: Oxford Univ. Pr., 35 - 49.

Hasan, Rumy. 2017. Religion and Development in the Global South, Cham: Palgrave Macmillan.

Haynes, Jeffrey. 2007. Religion and Development: Conflict or Cooperation? New York: Palgrave Macmillan.

Jones, B. \& Petersen M. J., 2011. “Instrumental, Narrow, Normative? Reviewing Recent Work on Religion and Development”, Third World Quarterly, 32(7): 291-306.

Marshall, K. \& Keough L., 2004. Mind, Heart, and Soul: In the Fight Against Poverty, Washington, DC: World Bank. 
Putnam, R., 2000. Bowling Alone: The Collapse and Revival of American Community, New York: Simon \& Schuster.

Ruben, Ruerd. 2011. “Can Religion Contribute to Development? The Road from 'Truth' to 'Trust", Exchange 40, 225-234.

Sen, A. Development as freedom, Oxford: Oxford Univ. Pr., 1999.

Séverine Deneulin \& Masooda Bano. 2009. Religion in development. Rewriting the secular script, London, New York: Zed Books.

Smirzai, Adam. 2005. "Developing Countries and the Concept of Development”, The Dynamics of Socio-Economic Development: An Introduction, Cambridge: Cambridge Univ. Pr., 1-34.

Stark, R. \& Finke F. 2000., Acts of Faith: Explaining the Human Side of Religion, Berkeley: Univ. of California Pr.

Togarasei, L. 2011. "The Pentecostal Gospel of Prosperity in African Contexts of Poverty: An Appraisal. ” Exchange 40, 336-350.

UN General Assembly. 1987. Report of the world commission on environment and development: Our common future, Oslo, Norway: UN General Assembly, Development and International Co-operation: Environment.

Wong, Sam. 2013. "Using Religious Capital to Alleviate Poverty? A Case Study of Cross Border Migration in South China”, Carbonnier, Gilles (et al), International Development Policy: Religion and Development, New York: Palgrave Macmillan, 174191.

Woolcock, M., 2001. "The Place of Social Capital in Understanding Social and Economic Outcomes”, Canadian Journal of Policy Research 2/1, 11-17. 


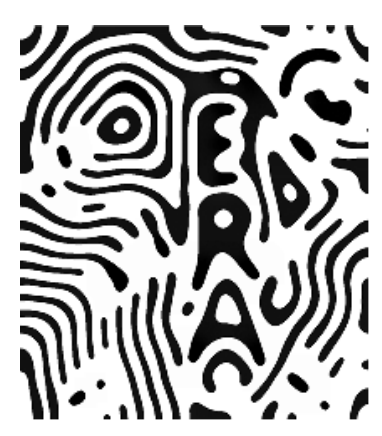




\title{
Religion and Development in Africa - A Critical Analysis
}

\author{
Chammah J. Kaunda a Sokfa France John
}

\section{Introduction}

Since the turn of the millennium, there has been an increasing shift in developmental practices and scholarship from viewing religion as out of bounds to engaging religion as essential to the achievement of developmental goals in Africa. There have been calls over the past two decades for greater incorporation of religion, and evidence demonstrating the role religion has played in several developmental contexts. In its consultation report "Religion and Development Post-2015" the UN Inter-Agency Task Force on Engaging Faith-based Organizations for Development (IATFFBO2015: v), acknowledged, "the work of development has always been the domain of faith-based entities. The 'intruders' may well be so-called secular organizations." The link between religion and development is increasingly acknowledged such that even the advancement in today's communist China is ascribed partly to recent resurgence of religion in the country (Hiagbe 2015; Deneulin \& Rakodi 2011; Stuckleberger 2007). Deneulin \& Rakodi (2011) attribute the resurfacing of religion in development scholarship to three trends. First, the emergence and spread of political Islam; second, the persistence and increasing importance of religion in the lives of people around the world, including the massive growth and popularity of Pentecostalism in majority world countries, and; third, the role of civil society organizations including Faith-Based Organizations (FBOs) as agents of development, especially in developing countries.

In this chapter, we critically review selected literature on religion and development in Africa. We examine the religious features and coverage of this literature as well as the conception and coverage of development. One of the key findings is that the notion of development used, and the field of investigation itself would benefit immensely from a thorough investigation of local dynamics of religion, including African Traditional religions (ATR), migrant religions such as Nigerian Pentecostalism in various parts of Africa and a broader and more nuanced coverage of the religious landscape in Africa. Although effort was made to cover as much relevant materials as possible, this review is by no means exhaustive; it is 
rather representative of the broad range of literature available depending on how broadly or narrowly one defines the field. To keep it manageable, we focused primarily on literature that is explicitly about religion, generally or specific religions, and development or specific developmental issues in Africa. ${ }^{1}$

\section{The 'Religion' in Religion and Development}

Literature on religion and development in Africa engages religion primarily as an institution, as established traditions and organizations. Thus, it examines Christianity, Islam and ATRs as the three religions most practiced in Africa, as well as Christian, Muslim, or interreligious Faith-based organizations (FBOs).

\section{Faith-Based Organizations and Development in Africa}

Literature on the subject has a major focus on FBOs and their developmental activities. But the criteria for inclusion and exclusion of what constitutes an FBO is not always clear. The underlying understanding and assumption in the literature reviewed is that FBOs are formal organizations that are inspired by, founded by, belong to, run by or based on the beliefs, values and practices of a religion, religious institution, religious groups or individuals. Bompani (2015) rightly argues that viewing FBOs only as organizations that are formally registered, like NGOs, is disregarding their faith as inspiration and impetus for their development work. She observed that much of the development work in underdeveloped countries is carried out, directly and indirectly, by religious based development actors, but these are overlooked because they do not operate with the popular NGO-style model of development.

Most secular organisations still approach the terrain of FBOs with some caution despite being viewed as collaborators for development in recent years. The reason for this, according to Olarinmoye (2012), is because the modern state is secular in orientation and informed by the separation of religion and state. Donors are therefore, afraid to fund sectarian organizations or denominations, but also due to the stronger fear of "the immense capacity of religion to mobilize and constitute by and in itself an

Ignatius Swart and Elsabe Neli (2016) have published an article comprising a chronological bibliography on religion and development to demonstrate the growth of the field. 
independent and legitimate arena of political action possibly in opposition to the state" (Olarinmoye 2012:2). Thus, like Bompani, Olarinmoye believes that many FBOs are effectively engaged in development in Africa, but their work goes unrecognized. However, for Olarinmoye (2012), it is not because the dominant framework for defining FBOs excludes them, but their religious nature which is viewed as being in opposition to the logic of the state, despite the several qualities that make them good development agents, including their ability to inspire trust and closeness to the people. However, the caution is perceived as important by secular organisations because the religious world is very complex such that while it is perceived as a constructive partner, it is also seen as having potential to disrupt development, especially in the context of religious conflict (Olarinmoye 2012).

Some scholars take a comparative approach to FBOs, examining differences between FBOs and NGOs, as well as the advantages of one over the other. Leurs (2012), for example, based on a study of Christian, Muslim and secular organizations working on HIV \& AIDS in Nigeria, observed that while most organizations received positive review from both beneficiaries and local observers of their activities, important differences were highlighted between religious and secular NGOs. While secular organizations locate their development goals, values and practices within the international discourse on development using secular humanitarian language, FBOs locate theirs in the discourse and language of their faith (Leurs 2012). Leurs (2012) noted, for instance, that Muslim and Christian FBOs both saw their developmental activities as a means to directly or indirectly achieve their primary goal of evangelization. In terms of advantages, FBOs are advantageous because they have a higher level of trust among communities, are more independent financially and in their response to local needs, have a long history, continuous presence and regular interaction with the communities, among other things (Leurs 2012; IATF-FBO 2015). Nonetheless, both FBOs and NGOs were considered to be better at different things, for example, NGOs are better with HIV-prevention campaigns, while FBOs are better at caring for people living with HIV \& AIDS. For Lipsky (2011), with respect to delivery of health services in Africa, the most important comparative advantage of FBOs over NGOs, is their ethical and moral positioning which is rooted in their faith. Lipsky believes that the strategies and policies of FBOs are informed by their faith, but more importantly, faith is crucial to their practices around recruitment, salaries, financial management, trust-building, and motivating 
the kinds of behavioural changes necessary for better health outcomes (Lipsky 2011). In addition to knowing their contexts better than NGOs, FBOs also provide more platforms for development service delivery such as during religious services and meetings (Lipsky 2011).

In other parts of Africa, as noted by Green et al (2012) in Tanzania, such comparisons may not be possible or fruitful because of blurred lines between the religious and the secular. Green et al (2012) observed that FBOs neither necessarily distinguished themselves nor are they always different from secular NGOs and other civil society organizations; rather, they are all favoured for the implementation of developmental strategies since they are believed to be closer to poor people. In cases where religious organizations seek to tackle particular developmental projects, some of them establish autonomous NGOs that operate like other civil society organizations (Green et al. 2012). Thus, they argue that insofar as the agendas are externally set or determined, there is a blurred line between secular organizations and FBOs in Tanzania. The question of context is, therefore, important for adequate representation of FBOs.

Freidus (2010) and van Santen (2014) offer examples of problematic developmental practices due to adoption and imposition of foreign constructs and meaning, and the misunderstanding of local experiences and meaning making by FBOs. Freidus (2010) examined how FBOs engaged in the care of orphans and vulnerable children in Malawi, which produced unintended negative consequence due to disconnection between western and Malawian understanding of orphans. Most FBOs adopt the UN definition of orphans as children who have lost a single or both of their parents as a result of death. As Freidus (2010:54) discovered "Most contributors to FBOs... assume a Western construction of an orphan that is more in line with an Oliver Twist-like child who has lost both parents, is isolated, abandoned, vulnerable, and stigmatized." However, children in Malawi are located within a broad network of extended family and different types of residence and kinship systems within which they could find care and support in the event that their parents are unable to care for them (Freidus 2010). Because they do not fully understand this, FBOs implemented projects for orphans which were not compatible with the broader local context. While the programmes had positive impact on the lives of the children, such as better education, better health and more, they also exposed the orphans to new challenges (Freidus 2010). Through arbitrary selection and maintenance methods, they severed relationships between 
children and their families, and created for them "privileged orphan identity" with material benefits at the cost of family ties, that were both desired and stigmatized in Malawi (Freidus 2010). In a different religious and developmental context, van Santen (2014) highlights the challenge posed by notions such as 'gender' to Muslim women in northern Cameroon, where 'gender' was not consistent with local ways of conceptualizing human relationships. While the women desired development in the form of education, they also did not want Western forms of development perceived in the model that the FBO employed.

\section{Christianity and Development in Africa}

Christianity is the most discussed tradition in the reviewed literature, which shows the role of different manifestations of Christianity in different aspects of development. Even some writings that claim to be concerned with multiple religions actually pay more attention to Christianity. For example, van Klinken and Chitando (2015) declared their use of religion to include Christianity, Islam and ATRs, but their work almost exclusively discussed Christianity and Christian theology and theologians. Other works did make attempt to fairly engage more than one religion. For example, Njoh and Akiwumi (2012) engaged Africa's three major religions and found that in terms of the Millennium Development Goals, Christianity has a more positive link to women empowerment than Islam and ATRs .

The issues and aspects examined by scholars who focused on Christianity are diverse. For instance, Bornstein (2002), observes that through the use of concepts such as 'holism' and 'lifestyle evangelism', Christian organizations are able to resolve the distance between the spiritual and the material, making material gains consistent with ideals about God and presenting non-Christian worldviews as opposed to development. Other scholars have highlighted the importance of religious personalities and leadership in faith-based projects for development (Bompani 2015). Kinny (2012) examines the role played by the transnational network of the Episcopal Church of South Sudan in development. She observed that while the initial purpose of the Christian partners in the network was not development as such, but advancement in faith, they are involved through supporting local NGOs in relief services. Thus, networks forged on Christian faith and its growth among partners becomes a significant source of support for developmental activities. 
The positive role of Christianity in development in Africa is presented in much of the reviewed literature as almost 'salvific' in the sense that Christianity is presented as bringing such change in the lives of individuals and communities that radically transforms not only their beliefs but their material realities. This is, perhaps, more enthusiastically articulated in an article by Walter and Anderson (2012) who argue that Africans become fundamentally different when they convert to Christianity and this change engenders development in ways that money or any other usually employed developmental strategies could never hope to achieve. These two authors are convinced that by insisting on individual and personal access to and reading of the Bible as crucial for spiritual growth, Christianity produces literate and thus, liberated African minds. But more importantly, that the motivation to become literate creates a shift to a broader Christian worldview linked to the social and individual subtleties of economic development (Walter and Anderson 2012). Thus, for Walter and Anderson (2012) Christianisation, through literacy and faith, brings about liberation and empowerment that fundamentally restructure the African Christian's position in life. Walter and Anderson only fell short of declaring Christianization the only hope for development in Africa. Their article relied heavily and approvingly on one Matthew Parris' newspaper argument that the "crushing passivity" of the mind-set of Africans is their greatest problem and only Christian missionaries, rather than aid money, can salvage Africans and make development possible (Walter \& Anderson 2012). Walter and Anderson also make reference to their personal observation over decades of working in Africa as supportive of their arguments.

The authors are right that Christianity makes a significant impact in the lives of many African converts at different levels; and almost all the literature reviewed agree that development practices and strategies in Africa need to take religion (not only Christianity) seriously. UN IATF-FBO (2015:v) has also cautioned secular development actors "against either ignoring the role of religion or over-simplifying the complexities and ambiguities often found in such domains, particularly around contentious rights-related issues." However, the work of Walter and Anderson is revelatory of underlying colonial and derogatory constructions of Africans and their realities, present - but not always obvious - in often externally crafted and superimposed approaches to development and frameworks for analysing Africans and their experience. Walter and Anderson use a fixity approach to analyse traditional religious and 'tribal' Africa, where people are laid back, passive and live in anxiety and fears of evil spirits, 
never making any progress in life until Christianity comes to liberate them and make it possible for them to develop. It shows a disappointingly high level of ignorance about ATRs and the general contemporary dynamics of religion in Africa.

Juxtaposing Christianity against certain distilled or frozen ideas about ATRs and culture in order to demonstrate impact is a more common practice among scholars who write on Pentecostalism in Africa. Freeman (2015), for example, shows that Pentecostalism does, in fact, shift the values, beliefs and morality of converts in ways that produce radical social transformation and economic liberation when other necessary factors favour such change. But to demonstrate this, Freeman draws a contrast between what he termed 'Traditional African' and the Pentecostal African. For Freeman, the traditional African belongs to a tight-knit network of community and kinship which has several economic demands including assisting less capable relatives and contributing towards costly ceremonies and rituals. The traditional African is also cautious of having more wealth than their peers to avoid being accused of using witchcraft and sorcery; choose stability over taking risks and are quitters who simply accept their situation (Freeman 2015). Freeman's Pentecostal African, on the other hand, is simply an individual who does not have economic demands beyond his immediate, often, nuclear family. They view becoming rich as God's desire, and thus, commit to its materialization; believes that hard work and prayer will make their situation better, able to risk and try something new, and has a strong agency (Freeman 2015). Like Walter and Anderson, Freeman exposes an essentialist colonial imagination of the black Africans based on flawed knowledge and interpretation of African traditional worldviews, their behaviours and the motivation for such behaviours. ATR is engaged in more detail below, but it suffices here to note that such arguments overlook the fact that ATRs are not singular, static or produce the same outcome in all adherents. Moreover, converts to Pentecostalism in Africa are largely members of other Christian traditions and the act of conversion, whether to Christianity in general or Pentecostalism, is an indication of agency, risk taking and ability to try something new. If Africans did not have these tendencies, Pentecostalism would not have followers on the continent.

Pentecostalism is widely explored in relation to development in Africa, especially economic development, although Pentecostal organizations are presented as not explicitly involved in development like other Christian traditions (James 2012; Wariboko 2012; Freeman 2015; Burgess 2015). 
These writings emphasise the dramatic transformational power of Pentecostal teachings to personal, and through that, community life, which directly or indirectly impact development; and a few examine deliberate and organized involvement of Pentecostals in development projects. Burgess (2015), for example, shows how Pentecostal teachings are directed beyond personal holiness to address the problems of poverty and violence in Zambia and Nigeria respectively. James (2012) presents a case in Malawi of a Pentecostal programme which challenges stereotypes of Pentecostals being concerned with only heavenly things, by equipping local congregations with the attitude and skills to initiate social development projects (James 2012). Their work is rooted in a belief in God as being interested in not only the spiritual needs of the person, but the material, social and emotional as well (James 2012). They teach that poverty is partly caused by lack of faith and relationship with God, and having faith in God, provides the courage and hope that believers need to overcome their fears and to advance in life (James 2012). This is among the teachings highlighted by Wariboko (2012), who identified the theological paradigms in the Pentecostal discourse on Africa's economic development. Some of these paradigms view poverty in Africa as a religious problem caused by lack of trust or faith in God's promise or disobedience of spiritual prosperity laws. Others see the poverty as caused by evil forces which are in control of the continent, hence the need for fervent and persistent prayers to reclaim the continent (Wariboko 2012). Poverty is also seen as the result of immorality of individuals and leaders, inferiority complex due to historical colonialism, slavery and racism (Wariboko 2012). Thus, the way particular Pentecostals respond to national poverty is largely determined by which paradigm they use to understand poverty.

There are a few articles that do not entirely subscribe to the narrative about Pentecostalism transforming individuals and, consequently, their socio-economic lives in a positive way. Deacon (2015) looks at how Pentecostal narratives have contributed to the emergence and evolution of the Kenyan nation and state. According to Deacon, this was played out in the 2013 national elections where religio-political narratives were used to present the elections as a chance to 'save' Kenya, using a narrative of a bornagain nation and thus, a state was produced that in effect, only benefited the winning side of the political battle rather than achieving noble social visions upheld in Christianity (Deacon 2015). In a different case in Kibera, an informal settlement in Kenya, Deacon (2015) observed that the effort of a Pentecostal organization to transform the community, while assisting 
with personal skills such as self-confidence and marketing, failed to improve livelihoods. This was because they overlooked the local conditions that made such improvements impossible and made the skills they equipped their adherents with not actionable (Deacon 2015). Deacon noted that rather than transforming them and their situations, their Pentecostal faith and church activities became survival strategies in their very challenging environments. There was no evidence of better, long-term, economic transformation, better security or wellbeing (Deacon 2015).

\section{Islam and Development in Africa}

With regard to Islam, religious beliefs, values and principles also emerge as playing significant roles in development in Africa through organizations that explore such principles to tackle specific developmental challenges. Renders (2002), for example, notes that by using the notion of 'Islamic development', Muslim organizations in Senegal pursue a more moral and ethical development strategy and uphold Islam as a cultural framework for delivering development. In her critique of Western funders for their lack of interest in funding Islamic NGOs, Adamu (1999) presents the efforts of Muslim women in northern Nigeria to redefine Islam as a legitimate instrument for addressing gender issues. She highlights the importance of viewing gender within the context of Islam as not separate from the religion, because religion, for Muslims, is their total way of life and not simply rituals they perform (Adamu 1999). The lack of this understanding, she suggests, is partly responsible for failure of Western models of development in Muslim contexts, and the lack of cooperation western NGOs receive in some Muslim communities where they are viewed as Anti-Islam United States' agents, and Muslim activists working for such organizations are also mistrusted. In Cochrane and Nawab (2012), the focus is on the ways Muslims put the tenets of their beliefs into practice by providing a development practice guidance that sought to address HIV \& AIDS in South Africa. Cochrane and Nawab (2012) identify the Islamic principles used by two Muslim organizations to achieve this goal. These principles include the religious duty to assist others, reduce harm, take a holistic approach, inclusiveness or non-discrimination, and cooperate with others. 


\section{African Traditional Religion and Development in Africa}

ATRs, in their own right as religions, are the least examined in the literature on religion and development in Africa. As stated already, they are more often used in a shallow manner to reflect or bounce off the "profound' developmental benefits of Christianity, especially Pentecostalism. This is rather problematic considering the fact that ATRs adapt to modernity and social change, and that conversion to Islam and Christianity has only seen ATRs taking new forms and persisting in the lives of Africans, including Christians and Muslims, in new ways that are both beneficial to them and accommodating of their Christian or Muslim faith (Olupona 2004). Additionally, a thorough examination of ATR, which is hardly present in these literatures, would reveal that they are not exactly the impediments to developments that some writings imagine them to be. In his work on ATR's perspective on religion and development in Africa, AwuahNyamekye (2012) used the example of the Akan traditional worldview to bring ATR to the discourse on development. Awuah-Nyamekye observes that contrary to the modern tying of development to economic figures, the indicators of development for the Akan people of Ghana are the real and total conditions of people marked by, first, the absence of life-denying experiences such as poverty, diseases, crop failure, barrenness, premature deaths and several other misfortunes; and second, the presence of events and experiences that are affirming of all life, including long life, security, many children, desirable harvest and the general absence of misfortune (Awuah-Nyamekye 2012). Very importantly, Awuah-Nyamekye, highlights that Africans strongly believe that development results from conscious and deliberate individual, and better still, collective effort and hard work. He also notes that for the Akan, the notion of development is more oriented towards human and holistic development, beyond good roads, impressive economic growth indicators, housing, good health care facilities. These are problematic when they exist side-by side with increased armed robbery, marginalization, a culture of rape, injustices and other social ills.

Awuah-Nyamekye (2012) does not suggest, in his work, that the Akan have the perfect approach to development, or that the lives of the Akan people are dramatically better because of these traditional beliefs. Some of the Akan development indicators and the structures established to achieve development (such as chieftaincy, kinship ties, gerontocracy, etc.) may, in fact, be viewed through modern, Western-derived frameworks as 
retrogressive and obstacles to development. But his work offers very useful insight into ATRs which seems to be analysed in some religions and development scholarship with the intent on presenting them as stalling Africa's development. The factors that are responsible to contribute to and sustain underdevelopment in Africa are several and interwoven, including the misunderstanding of African worldviews and ways of life as demonstrated by incompatible and counterproductive strategies and polices.

In a similar work, Alolo (2007) examines how ATR views certain development concepts. Alolo points out that the notion of justice, for example, is conceived in ways that do not separate it from ideas about society. Thus, the existence, continuity and stability of the community takes precedence over individuals' rights, and the identity of the individual is forged from that of the community. Justice did not also include vindictiveness, and the notion of retributive justice was rare (Alolo 2007). Thus, penal institutions were rare, and punishment from crimes was often immediate with hardly any follow up on past crimes. While crime was also conceived as anti-social, the preservation of social cohesion was more important (Alolo 2007). Alolo ties ATR to precolonial times, which underrepresents the dynamics of ATR as relevant to development today. However, he acknowledged that ATRs are not static but evolve, and that there is a danger of presenting a romanticized and outdated image of ATR. Alolo's work, again, offers a deeper and different narrative on ATRs that is relevant to development and require further exploration. However, beyond conceptual exploration of ATRs and development, Ogbonnaya (2012) argues that despite not being institutionalized like Islam and Christianity, ATRs make especially psychological contribution to sustainable development. ATRs, he argues, give Africans a sense of security and the assurance of the protection and continuous assistance of the spirits of their ancestors. This provides confidence due to the belief that the ancestors protect them from evil forces that are capable of disrupting the development of the community (Ogbonnaya 2012). Ogbonnaya further makes the important observation that in the face of suffering, and hardship, millions of African Christians and Muslims resort to traditional religion. They have also found ways to incorporate elements of ATRs into their value and belief systems.

Additionally, he notes that ATRs have shown invaluable tolerance of other religions, especially Islam and Christianity in Africa, which the warring religions in places like Nigeria could learn from (Ogbonnaya 2012). It can be argued, then, that rather than being an obstacle to development, ATRs offer more conducive environments for development in places such as 
Nigeria, where Christianity and Islam have many times undone what developmental progress they have made through antagonistic relationships that have led to several conflicts, causing massive destruction of lives and properties, as well as being entangled in detrimental politics and corrupt practices that thwart development. Kubai (2014), further confirms the value of ATR for development in the Rwandan government's use and reinvention of traditional worldviews and practices for post-conflict development in Rwanda.

\section{Conception and Coverage of Development}

The concept of development is very broad, and that is perhaps, why several of the reviewed authors did not spend time on the concept itself. Ellis and ter Haar, over a decade ago, observed that development had been primarily considered in economic terms, thus limited to economic development (Ellis \& ter Haar 2004). They also noted that while the notion of human development had emerged to take the emphasis beyond economic development to include other important aspects of life such as education and health, the concept of human development had not been made a reality (Ellis \& ter Haar 2004). They suggested that the notion of human development, especially in relation to Africa, should include the spiritual dimension. Ter Haar (2014) has developed this argument further in a more recent work. She argues that, in fact, from an African perspective, both religion and development have the same objective of enhancing the quality of life of Africans and advancing their material welfare. She further argues that because the African worldview is holistic and does not separate the non-material from the material, development for Africans is equally spiritual and not limited to the material. Thus, at the heart of progress, which is the central term in notions of development, is spiritual growth, and spiritual and material wealth go together (ter Haar 2014).

There is a strong indication in literature that although economic development remains a major concern of developmental practice today, several other aspects of the human life are also increasingly receiving attention. The range of developmental issues covered in the reviewed literature, as already visible in the foregoing, include, violence and poverty, migration, health, education, political participation, economics and gender. These developmental issues are also interconnected and thus, sometimes impossible to engage any one of them exclusively. When engaging the question of gender from a developmental perspective, for instance, several 
other interconnected issues are brought to light. For example, van Klinken $\&$ Chitando show that it is difficult to examine masculinities and religion in Africa without paying attention to HIV \& AIDS and its impact on both women and men (van Klinken \& Chitando 2015); Adamu (1999) in her examination of Islamic women's developmental work, highlights the attitude of Western donors and benefactors towards supporting Muslim development NGOs and how the tension between Islam and the West is played out on the terrain of gender and development in Muslim societies. Ahmed's (1999) examination of the impact of Islamic extremism on Somali women, particularly in terms of economic development, also highlighted important questions around censorship, veiling and religious education.

Religion and spirituality, in the reviewed literature only seem to matter as a tool or means to achieve developmental goals. Religion and spirituality do not constitute developmental goals in themselves. The general attitude is that development marked by economic prosperity, good health, education, among other things, needs to be achieved and every useful resource needs to be deployed for this purpose; and religion in the African context, evidently, is one such powerful tool for achieving developmental goals. This is not to suggest that developmental organizations should invest in the spirituality of individuals and communities. However, it might be necessary to consider reframing development in ways that show a genuine care for people's faith beyond utility, especially for people who place more value in their faith than developmental concerns, and in places where religion permeates or is not distinguished from other spheres of life.

As suggested above, development work will benefit from closer examination of religions and how certain developmental notions are conceived within specific religions. This will assist with the refinement of developmental approaches to be more relevant to context. Hiagbe (2015) rightly contends that the notion of progress is at the centre of developmental approaches, as they aim to achieve a shift towards a better vision of the realities they seek to address. Hiagbe (2015) highlights the essence of development found in several African cultures which connote enabling the individual or community to 'come out,' in the sense of realizing their full potential, rather than imposition of external agendas on them. In addition to Hiagbe's belief that Christianity holds great promise for economic development in Africa, he also argues that theological reflections that seek to respond to the challenges on the continent must be rooted in the cultures of the people. 


\section{Conclusion}

In this literature review on religion and development in Africa, we have highlighted some of the important works on the subject, and thereby, made visible other possibilities and potentials for continuing scholarship and praxis. We noted that Christianity, especially Pentecostalism, has received disproportionate attention from scholars. This is perhaps, understandable given the exponential growth of the movement in Africa. However, more investigation is needed into other aspects of Christianity, including pre-Pentecostal forms and denominations, and African Independent Churches (AICs). While the growth trend may appear to favour Pentecostalism, other forms of Christianity are not static and may reveal hidden dynamics of development in Africa. The same applies to Islam and ATRs, which calls for more investigations in the present context. Additionally, and very crucial, there is a deafening silence on other religions in Africa. While Christianity, ATR and Islam are considered the major religions in Africa, there is a growing presence of other religions on the continent such as Hinduism, Judaism, the Baha'i faith, Eckankar, and other new religious movements. Are these also involved in any developmental projects? Do their religious beliefs produce any transformation relevant to the question of development in Africa? Is there anything we can learn from them to advance our understanding of the subject?

Overall, there are indications that the FBOs and other forms of religioninspired and supported development work in Africa still struggle to respond to local development needs in ways that demonstrate adequate understanding of the contexts, the people, their religion and the most effective model of development to implement. It is suggested that with particular regards to ATR and general religious practice in Africa, international and even local organizations and policies could be perpetuating colonial stereotypes and imaginaries of Africans and their realities in their developmental engagements. Thus, development studies and practice in Africa need to incorporate a significant investment in reflexivity in order to achieve maximum effectiveness.

\section{References}

Adamu, F. L. 1999. A double-edged sword: Challenging women's oppression within Muslim society in Northern Nigeria. Gender \& Development 7 (1): 56-61.

Ahmed, S. 1999. Islam and development: Opportunities and constraints for Somali women. Gender \& Development 7 (1): 69-72. 
Alolo, N. 2007. African traditional religion and concepts of development: A background paper. RAD Working Papers Series.

Awuah-Nyamekye, S. 2012. Religion and Development: African Traditional Religion's Perspective. Religious Studies and Theology 31(1): 75-90.

Bompani, B. 2015. Local religious organisations performing development: Refugees in the Central Methodist Mission in Johannesburg. Journal of International Development 27(2): 197-212.

Bornstein, E. 2002. Developing faith: theologies of economic development in Zimbabwe. Journal of Religion in Africa 32 (1): 4-31.

Burgess, R. 2015. Pentecostals and Development in Nigeria and Zambia: Community Organizing as a Response to Poverty and Violence. PentecoStudies: An Interdisciplinary Journal for Research on the Pentecostal and Charismatic Movements 14(2): 176-204.

Cochrane, L. \& Nawab, S. 2012. Islam and development practice: HIV/AIDS in South Africa. Development in Practice 22 (5-6): 875-882.

Deacon, G. 2015. Kenya: A nation born again. Penteco Studies, 14, 219-240.

Deneulin, S. \& C. Rakodi. 2011, Revisiting Religion: Development Studies Thirty Years On, World Development 39 (1): 45-54. DOI: http://dx. doi.org/10. 1016/j. worlddev. 2010. 05. 007.

Ellis, S. \& ter Haar, G. 2004. Religion and development in Africa. Commission for Africa background paper.

Freeman, D. 2015. Pentecostalism and Economic Development in Sub-Saharan Africa. In The Routledge Handbook of Religions and Global Development. Edited by Emma Tomlin. Oxford: Taylor \& Francis.

Freidus, A. 2010. "Saving” Malawi: faithful responses to orphans and vulnerable children. " Annals of Anthropological Practice 33(1): 50-67.

Green, M., Mercer, C. \& Mesaki. S. 2012. Faith in forms: civil society evangelism and development in Tanzania. Development in Practice 22(5-6): 721-734.

Hiagbe, K. A. 2015. The Church and Sustainable Development in Sub-Saharan Africa. Studia Historiae Ecclesiasticae, 41(2): 164-179.

James, R. 2012. Addressing dependency with faith and hope: the Eagles Relief and Development Programme of the Living Waters church in Malawi. Development in Practice 22(5-6): 883-892.

Kinney, N. T. 2012. "The role of a transnational religious network in development in a weak state: the international links of the Episcopal Church of Sudan. " Development in Practice 22 (5-6): 749-762.

Kubai, A. 2014. Reinventing “Tradition”: Social Reconstruction and Development in Post-Genocide Rwanda. Dronen, T. S. (ed.). Religion and Development: Nordic Perspectives on Involvement in Africa. New York: Peter Lang, 87-107.

Leurs, R. 2012. Are faith-based organisations distinctive? Comparing religious and secular NGOs in Nigeria. Development in Practice 22(5-6): 704-720. 
Lipsky, A. B. 2011. Evaluating the strength of faith: Potential comparative advantages of faith-based organizations providing health services in sub-Saharan Africa. Public Administration and Development 31(1): 25-36.

Njoh, A. J. \& Akiwumi, F. A. 2012. The impact of religion on women empowerment as a millennium development goal in Africa. Social Indicators Research 107(1): 1-18.

Olarinmoye, O. O. 2012. Faith-based organizations and development: Prospects and constraints. Transformation 29(1): 1-14.

Olupona, J. K. (ed). 2004. Beyond primitivism: indigenous religious traditions and modernity. New York: Routledge.

Ogbonnaya, J. 2012. Religion and sustainable development in Africa: The case of Nigeria. International Journal of African Catholicism3 (2): 1-22.

Renders, M. 2002. An ambiguous adventure: Muslim organisations and the discourse of development in Senegal. Journal of religion in Africa 32(1): 61-82.

Stuckleberger, C. 2007. Calvin, Calvinism and Capitalism, in Edward Dommen \& James D. Bratt (eds), Calvin Rediscovered: The Impact of his Economic Thought, Louisville: Westminster: John Knox Pr. 121-131.

Swart, I \& Neli, E. 2016. "Religion and Development: The Rise of a Bibliography," HTS Teologiese Studies/Theological Studies 72 (4): 1-27.

ter Haar, G. 2014. Poverty and Prosperity in Africa. Dronen, T. S. (ed.). Religion and Development: Nordic Perspectives on Involvement in Africa. New York: Peter Lang. 1125.

UN Inter-Agency Task Force on Engaging Faith-based Organizations for Development (IATF-FBO). 2015. Religion and Development Post-2015: Report of a Consultation among Donor Organizations, UN Development Agencies and Faith-Based Organizations. New York: UNFPA.

van Klinken, A. \& Chitando, E. 2015. Masculinities, HIV and Religion in Africa, Tomalin, Emma, ed. The Routledge handbook of religions and global development. Routledge. 127-137.

van Santen, J. 2014. 'Educating A Girl Means Educating A Whole Nation' Gender Mainstreaming, Development And Islamic Resurgence In North Cameroon. Journal of International Development 26(3): 368-381.

Walter, S. L, \& Anderson, J. B. 2010. Liberated Mindsets, Literate Minds: Reflections on Christianity and Development in Africa. The Review of Faith Q International Affairs 8(4): 79-83.

Wariboko, N. 2012. Pentecostal Paradigms of National Economic Prosperity. In: K. Attanasi \& A. Yong. Pentecostalism and Prosperity: Socio-Economics of the Global Charismatic Movement. New York: Palgrave MacMillan. 35-59. 


\section{Religion and Development in Sub-Saharan Africa Understanding the Challenges and Prospects}

Tarisayi Andrea Chimuka

\section{Introduction}

This chapter examines the role of religion in development. This comes at the backdrop of a mischievious attitude, mostly by politicians, that religion is a private and personal affair. History, particularly the rise of European modernity, has also pushed religion to the sidelines of human civilization, a position it has maintained for a very long time. Naturally this produces the view of the ineffectiveness of religion in matters of social transformation. Is this position correct? The chapter seeks to burst this assumption as unfounded and suggest ways religion can contribue to national development.

In pursuance of the objectives set above, the chapter adopts the historical as well as critical analysis. Situations in which religion has been cast in the negative will be analyzed in contradistinction to those cast in favourable light. In the end, the chapter shall glean for transformative possibilities embeded in religion. The first part of the chapter examines the historical snippets exhibiting the controversies surrounding religion in social transformation. The next section focuses on the negative agency of religion. The third examines the transformative power of religion in social development. Section four concludes the chapter by suggesting areas of transformative engagement by religion.

\section{The Controversies Surrounding the Transformative Powers of Religion}

For a very long time since the Enlightenment, the role of religion in social transformation has been relegated to the sidelines (Shah 2013). With Enlightenment thinking came secularization of the state, leading to marginalization of religion and the diminishing of religious authority (Chaves 1994). Religion was also relegated because it was considered irrational and stifling the progress in science. Also in many of the global initiatives on development, religion has been sidelined (Marshall 2001). 
This situation has begun to change and religion has begun to be revived. One trigger, were the events of September 11, 2001 which Katherine Marshall says, "have underscored starkly the powerful links between religion and modernization and posed a host of new questions about how the links operate and how thinkers and actors should respond" (Marshall 2001:339).

In those contexts where religion has been allowed to flourish, it has courted a lot of controversy. In some cases, it has been regarded as the opium of the people for allegedly preventing them from seeing the economic and social realities affecting them (Guiso et al. 2003, 226). In others, it led to unrestrained and irresponsible assault on the environment. According to some scholars, for instance, Shehu, the looming environmental crisis experienced today was historically triggered by religion (2014:28). Mention is made of the biblical injunction found in Genesis $(1: 26,28)$. According to the text, God gave humankind dominion over all other creatures on the surface of the earth and in the seas. This, it is argued, has given humanity the attitude of superiority and the belief that the reason nature exists is to serve the needs of man (Das 2012:224). In other areas, religion has been responsible for extremism and violence. Some Faith Based Organisations (FBOs) have been painted as dangerous and undesirable. This is basically because these groups of people can carry out extreme actions all in the service of their God (Iannaccone 2005). Religion has been largely responsible for crusades and conquest wars (Jinging 2006). These are just a few examples pointing to the role of religion in fanning and executing violence. According to Jinging:

Nowadays, religiously motivated terrorism has superseded other forms of terrorism and leads to more intense forms of violence and bloodshed. Religious terrorist groups include the AI Qaeda network, various American white supremacist militias (including the Christian Patriot movement), the Jewish Kach/Kahane Chai, the Sikh Dal Khals and Dashmesh, and Japan's Aum Shinrikyo, among others (Jinging 2006:12).

Jinging further argues that it is no longer accurate to identify 'religious terrorism' with Islamic groups. There are now many more religious groups involved in terrorism. In addition there are now other queer groups in the United States of America and even in Britain called white supremacists that also pose a problem to peace (Jinging 2006:12).

A distinction ought to be made between social transformation and development. While the mobile or cellphone has transformed the lives of many in Southern Africa, it did not necessarily bring development, since 
the technology is not developed and owned by indigenous Africans. The former alludes to any changes in society while the latter is mostly associated with economic progress.

\section{Is Religion a Bad Master?}

Throughout history, religion has always been a force to reckon with. Initially one can treat it as a tool for repression and oppression. Whole communities were decimated and survivors turned into slaves on account of religion. Religion in other contexts has been responsible for the oppression of women (Gcabashe 1995). In other contexts, religious minorities are discriminated against (Weller 2006). Religion also stands accused of potentially destroying the health of patients. According to Krause and Wulff (2004:36) "instead of promoting health and well-being, exposure to the negative aspects of religion may erode physical and mental health."

Krause and Wullf contend that there are three major areas religion has profound effects on believers. In the first instance, it can cause negative interaction among fellow church members. Secondly, it causes negative coping responses in people and finally, it fans scepticism (2004:36). Krause and Wullf further point at negative coping responses and the growing doubt in religion (ibid.). The patient loses faith in religion and actually deteriorates in health and psychological distress (Krause 2004:36). Other scholars even give a global outcry against religion. According to Timothy Shah (2013), the world is under attack from what he calls, "Global crisis of reactive religious militancy. " These groups where ever they occur are often a reacton to high levels of religious repression.

Religious militancy is among the most dangerous and pervasive global security challenges that fits this category because numerous factors have fueled a rising expectation on the part of religious communities everywhere that they should exercise greater influence in their societies, while the reality is that numerous factors have conspired to block or reduce their influence or repress them altogether. Indeed, the reality is that there is today what could be called a growing, gaping global religious freedom deficit. The combination of rising expectation and worsening reality is a combustible mix that is generating a growing number of violent religious ideologies and movements - and has been doing so at an accelerating rate across the globe for most of the last one hundred and fifty years (Shah 2013:1).

The passage above underscores the role played by religion in ideology formation in communities. Heightened expectations and worsening 
situations precipitate action on the ground. Religious leaders are quick to spot oppression and constriction of their spiritual spaces and this results in agitation:

Religious ideology is an especially powerful trigger of reactive violence in the face of severe repression because it often gives groups not only a great expectation but a transcendent expectation (if not a divine, prophetic promise) they can and will prevail against even overwhelming opposition that a transcendent power guarantees their eventual success, however unpropitious immediate circumstances may be. Religious ideology also widens the sense of an intolerable normative gap between the way things are now, in which the religious group is severely repressed and stymied and unable to carry out the will of God, and the way things would and should be, in which a religious vision provides a picture of perfect peace, harmony, and fulfillment of the divine will (Shah 2013:2).

In other contexts, religions have produced intolerance and xenophobic tendencies. This happens mostly when violence is meted out at those religious others, usually minorities, or based on intense insecurity among groups (Inglehart 2006). It is a given that religion has been responsible for bad outcomes in some cases. This only shows the ambivalent nature of the phenomenon. Does it follow that religion has no capacity to bring about the good? The next section examines this theme in some detail.

\section{Religion's Transformative Powers in Southern Africa}

Debate on the involvement of religion in the political arena is raging in Africa. However, it is beyond doubt that religion has been active in the democratization of states (Riedl 2011). Most people belong to and are active in one religious organization or other in Africa. This membership and social belonging to churches or faith-based organizations (FBOs) has tremendous impact if directed on politics (Riedl 2011:30). Riedl (2011:30) contends that religion and politics have mutual influence:

... religion is a domestic factor that interacts with other social cleavages of race, ethnicity, region, social class, and political position, it also has an international dimension in terms of the resources, networks, and ideologies that are shared in a globalized world ... in many regions across the world, religious actors were highly influential in the initial stages of the "third wave" of democratization ... While democratization has proceeded to different extents across the continent, there is no doubt that religious associations have increased latitude to organize for obvious political purpose, in newly pluralistic societies. 
Since humanity is naturally fragmented into the various religious communities, it is impossible to ignore the latent influence of religious ideology. Religions have values which go beyond the particularism found on the ground:

The key point is that religion offers a form of transcendence from the divisive and bitter particularities that animate contemporary political conflicts. It does this through the spiritual affirmation of our shared human worth due to the love of God(s). From this recognition, achieved through spiritual appeals, the conditions for more rational and democratic debate can be retrieved. In addition, religious transcendence redeems the value of Utopian thinking, and thus could help re-orientate public debate from a politics of blame for past wrongs to a politics of imagining of future rights (Piper 2010:77).

According to Piper, FBOs have great potential in fostering democracy and development. In Southern Africa, these FBOs have been doing sterling work in providing education, healthcare systems, providing relief aid in times of disasters and in social welfare efforts. In this respect religion is unique in that it bears normative commitment and offers alternatives on the ground (Piper 2010:78). Religion deals with matters of spirituality and is central to human activities (Piper 2010:78).

Apart from the profound influence religion has on politics, it can also impact the social transformation and on economic development. As Guiso et. al see it, religious beliefs are associated with good economic attitudes (Guiso et al 2003:225). Max Weber (1930) observed that religion, particularly Protestant Reformation, has been responsible for the rise of captitalism. Hence the social influence of religion cannot be overemphasized. Spirtuality has fond a ignificant place in business (Bouckaert and Zslonai 2012:491). Religion can even influence people to venture in economic activities, including enterpreneurship (Henry 2014:1). Shah (2013) maintains that religions have become more assertive and aggressive. Thus:

At the same time, religious ideology combines with these democratizing trends to further heighten the political expectations of religious communities all over the world. Virtually all of the world's religious communities have developed increasingly assertive and in some cases militant political theologies over the last two centuries and particularly in the last one hundred years ... but every major religious tradition has witnessed the displacement of relatively quiescent and passive political theologies by more activist, engaged, and sometimes militant political theologies and religio-political movements, with Sinhalese Buddhist nationalism, Hindu revivalism and nationalism, Christian Democracy, 
Christian "liberation theology," modern Islamism, militant forms of Pentecostalism and charismatic Christianity, and "Engaged Buddhism" being just a few prominent examples (Shah 2013:2).

Elsewhere religious ideas are seen to play a much more significant role in positive social health (Sherkat 2007). Religion also plays a positive role in Higher Education. This is captured by Sherkat (2007:5):

Students who participate in religious groups have made a choice about social commitments. Being active in religion precludes other types of social ties, particularly ones which might cut against the prescriptions and proscriptions of religious traditions. If a student is going to Mosque on Friday, she is unlikely to be found at the bar. Commitments to religious groups also preclude negative behaviors like going home for the weekend, or taking impromptu road trips. Connections to positive social groups promote conformity, and in the college setting, conformity means going to class and completing assignments. Alcohol and substance abuse are among the most important factors predicting negative educational outcomes. Most religious groups oppose alcohol use, or at least militate against drunkenness. Hence, students who choose to join religious groups are going to be less likely to abuse alcohol and other drugs.

\section{Rethinking Development in Africa and the Role of Religion}

Most of the development initiatives in Africa have been framed from Eurocentric ideas. In this regard, the FBOs had to assume the mould of the dominant paradigms of power. In the words of Dei and Adjei (2014:3):

Much of ongoing intellectual discussion on 'development' is caught up in the dominant paradigms of Western thinking. Alternative visions and counter theoretical perspectives of development even struggle to disengage themselves from the influence of a Eurocentric paradigms.

The whole of Southern Africa is now independent, thus, there is need to be cognisant of a myriad of factors that feed into the concept of development. Do we continue with the Western paths to development or there is need to rescucitate the traditional African views as well? As Dei and Adjei (2014:2) put it:

We must critically engage the many ways of presenting current challenges on 'development' and the interplay of tradition and modernity, as well as contestations over knowledge production in post-colonial' Africa. We must include the roles and significance of Indigenous/local cultural resource knowledges, science, gender, ethnicity, language, and religion for understanding of African development. Other related questions of interest should include social stratification and cultural pluralism; formulation of 
national identity; political ideology and the growth of nationalism; and the search for peace, cooperation, and social justice.

It is interesting to note how Dei and Adjei have alluded to the contribution of religion in understanding African Development. However, it may be inquired whether it holds hidden in its belly, the possibilities for African progress beyond European models.

Thus, in order for meaningful and sustained development to proceed, we must interrogate the power of ideas to bring about social change. We must also begin by developing Indigenous, non-Western concepts and categories for understanding African societies. This requires that we pay particular attention to the production and the social organization of knowledge, and particularly to culture and the cultural dimensions of development (Dei and Adjei and Adjei 2014:3).

Development is not just about an increase in physical capital. It requires changes both in ways of thinking and in the social, political, cultural, and economic institutions of society (Dei and Adjei 2014:3). Thus, as we look at Southern Africa, the challenge apart from economic prosperity is to raise the intellectual capital of the region to levels which facilitate other forms of growth such as investiment, enterpreneurship, technological advancement and the like. Again Dei and Adjei (2014:4) have this to say:

In recasting and bringing new readings to African development' we call for placing at the center the questions of the environment (specifically Land and Earth), spirituality and culture, and different ontological and epistemological bases for knowledge production and practice within an Indigenous African context. This approach begins with a deeper appreciation of the Land and the Earth and how they may inform the ways in which groups live their lives as peoples. Understanding the Land and the Earth is an acknowledgment of the environment and the spiritual knowings that guide everyday social interactions - be they political, economic, material, or physical. Development begins with local peoples' understandings of the self and connections to others and communities. Development is about satisfying locally determined needs and aspirations in synchrony with what the local environments (defined as social, physical, and natural) have to offer. Development is about developing our relations with the Divine, Mother Earth, and the Land and creating a self and the collective connection. This also means developing a higher purpose of life and social existence for all. Development is living in relation to the Land, Earth, and Nature and coming to know how these relations inform the way we act responsibly.

Central to Dei and Adjei's postulation, development in Southern Africa needs to be holistic to include concerns for the land, ecosystems, economic configurations and social and intellectual capital. This is where religion comes in because development begins with the way local 
inhabitants view themselves and their surroundings. Certain key relationships with the land and ecosystems need to be forged. If this is not factored in, efforts at development often end in futility. This is perhaps what Marshall (2001:344) alludes to:

It is no accident that development actors are often exhorted to take a comprehensive or holistic approach. Current trends and vocabulary are the product of much bitter experience and a process of learning that the earlier and seemingly straightforward visions of linear progress toward development need rigorous and comprehensive rethinking. Time and time again disappointing results can be laid at the door of experience ignored, a piece of perspective missing in analysis, design, or implementation. Forgetting the roles of women in village planning, of religious calendars in planting advice, or of social patterns in location of water points or schools are examples of evident gaps with clear consequences. Almost as telling, development actors have often operated in ignorance or oblivion of the actions and perspectives of others, with the proverbial left hand and right hand moving in conflicting directions. This is as true for government departments as for development agencies. To give just one example, the optimistic and sensible plans.

Picking on the idea of capacity building under religion, one may posit on the possibility of religion educating members on the value of hard work as opposed to miraculous blessings in obtaining jobs, cars, houses and the like, as promised by some Pastors. This is by no means an attempt at questioning God's miraculous blessings on God's people. It is God's prerogative. However, of late we have witnessed some men of the cloth premising the Gospel of prosperity on expectation rather than hard work. This promotes laziness among citizens. This chapter challenges the raising of the expectation of people to receive at the expense of diligence and hardwork.

The argument proffered here is that religion, by way of FBOs, has a significant role to play in capacity building for Development. FBOs could teach the virtues of diligence and hard work. There is also the imperative to cultivate intellectual skills of citizens. This is possible given that over the years, FBOs have complemented the efforts of governments in providing education, healthcare facilities, shelter and welfare. Hardwork and the exercise of intellectual skills such as critical thinking, innovation and creativity are indispensable ingredients of social transformation.

FBOs can nurture and cultivate critical thinking skills as a way of taping into and utilizing the potent human capital for development. Village initiatives, especially household projects such as gardening and land preparation and planting dates must be co-ordinated. In Zimbabwe, for 
example the concept of mushandirapamwe (co-operative ventures) is central to development (Chimuka 2001). Women ought to be empowered. A case in point is the maTarenta (Talents) initiatve by the ZAOGA FIF ${ }^{1}$ Church to empower women to work hard and creatively embark on projects to raise funds for the Church and their own households (Musevenzo et al 2017):

Through talents, women are empowered to execute both formal and informal businesses from a religious background. Equally important, these talents have effected and triggered the realisation of women capabilities both at home and outside home. At home, some men have also benefited from the projects undertaken by women thereby raising the livelihood status of the family at large (Musevenzo et al 2017:32).

This is just one illustration of the role religion can play in capacity building for development. In those areas where destruction and mistrust had developed, religion can build the bridges of trust again (Reuben 2011:226). FBO's can also prop up their educational efforts in the promotion of human capital, especially the cultivation of a certain kind of thinking among the citizenry which engenders development. McFadden defines human capital as, "the stock of skills by workers through education, on-the-job training, and sef- improvement" (McFadden 2008:380). Society derives a lot of benefit from investing in people (Sweetland 1996:341). A citizenry that is equiped with critical thinking skills is very useful towards that society's development in the sense that the way the people think about how to produce goods and services impacts on their quality of life (Oliver 2004:120). It is these intangible skills and values in people that are now considered as drivers of development (CIPD 2017:5). These critical skills, usually highly sought after by companies and organizations, are very important for society as a whole. Religion, by way of FBOs, can exploit this opportunity andcontribute immensely to develop social capital.

Since FBOs are already involved in education by way of building and running schools and universities in Southern Africa, they can also be directly involved in curriculum design and in slotting in subjects such as logic and critical thinking in high schools. They can also do a lot to encourage the same said skills in the various other fora where sermons, workshops and leadership trainings are conducted. Imparting critical

1 ZAOGA FIF is an acronym for Zimbabwe Assemblies of God in Africa Forward in Faith. 
thinking skills, fostering innovation and encouraging creativity are invaluable for a citizenry.

The critical thinking skills for any citizenry goes hand in hand with health (CIPD 2017). The people need to stay healthy and alive for them to contribute towards development. Thus, when examining development, it is important also to factor in the well-being of the people. Religion wants to develop the whole person. This includes taking care of the health, the spiritual and the intellectual aspects of life. One of the advantages of the intellectual skills such as critical thinking is that it frees citizens of gullibility ${ }^{1}$. Gullibility is generally a phenomenon in society where citizens believe anything without warrant. In the end, they are manipulated by politicians, fraudsters, and other unruly individuals. A gullible citizenry cannot fully participate in a democracy as they would be susceptible to manipulation by politicians. A lot of people end up being victims of cyber-scams. They would make bad economic decisions too. A case in point was the money scheme in Botswana $(2008 / 9)^{2}$ where whoever joined by paying any amount would receive a dividend equal to the sum invested just in one day! The scheme operated efficiently for a month and people really got excited with the prospect of getting a very high dividend. They invested more each day. They woke up one day to find the offices closed and that was the last time they saw or heard of the company.

The pulpit is a very important platform to impart critical thinking skills at an informal level. The pulpit has been used to motivate people to venture into business, embark on maTarenta (as in the case of ZAOGA referred to above) and so forth. Through the pulpit, congregants can cast away all trepidation and be willing to take risks while anchored in faith (Reuben 2011:226). Even where social relations had gone sour due to conflict or even war, religion can pacify the belligerents and make them start trusting again (Reuben 2011:226). The same approach of reaching out to people can be used to improve people's intellectual skills. Religious leaders can teach in ways which cultivate these skills in converts. Paradoxically, the pulpit can be a source of paternalism and a barrier to creativity and critical thinking. In this regard, emphasis would have been placed on feelings, passions, emotions, faith, authority, tradition and revelation. Where this happens, alternative ways of interrogating reality are lost. Where dogma

There is a forthcoming publication of religion and gullibility by this author.

See Chimuka and Mashumba (2016: 115). 
is the only route towards an interpretation of reality, religion would have operated as a foil against the development of social capital. However, where the pulpit is used to promote a general scientific outlook, the results are often rewarding. When religious leaders use critical pedagogy in discipling Christians, this produces well grounded believers and at the same time helps raise the social and intellectual capital of a country. In this respect, religion would be partnering with other players in promoting development. Perhaps one of the main challenges is whether the training of pastors and other religious leaders in the FBOs include the critical component. This critical component has the potential for social transformation.

Just as critical pedagogy is used in classrooms to develop openmindedness in students, it can also be used by those offered second chances and FBOs in informal settings to achieve the same objective (Canaan 2010:5). Critical pedagogy can be used by FBOs to produce political clarity. Political clarity has been defined as:

...the ongoing process by which individuals achieve ever-deepening consciousness of the socio-political and economic realities that shape their lives and their capacity to transform such material and symbolic conditions. (Bartolomé 2004:98).

Citizens of a country ought to be raised to a certain level of intellectual competence so that they are able to function in social transformation. This may include participation in business, entrepreneurship, democratic participation and the like. Religion has the connectedness with the people and has power to raise their consciousness through its educational programs. In this respect, religion can function as an agent for development.

\section{The Importance of Religion in Social and Economic Development}

The chapter has shown the ambivalent nature of religion. Although religion has been accused of fanning divisions and wars in the world, it has also brought unity and peace. In other cases, although it has been condemned and subverted by Enlightenment thinkers as wimsical and superstitious, it has re-surfaced in various modes in society. Although it has in some cases caused terror and extremism, in others it has been responsible for building bridges and reconstructing broken societies. Although it has caused wars in some areas, it has been responsible for receiving and caring for refugees and victims of natural disasters. 
In Southern Africa, religion has been responsible for apartheid and other forms of racial oppression, yet it has also been responsible for decolonization through its active role in providing education to the Africans. In recent times, religion has been very active in the fight against HIV/AIDS. In other contexts, religion has been central to the fight against autocratic regimes and to champion for democracy and the rule of law. Religious leaders are trusted by their followers, hence if they have something to offer society, it will be easily received.

Thus, although there is a lot religion has done wrong, there is plenty of potential to do more in capacity building for development. Southern Africa needs to develop social and human capital to lift the region up in its quest for economic development. It has been highlighted that the focus of development has been the need to harness human capital for development. Once the intellectual skills of Southern Africa are nurtured and cultivated, the prospect for social progress and economic development is great. The chapter has argued for the need for FBOs to train students in critical, creative and innovative skill in schools and universities. This might require re-visiting the curriculum to effect such changes. As alluded to in the chapter, FBOs may have to infuse critical thinking in homiletics and Bible study activities. At fellowships and other meetings, there must be conscious and deliberate effort to create space for all the people by encouraging to critically reflect on the issues under discussion. At a much informal and popular level of education for citizenship, FBOs can encourage older people to be critical and openminded. This way, religion would be contributing towards minimizing gullibility and encouraging people to make warranted beliefs and well considered decisions. This critical spirit once cultivated will allow for the numerous possibilities of growth.

\section{References}

Bartolomé, L. I. (2004). Critical Pedagogy and Teacher Education: Radicalizing Prospective Teachers. Critical Pedagogy and Teacher Education, (Winter): 97-122.

Berman Eli, \& Lawrence R. Iannaccone, (2006), Religious Extremism: The Good, the Bad, and the Deadly, Public Choice, 1- 45.

Bouckaert, L. a. (2012). Spirituality and Business: an Interdisciplinary Overview. Society and Economy, 34(3): 489-512. 
Canaan, J. E. (2010). Introduction to 'Why Critical Pedagogy and Popular Education Matter Today'. In Amsler Sarah Joyce E. Canaan, Stephen Cowden, Sarah Motta \& Gurnam Singh, Why Critical Pedagogy and Popular Education Matters Today, (5-10). Cambridge: C-SAP: Higher Education Academy Subject Network for Sociology, Anthropology, Politics, http://www.c-sap.bham.ac.uk.

Chaves Mark (1994), Secularization as Declining Religious Authority, Social Forces, 72 (3): 747-774.

Chimuka, T. A. (2001). Ethics among the Shona. Zambezia, 28(1): 23-39.

Chimuka T. A \& Lesedi Mashumba (2016), Understanding Cyber Scams: An Assessment of the Challenges of Law Enforcement in Botswana, Journal of Sustainable Development in Africa (Volume 18, No. 2: 111-126.

CIPD. (2017). Human Capital Theory: Assessing the Evidence for the Value and Importance of People to Organisational Success. London: Chartered Institute of Personnel and Development.

Daddis, Gregory A. (2016), Faith in War: The American Roots of Global Conflict, Parameters 46 (4): 43-53.

Das Pinki (2012), Human's Attitude Towards Nature, International Journal of Multidisciplinary Educational Research, 1 (4): 218-228.

Dei, George Sefa J. \& Paul Banahene Adjei. (2014). Introduction: Emerging Perspectives on 'African Development': An Introduction. Counterpoints, 443: 1-15.

Gcabashe, Leah. “Spiritual Liberation or Spiritual Oppression?” Agenda: Empowering Women for Gender Equity, no. 25 (1995): 7-15.

Guiso, Luigi, Paola Sapienza \& Luigi Zingales (2003). People's Opium? Religion and Economic Atitudes. Journal of Monetary Economics, 50: 225-282.

Henry, A. (2014, Apr.). Is Religion Associated with Entrepreneurial Activity? Discussion Paper. Germany: IZA.

Iannaccone, R. a. (nd). Religious extremism: the good, the bad, and the deadly. Public Choice, 1- 45.

Inglehart, Ronald \& Mansoor Moaddel \& Mark Tessler. "Xenophobia and In-Group Solidarity in Iraq: A Natural Experiment on the Impact of Insecurity. " Perspectives On Politics 4, no. 3 (2006): 495-505.

Jinging, F. (2006). Terrorism, Religion and World Peace. Policy Perspectives, Vol. 3 (No. 2): $11-18$.

Krause, Neal \& Keith M. Wulff. "Religious Doubt and Health: Exploring the Potential Dark Side of Religion. ” Sociology of Religion 65, no. 1 (2004): 35-56.

Marshall, K. (2001). Development and Religion: A Different Lens on Development Debates. Peabody Journal of Education, 76(3/4): 339-375.

McFadden, D. (2008). Human Capital Accumulation and Depreciation. Review of Agricultural Economics, 30 (3): 379-385.

Musevenzo, A. a. (2017). Faith Based Institutions and Women Economic Empowerment: A Gendered Analysis of ZAOGA FIF in Bindura, Zimbabwe. International Journal of Academic Research and Reflection, 5(5): 32- 40. 
Oliver, D. E. (2004). Human Capital Theory and Higher Education in Developing Countries. Journal of Thought, 39 (1): 119-130.

Piper, L. (2010). From Religious Transcendence to Political Utopia: The Legacy of Richard Turner for Post-Apartheid Political Thought. Theoria: A Journal of Social and Political Theory, 57 (123): 77-98.

Reuben, R. (2011). Can Religion Contribute to Development?:The Road from 'Truth' to 'Trust'. Exchange: 225-234.

Riedl, B. R. (2011). Transforming Politics, Dynamic Religion: Religion's Political Impact in Contemporary Africa. African Conflict and Peacebuilding Review, 2(2): 29-59.

Shah, S. T. (2013). In God's Name: Politics, Religion, and Economic Development. Presented at the Religious Freedom Center, Georgetown Univ. . www.sivicouncil.org/history.htm, 1-26.

Shehu, M. \& Molyneux-Hodgson, S. (2014) Faith communities and environmental degradation in Northeast Nigeria. International Journal of Environmental Sustainability, 10 (1): 27-40.

Sherkat, D. E. (2007). Religion and Higher Education: The Good, the Bad, and the Ugly. SSRG, 1-9.

Sweetland, R. S. (1996). Human Capital Theory: Foundations of a Field of Inquiry. Review of Educational Research, 66 (3): 341-359.

Weber Max (1930). The Protestant Ethic and the Spirit of Capitalism, Translated by Talcott Parsons, London: Routledge.

Weller, Paul. "Addressing Religious dicrimination Discrimination and Islamophobia: Muslims and Liberal Democracies. The Case of the United Kingdom. " Journal of Islamic Studies 17, no. 3 (2006): 295-235.

Witoszek Nina, (2013), Religion and Modernity, Nature and Culture, 8 (3): 237-248. 


\title{
Gender in Religion and Development Research
}

\author{
Appropriating Feminist Epistemology and Methodology for \\ Religion and Development Research in sub-Saharan Africa
}

\section{Loreen Maseno}

\section{Introduction}

A rights-based approach to development considers specific ways in which sustainable development is interlinked to human rights and how achieving them may transform human societies. Religion and development research, in this context, seeks to investigate the entrenchment of myriad forms of human rights abuses taking place across the world, develop interventions targeting the most vulnerable and to further make important contributions in the quest to improving the livelihood of people globally. This chapter is about the intersections of religion and development research with a special focus on gender inquiries. What can feminist epistemology and methodology contribute toward religion and development research? Consequently, it considers the appropriation of feminist epistemologies and methodologies for religion and development research ${ }^{1}$. The chapter uses one narration from a Non-Governmental Organisation $(\mathrm{NGO})^{2}$ annual report in Kenya ${ }^{3}$ as an illustration. The chapter begins with an overview of religion and sustainable development in Africa and points to the vitality of religion on the continent. It highlights feminist epistemological and methodological positions useful for religion and development research. Further, the chapter shows that feminist methodologies contribute to Religion and Development research as these methodologies resist metanarratives and sweeping claims but opt for contextualised

1 This chapter draws substantially from my paper "Gender Perspectives for Research: Contributions from Feminist Research" presented at the BIGSAS Workshop, Research methods, data analysis and thesis write-up. Oct. 25-27, 2017. University of Bayreuth, Germany.

2 This Non-Governmental Organisation (NGO) is popular in Kenya. In this chapter it is anonymised. It is also important to note that its annual reports are available in the public domain.

3 This example includes accounts of experiences by persons reached through this NGO in its quest for sustainable development. 
works. On the other hand, feminist epistemologies add value to religion and development research as they foreground subjects previously overlooked and whose ideas were made invisible in relation to systems of power.

\section{Religion and Sustainable Development in Africa}

The Beijing Conference saw remarkable commitment by diverse groups to improve the health, educational standing and economic power of women across the world (Bonnet \& Bilton 2002:130). Thereafter, development interventions targeting women for improved livelihoods were set up. However, there is evidence that women and girls in sub-Saharan Africa continue to suffer inequalities in different ways (Maseno \& Kilonzo 2011). ${ }^{1}$ Women in Development (WID) became outdated as many development actors identified themselves as working in human rights. This signalled an important shift in the discourse and practice in the field, with women's rights providing the powerful language and monitoring system while gender and development provided an enabling tool for overcoming the social realities that violate those rights (Kerr 2002:10).

Subsequently, over the years, the human rights approach was embraced by development actors to include an understanding of development and human rights as interwoven and to include the principles of accountability, empowerment, participation, equality and equity in development programmes (Tomalin 2006:93). According to Petersen (2015:361-362) the human rights approach is still relevant as it offers a coherent and consistent framework that is grounded in a consensual global regime. It also has the potential to make people actively aware of their rights, empower people as holders of rights, assign duties to the people and address structural inequalities. Instrumentally, this approach improves development outcomes which lead to more effective poverty reduction. On the other hand, the rights-based approach is deemed capable of marginalising people from the south when it does not take into consideration the social, cultural and religious milieu which shape social ethics. Petersen (2015) suggests that religious organisations firmly rooted in the local context can assist in the translation of human rights' discourse from the global to local context.

1 There was a failure of implementation of structures that dictate against subordination of women in sub-Saharan African countries which is clearly manifest. 
The influence of religious institutions in developing countries continues to be demonstrated in various sectors. Religion is highly mediated. Over the weekends are chains of services filling hours of television and radio broadcasts. This attests to churches openness to use media technology (Asamoah-Gyadu 2005). One cannot miss energetic and charismatic pastors preaching their convictions and demonstrating their spiritual powers. Indeed, religion is at the centre of the Ghanaian public sphere, for example (de Witte 2011:190-191). This phenomenon is also observable in many sub-Saharan African countries. This runs antithesis to the expectation of a shrinking religious public even as African countries progress. It is clear that as African nations progress and change, they have continued to carry along religious motifs and motivations (Pew Forum on Religion \& Public Life 2010). The resilience of religion in sub-Saharan Africa has led to various inquiries that link religion and sustainable development on the continent. Studies have avoided essentializing religious communities, in recognizing the dynamic and social process of religion and religious identity construction. Instead they have tried to make sense of their varied responses to ecology, human rights, economy and even sustainable development (Dreher \& Smith 2016; Spinks 2003; Bergmann 2015).

Bompani attests to the centrality of development work emanating from religion in sub-Saharan Africa. She traces the contribution of religion to development on the continent from the precolonial settings where missionaries offered social services like health and education. With the rapid change on the continent, Structural Adjustment Programmes (SAPs), rising inflation and the economic crisis, religion would gain traction and not retreat (Bompani 2015:101-103). This traction led to the rapid growth of churches, mosques, temples and faith inspired organisations which continue to carry out different development and social services programmes (Pawlikova-Vilhanova 2007). The programmes that the churches take, cover huge gaps in social services that the government has left unmet such as health (World Faiths Development Dialogue 2012). In sum, religion has an increasingly central role in the developmental life of sub-Saharan Africa even as religious institutions take on development work, which they deem is in line with their ethos such as justice, service and charity (Bompani 2015:103).

Yet, religious initiatives have historically also been seen to acquiesce to the disempowerment of certain groups of people. Girls were for a long time denied higher levels of education and only later were they admitted taking courses in homemaking. This would in the end weaken the socio- 
economic and political position of many women in comparison to men in Africa. At the same time, Christian missions that provided formal education denied other groups of people access unless they were Christians (Njoh 2006).

Religion and development research provides a variety of angles to interrogate how religious groups shape the economy in which they participate. Examples of what is interrogated is how religious groups supplement local government in provision of services; assess the relationship between religious identity and sustainable development from a historical, economic and even theological perspectives.

\section{Feminist Epistemologies ${ }^{1}$ in Support of Religion and Development Research}

Scholars point out ways in which feminist theories have shaped methodologies over the years (Clark and Chiou 2013). These include how a researcher goes about the epistemology, (that is, how we know what we know, how we decide what is valid knowledge), method (which is the means of gathering evidence) and methodology (a theory about how the said research is to be undertaken and its guiding assumptions) is an important question for feminist inquiries (Clark and Chiou 2013:35). Traditional approaches to methodology and knowledge production held that what was researched and written was unproblematic, value free and generally reflected the truth. A gender perspective to religion and development research, however, shows that there are a number of influences on the conduct of research and offers a critique of traditional methodology and knowledge production (Sarantakos 2005).

Imam et al (2017:27) have suggested a focus on empirical information to unravel multiple and collective identities by which persons exist, in intersections of religion, gender and development. To them, the importance of empirical information is its capacity to stand out and resist definitions of persons or communities by religion alone. They demonstrate that religious discourse keeps changing over time and place and collective identities continue to be contested (Imam et al 2017:25-26). Likewise, Petersen

1 There are different epistemological approaches such as positivism and social constructionism. For the latter, reality does not exist by itself but is constructed and given meaning. In which case the focus is therefore on beliefs, feelings and thoughts, and how these are communicated. 
has shown that human rights is not a fixed legal discourse, but shifting, contested social claims of actual individuals and institutions. Suitable processes are necessary to collect reliable empirical religion and sustainable development research data in the midst of these changes and shifts in religious and human rights discourse.

There have been challenges to knowledge production from a gender perspective. ${ }^{1}$ Feminist theorists and gender researchers question the absence of women and marginalized groups whose accounts are routinely missing or taken for granted in stories. According to Lövheim, a gender perspective on epistemology is alive to the fact that knowledge is not neutral but situated and produced by individuals within a personal, historical and social context who are in positions to act and make themselves heard. In sum, knowledge is deeply connected to identity, social relations, power and agency (Lövheim 2013:15).

The example below is obtained from one of the 47 counties $^{2}$ of Kenya. Its description is taken as the basis of teasing out epistemological and methodological ques for religion and development research.

The gloomy, wrinkled face that 54-year-old Bishop Samuel ${ }^{3}$ wears as he narrates the ordeal women and children undergo in the area betrays his disappointment with the authorities.

"There is a lot of gender-based violence going on in our community. We have been living like animals, men having intercourse with their wives and children," says the prelate.

Samuel has been following up a case of two young sisters aged 12 and 9 years who were raped by their stepfather sometime in January this year. The case has however been dragged to the local magistrate's court, forcing him to sue the lower court at the High Court in Embu.

1 Proponents of feminist epistemology argue that dominant knowledge practices disadvantage women by (1) excluding them from inquiry, (2) denying them epistemic authority, (3) denigrating their "feminine" cognitive styles and modes of knowledge, (4) producing theories of women that represent them as inferior, deviant, or significant only in the ways they serve male interests, and (5) producing theories of social phenomena that render women's activities and interests, or gendered power relations, invisible. See https://plato. stanford. edu/entries/feminism-epistemology/\#auth acc. on 13. 10. 17.

2 Kenya went through a decentralisation in 2013, a constitutional change that introduced 47 regional governments called counties. Within the counties are more sub counties which were formerly known as districts. The account is from an annual report of an NGO (herein anonymised) that is working in Kenya.

3 Owing to the nature of the example cited, besides the NGO being anonymised, the name of the Bishop has also been changed for the purposes of anonymity. 


\begin{abstract}
"We reported the case to the police and took the children to hospital for medical examination and treatment. When the case went to court, the accused was freed on a bond, went back home and raped the girls again," he says in a calm baritone voice. Samuel who is also the chairman of the local Gender Based Violence community-based organization alleges bribery and tribalism are to blame for the slow pace of the wheels of justice.

His frustration with the case of the two girls who have since been moved to a children-rescue centre reflects the challenges organizations face in addressing violence against women and girls. "We do not have any budgets to follow up the cases to their successful completion once we have reported to the police. As volunteers, sometimes, we are forced to dig into our pockets to cater for bus fare for the victims and witnesses to attend court proceedings," says Samuel.

In some instances, witnesses are unwilling to testify against the accused when the cases go to the courts. The prelate also talks of threats from the accused and their families whenever they take up cases that certain members of the community want to keep secret.
\end{abstract}

Population based surveys such as the Kenya Demographic Health Survey (DHS) 2016, the sixth of the national survey, document the abuse of women: $49 \%$ of women have experienced physical violence and about $14 \%$ of women have experienced sexual violence committed by a spouse/partner; that the youngest women (age 15-19) are less likely than older women (age 30-49) to report sexual violence Kenya National Bureau Statistics et al (2014:291-297). ${ }^{1}$ There are policies and regulations in place by the government of Kenya to prevent and control various forms of violence against women and children including in the Constitution of Kenya (2010), the Sexual Offences Act (2006), the Children's Act (2001), the Penal Code (2009) and the National Gender and Equality Commission Act (2011). However, the problem persists across the country. Its prevalence led the DHS of 2014 to include a survey on violence against women.

The NGO from which the above illustration derives has three strategic mission objectives, one of which is to empower women and girls living in poverty and exclusion to challenge violence. Using the rights approach, it envisions keeping women and girls safe in public and private spaces. To achieve this mission, the NGO has organised women living in poverty and exclusion into local movements with the aim of addressing Violence Against Women and Girls (VAW/G). Additionally, members of these local women's movements sit in multi-sectoral county and sub-county Gender Based Violence (GBV) working groups, one of which is mentioned in the

1 DHS. https://dhsprogram.com/pubs/pdf/fr308/fr308.pdf acc. on 10. 12. 2017. See page 291-297. 
above account. In these GBV working groups, cases of violation of women's rights and programmes are reviewed, so that the local administrators, police, judiciary, children's department, Gender Ministry, school heads and the other parties involved are held accountable for their (in)action in cases of GBV. This approach to achieving sustainable development goals take into cognisance human right and gender equality. Consequently, the NGO's annual reports attest that through its GBV working groups in various counties, reporting of Violence Against Women and Girls (VAG) cases has since increased.

In the account provided, it is clear that a focus on empirical information brings to fore the multiple identities by which Samuel is known in the community. He is a religious minister at a local congregation and at the same time, he serves as chair for the local Gender Based Violence community-based organisation. In his capacity as chair of the GBV working group, he receives reports of incidents of violence, which he and his team act upon.

The interplay of religion and development is evident in his collective identities within the community. An interpretivist investigation of this account brings into sharp focus how both these identities may enhance or even impede his engagement in sustainable development. First, the trust placed upon him as a religious minister, victims of sexual gender-based violence are able to approach him for help in their distresses. On the other hand, it might as well be that his positionality makes it hard for victims who are full of guilt and shame to come out and share the information with him. In general, his multiple identities may aid or hinder his engagement with women or children's rights and sustainable development at large.

\section{Feminist Epistemologies ${ }^{1}$ for Religion and Development Research}

The account above is situated in a particular context, period and place. It can be used to exemplify some epistemological contributions to religion and development research in several ways. First, that knowledge is situated. In the account above, a gender perspective to religion and development research is interested in the knowledge that reflects the particular perspectives of the participants. Consequently, noting the respondent's

1 A classification of feminist epistemologies includes empiricism, standpoint theory and postmodernism. 
specificity, location, partiality and finitude, one also chooses to recognize that the participants are the experts and authorities of their own experiences. In general, situated knowledges are inseparable from experience and are produced in a specific time and space (contextualized). When researching religions and development, in opposition to the positivist approach, the interpretivism approach holds that the specific context is so central to any set of values, beliefs and practices. This way, knowledge is attached to the phenomena studied, with multiple realities which are ever shifting and context dependent (Hefferan 2015:36).

Second, is reclaiming epistemic authority ${ }^{1}$ for marginalized groups or women. Feminist epistemologists explore the ways gender and other hierarchical social relations influence attributions of epistemic authority (Janack 1997). To correct the finding by feminist epistemologists arising from the absence of women and other marginalized groups in knowledge production, religion and development researchers ought to take up the challenge to seek out these marginalised groups and centre their voices and experiences.

The account above can be said to describe the micro-level which includes face to face and local level interactions of individuals (Hefferan 2015:39). However, in some ways the account does not bring to fore the voices of the individual women and girls who are victims of sexual violence. Indeed, it could be argued that the two girls are minors and therefore their full voices are muted for their own protection. However, the mothers' voice in these misfortunes have not been captured. When taking up religion and development research from an interpretivist position, it is important to centre the voices of women, as this demonstrates their epistemic authority and that their accounts are taken to be trustworthy.

It is clear that Samuel, a church leader, has been granted epistemic privilege. He speaks on behalf of the two girls and their mother. It is about how he and his GBV working group are involved and even using their own resources to help women and children living in poverty and facing violence. Perhaps this NGO, is primarily interested to capture what is being done at the level of GBV mobilisation in the community and its line of work and not to delve into the finer details of the case. Indeed, it is the Church leader who is also the chairman of the local Sexual Gender Based Violence group whose voice is pronounced.

1 These broadly includes views or attitudes about people's competence, expertise, epistemic responsibility, and trustworthiness. 
Feminist epistemologies contribute to gender and development research by insisting that there are multiple perspectives and differing claims to truth. In the case above, there is the perspective of the GBV chairperson and religious leader. At that level, he decries the inaction from the authorities. However, when he calls out humans as living like animals, it could be drawn from his religious knowledge. Animals lack self-control, a virtue which he, a church leader, expects from his members. On the other hand, little is heard of the girls' stepfather, another key factor in this issue apart from the mother. Other perspectives could also emerge from the local authorities, schools, courts, other GBV working group members to provide a holistic picture for analysis. These multiplicities allow for one to be able to bring in various and much needed perspectives on a phenomenon.

Feminist epistemologies contribute to gender and development research by asserting that researchers make choices within the process of research and its analysis to negotiate meaning of the final outcome. At face value, the account given shows choices made, such as privileging Samuel with epistemic authority, emphasising the process of seeking legal redress at the expense of how the individuals involved in the violence are coping or are being helped to cope and other themes. In the end, these choices had an impact on the final output and focus for consequent research.

Gender and development research can gain from feminist epistemologies through participatory approaches. Here, special attention is given to the agency of the participants.

Research participants in these studies are seen as partners in the production of knowledge. Their agency is seen when they are allowed in the research process to produce their own depiction of the situation at hand as he sees it. As an actor, Samuel goes on to say what challenges he has faced and what he has had to do in the situations.

In the production of knowledge from a feminist perspective, religion and development research should consider the subject/object nature of the research. It should engage with Kenyans, not only as respondents to research instruments but also as a people who bear knowledge that only they have.

Research is not value free (Wolf 1996). Gender and feminist inquiries are politically value laden to facilitate creative processes that engage oppressive structures (Sarantakos 2013:68). In the production of knowledge from a feminist perspective, religion and development research should adopt several values. These can be non-hierarchical or partial identification. 
Feminist researchers have argued that neutrality and indifference towards research objects has to be replaced by conscious partiality which is achieved through partial identification with the research objects (Bryman 2004:22,288). These two values are in opposition to the value of control where respondents and the research context are controlled to elicit oneway traffic, and information extracted from them with nothing given in return. Such values are seen as exploitative and incompatible with gender and feminist inquiries. Indeed, since religion and development researchers cannot be value free, they ought to be self-reflective about the role played by these values.

\section{Feminist Methodologies for Religion and Development Research}

These perspectives to religion and development research arise from feminist critique of traditional research practice in matters such as conducting research from a male perspective, being oblivious of one's implicit biases and the failure of taking into account structural and systemic privilege. The contribution to religion and development research from feminist methodologies ${ }^{1}$ that enhance gender inquiries (Clark and Chiou 2013:35) include the following;

First, religion and development research could include personal experiences which are brought to the fore. Foregrounding personal experiences and embodiment brings insight to how people experience the world variously by using their bodies, which are differently located in space and time. This speaks to the basic principles of feminist and gender inquiries which assert that most societies are patriarchal, that there have been unequal relations between men and women, with women being subjugated and that all social institutions i. e. family, politics, religion have been characterized by domination, competition and hierarchy (Maseno-Ouma 2014). Consequently, some voices of marginalized groups have been muted which can only be brought to bear in religion and development research through direct access to them, their experiences and how they make sense of their world.

1 These are the assumptions that guide how research is to proceed/ to be conducted. It is methodology which enhance feminist/ gender inquiries. In feminist research, methodology is defined as a field of inquiry rooted in feminist activism and critiques of the standard procedures of social science (Sarantakos 2013: 69). 
Then there is the feminist methodological concern regarding context for religion and development research. Herein is the importance of noting a respondent's specificity, location, partiality and finitude. Religion and development researchers should note how much of the context they know and how it further affects or/and informs what findings they may obtain in the course of the research. In the same vein, there is an importance of seeking meaning and interpretation of people's lives within their cultural context. The example above is set in the Kenyan county of Embu. The respondent Mr. Samuel's finitude and partiality is seen in the wider context of the unfolding VAG case.

A feminist methodological input to religion and development research is the consideration of how power relations are maintained, sustained and to whose benefit power dynamics are reproduced through everyday life. In daily dealings at the different levels of society and its institutions are traces of power and hierarchy. Mr Samuel gives his version of the sexual violence. He occupies positions of power, first as the chairperson of the GBV workgroup. As chairperson, he has a voice over and above ordinary members of the group. It is taken for granted that he is more informed than ordinary members of the GBV workgroup. A second dynamic of power is his position as a bishop. A third position of power is that he is male. Though the victims of the violence are female, their own or mother's account is not captured.

Fourth; methodology that enhances feminist-gender inquiries for religion and development research considers and integrates approaches which recognize the agency of the participants. This agency may be both resistance and coping mechanisms to oppressive structures by the participants (Maseno-Ouma 2014). Agency may include engaging in conversations, an exchange of ideas and thinking whether formal or informal. Mr. Samuel's agency is demonstrated in his efforts to help and protect the two children. He is providing resistance to the oppression meted on the girls, demanding legal redress through the incarceration of the stepfather and legal redress.

What is missing from the example above is an in-depth consideration of marginalized groups and women's situations, concerns, experiences and perspectives as the basis for research, thereby embodying marginalized women's experiences in the social world from their own interpretation and language. The mother to the girl's concern may not necessarily be the authorities who released her husband back to the family, but her safety and that of her children. Her perspective in the greater scheme of things 
is rather lacking. Feminist methodology adds to religion and development research by taking marginalized groups/women's self-understanding seriously and mainstreaming voices of marginalized groups/women's experiences within society.

\section{Conclusion}

The quest to infuse gender as an analytical category for religion and development research in sub-Saharan Africa makes it possible to foreground subjects previously overlooked, those whose bodies and ideas have been made invisible in relation to systems of power. A firm commitment to feminist methodology and epistemology for religion and development research will enhance explorations of the social dynamics and relationships in patriarchal society. Related research could locate gender as a factor which affects the situation and positions of identity, social relations, power and agency and also take into account women's viewpoints, experiences, needs and ideas of the social world.

Methodology that enhances feminist/gender inquiries in religion and development research would resist sweeping claims and metanarratives by constructing thorough and contextualized work. It will consider the multilayered and multi-level communication engagement since at the epicentre of these methodologies is the politics of transformation.

The religion and development researcher who chooses to use gender as an analytical category should find feminist epistemological and methodological considerations of great importance.

\section{References}

Asamoah-Gyadu, K. 2005. "Born of water and the Spirit: Pentecostal/Charismatic

Christianity in Africa,” In: O. Kalu (Ed.) African Christianity: An African story.

Pretoria: Univ. of Pretoria Pr. series 5. Vol (3).

Bergmann, S. 2015. “Sustainable development. Climate change and Religion,” In: E.

Tomalin (Ed.), The Routledge Handbook of Religions and Global Development. New

York: Routledge, 389-404.

Bompani, B. 2015. "Religion and Development in Sub-Saharan Africa: An overview," In:

E. Tomalin (Ed.), The Routledge Handbook of Religions and Global Development. New

York: Routledge, 101-113.

Bonnet. K. \& Bilton T. 2002. Introductory Sociology. Houndmills: Hampshire. Palgrave,

Macmillan. 
Clark, L. \& Chiou, G. 2013. "Feminist orientations in the methodologies of the media, religion and culture field." In: M. Lövheim (Ed). Media, Religion and Gender: Key Issues and New Challenges. New York: Routledge. 33-51.

Bryman, A. 2004. Social Research Methods, 4th Edition. Oxford: Oxford Univ. Pr.

de Witte, M. 2011. "Business of the Spirit: Ghanaian Broadcast Media and the Commercial Exploitation of Pentecostalism," Journal of African Media Studies, 3(2): 189-205.

Dreher, S. \& P. Smith. 2016. Religious Activism in the Global Economy, London, England: Rowman \& Littlefield International.

Hefferan, T 2015. "Researching religions and development." In: E. Tomalin (Ed.) The Routledge Handbook of Religions and Global Development. New York: Routledge, 3652.

Imam. A, Gokal, S, \& Marler, I. 2017. "The devil is in the details: A feminist perspective on development, women's rights and fundamentalisms," Gender and Development. Vol. 25, No. 1: 15-36.

Janack, M. 1997. “Standpoint Epistemology Without the 'Standpoint'? An Examination of Epistemic Privilege and Epistemic Authority," Hypatia 12: 125-139.

Kerr, J. 2002. "From "WID” to "GAD” to Women's Rights: The First Twenty Years of AWID. ” AWID's Occasional Paper no. 9.

https://www.awid.org/sites/default/files/atoms/files/the_first_twenty_years_of_awi d.pdf.

Kenya National Bureau Statistics, Council National AIDS Control, Ministry of Health of Kenya, Kenya Medical Research Institute, National Council of Population, Development, A., \& The DHS Program, I. I. (2014). Kenya Demographic Health Survey, 2014.

Lövheim, M. 2013. "Media and Religion through the lens of feminist and gender theory,” In: M. Lövheim. (Ed.) Media, Religion and Gender: Key Issues and New Challenges.

Maseno-Ouma, L. 2014. How Abanyole African Widows Understand Christ: Explaining Redemption Through the Propagation of Lineage. New York: Edwin Mellen Pr.

Maseno, L. \& Kilonzo, S. 2011. “Engendering development: Demystifying patriarchy and its effects on women in rural Kenya," International Journal of Sociology and Anthropology Vol. 3(2): 45-55.

Njoh, A. J. 2006. Tradition, culture and development in Africa: Historical lessons for modern development planning. Aldershot, UK: Ashgate.

Pawlikova-Vilhanova, V. 2007. "Christian Missions in Africa and Their Role in the Transformation of African Societies," Asian and African Studies, 16(2): 249-260.

Petersen, M. 2015. "Conflict or Compatibility? Reflections on the nexus between Human Rights, Development and Religion in Muslim Organisations,” In: E. Tomalin (Ed.) The Routledge Handbook of Religions and Global Development. New York: Routledge, 359-372.

Pew Forum on Religion \& Public Life. 2010. “Tolerance \& Tension: Islam and Christianity in Sub-Saharan Africa," Methodology, (Apr.), 324. http://features. pewforum.org/africa/\%5Cnwww.pewforum.org 
Sarantakos, S. 2013. Social Research. New York: Palgrave McMillan.

Sarantakos, S. 2005. “Feminist Research”. In: S. Sarantakos (Ed.). Social Research. New York: Palgrave McMillan, 53-71.

Spinks, C. 2003. "Panacea or Painkiller?: The impact of Pentecostal Christianity on women in Africa. " Critical half: Annual Journal of Women for Women international 1(1): 21-25.

Tomalin, E. 2006. "Religion and a Rights based approach to development," Progress in Development Studies, 6 (2): 93-108.

West, C. \& Zimmerman, D. 1987. “Doing Gender," Gender and Society 1(2): 125-151.

Wolf, D. L. 1996. “Situating Feminist Dilemmas in Fieldwork,” In D. L. Wolf (Ed.), In: Feminist Dilemmas in Fieldwork. Colorado: Westview Pr., 1-55.

World Faiths Development Dialogue. 2012. Global Health and Africa: Assessing Faith Work and Research Priorities. Connecticut. 


\title{
Youth, Religion, and Development in Africa
}

\author{
Susan Mbula Kilonzo
}

\section{Introduction}

The youth are a force to reckon with in most countries across the globe. They form the largest category of most countries' population. In many instances, the youth enter popular discussions as a difficult lot; a problematic group. In most cities and rural localities, there are youth groupings that are popularly known to cause trouble. In Africa, they have been branded many names that characterize what societies believe they are. Ojok and Acol (2017:96) give examples of these: township youth in the heyday of apartheid South Africa; rarray boys in the ghettos of Freetown; egbesu boys in Nigeria's oil delta; and, area boys in Lagos. Other examples are Bagdad boys in informal settlements of Nairobi and the renowned Mungiki in Kenya. In most cases, in the African context, the youth are perceived as perpetrators of political and civil conflicts, crimes. The main challenges that the youth seem to face are blamed for their involvement in crime.

The youth face mass unemployment or lack of decent work opportunities, ineffective and undemocratic political participation structures, exclusion, poor health problems, poverty, protracted conflicts, HIV and lack of education (Commonwealth 2016; Makori 2015). These social and economic challenges define youth's inability to realize their potential. They have been sidelined and pushed towards certain forms of popular culture including music, dance, art - mainly secondary sectors of the economy where they have to struggle on their own to make ends meet. They are relegated to secondary positions in any form of leadership and, as Abbink (2005) indicates, youth are facing tremendous odds and do not seem to have the future in their own hands. One of the key challenges that Abbink cites is the fact that many African families are disintegrating and malfunctioning. This has a moral implication in the lives of the youth since the source of identification and the moral reference that the families once provided have succumbed to current economic needs.

Abbink (2005:2-3) explains that, it is a challenge to write about the youth in Africa without referring to the crisis, violence and crimes associated 
with them, yet, there are various positive stories about the youth on the continent. Subsequently, the current indications are that the youth are carving out spaces for themselves and slowly asserting their relevance in the society. This is with an aim of developing themselves as well as taking part in the continent's development agenda. Currently, as the paper will show, there are factors that have favoured this transformation, albeit the many challenges that the youth face in an effort to carve and build these spaces for themselves and explore avenues for inclusion in the development agenda.

Development is a wide terminology. It includes economic, social, political, religious and cultural aspects. August (2013:71) explains that development is that which exists where people act as subjects and are not acted upon as objects, targets and beneficiaries, nor manipulated as participants in designs and projects that are not of their doing. Quite a big chunk of the existing literature on development studies show that the youth have been a marginalized lot in mainstream development, yet they are the majority of Africa's population, as we discuss in the paper. Literature has further highlighted to a great extent the role that governments, unions and non-governmental institutions are playing or not playing to help the youth within the development agenda (Miles 2000; Honwana \& Deboeck 2005; Quadros 2014; and Makori 2015). There, however, exists a gap on the role that religion as an institution plays in the lives of the youth. Where studies have been done on religion and youth, the focus is more on psychological perspectives since the assumption is that youth fall under teen age (Smith \& Dandon 2005; Brittian, Lewin \& Norris 2013). Currently, research has tended to focus on religious extremism and youth are seen as the key perpetrators of religious violence. The blame for this kind of behaviour has largely been placed on governments and their responsibilities in providing decent jobs and livelihoods to the youth (Botha 2013; Mohamed 2010; Onuoha 2014 and Walker 2012). This literature refers to perpetrators as youth in general and again little attention is given to the role that religion and religious institutions can play for this category of youth.

On the African continent, the population of the youth indicates a sharp increase. According to UNDP (2015) 226 million youth aged 15-24 lived in Africa in 2015, accounting for 19 per cent of the global youth population. By 2030, it is projected that the number of youths in Africa will have increased by 42 per cent. A shift of this number to include all the young men and women under the age of 35 years - these are still youth as the 
paper later shows - would mean that this category of the population represents more than 42 per cent of Africa's population. Whereas in many continents this population of youth is projected to drop from the year 2020, the trend in Africa is going up.

If we are to go by the statistics that one in every three persons in the world currently is a youth, how then is a population so significant always ignored in the development agenda? What is their role in the decision-making and development processes? In which ways have the youth repositioned themselves to fit within a context of limited opportunities? Does religion have any place in the lives of African youth within the context of the development agenda?

The section below engages the three key terminologies that are a focus to this study - youth, religion and development - before discussing these in the context of politics, radicalization, and religious tolerance in the African context.

\section{Defining youth}

There are a number of studies that have tried to unpack the meaning of the term 'youth'. Earlier scholars restricted their perspectives to the age brackets provided for by constitutions, development agencies, and continental unions (Wamucii and Idwasi 2011). These age brackets have been contested and the definition of the term youth has made shifts to accommodate men and women who initially, were termed as adults. Wamucii and Idwasi (2011:188-90) argue that although age specifications are important for policy-making purposes, this representation has been contested from people's opinions, standpoints and differences that exist within a population. The social, economic, political and cultural developments have also complicated the efforts to determine who a youth is and who is not. Defining youth in a way that we can claim universal application of the term, therefore, is challenged by these norms.

Abbink (2005:5) avers that youth is a socially constructed and constituted category, like most social phenomena. He cites people who are in their thirties and have not completed their education, have no jobs and cannot raise a family. It is now clear that different countries; and, development and human rights agencies, apply the term 'youth' differently, and subsequently, contextual definitions that rely on formal nomenclatures and informal factors like culture, tradition and socio-economic conditions that 
have become more prominent. This is the case in Africa, where the process of acquiring formal education may run up to the age of 30 and beyond (Commonwealth 2016). Again, graduating from education to employment is not automatic; and, moving from dependent to independent status is no longer a linear process. Miles (2000) indicates that youth should be viewed as a lifestyle construed through social processes such as family relationships, labour markets, schooling and training. Due to these variations, some literature has had to distinguish between linear and non-linear transitions, which they have termed as accelerated or delayed transitions. The Commonwealth captures these transitions in the following description:

... [I]n many developing countries, young people continue to live at the parental home even after achieving full economic independence. In the Middle East, Africa and parts of Asia, the term 'waithood' has been used to describe the delay in achieving full adult rights and responsibilities... terms such as 'young adulthood' and 'emerging adulthood' [have been] introduced to mark what is regarded as a new intermediate stage between youth and adulthood. [Therefore] the speed, scale, shape and consequences of youth transitions vary across countries and contexts depending on a combination of structural constraints and opportunities, societal expectations and policy frameworks, as well as individual agency (2016:7).

From these observations, I will not belabour defining the term from a biological standpoint especially due to the observation that, youth is the category of population that lies within puberty/adolescent period (see classification by UN, Educational, Scientific and Cultural Organization [UNESCO], International Labour Organization [ILO], and UN Population Fund who provide an age bracket of 10 through 15 to 24 years). I underscore that youth in the African context, is any person that is between the ages of 15-35 years. This is the age bracket provided for by the African Union (AU). This population, in Africa, is most likely to be construed as persons who have not settled in for social, economic, political and religious responsibilities. Most of them are in search of employment and leadership roles in the society. Below the age of 15, in most cases, the category is termed as children, dependents, and not always accepted as adults. ${ }^{1}$ Beyond the age of 35, as Abbink argues, people are getting into middle age and have "lost" the promise of youth.

1 In the African context however, in the case of orphans, especially resulting from HIV \& AIDS, children have taken parenting roles and are forced by circumstances to become adults (see Nyambedha, 2005). 


\section{Youth, Religion and Development}

Inequalities persist within the society and particularly in the youth cohorts. According to the Commonwealth (2016:6), many young people face inequalities and discrimination because of their gender, social class, sexual orientation, geographical location, disabilities and ethnicity. In 2015, as the report of Commonwealth documents, out of 183 countries, just over one third had achieved gender parity in enrollment at secondary school level, with the gap widening at tertiary level where only 4 per cent had achieved gender parity in enrolment. In developing countries, these achievements are lower. More inequalities in the context of Africa can be clearly explained through early marriages, genital mutilation, sexual assaults, child labour, child soldiers, among many. These are traps for young people and their potential in the development agenda of the continent is, therefore, compromised.

Young people respond to the challenges they face in different ways. Now, more than ever, young people are bypassing the traditional participation structures and institutions to express themselves. The advent of social media and mobile telephony has made it possible for leaders to read and understand the minds and feelings of the youth. Through these media, the youth are able to mobilize and organize themselves quickly and spearhead as well as spread their agenda quickly beyond the geographical, cultural and legal boundaries. It is amazing how the youth are using various social media platforms to articulate their agenda. The mainstream media has had to borrow and update their information from the knowledge of the youth as displayed in the social media. The social media vibe has also meant that the youth have devised ways of interacting, not just in their social lives, but also in religious affairs, whether negative or positive. Religious institutions need to recognize these efforts by young people and mentor them towards achieving their dreams. The youth have the potential to contribute to the development of African countries in many ways.

Religion as one of societal institutions has been shown to play both positive and negative roles. According to Kristian \& Hanne (2008:352), despite its intensity, influence and magnitude, worldwide, religion is a multifaceted phenomenon, which shapes one's explanation of its very role in the society. The two scholars further argue that within the discipline of religious studies, it is common to distinguish between two basic perspectives: on the one hand, there is the substantive approach which focuses on the elements that constitute religion, or what religion is. This is contrasted on the other hand by the functionalist approach, which focuses on the social 
and cultural consequences of religion, or what religion does for a social group or for an individual (also see Biehl 2012:99). These ideas, as Biehl puts it, display an underlying critical thrust as the functional approach insinuates that it is not religious belief as such that counts, but what these beliefs accomplish. In understanding the role of religion, we, therefore, underscore our role in the society and how this role relates to the others, the environment, culture and the nature of cosmos. Religion as a guiding map, therefore, draws on the functionalist approach and subsequently the practical orientation that motivates attitudes into action that are not just centred at an individual, but the community.

Kilonzo (2011:9) avers that, there are various reasons that can be used to explain why religious institutions seem to be viable mobilizing [and development] agents in the community. She shows that religious institutions can accommodate diverse ethnicities/groups and therefore, different community organs can use this advantage as a point of entry. However, literature is also quick to point out that religion can be a source of destruction and harm. Batson (1993:4) explains that the mass suicide and the murder of the 913 members of Peoples Temple in Jonestown, Guyana in 1979 was a chilling reminder of the potentials of destructiveness of religious fanaticism. The suicide bombing of the twin towers in America on 11 September 2001 is another example that suffices. Wars and crusades have been waged in the name of religion, as have persecutions and torture. The youth have voluntarily or involuntarily participated in such atrocities. This then begs the question of whether religion has a significant and positive role to play in the lives of the youth in as far as development is concerned.

August (2013) shows that in the global South, the religious factor has become an acknowledged and strategic dimension in development thinking and practice. The South African government has emphatically stated that "[I]n striving for political and economic development, the ANC recognizes that social transformation cannot be separated from spiritual transformation" (August 2013:77). Statistics show that in the global South the church is an acknowledged institution that is close to the poor and, in most cases, is the church of the poor. Furthermore, religion is blossoming in those areas dominated by Islam.

Biehl (2012:105) argues that today, two thirds of all Christians live in the global South and churches in Africa, Asia and Latin America are continuing to grow. Churches and mosques, in the global South, are dominant forces. In South Africa, eighty percent of the population belongs to the 
church. The youth in particular, are a target of the Pentecostal movement on the continent. Their numbers and energy are suitable factors of target by the Pentecostal leadership. Little evidence, however, exists to provide statistics on the patterns of religious affiliations by the youth in many continents, and specifically in Africa. What is available are snippets of the same from various African countries. In South Africa for instance, the Usombona Youth Fund (2006) reported that $62.6 \%$ of the youth attended religious services at least once a month and of those who attend, $10.9 \%$ attended daily or almost daily. However, $20.2 \%$ reported that they never attended religious services (Brittian, Lewin \& Norris 2013). Another more recent study by Lekalake (2016) shows that 3 out of 10 youth (30\%) are active members or officials of a religious group in South Africa, while 15\% are actively involved in a voluntary association or community group.

Though most of the studies do not give particular attention to the involvement of the youth in religion and the role of religion in their livelihoods, the youth are indisputably an integral part of religious growth. This chapter slices three key aspects: politics; youth radicalization; and, religious tolerance in Africa; to explicate the role that religion plays in defining the youth in the context of these issues. These three have been selected from a pool of many factors as the youth prominently feature in the activities therein, plus these are current and trending issues that concern the security and development of African countries.

\section{Youth, Politics and Religion in Africa}

The relevance of youth participation in politics is recognized globally through international conventions and UN' declarations, including UN's World Programme of Action for Youth and African Union's African Youth Charter Article - 11 (Makori 2015). Literature shows that the youth are involved in informal, politically relevant processes such as activism or civic engagement. In the majority of country cases, they are however not formally represented in respective national political institutions such as the legislature, that may affect or impact on the quality of democratic governance (Makori 2005; Abbink 2005, UN 2013). There is evidence, not just in Africa, but also across the globe that, the participation of youth in formal, institutional political processes is relatively low compared to older citizens. Because of their demographic dominance, the political elite use the youth to champion their interests. They are exploited as climbing ladders for others' political ambitions (Ojok and Acol 2017:95). In political 
platforms, in the history of African elections, the youth have been used to disrupt normalcy whenever there are contentions on electoral or other political disputes. The many jobless and/or underpaid youth are easily convinced or compromised to take up roles that would benefit others, including acting as child soldiers; demonstrating to appropriate political agenda of certain leaders; and, forming movements that in the end benefit others more than they do the youth. This then questions the role of various institutions in the continent and specifically in the lives of the youth.

It is evident that the youth have the potential to carve out niches for themselves. They have recently used their involvement in informal politics to create their own agenda and spaces. Recent events orchestrated by the youth in various African countries are an indication of youth's ability to bring about social and political transformation in Africa. They were at the centre of the dissolution of the Apartheid Regime in South Africa in the early 1990s; the Arab Spring in Libya and Egypt in 2011; the Jasmine Revolution in Tunisia in 2011; the 'Y'en a Marre ('Enough is enough!'); the me carte d/electeur mon arme ('my voting card my weapon') campaigns in Senegal in 2011-12; and, the third term revolution in Burkina Faso in 2014 (IDEA 2015:1; and, Ojok \& Acol 2017:96). This lot remains at the forefront in Africa's democratic struggles. As they assert themselves for some important roles within the society, they are likely to be the leaders of movements of political reforms and religious renewals as well as innovators and dupes in the globalization culture (see Honwana \& De Boeck 2005:ix). Though these struggles are commendable, very few of Africa's people under the age of 35 are in formal political leadership positions. There are few cases that currently stand out.

Kenya's 2017 general elections was historic in many ways beyond the nullified Presidential contest. With more awareness through civic engagements, use of technology and the growing need for the youth to assert themselves, the 2017 elections introduced a number of youths who were elected into legislative posts. Paul Mwirigi, born in January 1994, campaigned on foot and was elected as the Igembe South (in Central Kenya) Member of Parliament. He was 23 years old at the time, and the country's youngest lawmaker. In Nandi County in North Rift Valley, 34-year-old Stephen Kipyego Sang made history after winning the gubernatorial seat. Initially, Sang was also the youngest elected Senator. Mohamed Ali, an investigative journalist ran as an independent candidate and won as the Nyali (in Mombasa County) Member of Parliament. Another youth, and a journalist by profession, Paul Katana also won the Kaloleni (in Kilifi 
County) Constituency seat. Among others were 30-year-old Johnson Sakaja who won the Nairobi Senatorial seat and John Kiarie, a former comedian who won in Dagoretti Constituency (Nairobi County). The Kenyan case is an example of how youth can excel in formal politics if given a chance or assert their willingness to participate. These few success stories cannot nevertheless erase certain historical and contextual facts about youth's involvement in politics.

Ojok \& Acol (2017:94) show that between 1990 and 2015, 60\% of elections in Africa experienced some form of electoral violence. The form of insecurity that comes with this violence threatens sustainability and subsequently the development of the country in question. At the center of this violence is youth; and this is the face that is mostly branded on the youth. In a survey conducted by the UNDP (2012), a majority of 13,000 respondents from 186 countries indicated that the main challenge for youth were limited opportunities for effective participation in decision-making processes. They also have limited resources and exposure, and this hampers their active participation in politics. The implication, therefore, is that greater trust between youth and institutions are needed. Young women should particularly be targeted as well as other vulnerable youth including the poor and those living with disabilities.

Religion in African politics has never been absent, as Bouta, Ayse and Abu-Nimer (2005) show. Though there is an effort to separate religion and politics, this has never succeeded in African politics. During pre-election periods, politicians take campaigns to the church pews and pulpits. Mosques, too, are not spared. Gospel songs are used to "bless" political campaigns, and some of them become the mantra of some political parties. Politicians have also used religious leaders to campaign for them and urge their congregations to take particular political stands. Kilonzo (2014) shows that, in Kenya's run up to the $2007 / 8$ elections, the religious leaders lost credibility. She explains:

In the run up to the 2007 general elections, several religious groups were [...] seen as being openly partisan along ethnic lines. Media reports showed "prophesies" especially by leaders of various Christian churches about who would win the presidential elections. The churches also had their preferred presidential candidates according to geographical and ethnic boundaries. [...] Muslims campaigned for their fellow Muslim candidates. Media releases were to comment that they had seen churches and mosques of Orange Democratic Movement and Party of National Unity but not of the faiths they profess (2014:114). 
Similar accounts are given in other African countries. Chitando (2013:46), while analyzing the role of the Church in Zimbabwe's politics, indicates that some church leaders have chosen to openly identify with Mugabe and ZANU-PF, from their identical ideologies and as beneficiaries of $\mathrm{Mu}-$ gabe's reforms, among other reasons. These leaders, as Chitando argues, are mainly from Protestant and Catholic traditions, but also a few Pentecostal leaders. It is to be reckoned that these leaders have good command over their congregation, including the youth. They, therefore, determine to a great extent the political alignment of the youth.

The above examples should not display religion as an institution of little value. Religious actors have been very helpful in resolving social, political and civil conflicts in Africa. An example that suffices is the role of Sant' Egidio. Sant'Egidio is a church-based public lay association, formally recognized by the Catholic Church but with an autonomous statute (Haynes 2009). One of the clearest success stories of Sant'Egidio's peacemaking efforts occurred between 1989 and 1992 when the organization was extremely influential in resolving the civil war that had ravaged Mozambique since the mid-1970s. Following well-intentioned but eventually unsuccessful efforts to end the war emanating from the international community, Archbishop Goncalves thought Sant'Egidio might succeed in bringing the government together to talk peace with the Mozambican National Resistance (RENAMO) insurgents - most of whose actors were the youth. Sant'Egidio could set up a meeting between RENAMO and the government without it meaning that the RENAMO rebels would be regarded as an entity with the same status as the ruling regime. Once peace negotiations were successfully completed in 1992, the UN assumed responsibility for the implementation of the peace agreement (Haynes 2009, Appleby 2006).

While some have argued that secularization has meant decline of "magical garden of religion" (Hunt 2005), others have shown that different religions (Mtata 2012) and religious actors are on the increase. This increase is, therefore, key as politicians use institutions within the society to reach out to the voters. Religious institutions should, therefore, use the advantage of their growth to create opportunities for youth and provide the much-needed support for their participation. Mtata (2012:31) argues that religion exudes the ethical values that protect human rights beyond mere formal individual rights. By taking care of the rights of the youth, and helping them develop politically, religious leaders are, therefore, showing the effectiveness of the role of religion in the society, especially how the 
leadership has an upper hand in mentoring the youth to positions of political participation. Smith and Dandon (2005) suggest that religion improves the lives of the youth by enhancing moral order; promoting learning competencies; increasing social and organizational ties; and, providing emotional and social support systems. These roles should therefore be harnessed to the benefit of the youth in Africa. Further, religion should be at the centre stage in playing the roles of advocacy, mediation, observatory and civic education. This will enlighten the youth and provide the right path towards political development.

\section{Youth Radicalization and Development in Africa}

The concept of radicalization has gained significant currency among government officials, media practitioners, scholars, and security officials in discourses on terrorism and violent extremism, especially since the terrorist attacks of September 11, 2001 (Onuoha 2014:2). The process of radicalization begins with changes in self-identification due to grievances, frequently driven by personal or group concerns regarding local issues as well as international events. A grievance is understood to create the sense of alienation or disenchantment that provides a cognitive opening for radicalization. A radical ideology - an extreme set of ideas - then provides the individual with a new outlook and explanation for the world in which he finds himself. An individual becomes mobilized as he slowly integrates into a community of other like-minded people (Onuoha 2014:2), and extremist or violent activities result (Onuoha 2014 and CLEEN 2014). The rise of religious radicalization is cited as a barometer of what Putzel (1997) calls the darker side of social capital (also see Shore 2008). Armstrong (2007:208) argues that Christian fundamentalists are ambivalent about peace - and especially peace in the Middle East - because their interpretation of the Bible is that the end times will be characterized by war in the region and that the antichrist will disguise itself as a peacemaker. However, in the African context, Islamic extremist groups are on the rise. Some of these include the al-Shabab (in Eastern Africa), Al qaeda (in North Africa), and Boko Haram (in West Africa).

The violent activities of the Boko Haram sect in Nigeria, which draws its members largely from the youth, have underpinned growing concern over youth radicalization and religious extremism in Northern Nigeria (CLEEN 2014). Boko Haram has been for a long time a cause for alarm. This group 
believes that politics of Northern Nigeria are in the hands of fake Muslims. Its aim is to wage war and create a "pure" Islamic state that is ruled by Sharia law (Walker 2012). Walker (2012:2) argues:

Since 2009 it has been driven by a desire for vengeance against politicians, police, and Islamic authorities for their role in a brutal suppression of the group that year. But the group has proved itself to be very adaptable, evolving its tactics swiftly and changing its targets at the behest of a charismatic leadership.

Narrating on the origin of Boko Haram, Walker explains that the group's origin lies in a group of radical Islamist youth who worshipped at the Alhaji Muhammadu Ndimi Mosque in Maiduguri a decade ago. In 2002, an offshoot of this youth group declared that it was embarking on Hirja (like Prophet Muhammad's withdrawal from Mecca to Medina), and moved from Maiduguri to a village called Kanama, Yobe State near the border with Niger to set up a community run on hard-line Islamic principles. In one of the fights with the police, they overpowered the police and took their weapons, and the resulting wrangles led to deaths of over seventy group members including their leader Mohammed Ali (Walker 2012:3). Boko Haram draws its members mainly from disaffected youth, unemployed high school and university graduates, and destitute children, mostly from but not limited to northern Nigeria. Its membership also includes some wealthy, educated, and influential people. Some of the reasons given for youth joining Boko Haram include: ignorance of religious teachings that are opposed to violence, unemployment and poverty, children with difficult upbringing, high illiteracy levels, response to excessive force by the military and corruption (Onuoha 2014:5-7). The movement is not in the international circle because, unlike Algeria's al-Qaeda in the Islamic Maghreb or al Shabab in Somalia, Boko Haram has not attacked any international interests (Walker 2012). The group, however, hit world news after kidnapping over 200 schoolgirls in May 2014 (Onuoha 2014). The al Shabab in Eastern Africa is quite similar to the Boko Haram. It appeared on the scene at a time when Somalia was on the verge of forming a stable government. However, just like Boko Haram, little is known about the al Shabab Islamic extremists worldwide. Mohamed (2010), while providing a historical background to the al Shabab, indicates that the group broke out from the militant wing of the pre-2008 Council of Islamic Courts (CIC) without long-term local or global strategies. They emerged from two previous Somali Islamist groups - the Islamic Union 
and the Islamic Courts Union (ICU). Their clear break from ICU happened during the Djibouti peace deal negotiations between the Transitional Federal Government (TFG) and the ICU. They refused to join in the negotiations, declaring the peace deal as a betrayal. The initial strategy of the group was to transform and change Somalia Sunni community to more radical wahabi/sufist followers.

The activities of the group started getting serious regional attention when the African Union sent a peacekeeping force, African Union Mission in Somalia (AMISOM) to help stabilize the floundering transitional Somalia government against a horde of militias, including al Shabab. Kenya was not part of the initial AMISOM but was quickly drawn in due to two main factors - the numerous cross-border incursions by the group and the escalation of piracy that started off the Somalia coast, but which quickly engulfed most of Eastern Africa coast. Frazer (2012) explains that the al Shabab's terrorist attacks became influential in Kenya in 2011, with kidnappings for ransom and other unprovoked attacks on civilian and military targets. In October 2011, the Government deployed the Kenya Defense Force in southern Somalia in an effort to stem the spate of attacks launched from there. The military operation was dubbed "Operation Linda Nchi"-Swahili for "protect the country". The military intervention appeared to have increased the number of attacks on Kenya. Botha (2013) shows that, between October 2012 and September 2013, there were 13 terrorist attacks on Kenya resulting in 36 deaths in various parts of the country. These attacks targeted business premises, pubs and restaurants, public transport vehicles, markets and churches. In Kampala, Uganda, on 11 July 2010 at approximately 22:25 at the Ethiopian Village Restaurant and at 23:15 at the Kyadondo Rugby Club, suicide bombers targeted crowds watching a live screening of a FIFA World Cup match, claiming 74 lives and leaving 70 others injured. Al-Shabab claimed responsibility for the attacks, saying they were in retaliation for Uganda's participation in AMISOM (Botha 2013).

Currently, there has been a marked increase in the number of youths drawn to al Shabab extremism as evidenced by rising recruitments and terrorist attacks in various parts of Kenya and re-emergence of radical groups such as the Mombasa Republican Council (MRC). Most of these youths are made vulnerable to the forces of radicalism and criminality due to the feelings of real and perceived marginalization, hopelessness, identity crisis, exclusion from national resources, frustrated expectations, and relative deprivation. Idleness and widespread unemployment make most 
of the youth be easily recruited. Most of the radicalized youths returning from Somalia have undergone military training on the use of explosives and are capable of launching lethal attacks which, besides the loss of lives and property, could undermine state stability and therefore regional stability (GOK 2015).

A number of policy recommendations have been suggested that are in line with government's role in taking care of the growing populations of the youth. There is, however, an important need to focus on the role of religion and religious institutions/actors and the services that they can give to the youth with an aim of building their capacities to acknowledge their relevance within the community. Since the factors that lead to radicalization of the youth are known, the need to design programmes that address these factors should be clarified. Religious institutions should come up with robust programmes for destitute children, engage the youth in civic education that promotes peace, and encourage literacy that should help them with the reading and correct interpretation of religious texts. There is also need for a coordinated approach between religious and interfaith groups on civic and religious education that should target the radicalized individuals and groups. Within different African countries where radicalization is rampant, the religious groups should establish a national faith-based framework for inter-faith engagement and dialogue on countering radicalization and extremism and promoting inter-faith tolerance and cohesion. In all the dialogue meetings for religious groups at various community level venues, the youth should be well represented and at the centre of discussions since they are the target group of radicalizations.

\section{Youth, Tolerance and Development in Africa}

The instrumentalization of violence in politics, where politicians use the youth to serve their personal interest, is in no way different from any other form of violence that the youth engage in, especially if they are following orders from the leadership. In religious circles, for youth to take part in any form of violence resulting from intolerance of religious beliefs and practices, much of the responsibility lies in the hands of the religious leaders, just like in politics. The youth can only increase mutual respect, tolerance and understanding if the risk for manipulation into violence reduces. This is, therefore, a shared responsibility of youth and their religious leaders. 
Religion has a valuable role in finding common ground for building peace and furthering the development agenda among divided groups. This is because many religious peacebuilding programmes focus on identifying shared values between religions while celebrating the uniqueness of their own differences in beliefs and practices (Ehmer et. al. no date). It is evident that beliefs promoting peace and development can be found in nearly every religion (Bouta, Ayse \& Abu-Nimer 2005). For instance, the golden rule of love is almost universal. By teaching young people to love, virtues such as empathy, compassion and support for neighbours are indirectly transmitted.

A specific case where the youth were in the mix of religious intolerance are the occurrences of the late 1980s in Nigeria when Muslim members of the Constituent Assembly wanted Sharia law in the Nigerian constitution, while Christians would not countenance such a move. Negotiations on the issue broke down (and were to an extent superseded by other controversies) whilst President Babangida was forced to affirm in October 1988 that Nigeria would remain a secular state. Tensions between the two communities had already escalated into political violence, and inevitably, the youth were the perpetrators. In early 1987, and again in May and October 1991, anti-Christian riots broke out in parts of northern Nigeria (Maier 2001). In total, over 3,000 people were killed in Christian-Muslim clashes between 1987 and 1993. One of the worst-hit regions was the northern state of Kaduna (Haynes 1996). This led to the founding of the Muslim-Christian Dialogue Forum (MCDF) in 1995, a charity to foster Christian-Muslim dialogue that would encourage religious tolerance. It was the result of the combined efforts of two former enemies - a Christian pastor, James Movel Wuye, and a Muslim imam, Muhammed Nurayn Ashafa, both esteemed members of their religious communities. They served as joint national coordinators of MCDF, based in Kaduna. Both made the decision to turn away from similar paths of violence and militancy. Instead, they embraced non-violence, reconciliation and the advocacy of peaceful relations between their communities and sought to encourage others to join them in this goal (Haynes 2009). This evidences the point that leaders are always at the centre of showing the way, and since youth rely on role models for directions, religious institutions through the leadership, hold the key to dialogue or conflict.

There are specific activities that organizations can engage the youth irrespective of their religious backgrounds. Community theatres for instance, that aim at coordination for education and provision of technical skills 
such as tailoring; photography and graphic design; and activities such as production of beadwork, crafts, murals; counseling and empowering communities through civic education, environmental conservation, waste disposal and cleanups. These activities can lead to peace and stability at varying degrees (Quadros 2014:5). Churches have used community organization to help youth from different religious backgrounds. Foundation of Hope, for example, is a youth-based organization established in 2006 with an aim of engaging youth to be catalysts of change. Its genre of community theatre uses choreograph and spontaneous group dance, forum theatre media and poetry, to discuss social and political issues. Through the youth, the foundation conscientizes the wider community about health matters, inter-ethnic cohesion and the need for peaceful co-existence within Kibera - an informal settlement in Kenya - (Quadros 2014:34). The structure of the group is such that it restores hope and dignity in people's lives through the use of life experience performances that relate to the problems that require solutions within the community (2014:35). Creating safe spaces for sharing ideas, inter-faith and inter-ethnic dialogue among the youth is therefore an incredible approach to building healthy relationships that translate to mature relationships free of hatred and suspicion along religious and ethnic divides.

While designing religious programmes for the youth with diverse religious perspectives, Ehmer et. al. (no date) explain that there is always the need to understand these backgrounds and perspectives, and how the programme can accommodate youth from these diverse backgrounds. If there are adjustments that need to be made to make the programme equitable to youth with diverse religious backgrounds, then that should be given priority. In fact, in times of crises, these backgrounds are often not prominent and reconciliation commissions, for instance, have all encompassing approach for brokering dialogue among the warring groups. An example that suffices here is the South Africa's Truth and Reconciliation Commission (TRC).

The 'truth' recovery process in South Africa was led by the churches through TRC, and Archbishop Tutu in particular, for they had a residue of legitimacy that came from their strong anti-apartheid credentials (Brewer, Higgins and Teeney 2010). Though in the proceedings of the TRC there was little or no mention of justice, in the hearings there was an explicit appeal to religion, especially Christianity, as a legitimate method for truth-telling, and as a way to foster reconciliation among former ene- 
mies. The TRC adopted a more restorative approach (forgiveness+reconciliation) than a retributive one (Justice=Punishment). This approach was not fair to those who wanted justice and therefore TRC adopted the African concept of Ubuntu, which is translated from the Xhosa axiom "umuntu ngumuntu ngabanye bantu", meaning people are people through other people. This approach created artificial polarity between reconciliation (Ubuntu) instead of adopting Western retributive approaches of justice. The TRC was a result of the political negotiations between Nelson Mandela's African National Congress and F. W de Klerk's National Party which ended over 40 years of apartheid (Shore 2008:161).

As a people who are at the centre of conflicts, especially in countries where ethnicity has played a key role in dividing communities, and religious perspectives, the youth can be taught certain key tenets that cut across all religions, including love, forgiveness and reconciliation. Religion in such instances should be used as a uniting force that fights against hatred and animosity that result from intolerance among communities. Such sensitizations change not only the perspective of community members, but also more specifically, the youth who perpetrate violence. Religion provides a number of tools that can be employed in any form of conflict. Religious rituals, sacred scriptures, religious leaders and community leaders as moral authority are just a few of these resources. In the African perspective, truth, justice and reconciliation commissions have always been informed by the role that religion provides in ceasefire, reconciliation, forgiveness, and healing processes.

The Mastercard Foundation (2015) survey on building economic opportunities for young people in Africa discovered that, some of the ways in which intolerance and insensitivity to religious and other rights of people can be avoided is through enlightening the youth to be sensitive to incitement and early warnings; strengthened intercultural, inter-ethnic and interreligious dialogue; development of conflict resolution and management mechanisms; civic education at all levels of schooling on histories of genocides and other atrocities; and, development of networks of resources and trainers who can be called upon to sensitize the youth on issues of concern. Religious non-governmental organizations are also an important resource in the community and can harness their experiences to build peace that encourages development. One case in point suffices here:

In December 2013, during the height of inter-communal conflicts in Central Africa Republic, schools were closed out of concern for staff and students' 
safety. Almost a year later, in October 2014, classes resumed but there were no Muslim students and teachers in schools because they were afraid to leave their neighbourhood. Concerned that their friends were not attending school, Christian students reached out to Search (an organization that works with people to transform how the world deals with conflict), who in turn trained 30 youth (15 Christians and 15 Muslims) on social cohesion and nonviolence including rumour control and conflict management. They worked together to organize community events that created confidence and eliminate fear as they advocated for Muslims' safe return to schools (Ehmer et. al. no date:8-9).

This is an indication of how organizations within communities can partner with youth from diverse religious backgrounds to create spaces for advocacy and train to equip the youth with skills needed for resolving and managing conflicts and encouraging conducive environment for holistic development (Krienbuehl 2014). At the heart of interreligious dialogue, there is an effort to build trust and deepen communication across conflict lines.

\section{Conclusion}

The youth cannot be ignored in Africa's development agenda; and, religion is an important aspect in shaping the youth towards this agenda. There is, therefore, need to make deliberate effort to effectively integrate youth in religious institutions and shape them towards becoming responsible citizens who are incorporated within the mainstream development. This therefore requires that the youth be given equal opportunities in leadership and employment. As Mtata (2012:32-3) shows, such inclusion depends on the efficacy of religious leadership or the main shapers of the dominant opinion. Education that strengthens this perspective and takes into account the role of religious leaders in the development agenda, and specifically guidance of the youth who in turn get involved in development, therefore, remains very vital. Radicalization, religious extremism and intolerance are retrogressive aspects that undermine development. Factors that push the youth towards these beliefs and practices should be addressed through programmes that are specific to their needs. Deliberate efforts to inculcate religious values and virtues that emancipate them from such are deemed key, if Africa's development agenda is to be accomplished. 


\section{References}

Abbink, J. 2005. "Being young in Africa: the politics of despair and renewal. " In Abbink, J \& I. Kessel (Eds.), Vanguard or vandals: youth, politics and conflict in Africa. 1-33. Leiden: Boston. Brill.

Appleby, Scott. 2006. 'Building sustainable peace: the roles of local and transnational religious actors. ' Paper presented at the Conference on New Religious Pluralism in World Politics, Georgetown Univ., Washington, DC.

Armstrong, K. 2007. The Bible: the biography. London: Atlantic Books.

August, K. 2013. "How development ethos emerged and is engrained and sustained in contact with local culture and religion," In K. Mtata (Ed.). Religion: Help or Hindrance to Development? Leipzig: EVA.

Batson, D. 1993. Religion and the individual: a socio-psychological perspective. Oxford: OUP.

Biehl, M. 2012. Religion development and mission. In K. Mtata (Ed.), Religion: Help or Hindrance to Development? Leipzig: EVA.

Botha, A. 2013. 'Assessing the vulnerability of Kenyan youths to radicalisation and extremism.' ISS, Paper 245. Addis Ababa.

Bouta, T., Ayse, K. \& Abu-Nimer, M. 2005. "Faith-based peacebuilding: mapping and analysis of Christian Muslim \& multi-faith actors. ” Netherlands Institute of International Relations.

Brewer J., Higgins G., \& Teeney F. 2010. "Religion and peacemaking: A Conceptualization,” Sociology. 44(6), 1019-1037.

Brittian, A. Lewin, N. \& Norris, S. 2013. "You must know where you come from: South African youth's perceptions of religion in tome of social change," Journal of Adolescence Research 28(6), 642-666.

Chitando, E. 2013. "Prayers, politics and peace: the Church's role in Zimbabwe's crisis," http://www.osisa.org/openspace/zimbabwe/prayers-politics-and-peace-churchsrole-zimbabwes-crisis.pdf. Acc. 13 Oct. 2017.

CLEEN, 2014. "Youths, radicalization and affiliation with insurgent groups in Northern Nigeria. ” CLEEN Foundation. Justice Sector Reform. 978-978-51062-8-2.

Commonwealth. 2016. 'Global youth development index report 2016.' Commonwealth UK. ISBN (e-book) 978-1-84859-053-6.

Ehmer, A. Musselman, B. Makadem, S. et al. no date. 'Accommodating religious identity in youth peacebuidling programs.' Search for Common Ground.

Frazer, O. 2012. "Somalia: little hope for peace. " Centre for security studies analysis in security policy. No. 119. Sept. 2012. ETH, Zurich.

GOK. 2015. "Strengthen community's capacity against radicalization and violent extremism in Kenya." Project Document. GOK \& UNDP.

Haynes J. 2009. "Conflict, conflict resolution and peace-building: The role of religion in Mozambique, Nigeria and Cambodia," Commonwealth a Comparative Politics. 47(1), 52-75.

Haynes, J. 1996. Religion and politics in Africa. London: Zed.

Honwana, A. \& De Boeck, F. 2005. Makers and breakers: children and youth in pre-colonial Africa. Eds. Trenton, NJ: Africa World Pr. 
Hunt, S. 2005. Religion and everyday life. New York, Abingdon: Routledge.

IDEA. 2015. "Youth participation in electoral processes: new roles for African electoral management bodies. " IDEA Policy Brief. Strömsborg: Sweden.

Kilonzo, S. 2011. "Awake o ye silent religions and promote post- conflict reconciliation! towards an understanding of the role of religion in peace building in Kenya," Journal of Conflict Transformation and Security, 1 (1): 90-107.

Kilonzo, S. 2014. "A Re-examination of church leadership in peace and ethnic conflict in post-independent Kenya," Journal of International Politics and Development, 12 (2), 105-122.

Krienbuehl, L. 2014. "Religion and peacebuilding. " KOFF newletter on Religious Dialogue. No. 124.

Kristian, H. \& Hanne, R. 2008. "Faithful Brokers? Potentials and pitfalls of religion in peacemaking," Conflict Resolution Quarterly, 25 (3), 351-373.

Makori, C. 2015. 'Youth perception and participation in electoral democracy in Kenya.' Unpublished Msc. Thesis. Norwegian Univ. of Life Sciences.

Lekalake, R. 2016. 'Youth political engagement in South Africa: beyond student protests. ' Afrobarometer Dispatch No. 101. The Institute for Justice and Reconciliation (IJR).

Maier, K. 2001. This house has fallen: Nigeria in crisis. Harmondsworth: Penguin.

Mastercard Foundation. 2015. "Youth at work: building economic opportunities for young people in Africa." The Master Card Foundation.

Makori, C. 2015. 'Youth perception of and participation in electoral democracy in Kenya.' Unpublished Msc. Thesis. Norwegian Univ. of Life Sciences.

Miles, S. 2000. Youth lifestyles in a changing world. Buckingham, PA: Open Univ. Pr.

Mohamed, I. 2010. "The al-Shabaab myth: notoriety not popularity. " NCEIS research papers Vol. 3 (5). National centre of excellence for Islamic studies. Univ. of Melbourne.

Mtata, K. 2013. Religion: help or hindrance to development? In K. Mtata (Ed.). Religion: help or hindrance to development? Leipzig: Evangelische Verlasastalt. .

Nyambedha, E. O. 2005. "Child vulnerability and migration in Western Kenya. AIDS in focus - In Review: A growing Orphan Crisis. ” International Poverty Centre. UNDP.

Ojok, D. \& Acol, T. 2017. "Connecting the dots: youth political participation and electoral violence in Africa," Journal of African Democracy and Development, 1(2), 94108.

Onuoha, F. 2014. "Why do youth join Boko Haram?: United States Institute of Peace Special Report, No. 348. USIP.

Quadros, L. 2014. 'Community theatre and peacebuilding in Kibera (Kenya), the case of Foundation of Hope.' Unpublished MA thesis in Peace Studies \& International Relations.

Putzel, J. (1997). “Accounting for the 'Dark Side' of Social Capital,” Journal of International Development. 9, 939-949. 
Shore, M. 2008. "Christianity and justice in the South African Truth and Reconciliation Commission: a case study in religious conflict resolution," Political Theology. 9(2), 161-178.

Smith, C. \& Dandon, M. 2005. Soul searching: the religious and spiritual lives of American teenagers. New York, NY: Oxford Univ. Pr.

UNDP. 2015. "Youth, population trends and sustainable development. " UNDP. New York.

UNDP. 2012. "Enhancing youth political participation throughout the electoral cycle." UNDP. New York.

UN. 2013. "Youth, political participation and decision making. " UNDP, New York.

Walker, A. 2012. What is Boko Haram? United States Institute of Peace Special Report, No. 308. USIP.

Wamucii, P. \& Idwasi, P. 2011. Social insecurity, youth and development issues in Kenya. In: Kondlo, K. \& Ejiogu, C. (eds). Governance in the 21st century. (Africa in Focus). Cape Town: HSRC Pr. 188-199. 


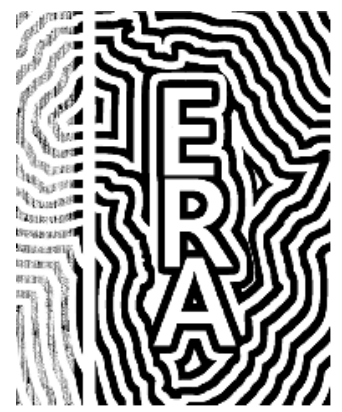




\title{
Sacralization of the Humanitarian Space: Faith Based Organizations, Mission-Aid and Development in Africa
}

\author{
Hassan J. Ndzovu
}

\section{Introduction}

For the last two decades, religious organizations have actively been engaged in development and humanitarian projects in Africa. Most African states and donor agencies seem to have confidence in religious bodies as reliable "partners in development" (Burchardt 2012). This attitude towards religious bodies is attributed to the re-assertion of religion as a key player in influencing public discourse across the world. The introduction of neo-liberal policies, de-privatization of religion, and the changing of state-religion relationships in the majority African states prepared the ground for the emergence of faith-based organizations (FBOs). The conspicuous low development due to neo-liberal policies, high rate of crisis among African states and the resultant insistence by the donors on allinclusive development initiatives and privatization of service delivery by the state worked favourably for the formation of FBOs across the continent (Lynch 2011; Saggiomo 2012). Despite skepticism towards religious institutions in development, the FBOs are still considered crucial partners in undertaking development projects that cut across the arena of education, health, civic awareness, democratic reforms, and conflict resolution. This scenario on the rise of FBOs in providing humanitarian aid and initiating development projects demonstrates the interaction between religion and development in contemporary Africa.

Though earlier considered as the duty of the government, the collaboration between the State and FBOs in offering social services in Africa is necessary as they are both devoted in addressing societal needs of their communities. Such cooperation can address the goals of government, the religious sector, and the targeted communities (Smith 2008). Due to developmental gaps and unresolved crises on the continent, religious actors took the responsibility to initiate development and resolving some of the long running conflicts thereby ensuring economic growth in the region. There have been remarkable illustrations of effective FBOs intervention 
in local civil conflicts and advocating for political reforms in Africa. The Inter-Religious Councils in Sierra Leone, Liberia and Sudan, for instance, were significantly involved in ending the long running civil wars in these countries (Conteh 2011), championing "human rights and increased governmental accountability” (Smith 2008). The religious bodies were successful in their efforts because they created inclusiveness that shrunk "political and religious boundaries" thereby increasing "the confidence of conflicting parties" during the dialogue (Smith 2008).

At this point we raise the question: What is a Faith Based Organization? The phenomenon of FBOs is complex and as a result challenging to define. But Jonathan C. Agensky (2013:6-7) has attempted to present a comprehensive understanding of FBOs arguing:

[Faith-Based Organization] encompasses a broad constellation of religious traditions, denominations, and communities. It entails various practices, such as disaster management, refugee resettlement, and the delivery of food and material goods. It entails direct and indirect forms of engagement, such as project implementation, emergency appeals and donations, and public awareness campaigns and community mobilisation. Last, it entails different forms and scales of organisation, ranging from large professionalised international organisations to ad hoc, informal projects initiated by small communities and groups. At root, [Faith-Based Organization] draws its moral imperative to alleviate the physical suffering of others from religious tenets.

Thus, FBOs are voluntary nonprofit organizations with a religious background whose major basic driving principle is their loyalty to serving fundamental human interests, by drawing religious support (Molloy and Heath 2014; Burchardt 2012; Schmidet al 2008). However, one should not confuse between religious congregations and FBOs engaged in delivering social services and development. John D. Terry (2015) gives a clear distinction of the two arguing, "FBOs are professional or paraprofessional organizations...Where FBOs have a primary social service mission, congregations may include social service as an important secondary mission" (Terry 2015:213). It is Terry's meaning of FBOs that will be used throughout this chapter.

Despite this theoretical distinction that seems to overlap, within the African context, both local and transnational FBOs have been operating in the region offering humanitarian services and developments. Undoubtedly, FBOs have been active in various parts of Africa since the 1980s, and as religious organizations they represent two of the significant power blocs in the contemporary world, Euro-Christianity and Islam. Africa has long been at the crossroad of Western and Middle Eastern spheres of influence, 
and for this reason has been a strategic area of intervention for Islamic and Christian FBOs. Among the transnational Christian FBOs that are known to have widely engaged in initiating developmental aid activities in sub-Saharan Africa include Catholic Relief Services (founded in 1943), World Vision International (founded in 1950), Lutheran World Relief (founded in 1945) among others, which operate across all major sites of conflict, emergency, and underdevelopment in the continent. Conversely, since the 1980s some of the transnational Islamic FBOs operating within the continent comprises International Islamic Relief Organization (founded in 1978), the Africa Muslims Agency (founded in 1982), the International Islamic Charitable Foundation (founded in 1986), Al-Haramain Foundation (founded in 1988), among others.

The numerous FBOs' participation in intricate humanitarian emergencies and development demonstrates the diversity of the agencies providing services in Africa, calling for attention to the role of the religious sector in initiating development on the continent. The chapter will, therefore, show how religious actors in Africa have mixed the spiritual and the material in their religious activities, a phenomenon influenced by "overlapping and sometimes competing 'religious' and 'emergency' imaginaries" (Agensky 2013:5). As 'professional' and 'paraprofessional' organizations, FBOs generate enormous operating budgets, demonstrating the crucial role of funding in the realization of humanitarian aid and development by the religious actors in Africa. Virtually all FBOs projects are mostly reliant on international funding, especially from the West and Muslim-Middle Eastern donors. This raises the salient questions: To what extent are the FBOs influencing certain projects while responding to emergencies in society? How are the various activities of FBOs affected by their respective religious beliefs and practices? While responding to these questions, the chapter will demonstrate how FBOs in Africa oscillate between the 'mission' and 'aid' end of the spectrum. Though FBOs are important actors in development and providing humanitarian aid in Africa, their religious nature can either be an obstacle or an advantage to their success.

\section{Background: Religious Agentive role in Humanitarian services and Development in Africa}

What is the role of religion in development in Africa? Africa has always been framed as a continent that is lagging behind in development, which 
is to a certain extent synonymous with modernity. Undeniably, "the modern idea of development has a genealogy in Western Christianity" and is linked with education, modernization, technological advancement and democratic nation building (Ter Haar 2009:76). Despite this understanding of development, religiously motivated social welfare provision is as old as the religious traditions themselves. Since the medieval period, social welfare and development support was traditionally provided by the various religious institutions, giving them power and prestige in society (Aksürmeli 2012).

All the three major religions observed in sub-Saharan Africa (African indigenous religions, Islam and Christianity), have historically been linked with development and provision of humanitarian services. Do the three religions have a religiously informed grassroots perception of development and humanitarian services? In the world view of African indigenous religions, development is observed by emphasizing the establishment of a harmonious relationship between the human and the spiritual (ancestors, spirits, deities and God(s)) realms (Awuah-Nyamekye 2012). Once human beings have succeeded in creating a harmonious order with the spiritual world, prosperity is guaranteed in societal life. More so, in African indigenous religions, the small ejaculatory prayers and petitions to the spiritual beings are usually intended for material blessings, and as Bolaji Idowu (1962:116) describes:

They consist usually of asking for protection from sicknesses and death, gifts of longevity, children, prosperity in enterprises, victory over enemies, protection from evil spirits and of relatives near and distant, rectification of unhappy destinies, and abundant provision of material things; blessings on all well-wishers and damnation on ill-wishers.

On the other hand, the construction of Christian humanitarianism and development is attributed to a series of biblical commandments, as well as to history of overall Christian activism as epitomized by the slave abolition movement, the medical mission, education empowerment and poverty reduction. Historically, Africa is awash with illustrations of Christian missionaries, acting as humanitarians, beginning with the evangelical movement that inspired Protestant initiatives at the end of the eighteenth century, with Anglican and Roman Catholic missions joining in later decades. Missionary organizations such as the Baptist Missionary Society (formed 1792), the interdenominational London Missionary Society (established in 1795), the evangelical Church Missionary Society (created in 1799), and many others played crucial roles in the evangelization of Africa, 
with anti-slavery agenda being part of their core mission (Vilhanová 2007). More so, during the colonial period, the missionary churches were in the forefront in providing education and health services to most African communities as a way of realizing their 'civilizing' mission. For many Christian-FBOs, humanitarianism links to a continuous legacy of Christian charity, activism, and compassion (Agensky 2013). To Christian-FBOs, therefore, their conceptualization of humanitarianism is a form of Christian call that focuses on assisting the less fortunate members of society.

With the appearance of the Pentecostals/Charismatic churches in Africa, the nexus between Christianity and development took another dimension through the preaching of the prosperity gospel that emphasizes "investing in the invisible world, in the hope for future returns in the form of material prosperity" (Ter Haar 2014:17). The prosperity gospel is considered biblical and "affirms a theological mindset of success and well-being associated" with these churches (Asamoah-Gyadu 2004:340). Within Pentecostal/Charismatic churches, the power of the Holy Spirit is believed to have the ability to change lives of the believers in a moral sense, but also in attaining material success. The prosperity theology teaches that salvation has the power over spiritual sin, and other earthly maladies like sickness and poverty, making these churches popular among certain segments of the African population. Such, religious "message can be very empowering with its emphasis on positive thinking, the maximization of potential and the use of abilities and talents, which encourage the upwardly mobile youth to have faith in the God who saves people in order to turn them into success stories" (Asamoah-Gyadu 2004:351).

Similarly, the amalgamation of religion and development is also evident among Muslim communities in Africa. Since Islam does not idealize a society that is classless, prosperity or poverty are conditions that are considered to be always there as long as humanity exists and are thereby regarded as test for believers (Quran 8:28). Each of the two conditions has certain moral obligations, which the believers are expected to abide with to win God's pleasure. One of the popular hadiths of Prophet Muhammad declares, "the one who sleeps full when his neighbor is hungry is not from us", illustrates that donating is an essential ritual for the wealthy Muslim members of society. Through the alms ritual, believers supposedly cleanse their property and themselves. Consequently, funding of FBOs engaged in initiating development and social services is considered a religious obligation and as an act of worship by donors (Aksürmeli 2012). Historically, Sufi orders in sub-Saharan Africa continue to be a powerful 
expression of Islam on the continent in which the Sufi saints integrated spiritual and material aspirations of their followers (Seesemann 2010: 608). One Sufi order, the Muridiyya, organized into agricultural communities, where the devotees had the opportunity to study Islamic knowledge from the sheikh while they in return provided manual labor on the peanut farms. The proceeds collected from the farms were kept by the sheikh in charge of a particular Sufi community, a practice that has been interpreted as exploitation of the masses by greedy and wealthy religious leaders. But to the disciples, working for the sheikh has a vital meaning "for the purification of the self" and entailed blessings in the hereafter together with worldly success (Seesemann 2010:610; Seesemann 2002:103). This religious innovation of the Sufi order in Africa, demonstrates a clear integration of "spiritual pursuits with material affairs", ingrained "on a strong master-disciple relationship” (Seesemann 2010:611).

With the advent of post-colonial States and their involvement in the provision of social welfare and development, religious institutions did not lose this crucial role to the States in Africa. Most post-colonial States in Africa realized that they could not continue to provide social services and initiate developments on their own, turning to the religious sector to support them in this area (Ndzovu 2014). The situation was made dire following the introduction of neo-liberal and structural adjustment policies that led to increasing unemployment and poverty across Africa as States reduced spending on provision of social services, facilitating the emergence of FBOs (Saggiomo 2012). As welfare provision by the State decreased, the religious sectors through the FBOs increased its involvement of providing social services by filling in the created gap. The emergence of FBOs in initiating development and providing aid contributed to social integration by addressing injustices created by neo-liberal and structural adjustment policies.

In justifying their participation in the provision of services, FBOs employ religious discourses that sanction philanthropic ventures and alleviation of poverty among the less fortunate members of society. As a consequence, personal donations that are considered as part of a religious ritual by the donors are significant in filling the budgets of FBOs. The over reliance of FBOs on private sources of funding, mostly their co-religionists, compels them to a large extent to continue adhering to the commitments and religious values of their donors. Here, the notion of 'mission and aid' comes into play. The two elements overlap the activities of FBOs as it is possible to find some FBOs also engaging in practices that contravene 
mainstream 'rules of engagement', such as distribution of religious books (bibles or Qur'an), constructing places of worship (church or mosque building), and discipleship or imam training. For instance, apart from offering humanitarian aid to various parts of Africa, the Voice of the Martyrs (VOM) has also a clear evangelizing agenda in which "bibles and blankets go hand in hand" (Agensky 2013).

As a powerful cultural force, religion has been observed to have negative attitudes on certain practices and policies. For instance, most of the major religious traditions in Africa are uncomfortable in discussing openly issues of sexuality; they are indifferent to female genital mutilation (FGM); prohibit the usage of condoms; discourage reproductive health education to the school going adolescents; fazed by homosexuals' rights campaigns; and increase stigmatization of people living with HIV \& AIDS (Schmid et al 2008). Despite this generalization about religious institutions, some religious leaders have been in the forefront in advocating for change, which has sometimes contradicted with the theological views of the majority in a particular religion. This double sidedness of religion in the development arena could be illustrated with the Catholic Church in Africa, which has been criticized for its position against condoms, but concurrently extolled for providing health and education on the continent (Schmidet al 2008).

\section{Mission and Aid: Religious Charity, Ambivalence and Suspicion against FBOs in Africa}

The engagement of religious actors in welfare in Africa is not a new phenomenon. In various parts of sub-Saharan Africa, humanitarian and development aid has mostly been undertaken by religious institutions due to their long history of social service provision in the continent. Unlike African indigenous religions, which are not properly institutionalized, Christianity and Islam are the two religious traditions that formally engage in development projects in Africa. Many of the global FBOs with affiliation to Christianity working in sub-Saharan Africa have significantly contributed in offering crucial social services projects and intervention programs. For instance, the Ecumenical Pharmaceutical Network (EPN, est. 1981) came into existence initially as the World Council of Churches' Christian Medical Commission. It later developed into an autonomous network with a secretariat in Africa. This FBO is a "non-profit Christian" organization working in reduction of poverty and providing health services on the continent (Schmid et al 2008:75). It is a global network, with 
members in thirty-one countries, supporting church-related health services by offering impartial, effective and well-organized pharmaceutical services.

Its mission is "to facilitate development of compassionate, just and sustainable quality pharmaceutical care in and through the church health care system" (Schmid et al 2008:75-76). The main focus of the EPN include: 1) development of an active network with increased impact, 2) maximizing access to crucial medicines for church health services, 3 ) increasing the capacity of church leaders and church-related health services to respond to the challenge of HIV \& AIDS treatment, 4) training of pharmaceutical assistance not recognized in most countries (Schmid et al 2008:76). EPN is credited for running various projects across sub-Saharan Africa, including Increasing Access to ARVs/ART in Africa Project whose intention is to increase the competence of church leaders and church health services to deal with HIV \& AIDS treatment and related organizational management.

Similarly, the Islamic Relief Worldwide is a transnational relief and development charity organization founded in the UK in 1984, with branches in 35 countries. "Regardless of race, religion or gender, Islamic Relief works in four main sectors: emergency relief, development, orphans, and poverty alleviation endowments (Waqf)" (Schmid et al 2008:77). Apart from addressing issues of relief services, the main activities of IR in the health sector includes: (1) the construction and rehabilitation of medical clinics in Mali; (2) distribution of medical equipment and ambulances to hospitals, e. g. in Sudan; (3) raising health and dietary awareness in poor communities, e. g. HIV \& AIDS awareness in South Africa, malaria campaigns in Sudan, cholera campaigns in Mali among others (Schmid et al 2008:77). Though the illustration by the two FBOs indicates that they operate in ways similar to secular NGOs, there are other FBOs that are unable to dissociate themselves from activities of evangelization and $d a^{\prime} w a$ (propagation) while delivering humanitarian services and initiating development in Africa.

There is a clear ambivalence and confusing overlap that exists between 'mission' and 'humanitarian aid' associated with FBOs in Africa, and elsewhere globally. The emerging connection involving development plan and religious practices, raises the question of how FBOs balance between mission and aid. For a long time religion has been perceived as an obstacle to development, thereby ignored as a relevant player in the process of 
development (Tomalin 2013). Despite its religious connection as illustrated above, development began to be conceptualized in secular terms relegating religion in the development programme (Bompani and Maria Frahm-Arp 2010). But this attitude shifted in the early 1990s when States and donors began to appreciate the significant contribution of the religious actors in advocating for democratization and economic initiatives, changing the "religious factor" from an impediment into a critical player in development. In the spirit of inclusive politics, the working relations between religion and development transformed from rivalry to collaboration as the liberalization wind was blowing across Africa. These changes were increasingly driven by the desire to reduce the role of the State and encouraging the participation of non-state actors in delivering humanitarian aid and initiating developments. These demands were occasioned with dissatisfaction and lack of trust with most African States in using the donor funding as intended due to rampant corruption.

In their judgment, the donors took for granted that, because of FBOs' proximity to local communities, religious actors are better placed in articulating the interests of target populations. As a result, religious communities participated in various strategies of articulating societal needs to enable them secure funding. Consequently, many religious institutions created humanitarian aid and development agencies, while some councils of the various religious traditions such as the Supreme Council of Kenya Muslims (SUPKEM) and the National Council of Churches of Kenya (NCCK) turned into effective FBOs (Ndzovu 2014). In order to improve their management and qualify for funding, religious institutions morphed into FBOs. Gradually, they embraced the NGOs' language of "capacity building," "gender mainstreaming," "social capital formation," and "community outreach," knowing that the usage of such categories conforms to the agendas of possible donors (Burchardt 2012).

Arguably, discourse on Christian FBOs working on development and humanitarian aid could be situated within the framework of the colonial era in Africa when Christian missionaries and their civilizing agenda acted as a forerunner to the project of development (Agensky 2013). In their civilizing project, the missionaries considered the conversion to Christianity as also synonymous with embracing modernity (Vilhanová 2007). Conversely, the appearance of Islamic FBOs in Africa is a post-colonial phenomenon. Following severe famine and conflicts in various parts of Africa in early 1980s, individual Muslims and Muslim majority governments founded a number of Islamic FBOs to provide humanitarian assistance 
(Lynch 2011). The historical connection between Christianity and colonization in Africa supports the suspicions surrounding contemporary Christian FBOs. Present day Christian FBOs re-ignite the dualism of 'missionary-colonialism', which frames debates about the genuineness of aid and development associated with these FBOs. This attitude is influenced by various past claims that associate Christian missionaries to colonialism, including; (1) the missionaries served as 'foot-soldiers' for European colonization; (2) they undermined local rulers for specific civilizing purposes; and (3) they condemned and looked down at local customs and beliefs (Agensky 2013:13).

Similarly, some Islamic-FBOs have also been treated with a lot of suspicion by States both in Africa and in the West, particularly following the 'Global War on Terror'. Numerous Muslim organizations have been closed and their bank accounts frozen. In Kenya, following the 1998 bombing of the US embassy in Nairobi, the State de-registered five Islamic FBOs. They include Mercy Relief International, Al-Haramain Foundation, Help African People, the International Islamic Relief Organisation and Ibrahim Bin Abdul Aziz Al Ibrahim Foundation on allegations that they were funding terror activities (Seesemann 2007). With the rise of jihadi-minded groups in various parts of Africa, any association of "Islam" with "development aid" and "relief" has stirred negative reactions from some African states and even the population. Though suspicion also surrounds some Christian FBOs, particularly the contemporary evangelical stream, their critique follows different lines of argument. For instance, the increasing relationship between African and American based evangelicals raises questions about the nature of their relationship. Thus, Evangelical Christianity has become an important political resource in which some African political leaders have used their evangelical membership to seek for support from the US leadership despite their poor track record in governance, democracy, and corruption (Agensky 2013).

More so, some Christian FBOs in Africa, mainly those led by the American evangelical missionaries, have been accused of using financial incentives to the needy with the intention of converting them to Christianity. Of concern for the FBOs affiliated to the evangelical stream is their unwavering support for supposedly fundamentalist churches in Africa; the 'natural family' agenda and 'pro-family' movement; and the influence of the conservative evangelical agenda on global HIV/AIDS policy. These seemingly rigid policies of the evangelical FBOs raise concerns about their agendas in delivering services, which seem to focus on evangelization and alleged "unethical conversion" (Agensky 2013). Correspondingly, Islamic FBOs have also been accused of proselytism in Africa. Apart from initiating missionary activities to 
those Muslims, who in the assessment of these organizations are not 'true' believers, in Africa such efforts have also been directed towards non-Muslim population. In some parts of Africa, for instance in southern Chad, Islamic FBOs such as al-Makka al-Mukarrama (Saudi Arabia), the Africa Muslim Agency (Kuwait) and al-Muntada (Saudi Arabia) have centers for new converts for religious instruction, feeding and accommodation (Kaag 2007).

As religious organizations, FBOs also have a missionary function apart from providing humanitarian aid and development. They are ultimately concerned with advancing their respective religious traditions. This missionary desire is demonstrated in their activities that involve distributing religious materials together with aid. While addressing humanitarian crises in Africa, FBOs respond in different ways. Most Christian FBOs address all forms of disaster and appear not to 'discriminate' in their delivery of aid. This could be demonstrated with the presence of Christian FBOs in non-Christian majority environments such as Somalia, Darfur and Chad, but which has been interpreted by Muslims as a strategy to win converts (Ahmed 2009). Some Christian FBOs are known for specifically targeting non-Christian sites for evangelism purposes through missionaid (Agensky 2013). Christianity in Africa is associated with development projects in the areas of education, health, housing, as well as relief and humanitarian services, which are intended to attract followers. Thus, "In this regard, salvation is not only equated to liberation of the human being from sin and hell but also from fear, hunger and anything that obscures God's image in human beings, distracts human potential and dehumanizes people", Oliver Mtapuri (2017:119) observed.

Despite the praising of Christian FBOs for their 'non-discrimination' in delivering aid, this does not suggest lack of some Christian FBOs that seem to favor helping their co-religionists. This attitude comes out clear during hiring of staff. With regard to recruitment policy, some Christian FBOs emphasize employment of Christians, except when working in a predominantly non-Christian zone. Such organizations would demand a statement of faith from prospective applicants; letters from church leaders; rigorous questions about the applicant's spiritual life, among other considerations (Agensky 2013). However, those Christian FBOs working in non-Christian areas have been compelled to hire non-Christian staff, but only to certain levels of seniority (Agensky 2013). Without doubt, emphasizing on specific criteria of employment, "religion operates as a mechanism of social closure, offering opportunities for some while excluding others" (Burchardt 2012:21). 
While Islamic-FBOs in sub-Saharan Africa have been criticized for allegedly engaging in discrimination in delivering services and initiating development, the example of Mustadafin Foundation (in South Africa) refutes this blanket condemnation of Muslim FBOs whose programmes also cater for "overall community irrespective of the religion or culture" (Sadouni 2007:112). The universality with which such Islamic FBOs distribute aid to underprivileged populations has enhanced their popularity among both Muslim and non-Muslim communities. Nevertheless, there seem to be a thin line between mission and aid framing during service delivery as far as FBOs are concerned. It should be appreciated that FBOs participation in humanitarian crises is mobilized through religious essentials, which desires specific religious end results such as increasing members to their respective religions. Despite this awareness, the involvement of FBOs in development aid also compels them to 'privatise' their religion, where they are expected to adhere to general codes of conduct while delivering services, which bars religiously biased activities. Such is the predominant framework through which FBOs operate in Africa.

\section{Conclusion}

This chapter has shown that Africa has witnessed the rise and institutionalization of an independent civil society reflected in the massive spread of FBOs since 1980s ranging from Christian FBOs to Islamic oriented FBOs. The appearance of FBOs delivering services has seen donors granting financial support to FBOs in various critical areas relevant to development in Africa. In their efforts to eradicate poverty and other devastating social circumstances, governments in Africa have come to the realization that FBOs are important agents for initiating development on the continent. The chapter focused on the interface of religion and development networks, raising broader questions about how religious institutions balance between the two notions of mission and aid while offering services and undertaking development. There are those FBOs that mix service delivery and proselytization, while others deal with social provision as the main domain of their activities. Since FBOs operate as intermediaries that depend on their co-religionist benefactors and constituencies, this religious connection influences "the ways people access the networks and resources offered by FBOs" (Burchardt 2012:16). Also demonstrated in the chapter are the successes and controversies surrounding the activities of most prominent FBOs in Africa, particularly, the alleged involvement in 
terror related activities and deliberate propagation of their faiths to the recipients of the humanitarian aid and development projects. Despite this supposed shortfall, FBOs' delivery of services should be broadened and encouraged on the continent to complement the dwindling efforts of the States in Africa.

\section{References}

Ahmed, Chanfi. 2009. Networks of Islamic NGOs in sub-Saharan Africa: Bilal Muslim Mission, African Muslim Agency (Direct Aid), and al-Haramayn, Journal of Eastern African Studies, Vol. 3, No. 3: 426-437.

Agensky, Jonathan C. 2013. Dr Livingstone, I Presume? Evangelicals, Africa and FaithBased Humanitarianism. Global Society, 1-21.

Aksürmeli, Mehmet. 2012. Faith Based Welfare Provision in Konya. Master Thesis, Middle East Technical Univ. .

Asamoah-Gyadu, J. Kwabena. 2004. Of Faith and Visual Alterness: The Message of "Mediated" Religion in an African Pentecostal Context. Material Religion. Vol. 1. Issue 3: 336-357.

Bompani, Barbara, \& Maria Frahm-Arp. 2010. Introduction. In Development and Politics from Below: Exploring Religious Spaces in the African State. New York: Palgrave MacMillan, 1-22.

Burchardt, Marian. 2012. Faith-Based Humanitarianism: Organizational Change and Everyday Meanings in South Africa, Sociology of Religion, 1-26.

Conteh, Prince Sorie. 2011. The Role of Religion during and After the Civil War in Sierra Leone. Journal for the Study of Religion, Vol. 24, No. 1: 55-76.

Idowu, Bolaji E. 1962. Oludumare: God in Yoruba Belief. London: Longmans.

Kaag, Mayke. 2007. Aid, Umma, and Politics: Transnational Islamic NGOs in Chad. In Islam and Muslim Politics in Africa. Benjamin Soares \& Rene Otayek (eds.). New York: Palgrave Macmillan, 85-102.

Lynch, Cecelia. 2011. Local and Global Influences on Islamic NGOS in Kenya. Journal of Peace-building a Development, Vol. 6, No. 1:21-34.

Molloy, K. Arianna \& Renee Guarriello Heath. 2014. Bridge Discourses and Organizational Ideologies: Managing Spiritual and Secular Communication in a Faith-Based, Nonprofit Organization. International Journal of Business Communication, Vol. 51(4): 386- 408.

Mtapuri, Oliver. 2017. Poverty and Fundamentalism in Africa. In Artwell Nhemachena \& Munyaradzi Mawere (eds). Africa at the Crossroads: Theorising Fundamentalism in the 21st Century. Mankon: Langaa Research \& Publ. CIG.

Ndzovu, Hassan J. 2014. Muslims in Kenyan Politics: Political Involvement, Marginalization and Minority Status. Evanston: Northwestern Univ. Pr.

Nyamekye, Samuel Awuah. 2012. Religion and Development: African Traditional Religion's Perspective. Religious Studies and Theology 31 (1):75-90. 
Sadouni, Samadia. 2007. New Religious Actors in South Africa: The Example of Islamic Humanitarianism. In Islam and Muslim Politics in Africa. Benjamin Soares \& Rene Otayek (eds.). New York: Palgrave Macmillan, 103- 118.

Schmid, B., Thomas, E., Olivier, J \& Cochrane, JR. 2008. The contribution of religious entities to health in sub-Saharan Africa. Study commissioned by B \& M Gates Foundation. Unpublished report. ARHAP, 1-235.

Seesemann, Ruediger. 2010. Sufism in West Africa. Religion Compass, 4/10: 606-614.

Seesemann, Ruediger. 2007. Kenyan Muslims, Aftermath of 9/11, and the "War on

Terror". In Islam and Muslim Politics in Africa. Benjamin Soares \& Rene Otayek (eds.). New York: Palgrave Macmillan, 157-176.

Seesemann, Ruediger. 2002. Sufi Leaders and Social Welfare: Two Examples from Contemporary Sudan. In Social Welfare in Muslim Societies in Africa. Holger Weiss (ed.). Uppsala: Nordiska Afrikainstitutet. 97-115.

Smith, R. Drew. 2008. Balancing Faith-Based Strategies in U. S. -Africa Policy. The Review of Faith a International Affairs, 47-51.

Saggiomo, Valeria. 2012. Islamic NGOs in Africa and their Notion of Development: The Case of Somalia. Storicamente, Vol. 8: 1-12.

TerHaar, Gerrie. 2014. Poverty and Prosperity in Africa. In Religion and Development: Nordic Perspectives on Involvement in Africa. Tomas Sundnes Drønen (ed.). New York: Peter Lang, 11-26.

Terry, John D. 2015. Incorporating Evidence-BasedPractices into Faith-Based

Organization Service Programs. Journal of Psychology Q Theology, Vol. 43, No. 3: 212 223.

Tomalin, Emma. 2013. Religions and Development. Abingdon: Routledge.

Vilhanová, Viera Pawliková. 2007. Christian Missions in Africa and their role in the Transformation of African Societies. Asian and African Studies, 16, 2: 249-260. 


\title{
Africa's Muslim Non-Governmental Organizations: Competitive Charities, Altruistic Allies?
}

\author{
Muhammed Haron
}

\section{Introduction}

Throughout the $20^{\text {th }}$ century both majority and minority Muslim communities have been ably represented by a plethora of organizations that have been active in various types of social welfare and humanitarian work. Over the years these organizations, which have been classified by social scientists as Faith Based Organizations (FBOs) that is a sub-category within the Non-Governmental Organizations' (NGOs) sector, have indeed made a qualitative difference in the lives of those communities that encountered severe starvation, famines, sanitation difficulties, and a host of other negative experiences. Since Africa has experienced many of these during the past decades without any relief in sight for some of these communities, the international and national Muslim NGOs - as they shall be referred to throughout this essay - have made substantial inputs to bring about some if not total relief to their plight; the pro-active position that these organizations displayed among Africa's nation-states where communities - irrespective of their social, ethnic, linguistic, cultural, and religious backgrounds - have gone through trying times, is admirable and commendable; they have most certainly helped to alleviate and assuage these communities' distressing circumstances.

This essay reflects upon the nexus between religion and development by looking at it through a Muslim lens; and also describes a few Muslim NGOs that have been involved in different parts of the continent and showing to what extent they complement and differ from each other; and in the process it also wishes to illustrate whether they are competitive charities or altruistic allies. And by way of concluding, it also questions whether these Muslim NGOs (and their Christian counterparts) are intently mission oriented or whether they are purely humanitarian agencies that complement one another as they purport to be. 


\section{Development and Religion (Islam): Their Nexus}

Before the new millennium ushered in, the relationship between 'Development and Religion' was generally understudied and an ignored field. Ver Beek (2000) reached this conclusion after he undertook a longitudinal study of the contents of three well-known and regularly circulated journals, namely World Development, Journal of Development Studies and Journal of Developing Areas. He assessed their contents over a period of 15 years (that is, from 1982 to 1998) and he argued that religion was given scant attention throughout this period. While one agrees with Ver Beek's overall conclusions, it appears that he neglected to factor in the World Development's special edition (Vol. 8 Issue 7-8) that gave special attention to this theme (Bosco 2017). In the same article Ver Beek correctly underlined that even its concomitant concept, that is 'spirituality' was sidelined and regarded as a taboo topic. Ver Beek's observations were further reinforced by, among others, the Danish Centre for Development Research's (DCDR) views; this centre's protagonists expressed the opinion that "religion has generally been ignored in the development debate. Development researchers and practitioners have devoted much too little attention to the theme although politics and religion in most non-western countries are closely intertwined and, in particular, political conflicts often have an obvious and very strong religious dimension" (www.dmcdd.org/knowledgecenter/religion-and-development/). According to DCDR, religion's neglect as a potential force in the development arena may be attributed to various processes that have been at work for a number of decades; the processes that affected development were secularization, modernization, and globalization.

On the whole it appears that Ver Beek's significant study seems to have but not necessarily so - stimulated a series of research projects (including those that were initiated by the mentioned Danish Centre). As a spin-off, one noted that in the 2000s the research theme was taken up by, inter alia, scholars at UK's University of Birmingham (that was guided by Carol Rakodi [http://www.idd.bham.ac.uk]), The Netherland's Erasmus University Rotterdam (that was led by Gerrie ter Haar [http://www.religionanddevelopment.nl/]), and USA's Georgetown University (that was mentored by Katherine Marshall [http://berkleycenter.georgetown.edu/]); these scholars and their teams of researchers set up special projects that had 'Religion and Development' as its main theme and focus. More than one and a half decades passed and looking back one observed that many studies have since been produced by the mentioned scholars and their 
teams/partners. Though much of the current research, as observed by Lodahl (2016: 3), leaned towards the study of Development and Christianity (Petersen 2010), others have turned to Islam and other religious traditions, as noted when browsing through Bosco's (2017) revealing article that succinctly assessed the field and Swart \& Nell's (2016) useful bibliographical essay (also see Jones \& Petersen 2011).

Since this chapter's concern is 'Islam', it confined itself to this religious tradition only. But before elaborating on it, the author wishes to comment, albeit briefly, on the definitions of both concepts; two variables that have been described by scholars such as Selinger (2004) as having an 'uneasy relationship' and by Mesbahuddin (2010) as 'uncomfortable bedfellows' because 'development' - as a crucial concept - has been underpinned by a neoliberal philosophical frame that not only challenged the position of religion in the secular sphere but one that went up against the spirit of religious traditions such as Islam. Be that as it may, here the focus turns to the concept 'development' that was defined and elaborated upon by numerous scholars including those who have chapters in this volume. The rationale for summarily capturing its definition here is to not only complement its coverage as discussed in this volume's other chapters, but it wishes to lay the grounds for how Muslims view and interpret it.

\section{Development Defined, Development Defended}

From the onset it should be mentioned that 'development' as a concept was mooted by social scientists; scholars who were influenced by secular thought. They thus defined and described the term in a rather restricted and narrow sense. These scholars stressed the significance of development with regards to economics, politics, and social issues as they were reflected in the South (aka the Third World) as opposed to their advancement and transformation in the North (aka First World), Since it was confined to these three interrelated sectors, it automatically implied that the meaning that it inherently contained and conveyed was indeed - and rightly so - a highly contested one (Tittensor \& Clarke 2014; Bosco 2017). Since the understanding of the concept varied in meaning from one group of scholars to another and even across a variety of disciplines, it is understandable why one social scientist observed that whilst it was "a product of personal preference", it too reflected a 'value judgment'; the concept has, moreover, also been termed a two-edged/ double-edged sword 
(Adamu 2011). On the one hand, development from a purely socio-economic perspective brought numerous benefits (such as improving a community's material well-being and its technological gains); and, on the other, it produced several losses and it also generated value conflicts (such as the destruction of settled communities' cultures through the twin processes of secularization \& modernization and damaging the pristine environment through excessive and uncontrolled mining).

Tyndale (2003) drew some of her ideas from the late Sri Lankan, A. T Ariyaratne, who was the founder of the Sarvodaya Shramadana Movement. Ariyaratne (1980) regarded development as a process of awakening of all; for him, the awakening procedure was an integrated one. In other words, it is an all-encompassing system that included the spiritual, moral, cultural, social, political and economic aspects of human life. Defining the concept slightly differently, the Dutch based Knowledge Centre borrowed Amartya Sen's (1999) thoughts and according to it the concept of 'development' should be "described as the expansion of the effective freedom of human beings to strive for what they find important (and) impediments to freedom are of a political and economic as well as an ecological, social and cultural nature. " Alkire (2006) expanded upon Sen's (1999) understanding and definition; she stressed the point that "if development aims to expand the freedoms (that) people value and have reason to value, and if religion is so valued, then religious freedoms should be part of development (along with tolerance and democratic practices". Since Alkire explained by building on this definition, this essay goes along with the idea of viewing development as a variable that integrates with the other mentioned variables seamlessly; via this process, it may be argued, it widens and enlarges the freedoms of people wherever they are located.

\section{Religion Defined. Islam Described}

When closely reflecting on what has so far been discussed by scholars outside the house of Islam, one may argue that Muslims would not differ much with Ariyaratne's conceptualization, nor would they disagree with Sen's notion of it as 'freedom' as expanded by Alkire; they would find synergies with these perspectives and reinforce them. The reason for making this assumption is based on the fact that when searching for a definition of religion, as articulated by Crawford (2002) and briefly discussed by Berger (2006), or more specifically for the definition of Islam as a religion as 
expressed by Nasr (1996) and noted by Shepard (2009), Muslims compellingly pronounced it as their 'way of life' (Pramanik 2002); they persuasively put forward, as Al-Jayyousi (2012) stated, the view that Islam encompasses everything that is associated with life.

Worded differently, for Muslims Islam is not a religion that can easily be compartmentalized and divided though some progressive Muslim groups hold this view. Aside from this, Islam is also not viewed as a religion that concerns itself with an individual's private or personal life (Selinger 2004). On the contrary, it is conceptualized as an indivisible structure that connects all its aspects such as politics, economics, and culture, and religion into an integrated whole. From this angle, Muslims always considered everything as one; according to their unwavering belief in the five articles of faith, they argued that all of these variables are rooted within the conceptualization of God whom they regard as indivisible and one. So, for the Muslims, politics and development form segments within the house of Islam and they are not apart from it. And in addition, they would consider humanitarianism as a natural spin-off or sub-section of development. Here it is appropriate to quote Saggiomo (2012) who stated that the "notion of development tended to be defined (according to Muslims) ... in terms of the(ir) struggle against poverty and fulfillment of the fundamental needs, interpreted under the Islamic religion as the achievement of peace and harmony at the individual and the collective levels (respectively)."

Related to this note, one turns to Kroessin's (2008) study; one that investigated the 'Concepts of Development in Islam'. This study provided reasonably deep insights into how Muslim scholars grappled with the concept though he did not offer a useful definition that one could appropriate and apply. In the light of this, one draws on Pramanik (2002) and AlJayyousi (2012), among others, who provided insightful reflections on the concept. While the former compared the secular vis-à-vis the Muslim view of development and made the seamless connection between development and Islam, the latter demonstrated the significant relationship between Islam and Sustainable Development during this era of globalization; a process that caused religious traditions (such as Islam and Christianity) to dramatically resurface and reclaim their rightful position in the public sphere.

When evaluating the definition of Islam as understood and expressed by the traditional Muslim scholars, then it is agreed that Islam, like other religious traditions, consists of an essential set of beliefs and practices that 
undergird its overall philosophy and outlook that are embedded in their two primary sources, namely the Qur'an (i.e. God's words) and Hadith (the prophetic statements). Drawing upon these sources and their general reflections regarding life, contemporary Muslims argue that Islam is 'a way of life'; one that does not see itself confined and restrictive but one that includes development and encompasses humanitarianism as essential extensions of it.

In other words, according to this contemporary understanding, development - and by implication humanitarianism - forms a fundamental part of the Muslims religious life; it is one that equally stresses both spiritual and material development; it does not give more weight to the latter at the expense of the other. However, even though they generally weigh equally in this temporary abode, they subscribe to the opinion that whatever good they undertake (such as extending a helping hand to their neighbour or assisting those who need humanitarian aid), they would eventually be rewarded by God in the eternal life-to-come for their material contributions in this locale. So, for them, all good deeds and tasks that were and are performed have spiritual value; these have tangible and intangible spiritual outcomes that will eventually come to their rescue and assistance when they return to God's eternal abode; a place where they will be handsomely rewarded in spiritual terms.

Since it is not the intention to unpack the notion of humanitarianism in this chapter, it briefly draws on Abuarqub and Philips (2009) Islamic Relief report that provided a helpful overview of its history in and beyond the Muslim world. In their report they pointed out that, “...humanitarianism is a very broad concept that encompasses traditional forms of charity, with which modern humanitarian aid is more often associated, and (it is) also more holistic interactions between human beings and indeed all creatures" (2009:3). They then went on to explain that there are obligatory and voluntary charities that by and large involve the material transfer from those who have to those who do not possess anything; besides these charitable acts, one may also perform charity by saying a kind word to one's neighbour or to a child. This implies that charity is not restricted to material matters but that it includes others as well. The two rapporteurs correctly argued that, "The concept of charity (in Islam) is central to social justice, which is (indeed a) sacred (act)..." (ibid.). They added that as a result of its sacredness within Islam, it is also regarded as a key tenet of Muslim belief that all should adhere to privately and publicly. In essence then, the act of doing humanitarian work within the house of Islam is a 
pivotal part of being and acting out one's beliefs in all sectors of human life; be it in political life, social affairs, or in the developmental sector.

\section{Islam and Development: Muslim NGOs Making the Move (Ragab 1980)}

Now when one considers charity or rather humanitarian work as a sacred act that contributes towards social justice, then one can understand the reason why, despite divergent approaches among Muslims, much emphasis has been placed on showing the intimate connection between Islam and Development. Since various ways of demonstrating this relationship exists, certain Muslim organizations have set up Muslim NGOs as a means of expressing their understanding and interpretation of Islam's primary sources. These sources inspired them to establish structures such as charitable organizations and humanitarian agencies in order that they may pursue their altruistic objectives in and beyond their religious communities.

While some of these Muslim institutions have thrown their nets wide by addressing various issues ranging from educational matters, health-care concerns and environmental affairs to human rights advocacy tasks, others restricted themselves to humanitarian aid since these groups saw this as a neglected sector. Returning to the understanding of Islam as expressed earlier and when viewing these organizations through a Muslim lens, it will be observed that they see all of these activities as part of a whole; and they do not really limit themselves to particular matters as might be the case with secular NGOs. Considering these points, it may be prudent to turn to the definition of Muslim NGOs; institutions that may be viewed as concrete extensions of their religious identity in action. Saggiomo (2012:1) simply defined Muslim NGOs as "formal and informal organizations that carry out aid work on the basis of their Islamic faith, while using Islamic charitable funds".

Even though Muslim NGOs form an integral part of those that have been categorized and defined as Faith Based Organizations (FBOs), this author chose to steer clear of using this term partly because of its impreciseness and its ambiguity. In fact, Clarke \& Ware (2015) mentioned that 'a precise definition' for it was not found. Even so and a decade prior to this, Clarke \& Jennings (2008:6) defined an FBO as, "any organization that derives inspiration and guidance for its activities from the teachings and principles of the faith or from a particular interpretation or school of thought 
within the faith". Though an acceptable term, another reason for employing the alternative term is that FBOs do share similar NGO characteristics; they are independent, voluntary, altruistic, and for non-profit purpose.

Coming back to Muslim NGOs, one may wish to assertively argue that the formation of the Muslim NGOs - though this was an unfamiliar term then - began more than a century ago if not earlier; as operational structures, they complemented the empire/state's public services when the need arose. As a matter of fact, newspaper reports of the early $20^{\text {th }}$ century reflect the presence of such Muslim NGOs in Muslim minority communities that were economically mobile and that responded to the needs in and beyond their communities. This thus counters the argument put forward by Osman (2003), Salih (2004), Petersen (2010), Saggiomo (2012), and Kobo (2016); each of them advocated the view that these types of organizations only came to the fore during the late $20^{\text {th }}$ century. In any case, Singer (2016) correctly pointed to the fact that some of these Muslim NGOs were preceded by Waqf (endowed) institutions that played the same role. Each of these institutions illustrated tangibly how they were able to bring about a qualitative difference in the lives of those that deserved attention and that needed moral-cum-financial support.

Before addressing the Muslim NGOs that have been and are active in Africa, it is important to acknowledge that some international Muslim NGOs were and continue to be monitored, restricted, and closed down. The reasons for these actions are largely connected to the USA's "War on Terror," justified or not. However, some national/regional organizations managed to escape the surveillance system by remaining loyal to the country where they operate since the services that they carried out were lauded by the local and regional government.

\section{Muslim NGOs in Africa: Making Interventions, Bringing Changes}

Over the years ample literature evaluated the contributions of FBOs generally and the Muslim NGOs specifically (Rakodi 2007; Jones \& Petersen 2011). These review texts demonstrated that there was bias towards 'Christianity and Development' and the reason for this was fairly simple; at the end of the $20^{\text {th }}$ century, Christian NGOs led by Archbishop of Canterbury led a delegation at the invitation of the World Bank, which had until then held onto a narrow notion of development (Petersen 2010), to discuss ways of partnering since the Christian NGO network was wider and more 
expansive than the secular ones. From then onwards they struck a meaningful partnership and received the necessary financial injection to pursue research. The outcomes of this relationship paid off handsomely in that conferences were hosted, and publications produced under the supervision of Katherine Marshall (Petersen 2010).

Even though Christianity has been the tradition that was given much attention by Marshall and others, she saw to it that other traditions such as Islam were also covered. Some of the research publications that she coauthored/co-edited had chapters or sections that dealt with the Muslim NGOs' activities. From among these were local (African) Muslim NGOs and others were international organizations; the latter were among those that were set up in the West and opted to extend their tentacles into Africa's heartlands where communities experienced unbearable hardships. These communities faced, among others, famine and hunger that negatively affected their health. In response to these developments, Muslim NGOs came to their rescue offering the necessary humanitarian aid. It is to these international Muslim NGOs that this essay first turns since they have been active for a very long time across the continent.

\section{International Muslim NGOs in Africa}

During the past number of years Muslim NGOs, which were set up in both Muslim majority countries and in Western-based Muslim minority communities, have expanded their networks and increased their activities from being small-time zakat collectors to big-time humanitarian aid agencies. These Muslim NGOs extended their hands to assist in whichever way they could in order to relieve those who were affected by the various calamities and misfortunes. As a consequence of these organizations' qualitative inputs, their contributions have been recognized by international bodies such as the UN and Organization of Islamic Cooperation. From among these transnational organizations that have extended their wings far and wide across borders (Weiss 2008; Nejima 2016), the following organizations come to mind: Britain's Islamic Relief World Wide, Britain's Muslim Hands International, Britain's Muslim Aid, Turkey's IHH, Kuwait's African Muslim Agency/Direct Aid, Sudan's Islamic African Relief Agency, Sudan's Munazzamat al-Da'wat al-Islamiya, and South Africa's Gift of the Givers (Petersen 2012). One may visit the following site to view a few well-known Muslim NGOs: (www.thoughtco .com/top-islamic-charitable-organizations-2004028). Since it is somewhat beyond the scope of 
this chapter to provide a fair insight into each of these, it will select some to show the extent of their presence in Africa.

\section{(a) Britain's Muslim Hands (www.muslimhands.org)}

Unlike Islamic Relief World-Wide's founder Hany al-Banna (Egyptian/British medical doctor) who witnessed the suffering in Sudan during December 1983, Muslim Hands (MH) had its origins a decade later when the regrettable Balkan communal conflict escalated. A group of Muslims from Britain's city of Nottingham realized the desperation of the Bosnian (Muslim and Christian) communities that were ethnically cleansed and literally wiped out by the oppressive Eastern Orthodox Serbian forces. Since 1993 Muslim Hands developed into one of Britain's foremost charities and it set up field offices in over 20 countries; it however, works in more than 40 countries and has an annual budget of more than $£ 7,000,000$. The expenditure covered a range of issues: from disaster relief to basic education and this has resulted in millions benefitting across the global village (Haron 2010; 2017). An important point to recall at this point is that organizations (such as $\mathrm{MH}$ that started out doing charitable work) were forced to shift their focus to disaster relief and humanitarian aid since the situations that they encountered necessitated that their net be thrown wider and include those communities that were heavily affected by natural disasters. $\mathrm{MH}$ and others did this quite naturally since their understanding of Islam's teachings was fairly broad and accommodative; one that considered humanitarian aid as part of developmental aid. Nevertheless, though MH started with activities in the Balkans, it eventually extended its wings to far beyond Europe and set up an 'Orphan Sponsorship Scheme' in Africa; a project that was also established in the Balkans and some Asian states. Apart from having paid attention to Africa's orphans, it concerned itself with building educational structures as was the case during 1994 when it built a primary school in Gambia; it planned to construct similar schools in Niger, Mali, and the Sudan. MH forwarded the following argument for pursuing this particular project: "Nearly onethird of children missing school are African and of the 40 million African children out of school, the majority (of them) are girls. Muslim Hands will work to build schools alongside ongoing work to treat and prevent HIV/AIDS as this disease is set to claim the lives of $10 \%$ of Africa's teachers in the next five years, with $20 \%$ of school-age children being AIDS orphans" (see www.muslimhands.org/en/gb/). One may wish to argue that $\mathrm{MH}$ addressed the education arena because of the pivotal role that it 
played and that it continues to play in churning out educated individuals who will eventually be making qualitative inputs to their societies.

As the organization gained strength, $\mathrm{MH}$ was able to stretch out its support to war ravaged Somalia in 1996. And when Somalia experienced severe drought, $\mathrm{MH}$ set up ten feeding centres. Even though much of the services were extended to South Asia, Eastern Europe, and Central Asia, MH did not neglect African communities. When Mozambique's communities were hit by the raging floods in 2000, MH secured 2 ambulances and, like what it did in Somalia, it established nutrition centres that served the refugees in the Xai-Xai region. During the same year it opened a library and computer literacy centre in The Gambia and it, in addition to having attended to five wells and water storage projects, distributed food and medicines. From these activities, one observed that MH moved between giving charity and addressing disaster relief areas.

By $2004 \mathrm{MH}$ was honoured with the ISO 9001:2000 Award that proved that it conformed to best practices in the NGO arena and innovatively introduced what it called 'MH Livelihood Schemes'; some of which were set up in parts of Africa. MH's work in Africa continued unabated and in 2005 West Africa was affected by famine; in response, $\mathrm{MH}$ distributed large amounts of aid to the people in Niger and Mali. In fact, during 2008 it launched the Cereal Aid project in Mali to assist the farmers in undertaking successful harvests. Apart from having offered them grains, $\mathrm{MH}$ also gave millet, rice and maize with the hope that they can trade through selling their production. Whilst MH was commended for successfully introducing this project, it initiated a sheep farming scheme in Senegal's Casamance. In this town, $\mathrm{MH}$ gave flocks of sheep to 30 families so that they may rear them; these sheep farming families were given regular veterinary support services too. Another unusual scheme that $\mathrm{MH}$ got involved in was the smoked fish business, which was set up in The Gambia. This project was managed almost exclusively by women who smoked fresh fish in their smoking rooms. These rooms were purchased through small reasonable loans that were given by $\mathrm{MH}$. An important point to note is that where $\mathrm{MH}$ operated it had a set of field staff that was hands-on by giving advice among others. They basically adopted what MH described as 'a reflective approach to income generation schemes'; this arrangement was drawn from studying the operational patterns in Africa's rural economies. $\mathrm{MH}$ was, however, not the only organization that was active in certain parts of Africa; its work was complemented by others such as Africa's 
Muslim Agency that had been operating for more than four decades on the African continent.

\section{(b) Kuwait's Africa Muslims Agency}

Africa Muslims Agency (AMA) also known as Direct Aid was the brainchild of the Kuwaiti born Dr. Abdul Rahman Hamoud al-Sumait (d. 2013) (Al-Toaimi 2017). During 1996, when he was still extremely active, he was awarded the King Faisal International Prize for 'service to Islam.' By 2008, he was conferred the Sheikh Hamdan Bin Rashid Al Maktoum Award for (his sterling services to the) Medical Sciences (Ahmad 2009). Al-Sumait, who belonged to a cadre of individuals that were influenced by Muslim revivalist movements such as the Muslim Brotherhood, created AMA in 1981 so that it may act as a viable charitable organization and a humanitarian aid organization. This was soon after he had visited Malawi where he laid the foundations for the Malawi Muslims Agency in 1980. Since the time of AMA's formation until 2008, he chaired the organization and according to Chanfi (2009) it operated for technical motives in certain African countries as Direct Aid Society. This was the case in Ghana where, according to Abubakar (2015), AMA was renamed Direct Aid for logistical reasons.

Even though Al-Sumait was keen on doing relief work and pursuing social welfare activities, he considered himself an ardent Muslim missionary; as a result of his passion for mission, he opted for a two-pronged approach in using AMA's services. On the one level, he saw it as a critical humanitarian organization and, on the other, he considered it an appropriate conduit to undertake Muslim missionary work; similar to the work of traditional Muslim mission organizations such Sudan's Munazzamat alDa'wa al-Islamiyya (that is, Organization for Muslim Mission). Armed with these twin objectives in the developmental sector, AMA thus extended its helping hands to the poor and needy communities continentally and at the same time some of its members undertook missionary work in accordance with al-Sumait's desire. While AMA's leadership expressed its particular vision, which was 'to uplift the standard of life, morality and education of the most deserving and needy', its dual approach of combining mission with humanitarian aid was questioned by secular NGOs that argued vehemently against the idea that FBOs such as AMA should preach Islam amidst giving aid to those vulnerable and those in need (Kroessin \& Mohamed 2008). 
In spite of the secular NGO strict policies regarding mission, AMA under the regional leadership of Mohamed Farid Choonara's (d. 2011) - the former loyal member of the Muslim Youth Movement of South Africa (est. 1970) - sterling regional leadership along with the support of Shaykh Sa'ad al-Talib ignored them. Choonara thus firmly directed AMA to continue offering financial aid and other forms of support to urban and rural communities in Southern and East Africa. From the Johannesburg office that was opened in 1987 - seven years after the Malawi office had been in operation - Choonara directed AMA's activities in Angola, Madagascar, Mozambique and Zimbabwe. In these countries under Choonara's leadership AMA built, among others, water-wells, boreholes, healthcare structures (such as clinics and hospitals) and educational institutions (such as schools and institutes). Apart from having set-up these structures, AMA provided continuous logistical support that indicated that it was around to sustain rather than abandon these projects. Bone (2009) described AMA positively when he observed that it was a 'progressive, development oriented da'wah organization' that built schools and erected mosques in Malawi and Zimbabwe.

Interestingly, even though AMA, according to the secular NGOs did not adhere to their policies, AMA was co-opted onto to the UN's Social, Economic Consultative Council as a member. For two years in a row it was awarded the Silver Arrow (2013/2014) and the Gold Arrow (2015/2016) PMR Africa Awards respectively; this was for humanitarian service across Africa where it has 31 full-time offices (AMA-SA 2017). Along with AMA's two important offices in Malawi and South Africa, AMA (aka Direct Aid International) crossed into other African countries where it reached agreements with their foreign ministries; through these tactful political pacts AMA's staff was granted diplomatic immunity. Apart from that, AMA's activities were well known in government circles across Africa and as a result of AMA's work government officials expressed their gratitude since they were unable to deliver as desired. Here one may refer to the Kenyan case as an example. During 2004 when the Kenyan parliament learnt that AMA was to be closed down because of external pressure applied by, among others, USA and other (anti-Muslim) watch-dogs, members were concerned regarding the repercussions if AMA's work should come to an abrupt end (KNAOR 2004); an issue that Kaag (2014) raised in her chapter when she observed the closing down of international Muslim NGOs in Chad. 
Related to the Kenyan members of parliament's concerns, Western Think Tanks such as the earlier mentioned Rand Corporation (www.rand.org) and the African Center for Strategic Studies (ACSS www.africacenter.org) during the post $9 / 11$ era constantly questioned the status of AMA and other Muslim NGOs. Their status, as viable Muslim charitable organizations, was interrogated by, among others, Terdman \& Paz (2007). These Think Tanks and a number of 'experts' did not only closely monitor these organizations' ostensible religious activities in order to (optimistically) find them guilty of money laundering, but they too put them under constant surveillance through devious tactics to obtain sufficient hard evidence to incriminate these organizations for abetting religious radicalism and extremism on the continent (Weiss 2008; Rabasa 2009; Ali-Koor 2016). In an ACSS Africa Security Brief contribution, Ali Koor was rather careful in his assessment when he stated that while "some activities supported by these foreign Islamic groups (such as AMA) are laudable... (some of) these humanitarian activities are not entirely benign, since many of these Islamic groups will integrate proselytization into all their activities or will require that participants abide by strict, conservative customs to access funds or benefits. " (Ali-Koor 2016:4).

If Ali-Koor had made reference to Bonate's (2015) text - or any other related article - that demonstrate to what extent AMA got tied up with Wahhbi/Salafi groups and the Sufi/Brelvi associations' disputes, then his statement could - to some extent - be appreciated. Nevertheless, here one wishes to make reference to Terdman's (2007) and Terdman \& Paz's (2007) controversial articles that belong to a set of texts that argue that organizations such as AMA do contribute towards extremism; hence, Terdman contentiously concluded, AMA is 'a real threat on the long run'! It is indeed this type of dubious scholarship that does much harm to legitimate charitable work that these bona fide Muslim NGOs duly perform (Petersen 2011; Haron 2017).

\section{Africa's Home-Grown Muslim NGOs: Two Cases}

Having shared thoughts on two international Muslim NGOs that have established their African brands, the essay moves to African nation-states that have given birth to their own Muslim NGOs that have been doing charitable and humanitarian work within and beyond their nation-states. As a result of desiring to be self-reliant, national Muslim NGOs came into 
existence with local funding to address communal and regional catastrophic concerns (Abubakar 2015). Though the focus in this section will only be on two case studies since it is beyond the essay's scope to accommodate all Africa's countries where civil society has been actively involved in setting up Muslim NGOs, it needs to summarily make reference to a few African states that have been the homes of significant Muslim NGOs. If one takes a handful of countries as examples, then one notes that they have numerous Muslim NGOs with some that focus on social welfare and relief work and others that concentrate on specific issues such as Muslim education. It should be mentioned that even though the names of these organizations do not reflect some of the work they do, evidence exists that they have been active in social welfare going beyond their organization's mandate. Nonetheless, here mention will only be made to a few representative organizations per nation state, and here one may start with Ghana (Mumuni 2002). This West African state has had a few noteworthy Muslim NGOs and they are: Muslim Relief Association of Ghana (MURAG est. 1986), Muslim Family Council Services (MFCS est. 1990), and the Islamic Council for Development and Humanitarian Services (ICODEHS, est. 1991). Each of these organizations, according to Abubakar (2015), "gained a good reputation both within and outside Ghana and have close links not only to international Muslim donor organizations but also Western ones" (online)

Cameroun is the home of, among others, the Association Culturelle Islamique du Cameroun ACIC est. 1963), Cameroun Muslim Students' Union (CAMSU est. 1988), and Organization de la femme pour l'Islam sans frontiers (OFIF est. 1995). Botswana opened up spaces for organizations such as the Botswana Muslim Association (BMA est. 1955), Gujarate Educational Society (est. 1960 [?]), and Al-Muslimah (est. 1990). Kenya created opportunities for Bilal Muslim Mission (BMM est. 1963/4) and the Muslim Education Welfare Association (MEW est. 1986) to pursue their social welfare and educational activities for many decades. And Uganda witnessed the formation of its Islamic Medical Association of Uganda (IMAU est. 1988) that contributed to two significant projects: the Family AIDS Education and Prevention through Imams Project and the Madrasa AIDS Education Project. From this selective catalogue it may be argued that these and an array of other Muslim NGOs have played and continue to play a critical role in Africa's developmental sector across all its nationstates; some of them came into existence before many of Africa's nationstates became independent. 
At this juncture, the essay turns to two home grown Muslim NGOs that operate in two different African countries and within two different sociopolitical contexts. Since these countries have been the home of many significant Muslim NGOs that complement the activities of those mentioned in the previous paragraph, it is quite fascinating to witness to what extent they succeeded to make a substantial contribution to development in general and to relief/humanitarian aid in particular.

\section{(a) Tanzania's Muslim NGO: Bilal Muslim Mission}

Tanzania, unlike its neighbour, Kenya, has a sizeable Muslim population and as a result the Muslims have made important inputs to Tanzania's socio-political and developmental landscape. Whilst much has been written as regards various aspects of the Muslim socio-educational and political life, few essays have captured their contributions towards the development sector. One should, however, state that in some cases texts that have been published covered aspects of this, but these have not been covered in a satisfactory manner. In fact, even this essay is not in a position to provide a fair insight into Tanzania's Muslim inputs since it will only pick one Muslim NGO to show to what degree it has made a critical contribution.

One of the important Muslim NGOs that made a mark since its formation in 1963 is the Bilal Muslim Mission of Tanzania (BMM). Ahmad (2009) noted that the organization was formed at the tri-annual Conference of the Federation of the Khoja Shia Ithna-Ashari Jamaats (KSIAJ) of Africa and that it was held on Tanga. However, before it came into existence it was Maulana Syed Saeed Akhtar Rizvi (d. 2002), the Indian born Muslim missionary, who had prepared in 1962 a scheme that was discussed in 1963 at the Arusha KSIAJ Supreme Council meeting. Though the scheme was not adopted as suggested, the Council approved the implementation of a pilot scheme. So, during 1964 Syed Rizvi submitted an amended detailed memorandum at the Tanga meeting where it was eventually adopted as a policy.

It was at this meeting that BMM was officially launched and Syed Rizvi was naturally picked as its first director and under him as Ahmad (2009) discussed much of its activities materialized. He, for example, sent students to study in Qum, Iran's sacred city, and he was also instrumental in setting up a series of hawza-e-ilmiyya. This centre functioned as a learning centre where Muslim preachers were and are trained. This institution 
has, however, transformed itself into a complete complex that offers learning from kindergarten to beyond the secondary school (Ahmad 2009).

BMM, however, only officially registered as a Muslim NGO with certificate Number 5349 dated 16th April 1968, under Act. No. 1954. At the time of its formation it was seen as part of the East African region but as soon as Tanzania became independent in 1964, it like other Muslim NGOs in that region demonstrated their loyalty to the Tanzanian government. MBB's vision states that it "supports those who want to get education on Islamic religious courses as well as the national curriculum, (and that it) promotes public health care and (it) assists indigents to uplift their economic status as much as possible" (http://www.bilaltz.org/about-us/).

It, in fact, added as part of its vision that it is more than willing to "cooperate with organizations, agencies and governments to promote humanitarian activities and make the world a better place". It basically considers its primary mission to be the fulfilment of the message of Islam; over the years and to this day, it continues to do so by propagating the faith and carrying out its basic teachings; in the process of undertaking this task it is concerned with 'uplifting' the Muslim community materially and spiritually as mentioned in its vision. In addition to this, it also aimed to aid the poor and the needy. So as part of its programme, among others, BMM conducts teacher training (for those involved in Muslim education), and it manages food programmes alongside health clinics. One of the important markers of BMM is the fact that it offers its service programmes to everyone and that is regardless of the groups' religious affiliation or ethnic background (Ahmad 2009).

Organizationally, it has its headquarters in Dar es Salaam, and it has since expanded in setting up 7 regional centres throughout Tanzania. These centres have further sub-divided into various regions and they are: the coastal region that has 5 subdivisions, the Kigoma region that has 21, the Moshi region that has 4, the Mwanza region that has 6, the Tanga region that has 11, and the Zanzibar region that has 4 subdivisions. Apart from having been concentrated within the country, BMM also set its sights beyond Tanzania and Kenya where it officially got off the ground as indicated earlier. Like other Muslim NGOs, BMM spread to other African counties and even beyond. It, for example, has branches in Burundi, Ghana, Nigeria, Congo-Kinshasa, Malawi, Mauritius and Comoros Island; all of these, fall under KSIAJ's umbrella. Its members felt that they have firmly established BMM that have, inter alia, been doing excellent humanitarian work (http://www.bilaltz.org/about-us/). 


\section{(b) South Africa's Muslim NGO: Gift of the Givers}

When one considers the South African environment as compared to others where Muslim NGOs are encountering difficulties, South African Muslim organizations found themselves a fairly free and a supportive environment; one in which the government gives them assistance as long as they are registered as non-profit organizations. Since many Muslim NGOs have been established since the late $19^{\text {th }}$ century within this growing Muslim minority, it is not at all possible to reflect on all of them except one. However, one needs to say a few words about the South African Muslim NGO fraternity in general before focusing on one example (Sadouni 2007; Sadouni 2012).

During the past two decades - and earlier - many Muslim organizations have emerged that made serious inputs in the humanitarian sector. From among the reasonably long list are: Mustadafin Foundation (www.mustadafin.org.za), the Gift of the Givers (www.giftofthegivers.org), Al-Imdaad Foundation (www.alimdaad.com), Muslim Hands (https://muslimhands .org.za), and Islamic Relief South Africa (www.islamic-relief.org). Each of these organizations filled significant gaps within this particular sector and one observes that some of these are international organizations that have set up home in South Africa. These have, in turn, been complemented by Muslim charitable trusts that form a sub-category within the Muslim NGO sector; one, for example, comes across the South African Muslim Charitable Trust (www.samct.co.za), Iqraa Trust South Africa (www.iqraa trust.org); and the Imam Abdullah Haron Educational Trust (www.iahet .co.za). Each of these points to the fact that despite the South African Muslim community's depressing conditions during and - and to some extent - after the apartheid era, its representatives have given ample attention to the social welfare sector with the sole purpose of assisting their fellow human beings nationally, regionally and internationally (Haron 2017). That said, here is the story of the Gift of the Givers that was narrated elsewhere (Haron 2017) and that will be repeated to underscore the role that it has played in the South African social welfare sector as a critical and indeed an important humanitarian organization.

During August 1992, Dr. Imtiaz Sooliman had an audience with his Istanbul-based spiritual mentor and guide, Shaykh Muhammed Saffer Effendi al-Jerrahi who instructed him to set up the Waqf-al-Waqifin (Gift of the Givers [GoG]). Sooliman was indeed taken in by his spiritual master's plea and immediately laid its foundations (Morton 2016). He, being highly inspired, immersed himself with the support of others in humanitarian 
aid. At the time this consisted of various activities and these ranged from coordinating 'search and rescue' teams, gathering medical personnel to attend to disaster areas; it offered and continues to offer vaccines to those affected by diseases such as malaria, and donated and continues to provide energy \& protein supplements to undernourished communities, and provided and continues to offer medical supplies to those in poverty stricken regions (Gabralla 2009; Khan, Gabralla \& Ebrahim 2015).

From its inception, Sooliman realized that apart from responding to disaster relief there was a need to deal with numerous other related matters. Consequently, Sooliman's organization grew exponentially with offices in South Africa and Malawi and it also works in different parts of Africa whenever the need arises. To date, GoG covers numerous kinds of projects that include, among others, providing water for some communities, establishing primary health care clinics, launching feeding schemes, distributing food parcels, supplying hygiene packs to households, and caring for the physically \& mentally challenged individuals. As a result of his commitment, Sooliman also became very inventive and creative as a trained medical doctor and disaster relief manager. He pioneered, inter alia, (a) the world's first containerized mobile hospital that comprised of 28 units; (b) its first groundnut-soya high energy and protein supplement in the use of severe malnutrition and other debilitating conditions, and (c) he opened Africa's largest Open Source Computer Lab.

For all of these ingenious and resourceful schemes, GoGs received more than hundred accolades that included four presidential awards. If one glances at the organization's activities during 2017, one observes that it was occupied with among others the distribution of hygiene packs to members of South Africa's Eastwood and Welbedact communities; during February it inaugurated a new water well in Yemen's Sujairah; towards the end of March it allotted mosquito coils to communities in Zimbabwe's Kwe Kwe; and it opened Gaza's Child Care Center during April. And during this period GoG signed a 1.08 million Rand Grant Agreement with the Embassy of Japan to construct irrigation facilities in Malawi's Blantyre and Chiradzulu districts respectively.

Each of these activities underlined that over the past twenty-five years GoG gained the trust and confidence not only of the communities that it served but it also managed to get the support of governments. For example, the Japanese government through its Embassy was quite convinced that GoG as a partner would be able to carry out the agreed task and complete it within the scheduled timeline. In fact, when Morton (2014) narrated how 
they landed in Niger without having had to have visas it was ample evidence that GoG's reputation as a trustworthy humanitarian organization had preceded it; so, wherever it went on the continent it was welcomed without any diplomatic complications. Whilst its reputation has been established across the continent for delivering and serving the continent's communities without fail, critical questions regarding its operations have been raised by Desai (2009) but these will be left for another essay or researcher to probe.

\section{Conclusion}

Though this essay had set itself three goals that it was able to generally accomplish, it realized that it was unable to do justice to an area that needed to be explored in greater detail. In the process of writing, it struck the researcher that it was definitely not possible to provide a satisfactory account of Muslim NGOs that are active in different parts of the continent. While this shortcoming has indeed been acknowledged, one should also admit that this chapter did not include a theory in which it wanted to frame the contents. Be that as it may, the essay managed to reflect upon the relationship between 'Religion and Development' in general and to briefly touch upon the status of humanitarianism in the house of Islam; this, it did, by viewing it via a Muslim lens.

The essay described and discussed four different Muslim NGOs that participated in developmental activities in and beyond the African continent. These case studies demonstrated that as a consequence of their understanding of their religious tradition's primary sources that they viewed development as a broad and an all-inclusive concept; one that was pliable within the African context. The chapter showed that though they complemented one another, they also differed markedly from one another. $\mathrm{MH}$, as compared to AMA for example, started as a charitable organization and eventually landed up addressing humanitarian issues. Though similar observations may be made of BMM, it differed profoundly from GoG that has indeed proven to be an adaptable relief agency continentally and elsewhere.

On the whole and as part of this conclusion, what needs to be stressed is that most of the Muslim NGOs understand humanitarian work as a necessary primary stepstone into development work because there is now way development can happen in areas exposed to extreme famine, droughts or 
other forms of immediate suffering unless humanitarian work is instituted first. Finally, and in response to this chapter's title: were these competitive charities or were they altruistic allies? The answer, simply, is both. A close look at each of the Muslim NGOs that were used as case studies shows that the chapter demonstrated that even though they operated separately, they were in one way or the other also competing with one another. And since they find inspiration from the same primary sources, one may comfortably argue that they are indeed altruistic allies that tried to undertake these tasks with the hope of pleasing God and with the hope that they be spiritually rewarded.

\section{References}

Abuarqub, Mamoun \& Isabel Philips. (2009). A Brief History of Humanitarianism in the Muslim World. Birmingham: Islamic Relief Worldwide. July.

Abubakar, Habib. (2015) The impact of Islamic NGOs in their operational communities in Ghana. Online: https://www.linkedin.com/pulse/impact-islamic-ngosoperational-communities-ghana-habib-abubakar.

Adamu, F. L., (2011), 'A double-edge sword: Challenging women's oppression within Muslim society in Northern Nigeria', in E. Tomalin (ed.), Gender, faith and development. Oxford: Practical Action Publ., 97-104.

Ahmed, Abdullah Chanfi. (2009) Networks of Islamic NGOs in Sub-Saharan Africa: Bilal Muslim Mission, Africa Muslim Agency (Direct Aid), and Al-Haramayn. In Journal of Eastern African Studies. 3(3): 426-437.

Ali-Koor, Abdisaid Musse (2016). Islamic Extremism in East Africa. Africa Security Brief No. 32, Washington: ASCC.

Al-Jayyosi, Odeh R (2012) Islam and Sustainable Development: New Worldviews. London: Gower Pr.

Alkire, S. (2006). Religion and Development. In The Elgar Companion to Developmental Economics. (Ed. D. Clark) Edward Elgar Publ.

Al-Toaimi, Bassam (2017) Dr. Abdul Rahman al-Sumait: The Story of a True Humanitarian. In Africa Muslims Agency South Africa: Inspiring the Spirit of Giving. Johannesburg: AMA; 8-9.

AMA-SA (2017) Africa Muslims Agency South Africa 1987-2017. Johannesburg: AMA.

Ariyaratne, A. T. (1980) The Role of Buddhist Monks in Development. In World Development 8(7-8): 587-599.

Berger, Maurits S (2006). Religion and Development Aid: The Special Case of Islam. Clingendael Diplomacy Papers No. 8. The Hague: Netherlands Institute of International Relations.

Bonate, Liazzat (2015) 'Between Da'wah and Development: Three Transnational Islamic NGOs' in Mozambique (c. 1980-2010). ' In Africa Research Initiative Newsletter, 1117, March. 
Bone, David (2009) Malawi's Muslim Communities in their Global and Local Contexts. Online: www.sharia-in-africa.net. Acc. 6 July 2014.

Bosco, Robert (2017) Development and Religion. Oxford. Online: http://internationalstudies. oxfordre.com/view/10. 1093/acrefore/9780190846626. 001. 0001/acrefore-9780190846626-e-143

Clarke, Gerard \& Michael Jennings (Eds) (2008), Development, Civil Society and Faithbased Organizations: Bridging the Sacred and the Secular, Basingstoke, Palgrave Macmillan. .

Clarke, Matthew (2016). Islamic International Aid Flows for Poverty Alleviation. In Islam and development: Exploring the invisible aid economy (Eds. Matthew Clarke \& David Tittensor). Farnham: Ashgate Publ. Ch. 3, 51-68.

Clarke, Matthew \& David Tittensor. (2016) Islam and development: Exploring the invisible aid economy. Farnham: Ashgate Publ.

Clarke. Matthew \& Vicki-Anne Ware (2015) Understanding Faith-Based Organizations: How FBOs are contrasted with NGOs in the international development literature. In Progress in Development Studies. 15(1): 37-48, Jan.

Crawford, Robert (2002). What is Religion? London: Routledge.

Desai, A. (2009). Responding to the May 2008 Xenophobic Attacks: A Case Study of the Gift of the Givers. Johannesburg: Univ. of Johannesburg.

Gabralla, A K. (2009) Islamic Institutions of Charity and International Disaster Relief: A Case Study of Gift of the Givers Foundation in South Africa. Durban: UKZN; unpublished MA Thesis.

Haron, M. (2010). Muslim Charities in the Development Sector: Fulfilling Political Ideas or Religious Duties? AwqafSA Insight. 3: 52-54.

Haron, Muhammed (2017) South African Muslim Philanthropists and Humanitarian Organizations: Making a Difference, Making a Mark. In E-Proceedings of the Conference on Philanthropy for Humanitarian Aid (23-24 May 2017) (Eds. Nozalina Zainudin, Ahmad F. Suhaimi, \& Syarif N. A. Nasaruddin). Brunei: Sultan Sharif Ali Islamic Univ. (UNISSA). Ch. 4, 50-61.

Jones, Ben \& Marie Juul Petersen (2011). Instrumental, Narrow, Normative? Reviewing Recent Work on Religion and Development. In Third World Quaterly 32\{7\}: 12911306, Jan.

Kaag, Mayke (2007). Aid, Umma, and politics: transnational Islamic NGOs in Chad. In Islam and Muslim Politics in Africa (Eds. Ben Soares \& Rene Otayek). Palgrave Macmillan: New York; 85-102.

Kenya National Assembly Official Record ([KNAOR] Hansard). (2004) National Assembly Official Report Tuesday 13 July.

Khan, Sultan, A. Gabralla, \& M. Ebrahim. (2015), The South African Indian Muslim community and its Role in Responding to International Disasters. In Indian Diaspora: Socio-Cultural and Religious Worlds (Ed. P. P. Kumar). Leiden: E. J. Brill Ch. 11, 199-226. 
Kobo, Ousman M 2016. Paths to Progress: Madrasa Education and Sub-Saharan Muslims' Pursuit of Socioeconomic Development. In The State of Social Progress of Islamic Societies: International Handbooks of Quality-of-Life (Eds Habib Tiliouine \& Richard J. Estes). Cham: Springer. 167-177.

Kohlmann, Evan F. 2006. The Role of Islamic Charities in International Terrorist Recruitment and Financing. Working Paper. Copenhagen: Danish Institute for International Studies.

Kroessing Mohammed R. 2008, Concepts of Development in Islam: a review of contemporary literature and practice, Univ. of Birmingham Research Papers No. 20, 1-74 http://epapers.bham.ac.uk/1501/1/Kroessin_2008_Concepts.pdf

Kroessin, M. R. \& Mohamed, A. S., 2008, 'Saudi Arabian NGOs in Somalia: "Wahabi” Da'wah or humanitarian aid?’, in G. Clarke \& M. Jennings (eds.), Development, civil society and faith-based organizations: Bridging the sacred and the secular, 187-213, Palgrave Macmillan, London.

Lodahl, Birgitte (2016) Annotated Bibliography on Religion and Development. Copenhagen: DanChurchAid.

Mesbahuddin, Tasmia (2010). Religion in Development: An Islamic Model Emerging in Bangladesh. In Journal of Southeast Asian Development. 5(2): 221-241, October.

Morton, Shafiq. (2014) Imtiaz Sooliman and the Gift of the Givers: A Mercy to All. Johannesburg: Bookstorm.

Mumuni, Sulemana. (2002) A Survey of Islamic NGOs in Accra' In Social Welfare in Muslim Societies in Africa (Ed. Holger Weiss). Stockholm: NAI. Ch. 7, 138-161.

Muslim American Public Affairs Council (2003). Retrieved from www.mpac.org.

Nasr, S. H. (1996), Religion and the Order of Nature. Oxford: OUP.

Nejima, Susumu (Ed). 2016. NGOs in the Muslim World: Faith and Social Services. New York: Routledge.

Osman, Moustapha (2003) Muslim NGOs can help bridge the culture gap. Online: https://www.globalpolicy.org/component/content/article/176/31237.html

Petersen, Marie Juul. (2010). International Religious NGOs at the UN: A Study of a Group of Religious Organizations. In Journal of Humanitarian Activities. Online: https://sites.tufts.edu/jha/archives/847.

Petersen, Marie Juul. (2011) For Humanity or for the Umma: Ideologies of Aid in Four Transnational Muslim NGOs. Unpublished Dissertation, Univ. of Copenhagen.

Petersen, Marie Juul. (2012) Trajectory of Transnational Muslim NGOs, In Development in Practice. 22 (5-6): 763-778.

Pramanik, Ataul H. (2002). Islam and Development Revisited with Evidences from Malaysia. In Islamic Economic Studies. 10(1): 39-74, Sept..

Rabasa, Angel. (2009). Radical Islam in East Africa. Santa Monica, CA: Rand Corp.

Rakodi, Carole. (2007) 'Understanding the Roles Religions in Development: The approach of the RaD programme', Working Paper 9, Religions and Development Research Programme, Univ. of Birmingham.

Ragab, A. (1980). Islam and Development. In World Development. 8(7-8): 513-521, JulyAug. 
Sadouni, Samadia. (2007) 'New Religious Actors in South Africa: The Example of Islamic Humanitarianism. ' In Benjamin Soares (Ed.) Islam and Muslim Politics in Africa (103-108). New York: Palgrave MacMillan.

Sadouni, Samadia. (2012) Political Engagements of Islamic NGOs in the South African Public Sphere. In Annual Review of Islam in Africa 11: 45-48.

Saggiomo, Valerie (2012) Islamic NGOs in Africa and their notion of development: The Case of Somalia. In Storicamente 8: 1-12.

Salih M. A. (2004) Islamic NGOs in Africa: The Promise and Peril of Islamic

Voluntarism'. In Islamism and Its Enemies in the Horn of Africa (Ed. Alexander de Waal) London: Hurst, 146-181.

Selinger, L. (2004) The Forgotten Factor: The Uneasy Relationship between Religion and Development. In Social Compass 51(4): 523-543.

Sen, Amartya. 1999. Development as Freedom. New York: Knopf.

Shepard, William (2009). Introducing Islam. London: Routledge.

Singer, Amy. (2016). Waqfs: Faith Based Islamic Institutions before Modern NGOs. In

NGOs in the Muslim World: Faith and Social Services. (Ed. Nejima Susumu). New

York: Routledge. Ch. 1, 17-28.

Swart, Ignatius \& Elsabe Nell (2016). Religion and Development: The Rise of a Bibliography. In HTS Theological Studies. 72(4): 1-27.

Terdman, Moshe (2007) Factors Facilitating the Rise of Radical Islamism and Terrorism in Sub-Saharan Africa. Online: www.e-prism.org. [06.07.2014]

Terdman, Moshe \& Reuven Paz. (2007) Islamization and Da'wah in Contemporary Sub-

Saharan Africa: The Case of the Africa Muslim Agency. Online: www.e-prism.org.

Vol. 1 No. 2 Acc. 6 July 2014.

Ter Haar, Gerrie \& Stephen Ellis. (2006). The Role of Religion in Development:

Towards a New Relationship between the European Union and Africa. In European Journal of Development Research. 18(3): 351-367.

Tittensor, David \& Matthew Clarke. (2016) Introduction: The Invisible Aid Sector. In Islam and development: Exploring the invisible aid economy (Eds. Matthew Clarke \& David Tittensor). Farnham: Ashgate Publ., 1-14.

Tyndale, W. (2003). Idealism and Practicality: The Role of Religion in Development. In Development. 46(4): 22-28.

Tyndale, W (ed.) (2006) Visions of Development: Faith-based Initiatives. Aldershot, Hampshire: Ashgate.

Ver Beek, Kurt A. (2000) Spirituality: A Development Taboo. In Development in Practice 10(1): 31-43.

Weiss, Holger (ed) (2002). Social Welfare in Muslim Societies in Africa. Stockholm: NAI. Weiss, Holger. (2008) The Expansion of Muslim NGOs.

Online: https://www.cetri.be/The-Expansion-of-Muslim-NGOs?lang=fr 


\section{Websites}

http://berkleycenter.georgetown.edu/programs/religion-and-global-development https://en.wikisource.org/wiki/CIA_Report_on_NGOs_With_Terror_Links http://islamic-relief.com https://sites.tufts.edu/jha/archives/847. https://www.cetri.be/The-Expansion-of-Muslim-NGOs?lang=fr https://www.globalpolicy.org/component/content/article/176/31237.html http://www.idd.bham.ac.uk/degree/pg/modules/religion-development.shtml https://www.linkedin.com/pulse/impact-islamic-ngos-operational-communities-ghanahabib-abubakar.

http://www.religionanddevelopment.nl/ http://www.religionsanddevelopment.org/index.php?section=1 http://www.diis.dk/graphics/CDR_Publications/cdr_publications/library_paper/lp-981.htm www.africacenter.org www.meforum.org/ www.muslimhands.org www.rand.org www.mustadafin.org.za www.giftofthegivers.org www.alimdaad.com https://muslimhands.org.za www.iahet.co.za. www.islamic-relief.org www.samct.co.za www.iqraatrust.org 


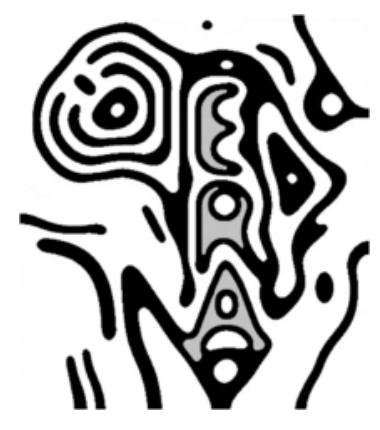




\title{
Religion's Contribution to Development: The Case of African Hindus in Ghana
}

\author{
Abamfo Ofori Atiemo
}

\section{Introduction}

Discourses on religion and development have increased in scholarship and among development workers in recent years (Ter Haar 2011:1). It is not as if scholarly and practical interest in the relationship between religion and development is itself new; rather, with practitioners - both from religious quarters and development work - the roles of institutions and personalities in development issues have always had space in academic as well as popular literature (Atiemo 2017a:252). It is what I have called the 'religious dimension' of religion such as ideas, beliefs and rituals that has been neglected in scholarship and in formal development work and which emerges as an area of new interest (Ter Haar 2011, Atiemo 2017a). Although the power of religious ideas and devotion to instigate economic development has been argued by Max Weber many years ago, development workers and scholars have, for the most part of history, been reluctant to take account of such dimensions of religion. Probably, in the context of the dominance of the secularisation paradigm, such elements were not considered sufficiently decent to be openly included in development work and scholarship (Atiemo 2017a:255).

In the context of contemporary contestation of conventional paradigms of development, a shift in approach can be observed in both scholarship and development work. Contemporary realities that could no longer hide the significant role religious ideas, belief, and rituals play in conflict and other crisis situations in societies of the global south have compelled a re-evaluation of the capital value of religion in development discourse (see, e. g. Ellis 2003; Marshall 2007; Weperner 2015). Consequently, the development sector has seen several research and experimental projects in recent years, leading to a renewed interest in religion and development in both the academy and institutions of development work. 


\section{Hinduism and African Hindus}

There have always been Hinduisms. Perhaps the complexity of the diversity that the religious tradition, commonly called Hinduism and the intensity of the controversy the term itself evokes are unmatched in the history of religion. Described by one of its modern gurus as, 'a fellowship of faiths and a federation of philosophies,' (Swami Sivananda 2007) Hinduism has, traditionally, been diverse in form and content. Diversity, therefore, seems to be one of its most constant features. Usually, religious traditions are dynamic and diverse. As they develop, they break into branches at certain turning points, with each branch emphasising different aspects of teaching, ritual and organisational structure, which come to mark their uniqueness. At the same time, they continue to share important common features that bind them together as belonging to a single stock (Atiemo 2016:11).

Thus, not only are the frontiers of Hinduism's diversity extended but such developments have introduced additional complications to understanding the tradition in the context of religious studies. While the old disputes about the appropriateness of the term Hindu, which, originally, described the total way of life of the people of India to only the religious aspect of their culture (Renou 1961:18) continues, there is the widespread recognition that the use of the term in that sense is unavoidable.

Developments in the $19^{\text {th }}$ Century, which saw a brisk intellectual enterprise by Indian nationalists, such as Ram Mohan Roy, Swami Vivekananda, Tagore, Sarvepalli Radhakrishnan and Gandhi reinterpreting the religious history of their country, led to the emergence of new movements that opened Hinduism to nationals of other countries. Thus, "Hindu" as a term, became more than an ethnic indicator (Atiemo 2016:7). But this goes back beyond the $19^{\text {th }}$ Century. Andrew Nicholson explains: "Hindu" was originally an ethnic designator. But ample evidence from the fifteenth- and sixteenth - century writers show that by that time, the word "Hindu" had been adopted by vernacular-language authors and had in some contexts taken on a more specifically religious sense' (Nicholson 2011:200). David Lorenzen (2006:2) corroborates Nicholson's position and contests the widespread view that the term, in its religious sense, emerged in the $19^{\text {th }}$ century. Since the developments of the $19^{\text {th }}$ Century, the term, Hindu has been used as a religious category not equated with ethnicity or nationality, allowing non-Indians to become Hindus without becoming Indians by nationality. Similarly, through several Historical encounters 
many Indians have become devotees of other religious traditions and do not identify any more with "Hindu" in the religious sense.

The work of the $19^{\text {th }}$ and early twentieth century Indian nationalist intellectuals, which sought to reform Hinduism in the context of colonialism and Christian Missionary influences, led to the emergence of several reform movements, which came to be described as neo-Hinduism. Although their work and influence are largely responsible for the emergence of the non-Indian Hindu, since the term, neo-Hinduism is found to carry a baggage of derogatory connotations (Hatcher 2004:179), members of such movements in Ghana reject the term and claim continuity of their own movements with Sanatana Hinduism (Atiemo 2016:15).

\section{Hinduism in Ghana}

Hinduism in Ghana and several other places in Africa, consists of two main strands: Indian Hindus in the diaspora and African converts to Hinduism. In Eastern and Southern Africa, the large and long existing Indian settlements make Hinduism more established and more visible than West Africa. Indian presence in Ghana, for example, dates to the period before the 1930s, but in small numbers (Acquah 1958:43). Indian Hindus in Ghana are distinct from the African converts to the tradition, yet, they are not isolated from the latter. There is so much interaction between the two communities. They participate in the special programmes of each other and there is a cordial relationship between the two groups.

The Ghanaian Hindu groups include the Hindu Monastery of Africa (HMA), which is of local origins and of Ghanaian leadership, with a loose connection with Swami Shivananda's Divine Life Mission in Rishikesh; the Swami Prabhupada's International Society of Krishna Consciousness (ISKCON), the Satya Sai Baba Mission and lesser-known eclectic locallyfounded groups such as the Shiva Linga Church and Arcanum. Apart from ISKCON, which was introduced to the country by missionaries from the United States of America (USA), all the others were established by local initiative. The Ghanaian scholar in Florida, Albert Wuaku has done pioneering work on Hinduism in Ghana. In his writings he has not only helped document the history of the Hindu tradition in Ghana, but he also analysed how grassroot members of the Hindu groups in Ghana have appropriated several Hindu teachings and practices to their African cultural context (Wuaku 2009). Ghanaian Hindu groups, including both the HMA 
and the ISKCON, claim authentic connection with classical Sanatana Hinduism and reject the designation Neo-Hinduism (Atiemo 2017b:28). Initially, it was the perception of India as a land of powerful magic that attracted Ghanaians to Hinduism. This perception had built up over a long period of time. It came through stories spread by veteran soldiers who saw action in Burma and nearby places during the Second World War and through Hindi movies which have had a huge patronage in Ghana since the 1960s (Dovlo 2014:34). The other factor of attraction was the perceived affinity between Ghanaian cultures and Hinduism. Indeed, before Hinduism caught the eyes of the public, its fame had preceded it in the Ghanaian public space. Local magicians, astrologers and psychists who claimed to have received training in India or to be using supernatural powers obtained from Hindu deities were heavily patronised by the public. The first African swami, Swami Ghanananda Saraswati, was attracted by the colourful pictures of the Hindu deities because he equated the deities to Mami Wata, believed to be a marine spirit being, who is noted to be a powerful spirit who makes its devotees rich and, was believed to be the main spirit behind magicians and psychics (Wicker 2000). Apart from these factors, other features with which the tradition appeared in Ghana also became attractions: features such as yoga, vegetarianism, cremation after death, and the apparent inclusivist stance that did not condemn any tradition.

\section{Hinduism and Development}

Conventional discourses on religion and development tend to focus on religious personalities and institutions to the complete neglect of what I have described elsewhere as the 'religious dimensions of religion'. These are elements such as beliefs and rituals, which are easily overlooked in development work and scholarship because they appear irrational or too controversial or not too decent to bring to the table openly. Julia Berger (2003:15ff) observed that many Governments of Western Europe barred their official development agencies from dealing directly with religious organisations in the areas they operate. In certain cases, governments permitted dealing with religious groups but restricted such engagements to non-religious dimensions. Yet for many believers, life and all it entails cannot be separated from such components of their religion. As a matter of fact, such elements form the deep well out of which the public-spirited 
religious personalities and institutions that easily catch the eyes of scholars and from which activists draw inspiration and meaning.

It is important that in societies of the Southern hemisphere, analysis of religion's role in development be placed in a framework that is broader than the conventional Western European paradigm that is fixated on religious personalities and institutions and neglects beliefs and related ritual. This was acknowledged by James Wolfensohn, former President of the World Bank, in the 'Foreword' to a book edited by Gerrie ter Haar when he wrote:

Economic policy and management of public institutions are always embedded in an environment that is shaped by the societies themselves, and especially, their history and culture.... In exploring these broader dimensions of the development environment, it struck me forcibly that religion was a pervasive force in many of the World Bank's client countries.... It is, rather, a dimension of life that suffuses whatever people do. Religion has an effect on many people's attitudes to everything, including such matters as savings, investment and a host of economic decisions (Ter Haar 2011).

The past century was marked by recognition of the great contributions by religious institutions such as mission bodies and religious organisations to the development of societies around the world. It also saw the celebration of iconic individuals, who, inspired by religious conviction, stood for justice, equality, inclusion and the rights of peripheral individuals and groups in many places around the globe. Mohandas Gandhi, Martin Luther-King Jr, Desmond Tutu and Mother Teresa are examples of such persons who lived out their faith in the public arena of activism, risking their lives, with some, eventually, paying the ultimate price.

However, when Max Weber, more than a century ago, drew attention to religion as a catalyst for economic development in certain contexts, he was not primarily concerned about the role of leading activists, but also, the core of religion: ideas and beliefs that underpin and spur the attitudes and behaviours of religious individuals and groups. Thus, his intensive study project encompassed a tracing and the analysis of the history, texts, social structures, beliefs and rituals of different religions of the world. His conclusion that religions of India such as Hinduism and Buddhism were devoid of the essential variables for capitalism to emerge in the sub-continent was based on his analyses of the core philosophies of those traditions. The mystical orientation of Indian religions, from his perspective, turned the believer away from this-worldly matters to eternal or other- 
worldly ones and, therefore, unlike protestant Christianity, which had "inner-worldly asceticism", traditions of the Dharma with their mystical philosophy of this world as illusory and the eternal metaphysical world as most real, lacked the capacity to receive the spirit of capitalism (Srivastava 2016:340).

The greatest impediment to Hindu tradition's contribution to socio-economic transformation, for Weber, was the twin-law of karma and samsara which provided an explanatory framework for the law of the varnas, or the caste system, which, from his understanding, dissuaded individuals from thinking of life apart from the community and made them resign to their present stations in life with no desire or motivation to work toward societal and economic change. Therefore, for Weber, "So long as the karma doctrine was unshaken, revolutionary ideas or progressivism were inconceivable" (Weber 1958:123). Thus, Weber's perspective places certain kinds of religion, for example, protestant Christianity, in favourable light as propellers of economic development and social transformation; while others, such as Hinduism, may be regarded as lacking the dynamism for the realisation of a transformative agenda (Singer 1966). Not unexpectedly, like other aspects of his works, Weber's thesis with respect to Hinduism has attracted some criticism (e.g. Badrinath 1986; Srivastava 2016). Be that as it may, his relevance for the point I wish to make here is not in dispute: religion, in terms of its core 'religious form' has potential or real significance for socio-economic development.

\section{Hinduism and Development in Ghana}

Despite the growing recognition of the important relationship between religion and development, the roles of minority religions in societies are ignored in scholarship. For example, several religious traditions from the East, especially, Buddhism and Hinduism, have been thriving in Ghana since before the 1930s (Acquah 1958), yet their contribution to, or potential for, socio-economic development has been hardly explored. However, studies about the contribution of Christianity and Islam abound in the existing and constantly growing literature. It has been the conventional understanding of the relationship between religion and development rather than the lack of potential or real contribution to development that is responsible for this neglect. The conventional approach to the study of the relationship between religion and development, as I pointed out above, 
has focused primarily on religious personalities and institutions to the almost total neglect of aspects such as beliefs, ideas and rituals.

If a scholar sets out to study the relationship between Hinduism and development in Ghana, using the conventional paradigm, expecting to find many physical structures and outstanding public-spirited persons of influence, they are likely to find very little. This is because, the Hindu religion is relatively new in the country and its growth has been slow, having been confined, initially, to the Indian settlers in the country. When it broke out of its confinement and started to attract Africans, the pace of its growth did not change much since the public space was already choked with Christianity and Islam, whose publics reacted to what was considered a strange religion with suspicion and caution (Atiemo 2017b:15-17).

Hinduism's contribution to the development of Ghana, may be considered from two angles. First, the contribution of the Indian diasporic Hindus and, second, that of the African converts to Hinduism. Members of the Indian diaspora community in Ghana would normally, prefer to wear the identity badge of citizenship to that of religion. Traditionally, the difference between being a Hindu and being an Indian did not matter much since being an Indian was equivalent to being a Hindu. Though, this no longer pertains, most of the Indians in Ghana are Hindus, with a few being Sikhs and Christians. The Indian community has built a Temple complex at Osu, one of the most important suburbs of Accra, the capital city of Ghana. This Temple doubles as a social and cultural centre for Indians and it has the images of most of the gods of Hinduism, making it possible for members of the different sects to consider it their own. Indeed, many Indians, home and abroad, prefer to understand Hinduism as a 'way of life' rather than a religion. There is also a Gurdwara at Tudu in the centre of Accra.

Not much has been done by way of direct involvement in development matters under the banner of Hinduism by the Indian Hindus in Ghana. Therefore, not much exists by way of infrastructure or service to be investigated by scholars to gauge the level of relationship between Hinduism and development. However, many Hindu individuals and groups are behind businesses and charity works carried out in the name of the Indian Association of Ghana. This is in areas such as pharmaceuticals, farming, trading, automobiles, agro-processing, Information Technology (IT) and supply of tractors and other agricultural equipment. While, the involvement in socio-economic activities by these Indians is not done under a 
banner of Hinduism, their regular participation in temple activities certainly inspires aspect of their work. The temple is the centre of social and cultural life of most of them.

As indicated above, organisations bringing together African converts to Hinduism are distributed among the various sects present in the country. They include the International Society for Krishna Consciousness (ISKCON), the Hindu Monastery of Africa, Sri Sathya Sai and Brahman Kumaris. Being a tiny minority in a country where aggressively proselytising traditions such as Christianity (especially, Pentecostal Christianity) and Islam dominate, the impact of Hinduism is not extensively felt. Nevertheless, Hinduism in Ghana is taking after these more established traditions, which have for two centuries, been present in the country and have provided a pattern of what it means to be a religious organisation in that context.

Churches and mosques have always sprung up and developed together with educational institutions, clinics and other charity works. Early Christian missionaries to the Gold Coast, especially, in addition to the spread of their message, also promoted the development of education, health, vocational training and agriculture. Several churches continue in this tradition and the newer, independent Pentecostal/Charismatic churches continue to tread that path. Therefore, the relatively new arrivals, the Hindus have started, though in a modest way, to build schools and clinics and promote sustainable approaches to the environment. For example, the International Society for Krishna Consciousness (ISKCON) has a primary school and a Junior High School at Samsam, near Accra. They also have a clinic serving the same community. Since 2010, they have been supplying meals to some students of the University of Ghana who are not able to afford regular meals on their own. This activity has been suspended due to the lack of interest in vegetarian dishes by the new generation of students since 2013. ISKCON also has farms in several parts of the country, where, they train believers to engage in organic farming, especially, in the cultivation of vegetables, since they also teach vegetarian lifestyles.

The Hindu Monastery of Africa does not have a school yet; but it promotes health care and other forms of charity work. For example, the Monastery, on monthly basis reaches out to public institutions with support. They have outreach programmes for the prisons, psychiatric hospitals and orphanage homes. This practice has been going on since the beginning of the Monastery in the 1970s. Every Christmas day, the Monastery sends out gifts to every patient on admission at the Korle Bu Teaching Hospital, 
the leading referral and the largest hospital in Ghana where the leading Medical School of the country is situated.

However, focussing on what I introduced above as the 'religious dimension' of religion, I explore the potential and the actual capacity of this relatively new arrival to contribute to Ghana's effort toward socio-economic development. This approach has two advantages: first, it circumvents the challenge presented by the absence of many significant Hindu individuals and institutions playing leading roles in society; second, it addresses elements relevant to the discourse, which are normally glossed over in development studies. I have in mind here, issues such as the difference between the ideal versions of religion prescribed in text and practical religion as lived by devotees; adaptation of teachings and practices as the religion travels beyond the borders of its birthplace and encounters new cultures, and the existential import of doctrines and rituals for believers.

As it has already been mentioned above, Hinduism is quite new in Ghana and it is yet to produce huge public figures or leaders or build institutions, influential enough to make recognisable impact on the public. The indigenous Ghanaian Hindus are still negotiating their own identity as African members of a tradition that originally did not make converts because it is ethnic-based (Atiemo 2017b). They are also negotiating space in an environment where almost every religious space is already taken. A revitalization of the religions in Ghana, which had been occurring since the 1960s and continued through the 1990s, and, which saw a general search for healing, protection and meaning led to the proliferation of religious groups of various kinds. Older traditions such as the African indigenous religions, Christianity and Islam experienced a general revival. It was in that era that Evangelicalism and Pentecostalism spread and became the dominant expressions of Christianity, cutting across denominations. Islam also experienced a proliferation of new sects and the seeping into the existing traditional Sunni brand of new ideas and expressions from North Africa and the Arab world. It was within this period that the Salafi, the Shia and Libyan Third Universal Theory versions of Islam arrived in Ghana and registered on the consciousness of the public (Dumbe 2013). Into such a context was introduced the Hindu groups. The public reaction was a mixed one of curiosity, caution and, in a few cases, hostility. Initially, the strangeness of their dressing, teaching and worship forms aroused the curiosity of many people. But when they started to make some converts from the existing traditions, sections of the public became hostile toward them. For example, Christian preaching in the streets equated the Hindu 
deities to Mami Wata, a marine spirit in popular West African beliefs and condemned it the same way they condemned the indigenous religious beliefs and practices. Nevertheless, Hinduism has continued to grow, making converts from the already existing groups, especially, the Christian groups in the principal cities and towns such as Accra, Kumasi, Koforidua, Cape Coast, Takoradi and Nkawkaw. Yet, the influence of Hinduism in Ghana does not show off only in terms of numbers of converts and temples, but also in the gradual spread of Hindu ideas and expressions such as diva, mantra, karma, guru, yoga, prajna, and dharma. This development is helping to gradually remove the ring of strangeness in the public's eye from the tradition.

\section{"India/Hinduism does not throw away anything"}

Weber's inability to see any possibility of Hinduism contributing to socioeconomic development of India at the time of his investigations can only be understood in the context of those times. His argument that Hinduism's lack of social and cultural elements like those found in Protestantism made it difficult for it to produce the kind of results he claimed to have found in Western Europe was grounded in the presumed dichotomy between tradition and modernity. His understanding of societies in terms of the then emerging binary opposites of 'the traditional' and 'the modern,' did not allow the consideration of a third possibility where modernity and tradition may exist together, and yet, be a factor of progress and transformation. The era in which he lived was characterised by a concentration on textual instead of lived religion; and textual religion entrenched generalised stereotypes, which on the ground had changed in understanding and practice. A dwelling on textual religion by scholars often ignores the inner dynamism of cultural phenomena.

One of the greatest features of Hinduism, which usually escapes the eyes of scholars and commentators, is the capacity to absorb new ideas and practices without discarding, completely, the older ones. This feature was given an apt description by Professor Triparthie in 2012 when I was a Senior Fellow at the Indian Institute of Advance Study (IIAS) in Shimla in India. In a conversation with him about the complexity of Hinduism, which has been complicated by new developments connected to it, he said, "India does not throw away anything." Explaining himself, he added: "All you need to do is to stand by the roadside in any city of India. You will see modern motor vehicles driven on first class asphalted road, but you 
will also see carts being drawn by bulls, donkeys or horses." He continued: "if you go to any city centre, you are likely to meet Indian gentlemen dressed in designer suits and Indian ladies wearing designer dresses made by modern trained tailors. But you would also find others dressed in traditional kurtas and saris."

Thus, modern ways of life based on advances in the latest state of the art technology coexist with traditional ways of living. This, as he explained to me, was the 'kernel of the Hindu culture,' which has developed modern forms that are still strongly related to the traditional and classical forms of the religion. Shirly Firth cites Menski who shows 'that classical Hindu law favoured continued ritual innovation and flexibility' (Firth 1997:195). A. L. Basham, who surveyed various developments in Hindu history, since the 'classical' period, arrived at the following conclusion:

Hinduism in the modern age is characterized by its adaptability. Using a foundation of classical Hindu thought and practice, Hindus of all types are adjusting to their present time and place. This flexibility and openness, while following the age-old traditions and teachings of the sages, will permit Hinduism to remain one of the world's major religious forces in the future (Basham 1990:115).

Currently, India has embraced the principles of capitalism and democracy and it is lauded as one of the biggest democracies in the world. It is already an industrial giant and a leader in ICTs. Both at home and in the diaspora, Indians are engaged in serious businesses and are making great contribution to the world's economy. In many major cities of the world Indian shops and industries are part of the most visible features.

Furthermore, because of the Hindu diaspora and the work of the $19^{\text {th }}$ and early $20^{\text {th }}$ century Indian reformers such as Swami Vivekananda and Ram Mohan Roy, Hinduism now has in its fold converts from regions other than India living in different parts of the world. These contexts emerge with new understandings of the tradition, not always in harmony with traditional interpretations and attitudes. For example, whereas in India, attitudes instigated by caste persists, though with some modifications (Singh Swapnil 2015:2), African Hindus in Ghana do not define their identity in terms of caste. While maintaining that caste as understood in the doctrine of the varnāśrama-dharma was created by God to maintain the harmony of society by ensuring that people engage in occupations that accord with their natural propensities for an efficient society, they insist it 
is of no consequence in contemporary times. For them, caste and its inherent inequalities are a case of an originally sound social arrangement becoming corrupted (Atiemo 2017b:17).

Interestingly, the Ghanaian, like the Indian, has the propensity to incorporate new ideas and practices into religion when they perceive them to be beneficial. Indeed, they have the tendency to abandon deities that seem not able to maintain their potency in new situations (Busia 1954:2015). This is because religion in Ghana has strong utility value. Religion must be beneficial to society; traditionally, if any form of religion was found not to be beneficial to society, it was abandoned. Therefore, in Ghana, religion becomes the source of confidence, security, the motivation and other inspirational virtues to pursue modern lifegoals. There is no contradiction between the traditional and the modern in many cases; traditional and modern are not exclusive fields of historical existence. This has been the case with the Pentecostal revival where traditional beliefs in witchcraft and black magic and their accompanying practices of healings and exorcism exist with sophisticated business ideas and the use of latest technology in worship and evangelism.

The religious beliefs and practices exist also in the context of the modern nation with a secularist constitution that allows the thriving of religious diversity, where the various traditions survive or perish only based on the public's acceptance or rejection of their message. Contribution to prosperity demonstrated in the lives of believers and a tradition's contribution to the welfare of the society are important in determining the acceptance or rejection of a religious group or institution. This public expectation, combined with a tradition's doctrinal motivations toward service to society, necessarily makes religious organisations players in the arena of socioeconomic development. Hinduism in Ghana is compelled by this critical public expectation and its own sense of social responsibility, to contribute to socio-economic development one way or another. But which specific ideas or doctrines contribute, or may contribute, to the developmental efforts of Hindus in Ghana?

\section{Belief in the unity of the universe}

An important concept of Hinduism is rta. The concept of $r t a$ refers to the idea that the universe is held together by a principle that makes the universe an ordered whole rather than disjointed and arbitrary world. It is the 'established route of the world, of the sun, moon and stars, morning and 
evening, day and night. " (Radhakrishnan 2006:79). Rta ensures the balance and harmony of nature. It connects the different parts of the universe into one whole. In addition, the Vedic understanding of the universe is monistic. It assigns a single essence to the universe so that the human being and the rest of nature share in the same single essence. The doctrine holds that any distinctions that exist in creation are not real; they are maya (an illusion). They stem from ignorance, which also is the primary cause of the human predicament. Overcoming that ignorance and discovering one's essential unity with Brahman, the only reality that exists, is moksha (liberation). Dharma, which has similar meaning to rta has evolved from $r t a$ is now more widely used (William K. Mahony 1987).

Contemporary concerns about the environment, which have triggered activism and scholarship in search for ways of preserving and sustaining the ecosystem, means anything that has the potential to contribute to those ends ought to be accepted as an important resource. Thus, this Hindu idea of the unity of the universe, which encompasses humanity and the rest of creation comes in as a powerful resource for mobilising support for the preservation of eco-systems and the promotion of sustainable development approaches to dealing with the environment. In that case, religion becomes an important resource to be considered by those concerned about preserving the environment. Ghanaian Hindus of the various sects such as ISKCON, HMA and Sri Satya Sai Baba mission exhibit high reverence for the environment and seek to promote sustainable approach to life in general, especially, through farming. They opt for non-destructive lifestyles such as organic farming. This is in keeping with the principle known as "Vasudhaiv Kutumbakam"- (The Earth as one Family), which has inspired environmental activism and peace initiatives in Hinduism in certain cases (Reeta Rautela nd). Ghanaian Hindus reverence for nature and their conscious effort to refrain from practices that are destructive to the ecosystem can be important in the collective national efforts to promote eco-friendly ways of life. For example, in their teaching, they encourage reverence toward the rest of nature and the importance of keeping clean environment. Wuaku (2009:15-17), reports how Ghanaian Hindu devotees of the Govinda Temple in Medie, near Accra, pay reverence to the cow and appropriate the Hindu understanding of the cow to their own local situation.

This attitude of reverence for nature meshes with their own traditional Ghanaian attribution of sacredness to nature. So, while they quote from Hindu sources to support the need to care for the ecosystem as a duty, 
they also draw inspiration from their traditional Ghanaian cultures (Atiemo 2013). For instance, several ethnic groups in Ghana refer to the earth as Mother. Therefore, traditionally, there were many taboos regarding the earth, and it was immoral to treat the earth with carelessness. Then also, the promotion of vegetarian lifestyles that reduce the consumption of meat is catching on among believers. This is positive to sustainable development since it is proven that animal agriculture and the eating of meat contribute significantly to global warming (UN Environment 2018).

Furthermore, the Hindu mode of disposing dead bodies through cremation is spreading beyond Hindu frontiers and is gradually, becoming, even for non-Hindus, an acceptable way of disposing of dead bodies. Mainly based on the need for hygiene and the need to preserve land, the argument for cremation is increasingly winning and it is gradually, becoming accepted by the Ghanaian public. The formation of the Ghana Cremation Society, which seeks to promote cremation through public education, and the establishment of modern crematoriums, have helped the effort of the oriental religious traditions such as Hinduism and Buddhism to introduce cremation as a legitimate way of disposing dead bodies.

\section{Seva}

In all the modest contribution Ghanaian Hindus make to society, they have done so in ways that create a connection between service and inner piety. Service, they explain, must come out of a sense of duty. Consequently, the HMA's social outreach programmes are conducted quietly without any publicity in the media. This approach to service accords with the concept and practice of seva in Hinduism as it has come to be popularised around the world since the Indian social reform movements of the $19^{\text {th }}$ century. Seva is translated 'service' in English but its meaning appears deeper than that as it has evolved from its traditional meanings to its modern understandings as has been complicated through the undecidable debates between the various protagonists of the Indian nationalist struggle (Srivatava 427). The basic meaning in the Bhagavad-Gita is doing charity work or doing good without expecting to benefit in any way. The Gita 17:20 - 23 reads:

"Charity given to a worthy person simply because it is right to give, without consideration of anything in return, at the proper time and in the proper place, is stated to be in the mode of goodness. But charity given with reluctance, with the hope of a return or in expectation of a reward, is said to be 
in the mode of passion. And that charity, which is given at the wrong place and wrong time to unworthy persons, without showing respect, or with contempt, is held to be of the nature of nescience."

Seva as a concept, among other things, sanctifies service to all, even lower castes or persons of lower estate than the one doing service without any diminishing sense of the dignity of either the one doing the service or the beneficiary. Seva is done in the recognition of the belief that "service to humanity is service to God".

The Sathya Sai Baba Mission in Ghana, which seems to promote the concept more than any other has, in the spirit of the concept, been engaged in several activities around the year as part of their contribution to the development of the Ghanaian society. Indeed, devotees are taught to consciously approach service with the 'seva' mindset. For example, since October 2013, every year, the young adult devotees of the Mission organise special outreach activities to help protect and heal the environment. Activities include cleaning the beaches, planting trees and educating the public about the benefits of environmental-friendly lifestyles.

Other activities aimed at making life in the communities better include supporting health and rehabilitation institutions. For example, in December 2016 the Sathya Sai international Organisation members visited the Nsawam Orthopedic Training Centre (NOTC), where persons, especially children, who have lost one or both limbs because of accidents or birth defects are helped. They spent time with the children at the Centre and fed them with bread, cooked rice and fruit. The concept and practice of seva has the potential to instigate deep social concerns among Hindus in Ghana, as it has already inspired many contributions to social service.

Seva, being a religious concept and practice, holds the potential to link Hinduism to contemporary values important for the promotion of human rights such as upholding the human dignity of every individual, no matter their status, inclusion and avoidance of discrimination. These, which in traditional Hindu culture have been easy to violate because doctrines such as the varnadharma and karma and samsara provided justification for the violation. However, the deep meaning involved in the concept of seva, which involves serving others as a duty imposed by God and the belief that all things are held together in indivisible oneness so that, that which constitutes the source of dignity in one is that which gives dignity in all. In that case there is no feeling of superiority in that one who serves or cares for another, even if the recipient is of socially inferior status than the giver. 


\section{Stages and Goals of life}

Ghanaian Hindus of the HMA, while they claim that the varna dharma does not apply to them, know about the four āśramas (institutions) to an extent. The four āśramas, each of which is about twenty-five years duration prescribes stages of life for male Hindus. Boys of the three upper castes, when they are between eight and twelve years old are initiated into the brahmacaryāśrama (stage of the religious student). At this stage a person may take a vow of celibacy and engage in exercises meant to build his physical and mental capacities. A person at this stage goes through a study of the Vedas under a teacher and performs yoga and meditation. In the second twenty-five years, he graduates into the grhasthāśrama (stage of the householder). This stage allows the pursuit of material wealth and pleasure. Most Hindus do not go beyond this stage. The last two of the institutions, Vānaprastha (stage of the Forest dweller) and Sanyāsa (stage of the wandering ascetic or the renouncer) are the direct roads towards liberation.

These four institutions or stages of life correlate with the puruşārthas, which delineate the following four goals of life that Hindus may pursue: artha, kama, dharma and moksha. The stage of the religious student connects with dharma and enjoins on the religious student the study of the Vedas with the disciplines of celibacy, frugality and the pursuit of other such relevant virtues. The stage of the householder connects with artha and kama and commits one to household life - earning wealth, marrying, enjoying sex for begetting offspring. The third and the fourth stages dharma (duties) and moksha (liberation) bring one back to spiritual pursuits. The goal at these stages is to seek to obtain the essential ultimate liberative oneness with Brahman through meditation and yoga practices. Hinduism in Ghana is mainly a householder religion (grhasthāśrama). Converts, generally, start as religious students at whatever age they become Hindus; and virtually none of those born into the tradition go beyond the householder stage. In that case, the restrictions to the pursuit of wealth and legitimate pleasure do not exist for most of them. The young men and, also the women, vigorously pursue these lifegoals of wealth and pleasure but within limits of moral demands placed on them by the comprehensive renouncer-orientation of the Hindu Dharma. Therefore, while pursuit of material wealth and the pursuit of pleasure are found within the acceptable boundaries of the religion, there is strong sense of ethical responsibility that accompanies converts' approaches to work and business. The goal of artha that permits Hindus to pursue and enjoy material 
wealth without sense of guilt frees the Ghanaian Hindu from the traditional sense of guilt attached to opulence in the religious traditions such as traditional Christianity that preceded Hinduism.

Such this-worldly orientation sanctioned by religious tenets has great power to motivate believers to work hard at their secular callings with unhindered zeal and confidence. Religious traditions, usually, hold in an ethical tension the call to stay detached from material things in order to hasten or secure one's attainment of spiritual liberation and the necessity of material wellbeing in order to respond to the call to help eradicate suffering in the world as part of the tradition's mission. In Hinduism, specifically, poverty is a virtue when it is as a result of renunciation; but it may be seen in a negative light because it can be the result of one's karma - bad accumulated in a previous existence. Wealth can be the reward from the karma of previous life.

Yet, karma and samsara are not anti-development tenets that freeze motivation toward upward socio-economic mobility. They can be motivating in many ways and can be explored to support the development of individuals and societies. In social media exchanges with some young Ghanaian devotees of the Hindu Monastery of Africa, one explained: "karma refers to action and the result of it. That is, there is no action that bears no fruit. It is not connected to any God or any supernatural superintendent: it is naturally arranged and operates automatically. It helps me approach life in consciousness as an individual whose every action has long-term consequences. It also sharpens my moral sense of responsibility" (Narayana Nyarko 2018). Another wrote: "Hindu philosophy, including the karmasamsara principles help me to cope with suffering, evil and pain and puts me on guard to consider every action I take carefully in order to improve myself in righteousness. Talking about tolerance, humility and self-control and many great attributes, our teaching and practices inspire young and adult African Hindus to be better human beings. Our faith also inspires us to be involved in social services and activism to help build communities through teaching of morals and values. This is all possible because some aspects of Hindu teaching, relevant for development, connects with similar ones in our traditional African culture" (Shiva Campbell 2018).

Shiva Oppong Banahene, a freelance journalist and a public relations practitioner, has taken a definite activist stance on social media, fearlessly exposing corruption and injustices of various kinds in Ghanaian society. About twelve young persons and young adults I have been following on 
Facebook or interacting with are all involved in championing one cause or another. As one of them put it, belief in "karma" sharpens the individual moral sense. This makes you want to perform your dharma (duty) well. In the process you find yourself, serving as a role-model for others Hindus and non-Hindus (Campbell 2018). Victoria Lakshmi Hama, who has served as deputy minister in a previous government is an active gender advocate. Thus, dimensions of Hinduism such as beliefs and practices that have been considered inconsequential in development work and discourse, are proving to be important resources for socio-economic development among Ghanaian Hindus. Aspects of Hinduism, including karma, samsara and other teachings, which were considered as limiting individual sense of freedom and responsibility are rather found to be enabling of freedom and heighten individual moral sense.

The devotees of the Hindu Monastery of Africa draw inspiration from the Late Swami Ghananand Saraswati, the first African Swami and founder of the Monastery. He encouraged them to consider every work they engage in as God's work. He also encouraged devotees to work hard and assured them of success if they focus. One of his sayings in this direction that has become popular among Hindus in Ghana goes as follows: "Adopt the motto: 'Planned living and high thinking; "Become the embodiment of Truth, Love and Purity. Embrace the idea of selfless service. Know that work is worship. These may be difficult in the beginning, but your effort will be crowned with success" (Ghananand Saraswati 2008).

\section{Conclusion}

Previous approaches to development work and development studies engaged religion only in the sense of significant public-spirited individuals and institutions and neglected the core religious dimensions. Then also, the $19^{\text {th }}$ and the $20^{\text {th }}$ century modernization-inspired studies focused on texts instead of the phenomenon at the practice level. The results of these studies included generalizations that were not true to the facts on the ground. Furthermore, conclusions by studies based on works of scholars such as Max Weber that certain aspects of Hinduism could not admit of modern trends such as democracy and capitalism have proven to be adaptable in contemporary Ghanaian contexts. In a post-modernist era when ecological concerns and cultural trends such as diversity and free choice dominate various discourses, Hindu philosophical tenets such as rta, 
kama, artha, karma, and samsara can be developed to support socio-economic developmental efforts of societies where religion still plays a role in development.

\section{References}

Basham, A. L. 1990. The Origins and Development of Classical Hinduism. Oxford Univ. Pr. Acquah, Ioné. 1958. Accra Survey, London: Univ. of London Pr.

Atiemo, Abamfo O. 2013. Religion and the Inculturation of Human Rights in Ghana, London: Bloomsbury.

Atiemo, Abamfo O. 2016. "Hinduism, African Hindus and Neo-Hinduism: between Nomenclature and Authenticity". Philosophy and the Life-world, Vol. 18.5 -17.

Atiemo, Abamfo O. 2017(a). “In Need of a New Lens: An African Christian Scholar's Religious Critique of Western European Attitudes toward Religion and Development in Africa. " Religion \& Theology 24 (2017) 250-273.

Atiemo, Abamfo O. 2017(b). "Returning to our Spiritual Roots': African Hindus in Ghana Negotiating Religious Space and Identity. " Journal of Religion in Africa 47, 405-437.

Badrinath, C. 1986. “Max Weber's wrong understanding of Indian civilization”. In Detlef Kantowsky (Ed.), Recent research on Max Weber's studies of Hinduism (45-58). München: Weltforum Verlag. 45-58.

Berger, Julia. 2003. “Religious Nongovernmental Organizations: An Exploratory Analysis. "Voluntas: International Journal of Voluntary and Nonprofit Organizations 14:1, 15-39.

Busia, K. A. 1954. “The Ashanti”, in Daryll Forde, African Worlds. Oxford: Oxford Univ. Pr.

David N. Lorenzen, David N. 2006. Who Invented Hinduism? Essays on Religion and History, New Delhi: Yoda Pr.

Dovlo, Elom. 2014. 'Africans in Saffron Robes: Ghanaian Experiences in Oriental Spirituality'. In: Abamfo O. Atiemo, Ben-Willie Golo \& Lawrence Boakye (eds.) Unpacking the Sense of the Sacred: A Reader in the Study of Religion. London: Ayebea Clarke.

Dumbe, Yunus. 2013. Islamic Revivalism in Contemporary Ghana, Södertörn Studies on Religion 5.

Ellis, Stephen. 2003. "Young Soldiers and the Significance of Initiation: Some Notes from Liberia," (paper pres. at the ASC, Univ. of Leiden, 24/03/2003), online: http://www.ascleiden.nl/pdf/conference24042003-ellis.pdf (acc. 15/06/2014).

Firth, Shirley. 1997. Dying, Death and Bereavement in a British Hindu Community. Leuven: Peeters.

Hatcher, Brian A. 2004. 'Contemporary Hindu Thought.' In Robin Rinehart (ed.) Contemporary Hinduism: Ritual, Culture and Practice. Santa Barbara: ABC-CLIO.

https://www.unenvironment.org/news-and-stories/story/tackling-worlds-most-urgentproblem-meat (acc. 2nd Jan. 2019). 
Mahony, William K. 1987. "R.ta" Encyclopedia of Religion. Encyclopedia.com. (Jan. 24, 2019). https://www.encyclopedia.com/environment/encyclopedias-almanacstranscripts-and-maps/rta.

Mahony, William K. 1987. “The Divinity of Krishna by Noel Sheth; Vallabhācārya on the Love Games of Kụṣna by James D. Redington” History of Religions . 26:3, 333 - 335.

Marshall, Kathrine \& Marisa Van Saanen. 2007. Development and Faith: Where Mind, Heart, and Soul Work Together. Washington, DC: World Bank.

Nicholson, Andrew. 2011. Unifying Hinduism: Philosophy and Identity in Indian Intellectual History. Ranikhet: Permanent Black.

Radhakrishnan, S. 2006. Indian Philosophy Vol 1. Oxford Univ. Pr.

Rautela, Reeta. nd "Role of Hinduism in Maintaining Sustainable Development". International Journal of Socio-Legal Analysis and Rural Development, 2:1.

Renou, Louis. 1961. Hinduism. New York: George Braziller.

Singer, M. 1966. Religion and social change in India: The Max Weber thesis, phase three. Economic Development and Cultural Change, 14:4, 497-505.

Sivānanda, Swami. 2007. All about Hinduism, 9th ed. Rishikesh: Divine Life Society.

Smith, Brian K. 1987. "Exorcising the Transcendent: Strategies for Defining Hinduism and Religion," History of Religions, 27: 1, 32-55.

Smith, E. W. (ed.). 1950. African Ideas of God. London: Edinburgh House Pr.

Srivastava, Vinay Kumar. 2016. “Social Change Religion and Development: Understanding their Relationship with Reference to Hinduism: A Study Marking the Centenary of Weber's Religions of India” Social Change, 46(3) 337-354.

Swapnil, Singh. 2015. 'Caste and Diaspora,' International Journal of Social Science and Humanity, Vol. 5, No. 1, 80-82.

Ter Haar, Gerrie. 2011. Religion and Development: Ways of Transforming the World. London: Hurst.

Weber, Max 1958. The religion of India. New York \& London: The Free Pr.

Wepener, Cas. 2015. “African Therapy for a Fractured World (View): The Life of Founder Bishop Johannes Richmond and the Invention of Tradition and Group Cohesion in an African Initiated Church," hts Teologiese Studies/Theological Studies 71, no. 1 (2015).

Wicker, Kathleen O’Brien. 2000. “Mami Water in African Religion and Spirituality. ” In African Spirituality: Forms, Meanings, and Expressions. Olupona Jacob K. (ed.) New York: The Crossroad Publ. Company.

Wuaku, Albert Kafui. 2009. "Hinduizing from the Top, Indigenizing from Below: Localizing Krishna Rituals in Southern Ghana," Journal of Religion in Africa 39. 403 -428 .

Wuaku, Albert Kafui. 2013. Hindu Gods in West Africa: Ghanaian Devotees of Shiva and Krishna. Leiden/Boston: Brill. 


\title{
Sowing the Seeds of Dhamma - Buddhism and Development in Africa
}

\author{
Elizabeth Pulane Motswapong
}

\section{Introduction: Buddhism: A Brief Preview}

Buddhism is one of the major religions of the world which originated in India. It is dominant in several East Asian countries and has gradually established itself in the West. Since the early seventies, the profound Buddhist view, with its vast number of methods, has inspired and fascinated a growing number of people in Western cultures. The religion has found its way into the African soil as well, however, it is not as widespread as its counterparts, namely Christianity and Islam. Buddhism dhamma teaches about the ultimate and conditioned existence in a way that makes the religion Buddhism directly relevant to the lives of individuals and communities especially in Africa. The religion continues to make its mark which can be accredited to its focal teaching of suffering which reverberates very well with Africa as a whole, a continent staggering in the woes of suffering; politically, socially and economically.

Before venturing into why the religion has not spread like its counterparts, the life of the founder will be discussed very briefly. It is important to give an account on the life of the founder because his teaching was very fundamental to the development of the human mind. Once the human mind is developed all other consequential developments be they social or physical falls into place. Buddhism was founded by Siddhartha Gautama. The name "Buddha" was given to him after he attained Enlightenment and realised the truth. The name Buddha is a title which means the 'awakened or enlightened one' (Harvey 2013, Keown 2013). He generally called himself the Tathagata, meaning one who has come from the realm of truth, while his followers called him Bhagava, 'the blessed one'. Others spoke of him as Gotama or Sakyamuni (Dhammananda 1993), by virtue of coming from the Shakyamuni clan. He is believed to have been born in Lumbini in today's Nepal about 2560 years ago. The Buddha taught for 45 years before he entered his parinrivana. His religion teaches about human suffering, Pali dukkha / Sanskrit dukkha, which results from craving and desire tanha/ trishna for things external to the individual (Keown 2013). The 
Buddha was more concerned with the human condition: Birth, sickness, old age and death, which makes his teachings very relevant to Africa. The path means coming to a place of acceptance with these painful aspects of life, and not suffering through them. These teachings are known as the noble truths. They can be summarised as follows: suffering exists, suffering has an origin, which is craving, that suffering has a cessation and the path leading to the cessation of suffering/dukkha is following the eightfold path of right view, right intention, right speech, right action, right livelihood, right effort, right mindfulness and right concentration (Harvey 2013).

\section{Planting the seed of Dhamma in Africa}

The planting of Buddhism in Africa has not been a smooth one because Africa is predominantly Islam, Christian and/or Traditionalist. According to Venerable Ilukpitiye Pnnasekara Nayaka Thero (2018), Buddhism has been in Africa for not more than 100 years. About half of African Buddhists are now living in South Africa, making them the majority where there are more Buddhist centres and temples and organisations from various Buddhist Schools. There is also a substantative number of Buddhists in Mauritius and pockets of them in Botswana, Tanzania, Kenya, Uganda, Malawi (Thero 2018). The religion is relatively 'new' in Africa and was brought about by migrants from Sri Lanka, Burma, Taiwan and Thailand (Loon 2017). The migrants later erected Buddhist temples transforming the African landscape forever. The oldest temple was established in Tanzania by a Sri Lankan group in the 1920s where about 400-450 Sri Lankan Buddhists were working. It is the oldest temple in Africa. Notwithstanding, there is only one temple in Uganda which was established by an African. It was built in the year 2005 by an African Monk named Venerable Bhikku Buddharakkhita (Thero 2018). The Buddhist Association Hall was built in 1927 in Tanzania which housed a nursery school. It is worth noting that there was no Buddhist monk residing in Tanzania until in the early 1960s. Initially the Association was referred to as Sinhalese Buddhist Association, but later changed to Buddhist Association in the bid to be inclusive and mindful of the diversity of the Buddhists from other countries, like Thailand, Burma, China, and elsewhere in Africa. This followed the building of the pagoda and Buddha mandir (temple) in 1956 which was opened to all, Buddhist and non-Buddhist alike. There was no resident monk in Tanzania until 1983 when the first monk by the name of 
Venerable Puhulwelle Vipassi Thero arrived, followed by Venerable Witharandeniye Kassapa, and the third Venerable Pidwille Piyatissa Thero. The current, monk Venerable Iluptikiye Pannasekara, who is also called the Chief Monk for the African Continent is the $12^{\text {th }}$ Monk to be housed in Tanzania. He oversees the African countries and since 1998 he has been offering his services to many African countries where there are no resident monks (Thero 2018). These countries include among other, Kenya, Malawi, Zambia, Swaziland where he performs various Buddhists religious ceremonies and rituals. Tanzania Buddhist Centre is used as the Centre for the whole African continent.

There are challenges encountered by Buddhism which are mainly due to the complexity of the religion, especially its lifestyle and teachings which are relatively 'new', therefore alien to Africans. Furthermore, there are a lot of misconceptions coupled with ignorance regarding Buddhism, especially in Africa, making it almost impossible for the religion to spread like its counterparts, Christianity and Islam. Although, the Buddhist schools of thought introduced to Africa are diverse, it is Theravada or the teachings of the elders which is popular, especially in countries such as Botswana and Kenya as well as Tanzania. The school professes to teach Buddha's dhamma in its original form. This school of thought is dominant in countries like Sri Lanka. Therefore, it does not come as a surprise that the Sri Lankan migrants brought the religion with them when they came to work in Africa but ultimately settled. It was during this time that they brought the religion with them and ultimately introduced Buddhism to the Africans. Notwithstanding, there are other schools of thought like Mahayana Buddhism, which means "Greater vehicle" and is popular in countries like China. According to Mahayana school of thought, a boddhisattva (an aspiring Buddha) acting out of compassion, upon attaining his enlightenment, postpones it in order to take as many people as possible with him unlike in Theravada, (the teaching of the elders), which is also known as Hinayana (a contested name for its adherents), where only a few individual arahats are worthy of nibbana hence the name Hinayana "lesser vehicle" (Harvey 2013). Lastly, there is Vajrayana/ Diamond Way Buddhism or Tantric Buddhism which is popular in Tibet. Where people had strong confidence in their own and others' Buddha nature, Buddha taught the Diamond Way (skt. Vajrayana). Here, he manifested as forms of energy and light or directly transmitted his enlightened view as a flow of awareness, the "Great Seal" (skt. Mahamudra). In the Diamond Way one learns to experience the world from a rich and self-liberating viewpoint. 
Finally, there is Zen Buddhism where the majority of its adherents are found in Japan. Zen Buddhism teaches achieving enlightenment by seeing one's original mind (or original nature) directly, without the intervention of the intellect. The most common way of teaching is for enlightenment to be communicated directly from master to pupil (Dumoulin 2005). All the followers of these schools are found in Africa, with the majority being in South Africa. The first Buddhist retreat centre in South Africa was built by Dr Luis Van Loon near Durban. The centre was officially opened to the public in the year 1980. It offers a serene dwelling to practice and reading philosophy, theology, meditation and Buddhist art. It also inspires practice of certain ethical codes during retreats (Thero 2018). It was after the establishment of that centre that South Africa realised a mushrooming of Buddhist centres across the country representing different Buddhist schools of Thought. For instance, Benoni Cultural centre, Buddhist Theravada Centre, in Cape Town, Capetown Samye Dzong, Diamond way Buddhist Centre in Western Cape. Mahasiddha Kadampa Buddhism, Goenka Vipassana in Eastern Cape, Durban Zen Group and Grahamstown Zen Group (Thero 2018). Furthermore, in Malawi, Mahayana Buddhism is in practice with an established Buddhist centre run by the Taiwanese, while Botswana is predominantly Theravada with pockets of Zen Buddhists. There are also Tibetan Buddhist schools, like Karma Kagyus, which are well established and very popular even amongst Black Africans in South Africa (Clasquin 1999).

\section{Buddhism Meets the 'Other'}

Although Buddhism has been regarded to be alien to the African soil, when it encountered other religions such as Christianity and Islam, it managed to coexist with them without any tensions. Since Africa is predominantly Christian and Islamic, the spread of Buddhism has been stalled mainly because of its teachings which are in contradiction with what the other two teach respectively. As a result, it has become very difficult for the locals to embrace Buddhism and make it part of their lives in earnest. One of the main obstacles that hinders the growth and spread of dhamma in the African soil is that Buddhism like Hinduism is not a proselytising religion. They do not preach and convert, as is the case with the two well established religions in Africa, Christianity and Islam respectively. This poses as a drawback when it comes to growth and development in Africa. It further explains why there is no increase in the number of 
Africans who are interested in becoming monks. The reality on the ground is that there are only a handful of African Buddhist monks (Thero 2018). Besides, lack of proselytization, the concept of God, as the ultimate truth, the vow of celibacy are impediments to the growth of the dhamma in the African soil. These impediments will be discussed briefly below.

\section{Buddhism vs Proselytising}

Buddhism has historically been an actively proselytising faith, which spread mainly through monks and missionaries all over India, South Asia and Indo China. However, it is not as aggressive as Christianity and Islam, to borrow, Venerable Dalai Lama's words. Credit has been given to Emperor Ashoka, the one king who is known to have revived Buddhism dhamma elsewhere when the religion almost disappeared in India in the $12^{\text {th }}$ century when he sent royal missionaries to various Kingdoms of South Asia with the message of the Dhamma of the Buddha. He even sent his son and daughter as missionaries to Sri Lanka (Harvey 2013). Today Buddhism is a growing religion in the West because of the role of the bhikkhus and bhikkhunis (monks and nuns) who have helped in the spread of the Buddha dhamma (Loon 2018).

Buddhism admits converts without any distinction of race, previous religion or gender and any adherent of Buddhism can at least theoretically aspire to reach the highest ecclesiastical offices or even attain the status of Buddha or Bodhisattva. However, adherents of Nichiren Buddhism are known for actively proselytizing, but all in all Buddhism is passive in its drive to preach and convert. This was confirmed by H. H. Dalai Lama on 25 Jan. 2001, during the World Hindu Council when he joined the Hindu leaders in condemning the Muslim and Christian practice of proselytising because Hindus and Buddhists generally do not proselytize. He said, "Whether Hindu or Muslim or Christian, whoever tries to convert, it's wrong, not good". "I always believe it's safer and better and reasonable to keep one's own tradition or belief. " He concluded, "Buddhism, Hinduism and other non-aggressive religions have to unite to douse Islam ... an aggressive religion" (Lee 2004). H. H. Dalai Lama and others later signed a statement saying: "We oppose conversions by any religious tradition using various methods of enticement" (Lee 2004). It is this lack of proselytising that has contributed to Buddhism not spreading as fast as Islam and Christianity thus becoming an impediment to the growth of Buddhism in Africa. 


\section{God not the centerfold}

Kusala Bikshu during a talk at a high school in Los Angeles titled "Do Buddhists believe in God" stated a wise man was asked to give his opinion regarding God, and this is what he said:

I do not take it to be true

I do not take it to be false

I do not say that you are wrong

I do not say that you are right,

I do not say it is true or false

It is both wrong and right, true and false at the same time.

Such is the dilemma of relative truth. It is just finger pointing.

The wise man's sayings summarise the perception of god and Buddhism. It is this complexity of God with Buddhism that controverts what Africans believe whether it is in their African Traditional Religion, or the ones they espoused namely Christianity and Islam. To Africans there is an omnipotent, omniscient God somewhere who is an overseer of their day to day lives. As such God is always at the centre of their lives and whatever misfortunes or fortunes that they come across, God is seen to be one who can intervene and counsel in the former and bring more in the latter (Mbiti 1970). This has been seen as an impediment to Africans in their adoption of Buddhism as a religion because there is undoubtely the laxity where Africans fail to make any effort, because they always want others, including God to help them. If there is no rain the prayers for rain will be carried out and as soon as it rains God will be credited for that. In the case of death, for example, Africans will say the dead is one with the father and that God has taken them away (Mbiti 1990:1970). As a result, everything revolves around God, but in Buddhism a human being is God himself and because of such contradictory views, it is very difficult to be a Buddhist in Africa as a whole. God and Africans are inseparable because in Christianity, Islam and ATR, there is a God or even a higher power who becomes part of the individual or community life. In Buddhism God is in the mind, because mind is the master, because mind is everything and when one experiences peace of mind, happiness and contentment becomes guaranteed, but the absence of happiness will only lead to agitation in the mind resulting in sorrow (Jackson 1941). 


\section{Celibacy and the Buddhist Sangha}

Initially the Buddhist sangha (community) comprised Monks only. However, later the meaning of the sangha evolved because women wanted to be part of the monastic life. This was after a special plea by the Buddha's aunt who was also his stepmother, Mahapajapati Gotami. The Buddha was not pleased with the new development because he felt the presence of women within the sangha would destabilize the order and even impact its lifespan. After some persuasion he relented but he devised stricter and many rules for bikkhuni (nuns) as compared to bikkhus (monks). In addition, to the two groups were people who wanted to be Buddhists, yet, did not want to be burdened with monastic life. They wanted to pursue householder life where they were allowed to marry and have children. Their main role was to support the other two. With the addition of the third group the sangha is further expanded. The group is referred to as the Laity. Although Buddhism teaches that the desire for sex always lead to suffering because the Buddha preached that the activity of sex will never ultimately satisfy their being (Stevens 1990), this teaching applies only to the bikkhus and bhikkuni because they have to take a vow of chastity. Whenever a person becomes a monk or a nun, he or she takes the vow of celibacy. It is a cornerstone of the monastic life. There are innumerable and meticulous rules hedged in the conduct of monks towards the women he met on his rounds of alms or whom as nuns he must interact with. Unchastity was an offence which automatically led to expulsion from the order. As a result, chastity was a great ideal from which the monk must not swerve even at the cost of his life. The orthodox decried sexual intercourse as the 'bovine' or bestial habit and they cultivated a certain contempt for women. The monk was warned to be perpetually on his guard and a short dialogue between The Buddha and Ananda, admirably sums up the attitude of early Buddhists towards women:
Ananda: 'How should we behave to women?'
Lord: 'Not see them!'
Ananda: 'And if we have to see them?'
Lord: 'Not speak to them!
Ananda: 'And if we have to speak to them?'
Lord: 'Keep your thoughts tightly controlled!'
(See Schireson 2009; Beckerlegge 2001).

In the African culture marriage is an expectation because the man has to carry the family line through procreation. Hence it is a taboo for a man not to have children. Once you are married it is taken for granted that 
children will result from the union. Therefore, not procreating is not an option. A man must marry and produce children (Mbiti 1973). In contrast, in Buddhism sexual relations may lead to children, and children would pose as a threat because they tend to tie down anyone who wishes to live outside society in carefree independence (Stevens 1990). Despite the three main challenges discussed above Buddhism has managed to establish itself in Africa, though slowly at first, it is gradually gaining momentum, especially by contributing to the development in Africa. Buddhism has proven that it has so much to offer to the African continent but what remains is a little acknowledgment and acceptance by Africans. Buddhism has done a lot when it comes to social justice and welfare, meditation, education, the environment to mention but a few. Some of its contributions are outlined and discussed below.

\section{Social Justice and Welfare}

Buddhism has contributed to Africa by not only providing education, care and accommodation for hundreds of children. There are also arrangements in place where outreach programmes have been rolled out for vulnerable children. Those who cannot make it to the centre and are supported directly in Community Based Organisations (CBO). For example, in Blantyre, Malawi there is a Taiwanese Buddhist centre working with street children. The centre was founded in 2001 and is known by the name Amitofo Care Centre (ACC). This is an FBO (Faith Based Organisation) which was founded by Master Hui Lee after visiting Malawi in 2000. The centre trained students from African Buddhist seminary on acceptable conduct and social services for the centre. The students also are responsible for the upkeep of the centre's shrine, the boddhi tree. Furthermore "the FBO offers supplementary activities, services and their mission is to 'care for street children and improve the quality of life of the people infected and affected by HIV \& AIDS in the country - four components: where they provide children's' home for the orphans, function as an educational centre, offer guidance and counselling, construct a health centre at the former men's young Pioneer in Mpanga. The centre in Malawi currently supports 452 children from several districts" (Xing 2018:3).

It is worth noting that the ACC is organised around the concept of a 'big family 'or a children's village where children are put in groups of 16-20 that function like a family, with one nanny or mother and one child care teacher living under the same roof, who are responsible for managing the 
home and taking care of the children. The system provides an atmosphere of warmth reminiscent of a family. Twelve such families then form a village. The children practice each day before and after school - a strict training schedule that inculcates discipline, persistence, and concentration, all qualities that will be deemed useful to their lives and careers later in life. The greatest achievement of the "organization is the impact it has made complementing government efforts to reduce poverty and increase the opportunities of disadvantaged Malawians by educating, accommodating, feeding and providing all basic needs to people who are unable to provide for themselves" (Xing 2018:3). Furthermore, there are employment opportunities for the local Malawians where they have employed 130 local staff in support of the government local hiring policy.

In Uganda, Buddhism offers insights and retreats and Buddhist and study programs to the general public. They also provide a space for a limited number of lay people who assist in the running of the temple. Furthermore, Buddhism has worked tirelessly in charitable works, to reduce poverty as well as introduce new cultures. Since the community wants to see the contribution of Buddhism to their lives, before they can join the religion, Venerable Ugandawe Buddharakkitha, during an interview with Sean Mos said there is a project in Uganda, where the Buddhist monk has initiated the drilling of a borehole, which will address the current acute shortage of water in the area (Mos 2015). Through this initiative the community realises that the religion also has their wellbeing at heart and are slowly joining the religion though a lot of reluctance is still realised. It is through initiatives like this that Buddhism is gradually becoming visible because it has struck the very chord that needed to be addressed, that of drinking water shortage in the area. The funding for the project was courtesy of Malaysian Buddhists. Although the community was riddled with doubts and suspicions regarding 'the newcomers' in the village, they are grateful for the water provided by the Buddhists in the area. After seeing the benefit of the well, another borehole was dug outside of the temple as well so that everybody could benefit from it, Buddhist and non-Buddhist alike (Mos 2015).

Finally, In South Africa, Thanissara (2018) said they have been involved in the countries journey through "the pernicious legacy of racism and the impact of a devastating AIDS pandemic. They together with her husband Kittasaro launched a Buddhist non-profit organization, built the Dharmagiri insight Meditation Centre, initiated local welfare projects, and raised 
funds to secure a home for vulnerable children that is run by Sister Abegail Ntleko, author of the memoir Empty Hands and winner of the unsung Hero Award presented by H. H. Dalai Lama in 2009 (Thanissara 2018:1). In, Mozambique, for instance, Vietnamese Buddhist Society presented 300 school bags to poor students which was presented through the Ministry of Education and Culture (Viet Nam News 2017).

\section{Meditation}

For Buddhism, development starts in the mind that is why meditation becomes a very important aspect of its contribution to humanity. Mediation is one of the pinnacles of Buddhism which every practitioner is expected to practice. In Africa this pinnacle has been transferred to the laity who are benefiting a lot especially in the world we live in where stress and depression are on the rise. Thus, "the Buddhist practice of meditation is that of mental cultivation, of penetrating concentration and wisdom (or insight), where the final goal is the attainment of the highest state of disillusionment and enlightenment" (Dwivedi 1994:504). While the mind is used each and every day, very few people have taken time to cultivate a deep understanding of its nature and function. This is where Buddhism comes into the picture, because once one is trained in Buddha's teachings it becomes impossible to understand life in general. Happiness and suffering are seen as states of the mind. For one to be truly free from suffering and enjoy happiness in every moment, it is imperative that they possess a thorough and profound understanding of the mind and how to maintain control over it (Sadhu 2005). Happiness only exists in the mind and so their origins cannot be found outside the mind, in order to achieve permanent happiness and freedom from all suffering, one must achieve a thorough understanding of the mind (Moore 2009). This can only be done through meditation. No one can attain nibbana or salvation without developing the mind through meditation. Any amount of meritorious deeds alone will not lead a person to attain the final goal without the corresponding mental purification. Naturally, the untrained mind is very elusive and persuades people to commit evil and become slaves of their sense. One who knows how to practice meditation will be able to control one's mind when it is misled by the senses (Dhammananda 1993)

Meditation is one great development that Buddhism has brought to Africa where there is emphasis on lay practice and participation. Given that there 
are monastics only in the Pietermaritzburg monastery and the Bronkhorstspruit temple in South Africa, lay participation is clearly a key factor in African Buddhism. Many leading figures do lead a semi-monastic lifestyle but remain lay members who hold down full-time jobs. For instance, the South African Buddhist scene has two main loci: the meditation or retreat centre, often a permanent establishment out in the countryside, but sometimes an urban school or church property rented for the weekend; and the small group of lay meditators meeting in a prominent member's house for an evening meditation session.

In Uganda, they have 15 Buddhist members who regularly attend chanting, dhamma discussions, and meditation training. The number may look insignificant, but in Africa it is not the case, it is a welcome development (Mos 2015). Buddhism teaches compassion and in the case of Botswana, the religion has dedicated its efforts to arrange some group meditations, which are led by elders and from time to time a visiting monk since there is no resident monk in Botswana. Likewise, in Uganda there is the Peace School, which is open to the public on Sundays. The children attend regular school in the morning, and they can come and be introduced to the Dhamma in the afternoon (Mos 2015). There are times when volunteers from other parts of the world pay a visit to the centre where they participate by teaching the children and other members of the community the basics of the English language. It is worth noting that The Dhamma School runs every Sunday subject to the availability of the Chief Monk. However, the centre has experienced some setback due to monetary constraints Venerable Ugandawe Buddharakkitha confirmed. Despite the setback, the centre continues to work hard through collection of some donations and are hopeful that in not a long distant future, the collections will

be used to purchase some sewing machines which will ultimately be given to the poor for self-sustenance. Lastly, The Buddhist University is in the pipeline, Buddhism can be taught to Africans in large numbers (Mos 2015).

\section{Education and Buddhism}

In order to familiarise Buddhism to the Africans, there has been a move in the education setting to address that issue fully. In Malawi, in the Amitofo Care Centre, as Ben Xing (2018:2) asserts that "as part of their curriculum, the children are taught the Chinese language, which will provide them with the future opportunities as trade relations between China and 
Africa continue to grow. "Furthermore, in addition to the curricula the centre provides unique cultural activities and sports for the students. It must be noted that the students are not just offered proficiency in sports but also taught kung fu which is beneficial to their health but also passes as a special skill (Xing 2018). In addition, the local Africans (in this case Malawian) are taught culture, traditions, religion and language from the caregivers and schoolteachers. Botswana, for instance has experienced many changes in the political, economic, social and religious life since 1966. These changes are reflected in the composition of Botswana modern society. Botswana is a pluralistic society as reflected in the constitution that recognises a variety of religious traditions. The Ministry of Education and Skills Development through the Education Act allows Religious Education to be taught in its schools, dating back to the missionaries' era. This shows that the Ministry of Education recognises the importance of religious education as part of a balanced curriculum and its crucial contribution to the spiritual, moral and social development of learners. In recognition of the plurality of Botswana society, the multi-faith Religious Education was introduced in 1996 at Junior Certificate level. The multi faith approach ensured that learners become aware of and are sensitised to a variety of religions in the country. The inclusion of multi faith religious education contributes to interfaith tolerance and understanding. Buddhism forms part of the new curricula. The curricula is consistent with the national philosophy of kagisano (social harmony), the principle of botho and tolerance as emphasised in Vision 2016 and Vision 2036 which state "Batswana will be morally upright and tolerant of one another, irrespective of gender, age, location, religion or creed, ethnic origin, sex, disability, language or political opinion... the principle of Botho will be an anchor that guides our lives, among others, faith based institutions will play a significant role in shaping the morality of our society" (p. 19).

Furthermore, the Constitution of Botswana has always supported the teaching of RE during its inception. The openness of the constitution gave freedom of worship and association, thus safeguarding the rights of all its citizens to practice any religion of their choice. The Constitution clearly states:

Except with his own consent, no person shall be hindered in the enjoyment of his freedom of conscience, and for the purposes of this section the said freedom includes freedom of thought and of religion, freedom to change his religion or belief, and freedom, either alone or in worship, teaching, practice and observance (Republic of Botswana 1966). 
Because of the freedom of worship and with the changing religious landscape of Botswana, there was a need to revisit the RE curriculum which was predominantly Christian studies. This was a move to further display the religious tolerance and dialogue that has always been promoted by the constitution of Botswana. There was benchmarking on the Kedikilwe's Commission of 1993, where a strong recommendation was taken into consideration when the multi faith approach was initiated. There was a task force set up to that effect which mainly comprised of representatives from different religious denominations and traditions in Botswana, for instance, Catholic Church, Pentecostal churches, as well as religious traditions such as Baha'i Faith, Hinduism and Buddhism (Nkomazana and Setume 2016). Although there was a lot of resistance from Batswana before the curriculum inception, later they came to terms with it by allowing it to be introduced and taught to their children.

In order to align to the 1996 Junior Secondary Multi faith syllabus, in 2002, and the multi faith landscape of Botswana, The Department of Theology and Religious Studies (University of Botswana) introduced world religions as part of revamping the BA programme. Initially, the courses on offer were inclined and limited to Christian studies, from reformation to Biblical Studies. However, there was only one course which was called TRS 403: Some World Religions which was offered at level 400. Under this banner, the following religions were introduced, Islam, Hinduism, Buddhism, Baha'i Faith and Judaism. The first four religions were practiced in Botswana and the last one that is Judaism was taught because it was considered as one of the world's major religion. Consequently, it turned out that there was too much content to be covered and digested by the students who were seeing the course for the first time, so there were injustices done for the religion and for the student. As a way of addressing this shortfall, when University of Botswana decided to be at par with other international universities, by adopting a semesterisation process, Department of TRS leapt at the new development and immediately recruited two scholars in Religious Studies. One was a specialist in Islamic Studies, and the other was trained in Indian Religions. These new posts neutralised the already lopsided Christian studies and for the first time, a number of courses were introduced in religious studies where Buddhism formed part of the package. At undergraduate level these courses are as follows:

Level 100 (Semester 1)

TRS 103: Religions of Botswana (Semester 1. Option)

TRS 105: Asian Religions: A Survey (Semester 1: Option) 
Level 300 (Semester 6: Options)

TRS 319: Philosophy of Religion (option)

Level 400 (Semester 7- Core)

TRS 401 New Religious Movement

TRS 402 Religion and Politics

Level 400 (Semester 8)

TRS 424: Buddhism (option)

TRS 428: Religious Pluralism (option) (See Handbook of Theology and Religious Studies (pp16-19)

For Post Graduate, MA (TRS) Programme was revamped and the following courses were offered: TRS 631: Buddhism: Its Essence and Development. TRS 632: Buddhism in Modern World. (Each Course is 3 credits). See Departmental Handbook (p42).

The illustration above is indicative of how Buddhism has contributed to the development of religious education landscape in Botswana, hence its relevance to development in Africa.

Furthermore, the University of Pretoria views Religion as a human phenomenon and has made adjustments in their programme where they incorporated not only the teaching of Biblical but also of Religion Studies where religions / faiths (Buddhism included) have been introduced to students. In order to be aligned to the requirements of the new South African National Curriculum Policy on Education where the emphasis is on religious education which focuses on the general phenomenon of religion and not inclined towards a specific religion only, the University of Pretoria has changed subject Biblical and Religious Studies to Biblical and Religion Studies (code: REL) in 2006. This means the contents of the course now focus not only on the Bible, but also on various other world religions, without alienating the traditional students from the subject. As a result, there is a wide menu for the students to choose from. In this programme world religions are on offer, these include among others, African Traditional Religions, Baha'i, Buddhism, Christianity, Hinduism, Islam and Judaism. It is through the introduction of the multi faith syllabus that students gain valuable knowledge about the different world religions and as a result they become prepared for directing themselves in a diverse religious and cultural environment. Therefore, the subject fits into almost all the programmes at University of Pretoria as an elective subject and students from various disciplines can opt for the course if they want. Similarly, at the University of South Africa, UNISA (University of South Africa), Buddhist studies are on offer from undergraduate up to Doctorate under Religious Studies (Thero 2018). There are also plans to set up a Buddhist university in Uganda in the future so that they can teach more 
of Buddhism thus sharing in an educational setting. A further move that shows there is a future for Buddhism in Africa. Lastly, the University of Kwazulu Natal in South Africa also offers courses from undergraduate to PhD.

\section{Buddhism and the Environment}

If the minds are pure, so is their land. There are not two lands, pure and impure, in themselves. The difference lies solely in the good and evil of our minds. (Japanese monk Nichiren (1222-82)

Joan Anderson (2017:1), rightly points out that "Buddhist philosophy based on respect and concern for all life accords closely with the concept of sustainable development ... it means creating social harmony and equality protecting the environment." As a result "Buddhism itself is essentially about bringing all these elements of life into balance, whether on a personal level or a community or global level. . . life, including the natural environment, for ultimately we ourselves will suffer the consequences" (Anderson 2017:1). Africa has over the years grappled with the issues of environment and the implanting of Buddhism, may be an answer to address these issues head on. The teaching of Buddhism emphasizes a lot on environmental issues where focus is on interconnectedness, or dependent origination, and the oneness of life and its environment. Buddhism in Africa will have to work tirelessly in this endeavour because "Buddhism teaches the oneness of self and environment, the process where the mutually interrelated human life and its environment operate together in a creative way. This means the Buddhist have to take action as a bid to alleviate suffering and create real value in this troubled continent of Africa. Thinassara (2017:3) writes that in the last decade "Africa has gone through a devastating and tragic decimation of its unique and resplendent wildlife through poaching that supplies the demand for illegal wildlife parts and products". Due to this "insatiable and destructive industry, wildlife tracking has grown into highly militarized mafia, dwarfing the teams of park rangers and overwhelming conservation efforts" (Thinassara 2017:3). While many major species are being decimated, the most endangered are rhino and elephants.

The inhuman trade is operated by kingpins from Asia who work in cahoots with vast networks of local and regional groups that bribe the police and government officials and indenture people, while generating a vastly corrupting influence that is changing the fabric of society in the region. 
The global wildlife crises have erupted from this crisis resulting in the annihilation of the lion, elephant, tiger, rhino and other numerous rare species. Further, South African stiffer penalties have been enforced in order to curb the trade in animal products such as trinkets, fashion accessories of other articles that include crocodile, alligator, python and other animal skins, fur or bone. Once the Buddhist teaching is adopted, Africans will see beyond human-centric perspective and come to an understanding that humans are dependent on the environment. The year 2015 saw Botswana, banning hunting as a way of conservation and preservation of her wildlife. This was after the much-publicized killing of Cecil the lion by Walter Palmer. Even though the incident took place in Zimbabwe, it influenced developments in Botswana. On a positive note, in Botswana there has been an initiative to train and tame the African elephants. These can be used during Buddhist rituals, especially as a pinnacle around the pagoda during the temple celebrations. This elephant training was the initiative of Mr Uttum Corea and Mrs Dinky Corea who established the Buddhist centre in Gaborone north in Botswana. The main drive behind the elephant training was to merely promote their preservation after being saved from culling operation.

\section{Conclusion}

This chapter has demonstrated that Buddhism, a long-standing Indian religion, but relatively new on the African soil, has a lot to offer to the Africans. It further demonstrates the ground the religion has covered in developing Africans, be it socially and economically. Although the religion might not be as popular as its counterparts because of lack of proselytising and not believing in God as the ultimate truth, celibacy and others, given the chance, there is a lot that Africans can benefit from it, hence it is a welcome development. Meditation, which has been a crowd puller in the West, can equally benefit Africans especially with the social challenges faced by an average African on a day to day basis. Due to the developments put in place by Buddhism, for instance addressing the issue of water shortages, poverty and other challenges, Africans are slowly warming up to the religion and a steady growth in their numbers growing is slowly being realised. It is a matter of time that the benefits of Buddhism on the African soil reach full potential. 


\section{References}

Anderson, Joan (2017) SGI and Enviromental Care: Nurturing Boddhissatva who will help save the Planet. @: https://www.buddhistdoor.net/features/sgi and environ mental care nurturing boddhisattva who will help save the planet. [07. 02. 2018]

Beckerlegge, G. (2001) The World Religions Reader. London: Routledge,

Bhiksu, K. (---) Do Buddhist Believe in God (A talk given at high school in LA) @: http://www.buddhamountain. ca/Do Buddhists believe in God php. [08. 10. 2018]

Clasquin, M. (1999) (ed.) Buddhism in Africa. South Africa: Unisa Pr.

Constitution of the Republic of Botswana. Gaborone: Government Printer.

Dhammananda, K. J. (1993) What the Buddhist Believe. Taipei: CBBE.

Diamond Way, Karma Kargu lineage @: http://www.buddhismsouthafrica.org/en/buddhism/ [04. 02. 2018]

Dumoulin, H. (2005) Zen Buddhism: A History. Trnls. Heising James, W., \& Knitter P. World Wisdom Inc. www.google. books.com.

Dwivedi, K. N. (1994) "Mental Cultivation (Meditation) in Buddhism," Psychiatric Bulletin 18:503-504.

Harvey, P. (2013) An Introduction to Buddhism: Teachings, History and Practices, $2^{\text {nd }}$ Ed. Cambridge: CUP.

Jackson, R. J. (1941) Buddhism and God. Sri Lanka: Buddhist Publication Society.

Keown D. (2013). Buddhism: A Short Introduction. UK: Oxford Pr.

Lee Penn, (2004). Religion. @: https://books. google.co.bw/books?isbn=159731000X. [01. 02. 2018]

Loon, V. L. (1999). Buddhism in South Africa: Its History, Present Status and Likely Furture, in Clasquin, M. (ed.) Buddhism in Africa. Unisa Pr.

Mbiti, J. S. (1970) Concepts of God in Africa. Praeger Publ.

Mbiti, J. S. (1973) Love and Marriage in Africa. England: Longman.

Mbiti, J. S., (1990) African Religion and Philosophy. Norfolk: Biddles.

Moore, A, (2009) Meditation. NY: The Rosen Publ. Group.

Mos Sean, (2015). A new: The Birth OF Buddhism in Uganda, @: http://www.buddhist door.net/features/a new wave the birth of Buddhism in Uganda.

Most Buddhist Nations (2010) - "QuickLists - The Association of Religion Data Archives". [13. 03. 2018]

Most Chinese University Nations (2010) - "QuickLists - The Association of Religion Data Archives". [13. 03. 2018]

Nkomazana, F. \& Setume, S. (2016). The Development of Religious Education Curriculum on Moral Values in Botswana since 1966. Botswana Notes a Records, 48 (1].

Sadhu, M. (2005) Meditation: An Outline for Practical Study. UK: Aeon Book.

Schireson, G. (2009). Zen Women beyond Tea Ladies, Iron Maidens and Macho Mistress. Boston: Wisdom.

Stevens, John (1990) Lust for Enlightenment: Buddhism and Sex. Mass.: Shambala.

Thanissara (2017) Wildlife on the Brink. Buddhistdoor @:

https//www.buddhistdoor.net/features/ wildlife-on-the-brink. [07. 02. 2018] 
Theology and Religious Studies Departmental Handbook. Univ. of Botswana: Gaborone. Thero, P. (2018) Development in Africa: Buddhism in Africa: Planting of the Dhamma Seed. @: http://dharma. lib.net/how is Buddhism spreading in Africa. [12.01. 2018]

Univ. of Pretoria @: http://www.up.ac.za/biblical religion studies. [2. 05. 2018]

Vietnamese Buddhism Introduced in Africa @: http://tgvn.com.vn/vietnamese Buddhism introduced in africa-59761.html. [10. 01. 2018]

Vision 2016 A Long Term vision for Botswana. Prepared by Presidential Task Team. Gaborone: Government Printers.

Vision 2036 Achieving Prosperity for All. Prepared by Presidential Task, July 2016. Gaborone: Lentswe La Lesedi (PTY).

Xing, B. Status Report from the Amitofo Care Center in Malawi, Buddhistdoor Global @: https://www.buddhistdoor.net/news/status report from the amitofa care in Malawi [07. 02. 2018] 


\title{
Religion and Economic Justice: Jewish Migrants and the Making of Zambia
}

\author{
Telling "the Forgotten Story"
}

Lilian C. Siwila, Nelly Mwale, Chita Joseph Chita

\section{Introduction}

The Jews did not need to wait to contribute to the development of a country now known as Zambia. At the time when the country was beginning to develop economically, Jews were among the settlers that came from different parts of the world seeking opportunities for economic development, and out of that quest, Jews were among the settlers that laid the foundation for economic development in the country. Most of the scholarship on religion and development in Zambia has focused on Christianity and Islam as the two world religions that have made a contribution to the economic development in Zambia, neglecting Judaism which is not only one of the earliest religions to come to Zambia, but also an important religion in the economic development of the country. This observation is not only peculiar to Zambia, Chitando (2005) also laments the neglect of the recognition of the Jews and Judaism as a religion in Zimbabwe. Macmillan and Shapiro (1999) note that Judaism was among the pioneering religions that entered 'Zambia' driven by their desire to trade and make a living. The authors outline a number of Jewish families and Rabbis who established themselves in cities such as Lusaka, Livingstone and Kabwe in the early years of the country's development. It is such a scenario of neglect that prompts reflections like that of Tutton (2012) when he titles his CNN documentary, the 'Forgotten Story of Zambia's Jewish settlers'. A story that not only carries religious significance, but also economic history that need to be re-told.

This chapter reflects on the role of Jewish migrants in the economic development of Zambia in the period between 1900 and the 1960s. The chapter hopes to demonstrate how Jews contributed to the economic development of Zambia. "Making Zambia" in this study is spoken of in terms of contributing to what became of the country before and after independence in different spheres of development. The making of Zambia 
is seen through the religious capital injected by the Jews. When we refer to the Jews, we are cognisant of the existing debates on who Jews are with reference to Jews of no religion and Jews by religion (Keysar 2010). We, therefore, broadly refer to Jews as all those who could have assumed that identity by birth, origin, marriage, confession et cetera (De Lange 2000) and formed the Zambian Jewish community. This Jewish tag attracts a religious identity among other concepts with a religious connotation. Hence, in the Zambian context, we speak of Jews as adherents of Judaism given that the Jewish migrants who came to Zambia were followers of Judaism. For the sake of this chapter, we will draw on the experiences of people with that identity to mirror their contribution in the growth and development of present-day Zambia.

A historical case study approach was adopted in the study owing to the nature of the inquiry. Cognisant of the often neglected and ignored use of document review in favour of methods in which researchers are actively involved in producing data for their own purposes (McCulloch 2004; Ahmed 2010), the study employed document review as the main method of collecting data. As such, various archival sources of Jewish history and activities in the then Northern Rhodesia (which we will henceforth simply refer to as Zambia) were analysed in an effort to utilise the rich data in documentary research.

\section{Methodology}

The Jewish migrants whose contributions informed this chapter were purposively chosen, and hence the population of Jews that are referred to in this work was restricted to those whose works and contributions left a footprint in the growth and development of the country. A thematic approach to organizing, relating and interpreting data as it related to religion and development was employed. The study covered the period of the Jews' first arrival in the country to the 1960 s, because after the 1960 s, the population of the Jews began to dwindle due to numerous reasons, some of which will be referred to in the chapter.

Few notable studies on the Jews in Zambia have focused on their history, such as the prominent work of Macmillan and Shapiro (1999) who provided a comprehensive history of the Jews in Zambia and Warongker (2010) who studied the Jews in Zambia with reference to the architectural remnants of Jewish life in the country. Other accounts of the Jews in Zam- 
bia have been provided by Zukas (2002) and Ehrlich (2009) who gave insights on the evolution and dynamics of the Jewish diaspora as it played out around the world. While acknowledging the contributions of the Jews in fostering the development agenda in the places where they settled, the driving force behind the success of the Jews has been tied to their nonmonetary capital and not religion. For example, Macmillan \& Shapiro (2007:39) argue that what the Jews had in common was not so much a similar creed for them to flourish as a solidarity coming from tight-knit families and shared membership in a minority ethnic group.

We assert that the solidarity exhibited in family networks is part of the broader religious capital (a concept we apply in its initial usage as will be shown in the subsequent sections) which the Jewish community had at their disposal. As such, contrary to the perceptions that detach the religious identity of the Jews in their contributions to the development of Zambia, we contend that religion was (a) significant capital which fostered Jewish developmental activities in the country. In this way, the religious capital embodied by the Jews contributed to making 'Zambia.' We argue that their religious identity, skills, work ethic, family networks and financial resources formed the necessary capital which was injected into various activities, which not only left a footprint in the development of the country, but also enriched the influence of religion on the country's development process.

The chapter proceeds by linking religion and development from a Jewish perspective and delves into a background that provides a context in order to mirror development in the life of Jews in Zambia. This is achieved by way of highlighting who the Jews were and are, tracing their footprints in Zambia and analysing their role in its making, though sparingly.

\section{Linking Religion and Development from a Jewish Perspective}

This chapter uses the concept of religious capital to link religion and development from the activities of the Jews in Zambia. Acknowledging that the concept of religious capital has been revisited over time ${ }^{1}$, we adopt the original understanding, which relates to the skills and experiences specific to one's religion including religious knowledge, familiarity with ritual and doctrine and friendliness with fellow worshippers (Iannaccone 1990). The

1 Religious capital as a concept was initially used to explain people's religious beliefs and behaviours (Iannaccone \& Klick, 1993: 6). 
concept of religious capital has also been used mostly to explain religious commitment and organisational change at the individual and household levels (Finke 2003; Iannaccone \& Klick 2003) and measured in ways similar to human capital - years of experience, and levels of knowledge and skills (Iannaccone \& Klick 1993:6).

While adopting the initial usage of the concept of religious capital, we acknowledge that religious capital is closely linked to Smart's widely used seven dimensions of religion (1989) and Ter Haar \& Ellis's (2006) conceptualization of religious resource. Smart suggested a framework for understanding religion that identifies seven possible dimensions of religion (practical/ritual, experiential/emotional, narrative/mythic, doctrinal/philosophical, ethical/legal, social/institutional and material dimensions), which may be emphasized differently across different religions. It is these dimensions of religion that relate to religious capital, which Ter Haar \& Ellis (2006) speak of as the religious resource. They note that religious resources produce knowledge that could be beneficial to a community for development purposes. These include religious ideas (what people actually believe), religious practices (ritual behaviour), religious organisation (how religious communities are formed and function), and religious - or spiritual - experiences (such as the subjective experience of inner change or transformation) (Ter Haar 2005:22-7).

Thus, by using religious capital, we sought to show how all the activities and successes of the Jews in creating Zambia could not be detached from their use of skills and experiences specific to their religion in addition to religious knowledge, familiarity with doctrine and friendliness with fellow Jews given that Judaism permeates all spheres of life.

We are also linking development to the 'making' of Zambia. This is based on the understanding that development relates to the efforts which were made by the Jews in initiating the process of change or a new stage in changing a situation. Development was also associated with laying the foundation for the process of change, or that, which constitutes a new stage in a changing situation (Sen 1988).

\section{Historical Background of Jews in Zambia}

In 1890, what is today known as Zambia (then Northern Rhodesia) came under the control of the British South Africa Company (BSAC) whose administration lasted until 1924 when it handed over the territory to the British Colonial Office (Roberts 1976). The BSA Company administration had 
replaced the various chiefdoms as a unified state from 1890. The BSA Company era was also characterized by Christian missionary presence who came into the territory to spread the Christian faith. The Christian missionaries were welcomed and encouraged to establish themselves in Northern Rhodesia (Snelson 1974:121; Gadsden 1972:98). The end of BSA Company rule set the process in motion by which Northern Rhodesia was changed from a traditional to a 'modern' realm.

From $1^{\text {st }}$ April 1924, the British Colonial Office took over administration from the BSA Company. Unlike the BSA Company state, the British colonial state administration was more elaborate in which the British Colonial Office in London was the Governor of Northern Rhodesia and was assisted by the Secretary of State at the capital (Chipungu 1992). Perhaps the colonial era has been known for the colour bar, exclusion of Africans from politics and the quest for independence including the Lenshina uprising (movement) and chachacha (civil disobedience) movement (Phiri 2006; Komakoma 2003). All this culminated in Northern Rhodesia attaining independence in 1964.

The different groups, which have ruled the country show that Zambia was, since inception, a nation of migrants. By this, it embraced various groups of people who included: The Bantu-migrants, Missionaries, Colonialists, Jews, Asians, and others (Taylor 2006). Of these migrants, our interest is in the Jews who before coming to Zambia were shaped by different religious experiences, which imprinted an identity on them. Thus, at the time when Jewish presence was being reported in the territory, the then Northern Rhodesia was divided into North-Western and North-Eastern Rhodesia, with two capitals, Kalomo (though later moved to Livingstone) and Chipata.

The Jews who settled in Zambia are described to have arrived in two main waves. The Jews first came to Zambia in the late 1880s seeking economic prosperity by way of looking for a place where they could make a better living (Shapiro 2001).

The Jewish settlers were, therefore, among the first Europeans to come in the country. According to MacMillan \& Shapiro (2017), Jan Africa was the first person of Jewish identity to cross into Zambia. He was a Jew by descent, like many that we will refer to. Many of the first Jewish immigrants came from mostly German-speaking areas of Western Europe (Lithuania and Latvia) (Zukas 2002). Lithuanian Jews in particular migrated to South Africa during the diamond and gold rushes at the end of the $19^{\text {th }}$ century, 
but some pioneers ventured further afield and the ones who got to Northern Rhodesia early on were the most adventurous (MacMillan and Shapiro 1999). The majority were economic refugees running away from anti-Semitism and extermination; in the process some sought peaceful lives, reunions with scattered families and founding new ones (Macmillan \& Shapiro 1999). By 1921, 110 Jews lived in Northern Rhodesia.

By the 1930s, there were hundreds of Jews living in Zambia and the rise of the Nazis in Europe brought a new wave of Jewish immigration. In 1938 and 1939 around 300 German Jews fleeing Nazi persecution found their way to Northern Rhodesia, as did smaller numbers of Jews from Lithuania and Latvia (Zukas 2002). While the first wave of Jewish migrants was sparked off by economic reasons, the Jews who later came to Zambia were both economic migrants and refugees, escaping from a kind of religious and political persecution. These Jewish immigrants arrived in the country following the World War II. Northern Rhodesia was a potential refugee haven during World War II because it had no immigration restrictions and was constitutionally under the authority of Britain. In addition, the British Colonial Office was fully aware of its potential and seriously considered plans for fairly large-scale Jewish settlement (Ehrlich 2009). The population peaked at 1, 200 in the mid-1950s by which time the centre of Jewish life had shifted to Lusaka, and the Copperbelt centre of the country. The Jewish presence resulted in the establishment of synagogues and other Jewish institutions (Warongker 2010). For instance, the first synagogue was built in 1928 in Livingstone and others more than a decade later in Lusaka and Copperbelt cities.

The Jewish community thrived until the first half of the $20^{\text {th }}$ century when the political and economic situation began to change in the wake of the 1960s struggle for independence. During this time, the number of Jews, which had remained steady for some decades, began to decline further (Zukas 2002). During the 1960s, much of the Jewish population emigrated abroad; by 1968, the Jewish community had declined to 600 people (Jewish Virtual Library). There are now fewer than 50 Jews left in Zambia, reflecting that the Jews have been part of the country from the 1900s to the present, and contributing to making Zambia in many ways. As MacMillan \& Shapiro (1999) note, though small in number, the Jewish community has shaped the country's history in many ways. 


\section{Jewish Hands in Making Zambia}

In a bid to map out how the Jews fostered the creation of Zambia, some of the activities in which they invested their religious capital in different spheres were explored. These spheres are broadly centred on the business enterprise, and civic and local government engagement. The categories which have been used are for purposes of exemplification, although Jewish contributions cut across spheres.

\section{Commerce and Trade}

The most prominent ways in which the Jews contributed to making Zambia was through the promotion and development of commerce and trade. For example, the pioneer Jew, Jan and his associates, explored the rubber frontiers in North-Eastern Rhodesia, while on the North-Western end, the first group to arrive in 1900 and 1901 were interested in cattle trade around the Barotseland. Prominent among the cattle traders were the Susman brothers (Elie and Harry) who grew their business in the region. For these brothers and other Jews, business had no boundaries (Ehrilch 2009). The Susman brothers were "remarkable not only for their role as pioneers of the cattle trade, but for their long-term commitment to trade, agriculture and industry in the country, as well as for their significant contribution to the development of the economies in Southern and Northern Rhodesia" (MacMillan \& Shapiro 2017:15).

The latter group (cattle traders) introduced cross border trade. They bought animals from Barotseland and supplied Southern Rhodesia among other neighbouring countries (Bhana 2000:1864). In this business, cattle were exchanged (bartered) for other goods like gold before new means of transactions were introduced. When the money economy was introduced, it was the Jews who played an important role in this development (MacMillan \& Shapiro 2017:41). As a result of such interactions, and good business atmosphere in the regions, many more Jewish traders conquered other frontiers of Northern Rhodesia, setting up stores, shops, and butcheries, among other businesses that we will cite later. Worth noting is the fact that the Jewish traders spread their economic activities to both rural and urban areas. One major reason for the traders' success in business among the locals was their willingness to break language and racial barriers. They became so familiar with the African way of life, capable of 
adapting, just to win favours with the general populace involved in business. Consequently, the Jewish traders came to be associated with fair trade, principled trading, and well-financed businesses.

Jewish involvement in commerce and trade was also closely related to the development of agriculture. Though cattle trade took centre stage among Jewish traders, they had also diversified into other subsidiary enterprises such as agriculture (ranching and butchery). Farming and ranching supported the cattle business in the advent of competition from new arrivals (businessmen), while butcheries were meeting the needs of the local market (feeding the locals, settlers, and the upcoming industries (mines) in the country).

\section{Transport, Hospitality and Tourism}

The growth of commerce and trade sparked off the need for developed transportation network. Elie and Harry Susman were the first to develop large-scale wagon and river transport. Thus, some Jews took up the transport contracts to ferry goods to different places. Suffice to say, these traders, settler farmers, and mining companies opened up means of communication especially with the establishment of the line of rail (Shapiro 2001). This development saw the growth of towns, spread of stores and commerce. Other than transportation of goods, Joe Furmanowsky started the first taxi business (1930s) in Livingstone to ferry tourists and guests within the town. Apart from Joe's enterprise in transport, his colleagues, Zemack and Zlotnik introduced the public bus services on the Copperbelt and in the Northern part (serving Mansa and Kasama) of the country respectively (MacMillan \& Shapiro 2017:94 \& 131). Joe's wife complemented the husband's business with hospitality services, offering boarding and restaurant services. In the like manner, the Wassersons also ran a tearoom and curio shop to cater for the same tourists.

The initiatives in communication through transport were also characterised by the development of newspapers. In this regard, the Jews introduced the advertising platforms - the newspapers. Leopold Moore founded Livingstone mail in 1906 the same period as Livingstone Pioneer and Advertiser were born. In 1920 the first airmail service was setup by Jim Trout (Macmillan \& Shapiro 1999). The 1940s saw the coming on board of the country's first commercial airline, after the Gersh's acquisition of shares in the Thatcher Hobson Airways, which later merged with Central African Airways (MacMillan \& Shapiro 2017:152). 


\section{Modern settlements and Social amenities}

The Jews also injected their efforts in the development of modern settlements and the associated social amenities. For example, some names were behind the founding and establishment of modern settlements in the country such as Livingstone and Lusaka. Livingstone, as the country's first town was laid out in 1905. Abraham Gelman 'was one of the Jewish founders... he was literally a builder of the new town, he was a brick maker' (MacMillan \& Shapiro 2017:44). Livingstone also witnessed the establishment of the first watchmaking and jeweller shop setup by Max Shapiro in 1908 , where he remained for over fifty years and celebrated his golden wedding anniversary there in 1954 .

Other than Livingstone, Lusaka was another major town founded in 1909 by Jewish traders. Behind the establishment of this commercial and agricultural town were two names, Benjamin Glasser, and Edward Kollenberg. The two families of the Glasser and Kollenberg initiated the investments in the new town of Lusaka by opening up a bakery and dairy shop. The latter enterprises saw the modernisation in marketing and branding of products. Macmillan \& Shapiro (2017:57) note that Glasser's wife, Frieda was the first businesswoman 'to produce and sell a bottle of milk and loaf of bread in Lusaka... and the inspiration of this enterprise was the need to feed her own children. ' Like the Glasser family, the Kollenberg too invested in a store and pioneered in establishing a milling company in the 1930s. With the growing population of children of the migrants, there was demand for a school and Benjamin spearheaded the initiative of opening an English Medium School in Lusaka (Shapiro 2001).

In addition to these families (Glassers and Kollenbergs) who helped to open up Lusaka, there were other families such as the Lipowskys, Susmans and Diamonds. Lipowskys registered their Lusaka Trading Company in 1912, while the Susman brothers invested in farming and ranching after buying a 25,000 acres piece of land in Leopard Hills area in 1912 and Kabulonga farms in the 1920s, where they stocked and bred pedigree bulls and cattle for cross border markets and produced crops like tobacco and wheat (Susman 2004). Some of these businesses and investments introduced modern technologies that accompanied various enterprises (Zukas 2002). For instance, the use of reaping machines, extraction processes of fertilizer, breeding of cattle, and introduction of new packaging of agricultural products, were all innovations which contributed to the 'making' of Zambia. 
Towards the end of the 1920s, David Shapiro had also arrived in Lusaka, bought a farm from the Susman brothers and invested in tile and brick factory to supply the construction projects of the new town - Lusaka. David and other businessmen were in the forefront of the construction sector at the time (Shapiro 2002). According to historical accounts, these projects saw the construction of modern structures - first storey buildings and the development of shopping arcades along the main road-Cairo (Macmillan \& Shapiro 1999). Alongside erecting shopping 'malls', David's company rented and sold structures that led to the spread and growth of trading areas in the city. He also bought structures from others, for instance he got the cinema from Sam Wolpowitz.

The area around Lusaka was not left untouched by Jews, as the Diamonds founded Diamondale Farms near Ngwerere River and also inaugurated the first motor garage (1920) in Lusaka. Like it was the case in Livingstone when Gertrude set up hers, Diamond's son (Victor Solomon) too ventured in the same business under the name Central Garage. Victor traded in Chevrolet cars and Triumph and Douglas motorcycles between 1920-30s (MacMillan \& Shapiro 1999).

Other Jewish names that setup businesses and traded in Lusaka and contributed to its growth included Rosenfields, Albermans, and Fischers. Associated with these late entry families were businesses such as Cafés, furniture shops, agencies (clearing), firearms trading and subsidiary stores (ZCBC Ltd) in Lusaka urban and rural (Zukas 2002; Shapiro 2002). This was so because they were pioneers in opening up regional distribution centres of their businesses thus playing a role in laying the foundations for would be modern towns.

The Jews were active in both infrastructure and land developments, and remnants of their architectural works were a landmark to real estate (Waronker 2010). This can be summed up in the following sentiment made by MacMillan and Shapiro (2017:69):

The town centers of Livingstone, Lusaka and Kabwe still owe many of their architectural features - their shop fronts and their distinctive and strangely attractive, urban characteristics, to their now largely forgotten... Jewish builders.

Although many of the structures have been defaced, renovated and even brought down to pave way for 'new' structures, by the late 1990s one could still find traces of the original structures that had a Jewish history attached to them. 
In addition, the Jews also introduced the entertainment industry - to take care of the social welfare of the townships. For example, Marcus Grill, his son and daughter introduced the first social centres in Livingstone when they set up a cinema in 1919, seconded by another one in 1931. Ehrlich (2009:517) notes that Marcus Grill, who was related to the Sossen and Susman families, was a pioneer trader, hotelier and the first cinema operator in Northern Rhodesia. Gertrude Grill was the lady behind the second cinema - the Capital theatre and happened to have been the first modern businesswoman to open the first car garage and motor works followed by a furniture factory (MacMillan and Shapiro 1999). Others from the same family line who were enterprising were Harry and Hymie Grill who ran the Public Services Association's Store (PSA) and a mineral water factory.

\section{Mining}

In addition to their efforts in setting up towns, the Jews invested their religious capital in mining. Thus in 1908, some Jews were reported to have also ventured into mineral exploration in Northern and Southern Rhodesia. For instance, Elie and Harry Susman, who arrived in 1900, secured the Nkana copper mine which they later sold and is now the largest copper mine in Zambia (MacMillan 2005). Sir Edmund Davis, Solly Joe and Sir Ernest Oppenheimer were also prominent in developing copper mining (Ehrlich 2009). Apart from being proprietors and shareholders of the mines, they also recruited the locals who were to work in these industries, thus opening up the labour market that come with these developments.

The locals grabbed this opportunity and migrated where labour was most wanted (Susman 2004). For instance, some worked with Jewish cattle traders to drive animals to different places, others worked on the line of rail project and farms just to mention a few. The shopkeeper job was reserved for Jews-especially the new entrants, the youths, children and siblings - family ties, a manifestation of how the Jews used their religious capital anchored on doctrines and the ethical code.

\section{Civic and political sector}

The Jews were also active in local government. For example, as early as the 1930s, Sir Roy Welensky was the leading political figure in Northern 
Rhodesia from the 1930s to the 1960s and served as prime minister of the Federation of Rhodesia and Nyasaland between 1956 and 1963 (Ehrlich 2009:517). Jews were also mayors in different towns (Livingstone, Broken Hill (Kabwe), Kitwe and Luanshya) due to their influence and presence.

On the Copperbelt, the Jewish presence was vivid in the different roles that they assumed in various portfolios. To start with, the first governor in the province was reported to have been Sir Herbert James Stanley. Others penetrated the public offices as members of the Legislative Councils of various districts on the Copperbelt. For instance, in Ndola the portfolio was once occupied by Kennedy Harris, Abel Loventhal and between 19371939 Hyam Schulman superintended over the municipality (as first mayor, supported by his wife who also assumed membership to the Town Council management), followed by Jim Trout.

Maurice Rosen, Harry Rayner, and Dennis Figov (1963-4, Mayor two terms) also served as members of the Township management board in Luanshya (Ehrlich 2009). Due to his dedication and long stay in the township, the latter became a member and branch treasurer of the ruling postindependence party- United National Independent Party (UNIP) (Zukas 2002).

Another township on the Copperbelt in which Jews actively participated in administration was Chingola, where Menashe and Israel took up responsibilities in the town's commerce and trade organization and Municipal Council respectively. Uri Illion served as a member of the Mufulira town management board.

Over time, Jews continued to play a significant role in the public across towns. By 1951-52, Livingstone recorded another Mayorship in the name of Maurice Rabb who occupied the same portfolio twice (1956-57) before Alex Shutzkin took over in 1958-1959 ${ }^{1}$. Alex was described as a dedicated public worker. Almost around the same time, Sam Fischer became a member of the Township Board Management Board (1956-59) in Lusaka before becoming the first Mayor in 1960-1. From 1962 to 1968, S. W. Magnus was a prominent member of the Zambian parliament. After 1968, Magnus was appointed a high court judge (Shapiro 2001).

1 From 1959 to 1962 , M. G. Rabb was elected to the national legislative assembly. 


\section{Critical voice -advocacy}

In many instances, Jews spoke against oppressive regulation and policies and from the onset Jews worked against commercial segregation by setting up such stores that did not exclude any group of people. Moss is cited as one who did not entertain racist talks, 'he insisted that black people should be treated with respect' (MacMillan \& Shapiro 2017:74). In later years, Abel Loventhal fought on behalf of the Africans for better housing and electrification of compounds on the Copperbelt with specific reference to Ndola Township.

Another Jew whose role on the Northern Rhodesian Education Advisory Board was pro-African was Peggy Rabb. She served on this board for many years (8), championing and promoting African education. Her passion and interest in African affairs made her protest and resign from her portfolio after noticing unfair policies that promoted segregation in the federation. A member of the same family, Maurice Rabb, was 'critical of the Federation, he felt that the policy of partnership had continued to subordinate Africans and that the Federation was run in the interest of Southern Rhodesia' (MacMillan \& Shapiro 2017:232).

The critical voice also enabled some of them to contribute to the fight against the federation and support the independence struggle, examples of such personalities that had liberal tendencies included Wulfsohns, Iljons, Radunski and Figov, said to have been 'sympathetic to the African nationalist movement and gave moral and financial help to it ...' (MacMillan \& Shapiro 2017:180). It can, therefore, be said that though they advocated fair play in certain instances, in other circumstances they did it to benefit their businesses. For example, when they assumed leadership positions in the Chamber of commerce and trade (Elias Koplowitz-Livingstone), they used the organisation in various towns to further their business interests.

\section{Towards an Explanatory account of the Jewish role in making Zambia}

The examples of the cited involvement of the Jews in different spheres point to how the Jews contributed to the creation of the nation. This involvement can be explained in different ways. When viewed through the prism of religious capital, the work of the Jews mirrors how the Jews used their religious capital towards the creation of Zambia, though not to sug- 
gest that they never erred. For example, some of the Jews directly and indirectly contributed to the consolidation and dislodging of colonial rule though by far, the good change dominated their shortcomings in the public sphere. As we argue in this chapter, any explanation of Jewish contributions to the creation of Zambia cannot be detached from the religious factor.

The driving force behind the Jewish contributions to development in Zambia were anchored in their religious beliefs which provided the religious capital because religion for the Jews permeates all spheres of life. To start with, Judaism as a community faith was manifested in the establishment of synagogues which were the nurseries for networks and partnerships. From their first arrival, the Jews established synagogues in different parts of the country. For example, the Livingstone congregation that was established in 1910 constructed a synagogue around 1927-28. In addition to the sanctuary, the community also built two small structures used for a Jewish school, social hall, and rabbi's house. By the late 1940s, some one hundred Jews were members of the synagogue. Other such facilities were built in Lusaka and the Copperbelt. While these synagogues were spaces for worship, they cemented the communal bonds among the Jewish community in Zambia, an attribute that was manifested in the networks which facilitated the developmental projects which the Jews embarked on.

The belief on the Jewish people's relationship with God as a chosen people was another element that ignited their religious capital. Jews believe that God appointed them to be God's chosen people so as to set an example of holiness and ethical behaviour to the world (Parrinder 1974:149). As "a chosen people," they turned the circumstances of their history into opportunities in numerous ways. For example, while described as a scattered people owing to their history of migration (De Lange 2000:1), from the time of the first Exile, the essence of Judaism was derived from stories of the book of Exodus. Hence Attali (2003:13) argues that 'Judaism begins in travel' and that the law which was given to Moses became the moral framework for any activity. Thus, the great masses of Jews scattered in history and settled in Germany and France, Italy and England, the Near East and far West, Holland, Austria, Eastern Asia, South Africa and other parts of the world as migrants.

As earlier alluded to, the Jews who came to Zambia were also migrants. For example, Macmillan \& Shapiro (2017) note that the Jews came to northern Rhodesia not for family, but to open up trading stations. By this, 
Jewish wholesalers in Bulawayo assisted their relatives and countrymen by giving them goods and oxen so that they could go to the new territory to open shops at railway stations and sidings (Shapiro 2001). With this opportunity of networks on their side, the Jews in the country were able to contribute to the creation of Zambia as guided by their religious teachings. For example, the assistance rendered to relatives and countrymen above finds an explanation in the value of family and human relationships in Judaism. Fel \& Zdun (2014:89) note that the Talmud teaches that the person whose wealth is pleasing to Yahweh, is also called to the fight against poverty, teaching that entails the obligation to do acts of charity for the members of the community so that the rich do not live for themselves, but rather strive to bring their brothers to a higher economic level. Hence the high level of motivation derived from their status as economic, religious or political refugees with no home to which they could easily return, and their membership of kinship networks functioned as channels for recruitment, credit supplies and commercial information (MacMillan \& Shapiro 2017). Sombart (2001) also notes that in truth, the Jew never carried on business as an isolated individual, but always as a member of the most extended trading company in the world.

Furthermore, their willingness to move from place to place was underpinned by their teaching on wealth; hence they were able to inject their religious capital in development. Fel \& Zdun (2014) note that just as money journeys, the Jewish person is constantly ready to abandon his or her present location. As Bourdieu (1984) noted in coining the term cultural capital to identify the investments that culture represents to each individual, people ideally resist migrating or emigrating, not only to protect social capital, but also to protect their cultural capital. When Stark \& Finke (2003) applied cultural capital to religious capital, they argued that in making religious choices, people will attempt to conserve their religious capital (Stark \& Finke 2000:121). In the case of the Jews in Zambia, they conserved their religious capital by migrating to new contexts and the resulting experience inspired them to work hard to make a living in the new settlement, which in turn had an impact towards making Zambia, not only as God's chosen people but as people who lived out their faith.

The Jewish pursuit for wealth and their consequent involvement in the creation of Zambia further found resonance with the teaching on wealth in Judaism. The Talmud argues that wealth is pleasing to God and that God gave man the earth, so as to derive profit from it. Hence, money can become an instrument, which can serve God; by bringing the sacred order 
into the profane (Attali 2003:87). It is, therefore, probable that Jews in Zambia tapped into their quest for wealth as guided by their religious teachings, which enabled them to be entrepreneurial in different spheres. This explains why with all the opportunities within their religion at their disposal which strengthened their wealth base, the Jewish community in Zambia was able to finance projects and businesses in the territory. For example, the Jewish company financed the development of Kitwe as a township. This was when from the 1930s; there was pressure from government for the opening of a public township which would not be on mine property. In short, they financed numerous projects out of their investments, a clear demonstration of Judaism's teaching on wealth for serving others.

The belief in the moral law could also not be detached from the contributions of the Jews in Zambia. It must be noted that Jewish law embraces practically all domains of Jewish life, and thus it becomes the principal means by which Judaism brings about the reign of God on earth (Fel \& Zdun 2014). As such, Jewish law is a total guide to religious and ethical conduct. For example, it covers both ritual (celebrating holidays, keeping the dietary laws, observing the Sabbath) and ethics (the proper treatment of strangers, neighbours, relatives, the poor, the elderly, the powerless). This explains how and why the Jews in Zambia sided with the oppressed and the poor. Thus, while by virtue of being migrants, the Jews in Zambia were strangers in the sense of being newcomers, they allowed their religion to guide their undertakings in the new land. Kaplan (1986) points out that the Jews knew to live on nothing as strangers. The acknowledgment that the Jews from the frontiers brought with them very little capital in the form of goods or money, but rather a good deal of non-material capital (Herbert 2001) attests to this. As strangers themselves, they were guided by their religious ethical dimensions on how to treat strangers, neighbours, poor and the powerless. Judaism's emphasis on charity further explains why in other instances, the Jews in Zambia contributed to infrastructure development that benefited the general populace. For example, some Jews were philanthropists such as Koplowitz who supported the Catholic convent and girls' school in Livingstone (MacMillan \& Shapiro 2017:49).

The ethical element among the Jewish community was also mirrored in not only how they carried out their activities, but also in the advocacy role they played. For example, as civic officials, they worked at improving the 
social amenities for the local populations in the colonial context, advocated for the welfare of the black people and fought against discriminating laws. Moss Dobkins was among those who 'insisted that black people should be treated with respect' (MacMillan \& Shapiro 2017:74). As Sombart (2001) notes, religion for the Jews, permeates all national life and not an affair of Sabbaths and holy days as it touches everyday life even in its minutest action and regulates all human activities. Judaism insists on living the faith to the point that almost everything a Jewish person does becomes an act of worship. This entails that holiness is brought into everything that the Jews do, as their actions are acts of praising and honouring everything God has done.

Above all, while Macmillan \& Shapiro posit that at the heart of Jewish success were their kinship ties or networks, we argue that the making of Zambia by the Jews was driven by the religious nature of the Jewish community in the territory. This is because other than the historical circumstances of their history being tied to religious capital, religion in itself was also a form of capital which enabled them to contribute in the manner they did. In this regard, the content of their faith in totality and their religion as a way of life was at the centre of these contributions. This demonstrates how and why the Jewish community in Zambia not only exhibited a peculiar work ethic, but also the charitable works they did.

In short, when the Jewish activities are seen through the concept of religious capital, it is evident that religious capital was closely related to their contributions in making Zambia. For example, their work demonstrates how experiences and skills specific to one's religion (seen through their understanding of humanity, wealth creation) familiarity with doctrines (seen through the establishment of synagogues for the Jewish community, ethical conduct and charity work) and friendships with fellow Jews (seen through the networks or linkages) resulted in the numerous activities they were involved in which laid the foundation for the newly independent Zambia. This is because at the turn of independence, it was the many initiatives and contributions of the Jews which formed the backbone of the new nation in that most of their investments were either sold or repossessed by the newly independent Zambian government in 1964 .

\section{Conclusion}

The chapter reflected on the Jewish migrant's role in making Zambia by linking religious capital as a concept to the contributions of the Jews from 
their first arrival in the territory until the birth of the new independent Zambia in the 1960s. Using the examples of the contributions of the Jews in different spheres of life, the chapter argues that at the centre of these contributions was the religious drive and capital which created an understanding of wealth creation and guided their conduct in business and human relations as Judaism was a way of life that provided the religious capital in their endeavours. While their activities were largely meant for their wellbeing, they benefited the new Zambia directly and indirectly by laying the foundation on which the country was anchored at the turn of independence.

\section{References}

Ahmed, J. U. 2010. Documentary research method: New dimensions. Indus Journal of Management \& Social Sciences, 4(1), 1-14.

Attali, J. 2003. The Jews, the World, the Money. Warsaw: Cyklady Publ. House.

Bhana, S. 2000. Hugh Macmillan and Frank Shapiro. Zion in Africa: The Jews of Zambia. London: IB Tauris; in association with the Council for Zambia Jewry. 1999.

Bourdieu, P. 1984. Distinction: A Social Critique of the Judgement of Taste. Cambridge, MA: Harvard Univ. Pr.

Chitando, E. 2005. Studying African Judaism: Some Methodological Challenges. Journal for the Study of Religion, 18 (2), 55-74.

De Lange, N. 2000. An introduction to Judaism. Cambridge: Cambridge Univ. Pr.

Ehrlich, M. A. 2009. Encyclopedia of the Jewish diaspora: origins, experiences, and culture (Vol. 1). Califonia: Abc-clio.

Fel, S., \& Zdun, M. 2014. Judaism and Economics: The Link between Judaism and Economic Life. The Person and the Challenges. The Journal of Theology, Education, Canon Law and Social Studies 4(2).

Finke, R. 2003. Spiritual capital: Definitions, applications, and new frontiers. Retrieved Apr., 24, 2005.

Gadsden, F 1992. Education and Society in Colonial Zambia. In S N Chipungu (ed) Guardians in Their Time: Experiences of Zambians under Colonial Rule, 1890 - 1964. London: Macmillan: 97 - 125.

Herbert, E. 2001. African Studies Review, 44(1), 158-160. doi:10. 2307/525417

Iannaccone, L. R. 1990. 'Religious Practice: A Human Capital Approach.' Journal for the Scientific Study of Religion 29:297-314.

Iannaccone, L. R. \& Klick, J. 2003. Spiritual Capital: An Introduction and Literature Review.

Kaplan, M. 1986. Jewish Roots in the South African Economy, Cape Town:C. Struik.

Keysar, A. 2010. Distancing from Israel: Evidence on Jews of No Religion. Contemporary Jewry, 30(2/3), 199-204. 
Komakoma, J. 2003. The Social Teaching of the Catholic Bishops and Other Christian

Leaders in Zambia: Major Pastoral Letters \& Statements 1953-2001. Ndola: Mission Pr.

Macmillan, H., \& Shapiro, F. 1999. Zion in Africa: The Jews of Zambia. London: Tauris.

McCulloch, G. 2004. Documentary research: In education, history and the social sciences. Routledge.

Parrinder, G. 1974. The World's Living Religions. London:Pan Books.

Phiri, B. J. 2006. A political history of Zambia: from colonial rule to the third republic, 18902001. Africa World Pr.

Roberts, A. 1976. A history of Zambia. Heinemann Educational.

Sen, A. 1988. The concept of development. Handbook of development economics, 1, 9-26.

Shapiro, F. 2002. Haven in Africa. Gefen Publ. House.

Shapiro, K. 2001. Zambian Jews. Journal of Southern African Studies, 27(4), 873-875.

Smart, N. 1989. The World's Religions. Cambridge: Cambridge Univ. Pr.

Snelson, P. 1974. Educational Development in Northern Rhodesia 1883-1945. Lusaka: NECZAM.

Sombart, W. 2001. The Jews and Modern Capitalism. Ontario: Batoche Books.

Stark, R. \& Finke, R. 2000. Acts of Faith: Explaining the Human Side of Religion. Berkeley: Univ. of California Pr.

Susman, D. 2004. An African Shopkeeper: Memoirs of David Susman. Fernwood Pr.

Taylor, S. D. 2006. Culture and Customs of Zambia. London: Greenwood Pr.

Ter Haar, G \& Ellis, S. 2006. 'The Role of Religion in Development: Towards a New Relationship between the European Union and Africa.' The European Journal of Development Research, 18(3):351-367.

Ter Haar, G. 2005. 'Religion: Source of Conflict or Resource for Peace?', in Gerrie ter Haar \& James J. Busuttil (eds.), Bridge or Barrier: Religion, Violence and Visions for Peace. Leiden / Boston, MA: Brill, 3-34.

Tutton, M. 2012. 'The forgotten story of Zambia's Jewish settlers. ' CNN Documentary, $19^{\text {th }}$ Jan..

Waronker, J. A. 2010. 'Architectural Remnants of Jewish Life in Zambia.' In Kulanu 18(1): 10-12.

Zukas, S. 2002. Into Exile and Back. Bookworld Publ. House. 


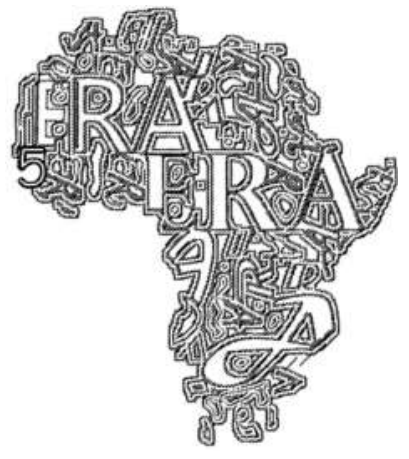




\title{
Navigating Imbusa in Public Spheres: Bemba Married Women, Work and Agency
}

\author{
Mutale Mulenga Kaunda
}

Even in the village, there were times of gardening for women, there were no offices, but women had a career in the fields, in the fields the woman planted various foods and used their hands to provide for their families because they never used to buy food long time ago. . . Today things have just changed because we are going to school and university, get educated and because this time there is education, and therefore we even change names and say career women!! - Delfister Ngosa (Oct. 2014). ${ }^{1}$

\section{Introduction ${ }^{2}$}

In precolonial Zambia, Bemba women received education from imbusa ${ }^{3}$ teachings and were working to provide for their families. Even in the colonial era, while the Bemba men were migrating for wage paying labour in the Copperbelt province, as Ault (1981) has explained, women remained in the village caring and providing for the family. This chapter has intentionally focused on Bemba women who have been to college or university and were working at the time of the interviews. Bemba women, like other ethnic groups within Zambia, look forward to imbusa teachings as they prepare for marriage. Simon Kapwepwe ${ }^{4}$ (1994:4) writes, mumwaka umo wine banjitile pa university of Zambia pakuti intitibile pa lwa fibelelo fyesu, translated as "in the same year I was called at the University

\footnotetext{
Delfister Ngosa interviewed by Mutale Kaunda in her office, Oct. 2014.

2 This chapter is taken from Mutale Mulenga Kaunda's PhD thesis which was submitted to the university of KwaZulu-Natal 2017.

3 Imbusa are sacred emblems/visual aids handed down to Bemba brides before the wedding.

4 Simon Kapwepwe was the first vice president in democratic Zambia. He was passionate about Zambian culture and languages that were seemingly getting eroded with the desire to be modernized by many Zambians.
} 
of Zambia to go and teach emphasising on our tradition". However, Kapwepwe $^{1}$ (1994:4) explains that what they really wanted was for him to emphasize on marriage; "after I had spoken, their leader expressed concern stating that 'we called to tell you that we are desperate as young women and men as we are going through life without any traditional" Bemba women and most, if not all, Zambian women from various ethnic groups still look forward to undergoing the imbusa teachings before they are married just as the women during the time Kapwepwe was called upon to teach University of Zambia (UNZA) students. Imbusa teachings have a critical place in the Bemba worldview as Bemba people believe that in order to live harmoniously and peacefully in a community, a code of conduct to guide action is important for each group. Imbusa teaching is fluid, not static and one can extract aspects that fit well with their context. Imbusa has both the cultural and religious dimensions that teach Bemba women to be agents of their lives as well as development.

In this chapter, data will be presented and analysed focusing on how Bemba women navigate imbusa in public/social spheres. This aligns with the main research question of this chapter: "How do married Bemba career women engage with the traditional cultural curriculum of marriage (amafunde yambusa) in their daily lives at home and workplace?" This question sought to analyse Bemba women's agency in the workplace and how they intentionally navigate the workplace. Public/social spheres have become open to women in Zambia, although these spaces remain entrenched in problematic gender power relations mirroring the colonial historical experiences of the Bemba people. Out of women's agency comes the courage to develop nations. Women who are empowered with skills and knowledge are key to the development and success of a country. Imbusa being a critical space of women's empowerment, is certainly a space of empowering women for development in all its forms.

The Bemba women were the apex of Bemba society as owners of their households and some of the women held political positions as chiefs or heads of their particular villages within the Bemba political kingdom. Thus, they were involved in the social spheres. Michael Burawoy (2009:118) argued that the Bemba women were more resourceful and in-

As a married man he had knowledge of imbusa because every woman who has received imbusa teaching is obligated to share that knowledge with her husband. The point however, is to show that educated men and women were eager to hear about the importance of imbusa in marriage. 
volved in the political life of the Bemba kingdom than scholars like Richard had acknowledged. Nevertheless, in postcolonial Zambia, imbusa seems to be functioning as a weapon of the powerful and not the weak. It is a tension because in the teachings of imbusa, a woman is taught to respect other men as well as her husband, just as Esnart Ng'andwe (2014) ${ }^{1}$ one of the participants explained:

'When you talk of respect it's not only the husband; even at work, you are taught that when you are home with your husband and his friends it's better to put on icitenge (traditional wrapping cloth) so even at work we become conscious since we were taught that you don't pass where men are if you are in a mini skirt/dress. '

This chapter examines whether women find imbusa teachings helpful in the workplace and whether imbusa encourages them to advance in their careers. ${ }^{2}$ Imbusa is a religio-cultural space where Bemba women, formally educated or not, are taught on various aspects of marital life for a Bemba woman. Finally, I demonstrate how Bemba career women are taking initiatives to creatively navigate amafunde yambusa in order to function as partners with their male colleagues in the work environment, thereby gendering the workplace. Through the process of the interview with Bemba career, married women, they were reflecting on their reality concerning imbusa and raised issues that they would like the instructors (banacimbusa $\left.^{3}\right)$ to critically reflect on as well. Further, Reinhaz (1992:19) declares that feminist interviewing allows the researcher access to their "ideas, thoughts and memories in their own words and not the words of the researcher".

\section{Research Methodology}

This section demonstrates the steps that were taken in inviting seventeen Bemba, married, career women to share their critical views about imbusa and discusses their experiences of imbusa in everyday life. The methods

1 Esnart Ng'andwe (2014) interviewed by Mutale Kaunda, interviewed at her workplace in the staff room (Nov.).

2 While imbusa teachings are marital teachings, women's experiences in the workplace have been that their male colleagues and at times even female colleagues expect married Bemba women to behave according to the teachings of imbusa even at work.

3 Banacimbusa are marriage mentors (older married women in the community) who give instructions on married women's behavior and they are the main instructors in imbusa space.) 
of data production and analysis align with feminist ways of producing knowledge. The purpose is to thematically describe, analyze and theorize Bemba career women's agency in understanding and negotiating amafunde yambusa between their workplace and home. As a qualitative feminist research, this research sought to engage Bemba women in conversations concerning their experiences of imbusa teachings and its impact in their workplace and homes. Being located in a critical postcolonial/decolonial feminist paradigm, this study sought to critically engage Bemba women's critical reflection on the knowledge that is received from imbusa in postcolonial Zambia and whether and how appropriately this knowledge fits into the contemporary Bemba career married women's experiences of everyday life in the home and work place. Poewe (1981) has discussed in detail the status of Luapula women in pre-colonial and colonial times, noting that women and men had similar positions in society; the question arises, are postcolonial Bemba women still holding those same positions in society in the Copperbelt province of Zambia? A feminist postcolonial/decolonial paradigm has the potential of probing Bemba women's lived experiences in connection with the prescribed norms of the society that define women's positions in their communities. A sample of seventeen career women who have undergone imbusa teachings was reached between October and November 2014 in order to critically engage with women on imbusa teachings. Pseudonymns have been used.

The sample of the study initially involved 15 (2 were included due to their availability and meeting the criteria, therefore 17) married, Bemba career women of Zambia in different fields of work, including high school teachers, accountants, human resource managers, information technologist, bank manager, health/ hospital administrator and a pastor. The age of the participants varied between twenty-eight to fifty-three years at the time of the interviews. The selection of these participants was because of their eligibility to contribute to the understanding of imbusa teachings and how these career women engage with the amafunde yambusa in their daily lives as married and career women. The supposition was that married career women give various interpretations to these teachings, depending on their perception of imbusa as well as their field of work. Hence, women from diverse fields of employment were selected to illuminate whether and how these teachings empowered them to take up careers and excel in their careers as women. I went to Zambia and I verbally requested the women to take part as well as asked them to sign a consent form after reading and understanding it. A letter requesting them to participate and explaining 
the purpose of the study was given to them after they had verbally agreed to participate in the interview. The letter described the research participants to be involved, that it was not every married Bemba woman, rather the ones that have been to university/college and were currently in employment. The fieldwork was conducted in October and November 2014.

\section{Theorizing Work: A Feminist Cultural Epistemology}

African feminists have explained how one cannot talk about African women without referring to culture and their cultural experiences (Phiri $\&$ Nadar 2006 and Wane 2005). Elsewhere I have argued that in precolonial times, imbusa was a matricentric moral source on which the traditional Bemba community was governed. Writing from an African theological perspective, Kenneth Mtata (2011) notes a connection between the spheres of culture and work. He argues that work is one significant area in which African cultures have found their greatest expressions. The ultimate purpose of work is not merely to meet human basic needs, but also to affirm the intrinsic worth of a person. Work can, therefore, be a place of affirmation or alienation. It can be argued that work is embedded in cultural spaces where meaning is derived. In traditional African societies, work was done communally, and every member of the household constituted a workforce unit, resulting in mutual respect and appreciation. It is important to also highlight that work was embedded in African religiocultural wisdom and philosophy. As Mtata (2011:38) affirms "whether the hunter had good dogs, the farmer had many cattle to plough the field, or one had a great voice to sing, in order to be successful in one's work, Africans believed in the final capital that came from the spiritual world, be they Ancestors or God or other benevolent powers". The spiritual awareness pervades every aspect of reality within African traditional social life (Evans-Pritchard (1956); Parrinder (1953; 1954; 1962); Mbiti (1975:1990); Idowu (1962:1973); Magesa (1997)). John Mbiti (1990:2) argues that:

Wherever the African is, there is his [sic] religion: he (sic) carries it to the fields where he (sic) is sowing seeds or harvesting a new crop; he (sic) takes it with him (sic) to the beer party or to attend a funeral ceremony; and if he is educated, he takes religion with him (sic) to the examination room at school or in the university; if he is a politician he (sic) takes it to the house of parliament. Although many African languages do not have a word for religion as such, it nevertheless accompanies the individual from long before his (sic) birth to long after his (sic) physical death. 
Religion and spirituality colour not just work but every aspect of an African's being. Thus, work and religion are perceived as interconnected, an understanding that is deeply entrenched within traditional imbusa teaching as well. The Bemba women know that they are expected to be taught how to behave as married women. In fact, Kapwepwe (1994:6) explained how, when he was speaking to University of Zambia female students concerning marriage and progress, they indicated their intention and desire to go through amafunde when they were to be married. Imbusa was specifically to prepare a bride for marriage and community life. Life lessons that her parents or guardians may have already started teaching her were re-taught and re-enforced, in readiness for marriage and taking up social responsibility as a mature and grown up woman. Thus, Wane's (2011:9) argument, "[i]n Africa, feminism did not develop in an academic setting, but in the villages where the inclusion of women was evident in the social, economic, ritual, and political spheres." Imbusa in precolonial times lasted six months as Kapwepwe (1994) notes; in that time, if it was a course in an academic setting, one would acquire a certificate. African feminist work ethics can be constructed through understanding that the "bonds women had with other women", in precolonial times, which engendered a feminist work ethic, were underpinned by the collective consciousness of women or "unified collective thought" (Wane 2011:9). Bemba women were aware that culture is pervasive and informs work relations (Hinfelaar 1994). Therefore, through imbusa, Bemba women constructed their agency that was adequate to function in the social spheres as equal labourers with their male counterparts. African feminists have rightly explained that African women's experiences are a basis for a feminist work ethic (Wane 2011).

Raising awareness of gender equality concerns through various campaigns and workshops have been on the rise in Zambia; women's lobby groups/organizations have been formed to promote women's empowerment, such as the Forum for African Educationalists of Zambia (FAWEZA), Zambia National Women's Lobby (ZNWL), Women for Change (WFC), Women's League (WL), and Campaign for Female Education (CAMFED). Most of these focus on girl child education. There are other women's groups that have focused on women's rights such as Zambia Association of University Women (ZAUW), Zambia Alliance of Women (ZAW), Zambia National Women Artists Documentation Project (ZNWADP), Women in the Media (WM), Business and Professional Women (BPW), and Medical Women's Association of Zambia (ZWAM). 
This is not an exhaustive list, there are many more. Mushibwe (2009:97) has argued, “These organizations [of women's empowerment] are best considered to be manifestations of liberal feminism because of their aims and processes of change advocated for." However, while all these women's organizations have been formed and are doing their best in women's empowerment, imbusa has not been critically considered as an institution, space or even methodology that can be utilized for women's empowerment among the Bemba and other women in Zambia. This space is even more significant now than previously as most of the ethnic groups have started teaching women using the teaching content equivalent to imbusa, especially in the many cities around the country. As argued above, culture pervades every aspect of life and it can be argued that even contemporary workspaces in Zambia are not left out when dealing with culture. Traditional culture pervades both the public and private spheres.

A growing number of Bemba women, like African-American women as explained by Patricia Parker (1996:189), "have broken through the glass ceiling and climbed over the concrete wall to assume positions of power and authority in dominant culture organizations." The corporate space has predominantly been for men; for Bemba people, colonial officials preferred a male work force, which meant Bemba women were sidelined from having employment and left to take care of their homes and family. The difference is, while Bemba women were in their villages, they were working together with their spouses and produced for their families together. When they came to the city, they were sidelined and left only to care for family; and they now had to depend on their spouses for everything they needed. Maria Frahm-Arp (2014:5) has observed in the South African context concerning Pentecostal women who have made decisions to seek wage-paying employment outside their homes. This is despite their churches' teaching against women who have small children being employed outside the home, saying they should be at home to take care of their children.

The complexity of a culture that has been so influenced by Western culture as well as various cultures within Zambia, makes it imperative to contemplate the cultural influence on career in women's everyday life, "to uncover specific meanings that people associated with their behavior" (Vochocova 2008:233). Vochocova (2008:239) notes that the fact that more and more women are getting into careers does not mean they get more power and influence; women begin to negotiate and navigate lower sala- 
ries and positions in the company or institution. Bemba women were restricted from moving into cities without being in the company of their spouse or male relatives etc (Ault 1983). African feminists like Chilisa $(2012: 19)^{1}$ have argued for postcolonial theories as "framework of belief systems that emanate from the lived experiences, values, and history of those belittled and marginalized by Euro-Western research paradigms". Tamale (2005:10) has argued that women's lives are controlled by

"male domination through men's control of resources and their relatively greater economic power. The patriarchal family engenders these economic relations, in which men, as household heads, exercise control over the lives of women and children."

This means that the workplace social spheres have been designed and fabricated largely for male progress and where women are in the workplace social spheres, they are expected to operate in a certain prescribed way that undermines their agency and subjectivities. For instance, a Bemba married career woman would be expected to treat men as she was taught in imbusa even at work. As one of the participants lamented:

'most males and most often even female colleagues would express opinions to a married woman that she is behaving or not behaving like someone who is taught.' (Esther Musama 2014).

A befitting example is when the then president of Zambia, His Excellency President Levy Mwanawasa, died in 2008; his grieving widow, Maureen Mwanawasa (a lawyer by profession), was castigated by Mr Michael Sata for commenting on political matters instead of mourning her husband. Mr Sata, the opposition leader (Patriotic Front PF) to the then ruling party (Movement for Multi part Democracy MMD), told the BBC's Focus on Africa programme that "It is her (Maureen Mwanawasa) who has turned the whole funeral into politics, a widow should stay at home to mourn not tour the country" (BBC 2008). Mr Sata further "sarcastically" stated that Maureen Mwanawasa should visit alangizi (a Chewa term for banacimbusa) because for her to comment on political issues during the time of mourning her husband implied that she was an uncultured woman. A woman who does that is referred to as chuumbu munshololwa, a crookedly bent potato that if one tries to straighten; it would only break instead of straightening. Ironically, when Sata died as president of Zambia six years later, his widow, Dr Christine Kaseba, a medical doctor by profession,

1 Delfister Ngosa (2014) interviewed by Mutale Kaunda in her office in Chingola Revelation Pentecostal Church (Oct.). 
wanted to stand as candidate for presidential elections. Dr Christine Kaseba's stance was met with similar sentiments from the public on social media. Some people even reminded her of her deceased husband's sentiments when Maureen Mwanawasa merely commented on the political status of the country at a similar time. On $20^{\text {th }}$ Nov. 2014, Zambian Watchdog reported that "a concerned elderly citizen from Mununga village demanded that PF presidential aspirant Dr Christine Kaseba vacates the state house to go and concentrate on her political career". The two cases above demonstrate the belief that as a woman, one's career should not be as important as marriage; if anything, career has to wait while a woman mourns her husband and she should take time before going back to work. Bwembya Mutale of Zambiatimes.com strongly wrote on $20^{\text {th }}$ Nov. 2014 that:

President Sata is gone (MHSRIP). But even before cement at his Grave site dries up, the lid in PF (Patriotic Front party) has blown off. The Zambian people have come face to face with PF madness in its overflow. Leading the whole madness in overdrive is the compromised widow Christine Kaseba wickedly defying every norm, culture, decency, and moral values synonymous with genuinely afflicted family members mourning. . . When a loved husband dies, a responsible woman prioritises to unite the family and provide leadership under a new situation. . . Unfortunately, Kaseba has shown she is more interested in power. If condoned, this Jezebel spirit may eat our country.

If the late president Sata was considered the father of the nation, then his widow Kaseba was doing the right thing by submitting her candidature for the PF party's presidency. Whenever a woman defies what has become "cultural" norms and expectations, it is often pointed out that she has not respected or taken the marital teachings seriously. A married woman is expected by society to behave in a particular way that resonates with what is defined as culture and consequently, her status as a married woman. Hence, Maureen Mwanawasa and Christine Kaseba-Sata were both castigated because they defied those expected norms. That is why this "concerned citizen" from Mununga village would demand that the widow be removed from the state house because the widow, by going to file for candidature, has not honoured the husband when she should be mourning. Such a widow is deemed to have no reason for staying in that house any longer. These two women referred to above are not only educated, they are public figures as well, yet, culturally they are expected to leave their careers and focus on mourning their husbands in order to honour their spouses. It is not only in matters of bereavement; women are expected to 
be more serene in the way they handle matters in almost all aspects of their lives.

Another example is from two of the participants who stressed that they wear ifitenge (traditional cloth) to cover themselves when wearing short dresses or skirts at work in order not to 'tempt' the men at the place of work. This is in order to give their male colleagues respect and not make the men feel uncomfortable while they are working. The Copperbelt province of Zambia, like many societies, is marked by the separation of public and private spheres. Tamale (2005:9-11; See also Osseina Alidou $(2005: 10))$ has explained that "the two spheres are highly gendered, with the former (public) inhabited by men and the locus of socially valued activities, such as politics and waged labor, while the latter (private) constitutes the mainly unremunerated and undervalued domestic activities performed by women. " In pre-colonial African societies, women and children were part of the labour force for the family; they all worked and contributed to the wellbeing of the family (Poewe 1981). With the coming of colonialism, all this changed as women and children were forced to become dependents on their males, making the situation difficult because this means that in a family of, for instance, five, four people will be dependent on the salary wage of one person. With all the transformation during the colonial era, imbusa has been affected. This, however, does not mean that Bemba women have taken the change uncritically. They found ways of navigating and negotiating it. As Nnaemeka (2003:378) has noted, African women use the same instrument that was meant for their oppression to find emancipation knowing "when to go around cultural land mines" and when to face them head on.

Clement Katulushi (1999:101) states that "African cultural continuity is perpetuated in the lives of Africans and ignoring tradition is akin to losing the African identity." The participants argued that they underwent amafunde and later on began to negotiate these teachings as their experiences developed. African feminism critically analyses women's experiences on a daily basis and aims at tackling issues that affect women's lives in their daily activities. Work is part of Bemba women's day-to-day experiences, and hence it is important to show how they navigate the workplace. Wane (2011:8) suggests "a need for an approach that is anchored in retrieval, revitalization or restoration of the African senses of indigenousness. That is, African people must reposition their cultural resource knowledge in order to appreciate the power of collective responsibility to tackle social issues." For Bemba women, their social status is constructed in amafunde 
yambusa and affects their daily lives in various ways. My argument is that Bemba career womens' unique cultural experiences, especially from amafunde yambusa, inform their participatory approach in the workplace. Issues of women in employment became important around the twentieth century as women began to infiltrate the labour force in large numbers. In the colonial and postcolonial Copperbelt province, women were expected to stay home and raise families.

Bemba women's experiences of the Copperbelt province became a reason for them as women to subvert the colonial officials and missionaries' expectations. Despite the pressure for women to stay home and care for their families, they have learnt that they will care for the families constructively if they are able to contribute to their wellbeing financially as well; hence, Bemba women have sought education and employment outside their homes. There is often a divide between the workspace and the home; the workspace is usually celebrated while the home space is erased or not seen as of much importance. It is because of this that Tamale (2005:12) argues that: Where there had been a blurred distinction between public and private life, colonial structures (legal and religious, for example) and policies (educational, for example) clarified and hardened this distinction, guided by an ideology that perceived men as public actors and women as private performers. Where domestic work had co-existed with commercial work in pre-colonial satellite households [in Africa], a new form of domesticity, which existed outside production, was constructed.

Since there is this divide between the home and the workplace, do Bemba career women live dual lives or function with a dual consciousness - as a different person at work and someone else at home? The binary between public and private spheres (that was one space in pre-colonial era for the Bemba) imposed the suppression of Bemba women and their reduction to the private sphere. Women provide care for the family in terms of childcare and household chores, and these continue to reproduce women's social life that is "economically dependent on their male partners" (Tamale 2005). Feminists around the globe have been looking at how women in workplaces experience life. Amafunde yambusa does not only form symbolic representations for charting Bemba femininity, but it has also come to symbolize Bemba women's identity in their places of work intentionally or unintentionally. It is, therefore, important to analyse Bemba women's experiences at their places of work, as well as their learnings and understandings attached to their experiences in their various places of work (Tamale 2005 and Reinharz 1992). African feminist cultural hermeneutics 
suggests looking at women's experiences of culture in ways that are lifegiving. Bemba women's navigation and negotiation of imbusa teachings in their workplace is a way in which Bemba women use their agency.

\section{Data Analysis}

One of the participants lamented that banacimbusa were seemingly not interested in her career as a woman. They taught her much about her supportive role in her husband's career and her own career was neglected during the teaching.

\section{Career is not Important for a Married Woman: Breaking the Taboo}

Most of the participants explained that during their teachings, banacimbusa never talked about them as career women despite the fact that most of them were working or had just finished their university/college studies at the time they underwent the teachings. One of the participants explained:

'As far as the banacimbusa were concerned, I would never work in my life, all I needed was to know how to take care of my home, husband and family. Despite the fact that I told them that I had just graduated from a secondary (high) schoolteachers' training college, they never touched on the subject of my career. I never asked them about it because I am just supposed to listen and learn, but in my mind, I had many questions because I always wanted to work.' (June Sampa 2014). ${ }^{1}$

This kind of teaching and learning that does not allow for dialogue or questioning seems to suggest that banacimbusa believe that they have all the knowledge regarding marriage and the young brides have no new things they can add to banacimbusa's experiential views of marriage. Viewing this through decolonial feminist lenses, there is a need for the 'decolonisation' of teaching methods of imbusa in order to allow for participation of the brides or students of imbusa. June Sampa and Mirriam Numba's response to banacimbusa's neglect of a woman's career in their teachings echoes the desire of many young Bemba women to be taught and empowered on how to progress in their careers as women.

'The part about my career was ignored completely even though they knew I was working; I was told that work should not come before my marriage. It

1 June Sampa (2014) interviewed by Mutale Kaunda in her home in Chingola (10 Nov.). 
was put as though I was a housewife. From banacimbusa's teaching, the emphasis was that when my husband gets home from work, he should find the house is clean, the food is cooked, the aroma of food is lingering in the air. It was assumed that I am staying home while he's going to work and career for me as a woman was never really talked about. And I was told that just because I get a salary doesn't mean I should be cheeky with my husband; just because I will be bringing in money doesn't mean I should talk to him anyhow. It was more of me supporting him in his career by making sure there's peace in the home; I don't nag him when he comes home from a long day at work. They taught me that I needed to prepare his lunch for work and make sure he's had proper breakfast before going to work, and his clothes were ironed.'

In the same way, Bernice Mulanda explained:

'I should be frank to say that they did not touch on the career topic per se. They knew that I was working, and our arrangement was that the teaching would take place after I knocked off from work, but they still didn't teach me anything concerning how to handle or hold my career and marriage in balance.'

Patricia Kabwe ${ }^{1}$ expressed the same sentiments concerning imbusa and a career:

'Banacimbusa teaches a young bride how to be obedient to her husband and how to take care of family but not necessarily how as a woman she should be independent. They won't teach you how to survive as an independent woman; you are solely dependent on a man.'

Imbusa teaching space does not allow the initiate/student to ask banacimbusa (and the women teaching her) questions as that is perceived as arrogance. Students or initiates have to be passive and listen to the older women who have been in marriage for a long time; they "followed" the same teachings they would be passing on to her as well. Banacimbusa believe that they kept their marriages intact because they followed the instructions from imbusa. In a feminist, decolonial approach, critical engagement is central, as learners are not passive. The learners are the focus of their agency and nacimbusa is just a facilitator who has a duty to engage the learners in the imbusa teaching space. Since much of the imbusa teachings are in symbols, I can argue that since brides or intitiates/students/ learners are not allowed to inquire from banacimbusa, they are symbolically being taught to replicate this relationship in their homes with their spouses.

1 Patricia Kabwe interviewed by Mutale Kaunda in her office, Chingola Mine (Oct.) 
After three years in marriage, June Sampa went into full time employment as a high school teacher and began to question further certain aspects of the imbusa teachings; some of the aspects she was already questioning during the teaching, however she could not ask or even suggest her ideas to banacimbusa. This also tallies with my personal experience; during the time I underwent the teachings, I was often left with unasked and inevitably unanswered questions. For instance, I had explained to my marriage mentors (banacimbusa) that my fiancée (then) and I had planned that I would be going to university in a few years' time; I was expecting them to talk me through this during our teaching sessions but alas, the topic was completely untouched. June Sampa (2014) negotiated the imbusa teachings despite banacimbusa not referring to career when they had taught her; she went on and got into professional work because she already had a qualification even during the time, she underwent imbusa teachings. Naphtali Nkole (2014) ${ }^{1}$ also lamented:

'I wouldn't say that I have not gotten everything from the teachings and applied them to my marriage. When it comes to a career, banacimbusa don't really come to encourage you to prosper in that regard. It's more like support your husband in his career; and you are the one that loses for sitting and listening to them talk about you supporting your hubby and you are told nothing about progressing in your own career I think.'

The participants in this chapter expressed concern that banacimbusa do not care whether a woman that is being taught has a career or not; they do not touch on issues of career, hence women as agents of their own careers begin to negotiate and navigate their workplace in ways that they can. This is similar to what Frahm-arp (2014:5) observed among Pentecostal women; she explains that "despite their churches' teaching that women should remain at home while caring for young children, structural constraints in the lives of members often meant they made decisions about work and family which were contrary to their churches' teaching". Bemba women have been navigating the teachings in order to emancipate themselves. With the realisation that they want to remain married and working, Bemba women have been navigating the imbusa teachings in order to experience the workplace differently. Mushibwe (2009:121) has succinctly argued that these teachings start from the time a child is born and "formal school may not have the capacity to alter such a mind-set." In fact, the initiation school such as imbusa re-enforces the teachings further from

1 Natasha Nkole (2014), interviewed by Mutale Kaunda in Chingola Zambia (Nov.). 
where one's parents/guardians left off. It can be argued that a Bemba woman goes into the workplace after amafunde yambusa feeling as if they have been given preferential treatment to have a job. This is because according to the participants, banacimbusa emphasize that a woman needs to stay home and take care of her family, even though they (banacimbusa) teach the bride/s that a woman must not just stay idle at home.

Two of the participants explained that banacimbusa still prefer a woman to have a garden instead of developing a professional career or wage-paying employment outside the home as it was taught in precolonial times. For instance, Nancy Chomba (2014) ${ }^{1}$ stated that she was told to have a vegetable garden in her yard so that she does not have to buy simple things such as vegetables. Mulenga Mukupa (2014) ${ }^{2}$ also explained that "they always tell a woman that even if she is just at home and not working, she has to have a garden". Instead of this focus on the gardening, as taught during precolonial times when Bemba people were egalitarian, banacimbusa have a duty to transcend this gardening teaching to focus more on careers that Bemba women on the Copperbelt province are currently working in. In the contemporary Copperbelt province, Bemba women have been in wage employment outside the home and this is where banacimbusa are supposed to provide teaching - on how a career woman needs to live her life in her home and at work. In traditional African societies, teachings and indigenous knowledge was left in the hands of the elderly to give and teach the young. Among the Bemba, for example, old women taught imbusa and were custodians of the teaching. They also chose from among the young women they taught who could become a nacimbusa, and they mentored such a woman. Similarly, Elisabetta Villa and Pia Grassivaro Gallo (2006:58.See also Annette Drews [1995]) expressed that:

Among the populations of Uganda, this was conveyed by considerable use of proverbs, sayings, maxims, riddles, epic poems, and fables. The expertise of an elder was not limited to telling, but rather shown in knowledge about how to apply such proverbs to different situations, offering suggestions rather than solutions, and leaving it up to the listener to find an answer.

This is also true of the Bemba people of Zambia, the elders in this case, banacimbusa, facilitated the teaching process and every invited woman

1 Nancy Chomba (2014) interviewed in her home in Chingola (Oct.).

2 Mulenga Mukupa (2014) interviewed in Chingola (Oct.). 
shared $^{1}$ their experiences with the bride as a way of teaching. It is often assumed that when a wife is working and especially when she makes a higher salary than her husband does, she would become pompous and disrespectful of her husband. Some of the participants explained, as shown in the quotes above, that they were taught not to become rude to their spouses just because they were working and bringing an income.

In the initiation process, the brides were and are still told that it is important to take all that they are being taught and use the teachings devotedly. This does not give room for questions from the part of the student or initiate. Imbusa teachings were constructed to be a means of Bemba women's agency as well as a way to face their marriages with wisdom. Nevertheless, in a society that is exposed to so much information, to reduce a teaching to a monologue is disempowering for women, especially because historically women in general have been told what to do, how to behave, and so on by others. I am aware, as Wane (2011:9) argues, that

"Struggling against oppression was not a singularly, individualistic task; rather, these women utilized their collective framework for support. In their struggle to overcome different oppressions, African women were the original feminists who sought to emancipate themselves from the bonds of servitude, inequality, and racial discrimination."

Like Wane's argument above, Bemba women collectively took steps to teach young brides how as women they can experience life-giving marriages.

Therefore, most Bemba women, like many other Zambian and African women who have been exposed to the women's struggle for gender justice, while they submit to such a teaching, have also devised ways of navigating culture and customs that are life-denying for them in everyday life. Marilyn Friedman (2003:vii) has argued,

"Many social groups were prevented from living autonomously by systematic injustice, subordination, and oppression, conditions that have scarcely disappeared. The lingering force of these practices has prompted many feminists to view autonomy with suspicion."

This is what most Bemba women face in their everyday lives, even in the space where they are in solidarity with other women who are supposedly

1 They never explicitly expressed that this was their experience in the whole teaching but there were some teachings where they would openly state that they had encountered or experienced what they were teaching. 
their mentors. Esther Musama ${ }^{1}$ (2014), another participant, in a similar vein also explained:

'I think that the teaching and encouragement on career in imbusa is one element that is usually lacking in there, maybe because they think that if you get to look at life from that angle, the submission part and respect for your husband would be affected. But not to blame them because there are certain times as a career woman, you leave the office as the boss, when you get home you really want to make sure your friend (husband) knows that you are the boss.' In the same line, Pengo ${ }^{2}$ explained:

'Banacimbusa never touched on the issue of my career as a woman; they kept telling me to support my husband in his work by making sure I prepared him food to take to work, for example, also make sure his clothes were ready for him to find in the morning and make the home favourable for him to rest after he comes back from work.'

Similarly, Betty Nonde also stated that banacimbusa never talked about her career during amafunde yambusa:

'Uumm they never talked about my career, in fact that time it was uncalled for. For me as a woman to be working, banacimbusa and even the in-laws would be questioning a woman's involvement in her home and family if she spends much of her time at work.'

Certain careers such as nursing were often perceived as inappropriate careers for a woman who wanted to be married. Nurses were seen as promiscuous and having extramarital affairs with the (male) doctors. This perception was worse for journalists, because female journalists were viewed as arrogant and would not make an "ideal wife". A suitable academic qualification for a woman who had a desire to marry was to be a teacher. In the early 1980s and mid 1990s men were discouraged from marrying nurses, journalists etc., because they got higher salaries than men and they were perceived as "uncontrollable" in postcolonial Zambia. This is probably why banacimbusa would make it hard for such women during imbusa teachings; they would emphasise submission and show to the educated young woman that they (banacimbusa) had better knowledge of imbusa teachings. Banacimbusa have a duty to teach young brides on how to take care of their marriages and ensure that even if they are career women, the man is always above them, according to the quote from the participants whose responses suggest that women with careers are in need of "fixing".

1 Esther Musama (2014) interviewed by Mutale Kaunda in her office in Chingola.

2 Pengo (2014) interviewed by Mutale Kaunda in her home in Chingola (Nov.). 
Tamale (2005:12; see also Nnaemeka 2003) has noted concerning the Ssenga institution in Uganda that it "facilitates and reinforces patriarchal power, while at the same time subverting and parodying it". In amafunde yambusa similarly, while Bemba women do not question the teachings while in the space and process of being taught, in their minds they have many questions and they later begin to navigate around these teachings and interpret them accordingly. One participant explained that "imbusa has tended to focus on marriage and not a woman's career; there is nothing like a woman taking a career, there is just teachings on caring for husbands, akatemba cuupo ${ }^{1}$, children, family etc." (Delfister Ngosa 2014). While banacimbusa instil these teachings into young brides, at the place of work, women are faced with the challenge of proving that they are able to get promotion. For some employers, being a woman and unmarried disqualifies female employees from certain responsibilities and promotions. A woman who is not married is seen as immature, unable to make concrete decisions and therefore, cannot be promoted.

\section{Conclusion}

This chapter has critically engaged with the collected data and demonstrated that Bemba women often have to negotiate being career women and being married women. I have argued that Imbusa remains that Bemba space for women, within which a new Bemba woman can be constructed - one who can adequately function in contemporary society by maintaining an intricate balance between tradition and modernity within workplace social spheres and home. The participants expressed concern over banacimbusa's lack of interest in women's careers. For instance, Esther Musama (2014) explained: "look at when these teachings were started and now; definitely we can't run away from the fact that things have changed."

Food that is romantically prepared for one's husband and cannot be given to anyone, this is the same food that most women use/d to keep their husbands under control by mixing it with some herbal concoctions (muti). 


\section{Bibliography}

Alidou, Ousseina. 2005. Engaging Modernity: Muslim Women and the Politics of Agency in Postcolonial Niger. Madison, Wisconsin: Univ. of Wisconsin Pr.

Ault, James. 1981 "Making "Modern" Marriage "Traditional": State Power and the Regulation of Marriage in Colonial Zambia" in Springer Theory and Society, Vol. 12. 2. 181-210.

Chilisa, Bagele. 2012. Indigenous Research Methodologies. Los Angeles: SAGE.

Corbeil, Jacob 1982. Mbusa: Sacred emblems of the Bemba. Mbala: Moto-Moto Museum.

Drews, Annette. 1995. "Covering and uncovering Secrets and the construction of gender identity among the Kunda of Zambia”, in Medische Antropologie Vol 7/I: 101113.

Haynes, Naomi. 2012. "Ambitions and Obligations: Pentecostalism, Social Life, and Political Economic on the Zambian Copperbelt,” PhD Thesis, Univ. of California, San Diego.

Kaunda, Mutale. 2011. “A Feminist Cultural Analysis of the Imbusa (sacred emblems) songs among the Bemba Married Women of Zambia," Honors Project, Univ. of KwaZulu-Natal, Pietermaritzburg.

Kaunda, Mutale. 2013. “A Search for Life-Giving Marriage: The Imbusa Initiation Rite as Space for Constructing 'Wellbeing' Among Married Bemba Women of Zambia Living in Pietermaritzburg”. Master's Thesis Univ. of KwaZulu-Natal, Pietermaritzburg.

Kanyoro, Musimbi. 2002. Introducing Feminist Cultural Hermeneutics: An African Perspective. Sheffield: Sheffield Academic Pr.

Kapwepwe, Simon M. 1994. Icuupo Nobuyantanshi. Lusaka: Zambia Educational Publ. House.

Katulushi, Clement. 1999. “Teaching Traditional African Religions and Gender Issues in Religious Education in Zambia," British Journal of Religious Education, 21/2 (Jan.), 101-111.

Mushibwe, Christine P. 2009. "What are the Effects of Cultural Traditions on the Education of women? (The Study of the Tumbuka People of Zambia)," Doctoral thesis, Univ. of Huddersfield.

Nnaemeka Obioma 2003. "Nego-Feminism: Theorizing, Practicing, and Pruning Africa's Way"in Signs: Journal of Women in Culture and Society Vol. 29 no. 21, 357384 .

Phiri, Isabel \& Sarojini Nadar. 2006. "What's in a Name? - Forging A Theological Framework for African Women's Theologies," Journal of Constructive Theology, 12/2, 5-24.

Poewe, Karla. 1981. Matrilineal Ideology: Male-Female Dynamics in Luapula, Zambia. Academic Pr.: New York.

Rasing, Thera. 2001. The Bush Burnt, the stones remain: female initiation rites in urban Zambia. London: African Studies Centre.

Reinharz, Shulamit. 1992. Feminist methods in Social Research. New York: Oxford Univ. Pr. 
Richards, Audrey 1956. Chisungu: A Girl's Initiation Ceremony Among the Bemba of Zambia. London: Tavistock.

Roberts, Andrew. 1973. A History of the Bemba: Political Growth and Change in NorthEastern Zambia before 1900. Madison: Univ. of Wisconsin Pr.

Tamale, Sylvia. 2005 “Eroticism, Sensuality and "Women's Secrets” among the Baganda: A critical Analysis”, Feminist Africa 5, 9-36.

Villa, Elisabetta \& Grassivaro Gallo, Pia 2006. "Psycholinguistic Approaches to Ritual Labia Minora Elongation Among the Baganda Women of Uganda. ” In Bodily Integrity and the Politics of Circumcision, edited by G. C. Denniston et al. 57 -64.

Wane, Njoki. 2011. "African Indigenous Feminist Thought: An Anti-Colonial Project," pages 7-21 in The Politics of Cultural Knowledge edited by Wane, Njoki, Arlo Kempf \& Marlon Simmons. Rotterdam/Boston/Taipei: Sense.

2013. "[Re]Claiming my Indigenous knowledge: Challenges, resistance, and

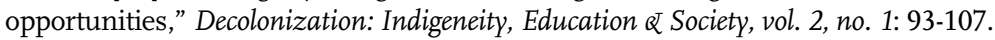




\section{The Interplay Between Religion and Development in Ghana}

Samuel Awuah-Nyamekye

\section{Introduction}

This chapter is a case study from Ghana, unearthing how religion and development have been faring in terms of the country's efforts to achieve development for its people. The chapter is structured into six sections. Section one is the introduction in which a brief overview of the debate over the nexus between religion and development is presented, Section two attempts to conceptualise the two key terms-Religion and Development. Section three is devoted to how religion and development work in Ghana. Here, some concrete evidence of how the three dominant religions in Ghana-African Traditional Religion, Christianity and Islamhave helped in the country's development are highlighted. In section four, some of the anti-development activities of the religious bodies in Ghana are pointed out. Section five looks at some interventions made to mitigate some of the effects of some of the anti-development posture of religious bodies in Ghana. The sixth section, which concludes the chapter, summarizes the key findings of the study and the way forward towards Ghana's development agenda.

One of the cardinal objectives of the developmental agenda of any society is the eradication or the keeping of poverty at minimum level. In achieving this goal, many scenarios have emerged, culminating in the debate on which of the scenarios is most suitable (see Deneulin \& Bano 2009). One of such debates is over the role religion can play in the eradication or minimization of poverty levels in a society's developmental agenda. The debate became more pronounced with the coming into being of the modernisation [approach] theory which 'not only dismisses local knowledge but also views it as part of the problem, being non-scientific, traditional and risk-averse, even irrational and primitive' (Sillitoe 2002:3)

The role of religion in development has been contested in the area of development studies and social science as a whole (Deneulin \& Bano 2009:1, 52). However, the interplay between religion and development debate may 
be categorized under three perspectives. One perspective (group) endorses religion as one of the key factors in development (Deneulin \& Bano 2009; Marcus Noland (2002), while another perspective (group) thinks otherwise, and even believes that religion rather obstructs or undermines development (Barro \& McCleary 2006). Evaluating this conceptual binary of the role of religion in development, Alkire (2006:502) says "the gusto of development experts who resonate with religion is enthusiastically matched by the repugnance of those who revile it". Yet, there is a third opinion that asserts that religion "is no panacea to but aspects of it can complement as well as motivate development" (Alkire 2006:502; Ruben 2011; Wilber \& Jameson 1980). This chapter, sides with the perspective that religion plays an ambivalent role in development--religion is no panacea, but aspects of it can complement as well as motivate developmentand consequently, aims to find out if this is the case in Ghana.

The chapter's perspective is also premised on the assumption that no group of people, particularly in Africa, can ignore their worldview, of which religion is a key element, in their developmental agenda. Ghana's legal framework, for instance, respects religious freedom and each and every one is free to profess any religion of his or her choice. This has made Ghana a religiously plural country. According to the Ghana 2015 International Religious Freedom Report:

The U. S. government estimates the total population at 26.3 million (July 2015 estimate). Approximately 71 percent is Christian, 18 percent is Muslim, 5 percent adheres to indigenous religious beliefs, and 6 percent identifies as belonging to other religious groups or having no religious beliefs. Other religious groups include the Bahai Faith, Buddhism, Judaism, Hinduism, Shintoism, Eckankar, and Rastafarianism.

The above data point to the fact that in Ghana, religion is real and thus wields much influence on human behaviour, either positively or negatively. What is, however, not permissible in the country is the formation of a political party along religious lines. In this chapter, however, the three dominant religions in Ghana - African Traditional Religion, Christianity and Islam — will be used to guide the discussion. 


\section{Religion and Development explained}

\section{Religion}

Despite the etymological conception of religion, the phenomenon has today been defined or conceptualized in different ways depending on one's background or orientation. The phenomenon is seen from, philosophical, psychological, sociological, anthropological, social, religio-cultural perspective (Cox 2010; Bellin 2008). It is based on this diversity of conception of the phenomenon of religion that informed Idowu to conclude that:

By now, everybody who is seriously engaged in the study of religion has been convinced that to attempt a definition of religion is an almost impossible, if not altogether impossible, task; and every serious scholar is on the verge of giving up the task (Idowu 1973:69).

But in Ghana, and in this chapter, religion is seen as a belief in a Supreme Being, which is in line with E. B. Tylor's (1851) definition of religion--the belief in spiritual beings. In Ghana, this Supreme Being is credited with the creation of the universe and all therein. This being is variously known as Onyame or Onyankopon by the Akan speaking Ghanaians and Christians, Mawu by the Ewe of the Volta Region of Ghana, Nawimne by the Dagaare of the Upper West Region of Ghana, Allah by Muslims. All of the three selected religious groups believe strongly that this being is capable of directing the course of events in human affairs and is the last arbiter in all cases. Therefore, the trust reposed in this being is unparalleled in their life and thought. A lot of proverbs and everyday sayings attest to this fact. In the words of Opoku (1978:1), for instance, 'religion is life and life, religion' in the life thought of the African and for that matter, the Ghanaian. Parrinder (1969:235) and Mbiti (1969:1) describe the African as 'incurably religious' and 'notoriously religious' respectively, although scholars such as Bitek (1971), Platvoet \& Rinsum (2003), do not support this view.

One of the arguments of Platvoet \& Rinsum (2003) is that "there is an absence of institutional differentiation and conceptual dichotomies in traditional cosmological and religious thought in African pre-colonial societies". This view, as they claim, was informed by Bitek's (1971) study among two ethnic groups in Kenya, the Luo and the Acholi, which claimed to have atheistic outlook (Platvoet \& Rinsum 2003:11). What Platvoet \& Rinsum did not get was that Bitek's study was limited to only two out of thousands of ethnic groups in Africa south of the Sahara. And in fact, there is a strong belief among Africans that although this universe has two dimensions — the spiritual and the physical—the physical runs at the 
back of the spiritual. This explains why the line between the spiritual and the secular is very thin and, so to speak, indistinguishable among the Africans. Again, there is enough evidence from pre-colonial, colonial and post-colonial Africa to support the views of Parrinder and Mbiti. For instance, religion is seen in all spheres of life of the African, be they social, political, economic or recreational. Even today, there is no way a Ghanaian farmer will cultivate land without one form of ritual or the other, particularly the offering of prayer to God first. As of now, there are festivals that precede harvesting of first fruits in many places in Ghana. It is not uncommon to find charcoal, pepper and onion in the items such as sugar, gari (local food produced from cassava) and others being sold by market women. The explanation behind such a practice is that charcoal, pepper and onion can ward off evil spirits from the items being sold.

Furthermore, when a Ghanaian who is hurt or feels cheated by someone and decides not to retaliate, he or she would usually say: mede amma nyame (lit. I have entrusted it to God). This saying is not found among only the traditional believers, but also among Christians and Muslims. In Ghana today, there are more churches than schools and all are filled to capacity during Saturday and Sunday worship. During a research I conducted in the Berekum Traditional Area in the Brong-Ahafo Region of Ghana in 2012, the Chairman of the Local Churches said their official records had more than thirty-three different churches in the Berekum Township alone. It is recorded on the net that as at 2014, there were more than ten thousand (10000) churches in Ghana (www.dw.com/en/too-manychesinn-ghana/a-19140778).

At all official functions of government such as the Independence or Republic day celebration, there is libation prayer, followed by Christian prayer and the Islamic prayer. It is on record that in 1979, Ghanaians elected Dr. Hilla Liman, a practicing Muslim as their president and in December 2016 a Christian was elected as the President while the sitting Vice President is a Muslim.

The above data point to the fact that in Ghana, religion is real. It wields much influence on human behaviour, either positively or negatively, and thus cannot be ignored when discussing factors that have bearings on nation building. This explains why the opening sentence in the preamble to Ghana's 1992 Constitution reads: 'IN THE NAME OF THE ALMIGHTY GOD WE THE PEOPLE OF GHANA...' although it does not officially declare Ghana a religious state. The implication of this is simply that one 
cannot ignore the input from religion in any serious development discourse in Ghana.

\section{Development}

Just as Williams and Millington (2004) said about 'sustainable development', the term 'development is a notoriously difficult, slippery and elusive concept to pin down' (Williams \& Millington 2004:99). In his Religion and Development, Haynes observes that the word 'development' has been a vague yet predictive term, struggling to acquire a precise meaning' (Haynes 2007:5). This opens it to subjective interpretation. Commenting on this dilemma, Sillitoe refers to Hobart's (1993) view that 'Development agencies have been casting around for several years with mounting evidence of resources wasted in ill-conceived, frequently centrally imposed schemes that have not only failed to improve matters in less developed countries, but which have also on occasion made them worse, arrogantly sending in the eggheads to sort out local problems' (Sillitoe 2002:1). For this reason, Kassam (2002) reports Hettne as opining that 'development as it is understood today is a Western concept, which does not reflect the social, cultural and historical realities of other peoples in the world' (Hettne 1995). That is, development has been conceptualized in secular or materialistic terms.

Aryeetey (2002) states that development has been viewed as a state of modernization as well as sustained increase in the real per capita income which results in social and structural changes in a country over a long period of time. These changes include the qualitative and quantitative improvement or transformation of a country's methods of production, roads, and hospitals, level of income, attitude and quality of life. In this conceptualization of development, it is clear that religion has no place in this secular understanding of the concept of development. But let me stress here that in Ghana, and for that matter many places in sub-Saharan Africa, religion is not completely ignored in matters of development by the people, because their understanding of development is informed by their worldview as traditionalists, Christians or Muslims. For this reason, adherents of the dominant religions in Ghana generally believe that development is related to the community's harmonious relationship with their creator--the Supreme Being. This is because in their worldview, the Supreme Being can make and unmake. It is against this backdrop that some intellectuals from the 'so-called' Third World nations have been trying to 
design theories that would work and cater for the realities and aspirations of their own milieus.

Sutton and Anderson (2010) have pointed out that as long as there are different cultures, there will be diverse approaches, even to similar problem(s). It can be argued that this view informed the development of what has become known now as 'ethno-development theory' nurtured by anthropologists such as Symour-Smith in the mid-1980s. 'Ethno-development' refers to 'the right of ethnic groups to participate (or not as the case may be) in modern development process on their own terms (see Kassam 2002:65).

In Ghana, the religious communities viewed development as any other human activity which aims at affirming life in a holistic way and will enable every generation to ensure its survival and be able to hand over the survival status to the future generation. Therefore, for the Ghanaian religious community, development involves the judicious utilization of resources (both natural and human) with the view to achieving growth and meaningful life for the present generation and the subsequent ones (see Awuah-Nyamekye 2009). Simply put, development involves ensuring a holistic or all-inclusive well-being of humans utilizing judiciously the total environment of the people from the religious or sacral point of view (human and economic development), but not a situation where there is economic growth at the cost of greater inequality, high unemployment, loss of cultural identity, consumption of foreign goods and depletion of resources needed by future generations (see Awuah-Nyamekye 2009). This explains the reason why religious communities in Ghana blame the low level of development in the country on not electing God fearing leaders to handle the affairs of the country.

\section{The interplay of Religion and development in Ghana}

To facilitate our appreciation of the contribution of religious communities to Ghana's development, I start by first looking at some of the concrete activities of the selected religious communities that can enhance development in the country.

\section{African Traditional Religion Believers' Contribution to Development in Ghana}

One of the important sources of knowing something about indigenous religion in Ghana is the institution of chieftaincy-traditional system of 
governance. The office of a chief is both religious and political. This is because they serve as the link between the living and the dead. In fact, the chiefs are the embodiment of the religio-cultural beliefs and practices of traditional/indigenous Ghanaians. This explains why they are seen as the earthly representatives of the ancestors; hence the office of a chief is sacred. They, therefore, hold the land and its resources in trust for their people. This also explains why in Ghana, a greater percentage of the land (an important element in development) is vested in the chiefs (traditional rulers). The country's constitution even regards the chiefs as the custodians of the land. For instance, the President of the National House of Chiefs serves on an important state institution like the Council of State (the body set up by the 1992 Constitution to advice the President of the country on important national issues. See Article 89 clause iiib of the 1992 Constitution of Ghana for details).

Land in Ghana also has a religious undertone because it is seen as a divine gift, which the living hold in trust not for themselves alone, but for future generations as well. In the words of Danquah (1928), for the Akyim of Ghana 'land is the property of the ancestors, it is not the property of the living but belongs to the future generation.' It is against this belief that in Ghana land is an unsalable commodity. In fact, taboos abound in the management and distribution of land among the members of a community. Research has shown that perceptions of many Ghanaians about land transcend its productive and resource endowment capacity (Amanor 2001). Ownership is often tied to the living, the dead and unborn (Parrinder 1961; Danquah 1968; Opoku 1978; McCaskie 1995).

Indigenous Ghanaians believe in communalism. This is one of the major bases of the extended family system which is considered as a socio-religious obligation. Elsewhere, it has been argued that 'Akan religion and culture inculcate in the people the sense of sharing and hospitality among kith and kin and even among members of the larger community' (AwuahNyamekye 2012:84). This belief in sharing 'ensures that no one becomes a social and economic liability so as to pose a threat to sustainable development of the community' (Awuah-Nyamekye 2012:85).

\section{Christian Contribution to Ghana's Development}

Enough literature exists (see Pobee 1979; 1991) to show that since its inception in Ghana, Christianity has played a key role in political life and development of the country. For instance, the Christian Council of Ghana vehemently opposed the Preventive Detention Act (PDA) introduced by 
Nkrumah's regime in 1958, which made it possible to arrest and detain some people purported to be saboteurs of the state without a trial. Kudajie and Aboagye-Mensah stressed that 'we ourselves are clear in our minds, that the church has a valid case to be involved in the affairs of the state in all aspects including national politics' (1991:33); while Yirenkyi (2000) explains that 'the clergy constitutes a class not easily intimidated by any government for they are insulated from the risks individual lay persons may face from brutal regimes. '

Aside this formidable political stance of Christians in Ghana, one can state without contradiction that most of what has been termed as grade 'A' Senior High Schools in Ghana today were set up by Christian-related institutions. One can mention a few of them--the Presbyterian Senior High School, Legon, Accra (Presbyterian Church), Wesley Girls Senior High School in Cape Coast (Methodist), Holy Child Senior High School in Cape Coast (Roman Catholic), Adisadel College, Cape Coast (Anglican). Church-based institutions are also not lacking at the tertiary level. We now have Methodist University College in Accra with satellite campuses dotted across the country, Catholic University College at Fiapre in the BrongAhafo Region, and Presbyterian University College at Abetifi in the Eastern part of Ghana. Central University in Accra established by ICGC, Dominion university College in Accra established by Christian Action Faith International, Pentecost University College Accra, and many others.

\section{Muslims' Contribution to Ghana's Development}

The contribution of Islam in the area of world civilization, particularly in medicine, science and technology is common knowledge. In Ghana, some of the contributions of Islam to development are discussed in the following paragraphs.

In terms of education, Muslim communities have contributed immensely to the advancement of formal education. Although many of their schools were set up with Islamic education in mind, secular education is never ignored. This is evidenced in the fact that most of the Islamic schools in Ghana accept non-Muslim students. In the case of Sunni Muslims in Ghana for instance, their contribution in the area of secular education cannot be discounted. Examples include Sheikh Appiah-Adu Senior High School in Kumasi, and Siddiq Senior High School at Agona Nyarkrom near Swedru. They also have the Nana Khadija Vocational School at Agona Swedru in the Central Region of Ghana. They have on many occasions awarded scholarships to deserving Ghanaians to pursue higher degrees 
both within and outside the country. They now own an Islamic University College in Accra, the capital city of Ghana. The Sunni Muslim community also helps in the provision of social amenities such as boreholes and wells for needy communities in many parts of the country. In the area of agriculture, they help by hiring out farming equipment such as tractors, and combined harvesters through the agriculture centre they have set up in Tamale, in the Northern Region of Ghana.

On the Ahmadiyya Movement front, their contribution to secular education is marvellous. Since its arrival in Ghana (the then Gold Coast) in 1921 at Saltpond in the Central Region of Ghana, the movement has set up an uncountable number of elementary schools throughout the country. One of their top Senior High Schools (SHS) in Ghana is the T. I Ahmadiyya Senior High School in Kumasi. The Movement has a Teacher Training College in Wa, the capital of the Upper West Region of Ghana producing teachers for secular education to complement the government's quest to train more teachers for formal education. In the area of health, the Mission has set up a number of hospitals and clinics largely in non-urban areas (Daboase, Agona Swedru, Agogo and other places) in Ghana. They have established a university at Mankessim in the Central Region of Ghana admitting students from all faiths. Not only these, but also, the Movement is into agriculture. It has a cattle ranch at Winneba in the Central Region of the country and a demonstration farm in the Northern Region of Ghana concentrating on wheat growing, one of the staple foods in that part of Ghana (see Gyasi 2004 for other details of the Movement's contribution to national development).

\section{Collective contribution of the three religious bodies to development in Ghana}

On environmental issues, there is evidence that all the religious bodies are making attempts to do something particularly in the area of environmental degradation. But indigenous religion's efforts are much better than the other religious traditions (see Awuah-Nyamekye 2014). Besides this, one can also talk about the collective contribution of religious bodies in Ghana towards offering help, particularly in times of national disasters. They mostly donate either in kind or cash to complement government's efforts. What this implies is that religion is a key factor in national development in Ghana. 


\section{The negative role of religion in Development in Chana}

The discussion above presented religious bodies in Ghana in a very good light in terms of their contribution towards national development. I must stress, however, that not all their activities ensure development. To say the least, some of their activities do not only undermine development but also pose a serious threat to human security in Ghana.

Chiefs are the fulcrum around whom local development revolves. But there is a countless number of chieftaincy-related conflicts in Ghana today. One of the characteristics of communities bedevilled with such disputes is a reduction in their speed of development. Life in such communities becomes less open and productive due to mutual suspicion, factionalism and recurrent violent escalations with the risk of harm to life and property among disputing factions.

There have been instances where some media houses have reported that some faith groups in Ghana have been preventing their members from receiving formal education and accessing formal healthcare. This situation in 2014 compelled Rev. Dr. Kwabena Opuni-Frimpong, the General Secretary of the Christian Council of Ghana, to issue a statement to the effect that "some self-styled 'pastors' are engaging in religious excesses by forbidding their members from going to school, accessing health care and working to earn a living, because they perceive such acts to be against the teachings of Christ (Opuni-Frimpong 2014). Clarifying this, he said that "recent media reports of some churches not allowing their school-going children to go to school, and pregnant women from accessing healthcare because they claim Jesus never went to school or the hospital, are but a few of the wide-spread religious excesses in the country today" (OpuniFrimpong 2014). A religious group such as the Jehovah's Witnesses does not permit its members to take part in elections in the country for the simple reason that it is 'unbiblical.' One question that needs an answer is that if all the religious groups in the country should accept this doctrine who would fulfil the responsibility of selecting people to lead the country? Other disturbing aspects of religious activities in Ghana today include the upsurge in the proliferation of churches usually founded by individuals claiming that they are capable of making people become rich overnight and even assist them to get visas to go to Europe and America. Their modus operandi includes the sale of what they claim to be 'holy handkerchiefs', 'holy water' anointing oils of all kinds, bracelets, and rings. These activities have attracted many people to such Churches. These items are often sold at higher prices to their clients. It is now a common practice for 
people to close their shops during weekdays to attend prayer and deliverance sessions organized by 'men of God' to become rich overnight. Even some government officials are anecdotally said to avail themselves of such prayer camps and their deliverance sessions. It said that some of these officials leave their offices during working hours surreptitiously.

There is now a new dimension to quick ways of acquiring wealth. These 'so-called men of God' own radio and TV stations and use these media to advertise their capabilities to attract the unsuspecting public. Even now some of the private radio and TV stations in the country give airtime to traditional African priests and priestesses, mallams (Muslim clerks/diviners as known in Ghana) to do the same. It is no wonder that even some teenagers have abandoned school to consult these 'magicians' to get wealthy overnight. In many communities in Ghana today, one can find people of less than twenty years of age owning mansions and a fleet of cars through the rituals they are directed to go through from these socalled spiritualists.

Asamoah-Gyadu (2005:10) puts the association of Christian Ministry with quick economic gains as: 'until the emergence of the charismatic movement (ministries) and for that matter (prosperity gospel), Christian ministry in Ghana was seldom considered an avenue for economic gain.' A notable feature of the prosperity preachers is that they arrange their services-prayer, counselling, consultation, healing--to cover almost the whole weekdays. The adverse effect of this arrangement is that precious time is always spent at such services throughout the weekdays; this will definitely have implication for production which is vital ingredient in development process. Most often, these services end with a sale of all manners of items-holy water, holy handkerchief, Florida water, anointing oil, wrist bangles, stickers, candles—at exorbitant prices to the members of the congregation.

Beside the above anti-development activities, there are some sporadic religion-related conflicts. These are mainly in the form of inter and intrareligious clashes. These are usually between Christians and Muslims or between Christians and indigenous religious practitioners of Ghana. The ones between Christians and indigenous religious practitioners are a result of an annual ban some chiefs and their elders place on drumming and dancing prior to their annual indigenous festivals. In the Muslim front, the clashes are usually between the Al-sunni (Orthodox/traditionalist Muslims) and Tijaniyya. Such conflicts normally lead to the destruction of lives and property. 
Undoubtedly, such behaviours are anti-development, but we must also not lose sight of the fact that though such activities are undesirable, yet they cannot write off or completely negate the positive role that religion has been playing in developing the nation as pointed out earlier in this discussion. It is against this backdrop that this chapter sides with the third perception or opinion that religion has an ambivalent character in terms of its interplay with development.

\section{Efforts to manage the undesirable activities of religious bodies for development}

Recognising the negative side of religion in its interplay with development in Ghana, one can point at the following as some of the measures put in place to mitigate the effects of some of the anti-development elements associated with religious beliefs and practices in Ghana:

- Ghana now has what is known as Peace Council in place. This Council draws its authority from the 1992 Constitution. Religious bodies are represented on this Council to deal with inter and intra-religious conflicts as well as socio-political conflicts in the country.

- The Ahmadiyya Movement has a radio and TV programme dubbed Islam in Perspective. This programme focuses on spiritual development, charity, religious tolerance among Muslims and between Muslims and non-Muslims. This programme has been accepted by both Muslims and non-Muslims in the country.

- Some of the private Christian-related TV and Radio stations are also using their stations to address the reality of religious pluralism in Ghana today. Some Muslim youth join their Christian counterparts to celebrate Christmas and Easter, while many Christians also in reciprocal manner join their Muslim brethren in Baraka da salah during the Eid festivals.

- There are instances, particularly during elections, where joint statements are issued by all the religious bodies to condemn behaviours of political parties which in their view can disturb the peace of the country.

- Some religious bodies are called in to mediate in chieftaincy disputes in some parts of the country. Such calls often become necessary when the disputants are suspicious of state institutions to deal with such conflicts. This role is crucial because the chiefs are fulcrum around whom local development revolves. 
Obviously, the above are healthy signs to prune religion of some of its anti-development tendencies in Ghana.

\section{Conclusion}

In this chapter an attempt has been made to examine the interplay between religion and development. It has also been pointed out that the role of religion in the development studies has been extremely diverse due to the reality of the ambivalent nature of religion particularly anti-development tendencies associated with the practice of religion and their cumulative effects in development process of Ghana, and for that matter, other places in the world. This notwithstanding, enough evidence has been adduced in the discussion to demonstrate that in spite of the negativities that characterize the expression of religion in Ghana, religion can still be a useful partner in the development agenda of a country provided it is managed well. Therefore, the central argument of this chapter has been that one will not be far from right to posit that there is a justification for not neglecting the input of religion in Ghana's quest to develop the country with the view to eradicate or mitigate the level of poverty in the country. In doing so, as the foregoing discussion has shown, it is recommended that the study of religion and development be given the needed boost by resourcing adequately the stakeholder institutions to do more research through workshops and conferences focusing on the interplay between religion and development in the country. In this way, more benefits could be derived from such a venture for Ghana's development agenda.

\section{References}

Alkire, Sabina. 2006. Religion and development, in Clark, David Alexander (ed.), The Elgar Companion to Development Studies, (502-510). Cheltenham: Edward Elgar, 2006.

Amanor, K. (2001). Land, labour and the family in Southern Ghana: A critique of land policy under neo-liberalisation. Goteborg, Sweden: Elanders Gigitaltryck AB.

Asamoah-Gyadu, J. K. 2005. African charismatism. Accra, Ghana. African Christian Pr. Aryetey, E. 2002. Working paper 41-informal finance fpor private sector development in Africa. Working paper series African Development Bank.

Awuah-Nyamekye, S. 2014. Managing the Environmental Crisis in Ghana: The Role of African Traditional Religion and Culture with Special reference to Berekum Traditional Area. Cambridge: Scholars Publ. Ltd. 
Awuah-Nyamekye, S. 2012. Religion and development: African Traditional Religion's perspective. Journal Religious Studies and Theology, 31(1):75-90.

Awuah-Nyamekye, S. 2009. Salvaging nature: The Akan religio-cultural perspective. Worldviews: Global Religions, Culture and Ecology, 13 (3):. 251-282.

Barro, Robert J. \& Rachel M. McCleary. 2006. Religion and political economy in an International Panel. Journal for Scientific Study of Religion 45(2), 149-175.

Bellin, Eva. (2008). Faith in politics: New trends in the study of religion and politics. World Politics 60(2): 315-347.

Bitek, Okot p', (1971) African religions in Western scholarship. Nairobi, etc.: East African Literature Bureau.

Cox, J. L. 2010. An introduction to the phenomenology of religion. London, New York: Continuum.

Danquah, J. B. (1928). Akan laws and customs and the Akyim Abuakwa Constitution. Oxford: Oxford Univ. Pr.

Danquah, J. B. (1968). The Akan doctrine of God. London: Frank Cass. FEP International Private Limited.

Deneulin, S. \& Bano, M . 2009. Religion and Development: Rewriting the secular script. London \& New York: Zed Books.

Ghana 2015 International Religious Freedom Report., available at http://www.state. gov/documents/organization/256241.pdf acc. Febr. 8, 2018

Gyasi, I. K. (2004). Ahmadiyya's Contribution to National Development. Ghanaian Chronicle, March 82004 edition, also available at http://www.jalsasalana.org/ghana/2004/news. 1.html acc. March 12, 2018.

Haynes, Jeffrey. 2007. Religion and Development: Conflict or cooperation? Palgrave: Macmillan.

Hettne, B. 1995. Development theory and three worlds: Towards an international political economy of development. London: Longman Scientific \& Technical.

Idowu, E. B. (1973). African tradition religion; A definition. London SCM Pr. Ltd.

Kassam, A. (2002). Ethonotheory, ethnopraxis: Enthnodevelopment in in the Oromia regional state of Ethiopian. In: Paul Sillitoe, Alan Bicker \& Johan Pottier (eds.).

Participating in Development: Approaches to Indigenous Knowledge. Routledge: London \& New York, 64-81.

McCaskey, T. C. (1995). State and society in pre-colonial Ashanti. Cambridge: Cambridge Univ. Pr.

Kudadjie, J. N. \& Aboagye-Mensah, R. 1991. Christian social ethics. Accra: Asempa.

Mbiti, John S. 1969. African religions and philosophy. London: Heinemann

Noland, Marcus. (2005). Religion and economic performance." World Development 33(8): 1215-1232.

Opoku, A. K . (1978). West African Religion. Accra, Bangkok, Hong Kong: FEP

Opuni-Frimpong, (2014). Pr. Statement condemning strange doctrines

Parrinder, G., (1969), Religion in Africa. Harmondsworth: Penguin Books

Platvoet, J. \& Rinsum, Henk van 2003. "Is Africa incurably religious?," Exchange, Jan. $54303 \times 00190$. 
Pobee, J. S. (1991). Religion and politics in Ghana, Accra: Asempa.

Pobee, John S. 1979. Toward an African Theology, Abingdon/Nasshville.

Ruben, Ruerd. 2011. Can Religion contribute to Development? The road from 'truth' to 'trust'. Exchange. 40: 225-234

Sillitoe, P. (2002). Participant observation to participatory development: Making anthropology work. In: Paul Sillitoe, Alan Bicker \& Johan Pottier (eds.). Participating in Development: Approaches to Indigenous Knowledge. Routledge: London \& New York, 1-23.

Sutton,M. Q. \& Anderson,E . N. 2010. Introduction to cultural ecology $2^{\text {nd }}$ edn. Lanham. New York, Toronto, Plymouth, UK: Altamira Pr.

The 1992 Ghana's Constitution

Too Many Churches in Ghana2014. Available at (www.dw.com/en/too-many-chesinnghana/a-19140778), Acc., 23-01-2018

Wilber, \& Jameson K. P. 1980. 'Religious Values and Social Limits to Development', World Development 8: 467-479.

Williams, C, Colin \& Millington, C Andrews . 2004. The diverse and contested meanings of sustainable Development. The Geographical Journal. 170 (2): 99-104.

Yirenkyi, Kwasi. The role of Christian churches in national politics: Reflections from laity clergy in Ghana. Available at file://A:/ai_66498059.htm . 



\title{
Religion and Development in Uganda
}

\author{
Andrew David Omona a Uzziah Maate Kiriaghe
}

\section{Introduction}

Religion, the valuation of the ideal, has been very instrumental to human life from time immemorial. As an aspect of culture, human beings have used it to "explain the workings of nature and the existence of things" (Glencoe, n.d:3, 22). Indeed, in many primal and modern cultures, religion was and still is the organizing principle of life. Given that religion is located within the total life of the person and not belonging to a separate realm, one could not distance oneself from it but rather reflect on it objectively. Even before the introduction of the Abrahamic religions, that is, Christianity, Judaism and Islam, and the non-Abrahamic religions like Hinduism, Sikhism and others, in Uganda, as Kenneth Mtata (2013:23) argues:

Religion was the belief and knowledge system around which all reality was organized. Such a system revolved around the ubiquitous presence of the gods who tended to manifest both malevolent and benevolent powers. Such a worldview comprised specific practices carried out within known institutions associated with such beliefs. As such, individual and community wellbeing was not conceivable outside this religious system. Life was assumed to be enabled by divine agency, assisted by special human agents acting on behalf of the gods. The gods gave victory in war, success in hunting, guaranteed rainfall and the fertility and productivity of the land and human beings. The mutual obligations of this covenantal relationship remained intact only as long as human beings acted within known boundaries of harmony and treated other created things as sacred as well as appeased the gods through certain rituals.

The above assertion by Mtata clearly explains the position of religion in human development even in traditional settings. Following the prescribed beliefs, rituals and practices helps to propel the people of a community forward. Given such pivotal role religion plays in development, the former President of the World Bank, James Wolfensohn, foresaw the need for closer collaboration of the World Bank and other development institutions with religion. According to him: 
Religion is an omnipresent and seamless part of daily life, taking an infinite variety of forms that are part of the distinctive quality of each community. Religion could thus not be seen as something apart and personal. It is, rather, a dimension of life that suffuses whatever people do. Religion has an effect on many people's attitudes to everything, including such matters as savings, investment and a host of economic decisions. It influences areas we had come to see as vital for successful development, like schooling, gender quality, and approaches to health care. In short, religion could be an important driver of change, even as it could be a break to progress. (Wolfensohn 2011:8).

Wolfensohn's assertion blends well with what foreign religions have done in Uganda's development right from their introduction. The religious faith of people helps shape their view on development and their life in general because it provides the unifying power that grounds the sociopolitical, economic, technological, cultural and moral dynamics of a culture.

The centrality of religion to development in Uganda did not just start with the introduction of foreign religions. During the pre-colonial era, whereas "development of communities was propagated through involvement in manual labor", Rosemary Wahu Mbogo rightly argues, "[a]t the center of this was the religion of the people.” (Mbogo 2015:172). To an extent, cultivation of land and expansion of tribal wealth through agriculture and livestock farming involved performance of religious rituals. As individuals in a given community sought to improve their wealth through marrying many wives who will in turn produce many children to provide the required manpower to cultivate expansive chunks of land, they did not go against their religious ideals while engaging in agriculture, but rather observed the required practices methodically (Mbogo 2015:172-173). By the time this traditional arrangement was interrupted by the introduction of Islam by the Arabs and Christianity by the missionaries, the various ethnic groups who live in present-day Uganda knew how to move themselves from one level of development to another using wisdom from their religious traditions.

Viewed from a theoretical perspective, this chapter uses the lenses of modernization, dependency, and globalization theories to analyze the deployment of religion in development in Uganda. Although these development theories started to be espoused by development theorists well after the Second World War and foreign religions were introduced in Uganda much earlier, the approaches used by the religious groups to participate in development could be seen using the theories, as below. 


\section{Theoretical approaches to Religion and Development in Uganda}

The participation of religion in development in Uganda could best be explained by theories of development like modernization theory, dependency theory, and globalization theory.

First, modernization theory is a theory that uses a systematic process to move underdeveloped countries to a more sophisticated level of development. As an American-centred and Euro-centric normative model of development, modernization theory focuses on cultural change directed at institutional structures in non-industrialized countries. The most celebrated and influential theorist of modernization theory was the American historian Walt Whitman Rostow. In his book Stages of Economic Growth (1960), he sees societies as lying within one of five categories, when speaking about their economic dimensions. The stages in order of his ranking are the traditional society, the precondition to take-off, the take-off, the drivers to maturity and the age of mass-consumption (Dang and SuiPheng 2015:16). According to Rostow it is possible to juxtapose the development going forward in Asia, the Middle East, Africa, and Latin America, with the transitions experienced by the Western world (Rostow 1990:139; Solhjell 2012:10).

Looking at the Modernization Theory from the perspective of the role of religion in development, the theory fits within David Livingstone's concept of the three "Cs" of: Civilization, Christianity and Commerce for African development. Using a Eurocentric prism to measure human development, the Christian missionaries deemed African cultures as primitive, hence they had the mission to modernize it using the Judeo-Christian philosophical framework. To the missionaries, as development theorists espoused, to modernize the African societies meant to make them more productive, through educating their children who would be able to receive more welfare (Giovanni 2001:2; Shareia 2015:79). Indeed, the foreign religions became the vehicle to human development in Uganda.

Second, the Dependency Theory- was presented as a theory of development that improves the Modernization Theory (Reyes 2001). It combines elements from a Neo-Marxist Theory and adopts a "revolution of underdeveloped nations' model". The focus of this theory is the totality of society and social system periphery, which highlights the differences between imperialistic countries in the first world and underdeveloped countries. Dependency Theory explains these differences by focusing on regions and structural conditions in different nation states (Lubale 2015:81). To limit the burden of dependency, the modern religions instilled in the people of 
Uganda the practical aspects of the principles of the "three self s: self-governing, self-propagating and self-supporting" that Henry Venn (18411872 ) and Rufus Anderson (1832-1866) espoused. The missionaries ensured that the indigenous Ugandans acquired the necessary skills to govern themselves, propagate the new religion and be industrious to meet their own desired goals (Reese 2007).

Through instilling the need to self-support, self-propagate, and self-govern, religious leaders were able to teach the local people to be productive thereby leading to development at local levels. Unlike Karl Marx who viewed religion as an opium of the people, the leaders who introduced modern religion in Uganda, like Max Weber, saw religion as having the power to influence cultures for positive purposes (Hitzler 2013:14-15). Therefore, they used the ideals of hard work espoused in the scriptures to teach people to engage in gainful work other than being idle. Consequently, through participation in actualizing these ideals espoused by religion, the adherents of these religions have developed certain personal traits such as work ethics, thrift, honesty, and openness. These traits in turn made them to be economically productive because it made people to develop in group trust and cooperation that help overcome collective actions problems (Lubale 2018:80).

Third, Globalization Theory. This is a theory of development (Reyes 2001) that uses a global mechanism of greater integration with particular emphasis on the sphere of economic transactions. It is a US- and Europecentric positive model of development whose feature is the spread of capitalism around the globe. Globalization Theory focuses on communications and international ties, which ties are directed towards cultural and economic factors in communication systems. The theory explains inequality through identifying cultural and economic factors in global connection (Lubale 2015:83). Religion, as an engine of globalization played a pivotal role to linking development that is taking place in one corner of the world to a particular place. In Uganda, the adherents of the different religions have travelled around the globe. Starting with the people who played a greater part in introducing foreign religion in Uganda, they were able to introduce what was taking place in their areas of origin into Uganda.

This chapter uses the theories highlighted above as a backdrop to explain the contribution of religion in development in Uganda. In the section that follows we now turn to discussing how religion helped in causing both qualitative and quantitative development in Uganda. 


\section{The contribution of religion to development in Uganda}

In most development literature the contribution of religion to development attracts mixed interpretation. The historical avoidance of religion in development literature is due to the fear of it imposing an outside perspective, an apprehension of creating conflict, and a lack of precedent for addressing the issue (Lubale 2018:79). Partly, the reservation that people have on religion in development could have been, as Mbiti observed due to "[t]he image that Africans received... of Christianity, that is much colored by colonial rule and all that was involved in it" (Mbiti 1969:231). However, in the case of Uganda religion has been a key factor in spearheading development in all spheres. Since beliefs, values and morality traditionally reside in the realm of religion and culture and thus a number of scholars from diverse disciplines such as Gerrie ter Haar \& Ellis Stephen (2006), Dana Freeman (2015) and others have recently started to look at the role of religion in development.

Quoting Adam Smith, Lubale (2018:78) observes that religion has played an important role in 'development' in terms of being a moral enforcement mechanism. According to him, over the years, religion has acted as catalyst for accumulation of social capital and thereby growth, which is a widely accepted arm in development (Lubale 2018:80). Indeed, as Amitore Fanfani (1935:2) observes, in Uganda, religion has influenced life in general and economic life in particular, either as a doctrinal system or as an organized system resonating with Adam Smith's view.

The introduction of foreign religion in Uganda came with the introduction of formal education. The initial education system was set up by the Christian missionaries, then the Muslims also joined in the venture after independence. While this is not to say that before the coming of missionaries there was no form of education, but this is to say that alongside the traditional form of education which was primarily transmitted through observation in natural settings, a formal education that follow written curricula was established. This formal education went side by side with the traditional education. In the traditional education where lessons were mastered through songs and dances, poetry and proverbs, the formal education introduced age and class specific areas to be covered (Omatseye, and Olijere 2008; Mbogo 2015:171). All over Uganda, where Christian Mission stations and indigenous churches are found, the missionaries set schools which are still being used today. They saw education to be necessary for the propagation of the Gospel and therefore, literacy was essential for enabling people to read the word of God. This same literacy is at the 
center of technology and scientific advancement, which promote development. It also supports skills for administration and management of resources and as well as structures for maintaining social, political and economic systems that sustain society. This has historically put the church at the center of development.

The education system introduced transformed the nation from the vestiges of traditional beliefs to modern knowledge. As each Christian group struggled to take centre stage in the affairs of the country, education continued to be their major contribution. Schools became the means through which development was propagated. The Church Missionary Society (CMS) opened schools such as Mwiri (Busoga), Nyakasura (Toro), Nabumali (Bugisu), and Gayaza for Girls. Kings College Budo was the apex of them all. The Roman Catholic on the other hand opened Kisubi (White Fathers), Namilyango (Mill Hill Fathers) and seminary that was set for training priests. The Muslims, after the 1960s, also joined in the provision of educational facilities. Apart from the so called "big name schools", everywhere places of worship were established, the faith organizations opened up rural schools for education of the masses. The missionaries used these schools as places of transformation of the local communities from the vestiges of what they thought was "backwardness to modernity".

Although in the first instance provision of education was not a priority on the agenda of the colonial administration, in the 1920s it sought more control of education and introduced a secular curriculum. In spite of this, the teaching of religious education was allowed by the government (Gottnied 1976; Balyage 1998). Instead of looking at each other as rivals in the provision of education to the local population, in the 1920s and 30s, both missionaries and government joined hands to improve standards by setting up teachers' training institutions. The unfortunate side of the education provided in these schools was that it was elitist in nature. When the Phelps Stokes Commission came to Uganda in 1924 and recommended the establishment of education "adapted to the needs of Africans", the commission's recommendation for training artisans was interpreted by Ugandans to mean they had intended to set up inferior schools for their children. This, therefore, somewhat frustrated the setting up of technical schools for a while, though as time went by, they were eventually established to train artisans.

As a pioneer body of educational institutions, to date in Uganda the faith bodies lead in provision of education right from primary, secondary and 
tertiary education (Stambach 2010). For example, among the over 45 universities registered and/or accredited by the government, over 10 of them were founded and are run by religious groups. Through these educational institutions, faith groups have labored to educate the people of Uganda and beyond as they sought ways to remain relevant with regard to modern developments in the nation and the world.

The people who went through religious schools actively participated in the political development of Uganda. These educated people provided the required human resources that became essential for leadership in the country. In the Kingdom and chiefdom areas, the kings and chiefs sent the children of the peasants to acquire modern education. On getting the required education they became administrators, secretaries and clerks in the colonial administration. The literacy culture that these administrators got helped them to understand what is good for their people. Although some of the leaders who were educated joined in torturing their own people, by and large, others provided the needed administrative support and participated in the political development in the country.

The interest of religion in both the temporal and futuristic wellbeing on human beings need not be overemphasized. When the missionaries came to Uganda, they did understand this well. They knew that for a person to be attentive to the word, his or her temporal life has to be taken care of. To this end, to help improve the temporal lives of the local people, the missionaries enhanced cash economy by encouraging the growth of tropical raw materials like coffee, cotton to satisfy the British industrialists urge. Bishop Boroup, for example, introduced cotton growing in Uganda (Africason, n.d). This was somewhat an implementation of what David Livingstone had in mind when he advocated for the three "C" policy: Christianity, Civilization and Commerce (Nkomazana 1998:45). Livingstone believed that "Christianity would provide principles for moral guidance, while legitimate commerce and education would encourage Africans to produce their own goods from their fertile soil to trade with Europeans." (Manala 2013). The missionaries introduced cultivation of cash crops like coffee and cotton in large scales. The sales of the produce from these cash crops boosted the economy of the local people, thus helping them to avert poverty, pay their children's school fees and afford to pay for their heath bills.

Initially, trade during the pre- foreign religions in Uganda was barter trade. Eventually trade in human beings was introduced by the slave traders. When the Christian missionaries introduced trade in goods other 
than human beings, they definitely made an affront to some kings and chiefs who had collaborated with the slave traders to sell the powerless who could not protect themselves into slavery. As a starting point the modern religions created "societies where there was widespread belief in God", that resulted in the prevalence of values of honesty and integrity. One such group that stood out in this venture was influenced by the East African Revival Movement. To the members of the revival movement, the tenets of hard work espoused in the Bible made them encourage hard work amongst the brethren. This made the people who joined this group to become different from their neighbors whose lives had not been touched by the spirit of the revival. Those who got 'saved' kept healthy lifestyles free of alcohol, tobacco and other forms of additives. They shunned sexual immorality, sent their children to school using the monies they generated, and kept their bodies and homes clean by observing a high level of hygiene. On average, they lived a better quality of life as compared to those who chose to live reckless lifestyles. Consequently, they became leaders in their communities by showing to the masses the right way of using resources.

Given that health is a prerequisite for the productivity of a population and their receptivity to the gospel, the missionaries spearheaded the health sector development. The CMS established Mengo Hospital in 1897 under the auspices of Sir Albert Cook and his wife Kathleen Cook and the Roman Catholic Church (RCC) established Rubaga Hospital, Nsamby Hospital (Tuma 1978:25-26), and several other health facilities. Later on, the Muslims opened up Kibuli Hospital and other health centres around the country. The introduction of these hospitals and other health facilities around the country rescued people from the brunt of different forms of ailments. Sleeping sickness, gonorrhoea and other diseases that were prevalent in Uganda when the missionaries arrived were taken care of. For example, as early as 1901, when the epidemic of smallpox broke out in Bukedi, Bishop Tucker and Doctor Cook responded swiftly to contain it. This was because they knew that a sick body will not be able to listen to the Good News they had come to preach. This quick response enabled the menace of the smallpox to be addressed by 1903. Furthermore, in 1901 and 1910 when famine and sleeping sickness broke out in Busoga, the missionaries' health team helped in addressing the situation as part of the holistic ministry they came to provide in Uganda. Whereas the traditionalists who had occupied the developmental agenda amongst the local peo- 
ple over the years explained the outbreak of the famine and diseases superstitiously that they were as a result of the unhappiness of the gods against the local people for welcoming of the foreigners, the intervention of the religious groups helped to increase the trust of the people in what they were doing amongst them. In other words, as Tom Tuma observes, this afforded the religious leaders with an 'opportunity to exercise their medical missions more fully than ever before' (Tuma 1978:53).

In the bid to make health services available to the masses of the population of Uganda, the Protestant churches set up the Uganda Protestant Medical Bureau (UPMB), the Roman Catholic has the Uganda Catholic Medical Bureau (UCMB), and the Muslims also have theirs. These Medical Bureaus assist the Joint Clinical Stores (JCS), the government medical stores, to procure and supply health kits and medicine to religious founded hospitals, health centers and clinics across the country. Besides these, there are a host of traditional practitioners who use local herbs to treat the people of Uganda. This, they do because they know unless a human being is healthy, he or she cannot be productive. Through the health facilities, the religious bodies carry out health education, immunization programmes and other public health awareness campaigns.

The historiography of Christian missionary enterprise in Africa exploring the interplay of missionary encounters with African peoples shows that the cultural contacts transform African societies (Pawliková-Vilhanová 2002:49). The major cultural shade that was behind this was religion. While some people argue, as Jacob Zuma, the former President of South Africa that "Christianity - introduced by European missionaries mainly in the nineteenth century-had destroyed the safety net for orphans, elderly people and the poor" (Smith 2011), on the contrary in Uganda it has been associated with being a 'civilizing' force. It has had influence on cultures through reforming some for the better. The teachings espoused in the modern religions have helped people to do away with superstition and cultural practices that are harmful to human well-being. The teaching on the equality of humanity has helped to curb the oppression of women and torturing of pregnant women, in particular. Modern religion, following Niebuhr's Christ and culture model (Menuge 1999) used Christianity as an engine for positive cultural transformation by ushering better lifestyle, thus making people to embrace modernity.

Still in cultural perspective, modern religions have positively improved the belief system of the people of Uganda. However, this is not to say that before the introduction of the modern religions there was nothing positive 
about traditional beliefs of the people of Uganda, but rather it is to say the introduction of the modern religions helped to reduce some bad practices such as the use of charms, twin neglect, abuse of human rights, treating of women inhumanly and other practices. By preaching equality of human beings, the missionaries opened people's eyes so much so that even the people who used to see women and twins as less human started to see them as God's creation who deserved to be protected.

Furthermore, modern religions have opened the eyes of people to look beyond the narrow perspective of a community in terms of a clan and ethnic groups. To the extent, modern religions developed, in the people, religious norms that enabled them to expand the horizon of their concept of the society from the micro to the macro level (Emerson, Monahan, \& Mirola 2011). This, in Uganda, as elsewhere, created a covenant community: a community of relationships, where people of diverse backgrounds are united by sharing in common identity and purpose. Therefore, such exercise of neighborliness and belonging to a common kingdom where God is the King made much sense. At both micro and macro levels, it brought peace between communities that used to be in conflict with one another (Omona 2007:58).

In as far as social development in Uganda is concerned, religion has also played a great role. Over the years, issues of human rights, social justice, social services, disaster and relief and others have been central on the agenda of the religious organizations. Never in the difficult times in Uganda did religious organizations left the center stage and took a peripheral stage. The presence of religious bodies in all these spheres has made religion to be a force to reckon with in providing social protection based on charity principles (Kaag \& Saint-Lary 2012; Weiss 2002). There are several empirical studies that demonstrate the centrality of religion in enforcing change in as far as development is concerned in Uganda. The specific and growing corpus of literature shows that faith-based organizations (Bornstein 2003) are at the forefront of development agenda in different countries, including Uganda. While such organizations may have diverse objectives other than evangelization, they have also worked tirelessly in the promotion of local economies, fighting HIV \& AIDS (Bornstein 2003). In terms of performance, the organizations are generally considered to be more effective because they are culturally close to their target groups (Benthall 2007).

The above assertion is buttressed by a surge of anthropological approaches that link religion and public life (Sounaye 2007) at the dawn of 
the $21^{\text {st }}$ Century. For example, Mayke Kaag and Maud Saint Lary (2012:12 ) show that the strong societal engagements of religious actors and religiously inspired forms of citizenship have awakened awareness of the local population's role in the political life of the country. Religion has enabled socially neglected groups such as the youth and women to be exposed to new modes of public expression (Masquelier 2009; Soares 2009). This has been very true in Uganda given the numbers of women and youth who have actively taken part in the affairs of the country.

During insurgencies in Uganda, religious places of worship have often been places of refuge and support. As their God-given mandate, religious groups in Uganda have swiftly responded to situations of war, refugees, famine, social strife and oppression. As early as 1901, in Busoga, the mission centers were used as centers to distribute food to the starving Basoga. This was also the case in West Nile in 1917 when severe hunger broke out, the district commissioner enlisted the support of the missionaries in the distribution of food relief (Russell 1978:57).

Besides, in Uganda religious leaders have been at the forefront of addressing contemporary issues of oppression, bad governance, corruption, equity, access to resources, protection of minority groups (individuals and cultures), environmental degradation, and the monster of poverty. Given that peace is a precondition for human development, religious ideas of various religions: indigenous religions as well as world religions, play an important role in addressing violence in Uganda. The increasing, largescale violence in Uganda that is associated with social conflicts had religious figures who tried to sort it. Though on the other hand, as Stephen Ellis \& Gerrie ter Haar (2014:4) observe "In many such conflicts fighters seek medicines or various objects or substances that they believe will make them effective in battle or will defend them against injury, and the persons who dispense such medicines exercise influence over the fighters". In Uganda, the Uganda Joint Christian Council (UJCC) and para religious organizations like the Acholi Religious Leaders' Peace Initiative (ALPI), for example, have been involved in civic matters including participation in the peace process in northern Uganda following the insurgency perpetuated by the Lord's Resistance Army (LRA) led by Joseph Kony (Omona 2009). As noted above, during the fierce battles between the government armies and the rebel outfits in northern Uganda, centers of worship became places of abode for the displaced. Many such leaders volunteered to speak to both the government and the rebels on the need to give peace a chance so as to reduce the suffering of the local population. 
In 2015 as the campaign for the 2016 elections was at its hottest point, the Religious Leaders' Justice and Peace Network (JuPeNet) came to the limelight to encourage peaceful campaigns and post-election co-existence amongst Ugandans. JuPeNet, a loose coalition of religious leaders of like minds, believes that justice and peace is a way for sustainable development. Indeed, the fervent efforts religious leaders of all shades have made acted as ingredients to development, because peace and stability are a prerequisite to meaningful development. In doing so, JuPeNet augmented the ongoing work of UJCC and Inter Religious Council of Uganda (IRCU). These organizations have constantly been issuing press statements and writing pastoral letters to the masses in Uganda to keep peace with each other. As part of the democratic development in Uganda, the IRCU in conjunction with the Elders' Forum of Uganda (EFU) organized Presidential Debates in which the presidential candidates presented to the people of Uganda their manifestos.

Given that religious convictions shape human attitude and worldview in very profound ways, people's concern on the environmental issues have been awakened by religion. Many faith bodies in Uganda have taken discourse on environmental sustainability seriously. Drawing from biblical principles, the advocates are greatly impacting knowledge on environmental sustainability. To them the concept of Christian Stewardship requires human beings to be responsible for the world and take care of the environment so that through that they will be able to feed themselves and leave the world a safer place for the generations to come. In response to this, some religious leaders have joined the campaign of tree planting on open lands (Ahimbisibwe 2010). Some clergy have ensured that all candidates who are to take part in sacraments plant at least a tree on the church land before they participate in such a ritual. Through this campaign, reforestation has been done in areas that have once been rendered waste lands.

Partly the participation of religious groups in matters of the environment sustainability stems from the fact that environmental degradation and climate change pose serious challenge by exacerbating communities' fragility and increased resource-based conflicts. In doing so, they are able to address conflicts especially pertaining to water and other natural resources. Given some of the religious groups in Uganda are members of the All Africa Conference of Churches (AACC), they did not only leave the statement that AACC issued in Nairobi in 2008 of urging "Christian leaders from across the continent to call on governments and donors to make 
environmental sustainability a priority, and take necessary measures to promote adaptation and mitigation efforts to the governments and the NGOs" (Yakubu, nd:52), but took it upon themselves to become messengers.

Cognizant of this call, as noted above, many Churches in Uganda have been sensitizing their members about environmental protection and encouraging tree planting as a way of responding to climate change. To this end, some religious organizations have set up tree nurseries, from which they supply communities with seedlings so as to encourage tree planting. The church, in particular, has encouraged a new form of farming code named "Farming God's way" where people are taught how to make use of small pieces of land productively. Besides, in some parts of the country, the church has set up demonstration farms, where farmers are taught sustainable farming techniques such as inter- cropping and compost production. Poultry production and animal husbandry are also important components of the programmes. These range of services provided by these faith-based institutions is available to communities without discrimination based on religion or ethnicity.

Currently, a growing number of religious groups are mainstreaming environmental sustainability in both development programs and theological education. Like in other countries in Africa, in Uganda there are numerous projects that are dedicated to climate change. These projects help to create awareness on environmental degradation and climate change (Olika 2010). The organizations carry out campaigns to sensitize the communities about environmental concerns through undertaking advocacy activities, organizing workshops and seminars, and establishing orchards and plantations. Some Churches make a cocktail of climate change initiatives with other programmatic areas such as peacebuilding, HIV \& AIDS, gender, water and sanitation and others. Furthermore, in some theological colleges or seminaries where church ministers are prepared for ministry, climate change has been incorporated into the curriculum. This is intended to equip the future Church leaders and theologians with the required skills so that they are able to draw the attention of their congregations on the dangers of climate change and environmental degradation. In some of the religious founded schools, environmental education has been included in the curriculum at all levels. Such strategic inclusion of environmental education in the curriculum is in line with the aspiration of the UN Decade of Education for Sustainable Development (DESD), that UN Scientific Cultural Organization (UNESCO) - as quoted by Joseph 
Yakubu (nd:52), asserts “...aims to integrate values, activities and principles that are inherently linked to sustainable development into all forms of education and learning and help usher in a change in attitudes, behaviors and values to ensure a more sustainable future in social, environmental and economic terms" (UNESCO, nd).

In doing all the above, religion has participated in promoting human security in its entirety. Through conscientization of the masses created by religion, many people in Uganda know their rights, and seek the protection of the rights of others. The spirit of hard work encouraged by the religious groups have enabled Ugandans to work hard for their food needs, protect the environment, be conscious of their health, get involved in addressing issues of conflicts and others. Although this does not mean to say all is well in all aspects of human security in Uganda, but at least some positive strides have been taken by the local population. Let us now turn to look at some of the challenges impeding the participation of religion in the development of Uganda.

\section{Challenges impeding the participation of religion in the development of Uganda}

While religion has good intentions in fostering development in Uganda, it faces several constraints. These include, among others, the following:

To start with, there is lack of adequate theology to propel development efforts of religion. The disparity in the way different religious groups look at development is a big challenge to participation in development. This lack of theology that balances the life here on earth and the life to come; the focus on eternal things and on material prosperity; salvation now and hereafter; salvation for heaven and salvation for service is bringing a lot of disparity in the development agenda. There has been a temptation for some religions to emphasize one of these dimensions over the others. Whereas, the Christian gospel needs to be presented holistically to provide for the abundance of life here and now, and the eternal joy in eternity at the consummation of time, other sections of Christians see such being more earthly than heavenly. To make matters even worse, some leaders of the religious groups are adamant to re-envision the mission of their religion to articulate an understanding of the relationship between religion and development. When concern for the poor is at the heart of the religious life religious leaders will have a development policy and focus 
priorities that guide the development process in accordance with the revealed word of God. But short of that, their efforts in development will keep being thwarted.

The inadequate involvement of local religious groups in development planning and implementation remains a big challenge. Whereas religious bodies have formed development agencies, for many these agencies are a preserve of the elite in the religious bodies. The agencies that have been formed appear to benefit those who work for them more than the people they purport to serve. The lack of mechanisms to strengthen the local religious congregation as both the agent, and beneficiary, of development is responsible for this. Unless local religious congregations are empowered at the community levels to effectively participate in the identification and addressing of development problems, whatever the religious groups have set in place will continue to be a preserve of a few individuals, thus becoming a frustrating venture. Changing such a trend in essence requires the equipping of the local people with the skills to play these roles, as well as equipping the local religious leaders with leadership and technical skills to support such communities in matters of development. Effective development training at local levels is key to avert this.

In another development, the lack of committed, visionary and servant leadership stands as a big setback in propelling religion in the development arena. Given that many religious leaders tend to look to their own interests, especially in the face of poverty, the projects that were set for the community of believers ends up becoming individual property. This has often translated into diversion of funds to individual's selfish use by some religious leaders, both stifling development and bringing the religious institutions into disrepute. There are instances where religion has not been the light of the world and salt of the earth. It has been beset by corruption, hunger for power, intrigue, and devastating internal conflicts. This is in addition to the unhealthy inter and intra religious rivalry, as if God were interested in how people brand God's work of salvation, rather than just make God's love known to the world. Love is the ultimate branding that God requires of religious community. As the Gospel of John says (Jn. 13:35) "By this shall all men know that you are my disciples: if you love one another as I have loved you". Unfortunately, many religious leaders do not heed this call for a transformed leadership, by setting good examples of stewardship as the starting point for development.

Whereas some religious groups have set deliberate training and mentoring of young leaders who are meant to take the mission of religion and 
development forward, many such people have ended up leaving what they have been trained to do and doing their own things. Hence initiating the youth in both the preaching of the gospel development and understanding the need to deal with all forms of oppression is not coming easily. Therefore, such lack of taking decisive action to address the situations that perpetuate poverty, ignorance, disease, powerlessness and all forms of evil has made most parts of Uganda to be moving in a vicious circle.

Given the need to self-preserve, some religious leaders have been co-opted into the ranks of oppressors and accepted to heed to the caution of politicians that they should not get involved in politics. Some religious leaders in Uganda have been accused of aligning with political authorities, thereby compromising the prophetic role religion plays in the society. On the other hand, political leaders in some instances have been keen on advising church leaders to concentrate on 'preaching the gospel' and leaving civic matters to them. Such a narrow definition of what 'religion' is has made some people to misquote the bible "give to Caesar what is Caesar's and to God what is God's" (Matt 22:21) to support their evil intention. In Uganda, there is a joke, "Leave the matters of the generals to the generals" - said by one minister of Justice and Constitutional Affairs. In other words, religious leaders are expected not to 'interfere' in political matters. Since some religious leaders have been compromised in one way or the other, they will indeed look on as things that negatively impact on their flock happen. Yet, it is the God-ordained mandate of the religion in general and the church in particular to shed light on all aspects of life in a nation, including politics or other civic matters. Development can only be achieved if there is a favorable political, social technological and economic environment.

Another challenge that is compromising the participation of religions in development in Uganda is over-dependence on foreign assistance for development work they want to undertake. Just as governments in Africa depend quite a lot on foreign aid for their development programmes, so do many religious organizations. This makes one to wonder if the principle of the three self's (self-governing, self-propagating, and self-supporting) espoused by Venn and Rufus (indicated earlier) have been made sense of by the religious bodies in Uganda as they try to participate in development. Given the spirit of dependency, many development projects established by religious organizations have collapsed because whatever funds that came were diverted by the management to their own treasuries. 
This therefore has made development work established by religious organization to be unpredictable, and thereby undermining sustainability of projects and empowerment of the poor.

The lack of accountability and transparency in using development funds by religious organizations made development partners to tighten the flow of funds to assist development projects in Uganda. Even if the flow is constant, the leaders continually express concerns over the dwindling resources flowing in from outside to support the development work of religious organizations. However, we believe that this reduction in external facilitation is good for the growth and independence of the church in Uganda. If religious organizations wake up to mobilize local resources, it will help to avoid the conditions that some western countries are setting as pre-requisite to granting aid, at the expense of cherished religious values.

Furthermore, foreign funding promotes the spirit of dependence, undermining people's sense of self-worth and esteem. Unless religious organizations in Uganda find means of financing their own development endeavours through frugal management of available resources; prioritizing development as a central element of ministry; and deliberately engaging in profitable ventures for accumulation of resources to invest in development, they will continue to cry and accept all sorts of nonsense from the Global North. There is need for development financing to take a central place in the budgets of religious organizations in Uganda so as to be able to realize self-propagating, self-administering and self-financing bodies.

One other negative force that is retarding the participation of religion in development in Uganda is the disunity brought about by inter and intra religious conflicts. Right from the introduction of foreign religions in Uganda, the religious groups have conflicted, which is proof to Scott Appleby's theory of "the ambivalence of the sacred" (Appleby 2000). Although apart from the religious wars in the late 1800 s where there were open contests between the traditionalists and new religious groups, and also between and within the religions, there has not been such overt expression of wars of religion in Uganda (Niringiye 2016). However, in spite of the simmering calm tides, there has been a lot of undercurrent discontent between the people who belong to different religions and denominations. Such disunity has made it difficult, in some instances, to bring the different religious groups to work together for the good of the population. In some instances, there have been dubious schemes devised to frustrate 
the efforts of one group so that they are not seen to be doing anything productive for the population.

\section{Conclusion and recommendation}

In the foregone discussion, it is shown that religion is both a positive and negative force in development in Uganda. For a long time, the people who live in the present geopolitical confines of Uganda have used religion to propel them to greater heights. For example, apart from traditional religion that has been part of the different tribal groups, in Uganda modern religions are credited for establishing formal schools, western health facilities, enhanced cash economy, climate and environmental protection, human protection, and participating in political development. Whereas a lot of obstacles such as internal fights, encouragement of dependency, joining ranks of oppressors, and involvement of some of the leaders of these religions in corrupt practices work negatively to frustrate the robust work of religion in sustainable development of Uganda, what they have so far done attest to their concern in holistic development of the country.

In order to eliminate some of the simmering contentions between the different religious groups so that they all focus to work together for the common good of the population, the religious groups have set up the Uganda Joint Christian Council (UJCC), the Inter-religious Council of Uganda (IRCU), and the Uganda Muslim Supreme Council (UMSC). These umbrella organizations have assisted in coordinating the programmes the religious organizations have for the development of the common person in the country.

\section{References}

Africason (nd), "Role of Christian Missionaries in the Colonisation of East Africa", available from www.africason.com, acc. on 23/6/2018.

Ahimbisibwe, M. (2010). The role of the Church in Environmental protection in Kampala Diocese, MDiv Dissertation: Mukono, Uganda Christian Univ. .

Appleby, S. R. (2000), Ambivalence of the Sacred: Religion, Violence and Reconciliation, New York: Rowman \& Littlefield.

Balyage, Y. (1998), The Christian Religious Education Syllabi for secondary Schools: An Adventist assessment and a proposal, Prepared for the $23^{\text {rd }}$ Faith and Learning Seminar Held at the Univ. of Eastern Africa - Baraton, Kenya.

Benthall, J., (2007), Islamic Charities in Southern Mali Today. Islam et sociétés au sud du Sahara 1, 2007: 165-174. 
Bornstein, L. (2003), Management standards and development practice in the South African aid chain, in Journal of Public Administration and Development, Vol. 23. Issue 5, 393-404.

Dang, G. \& Sui-Pheng, L (2015), “Chapter two- Theories of Economic Development” in Infrastructure investment in development economics, Soul: Springer science + Business media Singapore.

Ellis, S. \& Gerrie ter H. (2004), Religion and Development in Africa, available from https://openaccess. leidenuniv.nl/bitstream/handle/1887/12909/ASC-071342346174-01.pdf? sequence=1, acc. on 22/7/2018.

Emerson, M. O., Monahan, S. C., \& Mirola, W. A. (2011). Religion matters: What sociology teaches us about religion in our world. Upper Saddle River, NJ: Prentice Hall.

Fanfani, A. (1935) Catholicism, Protestantism and Capitalism, London: Sheed \& Ward.

Freeman, D. (2015), Pentecostalism and economic development in Sub-Saharan Africa, in Tomalin, Emma, (ed.) The Routledge Handbook of Religions and Global Development. Abingdon, Oxon: Routledge, 1-19.

Glencoe (nd) World history- modern times: Daily lecture and discussion notes, New York: McGraw Hill.

Gottneid J. A., (ed). (1976), Church and education in Tanzania. Nairobi: East African Publ. House.

Haar, G. Ter. \& Ellis, S. (2006), “The Role of Religion in Development: Towards a New Relationship between the European Union and Africa”, in The European Journal of Development Research, Volume 18, Issue 3, 351-367.

Hitzler, (2013), “Foreword”, in Mtata, K. (ed.) Religion: Help or Hindrance to Development? LWF Documentation 58, Geneva 2: LWF, 14-15.

Kaag, M. \& Maud Saint-Lary, M. (2012), The New Visibility of Religion in the Development Arena, Bulletin de l'APAD 33, available from http://apad. revues.org/4075, acc. on 23/6/2018.

Lubale, G. (2018), Church and development: History of the church, growth of the Anglican Church and expansion of Pentecostal churches in Uganda, Kampala: Panamaline Book Distributors Ltd.

Niringiye, D. Z (2016), The church in the World: A historical ecclesiological study of the Church of Uganda with particular reference to post independence Uganda- 1962-1993. London: Langham.

Manala, M. J. (2013), “The impact of Christianity on sub-Saharan Africa”, a paper that was presented at the Africa Conference under the theme, Social Movements, Religion, and Political Expression in Africa, held at the Univ. of Texas at Austin.

Menuge, A. J. L., (ed.) (1999), Christ and Culture in Dialogue: Constructive Themes and Practical Applications. St. Louis. Mo: Concordia Academic Pr.

Masquelier, A. (2009), Women and Islamic Revival in a West African Town, Bloomington: Indiana Univ. Pr.

Mayke K. \& Maud S. L. (2012) “Christian and Muslim elites' engagement with public policies in Africa", in The New Visibility of Religion in the Development Arena, Bulletin de l'APAD, 33, (1-2). 
Mbiti, J. S. (1969). African Religions and Philosophy, London: Heinemann.

Mbogo, R. W. (2015). “Historical factors for the Church's involvement in Holistic Community Development in East Africa”, in Developing Country Studies, Vol. 5, No. 21, 172-173 available from www.iiste.org acc. on 20/5/2018.

Mtata, K. (2013) “Religion and Development: Friends or Foes?” in Mtata, K. (ed.) Religion: Help or Hindrance to Development? LWF Documentation 58, Geneva 2: LWF,, 23-36.

Nkomazana, F. (1998), "Livingstone's ideas of Christianity, commerce and civilization”, in Pula: Botswana Journal of African Studies, vo1. 12, nos. 1 Q 2, 44-57.

Olika, S. E. (2010). The impact of climate change on food security in Soroti Diocese, MDiv Dissertation: Mukono, Uganda Christian Univ. .

Omatseye, J. N. E. \& Olijere O. B. (2008) Going to school in Sub-Sahara Africa: The global school room. Westport, Connecticut: Greenwood Publ. Group.

Omona, A. D. (2007), Globalization and cultural transformation in Uganda: A case of the Madi, MA Dissertation: Kampala, Nkumba Univ.

Omona, A. D. (2009), "Northern Uganda Peace Process: Why the parties have failed to agree”, in Jesuit Journal of Social Justice in East Africa, Issue 01/09, Nairobi: Hekimani, 64-73.

Pawliková-Vilhanová, V. (2002), Christian missionary enterprise in Africa: A synonym for "cultural imperialism? In Asian and African Studies, 1, 49-68.

Tuma, T. (1978), 'The church extend to the east', in Tuma, T. \& Mutiabwa, P (eds), A century of Christianity in Uganda, Nairobi: Uzima.

Reese, R. (2007), “The surprising relevance of the three self's formula”, in Mission Frontiers, 25- 27, available from www.missionfrontiers.org acc. on 23/6/2018.

Reyes, G. E. (2001). "Four main Theories of Development: Modernization, Dependency, World -Systems, and Globalization " NOMADAS 4: 1-12.

Rostow, W. W. (1990). The stages of economic growth: a non-communist manifesto, Cambridge, Cambridge Univ. Pr.

Russell, J. K. (1978), 'Christianity in West Nile', in Tuma, T. \& Mutiabwa, P (eds), A century of Christianity in Uganda, Nairobi: Uzima.

Shareia, B. F. (2015), “Theories of Development”, in International Journal of Language and Linguistics, Vol. 2, No. 1, 78- 90.

Smith, David. 2011. Jacob Zuma blames Christianity for breakdown of South African traditions, The Guardian, Wednesday 21 Dec. 2011, 17. 02 GMT. Available at http://www.guardian.co.uk/word/2011- /dec/21/Jacob-zuma-blames-christianity. Acc. on 23/5/2018.

Soares, B. F. (1996), "The prayer economy in a Malian town", Paris, Cahiers d'Etudes Africaines, 36 (4): 739-753.

Solhjell, T. (2012), Religion in Development: How is the role and meaning of religion in development interpreted by organization staff and local participants of Norwegian development aid? MA Thesis: Oslo, MF Norwegian School of Theology.

Stambach, A. (2010), Faith in schools, religion, education, and American evangelicals in East Africa. Stanford, CA: Stanford Univ. Pr. 
Sounaye, A. (2007), “Instrumentalizing the Qur'an in Niger's Public Life”, Journal for Islamic Studies, vol. 27: 211-239.

Tyndale, W. (2011), "Religions and the Millennium Development Goals. ” In Gerrie ter Haar, (ed.) Religion and Development. New York: Columbia Univ. Pr., 207- 229.

UNESCO, (nd), UN Decade of Education for Sustainable Development (DESD) 20052014, available from http://unesdoc. unesco.org/images/0015/001540/14093e.pdf acc. on $22 / 7 / 2018$.

Weiss, H., (ed) (2002). Social Welfare in Muslim Societies in Africa, Uppsala: Nordiska Afrikainstitutet.

Wolfensohn, J. (2011), “Forward," in Gerrie ter Haar, (ed.), Religion and Development, New York: Colombia Univ. Pr.

Yakubu, J. (nd), Faith and sustainable development: An African Christian perspective, Tübingen Univ., 49-53. 


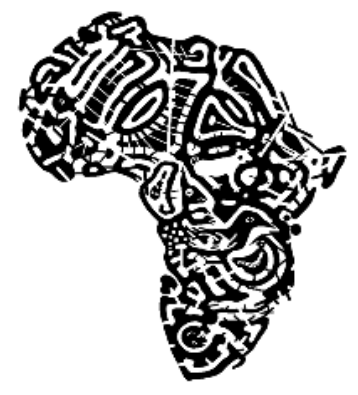




\title{
Religion and Civic Participation in Post-Colonial Kenya \\ The Case of Thomas Kalume ${ }^{1}$
}

\author{
Julius Gathogo
}

\section{Introduction}

In his book, Troubled But Not Destroyed, Archbishop David Gitari (19372013) talks about his troubled life - a life characterized by difficult challenges - troubles from his family, school, college, university, church ministry and in the political life of the Kenyan nation where he was a major player in socio-ecclesial scene. ${ }^{2}$ Likewise, the case of Thomas Johnson Kuto Kalume has similar characteristics, a life full of troubles, but ironically with great triumphs. Kalume, who died while relatively young, left before he published his own memoirs, unlike Gitari and Okullu; hence he rested with a lot of socio-ecclesial information. In his recollections, Gitari recalls his ordination to priesthood, in early 1970s, which was full of troubles as the then Archbishop of the Anglican church of Kenya, Festo Habakkuk Olang, did not accept his offer of service and was most likely working "on the advice of his Archdeacon", the Ven. Ken Stovold. He goes on to say: "at that time, I was only the fourth Anglican Kenyan to obtain a University degree in Theology after Dr. John Mbiti, the Revd Thomas Kalume (who became a Member of Parliament) and the Revd Henry Okullu (who at that time was the Editor of Target Newspaper)."

Nonetheless, both Gitari and Kalume are Kenyan heroes who did not despair as they wrestled with the vicissitudes of life; and as they gallantly sought to reform their respective conservative societies for the better. Interestingly, Kalume's diary records all his major life events from the year he was born in 1925 to 1974, a few months before he died on March 15, 1975. In turn, it shows his deep troubles that run throughout his earthly lifetimes, but which have relevance for the $21^{\text {st }}$ century Africa. Till he was

\footnotetext{
1 This is a revision of an article that was entitled "Ecclesiastical and Political Leaderships in One Armpit: Reconstructing the Memory of Thomas Kalume”, published Studia Historiae Ecclesiasticae, Vol 41, No 3 (2015), 92-110.

2 Gitari, 2014.

3 Gitari, 2014: 31.
} 
free at last, Kalume would have shared St. Paul's words and probably confess, "We are troubled on every side, yet not distressed; we are perplexed, but not in despair" (2 Corinthians 4:8).

In view of the above, the chapter endeavours to focus mainly on the manner in which the memory of Thomas Johnson Kuto Kalume has been celebrated and/or reconstructed half a century after the independence of Kenya. Indeed, as Kenya celebrates her $52^{\text {nd }}$ year of independence, on $12^{\text {th }}$ December 2015, Kalume is remembered for seven key issues. First, his roots as a member of the 'minority' Kambe ethnic group living among the predominantly Giriama ethnic group of the larger Miji Kenda nation of Kenya; second, his passion for education; third, his contribution as a family man; fourth, his critical role in the composition of Kenya national anthem; fifth, his role as an Anglican clergyman (1964-1975); sixth, his contribution in the elective politics (1969-1974); and seventh, his relevance for the post-colonial reconstruction of Africa, Kenya in particular.

\section{Kalume's pedigree}

Thomas Johnson Kuto Kalume (1925-1975) traces his roots among the Kambe ethnic group of the larger Miji Kenda nation of Kenya. In general, the Kambes, who are part of the nine ethnic groups that make up the Miji Kenda community, are largely settled in Kambe location, Kilifi county of Kenya. Geographically, the Mijikenda (meaning, the nine ethnic groups) are nine Bantu ethnic groups inhabiting the coast of Kenya, between the Sabaki and the Umba rivers, in an area stretching from the border with Tanzania in the south to the border near Somalia in the north. Historically, the Miji Kenda peoples have derogatorily been called the Nyika (meaning, bush people) by outsiders. It includes the northern Miji Kenda: the Chonyi, Kambe, Duruma, Kauma, Ribe, Rabai, Jibana, and Giriama. It also includes the southern Miji Kenda, the Digo, who are also found in Tanzania due to their proximity to the common border.

Culturally, each of the Mijikenda groups has a sacred forest called kaya, which is a place of prayer. Significantly, eleven of the approximately 30 kaya forests have been inscribed together as a UNESCO World Heritage Site, the Sacred Mijikenda Kaya Forests. ${ }^{1}$ Mijikenda people are also known for creating wooden kigango funerary statues for which there is an illegal international market. Archaeologist Chapuruka Kusimba contends

1 UNESCO, 2008. 
that the Mijikenda formerly resided in coastal cities, but later settled in Kenya's hinterlands to avoid submission to dominant Portuguese forces that were then in control. ${ }^{1}$ Mythological explanations have it that Shungwaya, situated to the north of the Tana River, is the actual origin of Mijikenda peoples who were Bantu migrants, and speakers of Sabaki Bantu languages. ${ }^{2}$ Each ethnic group has unique customs and dialect of the Mijikenda language, although the dialects are similar to each other and to the Swahili language.

In the case of Kalume thus, his family originated from Kambe location though he was born in Bate village, Dagamra location, Malindi North district, in the Kilifi County of Kenya. In his Diary, he explains that it was in 1882 that his grandfather Kambu wa Mwambaru migrated from Kambe location to Magarini, in Malindi North. Kambu begot a son whom he named Tunje; while Tunje sired Kalume. Tunje had two wives. The first one was called Dama while the second one was Munyazi - the mother of Kalume. Interestingly, Dama had only one son called Chivuga; while Munyazi had several children. Two of them were Raheli and Kandzje (the only one alive by 2015). By 2015, Kandzje who was born in 1930s was living in Bate, Malindi North. Kalume was the fourth born in the entire family, but the third child of Munyazi. As a person who was brought up in a polygamous family, Kalume encountered the problems that go with it, a phenomenon that hardened his resolve to make a better family when he got of age (Tunje 10:06:15).

At this juncture, it is critical to ask: why did his grandparents migrate from Kambe-Rabai to Bate-Malindi in 1882? First, there was a great famine called Njaa ya Mwakisenge. This was a famine that Mwakisenge had prophesied. Mwakisenge was a Seer who had predicted doom, a prophesy that ultimately happened. Hence Kambu wa Mwambaru, Kalume's grandfather and his family, moved to the North so as to look for food, and eventually settled in Malindi North. As they moved on, they first settled at Kauma village (now a location) where they established a home called Kambe-Katune (meaning, the red Kambe). Perhaps, this place had red soil. They didn't stay at Kambe-Katune for a long time; as they left for Magarini (meaning, beyond Malindi), or Malindi North; to a place where an Arab by name Suleimani had settled. In other words, they settled on his farm. Why? He had a big farm which was producing pigeon peas (kunde) and

Gilbert, 2008: 229.

2 Preucel \&Mrozowski, 2011: 411. 
other foods; hence there was a lot of food on his farm. In the new dispensation, they felt food-secure. This place is the current Bate; and from there, they saw no reason of returning to Kambe, and so Kalume began schooling at Bate primary school.

\section{Kalume as a herd's boy}

During his early school days, Kalume doubled as a pupil and herd's boy, tending to his father's goats. Before he formally joined school, he would take the goats to the school compound and listen to the ongoing teachings through the widow while he continued herding. When his father learnt that he was herding in the school compound, he got very angry, beat him up and warned him sternly never to do it again. Indeed, Tunje, his father, did not want to hear anything to do with "European education", as he felt herding is enough wealth that could sustain his polygamous family. As a result, Kalume's troubles forced him to run away from home and went to live with his uncle John, who was renamed Said after converting to Islam. Indeed, it was said, not Tunje, who took Kalume to school in 1938. With Tunje's rejection of the so-called "European Education", it is no wonder that only one of Kalume's siblings got, at least, little education, and finally ended up as a police officer. Apart from Tunje having a big herd of goats and seeing it as sufficient for his family up-keep, he was also reacting to the ordinary politics of the day which saw school going pupils as lazy people who were avoiding home chores, farm work, livestock herding but instead preferring to just sit down in class "without doing substantial duties" (Tunje 10:06:15). Hence, school going, as "an occupation", was seen as the highest level of escapism in the locality.

\section{His Early School Days and Teaching Career}

In regard to his early education, Kalume began schooling in Bate primary school (1938-1939). He then joined Jilore primary school in 1940, and continued up to 1942; and in 1943, he joined St. John's Intermediate School, Kaloleni, then a boy's school and now renamed St. John's Girls Kaloleni, in the present day Kilifi County, and finally left in 1945. Between 1946 and 1949, he was at Alliance Boys High School (the leading secondary school in Kenya to date), Kikuyu, Kiambu County. Between 1950 and 1951, he was at Kagumo teacher's college, Nyeri County, for teachers' training. After training as a teacher, Kalume became a tutor at Ribe Teachers' college, 
now Ribe Girls Secondary school, from 1952-1953. Later in May 1967, the teachers' college, which was sponsored by the Methodist church, moved from Ribe to Shanzu ${ }^{1}$ where it was amalgamated with Bura-Taita-Taveta, Mutune-Kitui, and Coast Teachers' College-Mombasa. By 2015, Shanzu Teachers' Training College was located on a 45-hectare plot, $16 \mathrm{~km}$ North of Mombasa Island, along Mombasa/Malindi Road near Shimo-La-Tewa Prison, Shimo-La-Tewa Secondary School and boarders Shimo-La-Tewa Primary School.

Between 1954 and 1959, Kalume doubled as the Head Teacher of St. John's Intermediate School, Kaloleni and as Supervisor of primary schools in Southern Division of Kilifi District (later called Kaloleni Division). From 1959 to 1962, he was the Manager/Supervisor of Anglican Church Schools in the present day Taita-Taveta County. In those days, Managers were, in terms of ranking, like the present-day County Education Officers (CEOs).

At Alliance High School, Kikuyu, Kiambu County (1946-49), Kalume had demonstrated leadership qualities; for he was appointed the Captain of Livingstone House. As he left the school in 1949, his headmaster, Carey Francis, was happy with him. His House Master, Mr. J. S. Smith gave him a Day Book (Diary) which is preserved by his family to date. It is in this diary that the researcher was able to extract a lot of information about Kalume's handwritten materials. Interestingly, Smith, a British national, also taught Kalume's second born son, Graham Tunje.

\section{Kalume's Theological Education and Ordination}

While serving as the Principal of Kaloleni Boarding primary school (1958), Kalume enrolled at Ridley Hall Cambridge, England, for a Bachelor of Divinity (BD Hons) as an external student. He was to study the London degree while basing himself at St. Paul's United Theological College, Limuru (now St. Paul's University); and indeed, St. Paul's Limuru was allowed to offer the degree for the first time in its history that dates back to 1930. Earlier in 1961, Rev. J. O. Welsh became the Principal of St. Paul's

1 Shanzu Teachers' Training College is a public college for primary teachers' training. It also runs also private courses such as Business Administration, Human Resources, Management, Information Technology, etc. 
United Theological College (Tunje 10:06:15). Rev. Welsh was a Presbyterian Minister ${ }^{1}$, unlike all the previous Principals who were Anglicans.

Thus, in 1963, an External London University Bachelor of Divinity (BD) degree was inaugurated at St Paul's United Theological College, Limuru (Tunje 10:06:15). By then Thomas Kalume had already begun his studies (1958), but when St. Paul's Limuru began a degree programme in 1963, Kalume continued with his studies. Hence, as he continued his external degree, he teamed up with two other African students, namely, Elisha Wakube and John Crispin Onyango who commenced their University of London BD studies. ${ }^{2}$ The idea of training Africans up to the degree level was essential because the three Missionary Societies, that is, Church Missionary Society (CMS), Church of Scotland Mission (CSM) and the Methodist Missionary Society (MMS) were preparing to leave Kenya after the attainment of political independence.

In his well-kept diary since his Alliance high school days (1946-49), Kalume, who completed his bachelor's degree in 1965, recalls that he first travelled to England in 1958 so as to enroll as an external BD student. He was made an Anglican Deacon by Archbishop Leonard James Beecher (1906 -1987) in 1964, a year before he completed his London degree, while at St. Paul's Limuru. From there, he assumed the title of a Reverend. In turn, Beecher was an English-born Anglican Archbishop. He was the first Archbishop of the Province of East Africa, comprising Kenya and Tanzania, from 1960 to 1970 . He is also the last European missionary Archbishop in Kenya, as Festo Olang' took over as the first Archbishop of the Province of Kenya in 1970 when the Anglican province of East Africa was divided into Kenya and Tanzania provinces, each having its own archbishop. Beecher chose to take an early retirement and settled in Kenya till his death in 1987 and was buried at All Saints Limuru cemetery.

Following his return from the New York Theological Seminary (19661967) with a master's degree in Religious Education in 1967, Kalume was immediately ordained as a full priest in 1967 at Mombasa Memorial Cathedral by the then Diocesan bishop of Mombasa, Rt. Rev. Peter Mwang'ombe, who served as a bishop from 1964 to 1980. During the same period, 1967 and 1969, while working with the Bible Society of

PUR, 1994: 24.

Cole, 1960: 24. 
Kenya, he translated the New Testament from the original Greek language to Swahili ${ }^{1}$. At the same time, he was a part-time lecturer in Homiletics at the then Coast Bible School, Makande, renamed Bishop Hannington Institute, and transferred to Buxton, Mombasa (Muramba 05:06:15). In his diary, he notes some of his overseas travels as including: a visit to India, New Delhi's 1961 conference of the World Council of Churches, as a delegate and/or representative of East Africa; his 6 months stay in England in 1958 as he enrolled as an external Bachelor of Divinity student; a visit to the Union Theological Seminary in New York (1965-66); and the New York Theological Seminary (1966-1967). As noted earlier, it is in the latter that he obtained his master's degree.

As a translator in the Bible Society of Kenya (1967-69), operating from his Mombasa Memorial Cathedral house, Kalume was visibly present as a visiting preacher, seminar facilitator, and educator, among other ecclesiastical duties (Mwang'ombe 18:06:15). In particular, he was voluntarily attached to St. Paul's Rabai, St. Emmanuel's Freretown and St. Luke's Makupa. And between December 1969 and December 1974, he was the duly elected member of parliament (MP) for Malindi North, renamed Magarini.

\section{Kalume as a family man}

Kalume was joined in holy matrimony to Rebecca Florence Naswa d/o Andrea Chemiat from Chwele, Bungoma County, on Wednesday, $20^{\text {th }} \mathrm{Au}-$ gust 1952. It was conducted at St. John's Anglican Church, Kaloleni, by the Rev. David Mzungu. Professionally, Rebecca was a nurse, and a midwife for that matter. Together they bore nine children - six boys and three girls. That is: Onesmus Ngumbao (1953-2007), Graham Tunje (1954-), Dorcas Nelima (1954-), Kenneth Paul Mwambaru (1956-), Andrew Peter

1 The Swahili language, also known as Kiswahili, is a lingua franca of the African Great Lakes region and other parts of Southeast Africa, including Tanzania, Kenya, Uganda, Rwanda, Burundi, Mozambique and the Democratic Republic of the Congo. The closely related Comorian language, spoken in the Comoros Islands, is sometimes considered a dialect. Although only around fifteen to fifty million people speak Swahili as their first language, it is used as a lingua franca in much of Southeast Africa. Estimates of the total number of Swahili speakers vary widely, from 60 million to over 150 million. In 2018, the government of South Africa voted to teach Kiswahili in all South African schools. The decision was approved by the country's Council of Education Ministers, and the language will be offered at public, private and independent schools. (www.africanews .com/2018/09/18/south-african-schools-to-teach-kiswahili// acc. 23 Sept. 2018). 
Chango (1957-1994), Barnie Kambu (1959 -), Hilda Mnyazi (1959-2003), Tony Sirya (1961), and Irene Mary Amani Nazi (1963).

By the time of his death, he had bought several pieces of land that totaled about 350 acres, all in the present day Kilifi County. Of interest to note is that whenever he bought a piece of land, he never registered it under his name; rather, he registered all his pieces of land under his children. In other words, each piece would have a title deed featuring 3 or 4 children. After his demise, Rebecca (1926-2003) however steered the family well enabling some to acquire university degrees; and was eventually collated an Anglican Canon in 1999 by the Mombasa Diocesan Bishop, Julius Kalu.

\section{Kalume and the national anthem}

As Kenya moved towards independence in early 1963, the colonial government tasked Graham Hyslop to assist the incoming government under Jomo Kenyatta to identify their national anthem. Hyslop was by then the Inspector of Music and Drama - from the Ministry of Education. Before then, Hyslop had been a great friend of Kalume since 1950s, as they would severally meet as the former inspected Music and Drama in schools when the latter headed, St. Johns Intermediate School, Kaloleni, which was one of the leading schools in the country. Kalume's friendship with Graham Hyslop reached its zenith in 1954 when he got his second born son whom he named Graham Tunje, as an appreciation of the support that Graham Hyslop had given him as a teacher and in his music career (Thuva 15:06:15).

According to Mzee George Konde Thuva (1924-), with whom they taught in one school, the four characters whom Graham Hyslop called to help him compose the Kenya National Anthem are: Thomas Kalume, George Senoga Zake, Washington Omondi, and Peter Kibukosya (Thuva 15:06:15). Indeed, the task began in May 1963, with the formation of an advisory committee that comprised the above, plus Richard Koskey and Samuel Waruhiu.

The anthem was to be in both English and Kiswahili and was meant to stir up a sense of patriotism and be no more than 3 verses. With the task defined, an anthem commission was thus formed to come up with several anthems for consideration. Indeed, some of the proposals that came up included the Zulu tune of Nkosi Sikelele Africa (God bless Africa), but after a long debate, Graham Hyslop insisted that they stick to a Kenyan tune - 
which was finally found among the Pokomo of the present-day Tana River County. By then, they even thought the Nkosi Sikelele Africa was to be an entire African anthem (Chibule wa Tsuma 15:06:15). Indeed, this Pokomo lullaby went as follows:

Bee mdondo, bee, Bee mdondo bee (Oh Insect bitter, oh insect bitter?) Akudobee ni gani? (Who is disturbing the child?) Huenda hukawabige watu wa makoneah (Let's go and fight those disturbing you) Mwenzi upawa, ni nani? (The moon is clear, we shall see it clearly)

Considering that the tune had already been found from the solemn and prayerful lullaby of the Pokomo peoples, through Hyslop's efforts, Kalume was tasked with the job of the actual composition of the anthem. In other words, Kalume is the one who came up with the actual words as they are recited today. From time to time, the team of composers would visit him at his St. Paul's United Theological College, now St. Paul's University, Limuru, base - as he pursued his studies. Thus, it is from St. Paul's Limuru where Kalume composed the words of Kenya's national anthem, which was recorded in September 1963, and inaugurated at Uhuru Gardens on Dec. 12, 1963 during the independence celebrations. ${ }^{1}$ Hence, as Kenyans listen to it, the memory of Kalume is reconstructed.

\section{Kalume as a church leader}

Even before he was made an Anglican Deacon by Archbishop Beecher in 1964, Kalume remained an influential and a devoted church leader. As a spell-binding speaker, Kalume continued to preach at St. Andrews Malindi, Emmanuel church Jilore among other places, even when he was a member of parliament. Indeed, Archdeacon Nathaniel Mweri, the priestin-charge, put him in the official preaching programme of the churches where he superintended (1970-1974).

As a member of parliament for Malindi North, Bishop Obadiah Kariuki of Mount Kenya Anglican Diocese, and his wife Lilian Wairimu (the daughter of senior chief Koinange), visited the Kalumes and his family in their Beach house, Malindi; and stayed with them for four days (Tunje 10:06:15). During this visit by the senior most leader of the Anglican church of Kenya, after Archbishop Festo Olang', Kalume took the opportunity to show them round his private and constituency projects. Again, during the December 1972 burial of the coastal kingpin, Hon. Ronald

1 http://www.friendsofmombasa.com/ (acc. June 10, 2015) 
Ngala (1920-1972), the Hon. Rev. Kalume and Archdeacon Nathaniel Mweri conducted the burial ceremony, as George Konde Thuva led the choirs that consoled the people. Such gestures show that Kalume was not seen by his church as a deserter upon joining elective politics but as one whose territories had been expanded; as he did not cut ties with the former.

\section{Kalume's Journey to Politics}

Kalume journeyed his way to elective politics from the late 1950s through to 1960 s, as a teacher, college tutor, and school principal, as a church leader and as a chairman of various board memberships; and even as a chairman of various educational institutions in the locality. Indeed, he chaired boards for Kanamai conference centre, St. Luke's Hospital-Kaloleni, and St. John's Girls Secondary School among others. As he chaired the various boards, the locals could see a talented person. Coupled with this, their first member of parliament since Kenya's independence, Hon. Joshuah Malingi (1920-), who was also the first Speaker of Kenya's Upper House (the Senate), appeared "not to care" much as he by-passed his constituents without greeting them, as he drove off to the various destinations within and outside his constituency. In other words, he was not seen to be satisfactorily attending to the myriad of problems that befogged his constituents. Upon Kalume's return from the United States of America, while armed with a master's degree in Religious Education in 1967, all eyes were fixed on him as some preferred his elevation as an Assistant Bishop of Mombasa while others thought of him as an MP (Muramba 05:06:2015). As the erstwhile Anglican Bishop of Mombasa (Peter Mwang'ombe) failed to post him owing to his "high academic qualifications", the elders from Malindi North Constituency needed him in Kenya's parliament.

Was it Kalume's choice? Certainly not; for while being housed within the Mombasa Memorial Cathedral compound, around October 1968, a huge delegation from Malindi North constituency (renamed Magarini) came in buses and demanded to meet him there. As it turned out, Kalume was surprised to hear that theirs was not a pastoral issue but a political request that he becomes their member of parliament come December 1969. At first, he objected to the idea, citing psychological preparations and lack of financial muscle as the key challenge to mounting a parliamentary campaign. In turn, they responded that they had already campaigned on his 
behalf. After being assured of success, he finally accepted the offer with a "yes I will take it as service to God and humanity" that sent them in tears of joy and excitement that greeted the session since then (Mangi 05:06:15). To some, Kalume did not campaign; to others, he did minimal campaigning throughout the vast constituency. He finally garnered $93 \%$ of the votes cast $(3,401$ out of 3,657$)$. It is from there that he moved from the city of Mombasa to Malindi Township, as the area MP.

Upon his sweet victory, Rev. Kalume wrote on $6^{\text {th }}$ Dec. 1969 in his diary: "I have been elected by people of Malindi North to be their representative in parliament with 3, 401 votes. [I have made history for] being the first African clergy in Kenya to be elected in the national assembly" (KD). Kalume was in fact the first African priest to not only join elective politics and subsequently win but certainly not the first clergy in colonial and postcolonial Kenya to put religion and politics in one armpit. An explanation on this will suffice. First, a British Church Missionary Society (CMS) clergy, Archdeacon Walter Edwin Owen (1880-1945) ${ }^{1}$ of Kavirondo in the present-day Western Kenya, had as early as 1921 formed a political party, Young Kavirondo Association (YKA). This made the European settlerfarmers to call him derogatorily as Archdemon for supporting the pleas of African labourers in their farms.

After succeeding Walter Chadwick as the Anglican Archdeacon of Kavirondo in 1918, Owen thus identified with the life and aspirations of the peoples of Nyanza. By then Kavirondo (western Kenya) was then part of the diocese of Uganda. He was tasked with the responsibility of organizing the new, rapidly expanding church among the Luo, Luhya, and Kalenjin peoples. Kenya having been declared a British colony in 1920, Owen founded the Kavirondo Taxpayers' Welfare Association (1922) to teach Africans how to run their own affairs. His political party was strengthened to become a welfare movement that taught Africans how to manage economic development. This led to the introduction of ploughs, watermills, new crops, and bookkeeping as the secret of planned development. Over the years, he educated many Luo and Luhya civic and political leaders. From the 1920s onward thus, he was outspoken in opposition to colonial

1 Walter Edwin Owen (1878-1945) was Assistant Secretary in the CMS Office in Belfast. He was accepted as a missionary in 1904 and ordained as a deacon in 1904 by the Bishop of London and as a priest in 1905 by the Bishop of Uganda. He served in Uganda for 14 years and then succeeded Walter Chadwick as Archdeacon of Kavirondo. He was a skillful administrator. His brother, Owen John Simpson was also a CMS missionary in West Africa. 
legislation discriminating against Africans, such as forced labor and the hut tax. At the same time, he affirmed the right of missionaries to take part in local politics; but after 1935 he was held by suspicion by African radical politicians in western Kenya. As African nationalism heightened political activism in 1940s, Owen retreated to ecclesiastical work, revised the Anglican Book of Common Prayer (Luo version) until his death in Limuru, near Nairobi, in 1945. ${ }^{1}$ Was Kalume influenced by Owen and his predecessors?

Certainly, Kalume and Owen had to contend with various types of poverty. That is, Inherited poverty where poor parents pass on their poverty to their children; Instant poverty where sudden hazards and circumstances like earthquakes, typhoons, tsunami, drought, bankruptcy, war and refugee movements cloud it all; Temporary poverty which is caused by some of the hazards as in the case of instant poverty but lasts for a shorter time; New poverty - a phenomenon where income/savings of workers and pensioners are eroded by high unemployment, inflation rates, or small cashcrop farmers are ruined by high input costs and low prices of agricultural products; Relative poverty where we experience deprivation of opportunities, material assets and self-respect regarded as normal in the community to which people belong - as in the case of people having adequate food and basic households but still lacking material possessions, educational opportunities and so on; Absolute poverty where there is deprivation of elements necessary to sustain life and health such as adequate food, safe drinking water, shelter, land, employment and personal security; Hidden poverty which is largely similar to relative poverty in that people may have adequate food and shelter, but lack other basic needs, such as sufficient heat in cold weather or access to health care and do not report such needs; Endemic poverty which is caused by low productivity and poor resource base, reflected by low income, poor nutrition and health, often affecting smallholders on rain-fed farmlands, small-scale fishermen and herders; Overcrowding poverty where population is heavily concentrated into area of high density, for instance the Nairobi's Kibera slums, Dandora slum, Huruma slum, Mathare Valey slum, Mukuru Kwa Njenga slum, and Korogocho slum, plus the Western Kenya's Ruanda and Maragoli settlements among others; and Terminal poverty where those who are poor remain so from the beginning to the very end of their lives. In the case of Kalume, his coastal region remains the poorest region in Kenya to date.

$1 \quad$ For details, see Barrett, 1998. 
In eight regions of Kenya, namely, Nyanza, North Eastern, Western, Eastern, Coast, Rift Valley, Nairobi, and Central, Nyanza, leads with poverty levels of $65 \%$. It is followed by North Eastern with 64\%. Western has 61\%, Eastern 58\%, Coast 57.6\%, Rift Valley 48\%, Nairobi 44\% and Central just $31 \% .^{1}$

Another European missionary cleric who notably indulged in socio-political concerns without losing his gospel constituency is John William Arthur (1881-1952), a medical missionary and Church of Scotland minister who served in British East Africa (Kenya) from 1907 to 1937. Arthur succeeded Rev. Dr Henry E. Scott as head of the mission on Scott's death in 1911 and served in that capacity until 1937. He was known simply as "Dr Arthur" to generations of Africans and was appointed as a member of parliament in as early as 1924, in the so-called Legislative Council of the Kenyan colony. Dr Arthur, who was once described as "Africans' great friend" continued in his parliamentary position until his deep involvement in the female circumcision controversy in 1929-30, in central Kenya, proved an embarrassment to the government and necessitated his resignation in 1929. ${ }^{2}$ Apart from being an active representative of African interests on the Legislative Council (1924-1926), Arthur was also on the Kenyan Executive Council (1928-1929). Like Kalume who came later and was concerned with health issues, gender disparities, land acquisition, national unity, endemic poverty, and societal cohesion plus education for all among other concerns, Dr Arthur was particularly concerned with problems of education, land ownership and labor reforms, and was involved in debates over the practice of female genital mutilation amongst the indigenous population. ${ }^{3}$ Arthur, who championed African education, is indeed one of the fathers of education in Kenya and the rest of Africa.

After Arthur's political tribulation, little is heard about clergy's indulgencies in parliamentary politics save for the pockets of prophetic voices in central Kenya which, for instance, condemned the binding oath in central Kenya that sought to unite the Kikuyu community; and hence strengthen their unity as a political entity in 1969 . The resultant oath ceremonies were prophetically dismissed by ecclesiastical leaderships as divisive to a young nation which needed unity of all ethnic groups. These onslaughts were

1 https://www.google.com/search?ei=HEynW9XtN4W-affPtdgK\&q=poorest+region +in+kenya\&oq=poorest+region+in+kenya\&gs_l=psy-ab. 3 (acc. 23 Sept. 2018).

2 Rosberg \& Nottingham, 1970.

3 Anderson, 1977. 
led by Obadiah Kariuki the then Anglican Diocesan bishop of Mount Kenya. Previously, in 1953, the Kiambu Ecumenical Meeting of church leaders, led by European missionaries, engaged in the politics of the day by condemning the politics of Mau-Mau. Mau-Mau was a guerilla movement that was agitating for Kenya's freedom from the colonial government. In this Kiambu 1953 Meeting, the church leaders threatened to take up arms against the Mau-Mau rebels if the colonial government failed to do so. ${ }^{1}$ This again did not amount to engaging in elective politics. Did Kalume's case, of plunging into elective politics, open up a new socio-ecclesial trajectory that was to inform Kenya of the second half of the $20^{\text {th }}$ century and the $21^{\text {st }}$ century respectively? Was the new paradigm going to be buried with him or be re-ignited beyond his expectations?

\section{Kalume as an MP}

Kalume got into Kenya's second parliament which had fierce critics of the new African government in early 1970. This government had been accused of poor handling of the poverty of the masses, and land issues in particular that favoured the rich with its "willing-buyer-willing-seller" policies. The poor ex-Mau-Mau freedom fighters, to an extent, were seen as losers, and the collaborators - the barren of the land who saw no value for African freedom - were seen as winners. Hence debates in the second parliament were acrimonious, with the fiery Nyandarwa North MP, Josiah Mwangi Kariuki (popularly called JM), threatening to sub-divide his pieces of land and give it to the poor if the government didn't do so. Similarly, the members of the main opposition party, the Kenya African Democratic Union (KADU), who had by then rejoined the ruling party, Kenya African National Union (KANU), were insisting on a federal system of government (Majimbo), rather than the republican system. There were also pockets of MPs, in this cold war era (1917-1989), who were pro-East (communism) while the 'Non-Aligned' Kenyan government, was practically seen to be pro-West (capitalism). Apart from JM Kariuki, the second parliament had other fiery critics of the government such as Hon. Mark Mwithaga, Hon. Martin Shikuku, and Hon. Jean Marie Seroney among others. In his maiden speech, on $12^{\text {th }}$ Febr. 1970, where members of parliament were debating the President's speech in parliament, that had been delivered the previous week, Rev. Thomas Kalume struck a reconciliatory

1 For details, see Gathogo, 2014. 
speech, inviting his colleagues to be reasonable in handling the matters of the house. He said thus:

Thank you, Mr. Speaker. My name is Reverend Thomas Kalume from Malindi. I happen to have two constituencies, a geographical one of Malindi North and a spiritual one of this House and of Kenya. I want to assure the Mzee our President [Jomo Kenyatta] that the spiritual leaders of Kenya, that is: Christians, Muslims and African traditional leaders, pray for the long life of Mzee and for the highest standard of debate and conduct in the house to be maintained on a national level.

\section{Kalume went on to say:}

Now, going to the amendment, Mr. Speaker, I think that it is very important that what the Hon. Member for Tinderet [Hon. Jean Marie Seroney] has said should be included in the Presidential Address. It is obvious that he cannot foresee everything that is going to happen during the session, but at least he should have a scheme for running this place so that we know roughly what we are going to expect [and what] will be discussed in this place. If anything, that has not been foreseen before comes, we will include it even if it is not included in the [Presidential] Address. It is important to know that, because some of us who were teachers before know that you could not walk into a classroom and teach without having prepared your notes and have a scheme of work. In any department, you must have a syllabus and, therefore, this House should have that kind of guide so that we can know where we are heading to. Thank you, Mr. Speaker [Fred Mati]. ${ }^{1}$

As a Member of Parliament, he displayed sobriety and decorum even on contentious debates, a tendency that pleased both the regional political kingpin, Hon Ronald Ngala, and President Jomo Kenyatta. In particular, Ngala, who had known Kalume while they were both teachers in the 1950s, appreciated Kalume due to his passion for "education for all", his improvements in agriculture, education, health and infrastructural facilities. On the other hand, Kenyatta appreciated Kalume right from the time he and others composed the Kenya national anthem in early 1960s. When he later joined parliament in 1969, Kenyatta used to invite him at State House, Mombasa, where they did not only enjoy roasted goat-meat but also watched live performances by invited Miji-Kenda traditional dancers together. Kenyatta, who appears in Kalume's family photos, used to corrupt Kalume's name and fondly referred to him as Ka-a-rume (meaning the one from men or the young gentleman from the people). The same

1 Kenya National Assembly, 1970. 
renaming was done to his other close coastal friend, Hon. Kassim Mwamzandi - the MP for Msambweni, whom Kenyatta fondly called Wamuthandi, meaning 'son of sparks' (Wamuthoni 14:06:15).

In his recollections, Graham (1954 -), the son of Kalume, recalls a political rally which was addressed by the erstwhile coastal region political kingpin, Hon. Ronald Ngala. In this mid 1971 rally at Gongoni, both Ngala and Kalume spoke well of each other. In particular, Ngala, who had contested the presidency in 1961 and 1963 but had his KADU party losing to Kenyatta's KANU in both elections, praised Kalume for seemingly improving agriculture, education, health and infrastructural facilities within a short time. He told the audience that if the constituency needed a genuine leader, then Kalume was the best leader for Malindi North (Tunje 10:06: $15)$.

\section{Kalume and the 1974 general elections}

Kalume's prestigious beach house, in the Silver Sands Resort Centre, became a political concern during the December 1974 general election campaigns. In particular, his opponents used to exploit the ujamaa (communal) nature of the Giriama society to show that he was a capitalist who had lost touch with the rank-and-file of the constituency that he had represented in parliament for 5 years. How did he get all these monies to "acquire such a prestigious house when $99 \%$ of us are living in thatched houses and/or below poverty line?" "And why does he keep a tough dog that makes it hard for us to access him at his own house? Why only meet him in his office and after church service? Why is there an inscription, "Be aware of Fierce Dog' on the gate of his house?" His opponents in the political divide would ask loudly in order to incite the masses against him (Mangi 05:06:15). Certainly, as a member of parliament, he needed security at all costs; hence a tough dog and a security officer to guard the compound were necessary. Again, Kalume got his prestigious Beach House from a presidential decree. In other words, it is the then President Kenyatta who ordered the Ministry of Land and Settlement to allocate it to him so as to enable him serve better. This Beach House decree came after a request he had made following his electoral triumph.

Another critical concern that made Kalume lose his parliamentary seat is the divisive clan politics and negative ethnicity. Indeed, two years before the December 1974 elections, supporters of Joseph Kasena Yeri - a trade unionist then and who eventually ousted him - had begun to exploit the 
clan and ethnic divisions therein. First, Kalume was from the minority Kambe ethnic group, of the larger Miji Kenda nation, in a constituency that is largely dominated by the Giriama ethnic group. Second, his marriage to Rebecca Naswa, a Bukusu from the larger Luhya nation of Western Kenya was interpreted and politicized maliciously by his opponents as an insult to the local Giriama and the larger Miji Kenda women. How can he share his largesse with a person from the distant lands?

As it turned out, Kalume's quest for "education for all", a goal shared in the Millennium Development Goals (MDG) and the Sustainable Development Goals (SDGs) of the $21^{\text {st }}$ century, also became one of the factors that led to his political waterloo ${ }^{1}$. Why? Kalume "over concentrated" on the concern for education "while the people of Malindi North felt that their main problem was water, not education" (Tunje 10:06:15). As the OctoberNovember 1974 were going on, some could be heard saying, "why construct schools in a desert, while our concern is water?"

\section{Kalume and Dependency Syndrome}

As Kalume sought reelection during the December 1974 general elections, he was weighed down by his understanding of real development as empowerment, which was not well understood by the voters. Like President Nyerere of Tanzania, Kalume held that the better way of feeding a hungry person is not to give him fish but to show the person how to fish. ${ }^{2}$ It is for this reason that he sought to avoid giving monetary hand-outs to his poverty-stricken constituents but instead sought to empower people through building of schools, liaising with the national government so as to provide infrastructures and so on.

To this end, when his constituents went into office to seek financial handouts so as to pay fees for their children, Kalume would lecture to them about how to manage their little resources prudently and avoid relying on

1 Waterloo is a small town a few miles south of Brussels, Belgium. The Battle of Waterloo, as it has come to be known, is always included on lists of battles that changed the course of history. Napoleon was considered one of the greatest generals ever, yet he is often defined by this one terrific loss at the end of his career. Indeed, the Battle of Waterloo was fought on Sunday, 18 June 1815, near Waterloo in present-day Belgium, then part of the United Kingdom of the Netherlands. A French army under the command of Napoleon was defeated by the armies of the Seventh Coalition, comprising an Anglo-allied army under the command of the Duke of Wellington who combined with a Prussian army under the command of Gebhard von Blücher.

2 Gathogo, 2011. 
relief food, donors or handouts from individual rich people. He would also advise them to sell part of their livestock and/or farm produce. This refusal to give handouts was meant to empower them and thereby make them see their huge potentials; and indeed, their many assets. The ripple effect, he hoped they would avoid focusing on deficiencies rather than assets. In this, Kalume hoped, it would kill dependency syndrome in the society. Unfortunately, this made him unpopular with a section of his constituents who saw the legislator's role as that of "a weekend donor". Like the proverbial kicks of a thankless donkey, they sent him home come December 1974.

In putting too much emphasis on education and in his rejection of humanitarian handouts and eventually opting for increased productivity and astute management of resources, Kalume was vouching for sustainable development, which are indeed critical elements in the $21^{\text {st }}$ century models of growth and prosperity. If Africa were to follow Kalume's path, the reward would be immense. Certainly, Kalume could see the distinction between development and relief as in the diagram below:

\begin{tabular}{l|l} 
Development & Relief \\
\hline Is long-term & Is short-term \\
\hline $\begin{array}{l}\text { Solves ongoing con- } \\
\text { stant problem }\end{array}$ & $\begin{array}{l}\text { Solves an emergency situa- } \\
\text { tion }\end{array}$ \\
\hline $\begin{array}{l}\text { Helps people become } \\
\text { self-sufficient }\end{array}$ & Tends to build dependency \\
\hline $\begin{array}{l}\text { Builds people as well as } \\
\text { economic health }\end{array}$ & $\begin{array}{l}\text { Usually not concerned with } \\
\text { training, educating, empow- } \\
\text { ering or growth }\end{array}$ \\
\hline $\begin{array}{l}\text { Involves the people as } \\
\text { participants and con- } \\
\text { tributors }\end{array}$ & $\begin{array}{l}\text { Sees people as recipients, not } \\
\text { participants }\end{array}$ \\
\hline $\begin{array}{l}\text { Meets felt needs } \\
\text { Has a multi-sector ap- } \\
\text { proach }\end{array}$ & Meets presumed needs \\
\hline \begin{tabular}{l} 
Is insider controlled \\
\hline
\end{tabular}
\end{tabular}

In this understanding, Kalume understood relief as nothing but doing something for someone who cannot do it for himself or herself. It is a 
crisis intervention, an attempt to provide some form of assistance that will aid the individual or group to return to a prior condition. To an extent, intervention is needed to effect a rescue, but cannot remain perpetually. On other hand, Kalume understood development as that which assists people in effectively addressing their own concerns: fix their own sewages, fix their huge gaping holes without feeling inadequate or expecting someone else to solve their own problems. He knew that genuine development is seen when ordinary people are philosophically and intellectually empowered to appreciate that they are masters and servants of their respective destinies. Indeed, development assumes that people have the innate skills and abilities to take charge of their lives; while at the same time acknowledging the need for facilitators to provide example, instruction, and access to needed resources. In view of this, Kalume looked forward to genuine development that brings people together and eventually keeps them working together rather than begging from one another, or perpetually begging the few more endowed members of the society.

Upon losing the December 1974 general elections, Kalume continued with his church ministry, as a visiting speaker in churches and schools, despite having suffered a heart disease (in 1972) that had stabilized after being handled by a Mombasa based physician, Dr J. B. Okanga. Following his electoral defeat, his heart troubles re-emerged and started creating a hell out of his life. Hence, he could miss out on some occasions from time to time. Since then, he was on-and-off from the hospital. As he conducted the burial ceremony for a European friend in the Malindi Christian graveyard, on March 15, 1975, he collapsed dead to the bewilderment of the congregants. This is after he had just uttered the liturgical words, "from dust to dust, we return" (Muramba 05:06:15).

\section{Kalume's reconstructive philosophy}

Philosophically, Kalume propounded the view that the transformation of the community can best be done through education in concert with the Christian faith. As in the Plato's Republic, where he held that the ideal city-state is best ruled by philosopher-kings, or people who can genuinely and adequately philosophize (The Republic, 5. 473d), Kalume held strongly that only highly educated people can lead the Kenyan nation, and the rest of tropical Africa. He also stressed that their education must be spiced with the gospel of Christ. Was he reading from the same script with Mahatma Gandhi the Indian nationalist, of Hindu faith, who appreciated 
Christ's teaching and influenced the Civil Rights leader, Martin Luther King (1929-1968) in his non-violence movement of the 1960s in USA? Kalume also strikes a working chord with the Brazilian educationist, Paulo Freire (1921-1997) who held that all people could learn, and therefore, education should be for all; and dispelled the notion that the illiterate are too ignorant to learn. Rather, he espoused his "Education for critical consciousness" philosophy as a direct challenge to the elites in society, who usually tend to believe that the only privilege of the grassroots is on the terms of "assistentialism." ${ }^{1}$ That is, giving the wrong impression that the Government owned all the economic resources in the country and could choose to give assistance only to those they wished. In light of this, Kalume's legacy, especially as an MP, is characterized by establishment of schools, colleges, university education, setting bursaries for the less fortunate families so as to promote education for the greatest number.

Another dimension of Kalume's philosophical outlook is that he used to view Jesus Christ as the greatest politician who has ever lived. He was deeply against those who say that politics is a dirty game, as "the welfare of the people of God cannot be dirty" (Tunje 10:06:15). His dream was to have clean and honest politicians who necessarily shun corruption. As noted above, he was the first African clergyman to serve as a parliamentarian, though a European missionary by name Rev. Dr. Arthur had been nominated in 1924. Upon Kalume's electoral defeat in December 1974, the then President Kenyatta, like the biblical David who mourned his good general Abner when he was killed by a rival army leader, Joab (2 Samuel 3), lamented his defeat. Reportedly, Kenyatta uttered obscenities at the "bad" voters who had dethroned such an educated and far-sighted Kenyan, and whose religious background was a plus to the sobriety of the second parliament. It is from there that he nominated Bishop Lawi Imathiu of the Methodist church as a member of parliament, from 1975 to 1979. Since then, a number of clergy have plunged into politics, either as nominated or as elected MPs. In particular, Archbishop Stephen Oluoch Ondiek (1945-2011) of an African Instituted Church, Legio Maria, was elected as the MP for Ugenya in 1983. Other clerics who followed in Kalume's trajectory include: Prophetess Mary Wajiru of Kinangop, 199297; Bishop Allan Njeru of Mwea, 1992-97; Rev. Morris Dzoro of Kaloleni, 2002-2007; Rev. Moses Akaranga of Sabatia Constituency, 2002-2007 and later the Governor of Vihiga, 2013-2017; Bishop Margaret Wanjiru Kariuki

1 Freire, 1998. 
of Starehe, 2007-2012; Rev. Mutava Musyimi of Gachoka, now Mbeere South, 2007-2017; and Bishop Robert Mutemi Mutua, 2013-2017, as a Wiper Party's nominated MP among others.

Nevertheless, Kalume's foresightedness in the dark and ignorant histories of Kenya could not be understood then. Clearly, he was ahead of his time, and indeed a societal model in various facets of life. Conversely, he failed to contextualize his religio-political discourses by largely failing to balance the two. In a society where some were ardent adherents of African indigenous religion, and where others were Christians or Muslims, Kalume did not have to be seen to be tilting the balance unapologetically towards the church. To some, his office was in the church; hence he was more of a church leader than a parliamentarian. This may explain his loss, though by a small margin.

\section{Conclusion}

In conclusion, Thomas Kalume has lessons for the $21^{\text {st }}$ century Africa in matters to do with religion and civic engagements on one hand, and development and relief on the other hand. Should the church remain prophetic within its pulpits or should even go an extra mile and eventually let some of her clergy to contest political seats? How should the church and society address matters of relief and development? Does Kalume's approach to relief and development and on matters to do with religion and politics inform the $21^{\text {st }}$ century? Certainly, Kalume proved it's possible despite his shortcomings as a clergyman turned politician. Indeed, he was many things to different people. To the church, he was a Balokole (brethren) in the East African Revival Movement whose territories had been expanded by God so as to serve both "Wheat and Tares" - the society - as the day of the Lord approached (Hebrew 10:25b). To others in the church, he was an organist who played best in the church choir, a great preacher and a public theologian who used every opportunity to educate the masses on theo-ethical issues. To the rest of society, he was a fine footballer, polished orator, musician and a politician, champion of modern development and a great family man. He was a pragmatist politician who called a spade a spade, even when the political risk of rejection was beckoning. He was a man whose set task to empower the rank-and-file of society through the medium of education was misunderstood but later understood, years after he was free at last. 
To others, Kalume is the great Kenyan whose imprints will remain even after the promulgation of Kenya's new constitution on Aug. 27, 2010, for the words in the national anthem were not altered whatsoever. Hence, the anthem remains Kalume's as well as Kenya's prayer across the centuries. As it says: "O God of all creation; bless our land and nation; justice be our shield and defender; may we dwell in unity, peace and liberty; plenty be found within our borders." Indeed, the memory of Thomas Johnson Kuto Kalume has been celebrated and/or reconstructed half a century after Kenya's independence to indicate that his concerns remain in our national agenda. As a schoolteacher-turned-clergyman-turned-politician and a farmer owning acres of land, and as a person who called himself "a pioneer African clergy" in "electoral victories of Kenya's parliamentary history," Kalume epitomises the modern-day Africa. That is, a society that has to necessarily multi-task (or is it the "an all-inclusive approach"?) in order to reap huge benefits, without losing her identity and image. As minerals and petroleum products are being discovered in the $21^{\text {st }}$ century Kenya, and as the economy sets out to provide free education for primary, secondary and university, the memory of Kalume's vision and prayer for prosperity is reconstructed. As Africa wrestles with terrorism, negative ethnicity, divisive and genocide-engineered politics, xenophobia and democratic impediments, Kalume's prayer for "unity, peace and liberty" becomes not only a Kenyan prayer but a prayer for the wider African constituency across the generations.

\section{References}

Anderson, W. B. 1977. The Church in East Africa 1840-1974. Dodoma: Central Tanganyika Pr.

Barrett, D. B. 1998. "Walter Edwin Owen 1878 to 1945 Church Missionary Society (CMS) Kenya /Uganda," Gerald H. Anderson ed 1998. Biographical Dictionary of Christian Missions. W. B. Eerdmans, Grand Rapids, Michigan.

Cole, K 1960. Theological Training in East Africa. Unpublished typescript.

Gathogo, Julius, African hospitality from a missiological perspective. Saarbrücken: Lambert 2011.

Gathogo, Julius, "Mau-Mau War and the Church in Kirinyaga, Kenya: Accounting for the tension and conflict (1952-1960)", Studia Historiae Ecclesiasticae, Dec. 2014, 40(2): 19-41.

Gilbert, Erik; Reynolds, Jonathan T., 2008. Africa in World History: From Prehistory to The Present. Pearson Education, Limited.

Gitari, David. 2014. Troubled But Not Yet Destroyed: Autobiography of Dr. David M. Gitari, Retired Archbishop of the Anglican Church of Kenya. McLean: Isaac Publ. 
Kalume, Thomas Diary (KD) that keeps information about his lifetimes from 1925 to 1974.

Kenya National Assembly Official Record (Hansard), Febr. 6 - March 20, 1970.

Kuto, John Gamoyoni, interview 5th June 5th June 2015 at Gongoni, Malindi.

Freire Paulo 1998. Politics and education. Los Angeles, UCLA Latin American Center. Mangi, Morris, interview 5th June 2015 at Marikebuni, Malindi, Kilifi County.

Muramba, Justin Masha, interview 5th June 2015 at Gongoni, Malindi, Kilifi County.

Mwang'ombe, Newman, interview at Kenyatta Univ., Mombasa campus, June 18, 2015.

Mwaro, Alphonse Baya, interview 7th June 2015 at Changamwe, Mombasa County.

Preucel, Robert W. \& Mrozowski, Stephen A. 2011. Contemporary Archaeology in Theory: The New Pragmatism. John Wiley \& Sons.

Provincial Unit of Research (PUR) 1994. From Rabai to Mumias: a Short History of Church of the Province of Kenya 1844- 1994. Nairobi: Uzima.

Rosberg C. G. \& Nottingham, J. 1970. The Myth of Mau Mau: Nationalism in Kenya. New York: Meridian.

Thuva, George Konde, interview 15th June 2015 at Kenyatta Univ., Mombasa campus.

Tsuma, Anderson Chibule Wa, interview 15th June 2015 at Kenyatta Univ., Mombasa campus.

Tunje, Graham Kalume, interview 10th June 2015 at Mianzini village, Kambe location, Rabai sub-county, Kilifi County.

UNESCO 2008. "Canadian fossil park, an Icelandic volcanic island and archipelago in Yemen among sites added to UNESCO World Heritage List," UNESCO, July 7, 2008 (acc. June 14, 2015).

Wamuthoni, Patrick Gathimba, interview at Chege's Café, Changamwe, June 14, 2015. 


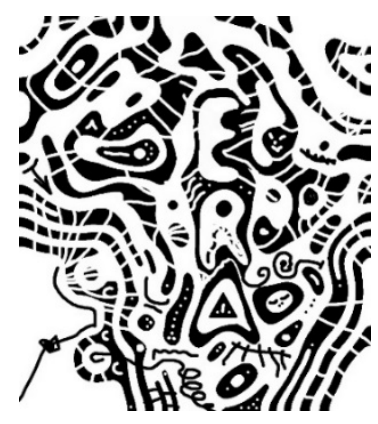




\section{Religion and Development in Swaziland ${ }^{1}$ \\ Advances and Reversals in the Case of Religious Education}

Sonene Nyawo

\section{Introduction}

The idea of "development" is conceptualized differently by different people, and at different times; hence what may be termed as 'development' is relative to time and space (Deneulin \& Bano 2009:24). However, the general understanding of development centers on the improvement of a country's economic and social conditions so that it reaches an acceptable standard of living for all people. Education is one of the key aspects of development that people would need to live. Sociologists such as Anthony Giddens have rightly perceived education as a complex political, economic, social and cultural issue that has become contentious in academic discourse (Giddens 2013:834). Amongst the many increasingly intricate questions raised in the education debate, Giddens identifies those that concern the type of education that should be delivered to people in a particular context, as well as the compulsory teaching of religion.

Christian missionary enterprise was of prime importance in the westernization of Africa because the missionary movement represented the first and most important facet of Western contact (Huhmann 2005). Missionaries used education to pursue the growing conception of Christian responsibility for the regeneration and development of African peoples. Thus, for the missionaries, conversion and education in the formation and development of Christian character were inseparable. A simple definition of development as viewed by the missionaries was that; "it is a process that creates growth, progress, positive change.... it is visible and useful, and it includes an aspect of quality change and the creation of conditions for a continuation of change" ${ }^{2}$ Hence, in their pursuit of development, missionaries established schools because education was deemed

1 In 2018, King Mswati III changed the name of the country from Swaziland to Kingdom of eSwatini. The initial rendition is retained in this chapter.

2 Society for International Development, 'What is development?' www.sid-israel.org/en /development-issues/what-is-development/ 
indispensable to their aim, and they always placed religion at the forefront of the school curriculum. Most missions provided basic education to ensure the inculcation of proper Christian principles and to enable Africans attending the mission schools to become good Christians. This is how Religious Education (RE) later enjoyed a lion's share in the schools' curriculum in African countries such as Swaziland. As stated in the definition of development, the process of development also involves a continuation of the change initiated by the developers. Thus, the Christian based RE curriculum in Swaziland has survived all threatening educational reforms, making the legacy of the western missionaries to live up to this day.

\section{Historical development of religion in Swaziland}

Swazis, like many African nations, are a religious people, whose belief system is rooted in the African cosmology. Long before western missionaries arrived, Swazis had their own indigenous religion, which Mzizi explains as "consciously organised beliefs, practices, and philosophical values that are focused on the transcendent being, the comprehension of human existence, the need to deal with the challenges of life.... "(Mzizi 2004a:104). A new religious orientation which Swazis had to embrace simultaneously with their indigenous religion was introduced in 1844, by royal invitation. King Somhlolo, the founder of the Swazi nation, had a vision on his deathbed. According to Swazi tradition, one night in 1836 King Somhlolo dreamt of people of a strange species, coming out of the sea and entering the country. They were the colour of red mealies, and their hair resembled the tail end of cattle. They were carrying two objects: a book (umculu) and money (indilinga). A voice cautioned the king that the Swazi should take the book and avoid the money, and that they should not fight against these strange people. He interpreted the vision to mean that Europeans would be coming to Swaziland with money and the Bible (Nyawo 2004:9). However, with a handful of Swazis it is not certain whether the scroll (or book) in the dream signified either the Bible or education. The church has taken the meaning to be the scriptures, while secularists feel it was education. Whatever interpretation is placed on the dream made little difference at that time since education of indigenous people was undertaken by the missionaries (Froise 1986:5). The king advised the Swazi to accept the book wholeheartedly. Soon after the vision had been related to royal councillors, the king died. King Mswati II, his 
successor followed up on his father's vision and sent emissaries to Grahamstown in South Africa in 1838 to invite the western missionaries to come to Swaziland (Kasenene 1993:10).

After a considerable delay, the Wesleyan Missionary Conference considered King Mswati's request and Western missionaries arrived in Swaziland on June 13, 1844 (Matsebula 1987:32). The 16-year-old king, the Queen mother and the royal councillors unanimously welcomed them. These were James Allison, the son of 1820 settlers in South Africa, who became a teacher, then lay-preacher and later a pioneer missionary in the Wesleyan Church. He was accompanied by Richard Giddy and Sotho evangelists. They were met and escorted to the residence of the regent who had oversight of the country until Mswati II, Sobhuza's young son, was old enough to take control (Kuper 1966:43). The enthusiastic welcome of the Wesleyan missionaries opened doors for many western missionaries to flow into the country. The fact that Christianity came to Swaziland through a cultural figure, the king, is significant. Swaziland has always been united and centralized under a dynastic monarchy. The monarchy is the incarnation of culture and tradition. The Swazi monarch remains a towering figure that commands respect and obedience from the Swazi people, and he is their mouthpiece. So, anything that is associated with the king is embraced easily and fully by his subjects. Christianity, therefore, has enjoyed that special privilege since its inception in Swaziland.

Currently, the Swazi indigenous religion coexists with Christianity. Legislatively, Swaziland has no official religion, but everyday practices point to Christianity's overriding popularity. Most Swazis identify as Christian ${ }^{1}$. Forms of Swazi Traditional Religion like divination, herbal healing and environmental and ancestral spirit veneration also make up this religious landscape (Golomski \& Nyawo 2017). Christian churches affiliate to three ecumenical bodies: the Swaziland Conference of Churches (SCC), the Council of Swaziland Churches (CSC) and the League of African Churches in Swaziland (LACS). In addition to the historical and independent churches which affiliate to the three ecumenical bodies, there is an influx of new churches known as 'prosperity gospel churches.' Some of these newer forms of worship, which mostly appeal to the elite, call

1 International Religious Freedom Report: Swaziland 2012 International Religious Freedom Report: Swaziland. 2012. Washington: Bureau of Democracy, Human Rights, and Labor, U. S. Department of State [Google Scholar]. 
themselves 'ministries' or 'charismatic churches.' Their membership derives mostly from industrialised areas of Mbabane and Manzini where most working population is concentrated (Kumalo [ed.] 2013:43).

Churches formerly established by European and US missionaries founded the SCC in 1929. The overriding aim of SCC has been to foster cooperation among the various mission churches engaged in Christian evangelism. They include several Protestant churches such as the Church of the Nazarene, Assemblies of God and the Evangelical Church. The SCC experienced a schism in 1976 when liberal members withdrew to form the CSC, which includes the Catholic, Methodist and Anglican churches. While SCC has primary aims in building new churches and conversion, CSC strives to address social concerns in society such as poverty, underdevelopment and injustice.

Unlike SCC and CSC, King Sobhuza II formed LACS in the early 1940s in liaison with clergy belonging to African Independent Churches and in response to attempts by the British colonial government and some European missionaries to ban these churches in Swaziland (Cazziol 1986:31). Similar to CSC and SCC, LACS aims to promote education, fellowship and unity among churches. Thus, the three ecumenical bodies have carried on the legacy of the white missionaries and established church-owned schools in Swaziland. At their establishment, western missionaries dominated the leadership of the SCC and CSC, and they continued for decades to influence the operations in all member churches.

\section{Education in Swaziland}

Currently, the education system in Swaziland (MOE 1999a:2) is organized as compulsory pre-school education which caters for children between 35 years of age; primary education which lasts 7 years and the official entry age is 6 years; secondary education which lasts five years, and is divided into junior secondary (a 3 year program that accrues learners a junior certificate) and senior secondary (a two year program that prepares learners for SGCSE, which replaced IGCSE). ${ }^{1}$ Thereafter they enrol in tertiary institutions.

The development of any country is assessed on how its citizens can sell high-value skills and insights in the world market. Although development

$1 \quad$ SGCSE $=$ Swaziland General Certificate of Secondary Education. IGCSE $=$ International

General Certificate of Secondary Education. 
is a process which has its origins in economics, it has spread to influence spheres such as education (Waugh 2000). This has necessitated curriculum reforms in Swaziland which would best prepare learners to engage effectively with international challenges and be successful citizens in the global society. Amongst other initiatives to improve education in Swaziland the government established a commission known as the National Education Review Commission (NERCOM) in 1985. NERCOM was tasked to conduct an inquiry into the applicability and relevance of the curricula offered in schools. In compliance with the recommendations of the commission an international two-year program, known as the International General Certificate of Secondary Education (IGCSE) was eventually introduced in Swaziland.

According to the October 2005 government national report on The Development of Education, one advantage of the new program was that "it promoted the development of problem-solving skills, knowledge and understanding and it explored the learner's ability to undertake individual projects" (MOE 2005:5). Glatthorn, A., Boschee F., \& Whitehead, B., describe this type of a program as one whose curriculum encourages learners to participate in the process of knowledge production which empowers them to become lifelong learners, "an approach representing a shift from a socalled product-oriented curriculum to a process - oriented curriculum" (Glatthorn, Boschee \& Whitehead 2006:37). The new program placed RE in Group 4 subjects that were electives, and this changed its status from being a core or compulsory subject.

\section{Different Shifts in the Religious Education Curriculum}

Although a lengthy discussion is not possible here, it is necessary to consider how RE has evolved over the years since the advent of Christianity in Swaziland. As Christian western missionaries pioneered formal education in the country, first in their priorities was to establish schools to convert Swazi children to the Christian religion. Put differently, missionaries used education as an effective tool for evangelization. Bible Knowledge or Scripture, as the subject was called, therefore, became important in the schools' curriculum, where "learners just read verses from the Bible and answered questions posed by the teacher" (Cazziol 1989:34). Cazziol states the aim of missionary education as being to teach new converts to read and write, and the brightest amongst them could be trained to be evangelists (Cazziol 1989:33). 
As education developed in different contexts, meaningful reforms were effected later. For instance, in the 1960s research inputs theoretically informed by the pedagogical arguments of Jean Piaget were motivated by educational psychologists (McMillan, \& Schumacher 2001:15). They posited that if religious instruction was to be of any relevance in the school curriculum it had to become child centred. This approach emphasized relating the moral teachings of the Bible with everyday experiences, as opposed to the rota-learning of dates, names, places and events outlined in the Bible, or even the memorization of key biblical verses (Cazziol 1989:36), as it was the case before. In response to this proposed learnercentred approach, the Ministry of Education in Swaziland issued a statement that changed the traditional Bible centred syllabus to integrate the Bible with social and personal topics called life-themes; hence the subject name changed from Bible Knowledge to Religious Knowledge. However, whilst the local syllabus was being modified to incorporate the life themes, Cazziol has it on record that the new integrating approach was attacked in many quarters as being 'humanist' and therefore unchristian (Cazziol 1989:40).

Another syllabus restructuring informed by the theories of educational philosophers such as Paul Hirst and Richard Peters was tried in the early 1970s. These theories presented religion as a holistic human phenomenon, whose instruction should not only be limited to Christianity, but should incorporate other major religions. A multi-faith syllabus was developed and briefly piloted in one school in Swaziland, but "was soon discontinued because no other school appeared interested in adopting it" (Cazziol 1989). All schools, with exception of one, remained with the old syllabus which comprised the Old and New Testament and Christian Doctrine. Of note is that the old Christian-based syllabus followed earlier before the 1960s survived all reforms, as it maintained its Bible centred approach, "despite the change of name of the subject from Bible Knowledge to Religious Knowledge” (Nyawo 2010:7).

The introduction of IGCSE in 2006 by Cambridge Assessment International Education in Swaziland brought another shift in Religious Education. The earlier rejected Junior Secondary multi-faith syllabus now came as part of the IGCSE package. As NERCOM had observed, the curricula that Swaziland inherited from the white missionaries and colonialists was said to be irrelevant to the lives of learners, and less applicable to their realities and the aspirations of the society; thus schools were fast producing ill-prepared learners who were hardly absorbed by the ever-changing 
working environment and they ended up being frustrated school leavers (NERCOM 1985:67). The commission then recommended that the government should adopt a model which would have efficacious educational methodologies that would nurture the learners' higher order cognitive and interpersonal skills. The commission also emphasized the socio-cultural relevance of any curriculum, that it must not be detached from the real world in which the learners live; it must be closely aligned to the values and work skills of that world. In compliance with the recommendations, the Ministry of Education in Swaziland formulated a new policy known as the National Policy Statement on Education which was based on the importance of quality education (MOE 1999a:8).

As stated earlier, the new programme for secondary schools was subsequently introduced in 2006. In addition to its major aim to align the education system with international education standards, it embraced the vision that secondary education should be "a flexible, responsive and integrated curriculum that would satisfy world-class learning standards compatible with higher and further education and the job market" (MOE 2005:9). This improvement, therefore, paved way for a new paradigm in Religious Education curriculum. The curriculum changed from being Bible based to a multi-faith model. The adoption of the new curriculum necessitated development of new syllabi and teaching materials that dovetailed each other at both junior and senior secondary levels. These sought to contribute to the physical, intellectual, moral and social life of the learners; preparing them to participate effectively in an increasingly intercultural global society. Four religions were now studied under IGCSE; Judaism, Christianity, Islam and Swazi Traditional Religion. RE now lost the long-cherished status of being a compulsory subject and it became an elective. The number of students who were examined on it dropped drastically. Most mission schools removed it from their subject offerings. This also had serious implications on the job market for RE teachers.

\section{The Perceptions of Stakeholders about the multi-faith syllabus}

The introduction of the new multi faith curriculum in Swaziland did not get a good reception from stakeholders who raised many concerns. Motivated by the public debate captured in local print media which had dragged for a couple of years, I conducted a quick inquiry on the public's perceptions of the newly introduced RE curriculum in 2009. I categorised 
the responses of my sample into four themes: the conservative, the progressive, the moderate and the extreme views ${ }^{1}$. The following section presents a synopsis of the collected data.

\section{Conservative view}

Nine of the seventeen respondents preferred the Bible based curriculum than the multi-faith model, claiming that the cornerstone of the old curriculum was the Bible and the teachings of the Lord Jesus. They asserted that the Bible was the key factor in character development, and it should therefore not be clouded with other religions which were of lesser value than Christianity. Speaking on behalf of mission schools, one of the respondents asserted that missionaries were the pioneers of education in Swaziland, and initially they trained evangelists who became teachers in the school system. The emphasis in the class instruction was placed on spiritual, physical and mental development. Hence leaders of this country, especially the Prime Ministers were products of mission schools. They also viewed studying four religions simultaneously as rather too cumbersome for the school going children. They preferred that they be offered only at tertiary, when learners had already formed a Christian value system that would inform their decision making. Some respondents, mostly the parents opposed the new RE curriculum on the grounds that Swaziland was a Christian country, and it should not be polluted with other faiths. More so some of these religions bred terrorists who targeted adherents of the Christian faith; in the words one respondent; "We cannot afford to see Swaziland, as it is the case with other countries, experiencing instabilities caused by religious conflicts."

One of the respondents, a Principal of a mission school, put it unequivocally clear that his church was against embracing the multi-faith curriculum. When the multi-faith syllabus was introduced in 2006, the Board of Governors for the school issued a directive that all schools under this church should scrap of Religious Education from their subject offerings;

1 The data I collected was presented in a paper titled: 'Multi-Faith Religious Education in Swaziland: A Response To Globalization' at the Annual BOLESWA TRS Conference, held at University Of Swaziland -Kwaluseni from $27^{\text {th }}$ Febr. $-1^{\text {st }}$ March 2010. I collected data from a sample of stakeholders who comprised 7 teachers from 3 mission schools and 4 public schools; 4 students from 2 mission schools and 2 public schools; 2 Christian leaders who were parents; and 4 other parents. 
"unless the new multi-faith syllabus is withdrawn from the school system we cannot bounce back to Religious Education", he stressed.

\section{The Progressive View}

Two of the respondents expressed that adopting the multi-faith model was necessary, and it was timely for a developing country like Swaziland, which had to work hard to create a space for itself in the global world. Additionally, the school being an important entity in a pluralistic society of the $21^{\text {st }}$ century could no longer be a passive transmitter of a single religion. It should innovatively create a reconciling environment in which learners from various religious backgrounds could learn to transcend those backgrounds; 'this does not mean rejecting your own belief system, but it is gaining the essential and liberating realisation that your religion is one amongst many', asserted one respondent. After all adherents to other religions contributed immensely to the socio-economic life of the Swazi, through poverty alleviation and providing scholarships to learners. Their religions therefore deserved to be heard through religious instruction in the schools.

\section{Moderate view}

Two of the respondents acknowledged the educational value of the multifaith curriculum, in terms of broadening the scope of knowledge of the learners, "so that they can make informed and unbiased decisions in the future." Also, it had the potential to enrich one's understanding of the background history of other religions, thus inculcating respect and tolerance towards other religions, as well as appreciating the similarities and differences amongst religions. However, these respondents still wished that Christianity would be given some preferential treatment in the syllabus and be discussed under many topics so as to "emphasize the one true God and the Gospel of Christ, the only Son of God."

\section{Extremist view}

According to four of the respondents, who claimed to be representing many voices that were whimpering at the background, multi-faith model was to be scrapped off completely from the school system because it was not useful; instead it created confusion to learners who were raised in 
Christian principles. Also, learning about other religions would be like being disrespectful to King Somhlolo who initiated the introduction of Christianity in Swaziland.

\section{A reversal, from elective to core}

Despite the antagonistic attitudes of the stakeholders towards the multi faith curriculum, it continued for 10 years in the school system until the year 2016. A directive reportedly from the Swazi Cabinet was announced on 10 Dec. 2016 which brought drastic changes to the school's curriculum. It specified that, with immediate effect, state schools in Swaziland would only teach Christianity in religious education classes, and that RE would now be a mandatory subject in private and secondary levels. "The main objective behind the Christian-based Religious Education is to enable the learner to develop Christian virtues and to build a personal Christian ideal that would inspire learners' development and maturity. The focus would be on transmitting knowledge of the life and teachings of Jesus Christ". ${ }^{1}$ It was argued that RE was designed to teach children the difference between right and wrong, and that "Christianity was the best way to achieve this". ${ }^{2}$ Implications of the new directive were that in a month's time Swazi Traditional Religion, Judaism and other faiths would be banned from the classroom. However, government stated that Muslims and other faith communities were free to worship as they pleased and to teach their faith in private institutions. Whilst a few lone voices spoke against the directive asserting that it would fuel religious intolerance, many Swazis applauded it. ${ }^{3}$ A leader of one ecumenical Christian organisation in Swaziland could also not hide his excitement as he was cited

1 This statement was said by the Minister of Finance during his address to Parliament on 24 Febr. 2017.

2 The Times of Swaziland on 19 Jan. 2017 reported the Principal Secretary in the Ministry of Education.

3 For example, an article published in the Times of Swaziland (BongumusaDlamini, 23/01/2017) titled "Public reacts to teaching of Christianity only in schools", stated that the removal of other religions in the RE syllabus had been received with mixed feelings from the public. However, a majority of those interviewed by the Times of Swaziland according to the article expressed that it was a good move by government especially because Swaziland was known to be a Christian country. The Sunday Times 29 Jan. 2017 also reported that there was great ululation at Mandvulo Grand Hall when Christian pastors thanked His Majesty the King, Her Majesty the Indlovukazi and government for ordering that all schools should teach Christianity only. It was emphasised that it was 
saying; "The country has gone back to normal now". He applauded the ministry of Education and Training for what he called a wise decision to remove other religions from the RE syllabus. "There is no other religion that this country was founded upon except Christianity; not that other religions are not important, but Christianity is the best". ${ }^{1}$ So, learning about other religions would pollute the learners and the "correct" religion would also be threatened.

Although many Swazis from different circles celebrated the reversal that carried forward the legacy of the western missionaries, there were a few voices that expressed their dissatisfaction. Some protested that the decision to ban other religions from the RE syllabus was taken by politicians without consulting important stakeholders such as teachers, moderators and those who represent the various religions in Swaziland. They perceived this change to best illustrate that in Swaziland religion and politics are intertwined. Thus, cabinet did not find it important to consult these stakeholders because they were exercising their right as politicians to decide on issues that pertain to religion. The lone voices disapprovingly expressed that this action took the country back to the Protestant Reformation era, where religious matters were debated and passed in parliament. For instance, the Act of Supremacy and the Act of Uniformity which were mostly on the status of Christianity in England were discussed and passed in parliament (Gonzalez 2010:56).

There were also some members of the public who raised a concern on the scrapping of Swazi Traditional Religion (STR) from the syllabus, which they regarded as part of the Swazi heritage. They wondered why the children were now denied their rights to learn about the Swazi culture - could this still be perpetuation of the missionaries' agenda in Africa, which demonised all indigenous cultural practices? Nkambule's assertion seems to best represent the protesters' sentiments when he notes that STR was described by missionaries as an evil practice centred on ancestor worship. Traditional religious practices, ceremonies and festivals together with religious beliefs were labelled Satanic. Swazi cultural norms and practices such as polygamy, medicine, arranged marriages, ritual ceremonies and even the traditional dress code were condemned (Nkambule 2010:21). People's reception of the sudden change of the RE syllabus was, therefore,

not good for Swazi children to be taught other religions, yet it was common knowledge that Swaziland was a Christian country.

1 The Times of Swaziland (Nondumiso Mtsetfwa, 19/01/2017) 
an indication that most Swazis still have phobia for cultural practices, such that any syllabus that would seek to promote culture should be eliminated.

\section{Conclusion}

The various shifts in the RE show that Christianity has always monopolised and dominated the school curriculum, and this has established a legacy that has proven difficult to expunge. The approach used by missionaries during instruction, and the objective of this instruction established a certain culture for the teaching of RE. Most missionaries regarded a school chiefly as an evangelising agency and looked to conversion as the final proof of the value of their educational activities. Perkins has recorded prominent western missionaries who pioneered education and health services in Swaziland, admitting that schools were the most successful means of evangelization, and have produced virtually all the first political Christian leaders of independent Swaziland (Perkins 1974:50). This approach in teaching RE made some stakeholders mistake classroom instruction with indoctrination.

The presented scenario on the status of RE in Swaziland best illustrates that western missionaries held a philosophy that education and religion were inextricably interwoven. They seem to have drawn their insights from western educational philosophers of the $18^{\text {th }}$ and $19^{\text {th }}$ century from Europe and America (Mac Ojongo 2008:53). These philosophers argued that the most important aim of education was to produce a religious and morally upright person. Christianity then turned out to be a major purveyor of education in developing Africa. Since the arrival of the Christian missionaries in Swaziland, education has been used to reproduce Christian traditions to ensure a generational transmission of Christian values, norms and attitudes. This becomes what Giddens has labelled a 'hidden curriculum', through which members of the society learn passive acceptance of the status quo (Giddens 2013:834). Hence, some stakeholders in Swaziland, as shown in the discussion, would, with excitement, assert that 'the country has gone back to normal' now that the Christian based curriculum has been brought back. Illich describes this as 'passive consumption' where stakeholders uncritically embrace the existing social order, and they are taught 'to know their place and to sit still in it' (Illich 1971:87). It is, therefore, fair to conclude that when considering the Swa- 
ziland educational context, there is an interface between the Christian religion and development, to an extent that Christianity has continued to have a pervasive influence in the education system down the generations.

\section{References}

Giddens, Antony. 2013. Sociology, 6th edition, Cambridge: Polity Pr.

Casey Golomski \& Sonene Nyawo. 2017. "Christians'cut: popular religion and the global health campaign for medical male circumcision in Swaziland. Culture, Health \& Sexuality 7.

Cazziol, R. J. 1986. 'The Origins and Development of the Zionist Movement in Swaziland. MA Thesis, Univ. of Natal.'

Cazziol, R. J. 1989. 'A Comparative Study of Christian Missions in Swaziland, 18451968,' Ph. D. Thesis, Univ. of Natal.

Froise, Marjorie, 1986. '150 Years Of Mission-Churches In Swaziland, 1844 -1994,' MA Thesis Univ. Of South Africa.

Froise, Marjorie. 1989. World Christianity Southern Africa. Monrovia California: MARC.

Glatthorn, A., Boschee F., \& Whitehead, B. 2006. Curriculum Leadership: Development and Implementation. London: SAGE.

Gonzalez, J. L. 2010. The Story of Christianity Vol. 1: The early Church to dawn of reformation. New York: Harper Collins.

Huhmann, Johannes. 2005 Munich, GRIN, www.grin.com/document/44777

Illich, I. D. 1971. Deschooling Society, Harmondsworth: Penguin.

Kasenene, P. 1993. Religion in Swaziland. Braamfontein: Skotaville Pr.

S. Kumalo (ed.), 2013. Religion \& Politics in Swaziland: The contributions of Dr J. B. Mzizi, Bloemfontein: SUN MeDIA.

Kuper, Hilda. 1966. The Swazi: A South African Kingdom (San Franscisco: Holt, Rinehart, \& Winston,),

— 1996. "The Swazi reaction to missions," African Studies Vol V, 177-188.

Marcelo, M. Suarez-Orozco \& Desiree Baolian Qui Hilliard. 2004. (eds.) Globalization: Culture and Education in the New Millennium. California: Univ. of California Pr.

Matsebula, J. S. M. 1987; A History of Swaziland, Cape Town: Longman.

McMillan, H., \& Schumacher, S. Research in Education: a conceptual introduction, $5^{\text {th }}$ ed. US: Longman, (2001).

Moroz, R., \& Waugh, R. F. Teacher receptivity to system-wide educational change. Journal of Educational Administration, (2000), pp159-171.

Mzizi, J. B. The dominance of the Swazi Monarchy and the moral dynamics of democratisation of the Swazi State. Journal of African Elections 3, (2004a.)

National Education Review Commission Reform Through Dialogue, Ministry of Education, Mbabane, Swaziland, (1985). 
Nkambule, F. S “The teaching methods in the International General Certificate of Secondary Education Syllabus of Religious Education teachers in Secondary Schools in Swaziland: A case of selected schools in the Manzini Region”. Univ. of Swaziland Research Centre, Kwaluseni, Swaziland, (2010).

Nyawo, S. 2004. 'The Early Encounter between the Swazi and the Western Missionaries: The Establishment of the Evangelical Church in Swaziland, 1892-1950, MA Thesis, Univ. of Natal.

Perkins, F. J. 1974. 'A History of Christian Missions in Swaziland to 1910,' Ph. D. Thesis, Univ. of the Witwatersrand, Johannesburg.

The Ministry of Education (MOE). 2005. 'International General Certificate of Secondary Education (IGCSE): Consultative Document.' Swaziland: Ministry of Education.

The Ministry of Education (MOE). 1999a. National Policy Statement on Education. Swaziland: Ministry of Education.

The Times of Swaziland, 19 Jan. 2017.

Mac Ojongo, Timothy Tabor, 2008. Philosophical and Historical Foundations of Education in Cameroon 1884-1960, Limbe: Design House.

Waugh, R. F. 2000. "Towards a model of teacher receptivity to planned system-wide educational change in a controlled system," Journal of Educational Administration, 350-360. 


\title{
Church-State Relations and the Political-Economy of Land and Development in Rhodesia ${ }^{1}$
}

\author{
The 1969 Land Tenure Act
}

\author{
Petronella Munhenzva
}

\section{Introduction}

The World Bank's 'Voices of the Poor' study (2000) found that religious leaders and institutions are often the most trusted institutions in developing countries. It also found that support from religious leaders can be essential in ensuring community involvement and ownership in development projects. According to Clarke \& Jennings (2008), 'Throughout history, religious groups have been at the forefront of advocacy including in the civil rights movement in the US, the Jubilee 2000 Debt Campaign, and the frequent religion-led resistance to dictatorships in Asia, Latin America and Africa.' It is within this context, that appreciating the church's response to the land question in Rhodesia (colonial Zimbabwe) provides valuable insights into the potential of the church in the development or lack thereof in a country.

In describing the relationship between the church and the state in colonial Africa, Mufuka categorises missionaries as 'precursors and later faithful allies of imperial powers' (Mufuka 1977:3). His words describe the nature of relationship that existed between the clergy and statesmen across colonial Africa in general and Rhodesia in particular. One of the most established views pertaining church and state is that the 'flag followed the cross' and that churches received preferential treatment from the state through land allocations for mission schools and hospitals etc. (cf. Mufuka 1977 and Sithole 1968). This chapter demonstrates that, although the church played a critical role in opening up space for colonialism and being an ally of the state, the state weakened the church in its effort to retain hegemony. The relationship between church and state was vulnerable to political, economic and social pressures. The developments ushered in by

1 Rhodesia became Zimbabwe on 18 Apr. 1980. 
the passing of the Land Tenure Act (LTA) in Rhodesia makes the Act a watershed in the political and economic history of Rhodesia.

Historically, relations between 'church'1 and state in Rhodesia tended to be co-operative and non-confrontational (cf. Chadya 1997 and Sithole 1968). However, in 1969 the government passed the Land Tenure Act which greatly affected the church's position and radically altered the relationship between church and state. The Act defined churches as Voluntary Associations. This meant that they lost control over lands that they had accrued from the preceding legislation like the Land Apportionment Act of 1930. The Act also imposed straining conditions on issues of expansion, transfers, subdivisions and consolidation of land. Furthermore, the Act evicted Africans from Mission Lands and restricted the churches 'operation in African areas. The church responded radically to these provisions, for instance, the Roman Catholic Church threatened to close all its institutions. To fully apprehend the implication of this threat it is important to appreciate the institutions that Roman Catholic Church controlled in Rhodesia. They operated 700 mission schools, 81 European convents, 43 African convents Rhodesia's main private hospitals; St Anne's in Salisbury and the Mater Dei in Bulawayo, 43 hospitals, 88 dispensaries, the Emerald hill orphanage, the Nazareth old people's home, dozens of secondary boarding schools, clinics and trade and home craft schools among many other institutions. ${ }^{2}$ Hence such a move by the Catholic Church would cause a lot of social and economic hardships. However, Smith refused to be swayed by these threats and the churches became 'militant.'

\section{Effects of Land Tenure Act on the Church}

The starting point of the contentious ACT is noting that it was passed by the government without consulting churches. In the passing of the Land Apportionment Act (LAA) of 1930 a preceding land law, the government consulted the churches. However, in the passing of the LTA the churches were not consulted. This was interpreted by the churches as way of the Rhodesian government to undermine and overlook the position of the church. Hence in as much as they were very angry at the provisions of the Act, they were also angry because its passing without their consultation

\footnotetext{
'Church' is used to represent more than ten different denominations.

The Chronicle, 30 Apr. 1970.
} 
demonstrated that the government no longer held them in high regard like what had been the case all along.

The provisions of the Act themselves were also a major cause for contention. The LTA classified land into European, African and National Area. There was no longer any such category as mission or unreserved land. ${ }^{1}$ There was a distinction between ownership and occupation of land, ownership, did not confer right to occupy or let others occupy except for members of the appropriate race in its own area. ${ }^{2}$ There was also no legal definition of 'church. '3 The LAA had referred to a religious body and classified mission land. The LTA replaced it with 'religious order or sect' which was included under Voluntary Associations like trade unions, boy scouts, among others. This gave the Minister control of the activities of the church. ${ }^{4}$ The Minister could authorize or deny the right to own lease land (RCBC 1970:12). The LTA also did not classify mission land churches had to register as either European or African. A non-racial church was forbidden to own land in the African or European areas unless it applied for a certificate to be a VA within the meaning of the Act. The church had until 1 September to register as VA. ${ }^{5}$ The churches were against this and they declared that they were non-racial and that they therefore could not be controlled by any particular race.

The Minister also kept a register open to inspection by members of the public which contained, the name of the VA; church, diocese and order, details of the land so owned or leased, term of conditions fixed by the Minister. Whichever certificate issued could be cancelled at any time any new land acquired after 2 March 1970, required a written application to the Ministry for permission under the LTA to own land specifically as a VA. ${ }^{6}$ New buildings on such land required the normal planning permission under the Town and Country planning Act. Rights to expand and transfer land were also vested in the hands of the Minister. In the case of transfers the Minister had to be notified seventy-two days before. Expansion of existing institutions or provision of new ones on what was formerly 'mission land' was not allowed unless specific approval was given

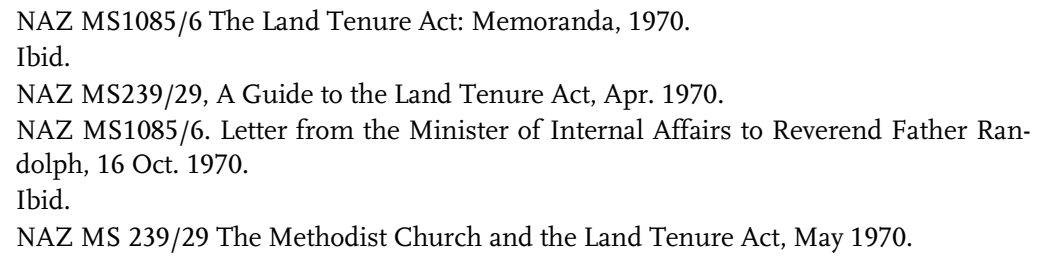


The church's position in the Tribal Trust Lands (TTLs) was also greatly regulated. Permission had to be sought to operate in TTLs. In terms of the LTA, a permit to be on church lands was issued for an indefinite period for any African who; was a pupil at a school established before the $2^{\text {nd }}$ of March 1970 regardless of whether such school had been registered in terms of the Education Act of 1956 or the African Education Act. ${ }^{1}$ According to the LTA, a preacher or teacher employed by the religious body owning that land, a doctor or employee or patient at a medical institution established before the $2^{\text {nd }}$ of March $1970 .^{2}$ In a letter from the Minister of internal affairs to Father Randolph and the heads of the denominations, the Minister clarified on some of the issues pertaining operations in TTLs. The letter stated that, mission staff, of whatever race were deemed to be mission employees and had the authority to occupy the leased land. These provisions demonstrate fully how the government sought to control and monitor the position and activities of the church in Rhodesia.

\section{Church Reaction}

The passing of the Act pitted the church against the state. The initial reactions by the church were aimed at reconciliation and sought an amicable solution from the state. Church leaders held a meeting with the Minister of Lands, Mr. Van Heerden. ${ }^{3}$ The meeting was for the church leaders to go through the Act and clear any points they did not understand. During the meeting the leaders also raised their concerns with the cancellation of the category of mission lands, and the minister urged them to write down their petitions to the ministry and he would consider them. With the meetings with state officials not yielding much churches resorted to press conferences and airing their views through the newspapers. The Anglican bishop of Mashonaland wrote to the Minister of lands, van Heerden, ${ }^{4}$ a letter that was published through the Rhodesia Herald. The bishop was responding to Mr. Van Heerden's comment that the church leaders had failed to take up an invitation to discuss their problems with him before issuing public statements about the LTA. In the letter the bishop expressed gratitude to the senator for meeting with delegations

NAZ MS239/29 Minutes of the meeting between the Minister and the heads of churches, 23 Jan. 1970.

Rhodesia Herald, May 2, 1970.

NAZ MS239/29, 1970.

NAZ MS1085/6 'Text of letter by bishop,' Rhodesia Herald, May 2, 1970. 
and making an effort to assist the churches to own land as Voluntary Associations. He went further to note that the churches however would not register as Voluntary Associations and seek permission to do their work. He noted that "churches found their situation desperate; they cannot work or exercise Christian charity to all men by permission.'1 The bishop further stated that, the courtesy of the senator was greatly appreciated but he was a single man he could not give them assurance about the future occupation of their lands.

According to the chronicle newspaper, the Catholic Archbishop Reverend Francis Markall and the superintendent of the Methodist Church and the Reverend Andrew Ndhlela associated themselves with the letter. ${ }^{2}$ This back and forth communication between the two groups through letters and newspapers shows a continuous dialogue between the two that was informed with hostility. It also goes to show that the tensions between them were escalating with time. Initially it had been meetings, but it quickly turned into newspaper outbursts. Professor George Boobyer, a visiting professor of theology at the University of Rhodesia told the Rhodesian National Affairs Association that that Christian principles had to be applied in both private and public life. Without referring directly to the church-state in Rhodesia that time, he stated that ' $t$ t]he church also reaches out beyond the boundaries of the state. ${ }^{3}$ Which was more of a subtle hint that in a church-state conflict the state could lose. The view is plausible in the context of the time, the Smith government did not have allies due to the UDI Unilateral Declaration of Independence and sanctions against it whilst the churches in Rhodesia enjoyed a lot of international support.

Churches held various meetings in a bid to stand against the government. There are records of informal discussions among church leaders. ${ }^{4}$ Reverend Burrough was one of the leaders at one of these meetings. He informed others that he had spoken with the minister who had told him that the government was trying to avoid a head on collision with the churches. He also noted that he had asked members of the cathedral in Salisbury to ask the Dean to write to the Prime Minister (PM) expressing their concern that his statement that he was prepared to talk to church leaders would

Ibid.

NAZ MS1085/6. 'Churchmen hope to see the Prime Minister,' Chronicle, May 2, 1970. Ibid.

NAZ MS1085/6. Unconfirmed record of informal discussions held at Paget House, Salisbury, 25 Apr. 1970. 
not go by default. The legal advisor to the church leaders asked Reverend Burrough if the minister had given any indications that the government was prepared to consider the position of the church. The bishop replied that the minister had made it clear that he did not want to make any rash promises. Other members like Reverend Fred Rea asked what principle the churches were basing their decision not to register as Vas. The meeting agreed that the first reason was that, by registering, the church was implicitly admitting the right of government to give or withhold permission. The churches had no objections to register as long as they retained some of their rights but registering placed them at the mercy of the minister. ${ }^{1}$ They also agreed that not registering was a tactical move, it was the most convenient point to make a protest. The meeting agreed that the government had to be made aware of the church's dilemma;

If we do register, we thereby concede the right of government to determine our use of land; our existence as churches depends on the use of land; therefore, our existence as churches will depend on the minister of government. ${ }^{2}$

They also agreed that they were ready and happy to accept the label VA but did not want to accept the right of a minister to limit their freedom in an area which was basic to their beliefs; 'the Christian precept of charity.' The Dean of Salisbury, Reverend Sam Wood said, 'If the government wants to pursue its present course of hostilities with the churches, then it should abandon the claim that Rhodesia is a Christian country. ${ }^{4}$ He noted that most people that actually supported the Rhodesian Front party were Christians that had no idea what the Act would do to the churches. Under the Land Apportionment Act of 1930, a preceding legislation to the LTA, missions were not designated as either black or white occupation, so that the church could operate without declaring itself as being one race of the other and with the right of both races to live and work on the missions. The passing of the LTA now required the churches to register as Voluntary Associations to avoid being designated and had to register with the minister for its operations. In the words of the dean Sam Wood, 'rights have been removed and permission substituted instead. ${ }^{5}$

Ibid.

Ibid p2.

Ibid p2.

NAZ MS1085/6. 'Dean hits out at hostility to the churches,' Rhodesia Herald, 4 May 1970 .

5 Ibid. 
The churches also reacted to the Act through the issue of special masses. The church leaders called for special masses to pray for the 'crisis' in the country. In the Dominican Convent Hall, a special nine days of masses started on the $3^{\text {rd }}$ of May 1970 which were held every day at 7:45 in the evening. The Convent Hall was also used, also Saint Georges College in Salisbury. The Roman Catholic Church also called for mass movements in towns for people to pray for the country and also protest to the government.

The churches in their fight against the government also took to informing the entire nation on the evils of the Act. In a memorandum of 20 June 1970, the Executive Committee of the Christian Council of Rhodesia the board appealed to the rest of the country to stand against the LTA. The memorandum contained 'implications' of the LTA as interpreted by the board. The first point that they noted was that the LTA had one main purpose which was to promote 'separate development' ${ }^{1}$ which they argued was informed by people who emphasise racial differences than common humanity. It also stated that the Act divided the land unequally at the expense of the Africans and it stood in the way of Christian activities. Thus, it urged the people to spread the news on the inequalities of the Act, speak to their chiefs, members of parliament and others able to influence public opinion. This demonstrates the intensity of the conflict between the churches and the state. The former was ready to take the fight to the public whilst the latter remained un-swayed. The Catholic bishop, Reverend Adolph said that he hoped for more discussions with the government and that the situation will not come to show down where the church will be forced to close all its institutions. He further noted that they hoped for support from the church and that those who supported the Act did not fully understand what it entailed. The Anglican bishop supported this position by stating that 'Anglican institutions are controlled by independent governing bodies, but if their Christian work is restricted by government legislation, the church's position in them would have to be reconsidered.' The Bishops issued an ultimatum to the state, 'Amend act or we close all institutions.' The Catholic bishops issued a statement and announced that unless Smith withdrew the Act, they would close every Roman Catholic

NAZ MS1085/6, Memorandum; The Land Tenure Act; to all Rhodesians, 20 June 1970. Ibid. 
school, hospital, orphanage and old people's home in Rhodesia. ${ }^{1}$ To understand the full implication of this move it is important to understand the institutions that Roman Catholic Church controlled in Rhodesia. They operated 700 mission schools, employing 3500 teachers and attended by more than 150000 African children, 4,400 European and 1400 coloreds, 81 European convents, 43 African convents, Rhodesia's main private hospitals; St Anne's in Salisbury and the Mater Dei in Bulawayo, 43 hospitals, 88 dispensaries, the Emerald hill orphanage, the Nazareth old people's home, dozens of secondary boarding schools, clinics and trade and home craft schools. ${ }^{2}$ In Salisbury, the 75-year-old St. George's College which had an enrolment of 700 boys nearly all of whom were European, the country's five Dominican convents for girls that dated back to the pioneer column faced the danger of closing. Hence such a move by the Catholic Bishops would cause a lot of social and economic hardship. After issuing the threat to Smith the Catholic bishops joined the heads of other major Christian Churches in agreement to defy the Act.

Bishop Lamont (A critical individual in the state-church relations during this period) defending the position taken by the catholic bishops to shut down operations if the state does not revise the LTA. He had once said that Rhodesia's racial ideology was in essence the same as that of Nazi Germany but only differed on the degree of application. ${ }^{3}$ The text stated that, the Catholic bishops had never said at any time that they would throw out school children, orphans, the sick or the aged from their institutions in Rhodesia, rather the bishops had said that the LTA principally by imposing a problem of conscience made impossible the staffing of their institutions and would thus in effect close them down. ${ }^{4}$ He further stated that bishops were not heartless monsters as interpreted by the state and the people, when they issued a statement that unless certain things happened, they would appoint a day for their work to be discontinued. He defended this position by pointing out that it was impossible to conduct a school, orphanage, hospital or any kind of institution in a state of uncertainty. The uncertainty of not knowing whether you are going to be able to provide the staff or not or the uncertainty of not knowing whether laws will be invoked to prosecute those who cannot conscientiously conform.

NAZ, The Times, 'Rhodesia Bishops warn Smith' 30 Apr. 1970.

NAZ, The Chronicle, 'Rhodesian bishops threaten Smith' 30 Apr. 1970.

NAZ, The Chronicle, 'Rhodesian racial policy 'like Nazi Germany's' 16 June 1974.

Ibid, p7. 


\section{Assessment of the motives behind the church's fight against the LTA}

The church asserted that their greatest problem with the state in relation to the LTA was due to its discriminatory and racist nature, however minutes of the meeting held on 27 April reveal interesting dynamics pertaining the position of the church in its fight against the LTA. The memorandum and the minutes for the meeting raises interesting insights that reveal that the church fought against the state on the LTA because it endangered their position more than the effect it had on Africans. The memorandum states that the points of focus for the meeting would be to address the following questions;

Do we take our stand on the principle that all discriminations are wrong? If so, we must be prepared to explain why we do not admit women into priesthood; why St George's and Peter house did not admit Africans until about six years ago and Ruzawi Hill still does not...Do we take our stand simply because the Act makes our position uncertain? Materially our position is uncertain because we cannot put money and effort into enterprises which are subject to a permit which can be withdrawn without parliamentary vote or appeal to any court or tribunal... ${ }^{1}$

The minutes of the meeting show that there was considerable debate among the clergy on why they were fighting against the LTA. The conclusion was that they were advocating to retain their position and at the same time fight for equality. This can further be explored in the context of the Native Land Husbandry Act (NLHA): after its passing the church did not do much if anything at all to oppose it although it was actually more oppressive to the Africans than the LTA. It limited the number of their cattle, alienated many urban workers by assigning specific areas of abode to Africans either you were an urban worker, or you were in the reserves you could not be both. This was actually repressive to the Africans more than the LTA and has actually been credited to have been one of the causes of the $2^{\text {nd }}$ Chimurenga war but the churches did not do or say anything!!! This feeds into the discourse on the true motives behind the church's actions; was it really for equality? Standing for the oppressed? Or it was because the church's position was threatened?? In their petitions against the government the churches constantly talked of the LTA, but they did not mention the NLHA.

1 NAZ MS1085/6., Memorandum for heads of churches 27 Apr. 1970. 


\section{State Reaction}

As the churches waged their war against the state, the state also reacted. The Minister of Lands, Mr Van Heerden, said that the church leaders had failed to take up the offer to discuss their problems with the minister before issuing their statements about the LTA. The Chronicle had a heading that said that 'Minister replies to church, talk offers repeated.' ${ }^{1}$ The minister stressed that an 'unnecessary confrontation' between the church and the state was something the government wanted to avoid. The minister further stated that he had opened the doors to church leaders to come to his office and discuss their problems like they had done in January when they clarified on the issue of VAs. He was surprised to learn of the public statement by the churches saying that they would not register as VAs without talking to him first. He further accused the churches of spreading a sense of insecurity among the people by making them think that Africans were no longer able to worship in European areas and vice versa. ${ }^{2}$

The Prime Minister, Ian Smith, issued a statement that he was stampeded by the bishops to meet them. He noted that 'I am not being stampeded. I shall just have a quiet little chat with the bishops. ${ }^{3}$ He further stated that if anyone questioned his Christian principles, he would like them to quote a chapter and a verse and further added that he did not believe that they could.

Subsequently, as the heads of denominations issued a statement stating that they were not going to accept the provisions of the LTA, the Prime Minister issued a statement asserting that he would amend part of the Act. ${ }^{4} \mathrm{He}$ indicated that he was aware of the displeasure of the churches with the LTA and that the government could not amend the Act in the manner requested by the churches. However, he could remove 'whatever causes of friction there may have been between the churches and the government. ${ }^{5}$ Two amendments were issued. The first one was the removal for the application of permits; 'in order to eliminate the need for churches to apply for these permits, it is our intention to propose an agreement whereby permits will be deemed to have been issued in these cases. ${ }^{6}$ The

NAZ The chronicle 1 May 1970.

Ibid.

NAZ, The Chronicle, PM says he has not been Stampeded, 5 May 1970.

Ibid.

Ibid.

Ibid. 
second one was conceding the existing rights of churches to own or lease land. The Prime Minister admitted that this fell short of what the churches wanted but also stated that there was nothing further he could do.

Smith told the bishops that they would not register as VAs. ${ }^{1}$ But other repressive clauses against the church were left intact. According to Rhodesia Herald, Smith conceded to the churches because he feared the explosion that would materialize if the churches were infuriated. ${ }^{2}$ One churchman commented, 'the proposed amendment now means, I feel that the running battle between the government and the church will now simmer down...I can't see any concerted and renewed opposition by the various denominations now. ${ }^{3}$ The Rhodesia Herald commenting on the issue reported that,

Had the churches been forced to carry their defiance through to September, (the deadline for registration under the Act) many hundreds of mission schools, hospitals and clinics throughout Rhodesia may have been closed, but the government's expected climb-down will waive the necessity for churches to register. This means that multi-racial work will continue as before. ${ }^{4}$

Though the amendment met some of the demands by the churches, they were still not fully satisfied, because they still had to apply for permits for all 'new' lands and extensions. The minister still reserved the rights to cancel any permit for occupation and to declare that attendance is occupation. It also increased the number of conditions for the cancellation of permits. Pertaining the activities of the church in TTLs, the amendment did not change anything as the church still had to ask for permission from the commissioner.

Certain members of the government advocated for 'the most stringent action' against the clergy of any denominations who were guilty of subversive or anti-Rhodesian activities. One of the major proponents for this course of action was Senator Jack Cary. In the Senate deliberations of 21 June 1973 on the president 'speech in response to the Bishops' stand, Jack Cary said, 'let's get active, gaol them if necessary but at least deport them and get them out of this country so that they do not continue with the harm they are doing at the moment. ${ }^{, 5}$ He further noted that he did not

NAZ, Rhodesia Herald, 'Smith yields point on Race' 25 Aug. 1970.

NAZ, Rhodesia Herald, 'Churches placated; Rhodesian Land Row Resolved' 5 Sept. 1970.

Ibid.

NAZ, Rhodesia Herald, 'Smith in Church Back down,' 25 Aug. 1970.

NAZ, The Chronicle, 'Hard line on 'subversive' clergy urged' 22 June 1973. 
want to hurt any religious feelings, but Rhodesia was fighting a war for survival and those who subverted others were enemies and had to be dealt with accordingly. It is in this context that we had the arrest and deportation of Bishop Lamont who had been an outspoken critic of the government. In Gwelo there was a court case involving another Roman Catholic priest, the one who had edited the article provided by Bishop Lamont.

Another measure taken by the state was putting spies in churches and having them report any criticism levelled against the state by the preachers. The state mainly used African spies that paid to attend services. ${ }^{1}$ Reverend Thomas Curtis of the United Methodist Church claimed that he had evidence of many Africans who could confirm that they had been paid by the police to sit in services and listen to preachers and note down any comments on the state. He said that they were many plain clothes policemen ready to report any thought or feeling which runs counter to the policies of the political party in power. According to him this was an 'unwelcome development.'2

Whilst the church was attacking the government for the provisions of the Act, the government was attacking the church for aiding African freedom fighters. ${ }^{3}$ It realised a law and order report to the world council of churches and other churches that gave out financial assistance to African fighters.

\section{The public and the church-state confrontation}

The tug of war was not only limited to the church and the state, but it also extended between the public; those who stood behind the government and those who stood against it.

Some whites were sympathetic of the government and were against the bishops for standing against Smith. One wrote to the Chronicle,

I hope that Mr. Smith has a nice talk with the bishops. I'm sure he won't stand for any Marxian ideas of doing unto others as we would want them do unto us. We just can't have bishops or anyone else suggesting that it is not Christian to give half the land to just one twentieth of the people: after all

NAZ, The Chronicle, 'Smith's police put spies in churches, say leaders' 31 Oct. 1971.

Ibid.

3 NAZ, The Chronicle, 'Rhodesia attacks church aid to African Guerillas' 5 June 1973. 
what are we white for? ... why seek God's will when we can legislate quite acceptably and much more comfortably in Salisbury? ${ }^{1}$

An article written about the evolution of the church's position in Rhodesia by a chronicle reporter named M. I. R. Hawthorn with the title; 'The church is becoming militant'2 He writes,

Over the past few years, the church has become increasingly aware of its inadequacy in maintaining contact with the people at large. As a result, churches have modified their approach, services and outlook, they have introduced reforms and even tried reaching down to the younger generation. This is all the more laudable when one considers the history of Christianity. Now the church in the name of Christianity is becoming outspoken, aggressive and even militant in the political field. In other words, the church has awoken. If it were not for the prejudice, torture and strife in the East and the hate and the warring in the Middle East I should at this time blush with shame at the antics of the so-called Christian churches. Organised religion on this planet has indeed reached its lowest ebb. The Christ Spirit teaches love...Jesus demonstrated the Christ love during his life...this is the teaching of Christianity not the threats and counter-threats used by our churchmen. A word of advice to these ones, you have taken the name of God in vain and as you sow you shall reap. You do not know the nature of your God and the life you lead on this earth. Read, contemplate, pray and learn before it is too late, and you and your manmade hierarchies and temples come crashing down. There is only one way to do God's work and that is the right way. ${ }^{3}$

While some stood against the bishops, one Nancy MacTaggart wrote to the Chronicle and expressed support for the bishops.

The general theme of the letters condemning the catholic bishops' stand against the LTA appears to be that the church should be seen but not heard. The 'gentle Jesus meek and mild theme is all very well in its place... but what about the time when Jesus whipped the money lenders out of the temple? Since they were plying their trade it was presumably with the permission of the authorities. This did not stop Jesus from doing what he knew to be right, he called the scribes and Pharisees 'whited sepulchres' which was hardly less violent than the word Bishop Lamont used against the Rhodesian government...the LTA should be amended to restore the freedom of action the churches have always had in their work for the benefit of all Christians. ${ }^{4}$

Another one also wrote to the Chronicle, 'now is the time for the Prime Minister Mr. Ian Smith, to show the world and Rhodesia that he is a

NAZ The Chronicle, 6 May 1970, Letter from 'Pure White'.

NAZ, The Chronicle, 'The Church is becoming militant' 4 May 1970.

Ibid.

4 NAZ The Chronicle, Letter from Nancy MacTaggart 12 May 1970. 
statesman and not a mere politician and admit that the LTA is a bad mistake. ${ }^{1}$ Someone else wrote,

Let us accept that to the majority of the Christian churches these are fundamental issues requiring theologically important and tragically difficult decisions. How fundamental or necessary are the objectionable aspects of the Act to the government? There seems no valid reason why the old LAA category of 'mission land' should not have been retained or why even a more restricted version says, 'ecclesiastical land' should not have been created on which the churches' rights of occupation would remain secure. It should be appreciated that registering as a VA entitles the churches to continue to own their land but does not entitle them to occupy it. After 70 years of full ownership rights registered in the title deeds they have. I consider, a right to complain. What else can they do? They have no rights of appeal... I also have a depressing feeling that this whole unnecessary confrontation could so easily have been avoided had the three relevant Ministers and their staffs attempted to understand the urgency of the churches 'problem...despite the churches' rather tactless and possibly precipitate action, it is incumbent on the government to accept the desperate sincerity of their action and to make amendments to those aspects of the Act which, to government are unimportant and unnecessary but to the churches are vital to their faith and function.'2

These responses and comments show the socio-political impact that the conflict between the church and state had to the people. The confrontations between the two were extended to the general populace and is evidence that conflict between the two greatly affected the country.

\section{Conclusion}

The Land Tenure Act was a watershed in the relationship between the state and the church in Rhodesia. The relationship between the duo was historically mutual and beneficial. This is not to say that it was always harmonious. There were points of contention between the pair, but the contentions were not significant in damaging the relationship. They disagreed on the issue of African education, UDI, proposed constitution. These disagreements were mainly on the basis of principle and belief system on what is wrong and what is right but did not significantly affect the relationship. The LTA became a direct threat on the position of the church because it undermined its position, reach and influence through curbing

NAZ The Chronicle, 'Land Tenure Act a Mistake' 2 May 1970.

NAZ The Chronicle. ‘Government must accept sincerity of the Churches’ action' 2 May 1970. 
the control on land. The Act created a great gulf between the two that affected the political, economic and social systems of Rhodesia. Politically, the government faced great opposition from within the country given the influence that the church had, economically the sabotage by the churches would greatly paralyse the nation since the churches had large controlling stakes in many institutions. The reactions by the church influenced the reaction of the state. The government was arm-twisted in amending the Act more than once. Yes, the state was hostile in some of its reactions but overall the state gave in to the church and amended the Act. This shows the central role that church played and still plays in the country. Religion and politics have intertwined from time to time and still do today.

\section{References}

\section{Primary Sources}

NAZ MS1085/6, Memorandum for heads of churches 27 Apr. 1970.

NAZ MS1085/6, The Land Tenure Act: Memoranda, 1970.

NAZ MS239/29, A Guide to the Land Tenure Act, Apr. 1970.

NAZ MS1085/6, Letter from the Minister of Internal Affairs to Reverend Father

Randolph, 16 Oct. 1970.

NAZ MS 239/29, The Methodist Church and the Land Tenure Act, May 1970.

NAZ MS239/29, Minutes of the meeting between the Minister and the heads of churches.

NAZ MS1085/6, 'Dean hits out at hostility to the churches,' Rhodesia Herald, 4 May 1970.

NAZ MS1085/6, Memorandum; The Land Tenure Act; to all Rhodesians, 20 June 1970. 23 Jan. 1970.

NAZ MS239/29, Minutes of the meeting between the minister and the heads of churches, 3 Jan. 1970.

NAZ MS1085/6, 'Text of letter by bishop,' Rhodesia Herald, May 2, 1970.

NAZ MS1085/6, 'Churchmen hope to see the Prime Minister,' Chronicle, May 2, 1970.

NAZ MS1085/6, Unconfirmed record of informal discussions held at Paget House, Salisbury, 25 Apr. 1970.

The Rhodesia Catholic Bishops 'conference (RCBC): The Land Tenure Act and the church, Mambo Pr., 1970.

\section{Newspapers}

NAZ, The Chronicle, 30 Apr. 1970.

NAZ, Rhodesia Herald, May 2, 1970.

NAZ, The Times, 30 Apr. 1970. 
NAZ, The Chronicle, 30 Apr. 1970.

NAZ, The Chronicle, 16 June 1974.

NAZ The chronicle, 1 May 1970.

NAZ, The Chronicle, 5 May 1970.

NAZ, Rhodesia Herald, 25 Aug. 1970.

NAZ, Rhodesia Herald, 5 Sept. 1970.

NAZ, Rhodesia Herald, 25 Aug. 1970.

NAZ, The Chronicle, 22 June 1973.

NAZ, The Chronicle, 31 Oct. 1971.

NAZ, The Chronicle, 5 June 1973.

NAZ, The Chronicle, 6 May 1970.

NAZ, The Chronicle, 4 May 1970.

NAZ, The Chronicle, 12 May 1970.

NAZ, The Chronicle, 2 May 1970.

NAZ, The Chronicle, 2 May 1970.

\section{Secondary Sources}

Chadya, M. J. 1997. 'Missionary land ownership: The case of the Roman Catholics at Chishawasha' Masters Dissertation, Univ. of Zimbabwe,.

Mufuka, K. N., 1977. Missions and Politics in Malawi, (Limestone Pr., Kingston, Ontario.).

Sithole, N. 1968. African Nationalism, (Oxford, OUP). 


\title{
Sustainable Peace and Development: Peace Building by the Ecumenical Church Leaders Forum
}

\author{
The Case of Zaka in Zimbabwe
}

Lindiwe Princess Maseko

\section{Introduction}

This chapter seeks to evaluate the Ecumenical Church Leaders Forum (ECLF) peace building work and how this work seeks to meet the Sustainable Development Goals (SDGs) in Zimbabwe. The chapter seeks to review the correlation between Church's peaceful initiatives and the 2030 SDGs. Zimbabwe, a nation dominated by Christianity, has been struggling to attain sustainable development due to past unresolved conflicts which ranged from family disputes, as well as political, religious and economic conflicts.

The foundation of the chapter is Lederach's (2003) theory which defines peace as a comprehensive term that encompasses the full array of stages and approaches needed to transform conflicts towards sustainable peace. The idea is that peace and development are inseparable, and it is very important to stimulate the church to continue engaging in local peace building work to promote sustainable development in Zimbabwe. This confirms that despite their religious, social and political differences, when people are united, they can work towards sustainable development.

Therefore, this chapter focuses on the connection between the ECLF's peace building work and the SDGs in three Zaka district wards, Zibowa (ward twenty), Rwemhepo (ward five), Chiromo (ward eight) in Zimbabwe. The chapter explores the true identity of sustainable peace and development. It also presents answers from the ground to the question on how the work of this Forum has benefited individuals and the community in Zaka district, specifically in the three wards mentioned above. This chapter will first define peace, development and the SDGs using Lederach's (2003) theory. It will also outline Zaka's background, ECLF's achievements, the contribution of ECLF to development in Zaka and finally show how peace and development have partly contributed to the attainment of the SDGs. 


\section{Definition of terms}

\section{Peace}

Defining peace is not easy. Several definitions have been forwarded: Anderson (2004) in Verbeek (2008:5), defines peace as a "behaviour through which individuals, families, groups or nations experience low levels of violence and engage in mutually harmonious interactions." This explains peace as being expressed in two broad perspectives. Peace in this sense is negatively portrayed when people encounter low levels of violence, which practically means that peace and violence sometimes exist at the same time. However, peace should be common and become the prevailing and preferred state in any given situation. Sanchez (1995) in Verbeek (2008:5) understands this idea very well and avers that "peace is not an ever-ending process, but it is an attitude, a way of life, a way of resolving problems and conflicts." In support of this, Boulding (2000) defines peace as a process and not a condition. Peace should deeply transform the lives of individuals and the whole world at large. This brings in the idea of "peace building" within communities, which is defined by the Fellowship of Christian Councils and Churches in the Greater Lakes and Horn of Africa (FECCLAHA 2015:13), as "any activity aimed at improving the quality of life, by preventing, reducing, transforming, and helping people to recover from all forms of violence."

According to Lederach (2003), the building of relationships is through reconciliation, which balances the four values, namely: truth, mercy, justice and peace. The gospel of reconciliation makes enemies to see God in each other's face. This definition, therefore, is a theological gift to the present church to adopt a mission of walking in the path of reconciliation. Truth telling makes people to feel for each other; it makes the society seek justice and pursue sustainable peace, which will make them to work together, despite their differences. Hence, peace is where people are able to determine their destiny, where human rights are respected, where freedom of expression, democracy, transparency, and access to justice is. This explanation matches what the Zimbabwean church has partly done in Zaka, through the ECLF's gospel of peace.

\section{Development}

Development can be referred to as an organized intervention in collective affairs according to a standard of improvement. In general understanding, development is the act of growing or causing something to become 
advanced. Sustainable development should be the continuous improving of the quality of social, economic, political and religious life for all. Morse and McNamara (2013), define development as a journey of advancement in societies, with push up factors which include advances in governance. Development is a typical set of projects to help the poor, hence this supports the work done in Zaka which helped the less privileged through different income generating projects initiated by the ECLF in Zimbabwe. Development, therefore, brings a broad change in society. Oswald (1992), highlights the three dimensions of development as follows: environmental, economic and social dimensions. The first dimension is the relation of human beings to the environment. If human beings are capable of relating well with their environment, they are able to build good relationships with others. Second, structural transformation and economic growth is a core factor of development. Where there is a poor economy, there is no development. To exemplify this, Zimbabwe's economy has been struggling, there are less job opportunities and citizens have not felt satisfied with the quality of the lives that they live. Lastly, Oswald characterizes development in social terms, which is also linked to vulnerability and equity.

\section{Sustainable Development Goals (SDGs)}

SDGs are a new framework building on the Millennium Development Goals (which were uneven and failed to reach the 2015 target). These are development goals targeted to change the communities, the nation and the whole world by 2030. The new framework has a unique vision and it goes a mile beyond the MDGs targeting to reach particularly the most vulnerable parts of the world (https://sustainabledevelopment.un.org). Alongside the development priorities such as poverty, education, and food security and nutrition, the new framework of the SDGs, also sets a wide range of economic objectives and also comprises more peaceful and inclusive societies. The SDGs are a win-win co-operation which brings in a huge gain to all countries, including Zimbabwe. The UN Sustainable Development Summit for the adoption of the Agenda 2030 and the SDGs was held from 25-27 September in 2015. The SDGs basically aim at ending poverty and hunger by 2030 . The SDGs are designed to make the world better now and forever than it was in 2000 and are building a consensus about a sustainable future (sustainabledevelopment.un .org/partnerships). The sustainable future referred to is where everybody has enough food, employment, sustainable peace and where there are health 
services and education for all, to mention a few. The quotation that is given by Nehlsen and Richard (2017:2), in the GPPAC background highlights that the SDGs are there to improve the quality of life for all. The quotation reads "a central promise of agenda 2030 is to leave no one behind...." This highlights that the SDGs by 2030 intend to improve and develop the whole world. In the case of Zimbabwe, the SDGs can only be achievable in the presence of sustainable peace.

\section{The Concepts of Peace and Development: Siamese Twins?}

The relationship between peace and development needs clarification. One cannot define peace in the absence of development, and development in the absence of peace. Hence in this section, these two concepts are inseparable. Peace building is not easy to measure. However, it can be seen and be felt through sustainable development. If peace is a measure used to make people not to live in violence, then it should precede development. Once the community is in that state, then it means that there can be development. Peace and development are different sides of the same coin. To understand the coin, one needs to turn it up the other side. This implies that for the SDGs to be attainable in Zimbabwe, there should be an understanding of peace before one talks of development. In this context Galtung (1975), in Ledwith (2005), states that peace is something more positive and dynamic than simply creating stability to prevent violent conflict. Hence, peace is change, peace is transformation, and peace is development. Peace should be the empirical evidence of sustainable peace and development. This way, McCandless and Karbo (2011), suggest that peace should not only help people resolve their conflicts, but should also improve the lifestyle of the individuals. Hence, where there is peace, there is a right level of income, where there is peace, there is sustained progress and improving economic situation. Where there is peace there is a set of strong formal institutions including property rights, democracy and trust (Reychler \& Langer 2006).

Lederach (2003), emphasizes more on the practicality of peace building, hence this has made development a successful story in Zimbabwe, particularly in Zaka district. People at individual, community and national levels should learn to live in harmony and in peace so that they can manage any situation peacefully. A peaceful community reconciles in a non-violent manner and develops, not for one individual, but for the benefit of the citizens. This is in contrast to a violent community where there is no sense of ownership; people tend to use other means to solve their conflict 
and development in that area is named after the partner or the donor instead of that particular community. Krause \& Jutersonke (2005) point out the problem of most peace building practitioners who follow a donor system where knowledge does not come from the local levels but is brought by the donors. However, the theory of transformation emphasizes that peace building should come first and make the community to opt for a way forward for developing their area, hence that is how peace strengthens development. Sustainable peace and development come from within, it is driven from oneself passing to another, hence it is sustainable peace which brings the idea of development. In support of this, Nehlsen \& Richard (2017) argue that there can be no sustainable development without peace and no peace without sustainable development.

\section{Background Information}

Zimbabwe is one of the countries which is generally classified as being on the path to development. As mentioned above, development in this nation has been compromised due to unresolved conflicts. The questions guiding this chapter are: What caused these conflicts, and what caused the conflicts to disturb mostly the economic stability in an independent country such as Zimbabwe? Were there any steps taken to resolve these kinds of conflicts?

After attaining political independence in 1980, there have been limitations to sustainable development. Over the years, Zimbabweans have lived with the pains of their past experience, hence this led the nation to an unpleasant situation. Initially, this has been caused by power hungry leaders, different political wills, the politics of the elite and social injustice. Also, victims and perpetrators have lived with trauma of the past grief, and this has affected their peaceful co-existence, hence causing disunity. In actual fact, the past encounters have divided the nation, and this resulted in under development in different communities in Zimbabwe.

A significant challenge in the Zimbabwean society has been identified in the 10 provinces of Zimbabwe, including districts like Zaka, Nkayi, Honde Valley, Chitungwiza, Mberengwa and others. The impact of poverty which was caused by the unstable economy also caused millions of youths flocking to neighbouring countries for greener pastures. This kind of situation has also led to early child marriages, causing many conflicts between families, marriage partners and mostly between the daughter/son in laws and father/mother in laws, hence a barrier to sustainable 
peace and development in Zimbabwe. Youth and women have been excluded from issues to do with development and this has caused the unsustainability of some developmental and income generating projects throughout the country. This also caused high levels of unemployment and limited access to livelihoods to community cohesion projects, hence falling prey to political manipulation during the campaign period.

Furthermore, there has been serious marginalization of women, and gender-based violence has been common. Whilst women have been excluded from peace building and most developmental work, they are the ones who suffer most in the Zimbabwean community. The political, social and religious violence which the Zimbabweans have been experiencing in the past 30 years, have negatively affected women. There have been several reports of rape, torture and intimidation, as stated by Vengeyi (2011). Vengeyi (2011), argues that during the war, rape was used as a political weapon to intimidate and suppress women. Magaisa (2010:367), also presents the evidence of this from one woman saying, "when a male victim is attacked, the weapon of choice is a stick, but when a woman victim is attacked, the choice of weapon is the male reproductive organ". This resulted in many cases of sexually violated women in the past years. This also exacerbated social conflicts, hence leading to unsustainable development.

Moreover, there has been corruption, lack of accountability and unequal distribution of the economic resources which came as a result of poor governance. The ZCC (2016) document presents that the Zimbabwean economy has been suffering from a number of problems which included corruption, underperforming parastatals kept draining national resources, withdrawal of international lines of credit and the difficulty of balancing market forces with a social welfare to economics. Dube and Makwere (2012), argue that the challenges that Zimbabwe has faced since attaining political independence have actually left a bad mark on the face of the country. More so, the distribution of land became an issue. It is in this scenario that the poor have become downtrodden in the communities. The poor and the rich could not work together for peace and development, hence there has been a tendency of "survival of the fittest." It is against such a background that this chapter presents an analysis of how the Ecumenical Church Leaders Forum has contributed to sustainable development, economically and socially, particularly in Zaka district. 


\section{Zaka District}

Zaka is a district in the Masvingo Province of Zimbabwe. It is in region 5 and is located $86 \mathrm{~km}$ southeast from Masvingo in the Ndanga communal lands, with a population of 181106 and a total of 34 wards, (ECLF Report 2016). The village was established in 1923 and lies in a very low-lying area, hence the Shona derived name kwo-ka-zaka which means 'to where it is going down.' Zaka district is a typical Karanga smallholder farming area, which is a semi-arid, mountainous area with erratic rainfall averaging $600-800 \mathrm{~mm} / \mathrm{yr}$. The soils are generally poor and subsistence farming is the central economic activity and the main crops grown are maize, groundnuts, cotton, sorghum, finger millet, sunflower and pumpkins.

The population density is more than 65 persons $/ \mathrm{km} 2$, which is quite high for a mountainous area where subsistence farming is the main economic activity. It is the most densely populated rural district in the province and probably in the whole country. Most families rely on support from breadwinners working in big towns and cities. Until recently, teachers and nurses used to be the major source of formal income to the small economy of Zaka. However, many afflicted people, including the less educated, have fled to South Africa. Jerera Growth Point accommodates the district administrative offices and is the hub of the district's activities, with locally owned shops, $95 \mathrm{~km}$ from Masvingo town, selling groceries. Other activities include income generating projects such poultry, welding and soap making. Different stakeholders such as CARE International doing humanitarian work in the district, are also based at the Growth Point. Although there are now more schools than before, many children still travel long distances of up to 10 kilometres to the nearest school, (ECLF Report (2016).

\section{Ecumenical Church Leaders Forum (ECLF)}

The Ecumenical Church Leaders Forum is a Faith Based Institution focused on Peace Building in Zimbabwe founded in 2008 and registered as a trust in August 2010. It is an inclusive body of a variety of church leaders, both clergy and lay, male and female. Ncube et al (2016), document that the ECLF was formed following the difficult situation of 2008 and the socio-economic and political situation which had worsened for years. "We knew that the nation was hurting and desperately needed to heal, we also knew that as a church we had the moral obligation to heal the people..." (Ncube et al 2014:7). Dhlembeu (2014), also acknowledges that the ECLF 
was formed against a background of people with pain, hurt and anger at personal, community and national levels. The challenges faced by the Zimbabweans pushed a group of concerned church leaders from different denominations to come together and examine the role of the church in response to such challenges, hence the formation of the ECLF. In this context, the ECLF reflects on the prophetic role of the church and on issues of peace and nation building, hence this forum works together with the community for peace and development in the ten provinces of Zimbabwe.

The ECLF plays a prophetic role in Zimbabwe, which is also supported by the Zimbabwe Council of Churches, the Zimbabwe Catholic Bishops Conference and the Evangelical Fellowship of Zimbabwe (2006) documentary work. This document emphasizes that the church is the divine institution in the world called to serve God. In this case, the background of the ECLF is based upon preaching the liberating gospel to alleviate human suffering in this world, hence the mandate to safeguard peace in Zimbabwe (ZCC, ZCBC, EFZ 2006). As a church forum, ECLF works to contribute towards the creation of a peaceful, just and democratic nation by capacitating the church, the community and its leaders with peace building skills.

The ECLF, comprises many churches affiliated to ecumenical bodies including the Zimbabwe Council of Churches (ZCC), Zimbabwe Catholic Bishops' Conference (ZCBC), Union for the Development of Apostolic Churches in Zimbabwe Africa (UDACIZA) and the Evangelical Fellowship of Zimbabwe (EFZ) (Dhlembeu 2014). It is made up of quite a number of staff members. The ECLF is in partnership with the UN Development Program (UNDP), the Lutheran Communion in Southern Africa (LUCSA), Bread for the World, American Friends Service Committee (AFSC) and the United Evangelical Lutheran Church of Germany (VELKD).

The ECLF acknowledges the past communal challenges and addresses them through the knowledge of church leaders together with the community leadership. Kadzikano \& Ittig (2014), bring out the idea of the ECLF in conducting community capacity building targeting everyone, including women, the youth and those living with disabilities as well. The ECLF has been able to touch more than 35000 lives nationally through its training sessions. These two authors also support that the ECLF is inclusive and as such, the outcome of the ECLF's engagement with political parties has 
greatly contributed to the parties adopting peace to be part and parcel of their life.

The ECLF uses the Conflict Prevention, Management, Resolution \& Transformation (CPMRT). This is a mechanism used to prevent conflict and violence, to manage it and to transform the communities through dialogue, negotiation, mediation and reconciliation. CPMRT is a programme used to show case that positive conflict resolution can lead to development. CPMRT is a model that focuses on the inner person, transforming human beings at a personal level, as well as leading to institutional level (Dhlembeu 2014). The approach includes the understanding of conflict in nature, types, the genesis, deep conflict, identification of the root causes through conflict analysis. It also looks at power dynamics, dialogue, facilitation, mediation and negotiation skills. Furthermore, the ECLF conducts healing of the past hurts, memories and trauma. The CPMRT programme strategies are based on ownership of initiatives by communities, participation of women, the youth and traditional, church, civic and political leaders. The CPMRT programme runs for all and includes diverse players, thus going beyond ecumenism to interfaith, partnering and networking with other stakeholders.

Alternative Dispute Resolution (ADR) is another ECLF programme covering all CPMRT activities to deepen the foundations for peace, dialogue and social cohesion in Zimbabwe. This programme extends CPMRT as a way of deepening peace and development in Zimbabwe. An analogy of ADR given likens CPMRT as secondary and ADR as tertiary level in ECLF peace building. ADR in simple terms seeks to make peace a lifestyle and not a syllabus. It is expected to contribute and to enhance the resilience of communities against disruptive disputes. The overall objective of this programme is to reduce potential threats to national and community peace and social cohesion, while improving capacities from timely and structural response to disputes before they escalate to violence (ONHRI 2014). In addition, the ADR programme seeks to develop a pool of Local Peace Connectors (LPC), amongst community leaders across sectors and through the LPC who will be nurtured through enrolling them in a tailored learning trajectory encompassing diverse skills for example, collaborative leadership, problem solving, facilitation and mediation. It also aims at developing Local Peace Facilitators (LPF), who are critical in facilitating community level engagement and dialogue, leveraging on the existing LPC structure. Another aspect of ADR is the establishment of Con- 
flict Early Warning and Early response (CEWER) mechanism to complement community dispute resolution efforts, a mechanism for early detection and response to disputes and conflicts which will be established with the leadership of the National Peace and Reconciliation Commission (NPRC) and other national stakeholders, including the civil society and the church amongst others (ONHRI 2014).

\section{The Ecumenical Church Leaders Forum's Achievements}

The situation before the intervention of the ECLF in the communities gives a picture of challenges which have caused conflicts and disharmony among community members. There have been conflicts exacerbated by episodes and series of challenges, due to political tensions and violence during the election period (Dhlembeu 2014). These interests included the manipulation in the political arena, the mismanagement of resources and unfair distribution of resources. Due to the fact that $90 \%$ of the population live below the poverty datum line, there has been negative peace in the country, no overt physical violence but people were hurting, their money was gone, and the situation was inflammable (Dhlembeu 2014). Hunger and violence were bedevilling the country. In the case of social gatherings and meetings in the society, there were clashes of interest and people tended to divert social to political issues and, worse still, fighting because of their political differences. It has been identified that the past political issues have actually planted graveyards instead of sustainable development. Since there was no peace, development practitioners have done contrary to what was expected. Development without peace caused civil war in Zimbabwe as reflected in Matt 3:3, "brother against a brother".

In particular, the Zaka community encountered such challenges. Before the peace programme, there was hatred among some family members. This caused tension among community members and development was not durable. Like in many other communities, some people in Zaka could not understand the idea of peace and development which go hand in hand. Also, violence was habitual and was in the physical form, which affected the majority; spiritually and psychologically. This has proven that the physical absence of violence does not mean the presence of peace in Zimbabwe.

Earlier on in this district, it was a 'crime' for one to have his or her own choice, especially in politics. "Unofarira chikwata chipi? What is your favourite team?" Such a question was asked diplomatically to find out where 
a person belonged politically. There was no "peace within" individuals and between different members of the community. As a result, people were hurting each other due to bitterness and status. Everything was politicized such as a football match and even the church activities. Churches have been renamed and relocated for political reasons. Further, some of the church choruses have been reframed to become political songs. These include:

"Tokwira makomo tomudana Mwari wedu!"

(We'll climb the hills calling our Lord!)

Changed to:

"Tokwira makomo tomudana Tsvangirai!"

(We'll climb the hills calling Tsvangirai!) or

"VeZvapupu muri nhumwe dzakatumwa kuzoparidza vhangeri

(The witnesses you are messengers sent to Preach the gospel!)

Changed to:

Baba Mugabe muri nhumwe yakatumwa kuzotungamira Zimbabwe

(Father Mugabe you are the messenger sent to lead Zimbabwe!)

This led to underdevelopment in areas such as health and wellbeing, morality and gender equity and equality. This was all exacerbated by the economic situation in the country.

This was the situation in the different communities, including Zaka. Regardless of how the situation was, the ECLF started to capacitate the church in Zimbabwe as from 2009. After the trainings, the communities had a positive view towards the programme. This work resulted in community ownership of the peace building initiatives, demonstrated by communities establishing their own Local Peace Committees, and leading to community cohesion. The cohesion is practically evidenced by communities identifying their priority needs and engaging in developing initiatives as a collective measure. The ECLF started as a church forum and later extended to church and community and this gave birth to a unique product called Local Peace Committees (LPC). Journeying together with the church and the community, the ECLF activities gave birth to dialogue so that communities were able to discuss issues affecting them at community level. Across the ten provinces of Zimbabwe there have been many healing sessions conducted and this has led to total human transformation. Healing sessions were conducted notably in Zaka, Mutoko, Mberengwa, Honde Valley, Nkayi, Vumba Mine and Gomwe communities, among others. The peace building component of the programme has brought about some notable changes to people's lives and violence has been reduced (Kadzikano \& Ittig 2014). 
Also, this forum prides itself with several examples of peace and development such as the three schools in Beitbridge, Masarakufa-Mudzi and Zibowa, constructed by communities after ECLF intervention (www.eclfz .org/aboutus). The ECLF puts emphasis on every citizen's participation in peace building as "one does not make peace with his friends, but with his or her enemies." This way, the ECLF is $100 \%$ non- partisan and does not seek to have converts.

\section{The Contribution of the Ecumenical Church Leaders Forum to Development in Zaka}

The ECLF started its peacebuilding work in Zaka in 2015. The ECLF has managed to carry out Conflict Prevention Management Resolution and Transformation (CPMRT) workshops in 30 wards and also conducted capacity building workshops for Local Peace Committees in 20 wards. There have been major changes in the district since this forum started. It is a testimony of many participants and the ECLF members that the forum has worked so hard in Zaka. Community members gave testimonies in support of the ECLF peace initiatives, highlighting how the initiative had healed their emotional wounds, transforming their behaviour and hence navigating a way for sustainable development. The ECLF has intervened in three wards in Zaka and community members were at work, not only for development, but for peaceful co-existence as well. Communities have been working together for forgiveness and reconciliation; hence people are mending broken relationships caused by previous grudges. Unity has been forged through community cohesion projects which are seen and proven by a school in Zibwowa, a bridge in Rwemhepo and a clinic in Chiromo. All these achievements are referred to as "blisters of peace" by community members (www.eclfz.org) .

Through the CPMRT sensitization programme, Zaka has embraced peace, which is also the Sustainable Development Goal number 16. This is witnessed by the peace dividends of community cohesion efforts emerging. Ultimately, the communities now see the need to work together, thereby transforming negative energies for development. There has been reduction in crime and there is now an improvement in relationships, which was done through the management of conflicts by the community leadership and members. The promotion of peace in Zaka is demonstrated by a cohesive community which can solve conflicts non-violently. 
Consequently, such a state can improve the nation and bring in sustainable development.

Furthermore, the ECLF transformed individuals by promoting sustainable peace from "within" and spreading it to others. LPC members and counsellors also testified that they had been changed in many aspects of life, especially on their attitude and behaviour. Individuals have managed to change their perspectives and have come to realize that at times perceptions exacerbate conflicts. As such, it is very important to pursue truth in things and that a positive attitude always attracts peace and tranquility. This programme is not only about improving the economy and other things per se, but it is also designed to bring a total transformation in the lives of individuals,' as testified in Zaka. The ECLF has also managed to tame the character of some of the individuals such that they become wellmannered, as this is a hall mark of any emerging leader. Actually, many of them have come to understand that a person is not defined by what is seen from him or her, hence in peace building, behind every human behaviour there is a story. The community members also acknowledged that they had been transformed and were now able to understand that conflict is everywhere, and the solution is not a global one, but one relevant to their specific context.

The church has sought to eradicate poverty in Zaka. The SDG 1 and 2 (zero poverty and zero hunger) as experienced in the community show that ECLF has managed to achieve sustainable development, hence the link between SDGs and ECLF peace building work in Zaka. From the accounts given, the people from Zaka tended not to work together due to political differences, but now many have put their differences aside and they can pull their resources together for income generating activities which can address poverty and hunger. Conflicts can now be managed during project implementation. There is now fair distribution of agricultural inputs and even social welfare handouts are now being distributed to the deserving individuals who used to be excluded on party lines.

As such, through its CPMRT, the ECLF has brought about joyous moments that communities are transformed through the spirit of "Ubuntu/ hunhu" which has been restored and people have seen the need of relating and working together, that is, community cohesion. This cohesion then gave birth to Community Cohesion Projects (CCPs), that range from gardening, chicken rearing and goat keeping. One person doing everything may be affected health wise. Peace building has also brought less labour to both the fit and the weak in health. Hence, this presentation adopts a 
Tanzanian proverb which says, "many hands make work lighter". In addition, hurt feelings negatively affect the immune system and consequently stress and other disorders become the order of the day. The ECFL intervention reduced these disorders, enabling individuals, families and the community to become more productive.

The togetherness that was brought by the ECLF programme made people to share ideas and to work together, which then means less effort is employed because of numbers, yet impressive results are achieved. In actual fact, people on the ground translated peace to their minds as individuals, and peace in an individual mind translates to a healthy thinking from a healthy body. Hence this is even supported biblically in Proverbs 17:22, "a cheerful heart does like medicine: but a broken spirit dries the bones". This implies that the ECLF represents the church in sustaining peace and also uses a theology of development to better the communities. Hence, ECLF peace programmes bestowed spiritual health and poverty reduction in Zaka.

The ECLF intervention is also important for its commitment to women's development. The presentation of women as "participants" and not only "beneficiaries", is a result of social transformation and development in Zaka. Nehlsen \& Richard (2017), report that the network responds to the persistent under representation of women in the local government and governance structures and their lack of responsiveness to women's security needs. Although there are some men who are challenged by women in different manners, ECLF's work alongside SDG number 5 emphasizes the improvement of girls in many areas. Ringgaard \& Ottosson (2015), argue that, women are most at threat because of many responsibilities such as feeding the family, and in their pursuit, they end up facing different threats such as rape or being asked for sexual favours. However, SDG numbers 10 and 5, namely, "reduced inequalities" and "gender issues" are being addressed as most of the Local Peace Committees in Zaka are female dominated and are actively involved in developmental activities. The ECLF approach has improved family relationships, thereby reducing GBV (Gender Based Violence) and DV (Domestic Violence).

Further, this forum has given rise to economic recovery in the three wards mentioned, in Zaka. This has also contributed towards achieving the SDG number 8 of decent work and economic growth which is linked to the ECLF peace building work in Zaka. Economic development at heart typically means more jobs, business opportunities, fair access to safe and de- 
cent livelihoods. The link between development and peace is easy to understand. War or physical violence cannot lead to economic growth. Taking for instance, the violence experienced in 2008 caused by political differences slowed down the economic growth in Zimbabwe, which also led to inflation. Considering this, there should be an understanding that mutual trust and functional relationships between people, groups and people's both grew and were nourished historically by trade, in a virtuous cycle (International Alert 2015). It is believed that in 1906, the economist Leon Walras was nominated for the Nobel Peace Prize by those who recognized the implication for peace of his work on economic equilibrium. In this context, the Zaka community have taken full responsibility in terms of development which will make them rise economically in the spirit of togetherness. Relationships have improved, which will see the communities supporting each other. They are working together very hard which means their revenue bases are adding to the GDP (Gross Domestic Product) of the country.

Fifth, the paragon of peace in this district is vividly seen through the construction of Rwemhepo bridge in ward 5 which is $50 \mathrm{~m}$ long, $6 \mathrm{~m}$ high and $4 \mathrm{~m}$ wide (ECLF Report 2017). This bridge is $22 \mathrm{~km}$ away from the tarred road leading to Jerera growth point in Zaka. The idea came to light after the ECLF had conducted a CPMRT workshop and the LPC capacity building in November 2016 and it had an impact, and this resulted in community cohesion. For the bridge to be constructed, the community members from different political parties and different religions took turns to carry sand, stones and water through manpower and from the little they got they also contributed some money towards the building of Rwemhepo bridge. This bridge had been planned by the community way back and people had been suffering for a long time. Some school children would walk 15 kilometres away to different schools because there was no way they could cross that bridge. All these inconveniences were being caused by the prevailing disunity of purpose and perceptions as well. The construction of roads, bridges and footbridges has enabled the improvement of road networks so that service providers can now reach this area and even developmental partners. Furthermore, this has partly improved the transportation system in Zimbabwe.

Besides the construction of the bridge, the community members also managed to put their heads together and construct a two-block secondary school in Zibwowa, ward 20, $20 \mathrm{~km}$ away from Jerera growth point. 
Guided by the SDG number 4, the ECLF has contributed to equitable quality education and learning opportunities for this community. This secondary school has become a success because of the unity and through income generating projects. Long back, school children were travelling for about 7 to $15 \mathrm{~km}$ away from their homes and hence this degraded their quality of education since they would reach school already tired after walking long distances. Through the ECLF peace building skills and the hard work done, today the community is full of joy because of the secondary school in ward 20. The school has already enrolled students from the local community. As such, development in Zaka through the infrastructure was strengthened by unity among community members and integral leaders. It is now easy for the children and the community at large to educate their children. Through such a way forward, Zibowa Development Association was very impressed by this and are still working hard towards getting the access to electricity for both the primary and the secondary schools.

Significantly, there is also the construction of a clinic in Chiromo ward 8 in Zaka, which is $40 \mathrm{~km}$ away from Jerera growth point. Together with the community, the LPCs came up with an idea to build a clinic after the ECLF's work in Zaka. The vision which has been blurred for so long, has actually come into light through hard labour, working together and the contribution from different stakeholders. The current situation shows that the clinic project is at the slab level, developing the community for better health facilities.

\section{Conclusion}

Building peace is building development and improving the nation's status. Peace without development is not durable and development without peace is unsustainable. This chapter appreciates the work initiated by the church in Zimbabwe towards sustainable development. The work of the ECLF in Zaka has imparted strategies of poverty alleviation and doing away with violence. This work by the ECLF is a foundation to the current and the future church to stand firm in building peace and development for all. Without a peaceful environment, there is no development. Therefore, development has been achieved in Zaka through the ECLF's peaceful activities, thereby confirming the nexus between religion, peace and development. 


\section{References}

\section{Interviews}

Guni J. ECLF Grassroots facilitator, Zaka Ward 5 Rwemhepo, Masvingo Province, 25 Aug. 2017.

Khanye S. ECLF staff member, Bulawayo, 4 Sept. 2017.

Mupinga M. ECLF local facilitator, Zaka Ward 3 Chimedza, Masvingo Province, 28 Aug. 2017.

Mucharuva M. ECLF local peace facilitator\& beneficiary, Zaka ward 5 Rwemhepo, Masvingo Province, 25 Aug. 2017.

Thaka P. ECLF Community Cohesion Projects Officer, Bulawayo, 4 Sept. 2017.

Richi N. ECLF Provincial Focal Person, Zaka Masvingo, 25 Aug. 2017.

Zhou N. ECLF facilitator, Bulawayo, 4 Sept. 2017.

\section{Books and Articles}

Anderson, R. 2004. "A definition of peace," Peace and Conflict 10:101-116.

Boulding, E. 2000. Cultures of Peace: The hidden side of history. Syracuse, NY: Syracuse Univ. Pr.

Dube, E. M. 2014., Strengthening Church Capacity in Negotiation Skills, Conflict Prevention Management, Resolution and Transformation. Project Midterm Review Report Harare, ECLF in partnership with ELCA, LUCSA, VELKD.

Dube, D. \& D. Makwere. 2012. “Zimbabwe: Towards a Comprehensive Peace Infrastructure," International Journal of Humanities 2(18), 297-307.

FECCLAHA, 2015. Youth Peace Clubs Workshops, Kenya: Nairobi.

Kadzikano, G. \& A. Ittig. 2014. Support to Peace Building and Increased Access to Sustainable Livelihoods: Midterm Evaluation to UNDP: Zimbabwe Integrated Peace Programme.

Krause, K. \& O. Jutersonke. 2005. "Peace, Security and Development in Post Conflicts Environments," Security Dialogue 36(4), 447-462.

Lederach, J. P. 2003. The Little Book of Conflict Transformation. Intercourse, PA: Good Books.

Ledwith, M. 2005. Community Development: A Critical Approach. Bristol: Univ. of Bristol.

Magaisa, A. 2010. 'Politics and Prejudice, Plight of Zimbabwean women,' newsZimababwe.com, Acc. on 24 June 2010.

McCandless, E. \& T. Karbo. 2011. Peace, Conflict and Development in Africa: A Reader. San Jose: Univ. of Peace.

Morse, S. \& McNamara, N. 2013. Sustainable Livelihood Approach: A Critique of theory and Practice. New York: Springer Science and Business Media.

Ncube, B. 2016. Community Level Peace Building Efforts in Zimbabwe, The experience of ECL with support from the UNDP: Bulawayo Zimbabwe.

Nelhsen I. \& Richard P. 2017. A Peace Building Lens on the SDGs, GPPAC Background paper: GPPAC. 
ONHRI. 2014. Strengthening the National Peace and Reconciliation Infrastructure in Zimbabwe, Key milestone of ONHRI, UNDP: Harare.

Oswald, S. U. 1992. Sustainable Development with Peace Building and Human Security and Development. Mexico City: National Univ. of Mexico.

Reychler, L. \& T. Paffenholz. 2001. Peace Building: A Field Guide, Boulder, CO: Lynne Rienner.

Ringgaard, A. \& K. Ottosson. 2015. Local and Global Protection: Local Perspectives on Protection: Recommendations for a Community Based Approach to Protection in Humanitarian Action. Uppsala: Church of Sweden.

Sanchez, O. A. 1995. “Understanding, Tolerance, Freedom andDemocracy,” In M. Three, ed., Peace! Paris: UNESCO.

Verbeek, P. 2008. “Peace Ethology,” Behaviour 145, 1479-1524.

Younan, M. A. 2012. A Voice for Justice and Reconciliation. Minneapolis, Minnesota: Lutheran Univ. Pr.

ZCBC, EFZ \& ZCC, 2006, The Zimbabwe We Want, Towards a National Vision for Zimbabwe: A discussion document. Harare: ZCBC, EFZ \& ZCC.

\section{Internet Sources}

https://sustainabledevelopment. un.org (acc. 11 Aug. 2017).

International Alert, www.inetrnational. alert.org, (acc. 5 Sept. 2017).

www.eclfz.org/whatwedoourwork (acc. 13 July 2017).

www.eclfz.org/zakaenflamed (acc. 12 July 2017).

sustainabledevelopment. un.org/partnerships (acc. 19 July 2017). 


\title{
"Thy Kingdom Come ... Even unto the End of the World" The Seventh-day Adventist Church and Development in Northern Zimbabwe
}

\author{
Blessing Nyahuma
}

\section{Introduction}

The notion of development itself has developed throughout the years. Its theory and conceptualisation have remained enigmatic. In earlier times, the concept and practice of development deliberately side-lined and censured religion. With the passage of time, religion became the centre of active development. This is seen in the numerous projects being undertaken by faith-based organisations (FBOs) such as World Vision International, Christian Care and Adventist Relief and Development Agency (ADRA) throughout Africa. In Zimbabwe, the Seventh-day Adventist Church took the initiative to engage in developmental work amongst the nomadic Doma clan at the periphery of Mbire district, in Kanyemba under Chief Chapoto.

In this chapter, I investigate the interface of the theory of development and religion, focusing on its modern conceptualization. Highlighting crisis as the mother of all forms of development, I make note of the emergence of religion as an essential partner to development. I buttress this idea with evidence from observations noted as a participating observer. I treat the subject of faith and development, interaction with national politics, setbacks in church politics and conclude by noting prospects and promises of FBOs in Zimbabwe.

\section{Methodology}

The chapter utilises the qualitative and phenomenological approach. It emerges out of the fieldwork I have undertaken as a participant observer during the period 2010 - 2017. This was under the auspices of the government of Zimbabwe, Pavel Bartolomeu (an SDA missionary from Poland), East and North Zimbabwe Conferences of the Seventh-day Adventist Church and ADRA Zimbabwe, and in my capacity as an academic and 
missionary. The chapter relies on analysis of primary and secondary data gathered in more than thirty trips that I have undertaken to Kanyemba representing the aforementioned organisations. The formal and informal interactions with members of staff from these organisations, chiefs, village heads and councillors, civic leaders, and the Doma and Chikunda people have equipped the researcher with invaluable data on religion and development and in-depth knowledge about the heavily mythologised Doma people. The chapter is, therefore, an ethnographic account of the researcher's own participation in religion and development, while interacting with scholarly sources on the same theme.

\section{Background: VaDoma/Wadoma: Myth, History and Reality}

In order to put the chapter into context, this section provides an overview of myths and legends relating to the people under study. The Doma/Vadoma or Wadoma (singular Mudoma), are an ethnic group living in the Zambezi River valley. Their way of life has hardly changed as they are still maintaining a semi-nomadic lifestyle. They are a withdrawn, reserved and secretive people, with little contact with the outside world, preferring to maintain their traditional ways in their isolated homeland. Outsiders/neighbours would describe them as being "less developed," as I illustrate below.

There has never been a group of people in Zimbabwe about whom so little has been written about more than the Doma people. They are spoken of in a great mystery, shrouded in myth and legend, yet at the same time in terms laden with pity, shame and disdain by the mainstream society. Legends about their ancestors emerging out of a tree are known far and wide. Legends about how they cut toes of their toddlers' after birth to enable a speedy climbing of trees, and that they build their houses on tall trees, are also known. Others say that at all cost they shun contact with the outside world and that they do not wear clothes. All these are regarded as the markers of "development," thereby insinuating that the Doma are among the most "underdeveloped" community in Zimbabwe.

\section{"Their Ancestors Emerged from a Huge Baobab Tree"}

The legend of the Doma ancestors emerging from a giant baobab tree is a widely circulated hyper-reality. Of all aspects of nature, trees have played 
a significant role in archetypical stories on primeval origins. In the legends of the Korekore (neighbours to the Doma) ancestors, some myths point to baobab trees (Lan 1985). The Judeo-creation narrative has the tree of knowledge of good and evil. To have a primeval creation myth associated with a tree is nothing that is outside the ordinary. According to oral history from the late VaDoma village head, Chiyambu ${ }^{1}$ and another senior community leader Saizi, ${ }^{2}$ Mozambique is the place of their origin. Another senior community leader Rangwani highlighted that they came from Zambia. Their language, Chidoma/Chikunda, is a mixture of Shona and Chichewa. Their neighbours, the Chikunda, and some clans in Zambia, also use the same language.

Oral history highlights that they have always withdrawn from outside interaction. The generations that emerged in the 50's had the need to integrate with the outside world. A handful of their rebellious youths in the 60 's, such as the late headman Chiyambu, left their traditional lands and went to as far as Mvurwi and Guruve where they worked as cattle herders. At the break of the second Chimurenga (1966-1979), a number of the young people came back to live with their people. At the height of the war, they withdrew deep into the Kamota and Mhebwe mountains. Chief Chapoto highlights that in the early 80's after the declaration of independence successful attempts were made to reach out to the Doma and to integrate them. It is during this time that they agreed to come and live under Chief Chapoto and the father of the late village headman Chiyambu was made the first village head in Mariga.

\section{"They Cut Their Toes": Perpetuating Stereotypes}

The hyper-reality of their ancestors emerging from a large baobab tree is bolstered by another legend of cutting toes of their children. A substantial minority of Doma has a condition known as ectrodactyly in which the middle three toes are absent, and the two outer ones are turned in, resulting in the ethnic group being known as the "two-toed" or "ostrich footed" ethnic group. Ectrodactyly is a congenital limb malformation characterised by a deep median cleft of the hand or foot. ${ }^{3}$ The word ectrodactyly was coined

\footnotetext{
Interview Chiyambu, Oct. 2012.

Interview Saizi \& Rangwani Dec 2016

http://www.podiatrym.com/cme/Jan09\%20CME.pdf
} 
from two Greek words - ektroma (abortion), and daktylos (finger). However, while the myth of underdevelopment suggests that all the Doma have this condition, what is experienced among the few Doma people is familial ectrodactyly. This is an autosomal dominant condition resulting from a single mutation on chromosome number seven. Ectrodactyly occurs in two forms, either as an isolated disorder or as a component of a syndrome.

Those I have interacted with who have this condition are not perceived as physically challenged and are well integrated into the ethnic group. The condition was prevalent in the former times because of a small genetic pool among the VaDoma and was propagated by the communal law that forbade members to marry outside their clan. The harsh economic conditions and the changes in lifestyle have seen the rules of inter-marriage become less binding. The ectrodactyly condition is now less frequent in the predominantly Doma communal lands in Mariga and Chiramba. Of those living in these two Doma communities, I saw only five families with this condition, an insignificant number compared to the 94 families in Mariga and Chiramba. The legend that all VaDoma have two toes is far from the truth. It is part of the myth of their "underdevelopment."

\section{Homes Trees: A Popular Myth}

The Doma people of Kanyemba, both in Mariga and Chiramba, live in areas infested with wild animals. Their daily interaction with the deadly beasts of prey is a thing of wonder and stranger than fiction. This crisis determined the design of their temporary shelters. Unlike the round huts scattered in rural Zimbabwe, their houses are built suspended on tall poles. This is a safety measure, especially at night against lions, leopards and hyenas. The encounter with wild animals is not altogether friendly as there have been numerous causalities, especially among women and children.

The idea that the Doma live in trees fits the trope of "underdevelopment." It exaggerates the perceived difference or "Otherness" of the Doma. Whereas Western media images of Africa seek to perpetuate the image of Africans as living in "the original state of nature" and as still swinging from trees like apes (racists who wish to demean blacks/Africans, mimic apes), neighbouring communities use the same template to deepen the sense of "underdevelopment" among the Doma. 


\section{"Disappearing Acts" and Nakedness}

The Doma tight seclusion has fuelled many spurious myths and allegations. Their ability to "disappear" is not a work of magic or sorcery, but a mastered art of living in oneness with nature and knowing how to hide from perceived danger. Their relocation in Mariga and Chiramba in the early 80's removed them from the places of natural habitat, which had thick trees. They would take barks from these trees, pound and straighten the barks until they would look like a piece of cloth. From this, they would fashion clothes and even hats. Their relocation did not only disturb their food security, but also robbed them of access to the material they used to cover their bodies; this left many of the Doma naked or at least scantily dressed. Their nakedness hindered them from interacting with the adequately dressed outsiders. Associating their nudity with omens of evil or witchcraft is a misinformed conclusion. The death of the Doma old guard was a loss of skill in making traditional clothes from tree barks. Nakedness made it challenging to interact with them, during our first trips we did not interact with them sometimes they would send representatives to communicate with us. In many instances, we would leave our donations at the banks of Mwanzamtanda River.

\section{Current Life Situation at the time of Study}

The fast-track land redistribution programme (FTLRP) undertaken in the early 2000s, the severe drought that followed and the mismanagement of political power by the Robert Mugabe regime left many Zimbabweans of all walks of life in a dire situation. A significant number of Zimbabweans resorted to poaching in national safari parks, communal lands and alienated private lands. The government resorted to enacting stiffer penalties against poachers. Amongst those who were significantly affected are the Doma people, modern hunters and gatherers. The anti-poaching Act took away more than $90 \%$ of their food supply. Their relocation to wander around the non-agrarian land in Mariga where the soil is poor, fine grey dust which becomes muddy with a little rain. During the rainy season, the place is uninhabitable as it becomes flooded and the site becomes unreachable. The Mwanzamtanda River, a tributary of the mighty Zambezi River, cuts off interaction with those across the river. This can be for months.

During this season, the Doma relocate and build their temporary shelters on higher grounds and mountains. During these times they can live in 
peace in the forbidden hunting grounds, without the game rangers bothering them. The life situation of the Doma within the Chapoto community is that of excessive deprivation. Their relationship with their close neighbours, the Chikundas, is extremely exploitative. It is capitalistic and based on equal interaction. The Doma people are subjected to different forms of severe exploitation. The Chikunda perceive the Doma as uncooperative and not willing to integrate. This led the Doma being left out in community enhancing programmes by FBOs such as Christian Care and World Vision. The fifteen boreholes drilled across Mwanzamtanda where the Chikunda live, two in Chiramba and none in Mariga tell deep stories of deception, class struggle and unequal distribution of donor resources. The emergence of the SDA directly targeting the Doma is seen as a lifeline by the Doma.

Having outlined the setting in life of the Doma in Zimbabwe, the next section discusses the concepts of religion and development. This will assist in clarifying whether the interventions that have been attempted can be considered as delivering development to the Doma.

\section{Religion and Development}

Crisis is the fundamental backdrop to many forms of development, from evolution (Burian 2005:235) to the development of tools (Edmonds 1995:1 and Lehneh (2003:8). However, the definition of development has been evolving, focusing on different meanings, scope and theories. In all the years, "development" has long been a vague yet predictive term, struggling to acquire a precise meaning. The word cannot unshackle itself from the etymologies and contexts in which the word was formed. It is associated with progress, evolution, and maturation. The word development is at the centre of an incredibly powerful semantic constellation...guiding thought and behaviour (Sachs 2009:3). In a broad sense, development can be reflected in diverse ways. Economics, politics, religion and culture sum up the bedrock of human development. It aims at social stability, wellbeing and economic opportunities for people. Literacy, education, communal connections and, more ambiguously, 'the worth of life' are encompassed under sociological development (Haynes 2008:4 ; Clarke 2013:2; Ellis \& Ter Haar 2005:1) The UN Development Programme (UNDP) notes that "human development" is a "complex concept of development, based on the priority of human well-being, aimed at ensuring and enlarging human choices leading to greater equality of opportunities for all people in 
society and empowerment of people so that they participate in - and benefit from - the development process" (Human Development Report 1996:5).

The raison d'être of this chapter is to challenge the 19th-century premise that Christian development is established on two categories of people, the developed evangelised and the unevangelized undeveloped (Cf. Ferguson 1994). Contrary to Max Weber's (2018) hypothesis that religion and development are two sides of a coin, as early as sixty years ago, 'development' and 'religion' were regarded in the West as entirely separate concerns. Thus, "Development was tied to secularisation and modernisation, conditions from which religion had been progressively excluded over time" (Haynes 1998).

On the contrary, many forms of development can be conceptualized. In Zimbabwe, there are religious actors, conceived and informed by religious ideology and ethics that are associated with development. Religious faith and zeal through ADRA, World Vision, Christian Care and the SDA are motivated by the kingdom God motif, adhering to a higher power engaged in human deeds that promulgate divine love. At the core of Christianity, Islam, Buddhism, Hinduism is a concern for the deprived people, the poor, those who are excluded, as well as those who suffer and are materially poor. Substantive research shows that there has been a change in conceptualising development, demonstrating the significance and indispensability of religion in development (Davis and Moor 1945; Malinowski 1936; Davis 1949).

It was James D. Wolfensohn, the former president of the World Bank, who popularised religion and development as two sides of the same coin. He established the World Faiths Development Dialogue (WFDD) ${ }^{1}$ and fostered dialogue with the World Council of Churches (WCC) (Cf. Robert and Judy 2005). This gave impetus to the rise of Non-Governmental Organizations (NGOs) that included FBOs within their ranks. NGOs provided different forms of development during the colonial era, through the liberation struggle and post-independent Zimbabwe. Missionaries were at the forefront of offering agricultural assistance, education, and self-help programmes for Africans (Gundani 1988; Hallencreutz \& Moyo 1988; Maxwell 1995; Ranger 1987; Alexander \& McGregor 2000). NGOs /FBOs

1 http://www.cpjustice.org/charitablechoice/101introduction (acc. 24 Oct. 2011). 
share a great deal regarding Christian, humanitarian philosophy and overall objectives, such as the eradication of rural poverty.

In Britain there is a growing recognition of the activities of FBOs and their contributions to development. This can be seen in the 1996 'Charitable Choice’ legislation. ${ }^{1}$ In America, both George Bush, 29 ${ }^{\text {th }}$ Jan. 2001 (cf. Judy 2005) and Barak Obama, $5^{\text {th }}$ Febr. $2009^{2}$ gave executive orders facilitating the union of religious / spiritual and socioeconomic, material in the field of development, a 'holistic development' (cf. Olarinmoye 2012). Ignoring the spiritual facets of life and nurturing development on purely socio-scientific platforms is a form of development that is foreign to an African worldview which is "notoriously religious" (Mbiti 1990:1). This dominance of religion makes it easy for FBOs to do their work, especially in rural Zimbabwe where providence is synonymous with the theology of divine favour. Socio-economic development mirrors liberation theologies and converses with theologies of economic salvation (Haynes 2008; Bradshaw 1993; Elliston 1989; Lingenfelter 1992; Verstraelen et al. 1995). Some scholars have gone as far as to argue for a 'theology of development' (Gundani 1988:243); while others have tackled the topic directly (Phiri et al. 1996).

Having explored the interface between religion and development, the chapter now proceeds to examine how ADRA has sought to interact with the Doma people. In previous sections, this chapter has described the context in which the Doma people are located. How does ADRA seek to transform their situation?

\section{"Thy Kingdom Come...Even unto the End of the World"}

The combination of the Lord's prayer (Mat 6:9-13, Luke 11:2-4), the great commission (Mat 28:18-20) and the three angels' message (Rev 14:7) summarises the philosophy behind the philanthropic work of the SDA church amongst the Doma people and in many other places. The then East Zimbabwe Conference mission statement highlights "The belief in the imminent return of Christ, the end of sin and suffering, salvation in Jesus Christ alone and the keeping of the ten commandments including the

http://www.cpjustice.org/charitablechoice/101introduction (acc. 24 Oct. 2011).

http://www.whitehouse. gov/video/Working-with-Faith-Febr.-5-2009 (acc. 5 July 2018). 
Sabbath Saturday as the day of worship. " The mission statement concludes by stating, "To accomplish this mission The East Zimbabwe Conference is committed to the gospel marching orders of Mat 28:18-20, total nurturing and empowerment of its constituency by providing administrative skills, training and resources through its departments, agencies, and ministries."

The kingdom of God motif is the underlying philosophy that spurs the notion of development among different Christian denominations in Zimbabwe. Pentecostal churches have a heavy emphasis on the "realized eschatology ${ }^{1}$, which triggers their gospel of prosperity. They also have a rather weak "Not Yet" inaugurated eschatology. ${ }^{2}$ The kingdom of God is, therefore "already" but "not yet." Inimical to this, the theology that informs the philanthropic work of the SDA is "Unrealized Realized." As such, the SDA church has been partially effective in Africa due to its failure in meeting needs of its members in the "Here and Now." The church's programme orientation over and against people orientation makes it unappealing. The neglected concept of the "Here and Now" cannot inform policies that foster mission and work. As a result, there is no expectation of miracles, healing and casting out of demons - everything belongs to the future, the lame cannot be healed in the here and now, the blind cannot be made to see in the here and now, as they all shall be made whole at the grand appearing of Jesus in the future.

Despite the SDA's bankruptcy of the Kingdom of God in the "here and now" aspects of the kingdom, their "unrealised realized" eschatology sees them extending divine acts of aid to the needy. A case in point is the work the Adventists have conducted among the Doma people. This work started in 2010 as an initiative by Pavel Bartolomeu, a Romanian missionary, Godfree Ngirishi, a Zimbabwean born missionary working in Romania, Dr Jonathan Musvosvi and Blessing Nyahuma. The secretive and non-engagement nature of the Doma made it impossible for interaction on the first encounter. The Doma find interaction with their local neighbours, VaChikunda, difficult. To then interact with strangers who had come

\footnotetext{
Cf. C. H. Dodd (1961), Robinson (1979) and Jeremias (2003).

Cf. Cullmann (1967), Dodd (1961) and Schweitzer (2012).

C. f. Nyahuma Blessing (2014) Unpublished MA dissertation, University of Zimbabwe: "Concept of the "Here and Now" with a Special Focus on the Gospel of John, Vis-à-Vis its Conceptualization in the Seventh - day Adventist Eschatology.'
} 
from as far as Harare, the capital city, let alone a white man from Romania, was almost impossible. Two years passed without proper personal intercommunication. We utilized a simple strategy of delivering clothes and food hampers. We would meet with their representatives at the banks of Mwanzandata River in "pick and drop" encounters.

Life for the Doma was that of poor health, no access to clean water, hygiene, sanitation, poor quality housing, hunger, illiteracy and premature death. Their capabilities were not being acknowledged (Chambers 1994:963). In these trying situations, FBOs strive to be effective agents of development in rural Zimbabwe. Their non-partisan modus operandi wins the trust of rural people who are now sceptical of free aid. The trust earned by these FBOs is a result of the favour they have acquired from the western secular institutions, politicians, and governments, which activates long-term funding. (Narayan et al. 2000) This enables them long time term unparalleled coverage and depth of visibility in communities (Haynes 2007:17). It equips them with the ability to solve complex community ethical-moral issues ranging from gender, ethnic conflicts, health, taboos and education. Any development enterprise must begin by considering how people's full range of resources, including their religious resources, which are to be considered as ideas; practices; institutions and experience (Ter Haar \& Busuttil 2005) and such is the work by Adventists amongst the Doma.

\section{Prospects and Constrains in Development: Firsthand Account}

The levels of underdevelopment in rural Zimbabwe would lead one to conclude that the most significant setback in developing rural Zimbabwe is the lack of willing donor organisations. The opposite is true; the immense task and the stiff requirements to acquire permission to work in Mashonaland Central during the Mugabe era would lead one to conclude that Mashonaland Central is a first world county. The tones of paperwork, numerous appointments and endless meetings, in government offices, District Administration offices and the political skill and etiquette needed to work with councillors, chiefs, villages heads are not for the fainthearted. In such environments, mental fortitude, negotiating, Machiavellian manoeuvring skills and techniques is a must-have. These skills are prodigious capital when dealing with the different layers of political power players. The various layers of power players have a pre-eminence attitude 
of making it distinctly clear that the developmental work can only be executed effectively with their approval. The unequivocally clear message is that the power players are the ones who do FBOs favour to work in their constituencies. Any power level, top-down or down-top can hinder the progress if they sense political discord.

In some cases, FBOs have to lick so many boots to develop communities living in appalling conditions. This political superiority complex enables the power players to gain political mileage on any form of development in their constituencies, as they would be the ones to have given the permission. Projects in progress or completed are hijacked and become the means to advertise the prowess of Zanu-Pf, the ruling party at the time of this study. In beating their drums, they showered praises to the senior political powers who brought in donor organisations. A case in point is the saga that transpired on the $01^{\text {st }}$ November 2012, after assessing the need to provide clean water to the Doma in Mariga. The work to sink a borehole was hampered by the local political players who wanted the borehole to be sunk at a village meeting point far from the Doma community. Phone calls to the Mbire District CEO, C. N. Majaya, the District Administrator and the Member of Parliament saved the day. Politics in community development projects is both a friend and foe. When cards have been played right, it pays. At the end of 2014, the work amongst the Doma had the government collaboration; through the Ministry of Primary and Secondary Education, the government donated US \$ 30000 worth of building material to assist in the construction of primary school classroom block.

Rumours started circulating amongst the power players that the then country president Robert Mugabe had shown keen interests to visit Mariga and to open the primary school officially. Visits from different government offices became frequent. The work was then thwarted by the then Minister of Primary and Secondary education, Dr Lazarus Dokora, who then stripped the SDA of control of the primary school, which the church had invested in. The then minister handed control to the local council, which could not run the school as the responsible authority. Ever since the closure, the primary school remains a white elephant. The SDA through the initiative of Maranatha Ministries further constructed a stateof-the-art secondary school in Mariga, which was also condemned by the Ministry of Education. In 2015 through my initiation with Dr Jonathan Musvosvi, Pavel Bartolomeu and Nicky Maheve, we constructed a clinic in Mariga, which was also condemned by the government ministry. However, the sudden demise of Robert Mugabe from the political throne in 
November 2017 brought new winds of fortune. New influential players such as the first lady, Auxilia Mnangagwa's, drive promoting health and well-being saw her visiting Kanyemba. She re-wrote the political script, turned the tables of the previous condemnations, to positive recognition: as from July 2018 the clinic was officially opened and in operation.

\section{Church Politics and Church Policies: A Lurking Trojan Horse}

Apart from national politics, internal church politics is a Trojan horse that stifles development by FBOs. Politicians from the life of the church also have an insatiable desire of having their egos massaged. The media coverage of the work amongst the Doma brought about two narratives within the SDA church power players. Some perceived the project as good work that had been hijacked for personal church political mileage. Others saw it as non-church political engagement. In this quagmire, Machiavellian manoeuvres and strong mental aptitude coated in bible verses was a necessity. The transition of the then East Zimbabwe conference leader, Dr Enoch Chifamba, to the Zimbabwe Union conference left a power vacuum. The then development director, Dr Jonathan Musvosvi, became the conference president. This move saw the developmental work amongst the Doma at its best. It is at this time that I was moved to another station, and the work reached its greatest peak, with life-transforming prospects, including initiating an irrigation scheme that would have seen the Doma becoming a self-sustaining people.

As was voted at the South-African-Indian-Division, East Zimbabwe Conference was then split into two conferences, North Zimbabwe Conference and East Zimbabwe Conference. At the constituency elections, Dr Jonathan Musvosvi did not retain the presidency. The new President, Dr Obert Mudzengi, did not give much attention to the work amongst the Doma during his tenure. Furthermore, the rapid successive turnovers of responsible officers in the Muzarabani District saw improper handover takeover and lack of continuity. However, the then-new North Zimbabwe Conference Development director, Albert Mangwende, did well to sustain the work amongst the Doma. It is at this time of momentum decline within the church governing body that ADRA, the church's NGO arm, took over the work of development.

The organisation (ADRA) has done numerous projects, ranging from community health, water sanitation and health, menstrual hygiene management, productive asset creation to sanitary pads manufacture projects. 
The current situation among the Doma is one full of promising prospects. The new political wave in Zimbabwe has had high profiled politicians visiting Kanyemba and the Doma. The Vice President Constantino Chiwenga and the first lady Auxilia Mnangagwa visits left an aura of impending good tidings, full of promise. Within the church it is also promising, the current North Zimbabwe Conference president, Albert. N. Mangwende, once tirelessly maintained the work amongst the Doma when he was the development director. The most urgent need was the aspect of sustainable development that would see the Doma being financially independent. There was also need for knowledge and skill to plough cash crops which will enable them to send their children to school and participate in the economic growth of the whole of Kanyemba.

\section{Points of Need}

The greatest limitation of the missionary churches in Zimbabwe was their failure to integrate the gospel to meet the needs of Africans in their Sitz im Leben. The missionary gospel had a somewhat sound status, but failed on matters of life, especially in areas where African traditional religions excelled. In the traditional Shona worldview matters of health are not acquired at a clinic, but at the traditional healer/place of spiritual connection/church. The concept of development that meets communities at their point of need was the secret of success for the SDA in Kanyemba. For the Doma, development is conceptualised in its most basic form, and it is more than a clinic structure, a school, a church, farming machinery or clean water; it is a progression that makes things easy to execute. It is, therefore, task-driven, aiming at getting more out of a task with minimal effort. The sinking of the borehole made it easy to access clean water and hence they welcomed the SDA because they met them at their point of desperate need. Despite the setback of working through their worldviews, which maintained their myths and superstitions, meeting their fundamental needs created a conducive environment for dialogue.

The inquiry on modernity as development is a question we had to deal with painfully. The idea of modernising the Doma, without proper structures for them to maintain the new standard of lifestyle, was a debacle. There was, indeed, the discomfort of working with and amongst the literally naked Doma men and women who did not sense our discomfort. The introduction of the modern forms of dress eased our chagrin, but modern 
clothes also need soap to wash. Any form of development without a sustaining structure that maintains the new system is developing amiss. Giving the Doma clothes without giving them the means to buy soap or building a school without creating a new system whereby they would be able to earn a living and pay school fees, is not development. Thinking of "modernizing" a group of people recovering from hunting and gathering tradition, without providing means of sustainable income, is the worst form of development.

\section{New Identity}

Religion played an essential role in conjuring new identity for the Doma. Their former identity was constructed from archaic behavioural patterns, which located and fixed them at the lowest strata of society. Their neighbours, the Chikundas, exploit them at every given opportunity. A day's ploughing using a hoe is rewarded by not more than $2.5 \mathrm{~kg}$ of maize, popularly known as "Kamedha." The poorest amongst the Chikunda who cannot marry amongst their own, can descend to the Doma and pay a bride price ranging from $\$ 50-\$ 200$ USD. Exploitative and deplorable as it is to outsiders, the Doma are conscious of their struggles, they understand the power struggles, identity and exploitation. Their choice is a temporary situation of dealing with the best of the worst. Marriage within the Doma does not fetch up as much as $\$ 100$. Paying of the dowry is an exchange of valuable aesthetic objects. Their incredible skill of tracking and hunting has been rendered obsolete and archaic; only two or three of them are hired to be trackers by the game rangers and anti-poaching unit to assist in tracking both animals and poachers. Bee harvesting is another skill, which they have had, but because the lucrative places where they can find bees are no trespass animal corridor zones. Their children do not go to school but are thoroughly knowledgeable about living in oneness with nature, animal behaviour and botany.

The work by Adventists among the Doma brought about new conscription of new identity. The life-enhancing activities became knowledge exchange platforms; they started learning modern skills like the process of brick making, how to operate machinery and some driving farm tractors. The recent project done by ADRA focusing on sanitary pads saw some Doma women and young girls acquiring knowledge and skills in manufacturing sanitary pads. During the construction of the schools, church and clinic saw the Doma also acquiring modern skills in construction. These skills 
are being utilised as they are moving away from their traditional temporary structure to the typical rural round huts. The church as a social support system has also fostered construction of healthy social relationships amongst the Doma by constructing new identities of brotherhood in Christ. Amongst other positives, positive religious expression, personal development, self-empowerment, techniques of economic resistance and religious participation. All these put together have become the emerging new identity of a modern Doma.

\section{One Love, Wealth Creation and Production}

The SDA has also played an essential role in the shunning and shaming of violence in its different forms, within the Doma and without, especially in their ethnic fights with the Chikunda. The deliberate move to have them worshipping every Saturday in one church building nurtures healthy relationships. Christianity's most influential relational ethics destroys the ethnic barrier walls and resentment and provides new values such as striving to love thy neighbour as thyself (Mk 12:31) to be one's brother's/sister's keeper (Gen 4:3-9) and the impossibilities of loving God while hating one's brother or sister (1 John 4:20).

\section{Education, Health and Wellness and Stewardship}

In the imparting of Adventist teaching, there is a transference of human skills. The reading of the Bible and church pamphlets has been a literacy programme utilising the Bible as a learning aid. The philosophy of Adventist education's 3H's which emphasises on the training of the Hand which represents skill and manual labour, the training of the Head stresses rigorous training of the mind and the Heart which is an emphasis on moral, ethical conduct. Personal development is further encouraged in a comprehensive healthy lifestyle through temperance. Preservation and living in oneness with nature is an exchange of information, which the Doma understand better. The developmental work by the SDA is one of the many examples of holistic community development programmes that are done by other FBOs like Christian Care and World Vision. Religion, as such, is an essential aspect of culture and lived experience (of the poor and non-poor), however, it has not yet been fully appreciated within development studies literature or within mainstream development practice (Clarke 2013:1). 


\section{Conclusion}

It is fair to say that a Christian development agency must emulate Jesus Christ. He brought people to the kingdom of God by meeting their pressing needs. Many needs of the poor around him were physical, such as illness and hunger. A prerequisite to entrance into the kingdom of God was and still is the admission that we are spiritually poor (Brandt 1995:260). Thus, the Doma are not the only ones who are poor. Poverty is characteristic of the human condition and people in different settings, including those in the global North, are spiritually poor. A combination of spirituality, "critical analysis, mutual learning and acceptance of its paradoxes and dilemmas in the culture and experiences of the communities in which they are aimed," (Clarke 2011:7) is an essential cardinal quality which will facilitate great success for FBOs. While there are challenges in rural communities on gender, which is a central theme of development studies, the challenges of short-term projects which hardly scratch the surface, proper training of community opinion leaders, and qualified staff still need attention. However, the work of development by FBOs is on the right path. From the first-hand account of working with communities on the way to development, good development is a process of childbirth and growth, which commences with courtship, transcending to marriage, pregnancy, birth pains, and then finally raising and rearing the child. In community development amongst the Doma, the birth pains have been felt, and the strategy of FBOs has made these pains bearable.

The chapter has exposed the ambiguities that accompany the term development. In their own context and before government initiatives disrupted their way of life, the Doma were developed and self-sufficient. They had mastered their environment and had intellectual and social capital. However, the project of modernity rendered them extremely vulnerable and generated myths of "under-development." The intervention by the Adventists has sought to mitigate the challenges of exploitation and voicelessness that the Doma communities have been subjected to. Respecting their traditions, seeking to improve their chances in life and taking their capabilities on board, the SDA has operated with a non-colonising approach to development. Although its theology needs further strengthening, the SDA has partnered the Doma community in its own journey towards expanding its horizons and pursuing new challenges. 


\section{References}

Alexander, J., McGregor, J., \& T. O. Ranger. 2000. Violence and Memory: One Hundred Years in the 'Dark Forests' of Matabeleland, Zimbabwe. . Heinemann Social History of Africa. Portsmouth NH \& Oxford: Heinemann \& James Currey.

ARHP. 2006. Appreciating Assets: The Contribution of Religion to Universal Access in Africa Mapping, Understanding, Translating and Engaging Religious Health Assets in Zambia and Lesotho In support of Universal Access to HIV/AIDS Treatment, Care and Prevention, African Religious Health In Zambia and Lesotho. Assets Program (ARHAP) for the World Health Organization (WHO), Oct. 2006.

Bornstein, E. 2002. "Developing Faith: Theologies of Economic Development in Zimbabwe. " Journal of Religion in Africa, 32(1): 4-31.

Burian, R. M. 2005. The Epistemology of Development, Evolution, and Genetics: Selected Essays. Cambridge Studies in Philosophy and Biology. Cambridge, England; New York: Cambridge Univ. Pr.

Carbonnier, G. 2013. International development policy: religion and development. Basingstoke: Palgrave Macmillan.

Clark, R. \& J. Mason. 2005. Community Action Agencies and Faith-based Organizations: A Legacy of Productive Partnerships. Washington DC: National Association of Community Action

Clarke, M. (Ed.). 2013. Handbook of research on development and religion. Cheltenham, Glos, UK; Northampton, MA: Edward Elgar.

Clarke, M. 2011. Development and religion: theology and practice. Cheltenham, Glos, UK; Northampton, MA: Edward Elgar.

Cullmann Oscar. 1967. Salvation in History. Univ. of Michigan: Harper \& Row.

Dark, K. R. 2000. Religion and international relations. Basingstoke: Macmillan.

Davis, K. 1949. Human Society. New York: Macmillan.

Davis, K. \& W. E. Moore. 1945. "Some principles of stratification," American Sociological Review 10:242-249.

Dodd, C. H. 1961. The parables of the kingdom. New York: Scribner.

Edmonds, M. R. 1995. Stone Tools and Society: Working Stone in Neolithic and Bronze Age Britain. London: Routledge.

Ellis, S., \& Haar, G. ter. 2005. Worlds of power: religious thought and political practice in Africa. New York: Oxford Univ. Pr.

England, E., \& Lyons, W. J. Eds. 2015. Reception history and biblical studies: theory and practice. London: Bloomsbury.

Ferguson, J. 1994. The anti-politics machine: “development," depoliticization, and bureaucratic power in Lesotho. Minneapolis: Univ. of Minnesota Pr.

Green, D. P., Hotchkiss, R. N., \& Pederson, W. C. Eds. 1999. Green's operative hand surgery (4th ed). New York: Churchill Livingstone.

Gundani, Paul. 1988. "The Catholic Church and National Development in Independent Zimbabwe," In C. F. Hallencreutz \& A. M. Moyo (Eds.), Church and State in Zimbabwe. Gweru: Mambo Pr. 
Hallencreutz, C. F., \& Moyo, A. (Eds.). 1988. Church and state in Zimbabwe. Gweru, Zimbabwe: Mambo Pr.

Jeremias, J. 2003. The parables of Jesus. London: S. C. M. Pr.

Ladd, G. E. 1993. A theology of the New Testament. Grand Rapids, Mich: Eerdmans.

Lan, D. 1999. Guns Q Rain: guerrillas Q spirit mediums in Zimbabwe. Harare: African Publ. Group.

Lingenfelter, S. G. 1998. Transforming Culture: a Challenge for Christian Mission. Grand Rapids: Baker Publ. Group.

Malinowski, B. 1936. The foundations of faith and morals: an anthropological analysis of primitive beliefs and conduct with special reference to the fundamental problems of religion and ethics Volume 7 of Riddell memorial lecture. Oxford: Oxford Univ. Pr.

Maxwell, D. 1995. "The Church and Democratisation of Africa: The Case of Zimbabwe," In P. Gifford, ed., The Christian Churches and the Democratisation of Africa. Leiden, New York, Brill.

Mbiti, J. S. 1990. African religions Q philosophy (2 ${ }^{\text {nd }}$ rev. Q e enl. ed $)$. Oxford/Portsmouth, NH, Heinemann.

McMichael, P. 2017. Development and social change: a global perspective. Los Angeles: SAGE.

Nafziger, W. 2006. Economic Development. New York: Cambridge Univ. Pr.

Nelson, L. 1974. "Functions and Dimensions of Religion," Sociological Analysis, 35(4): 263-272.

Nyahuma B. 2014. 'Concept of the "Here and Now" with a Special Focus on the Gospel of John, Vis-à-Vis its Conceptualization in the Seventh - day Adventist Eschatology', Unpublished Masters Dissertation, Univ. of Zimbabwe, Harare

Nyahuma, B. 2016. Dec. 13. Narrative Interview Sekuru Rangwani

Nyahuma, B. 2016. Dec. 19. Narrative Interview Sekuru Saizi

Nyahuma, B. 2012. Oct. 29. Narrative Interview Sabhuku Chiyambu,

Olarinmoye, O. 2012. "Faith-Based Organizations and Development: Prospects and Constraints," Transformation 29(1): 1-14.

Phiri, Isabel A. 1996. Et al. Eds., The Role of Christianity in Development, Peace and Reconstruction. Nairobi: All Africa Conference of Churches.

Ranger, T. 1987. "Taking Hold of the Land: Holy Places and Pilgrimages in TwentiethCentury Zimbabwe," Past \& Present 117, 158-194.

Robinson, J. A. T. 1979. Jesus and his coming. London: SCM.

Rostow, W. W. 1991. The Stages of Economic Growth: A Non-Communist Manifesto. Cambridge Univ. Pr.

Sachs, W. ed. 2010. The Development Dictionary: A Guide to Knowledge as Power. New York: Zed Books.

Schweitzer, A. 2012. The Quest of the Historical Jesus. Mineola, NY: Dover.

Stocks. Denys A. 2013. Experiments in Egyptian Archaeology: Stoneworking Technology in Ancient Egypt. London: Routledge.

Ter Haar, G. \& J. Busuttil. 2005. Eds., Bridge or Barrier: Religion, Violence and Visions of Peace. Leiden: Brill. 
Trottier, D. \& C. Fuchs. 2015. Social media, politics and the state: protests, revolutions, riots, crime and policing in the age of Facebook, Twitter and YouTube. London: Routledge.

Verstraelen, F. J. et al. 1995. Missiology: An Ecumenical Introduction. Grand Rapids, MI: William B. Eerdmans.

Weber, M. \& T. Parsons. 2003. The Protestant ethic and the spirit of capitalism. Mineola, N. Y: Dover.

\section{Websites}

http://www.cpjustice.org/charitablechoice/101introduction (acc. 17 July 2018).

http://www.podiatrym.com/cme/Jan09\%20CME.

http://www.whitehouse. gov/video/Working-with-Faith-Febr.-5-2009 (acc. 25 July 2018). 


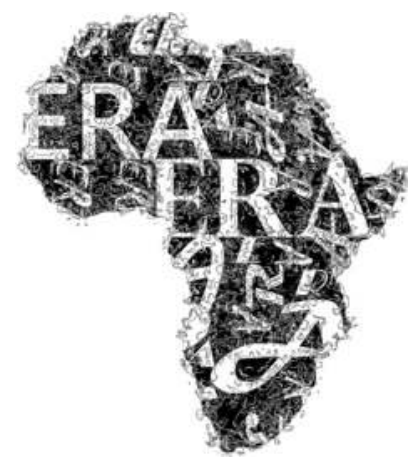




\section{Implications of the Wisdom Stored in Shona Oral Literature for Sustainable Economic Development in Zimbabwe}

Beatrice Taringa

\section{Introduction}

Having attained independence in 1980, Zimbabwe and the Shona in particular felt the need to redefine the knowledge approaches for the Shona people of Zimbabwe while appreciating the merits and demerits of globalisation and westernization, which are seemingly global dictates and inevitable. Sallitoe (2002), cited in Govender (2010:119), emphasised that in the 21 st century there is an "action approach and a growing desire to control their own cultural property and destiny ... to concerns of protecting cultural identity ... to demands for a voice." The indigenous knowledge systems, especially idioms, taboos and proverbs for the Shona is the truth that was tried, tested and found useful yesterday, today and tomorrow and indeed formed the basis of their survival.

The Zimbabwean government showed its unwavering support to cultural revival through the setting up of the National Arts Council of Zimbabwe in 1985 to promote the indigenous people's arts and cultural activities. To further strengthen the move, the Cultural Policy document was also crafted in line with this move. The recently elected ZANU PF government reaffirmed its commitment to promoting art and cultural activities through making the Arts, Sports and Culture a ministry on its own separating it from the Ministry of Education, Arts, Sports and Culture where it was overshadowed by academic activities. The Ministry of Information and Publicity also reaffirmed $70 \%$ local content on entertainment and broadcasting activities to promote local artists.

Many Zimbabweans are in business, though sometimes at a small scale. According to the ZANU PF manifesto (2013:2) the government is committed to "Economic empowerment of the blacks i) Land resettlement ii) Catering business iii) Co-operatives in transport, agriculture and housing". The ruling party is driving towards a $51 \%$ indigenous ownership in economic activities. In 2012 the government disbursed USD 37 million 
dollars as loans to youths across the country to fund projects ZANUPF manifesto (2013:9).

The Herald, 1 Oct. 2013, quoted the former president Robert Mugabe insisting that practical subjects be made compulsory in schools so that the youths will be self-employed after school. This is in harmony with the ZANU PF manifesto (2013:19) which encouraged institutions of higher learning to work with final year students to develop projects for implementation at the end of studies so that students can implement them in cities, growth points, throughout the country. This is helpful in reducing unemployment and rural urban migration. Thus, if proper business ethics are not inculcated into Zimbabweans in general the government's efforts will not reap any rewarding dividends.

Corruption cases are spreading like veld fires and seemingly unstoppable despite stiffer penalties, tightening of jail terms, coming up with new business management theories, increase in church denominations and rise in Christian enrolment. No efforts so far have been made to seek solutions in the wisdom bestowed in Shona oral literature because of the Western centre-periphery theory where everything African is viewed as naive, backward and irrelevant for contemporary needs in the face of the rise in corruption and unethical business practices and faithfulness.

The moral virtues of Shona oral wisdom and the seven principles of Gwaravanda (2011:126), referring to HIV \& AIDS context, discovered that although proverbs are formulated in historical and localised situations if applied to contemporary life does provide "... home grown, contextual, easy to grasp, open, flexible, dynamic and sustainable ..." solutions to current problems. Shona moral thought in this case, idioms, taboos and proverbial laws "... enshrined in the African philosophy of humanness, togetherness and solidarity" (Ramose 1999) promotes virtues such as selfcontrol, honesty, truthfulness admirable business practices agree in a number of idioms, taboos and proverbial laws.

There seems to be a direct co-relation between the drifting from Shona culture base and the increase in corruption and unethical business practices which is threatening sustainable economic development. It seems the nation has lost the moral guidance in form of values embodied in oral literature and heading towards doom as moral fibre degenerates. Each day newspapers are carrying news of obscene salaries, corruption, sexual abuse and other immoral practices which are directly and indirectly threatening national sustainable economic development. The major question is 'where are we going wrong especially as educationists?' 
Therefore, the chapter evaluates implications of oral literature to sustainable development basing on Moment's (2000:1) seven principles of admirable business ethics which include "be trustful, keep an open mind, meet obligations, have clear documents, become community involved, maintain accounting control and be respectful as the coding system."

\section{Theoretical Framework: Indigenous Knowledge Systems}

Indigenous knowledge systems, according to Ochollo (2007) is a 'complex set of knowledge and technologies existing and developed around specific conditions of population and communities which are indigenous to a particular geographical area.' The use of locally available cultural resources is readily acceptable to the people as it is already in the Shona people's cultural scheme of knowledge and no changes of transgressing which is likely to lead to tissue rejection. It is also another step towards the African and Shona cultural liberation from colonial hangover. This researcher agreed with Fayeraband (1988) who concluded that, traditional secrets coincide with present state of scientific research. Indigenous knowledge system (IKS) is the wisdom, which when instilled into the Zimbabwean citizens inculcates a self-policing attitude through the philosophy of Hunhu. Certainly (IKS) can be effectively harnessed and helps to significantly boost efforts that fight against corrupt and unethical business practices.

\section{Sustainable Development}

At this stage it is important to spell the meaning of sustainable development used in this paper. This paper assumes that sustainable development means development that meets the needs of the present, without compromising the ability of future generations to meet their own needs (World Commission on Environment and Development 1987). Kaul (1987) viewed human development as the widening of people's choices, for example, their ability to be healthy, to live longer, to be educated, to be properly housed, or to participate in economic, political, and social life. Shona oral literature in form of idioms, avoidance rules and proverbial laws can be useful for sustainable economic development as they provide basis for moral decision making in temptations which lead to corrupt and unethical practices. 


\section{Oral Literature and Sustainable Development}

This section has three sub-sections a) it explores implications of selected 9 madimikira (Shona idioms), b) 7 zviera (Shona avoidance rules) and c) 18 tsumo (Shona proverbs) to sustainable economic development in Zimbabwe. The above is only a small sample from a wide selection and it is hoped will suffice to indicate the general direction of wisdom bestowed in Shona oral literature and its possibility of fostering sustainable economic development.

\section{Madimikira (Shona Idioms) and Respect}

Through the wisdom bestowed in idioms it is easy to have people warned, given advice and even counselled and at the same time avoiding offending them and/or humiliating them. There is the culture ofShona people of hiding behind tongues. Feelings like pain, fear, shock, humiliation, shame and other nasty experiences are simplified through the use of idioms. Both the offenders and the offended benefited in their relationships through the simplification. Through the wisdom bestowed in idioms people were warned in life about the "dos and don'ts" and the acceptable and unacceptable behaviour in the community. Idioms communicate the virtues and vices of the communities. They were and are still useful warning signs in our lives like when people were encouraged to: kuzvininipisa/ kuzvirereka kune pundutso which means humility pays. This is in harmony with the business ethic of humility/respectfulness. This virtue is important in promoting sustainable development as people would be comfortable to do business with people who respect them and whom they respect. Every person needs and deserves respect regardless of office or position. This is in line with ethical principle of treating everyone with respect which is considered as the golden rule.

\section{Madimikira (Idioms) and Trustfulness}

In Shona people are encouraged through idioms to be trustful (munhu wose anosungirwa kuvimbika). This virtue was not only encouraged in business but in all contacts with others in life. This is a very important virtue and foster sustainable development in a number of ways. Like in this HIV $\&$ AIDS era in relationships and marriages being trustful is very important as this restrains married people from having multiple affairs which lead to the spread of HIV \& AIDS. This virtue agrees with the first 
principle of Moment's (2000) 7 principles of Admirable Business Ethics which states that, "be trustful, customers want to do business with a company they can trust, when trust is at the core of the company, it is easy to recognise. Trust is assured reliance on the character, ability, strength and truth of a business. Though this is mainly focusing on business practices, it is undoubtedly true that a person who is naturally trustful will always be so even in business and can easily get attuned to this ethic when it comes to business.

\section{Madimikira (Idioms) and Receptiveness to New Ideas}

Through several idioms, the Shona are encouraged to keep an open mind for continuous improvement in life. They are always advised in life that learning does not end in, kudzidza hakuperi. The Shona in this case are encouraged to keep eyes and ears open for new knowledge. This is well in harmony with the second principle of Moment's (2000) 7 principles of Admirable Business Ethics which states that, "keep an open mind, for continuous improvement of a company, the leader of an organisation must be open to new ideas, ask for opinions and feedback from both customers and team members and your company will continue to grow." Though this is mainly focusing on business lines, it is undoubtedly true that a person who is generally receptive to ideas in life is likely to value this virtue better than one who is rigid. The same virtue is also in harmony with Josephson's (2010) principle of commitment to excellence, reputation and morale where executives and directors are urged to exemplify honour and ethics and thrive to build and protect the company's good.

\section{Madimikira (Idioms) and Promise Keeping}

In life, the Shona through idioms, are encouraged to meet obligations as espoused in, kuita sezvakatenderanwa chero zvakaoma sei. In this the Shona were required to do whatever they will have promised to do no matter what. This is well in harmony with the third principle of Moment's (2000) 7 principles of Admirable Business Ethics which states that, "meet obligations regardless of circumstances, do everything possible to gain the trust of past customers and clients, particularly if something has gone awry. Reclaim all lost business by honouring all commitments and obligations. Though this is mainly focusing on business, what is certainly true 
is that a person who is self-driven in meeting commitments and obligations in life can easily take this virtue up. This is also in harmony with Josephson's (2010) third and fourth ethical principles for business executives of promise keeping and loyalty which insists that, "They do not interpret agreements in an unreasonably technical or legalistic manner in order to rationalise non-compliance or create justifications for escaping their commitments. ... nor use loyalty to others as an excuse for unprincipled conduct. According to the principle of fairness, in business executives are urged kuti vasadye chemupfupi nokureba, an idiom that states that, "They do not exercise power arbitrarily nor they use over-reaching or indecent means to gain or maintain any advantage nor take undue advantage on another's mistakes or difficulties. They are committed to justice, equal treatment tolerance for and acceptance of diversity and reasonably change positions."

\section{Madimikira (Idioms) and Honesty}

The Shona people are encouraged to thoroughly explain and clarify issues to avoid inconveniences that may be caused. This is espoused in idioms such as kuudza mwana hupedzisira. This again is in harmony with Moment's (2000) fourth principle of the 7 principles of Admirable Business Ethics which states that, "have clear documents, re-evaluate all print materials including business advertising, brochures and other business documents making sure they are clear, precise and professional. Most important make sure they do not misrepresent or misinterpret facts. " Even in life Shona people are not supposed to deliberately misrepresent facts and mislead people as it is cheating people. Thus, generally a person who values this virtue in life is likely to take this serious in business and leads to its success. This is in harmony with Josephson's (2010) first principle for business executives of honesty which states that, ethical executives do not deliberately mislead or deceive others by misrepresentations, overstatements, partial truths, selective omissions, or any other means and when trust requires it, they supply relevant information and correct misapprehensions of fact.

The Shona people can create madimikira (idioms) of their own depending on their relationships, situations and the reality that is taking place on the ground. So madimikira (idioms) have high chances of survival for they mutate quickly and can be in line with reality and developmental issues. The degree of flexibility in madimikira (idioms) gives them undoubted 
chances of survival and thus they have high possibility of reengagement in educating the nation.

\section{Zviera (taboos)}

Zviera (taboos) constitute the Shona traditional curriculum materials from which the succeeding generations learn the cultural values norms and belief system of the environmental ethic measure to check and regulate abuse of nature for the survival of the community at large. Gelfand (1973) noted that, when a collection of [Shona] avoidance rules is studied, it is evident that correct behaviour is being emphasised. However, they have one major weakness that their consequences have elements of lying which even the previous researchers like Tatira (2000), Chigidi (2009) and Gelfand (1974) could not dismiss. The position of this article is that taking taboos as having the weakness of lies is misrepresenting Shona reality by Western Eurocentric perspectives. Thus, the chapter advocates using the Afrocentric perspective and, in this case, the Indigenous Knowledge System in interpreting Shona knowledge systems.

\section{Zviera (Taboos) and Fauna Conservation}

The Shona employed totems as a wildlife preservation measure. By this, if a person belongs to a patrilineal clan of a certain animal that person was not supposed to eat meat or products from that animal. For example, those whose totem is $n z o u$ (elephant) were not supposed to eat elephant meat and its by-products lest they risk illness of losing teeth. In the process fauna (elephants) were conserved for tourism, as Shona people have various totems. Also, some have simply certain organs of an animal as their totems like moyo, (heart), gumbo, (leg) and others which then mean the meat of that animal is eaten except just that organ.

\section{Zviera (Taboos) and Land Conservation}

The research findings revealed that, the Shona made sure they lived in a healthy and smart environment through a number of zviera (taboos) (Chigidi 2009). The $z$ viera (taboos) forbids people from defecating in the path for they can develop boils at the back as in 'Ukaitira tsvina muzhira unozoita mamota kumagaro.' Today's children might want to know how that 
translates to a health problem. Again, this cannot be scientifically proven and hence questionable.

\section{Zviera (Taboos) and Water Conservation}

The findings from (not their real names) Zvavarundwi and Zinhumwe focus groups revealed that, the Shona made sure water is not polluted for they have zviera (taboos) which protect water bodies like, "if you urinate in water you risk suffering from bilharziasis. " Thus, they could afford to say, Mvura haina chiera, water from any source is safe to drink. They were quite sure that people were self-policing in protecting water bodies so could afford to drink water from an unprotected source. It was also said: ukachera mvura nechinhu chitema tsime rinozooma, fetching water with black container leads to the drying-up of the well. This was to make sure the community water is not polluted by using dirt containers. This promoted good health, which is paramount to sustainable economic development initiatives. This also promoted good business ethic of being honest and adhering to proper dumping of waste to designated sites which most manufacturing businesses ignore today. However, the focus groups note that there is lack of scientific evidence apart from just intimidating people with empty threats. The focus groups underestimated the issue of water borne diseases as a result of water pollution. This makes the survival of the taboos in this category undoubted and applicable in the modern environments.

\section{Zviera and Flora Conservation}

The interviews and focus group discussions revealed that, there were zviera (taboos) which foster environmental conservation mainly flora. They include the following, Ukatema muhacha mvura haizonayi (if a person cuts down muhacha the rains would not come). This was meant to conserve the flora which was a sound environmental ethic. There were also, taboos for protecting fruit trees like, miti yemichero (mihacha, mizhanje minhengeni) haiveswi inoita utsi hunokachidza (fruit trees are not supposed to be used as firewood as the smoke is chocking). The preservation of flora is a prerequisite for sustainable economic development and the above cases of taboos enhance flora preservation. For example, "Do not strip the bark on the tree that had been stripped by someone else." This helps as a way of preserving the environment as the tree will have 
time to recover the stripped bark. This is another set of zviera (taboos) which have reasonable consequences which can be geographically proven as violating them will lead to deforestation and consequently desertification. All the same the interviewees failed to realise that the Shona tailor the consequences accordingly that children may be too young to understand abstract concepts.

Zviera were meant to ensure a healthy population and sustainable economic development through protecting the natural resources. However, zviera no matter how resilient, need to be revisited from time to time with regards to relevance. Zviera can be upgraded or modified, especially on the consequences which should take science, technology and other developmental issues into account. In supporting this, the following examples were given: "Do not take too much fat for you risk being obese. Do not sleep around for you risk contracting sexually transmitted infections. Do not dump waste in undesignated areas for risk of killing the whole community through diseases."

To this end, taking into consideration the interviewees' suggestions, the chapter instead advocates for re-interpreting the taboos to make them address contemporary challenges. Just like the bible that is now over 2000 years old, it is the same text read across cultures and times with various interpretations to be meaningful. So, the essence is re-reading, re-interpreting the old text with new lens.

\section{Tsumo (Proverbs)}

Tsumo (Proverbs) is the entire stock that represents the distilled and collective experience of the Shona community, (Chimhundu 1980:40). Though they also need to be revisited from time to time for relevance, careful selection can possibly lead to sustainable economic development as highlighted below.

\section{Tsumo (Proverbs) in Self-Control and Honesty Personality}

There are those tsumo (proverbs) which foster self-control and honesty personality among the Shona people. This virtue allows one to exercise restraint. In Shona traditional thought, the virtue of self-control is highly valued. The virtue is wisely captured in, shiri huru haibatwi nohundi (a big bird cannot be trapped by chaff). Thus, restraining self from even very attractive circumstances was important. This is very importan,t especially 
in the face of rampant corruption in the country. This also is emphasised in 'chaona ziso ndecharaona, 'what the eye has seen is what it has seen.' In the face of rampant corruption, the above proverbs provide a rich moral base for self-policing against corruption and unethical activities. This discourages hurried decision making. People are encouraged to make careful reflections and weigh the future implications. This proverbial thinking will guide human behaviour against corruption and unethical practices. This is in harmony with Josephson's (2010) second principle for business executives of integrity which state that, "Mantaining intergrity requires moral courage, inner strength to do right things even when it may cost more than they want to pay. They live by ethical principles despite great pleasures to do otherwise. Ethical executives are principled, honourable, upright and scrupulous." This as it stands calls for naturally ethical personalities. It cannot be learnt over night.

\section{Tsumo (Proverbs) in Faithfulness and Honesty Personality}

There are tsumo (proverbs) which foster faithfulness and honesty personality. This is evidenced in chokuba hachipfumise, chokuba chinopa hurombe (stealing does not make a person rich but instead a beggar). In these tsumo trustworthiness, honesty and faithfulness are promoted which is in harmony with good business ethics. In Shona customs, all people were expected to be faithful in business dealings and interaction with the community. People were warned that stealing does not make a person rich, but a beggar instead. When this analogue is applied to the contemporary situation it entails faithfulness with everything we are entrusted. This may send a message to those who have names carried in newspaper headlines for corruption and obscene salaries, that stealing will not enrich them but make them either destitute when fired from work or beggars when imprisoned and even humiliated when paraded in press. This will also be strengthened by 'Kunzi dzipakate handi kunzi dziridze.' This proverbial thinking to the Shona people meant that, managers, directors, board members and supervisors out there are custodians of Zimbabwean wealth, and not owners. This undoubtedly promotes sustainability that administrators in organisations and institutions cannot just access any amount, any time at will as if we own the companies. 


\section{Tsumo (Proverbs) in Receptiveness to New Ideas}

When it comes to the principle of good business ethics that of being receptive to new ideas for continuous improvement, both interviews and focus group discussion continued to come up with, mazano moto anogokwa (ideas are fire which should be obtained from others.) In Shona traditional moral thought, the Shona have always advised community members to be morally upright. Even today people are advised to take ideas from others. There are proverbs that warn those who refuse ideas like 'rambakuudzwa akapisa jira' literally it means one who refuses advice burnt a blanket (an individualistic person ended up in problems). If one refuses advice about getting ideas from others even in business the business may not prosper. Thus, a wise person, therefore, should listen for advice and take informative advice in a responsible manner. The exposure from foreign moral practices may positively and negatively affect morality among the Shona.

\section{Tsumo (Proverbs) in Time Consciousness}

On the principle which encourages people to be time conscious and trying to accomplish tasks in the best shortest time possible, the following tsumo were mentioned, chinono chine ngwe bere rakadya richifamba (people need to be timeous), mberengera yakaradza mbuya nenzara (postponement ended up with losing opportunities), mandichati ndo akave mando (postponement ended up with loosing opportunities). This set and others encourage diligence and time consciousness in doing any work. For delays may sometimes lead to non-accomplishment of tasks in life generally.

\section{Tsumo (Proverbs) in Wise Use Resources}

Chawawana batisisa mudzimu haupi kaviri. The Shona are advised to value all the blessings no matter how small. This promoted sustainable economic development as people are encouraged to use whatever resources they have wisely and to appreciate the little they may have. This proverb encourages people to use whatever they have wisely. Budgeting in everything we do is another virtue cherished among the Shona. To use wisely include to care for those in need, which is another dimension of respecting them. Thus, it is said chawawana idya nehama mutorwa une hanaganwa. Hama in business refers to clients and teammates and genuine concern for the wellbeing of others is seen when business ploughs back 
to communities through community trust funds and other donations. This is well in harmony with Josephson (2010)'s principles of caring and respect for others.

Tsumo are still serving the Shona communities well. However, tsumo like any other teaching and learning materials, need upgrading for sustainability and to be in line with world developments like urbanisation, mechanisation and globalisation.

\section{Conclusion}

The purpose of this chapter was to explore the implications of the wisdom bestowed in selected Shona oral literature. The chapter highlighted how proverbs, taboos and idioms can be used as an invaluable source of wisdom among the Shona, which consequently impact on efforts towards the realisation of sustainable economic development as they encourage practices that enhance industry and regulate behaviour of Shona people towards high economic achievement. Entrepreneurship in Zimbabwe in general has a lot to benefit from oral tradition, specifically tsumo, madimikira and zviera as these foster values, which promote sustainable economic development if nurtured well in our citizens. Like in the section of the taboos, re-interpretation is still key in solving cotemporary challenges, instead of replacing or topping up the existing corpus.

\section{References}

Chigidi, W. L. (2009). The Shona Taboos: The Language of Manufacturing Fears for Sustainable Development. The Journal of Pan African Studies, Vol. 3, No. 1. 174-188.

Chimhundu, H (2001). Dura Mazwi Guru reChiShona: Rine Zvirungamutauro. Harare: College Pr.

Chimuka, T. A. (2001). Ethics among the Shona. Zambezia, XXV111 (1).

Dabengwa, D. (2000). (Commissioner) Voter Education Manual "Choosing future leaders" Ministry of Home affairs.

Gelfand, M. (1973). The Genuine Shona: Survival Values of an African Culture. Gweru: Mambo Pr.

Gwaravanda, E. T. (2011). Exploring Shona Proverbial Moral Teaching in the Face of HIV/AIDS: Implications for Sustainable development in Africa, The Journal of Pan African Studies vol. 13no. 2.

Hamutyinei, A. M \& Plangger, A. B (1974). Tsumo- Shumo: Shona proverbial Law and Wisdom, Gweru: Mambo Pr.

Hodza, A. C. (1983). Ngano Dzamatambidzanwa, Gweru: Mambo Pr. 
TARINGA | Wisdom Stored in Shona Oral Literature for Sustainable Economic Development

Josephson, M. (2010). 12 Ethical Principles for Business Executives, (http://goo.gl/uUAix)

Mbiti, J. S. (1988). The Role of women in African Traditional Religion, Cahiers Religions Africanes, 22, 69-82.

Moment, R. (2000). Seven Principles of admirable Business

Ethics, (sbinformation. about.com/od/bestpractices/a/businessethics.htm.

Ngwaru, C. K. J. (2012). Tsime reTsumo, Madimikira netuZvirevo. Harare: College Pr.

Nziramasanga Commission (1999). Report on 'The Presidential Commission of Inquiry into Education and Training. ' Harare: Government Printers.

Ochollo, D. (2007). The Marginalised Knowledge: An Agenda for Indigenous Knowledge Development and Intergration with other forms of Knowledge, An International view of information ethics, 7 (09): 1-10.

Osunade, M. A (1994). "Indigenous Climate Knowledge and Agricultural Practice in Southwest Nigeria”, Malaysian Journal of Tropical Geography, Vol. 2, No. 3, 21-28.

Ramose, M. B. (1999). African Philosophy through Ubuntu. Harare: Mond Books.

Taringa, N. T. (2006). 'How environmental is African traditional religion?' In Exchange Vol. 35(2), 10-21.

Tatira, L. (2000). Zviera zvaVaShoona. Gweru: Mambo Pr.

UN Development Programme Report (2002). Globalisation, Growth and Poverty. Oxford: Oxford Univ. Pr.

World Commission of Environment \& Development (1987). Our Common Future. Oslo, World Commission on Environment \& Development.

ZANUPF manifesto (2013). Indigenise, Empower, Develop and Create employment. Harare: Commissariat Department.

\section{Interviews}

HOD Languages - 22 May- 22 July 2017.

ChiShona HOS - 22 May- 22 July 2017.

ChiShona lecturer - 22 May- 22 July 2017.

ChiShona lecturer - 22 May- 22 July 2017.

ChiShona main student teacher 22 May- 22 July 2017.

ChiShona main student teacher - 22 May- 22 July 2017.

ChiShona bridging course student - 22 May- 22 July 2017.

ChiShona bridging course student - 22 May- 22 July 2017. 


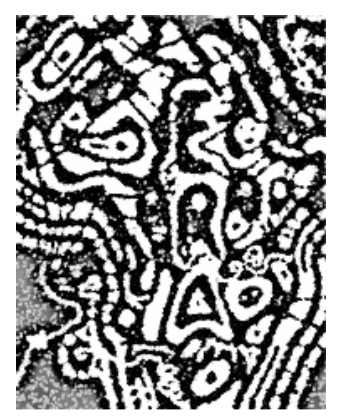




\title{
The Potential of Ubuntu Values for a Sustainable Ethic of the Environment and Development
}

\author{
Nisbert T. Taringa (†)
}

\section{Introduction}

The quest for development has generally been undertaken in ways that threaten the environment and is not sustainable. The dominant theories and approaches to development have been indifferent to the environment. Many development practitioners have not invested in reflecting on the extent to which proposed projects impact the environment. Challenges such as global warming have made it clear that development that does not take the environment into account is not real development. Capitalist, exploitative and market-based approaches to development tend to regard the environment as collateral damage. As some critics have argued,

Because economic growth requires expansive industrialization, which in turn accounts for the rapid depletion of resources, pollution of air and water, emission of hazardous gases, and use of toxic chemicals-all these eventually lead to environmental disorders like resource scarcity, global warming, ozone depletion, and so on (Haque 2000:13).

In the 1987 Brundtland Report, also known as, "Our Common Future," there is a call for "a new holistic ethic in which economic growth and environmental protection go hand in hand around the world" (Engel 1990:1). Brundtland was speaking for the UN Commission on Environment and Development (Engel 1990:1). Brundtland called for an ethic of sustainable development that includes the need to make adequate moral judgments about how we treat the environment and the direction of contemporary development. The report makes a passionate plea for human beings to adopt an ethic of responsibility towards the environment. Thus:

According to this report, the major objective of development should be to ensure the satisfaction of human needs and aspirations of a material kind. It emphasized the fact that over exploitation of resources may compel human societies to compromise their ability to meet the essential needs of their people in future. Settled agriculture, the diversion of watercourses, the extraction of minerals, the emission of heat and noxious gases into the atmosphere, commercial forests, and genetic manipulation, were all mentioned in the report as examples of human intervention in natural system 
during the course of development. It called upon all countries to adopt the objective of sustainable development as the overriding goal and test of national policy and international cooperation (Awan 2013:744).

This chapter explores the potential of Ubuntu values which can support an ethic of the environment and development. It focuses on how articulations of the tenets and assumptions of Ubuntu principles can potentially provide guidance on a sustainable ethic of environment and development. It begins by giving a background to the issues at hand. This is followed by a brief unpacking of Ubuntu. After this, the chapter engages in a content analysis of the following in the context of Ubuntu; Ubuntu's we-ness, humanity as member of a larger spiritual family, Ubuntu and respect for nature, and animistic inspiration to Ubuntu and nature.

The major findings are that Ubuntu presupposes a worldview where there is a seamless interconnection between the divine, human and natural worlds. Ubuntu stresses what has been described as an anthropo-cosmic worldview. At the heart of Ubuntu is an animistic relational epistemology. Divine-human relations are not considered more important than the relationship between humans and the natural. Ubuntu is, therefore, dark green; meaning Ubuntu considers nature to be sacred, imbued with intrinsic value, and worth of reverent care. Ubuntu expresses and promotes an ethic of kinship between human beings and other forms of life; plant and biological. Ubuntu turns attention to we-ness. Ubuntu, therefore, appreciates that humans share the local environment with other beings and emphasizes we-ness, echoed at the heart of Ubuntu's, "I am because we are; because we are therefore I am". Both the "I" and the "we" should be interpreted to also refer to nature. In this chapter I argue that Ubuntu, in the context of the Shona in Zimbabwe, can be a basis for developing an ethic of the environment and sustainable development. When properly conceptualised and deployed, the same concept can also promote an ethic of the environment and sustainable development in other parts of the world.

The turn to Ubuntu emerges out of the realization that most of the available development models are dominated by western theories. Unfortunately, such theories tend to place emphasis on the individual and exploitation of the environment. The global discourse on religion and development, therefore, tends to marginalize reflections from the global South. Ubuntu challenges such a focus by supporting an environmentally sensitive ethic. Therefore, this chapter is in fundamental agreement with Jacqueline Church when she writes: 
Here the central theme is that in African tradition, personal identity cannot be separated from the environment as a whole which encompass the natural, socio-cultural, physical and spiritual environment. The traditional view was that the universe was "a spiritual whole" in which all beings were interrelated and interdependent, existing in reciprocal relationship to one another: for example, one could not take without giving. Accordingly, instead of Descartes's "I think therefore I am" in this tradition the maxim is "I am because we are; and since we are, therefore, I am” (Church 2012:524).

\section{Background: Nature's Loss is Our Gain!}

How we treat the environment and the direction of contemporary development are not casual matters. In many places, development has been approached from a brutally utilitarian perspective, without any concerns about its impact on the environment, whether projects guarantee sustainability. The sole focus has been on pursuing development "by any means necessary." However, there is an urgent need to pay attention to growing concern in world conservation and development (Engel 1990:2). The sentiments insinuate the need for development and environmental responsibility. Brundtland's call is consistent with the 1980s call, at the launch of the World Conservation Strategy. The World Conservation Strategy had called for a new ethic qualified as follows:

Ultimately the behaviour of entire societies towards the biosphere must be transformed if the achievement of conservation objectives is to be assured. A new ethic, embracing plants and animals as well as people, is required for human societies to live in harmony with the natural world on which they depend for survival and well-being (Engel 1990:3).

This new ethic is urgent in Zimbabwe where two unsustainable economic activities are wounding the natural environment. First, regarding the effects of the Fast Track Land Reform Programme of 2000, one of the issues is massive destruction of trees. Below are a few examples. I collate these examples below without commentary in order to enable the reader to appreciate the massive impact of the land reform programme on the natural environment. 


\title{
"Clear most of the trees to farm! This section has not been used for crops..." Land Degradation under the Fast Track Land Reform Programme
}

\begin{abstract}
"When Phides Mazhawidza was shown her newly allocated A2 farm in Goromonzi, she was dismayed to find that it was covered with trees. While she admired the miombo woodlands with its beautiful musasa and munondo trees, her heart sank when she realized that she would have to clear much of it to farm. Phides' farm was a subdivision of a large commercial farm in a region of high agricultural potential and her section had not been used for crops". (Hanlon, Manjengwa \& Smart 2013:175).

"Land reform means unused land is being cleared and land is being used intensively, which makes trees a key issue. There is an increased demand for wood for fuel, in particular for curing tobacco and to sell to urban dwellers. So far land-reform farmers seem to be managing their trees, but they will need to be monitored. Fast track land reform and economic crisis caused by hyperinflation have created two serious environmental problems that will not be solved by simple enforcement." (Hanlon, Manjengwa \& Smart 2013:187).
\end{abstract}

\section{Cutting down trees, Veld fires}

Maposa, Hlongwani and Muguti (2011:160) decry the impact of the land reform on the environment. They observe that "In spite of the fact that the Land Reform program has posited some apparent successes in the particular provision of land as a source of livelihood for thousands of peasants who were landless, it is causing almost unmitigated environmental disaster. It is a hard reality to note that varimi vatsva (new farmers) are involved in wanton tree cutting in resettled farmlands. Trees are disappearing at catastrophic rapidity. This is causing deforestation, an issue that is intrinsically linked to environmental degradation. Kwekwe town is fast turning into a desert. The reasons are not far to seek. The new farmers have occupied the adjacent former white commercial farming properties such as Congela, Dunlope Extension, Milsonia Ranch and Maivalle Ranch.”

"Apart from the indiscriminate cutting down of trees, varimi vatsva have been widely accused of causing veld fires in the former white farmlands across the country. However, from the onset, it must be stated that the issue of who causes the fire is a contentious one. Firstly, it is alleged that communal peasants cause veld fires. Fire outbreaks commonly occur during the dry season when conditions favor the spread of the fire from one point to the other. The communal peasants move around and smoke out bees in search of honey from the veld. Secondly some varimi vatsva incidentally cause veld fire during land preparation. Despite being motivated by the practical need to survive, varimi vatsva are the chief culprits in the sense that they are also involved in hunting animals for game meat in their new-found domains." (Maposa, Hlongwani \& Muguti 2011:161). 
Second, Gwenero (2016:v) decries how artisanal small-scale mining activities have ravaged the environment. There is rampant land degradation, siltation, deforestation, water pollution and loss of aquatic life and loss of biodiversity. One does not wonder why as early as 2007 the then Deputy Minister of Environment made the following remarks when he visited the Marange Diamond fields:

The environment has been ruined. If we allow panning to continue the country cannot afford its reclamation... What I have seen is land destruction at its worst. Who will be responsible for filling these shafts? The extent of the plunder is shocking. It is as if these people were using motorized machinery like graders when they were using picks and shovels... (Manica Post 16 March 2007).

The above examples fall into the problem of anthropocentricism, that is, nature's value is being used as an instrument to ensure human interests. This debases nature to the level of being a mere human instrument. This brings about ecocide, namely, the deliberate destruction of the environment. In light of this ecocide, there has been a commensurate loss of trust in the capacities of modern science and technology to provide the knowledge and means required to bring human societies into harmony with their environment and one another. It is in light of this observation that I set out to explore Ubuntu's potential in providing a basis for an ethic of environment and sustainable development. However, it is critical to summarise the key tenets of Ubuntu first. I outline these in the section below.

\section{Unpacking the Philosophy of Ubuntu}

In this section, I examine the philosophy of Ubuntu with special reference to the Shona people of Zimbabwe. I will try to establish the basic ideas at the very core of Ubuntu, which I will need to consider in making sense of and evaluating the relevance of Ubuntu for an ethic of environment and sustainable development in part three of my paper. I begin by highlighting the general tenets of Ubuntu. It must be noted, however, that a full discussion of this concept lies beyond the scope of this chapter. Further, other scholars have undertaken such a task (Ramose 1999).

The problem one faces first is to establish the origin of the word Ubuntu in Africa. In a general way most scholars associate Ubuntu with a loose Bantu speaking family: the entire group of languages, spoken from Cape 
to the Sudanese belt where the word $n t u$ stands for human (Van Binsbergen 2002). In a more particular way, people associate Ubuntu with the languages of Southern and Central Africa. These people, like in the general observation, have in their language $n t u$ or a variation as the word for person (Samkange \& Samkange 1980:36). One of the results of comparison shows that in southern Africa the Shona have munhu (singular) and vanhu (plural), the Zulu, Xhosa and the Ndebele have umuntu (singular) and abantu (plural) and the Sotho and Tswana have muntu (singular) and bantu (plural) for person and persons respectively. As a result of this observation, this group of related languages is called Bantu and the speakers are called Bantu peoples (Samkange \& Samkange 1980:36). Since the focus of my paper is not mainly on the theories of the origin of Ubuntu, it is sufficient to note that there are as many as three hundred linguistic groups with $n t u$ or variation in the word for person, all believed to have originated from the same source (Samkange \& Samkange 1980:36). What is important for me now are the ideas at the core of Ubuntu.

The ideas at the core of Ubuntu lie in the distinction Van Binsbergen (2002) makes between the implications of $n t u$ in cosmological and sociallegal contexts. In the cosmological context, $n t u$ is primarily used to distinguish the non-human visible world of animal, vegetal, and mineral kingdom and the invisible world of the supernatural, spirit, ancestors, gods and God from people. It is in this context that scholars usually associate Ubuntu with humanness.

In the socio-legal context, $n t u$ is used as the opposite of the inhuman. The inhuman refers to a person who transgresses the scope of humanity (personhood/Ubuntu). This may apply to witches and sorcerers and people engaged in violence against kinsmen and those who transgress the codes of conduct that regulate behaviour among people, young and elder, junior and senior, male and female, people and spirits/gods. When the right relationship is broken in any of these ways, nature grinds to a halt. It reduces life force to a minimum and results in misfortunes such as death, diseases, drought and crop failure. The situation is restored through the cooperation of family/community (Van Binsbergen 2002). It is in this context that Ubuntu implies the attention that a person gives to another: kindness, courtesy, compassion, consideration and friendliness in relationship between people; a code of behavior, an attitude to other people and life (Samkange \& Samkange 1980:39). Ubuntu is, therefore, something more than just humanness deriving from the fact that one is a human being. 
Ubuntu is also used in relation to the local people in contrast to strangers whose $n t u$ (personhood) may be called into question or denied (Van Binsbergen 2002). Among the Shona, the word munhu means a person. They know also that it means more than just a person, human being or humanness because when one sees two people, one white and the other black, they say there is munhu (person) and a white man/woman. In fact, they say "there is munhu (a person) walking with murungu (a white person)." This means that there is a sense in which the Shona can say a white man/woman lacks something that they always identify as Ubuntu. What is it that the Shona call Ubuntu in this context?

Ubuntu is something identifiable among the Shona. It refers to attributes and traits characterized by a sense of community orientation, a sense of hospitality, a sense of kinship, a sense of belonging, integration of strangers, solidarity, sympathy, compassion, harmony, patience, conformity, kindness and cooperation. This is based on the idea that "An African is never regarded as a loose entity to be dealt with strictly individually. His (sic) being is based or coupled with that of others. Next to or behind or in front of him there is always someone through whom he is seen or with whom he is associated" (Paris 1995:101). Further, Ubuntu is also resiliently religious. The religious meaning of Ubuntu is that the person one is to become through the other person is ultimately an ancestor. The other person includes the ancestors. Ancestors are part of the extended family. Ubuntu, therefore, inevitably implies a deep respect and regard for African religious beliefs and practices. When misfortune has befallen Shona people, and biomedical approach has failed, they usually make a recommendation to follow chivanhu. This entails dealing with misfortune in the context of Shona beliefs and practices related to nature. Like most fundamental concepts, Ubuntu defies a single definition or characterization. In most cases it is not clear what Ubuntu means. According to the analysis I gave above, the essence of Ubuntu is humanness and communalism and the values they imply such as kinship/relationship, sharing, hospitality, compassion, empathy, harmony, humility, and cooperation. Ubuntu enjoins that what is morally good is what brings dignity, respect, contentment and prosperity to others, self and the community at large. This is captured in the cardinal belief of Ubuntu that a person is a person through others: "I am because we are, because we are therefore I am." However, some interpretations of this dictum have placed a lot of emphasis on the "I" and in turn restrict it to the individual person. Below, I argue that the "I" must be regarded as embracing nature. 


\section{Ubuntu's 'We-ness' and Nature}

Ubuntu turns attention to 'we-ness.' Ubuntu is against materialistic framing of the environment as discrete things. Instead, it stands as a relationality which frames the environment as "nested relatedness." Ubuntu is not premised on the dichotomous opposition of culture and nature. Ubuntu privileges knowing how to behave within relations in order to nourish these relations more than knowing things in and for themselves as objects separate from the knower. Based on relational personhood concept Ubuntu fosters a relational perception of the environment. Ubuntu does not take the axiomatic split between human and non-human as essential. The Shona person is a composite of relationships. The person is conceived of as dividual and not individual. The Shona is misrepresented if depicted as an individual. The person has a holistic collective identity. In essence, 'dividual' means a person is constitutive of relationships. The issue is how one relates to others, and part of the others is the natural environment, conscious of relatedness. So, there is consciousness of relatedness. The central idea is that one shares space, things, and actions with others. There is a strong sense of sharing with others, versus distribution. I explain this sense of shared identity below.

The Shona address each other by kinship terms: baba (father), mai (mother), mbuya (grandmother), sekuru (grandfather/uncle), muzukuru (grandchild/nephew), tezvara (father-in-law), mwana (child), mukoma (older brother), munin'ina (young brother/sister), hanzvadzi (sister/brother), tete (aunt), and also Totems (Dziva, Shumba, Tembo, etc.). Although I have used the English translations here, it is important to note that these relationships are deeper than their use in the English language and culture. For example, "mwana" does not refer to one's child only, but to potentially to all the children in the extended family or community. The Shona, therefore, do not, through Ubuntu, individuate but dividuate other beings in their environment, including the environment itself. They are attentive to, and work, towards making relatedness. The Shona not only share relationships with fellow Shona, but with members of other species in the vicinity. They make their personhood by producing and reproducing, sharing relationships with surrounding beings; humans and others. They do not dichotomize other beings vis-a-vis themselves but regard them, while differentiated, as nested within each other. For example, there is a proverb, "mudzimu weshiri uri mudendere" (literally, bird's ancestor is in the nest). This confirms the close interface between human beings and other beings in the environment. The relationship between a 
bird and its nest is used to teach Shona people about their relationship with their ancestors. They, therefore, appreciate that they share the local environment with other beings and emphasize a one we-ness, the heart of Ubuntu; "I am because we are." So, a relative means that or whom one interrelates with. It also confirms that humans are connected to others by blood or affinity. There is a we-ness that is different from sameness.

For all past centuries, Ubuntu has been hijacked by western worldview and has been interpreted from an anthropocentric perspective in order to avoid genocide, ignoring the biocentric perspective that fosters avoiding biocide and ecocide. The "I" is not the primary axis of Ubuntu. The "I am" is a smuggled western individualism referring to human beings only. The correct rendering is, "We are because we." The emphasis must not be on the individual, but on the community. This is consistent with Shona culture where the primary unit of the society is not the individual.

\section{Humans as Members of a Larger Spiritual Family}

The 'we-ness' I have explicated above points to an ethic of environment that recognises humanity as members of a larger spiritual community. As such, Ubuntu insinuates that human beings must live in a biocentric, as opposed to anthropocentric, world. Humans are not thought to be at the center of the world or superior to the rest of creation. Humans have souls and other parts of creation also have souls. In the Shona worldview, we may infer that people look out upon cosmos partaking at once the qualities of human beings, nature and God/ancestors. The Shona do not seem to confront multiple and diverse forms of existence. Instead, it is one thing with different aspects of vitality. We note that if we compare their worldview with a triangle of the three conceptions of human beings, nature and God/ancestors- the Shona worldview is one in which the triangle itself might not be very apparent. This unitary character of the cosmos in the case of Shona people is recognised when it is said that the world of the Shona is pervaded with sacredness.

For example, during the Second Chimurenga (the 1970s war of liberation), the guerrillas related immensely with the animal life (fauna) as well as the flora. There are abounding myths that explain the partnership that had been created between the freedom fighters and the environment. For example, they are said to have forged a strong partnership to the extent that animals could give warning to guerrillas about an impending danger and they would react accordingly. Various species in the animal kingdom 
such as baboons and snakes for example, were the most reliable spirit mediums. They could communicate with the spiritual world and transmit instructions that could guide the combatants. Communication with the spiritual world via the animal kingdom would not be possible if the environment was not conducive. The enemy was left puzzled: how could they have been detected? Even harmful animals and reptiles spared their lives. The combatants would not even kill these animals unless a proper ritual was conducted with the assistance of a spirit medium. This underlines the notion that there had to be a justifiable necessity to destroy animal life.

\section{Ubuntu and Respect for Nature}

We noted above that one of the tenets of Ubuntu is respect. Ubuntu implies, in the 'we-ness' a tremendous respect for nature. It sees human life as integrated in nature rather than as exploitative to nature. The outlook is, therefore, fundamentally ecological in character. The Shona people know that they belong to nature. Sometimes they refer to each other as "mwana wevhu" (child of the soil). They must live in harmony with nature in ways that honor the patterns and order of the universe. For example, sacred woodlands, wetlands and mountains were used as a refuge by both the combatants and masses during enemy attacks. In the war zones, it was a taboo to be seen felling trees or causing veld-fire because everyone knew that without good vegetation, they were like fish out of water. The bush also availed fruits and other edibles to energize the freedom fighters and some medicinal herbs to ensure that they remained in sound health. The land itself was the stage where the interplay of all these forces took place. It gave life to animals and the vegetation as well as hiding places like caves for the guerrillas; it was and is still the abode of the ancestor spirits to whom they give libations from time to time for spiritual guidance.

In short, the land is an invariant core in the equation of life and, therefore, a precious treasure. The spiritual attachment to the land inspired by ubuntu and revered by the people ensured a very positive environmental ethic. Overall, in the light of the traditional scenario, one can argue that in the past the Shona knew how to deal with nature and the environment. They knew how to use dams; they knew how to protect forests and water sources with the use of belief systems and value systems attached to places. They acted as custodians of these resources for future generations within the kinship social group. Ubuntu had been good during this period 
as it inspired an environmental conservation culture by fostering a society that respected some order and harmony amongst all the constituents of the cosmic totality. This is more urgent today. As Ferguson (2010) notes, the entire human family is coming to the realisation that we must live in ways that respect nature given the impact of the deteriorating environment and global warming.

\section{Animistic Inspiration to Ubuntu and Nature}

In this section I assume that animism underpins dark green Ubuntu. Dark green Ubuntu refers to Ubuntu that inspires an ethics that considers nature to be sacred, imbued with intrinsic value and worth of reverent care. I anchor my understanding of animism in its Latin etymology, the Latin word anima. In Latin, anima means life breath and soul. In this chapter I agree with Taylor (2010:15), to settle for what anima commonly refers to today. Taylor notes, "it refers to perceptions that natural entities, forces, and non-human life forms have one or more of the following: a soul or vital life force or spirit, personhood, and consciousness, often but not always including spiritual intelligence or powers." What is more important in the context of this chapter is that, regarding animism underpinning Ubuntu, animistic perceptions are often accompanied by ethical mores specifying the sorts of relationships that human beings should have or avoid having, with nature's diverse forces and beings. Further, sometimes animism involves communication and/or communion with such intelligences or life forces.

Underpinned by such an animistic orientation, ubuntu overcomes the dualism active and passive. Ubuntu departs from a dualism in environmental thinking that associates activity with humans and passivity with the natural (Riggio 2015:92). The major assumption of dry dualism is that humans are the only ones that act, and all other bodies react and are acted upon.

\section{Conclusion}

The nature-culture divide is Western ploy to establish the rationale for the exploitation, domination and preservation of nature. It justifies the ideology of conquest and domination towards nature. In contradistinction, nature in the context of Ubuntu is masango (sacred forests/the abode of the ancestors). At the heart of Ubuntu is biocentrism and ecocentrism. There 
is no idea of human supremacy over nature and notions of nature as other to human society and culture. Ubuntu transcends the nature-culture divide. The idea of nature and culture as separate entities is not part of Ubuntu. Nature among the Shona serves to define what it means to be human, to have unhu/Ubuntu.

It is my contention that this version of Ubuntu is critical for the development of Zimbabwe/Africa and the world. In this approach, nature is not there to be exploited, but is an equal partner in the created order of things. Whereas most of the contemporary development models result in the wanton exploitation of the environment, thereby triggering climate change, an Ubuntu-inspired ethic of the environment and sustainable development serves to promote ecological sensitivity and protection of the environment. Ubuntu equips individuals and communities to have a positive and respectful attitude towards the environment. Ubuntu is, therefore, a powerful resource in protecting the environment and promoting sustainable development. I am in fundamental agreement with Museka and Madondo (2012:264) when they write:

The teleology of the African (Shona/Ndebele) cosmology shows that human beings are one with nature, nature being the larger whole and humankind only a constituent. In this cosmos, human beings stand within the universe, not separate from it, but depend upon it, without dominating it. Abuse and exploitation of nature for selfish gains is immoral, unethical, unjust and sacrilegious. The intimate and ultimate relationship between humanity and nature resonate in the philosophy of unhu/ubuntu.

\section{References}

Awan, Abdul G. 2013. "Relationship between Environment and Sustainable Economic Development: A Theoretical Approach to Environmental Problems," International Journal of Asian Social Sciences 3(3), 741-761.

Church, J. 2012. "Sustainable Development and the Culture of uBuntu," De Jure, 511531.

Engel, J. R. 1990. Introduction: The Ethics of Sustainable Development in Engel, J. R \&

J. G. Engel, eds., Ethics of Environment and Development: Global Challenge and International Response. London: Belhaven Pr.

Ferguson, D. S. 2010. Exploring the Spirituality of The Worlds Religions: The Quest for Personal, Spiritual and Social Transformation. London: Continuum.

Gwenero, L. H. 2016. 'Effects Of Artisanal Small Scale Gold Mining on The Environment And Livelihoods: A Case Study Of Shurugwi. ' Bachelor of Arts in Development Studies Honours Dissertation, Faculty of Arts, Department of Development Studies, Midlands State Univ. . 
Hanlon, J., J. Manjengwa \& T. Smart. 2013. Zimbabwe Takes Back its Land. Sunnyside: Kumarian Pr.

Haque, M. S. 2000. "Environmental Discourse and Sustainable Development: Linkages and Limitations," Ethics and the Environment 5(1), 3-21.

Maposa, R. S., J. Hlongwani \& T. Muguti, 2011. "Liberation Theology and the Depletion of Natural Resources a Smart Partnership? An Appraisal on Varimi Vatsva in the Former Commercial White Farms," Journal of Sustainable Development in Africa, Vol. 13. 2, 155-167.

Museka, G. \& M. M. Madondo. 2012. “The Quest for a Relevant Environmental Pedagogy in the African Context: Insights from the Unhu/Ubuntu Philosophy," Journal of Ecology and the Natural Environment 4(10), 258-265.

Paris, P. J. (1995). The spirituality of African people: The search for moral discourse. Minnerapolis: Fortress Pr.

Ramose, M. G. 1999. African Philosophy through Ubuntu. Harare: Mond Books.

Riggio, A. 2015. Ecology, Earth and the Future of Humanity. New York: Palgrave.

Samkange, S. \& T. S. Samkange. 1980. Hunhuism/Ubuntuism: A Zimbabwean Indigenous Political Philosophy. Harare: Graham Publ.

Taringa, N. T. \& M. Sipeyiye. 2013. "Zimbabwean Indigenous Religions and Political Drama: The Fast-Track Land Reform and the Fast-Track Change of Attitudes to Nature, 2000-2008," in Chitando, E., ed. Prayers and Players: Religion and Politics in Zimbabwe. 51-62. Harare: SAPES Books.

Taylor, B. 2010. Dark Green Religion: Nature, Spirituality and The Planetary Future. Berkeley/Los Angels/London: Univ. of California Pr.

Van Binsbergen W. (2002) http//www.shikanda.net/general/ubuntu/htm 


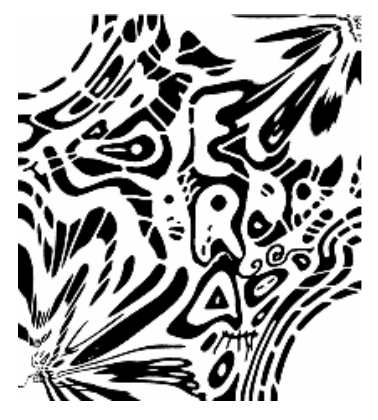




\title{
The Bible as a Resource for Development in Africa: Ten Considerations for Liberating Readings
}

\author{
Ezra Chitando
}

\section{Introduction}

The status of the Bible ${ }^{1}$ in Africa's development is heavily contested. On the one hand are critics who charge that expecting the Bible to contribute to Africa's development is similar to expecting a mosquito to cure malaria. They maintain that Christianity has used the Bible to disable African resistance and to accept poverty and underdevelopment. Thus, the Bible is indicted as an instrument in Africa's exploitation and as a "weapon of mass destruction." In such a scheme, Christianity is regarded as an accomplice in the theft of Africa's resources. In the words of one such critic:

For almost five centuries, European empire builders employed different strategies and tactics in Africa to make money through the ownership of human beings, exploration, evangelization, colonization, commercialization, terrorism, banditry, robbery and theft. The processes of merchandizing some young Africans, dominating and controlling trade, destroying African institutions, cultures and religions, imposing Christianity, destroying African leadership and sovereignties through establishing colonial governments, dispossessing lands and other economic resources, and transforming Africans into slaves or coerced laborers for the purpose of advancing private profit caused public disasters for Africans and people of African origins... (Asafa 2015:78).

I have cited Asafa at considerable length because he articulates the dominant African intellectual position against Christianity in a very clear way. African creative writers have expressed a similar stance against Christianity (Mugambi 1992). There is a hostile attitude towards Christianity and its key resource, namely, the Bible, among some African intellectuals. In this regard, the Bible is seen as an instrument of oppression that has prevented us as Africans from developing and reaching our full potential. On the other hand, there are African theologians and biblical scholars who

1 I recognise that some critics maintain that using the capital letter tends to add to the awe around this text. I retain the capital letter on phenomenological grounds because it refers to a specific sacred texts. Thus, the Quran must also be capitalised. 
regard the Bible as "the good news" that has galvanised Africans. For these scholars, the Bible has the potential of liberating different categories of oppressed people in Africa. For example, while acknowledging the problematic role of the Bible in Africa's encounter with colonialism, some African scholars contend that postcolonial interpretation of the Bible can be utilised to overcome such limitations (Dube, Mbuvi and Mbuwayesango 2012). Thus, this school of thought contends that biblical texts can be redeemed, appropriated and deployed to promote development in Africa. Although I would not describe it as "an emerging discipline," given the fact that it has been around for quite some time now, African Biblical Studies (Mbuvi 2017) must inspire non-specialist readers of the Bible in order to contribute towards development.

In this chapter, I do not take the ability of the Bible to promote development in Africa for granted. I am painfully aware of the ambivalence of the Bible in relation to African experiences. For example, in the response to HIV \& AIDS in Africa (and globally), the Bible was used both to stigmatise people living with HIV and to promote healing and integration. However, it would be very difficult and naive to overlook the role of the Bible in discourses on development in Africa. This is because, "[T]he Bible, as the single most important guide to the Christian faith and from which the majority of African Christians expect answers to the gnawing questions of daily living," (Hiagbe 2015:169) continues to hold sway in many parts of the continent. Although some critics contend that the Bible must not feature in any discussions on development, I am convinced that it is in fact possible to read the Bible for development in Africa (Dada 2010 and Ndyabahika 2007). Gerald West, who has devoted considerable intellectual energy towards exploring the role of the Bible in Africa, puts across a compelling argument on the necessity of engaging with the Bible in discourses on development. He writes:

One of the resources the church and church-related organizations have is the Bible. And yet the Bible is often read in a way that hampers real liberative and transformative community development. Again, the Bible is a resource we cannot ignore. If we do not show how it might be used for liberation and transformation, we simply hand it over to the forces of domination and death, who are not slow to take it up. We need guidance on how to take up the Bible in a way which hears the voice of God who hears the cries of slaves and the God who took human form as one of the marginalized and oppressed (West 2007:xi). 
In this chapter, my main concern is to tentatively set out ten considerations to promote liberating readings in the quest for development in Africa. I do not regard these ten as "commandments," but as potentially helpful principles that could contribute towards ensuring that the Bible becomes a resource in the search for development in Africa. Whereas some African biblical scholars, for example, Gunda (2015) call for a "debiblification" of the public sphere, that is, removing/radically reducing the influence of the Bible from the public sphere, I am persuaded that if progressive principles of interpretation are employed, the Bible could still play an important role in the lives of individuals and communities. In this regard, I am of the view that liberating readings of the Bible are still possible and that these would contribute towards development in Africa. While Togarasei (2008) has proposed that biblical interpretation should be guided by four principles: to save life, to seek justice for all, to promote love, and to liberate the marginalised, I amplify these to include other dimensions in the quest for development in Africa.

Given the complexity of and diversity in defining development, in this chapter I adopt only a tentative/working/exploratory definition of the concept (earlier chapters in this volume seek to clarify this concept in detail). I shall approach development as the holistic process aimed at the betterment of the lives (in their various dimensions) of individuals, families, communities, nations and continents. Thus, development is not solely economic, but entails addressing the social, cultural, political, environmental and other concerns. Further, development must be, "people centred" (Speckman 2007:xxv). Development is not exclusively about figures relating to economic growth, per capita income, the size of the sovereign wealth fund and so on. Rather, development is about the health, well-being and sense of fulfilment among citizens. The underlying idea is that development draws out the real person, making the total human evident. Masoka \& Mamvura (2017:31) refer to development as that "where people of African countries live under just, equitable and humane conditions."

The idea of "liberating readings" of the Bible in the title seeks to draw attention to interpretations of the sacred text that contribute towards promoting and enhancing the well-being of Africans in all aspects of life. Cezula (2015:131) clarifies that "reading the Bible" refers to three processes, namely, "looking at written words and comprehending their meaning, interpreting the meaning in relation to one's life experiences, and endorsing and concretising the interpretation in action. "While all three are related, 
it is the last one that is particularly critical to this chapter. When interpretations of the Bible are "endorsed and concretised in action," there are practical and existential consequences. In this chapter, it is these consequences that I have in mind, as I seek to promote those readings that galvanise individuals, communities, nations and the continent to improve themselves and their contexts. Further, I do concede that each one of the areas discussed below requires more detailed analysis in separate studies. Therefore, the approach adopted in this chapter is more exploratory rather than definitive.

\section{Maintain the Dignity of Africans}

Any biblical interpretation that suggests that somehow Africans have a contract with poverty and underdevelopment must not be accorded space in Africa. In order for the Bible to serve as a resource that promotes development in Africa, it is vital for readers to maintain our dignity as Africans. This means appreciating the non-negotiable truth that we Africans are created in the image of God, have inherent and inalienable dignity and that we do not have to apologise to anyone for who we are. Readings of the Bible that insinuate that Africans are/were cursed, as in myths that associate Africans with Ham, "servant of servants" (Genesis 9:25) must be resisted. Such myths developed in specific historical contexts and were meant to aid the exploitation of black Africans (Sanders 1969:523). Care must be taken to minimise the preoccupation with curses, demonic forces and evil spirits as authors of poverty in Africa (Kakwata 2017). I deliberately chose to say, "minimise" because I am acutely aware of how such ideas continue to be significant within many African contexts. This implies that a realistic and sensitive approach to address spiritual ideas is required when promoting development in Africa. However, placing emphasis on negative spiritual forces or ideologies that suggest that somehow God has condemned Africans to a low(er) status is unacceptable.

Maintaining the dignity of Africans in African interpretations of the Bible implies accepting the full humanity and worth of Africans as part of the human family. Space considerations prevent me from pursuing this theme in detail. Nonetheless, it is crucial to highlight that the world appears to still struggle to accept this basic truth: black Africans are full human beings! This is why ships full of young Africans can be denied entry into European ports, condemning many to their untimely and unneces- 
sary deaths. ${ }^{1}$ This would never happen if these were white people! Interpretations of the Bible that suggest that Africans are/were an afterthought in God's plans must be thrown away. This is because they sponsor a disabling ideology. If "African Biblical Studies support the principle of the interpretation of the Bible for transformation in Africa" (Adamo 2016:4), then it must take the inherent and full dignity of Africans as its sine qua non.

Although poverty and underdevelopment denude dignity, it is critical for liberating readings of the Bible to maintain the dignity of Africans. In order for the Bible to counter the trend of representing Africans in a negative way, it is vital for its readers to already approach the text with a positive and unflinching image of Africans and Africa. This is an urgent and abiding requirement. Global media networks have stripped us Africans of our dignity by beaming images that generate, deepen and reinforce a logical connection between Africa and poverty. Imathiu (2001) has explored how photographs of black Africans during colonialism were defined by the context and mindset of the white photographers. Unfortunately, such framing has persisted in the period after colonialism. Thus:

Western media reports portray Africa as a tragic and helpless continent unable to fend for itself. They depict the continent with a major chunk of its inhabitants dying of hunger, AIDS and war. The developing world in general is described with stories related to crime, violence, and terrorism, ethnic conflicts, fundamentalism and other forms of uncivilized backwardness. Particularly, Western media news about Africa is a dump of negative material related to disease, savagery, plague, war, famine, despotism, primitivism, poverty, and everywhere images of children, flies in their food and faces, their stomachs inflated, grand-propaganda campaign aimed at suppressing, blacklisting and condemning promising African governments, peoples and tribes (Adum et al 2015:2-3).

We would have failed in our responsibility as African scholars if we are only seized with the negative portrayal of Africans and Africa by "Others." Many times, we as African scholars have generated images that rob us and Africa of our dignity. We mourn and bemoan corruption, tyranny and inefficiency, as if "Others" have attained total and complete development. Of course, there are numerous challenges that Africa needs to address, but, who does not have their "fair" share of challenges? Therefore, I am

1 We could ask questions such as, "what are they escaping from?" but, this in no way justifies the refusal by some European governments to save human lives simply on the basis of the idea that to assist would precipitate a "deluge of armies of desperate young black people who will overrun Europe. " 
persuaded that one of the urgent struggles we must undertake when reading the Bible for development in Africa is the one relating to our mental images of Africa. To appreciate that as Africans, we too are "fearfully and wonderfully made" (Psalm 139:14) and that the call for abundant life (John 10:10) applies to us equally is a major step towards affirming the integrity of Africans. Without winning the battle of maintaining the dignity of Africa and Africans, it would be futile to approach the Bible for motivation.

\section{Defend Africa's Resources}

The Bible can be a veritable weapon in defending African resources. It should be read in ways that enable Africans to demand that we have exclusive rights to our resources and that we will do everything in our power to defend these resources. By extension, the Bible must be interpreted in ways that equip us as Africans to appreciate our inheritance and strive to utilise these resources optimally. Africa is simply too rich to be poor. The collusion between external looters and their internal collaborators has bled the continent dry. Therefore, passages that emphasise respecting inheritance from God and the ancestors, such as the story of Naboth's vineyard (1 Kings 21:1-29) need to feature more prominently in African biblical studies. As Vengeyi (2014) rightly observes, Naboth was convinced that his inheritance could not be commodified and given away, as it was from his ancestors.

Defending Africa's resources is critical in order to promote development that is premised on African resources. The latest scramble for Africa by global powers, including the Chinese who have joined the bandwagon, does not augur well for Africa. There is never a benign exploiter! Every exploiter is selfish and unbearable. Therefore, the notion that China strips Africa without giving anything back (unlike, say, the Europeans/Americans) is terribly mistaken. As Alden and Alves (2009) have argued, China's engagement with Africa follows most of the paths established by earlier players. For ideological reasons, China has adopted a different outward posture. Global economic players are interested in Africa solely for satisfying their own needs and whims. Although Africa is very well endowed with oil, minerals, arable land and other resources, the continent continues to reel from exploitation of the same by greedy and cunning external players who act in cahoots with crooked internal elites. 
The Bible can be deployed to defend Africa's resources by teaching and upholding the concept of effective stewardship. The African Union's Agenda 2063, "The Africa We Want" articulates the aspiration of a prosperous Africa based on inclusive growth and sustainable development. Elaborating on this Aspiration 1, the African Union aspires that by 2063, "Africa shall be a prosperous continent, with the means and resources to drive its own development, with sustainable and long-term stewardship of its resources..." (African Union 2015:2). This aspiration is critical, as "sustainable and long-term stewardship" of African resources is key to the success of Africa's development plans. Effective stewardship implies that we, as Africans, appreciate and value the resources that God has given us, and that we seek to get the best returns from them in a responsible and sustainable way. Bible studies that deepen awareness of stewardship will go a long way in achieving this goal (see for example, The Church of Scotland, Stewardship and Finance Department, nd).

\section{Uphold the Agency of Africans}

The Bible must serve to motivate us, as Africans, to be actively involved in the process of development. There can never be real development when we are reduced to objects. We as Africans must drive the agenda and process of development. Anything else is underdevelopment! Interpretations of the Bible that invite and inspire Africans to recognise our agency in development must be generated, popularised and promoted. Further, the rights of the whole people of God (often characterised as "ordinary people" in scholarly parlance) must never be sacrificed at the altar of "development." There is a worrying trend where some "African Big Men," or strong rulers who stifle dissent, are allowed to get away with it because they are seen as promoting "development." Thus:

In 2013, four of the ten most important aid recipients in Africa - Ethiopia, Mozambique, Uganda and Rwanda - were ruled by one-party regimes that do not allow for democratic participation and criminalize political dissent. While bilateral and multilateral donors constantly claim to be promoting democracy, good governance and human rights in Africa, many are effectively complicit in fostering development without democracy. The recent revival of the complicity between foreign aid and authoritarianism in the name of 'development' is not only problematic, but also went largely unnoticed by both academics and the broader public (Hagmann \& Reyntjens 2016:1). 
Below, I shall return to the theme of aid alluded to in the citation above. The key point I wish to underscore from the quote above is that there is a growing acceptance and tolerance of dictators, as long as they claim to be delivering "development" to "their people." This is effectively nothing more than a guarantee to protect the loot of their western partners. Dictatorship only becomes bad when it threatens the loot of the western looters of African resources. This is unacceptable, as there should never be any acceptance of dictators simply on the basis that they are "accelerating development." Of course, critics point to China's remarkable economic development that was not accompanied by democracy. It is important to appreciate that the Chinese system has its own checks and balances. However, this should not be used to justify denying full rights and participation in development to the whole people of God. Therefore, readings of the Bible that are liberating must ensure that the agency of Africans is upheld.

Narratives that emphasise the agency of individuals and communities in their release and liberation abound in the Bible. Such stories must be read to promote our role as Africans in working for Africa's development. For example, the narrative of the raising of Lazarus (John 11:1-44) can be read in ways that celebrate the role of the community in bringing individuals back to full life. Such a reading has been undertaken by Katongole (2012) in a brilliant and motivating way. Another example would be the healing of Bartimaeus (Mark 10:46-52). Whereas many would have expected Jesus to simply proceed with the miracle, he asks a preliminary, but critical question, namely, "What do you want me to do for you?" (Mark 10:51). If development workers would take such an approach, we as African citizens would be participating actively in our own development.

\section{Eliminate Dependency}

Often, development theorists give the impression that Africa's salvation shall come from external sources or players. They create and sustain the idea that Africa is not capable of initiating and implementing effective development programmes. It is assumed that Africa must continue to receive aid in order for the continent to escape poverty. Critics of aid (for example, Moyo 2009) are right in insisting that the continent will not develop through trinkets from the global North. Neither will African development be authored by Euro-American pop stars, although their solidarity 
is appreciated. As liberation theologians have insisted, no liberation takes place without the active participation of the oppressed!

Liberating readings that promote African development must equip us as African citizens to challenge dependency. African liberation theologians have been insistent that the Bible should not be used to placate us as Africans from demanding what is rightfully ours. The Bible should not give us a false sense of security or lull us into complacency. Neither should it sponsor fatalism and make us see the "will of God" too readily. It is not the will of God that many young people in Africa are feeling abandoned and have the conviction that they have had their future stolen in advance. It is not the will of God that many politicians in Africa enrich themselves and their cronies at our expense as citizens. It is also not the will of God that some governments prioritise status symbols instead of meeting our basic needs as citizens. Neither is it the will of God that some African elites collude with global financial institutions and other looters to plunder African resources. African liberation theology is forceful in its conviction that we as Africans must be vigilant in the face of such exploitation, now being sustained through the false celebration of globalization. Thus:

African theology of liberation is called, daily, to reflect on the fact that Africa's economic poverty and the concomitant powerlessness are not just "home-grown." There are international players whose actions are more subtle than the local immediate agents of poverty, human degradation and squalor. Whereas neo-colonialism replaced the departing colonial powers in the grand scheme of exploiting Africa's raw material and human resources, globalization is the "new kid on the block" on this economic power game (Gichaara 2005:81).

The Bible must be read in ways that inspire us as Africans to find internal solutions to our challenges, including those brought about by outsiders. To say this is not to impose a moratorium on the outside world. Yes, solidarity with all people of goodwill is good for Africa and Africans. Indeed, support from progressive individuals, organisations and states is most welcome. However, this should not in any way be thought of as replacing the urgency and agency of ourselves as Africans working for our own development. Therefore, it is important to mobilise the Bible to empower us as Africans to shun dependence, to "rise up and walk" and to own the process of development. In particular, there must be emphasis on approaching the whole issue of development afresh. There must be an abiding confidence in ourselves as Africans to have the capacity to propel our own development. Kwame Nkrumah, Ghana's founding father and Pan- 
Africanist, had a powerful and memorable expression. Thus, "We face neither east nor west, we face forward" (Essel 2014:49).

Reading the narrative in John 5:1-9, the story of the man who needed healing and took a strategic position by the pool of Bethesda, can be a very empowering undertaking. The man was "so near, yet so far." Similarly, we as Africans have our resources right within our grasp, but we struggle to access them and put them to maximum use. ${ }^{1}$ Reflecting on such passages can equip us as Africans to recognise that our breakthrough is quite close by. Speckman (2007:16) gives the example of Zimbabwe. The initial investment in education implies that the country has a well-developed human resource base. What is required in such contexts is to ensure that the right opportunities are availed to citizens and the nation will surge ahead. President Paul Kagame of Rwanda has rightly argued that we, as Africans, must re-engineer our perspectives in order to get rid of the dependency syndrome. He contends that we do not need to ask for assistance from anyone, as our continent is very well resourced. According to him:

...we need to mobilise the right mindsets, rather than more funding. After all, in Africa, we have everything we need, in real terms. Whatever is lacking, we have the means to acquire. And yet, we remain mentally married to the idea that nothing can get moving, without external finance. We are even begging for things we already have. That is absolutely a failure of mindset (Kagame 2018).

\section{Be Sensitive to Women's Experiences and Needs}

Without responding to women's experiences and needs, there can be no development. In Africa, the Circle of Concerned African Women Theologians (the Circle) has been consistent in demanding that women's rights be upheld in church/religion and society. They have called for "other ways of reading" (Dube 2001). "Development" that relegates African women to where they have always been, namely, at the bottom of the pile, is a contradiction in terms. Meaningful and transforming development only occurs when women have their lives improved. To say this, however, is not to suggest that women are objects, not subjects, of development in Africa. The status of women in Africa's development has generated a lot of scholarly attention. It requires several studies to do justice to this theme. For

1 I am indebted to Mai Olivia Charamba, a Zimbabwean gospel musician, for insights regarding the relationship between the man at the pool at Bethesda and Africa. 
the purposes of this chapter, I would like to draw attention to the fact that most studies on development undervalue the contribution of women. The prevailing gender ideologies have had the unfortunate effect of projecting African women as belonging to a rung lower than that occupied by men. This is a result of colonialism which served to make gender differences more rigid. Thus:

What colonial officials seemed not to have been aware of was the fluid state of gender relations, and the political, economic and social opportunities that women had had in the pre-colonial era. African chiefs and elders, unsettled by the changing political dispensation under colonial rule, and a colonial migrant economy that privileged young men, used the codification of customary law to cement as tradition their ideal resolution to what was a contested situation. They reified African patriarchy, highlighted their control over women and juniors, and converted marriage transactions into cash to benefit from the new income of migrant young men (Akyeampong \& Fofack 2012:24).

Readings of the Bible that promote women's development must be premised on women's inherent human rights and dignity. Women are human. This appears fairly straightforward. However, it is not always upheld in daily interactions. Patriarchy often reduces women to second rate citizens, while granting full citizenship to those of us who, by dint of a biological accident, happen to be males. For development to be meaningful in Africa, it must bring means to African women.

Across the various regions of the continent, the Circle has called upon the church/religion to bring good news to women. This implies critiquing patriarchy and its attendant evils (violence in all its forms, corruption, wastefulness, etc.). Further, it also suggests reading the Bible for women's advancement and flourishing. For example, writing from within South Africa, Nzimande (2009), proposes an Imbokodo (grinding stone) reading of the Bible in order to promote black women's emancipation in the various areas of life. Kiruki (2010) also calls for a "paradigm shift for development" when reflecting on women's liberation.

\section{Inspire Effective Leadership}

Africa's crisis, as many critics have rightly noted, is a crisis of leadership. We have had the misfortune of having too many rulers. Commande/ers. Rulers. Looters. Short-sighted despots who have invested in disinheriting their citizens. For every one Nelson Mandela, we have had scores of Mobutu Sese Sekos. For every Thomas Sankara, we have had multiple Yahya 
Jamehs. Jameh's official title was: His Excellency Sheikh Professor Alhaji Dr. Yahya Abdul-Aziz Awal Jemus Junkung Jammeh Naasiru Deen Babili Mansa. He was Commander in Chief of The Armed Forces and ChiefCustodian of the Sacred Constitution of the Gambia. On the one hand, one wants to simply laugh and marvel at the creativity of it all. On the other hand, one realises that this is no laughing matter! The quality of leaders has a very direct bearing on the quality of our lives as citizens. Inspired leadership will propel Africa's development, poor leadership will deepen poverty. There is need for more investment into reflections on leadership in postcolonial Africa (Jallow 2014).

The Bible must be read in Africa in ways that inspire a new cadre of leader(s). Kwame Bediako (1995) proposed readings of the Bible that desacralise political leaders in Africa. There is an urgent need of reading the Bible in order to promote compassionate and responsible leaders. The Bible itself has many lessons for leadership (Woolfe 2002) that contemporary African leaders at all levels could utilise in order to promote development. Effective leaders who embrace leadership principles inspired by the Bible are able to take our continent to the next level. Of course, they must be competent to operate in multi-religious contexts.

\section{Influence Critical Followership ${ }^{1}$}

Perhaps we have tended to place all the responsibility for development on leaders in Africa. It is becoming clear that our quality as followers must be transformed as a matter of urgency. We have tended to give our leaders a blank cheque. We ululate when they pronounce nonsensical policies. We lionise them when they make high sounding declarations. We worship them when they remind us of their revolutionary spirit. Oh, we even deify them when they invoke their sacred origins! Responsible readings of the Bible must equip us citizens to become critical followers who demand to be led in life giving ways.

The Bible can arm us as African citizens to demand more from our leaders and to make them more accountable. Readers of the Bible can be emboldened by calls to responsibility, stewardship, accountability, justice and other key concepts that run throughout the text. Naïve followership is a recipe for disaster. Critical followership is critical for development to take

1 I am indebted to Rev Dr Kenneth Mtata for the concept of critical followership. 
place (Jowah 2015). At any rate, even the so-called non-leaders are leaders in their own right. Therefore, we should challenge political leaders when they fail to deliver on their development promises.

\section{Challenge Fanciful Interpretations}

One of the biggest challenges regarding the role of the Bible in Africa has been the increase in fanciful interpretations of this particular sacred text. Such readings of the Bible suggest that development is only one strong and determined declaration away. They approach the Bible as a mystical and magical document that can be summoned to avail development. Sadly, there are no short cuts to development. No chanting will suffice. No breaking of curses will be adequate. Ideological rantings by populist politicians will not usher development in Africa. Painfully, not even this chapter on its own will facilitate development on our continent. It will take strategy, painstaking planning, shrewd calculating and even cunning (Maregere 2018). Very hard work is non-negotiable. No continent in the world has developed through some mysterious means. We, as Africans, will not be able to develop without investing in the process in meticulous and shrewd ways.

The Bible should not become a fetish that is appealed to in order to provide miracles for the development of Africa. It is, therefore, paramount that interpretations of the Bible must not be fanciful but be deeply realistic. No magic wand will propel Africa forward. Our development as Africans will depend to a very large extent on the quality of our planning and execution. As powerful as the Bible is, we should not hide behind it. Neither must we ask God to do that which we must accomplish. Therefore, in order for the Bible to contribute towards development in Africa, we should resist and challenge all fanciful interpretations of the same.

\section{Promote Sustainability}

Interpretations of the Bible must promote sustainability. Versions of "development" that take over wetlands for constructing high rise buildings in urban areas, or that necessitates the indiscriminate cutting down of trees must be resisted. The World Council of Churches (WCC) Assembly in Nairobi in 1975 drew attention to the urgency of sustainable development. The WCC has been insistent that development must be pursued in a sustainable way, otherwise it is not worthwhile (Marava 2015). Therefore, it 
is critical that interpretations of the Bible must prioritise sustainable development in Africa. As Thebe (2015:6) rightly observes, "The Bible contains plenty of contexts that can inspire a person to act in accordance to sustainability which the global world is aiming for."

How can Bible reading promote sustainable development in Africa? Principally, this can be achieved through emphasising inter-generational responsibility, challenging over-consumption, promoting good stewardship and caring for neighbours. All these ideas and concepts are found in the Bible and need to be underscored in African contexts. Naseri and Basey (2017) have demonstrated the need to approach the Bible from the perspective of eco-theology in order to promote sustainable development in Africa. Thus, the emerging work in African eco-theology can contribute towards this noble goal (see, among others, Okyere 2011).

\section{Read in Community}

Contextual Bible Study (CBS) has demonstrated to be a very powerful methodology for consciousness-raising and community transformation. It has been used effectively in South Africa (West 1993) and the WCC in diverse settings to address sexual and gender-based violence, HIV/AIDS and other challenges. I am persuaded that CBS must be embraced in order to promote readings that will facilitate development in Africa. The CBS methodology challenges readers to engage with the Bible in a critical way in order to identify oppression and formulate strategies for liberation. The methodology enables communities to read the Bible together and generate action plans for community transformation.

Utilising the CBS methodology will enable readers of the Bible in Africa (and elsewhere) to avoid the fanciful interpretations referred to in the previous section. The CBS methodology enables readers to be in dialogue with others, raise difficult questions relating to systems of oppression, as well as reasons why development efforts are being stifled in different African contexts. At the same time, the methodology facilitates practical action at the level of the community. Essentially, CBS has the potential to be subversive in a positive way. Hard questions regarding corruption, inefficiency, limitations of aid and other issues relating to development can be posed in a safe environment (see for example, KwaZulu-Natal Christian Council Consortium 2015). Members of the community are then mobilised to promote development. 


\section{Conclusion}

Is the Bible a weapon of mass destruction or a weapon of mass salvation in Africa? Can the Bible inspire development in Africa? If the Bible has an ambivalent position in Africa's quest for development, can we formulate some considerations or principles that could safeguard it from abuse? In this chapter, I have wrestled with these questions and have proffered some suggestions that could assist in having liberative readings of the Bible in Africa. As we scour the Bible in our devotions, CBS sessions, in lament and thanksgiving, we should remain alive to its potential as a veritable resource in our development as Africans.

\section{Bibliography}

Adamo, David T. 2016, "African Biblical Studies: Illusions, Realities and Challenges," die Skriflig 50(1), a1972. http://dx. doi.org/10. 4102/ ids. v50i1. 1972.

Adum, Allen N. et al. 2015. "Towards Media of Africa by Africans and for Africans," Mgbakoigba, Journal of African Studies 5(1), 1-9.

African Union. 2015. Agenda 2063: The Africa We Want. The Popular Version. Addis Ababa: The African Union.

Akyeampong, Emmanuel \& Hippolyte Fofack. 2012. “The Contribution of African Women to Economic Growth and Development: Historical Perspectives and Policy Implications Part I: The Pre-colonial and Colonial Periods," Policy Research Working Paper 6051, The World Bank, Poverty Reduction and Economic Management Network, Gender and Development Unit.

Alden, Chris \& Ana C. Alaves. 2009. China and Africa's Natural Resources: The Challenges and Implications for Development and Governance. Occasional Paper No. 41. Johannesburg: South African Institute of International Affairs.

Asafa, Jalata. 2015. "The Triple Causes of African Underdevelopment: Colonial Capitalism, State Terrorism and Racism," International Journal of Sociology and Anthropology 7(3), 75-91.

Bediako, Kwame. 1995. Christianity in Africa: The Renewal of a Non-Western Religion. Edinburgh: Edinburgh Univ. Pr.

Cezula, Ntozakhe. 2015. "Reading the Bible in the African Context: Assessing Africa's Love Affair with the Prosperity Gospel," Stellenbosch Theol. Journal 1(2), 131-153.

Dada, Adekunle. 2010. "Repositioning Contextual Biblical Hermeneutics in Africa Towards Holistic Empowerment,” Black Theology 8(2), 160-174.

Dube, Musa W. 2001. Ed., Other Ways of Reading: African Women a the Bible. Geneva: World Council of Churches.

Dube, Musa W., Andrew M. Mbuvi \& Dora R. Mbuwayesango. 2012. Eds., Postcolonial Perspectives in African Biblical Interpretation. Atlanta: Society of Biblical Literature.

Essel, Osuanyi Q. 2014. "Nkrumaism in Sculptural Archetypes of Nkrumah," Arts and Design Studies 17, 45-57. 
Gichaara, J. 2005. “Issues in African Liberation Theology,” Black Theology 3(1), 75-85.

Gunda, Masiiwa R. 2015. On the Public Role of the Bible in Zimbabwe: Unpacking

Banana's "Re-writing" Call for a Socially and Contextually Relevant Biblical Studies.

BiAS - Bible in Africa Studies 18. Bamberg: UBP

Hagmann, Tobias \& Filip Reyntjens. 2016. "Introduction: Aid and Authoritarianism in

Sub-Saharan Africa," in Tobias Hagmann \& Filip Reyntjens, eds., Aid and

Authoritarianism in Africa: Development without Democracy. London: Zed Books.

Hiagbe, Komi A. 2015. "The Church and Sustainable Development in Sub-Saharan

Africa," Studia Historiae Ecclesiasticae 41(2), 164-179.

Imathiu, G. R. 2001. "Reading between the lines: Power, Representation and Luke's Acts," in Nyambura J Njoroge \& Musa W Dube, eds., Talitha Cum! Theologies of African Women. Pietermaritzburg: Cluster.

Jallow, Baba G. 2014. Ed., Leadership in Postcolonial Africa: Trends Transformed by Independence. New York: Palgrave Macmillan.

Jowah, L. E. 2015. "Implicit Theory; The Cognitive Prototypes that Inform Followership - Impacts on Leadership Style," International Journal of Research in Economics and Business Management 4(1), 40-47.

Kagame, Paul. 2018. 'Remarks by President Kagame at the African Leadership Summit. ' 02 Aug., Kigali. Available at http://paulkagame.com/?p=13180 acc. 10 Aug. 2018.

Kakwata, Frederick. 2017. “The Progressive Pentecostal Conception of Development within an African Context of Poverty," Stellenbosch Theological Journal 2017, Vol 3 , No 1, 159-183.

Katongole, Emmanuel. 2012. "The Raising of Lazarus and the Sites for African Theological Exploration and Engagement," in Ambrose John Bwangatto, ed., Africa is Not Destined to Die: Signs of Hope and Renewal. Nairobi: Paulines.

Kiruki, Joseph K. 2010. Women's Liberation: A Paradigm Shift for Development. Eldoret: AMECEA Gaba. - CUEA Pr.

KwaZulu-Natal Christian Council Consortium. 2015. Contextual Bible Studies on Religion and Governance. A Project of the Religion and Governance Programme at the School of Religion and Theology, Univ. of KwaZulu-Natal \& the KwaZuluNatal Christian Council Consortium. Pietermaritzburg: KZNCC. Available at http://kzncc.org.za/contextual-bible-studies-on-religion-and-governance-booklet acc. 08 March 2019.

Marava, J. Moyounotsva. 2015. "The Role of Church Leadership in Promoting Sustainable Development in Zimbabwe," International Open and Distance Learning Journal 3(1), 19-33.

Marongedze, R. 2018. 'Hutsuro in Diplomatic Negotiations: Evoking African Folklore for a Winning Praxis,' A Conference Presentation at $19^{\text {th }}$ Interim Conference of the African Languages Association of Southern Africa and 7th Intern. Conference on Bantu Languages, $9^{\text {th }}-11^{\text {th }}$ July 2018, held at The River Club, Mowbray, Cape Town.

Masoka, Angeline \& Zvinashe Mamvura. 2017. “African Philosophy of Development as Expressed in Shona Proverbs," International Journal of Arts \& Humanities 6(2), 28-40.

Mbuvi, Andrew M. 2017. "African Biblical Studies: An Introduction to an Emerging Discipline," Currents in Biblical Research 15(2), 149-178. 
Moyo, Dambisa. 2009. Dead Aid: Why Aid is Not Working and How There is a Better Way for Africa. London: Allen Lane.

Mugambi, Jesse N. K. 1992. Ed., Critiques of Christianity in African Literature: With Particular Reference to the East African Context. Nairobi: EAE Publ.

Naseri, Christopher \& Patrick Bassey. 2017. "Biblical Paradigms for the Sustainable Use and Management of Natural Resources in Nigeria: Interpreting John 6:1-15 from an Eco-Theological Perspective," Intern. Journal of African Catholicism 9(1), 166-189.

Ndyabahika, James. 2007. "Biblical Economy, Wealth and Poverty: A Challenge to the Great Lakes Region of East Africa,” McMaster Journal of Theology Q Ministry 8, 64-81.

Nzimande, Makhosazana K. 2009. "Reconfiguring Jezebel: A Postcolonial Imbokodo Reading of the Story of Naboth's Vineyard (I Kings 21: 1-16," in Hans de Wit \& Gerald O. West, eds., African and European Readers of the Bible in Dialogue: In Quest of a Shared Meaning. Pietermaritzburg: Cluster.

Okyere, Kojo. 2011. "Bible, Ecology and Sustainable Development: A Reading of Genesis 1: 1-2:4A," Ilorin Journal of Religious Studies 1(2), 81-96.

Sanders, Edith R. 1969. “The Hamitic Hypothesis; Its Origins and Functions in Time Perspective," Journal of African History 10(4), 521-532.

Speckman, McGlory. 2007. A Biblical Vision for Africa's Development? Pietermaritzburg: Cluster.

The Church of Scotland, Stewardship and Finance Department. nd., Stewardship Resource: Bible Studies on Stewardship. Edinburgh: The Church of Scotland.

Thebe, Laxmi P. 2015. 'Faith Resources and Sustainability: How do individual Christians utilize their faith resources to contribute towards sustainability? Thesis, Diaconia Univ. of Applied Sciences Degree Programme in Social Services Bachelor of Social Services (UAP) (+ Option in Diaconia), Finland.

Togarasei, Lovemore. 2008, "Fighting HIV \& AIDS with the Bible: Towards HIV \& AIDS Biblical Criticism," in Ezra Chitando (ed.), Mainstreaming HIV in Theology and Religious Studies: Experiences and Explorations. Geneva: WCC Publ.

Vengeyi, Obvious. 2014. "Land as an Inalienable Asset: Lessons from I Kings 21: 1-29," in Claude G. Mararike, ed., Land: An Empowerment Asset: The Human Factor Perspective. Harare: Univ. of Zimbabwe Publ.

West, Gerald O. 1993. Contextual Bible Study. Pietermaritzburg: Cluster.

West, Gerald. 2007. "Foreword," in M. T. Speckman, A Biblical Vision for Africa's Development. Pietermaritzburg: Cluster.

Woolfe, Lorin. 2002. The Bible on Leadership: From Moses to Matthew: Management Lessons for Contemporary Leaders. New York: AMACOM. 


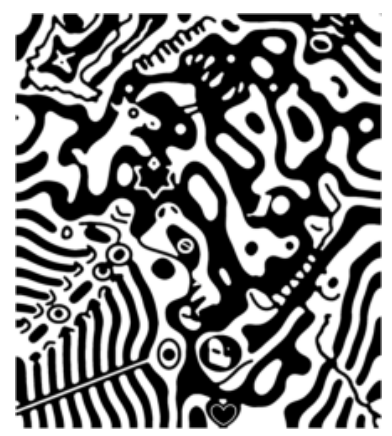




\title{
"Liberating the Word" - One African Feminist Reading of Matthew 23
}

\author{
Musa W. Dube
}

The Spaniard (colonizer) is like the male, the adult, the father, the human being; the Indian [the colonized] is like the female, the child, the son, the animal. The relationship that obtains between the two is one of domination: Wild beasts are domesticated and made subject to the rule of man... the man rules over the females. As a result, the inherent relationship among the colonial domination (Spanish/Indian), gender domination (male/female), generational domination (adult/child), and natural domination (human being/animal) becomes evident. Colonial domination is global in character and encompasses all dimensions of both the human being and nature. (Richard 1997:266)

\section{Introduction: Defining the Problem}

The title of this paper, "liberating the Word,"1 implies that the scripture is not free; it is under captivity or constraints to do its proper job. Biblical texts are assumed by communities that use them to be authoritative texts; godly texts that should guide human relations positively. The phrase liberating the word originating among biblical feminists, however, suggests two issues; first, it points to the inherent limitations of biblical scriptures (Russell 1985:137-146; Schüssler Fiorenza 1995:1-14). Second, it places an ethical call on the reader/interpreter to take responsibility for liberating the word. Commenting on the constraints of biblical scriptures, Mary Ann Tolbert points out that

"for Christian feminists, the question of the Bible's authority is notoriously troublesome because it has been appealed to so often as providing a divine mandate for second-class status within many church structures...this same claim of biblical authority was employed by many Euro-Americans... to justify as divinely ordained the despicable evil of racial slavery" (1999:141-142).

1 This title is borrowed from the book edited by L. Russell, which is a collection of essays that proposed a non-sexist interpretation of the bible by identifying gender-exclusive language as well as proposing some alternatives. 
Given the lack of neutrality of texts, Edward Said maintains that, "the critic is responsible to a degree for articulating those voices dominated, displaced or silenced by the textuality of texts" (1983:53), hence the title, "liberating the word. " For feminist readers this means that "the starting point of feminist criticism of the Bible is not the biblical texts in their own right, but the concerns of feminism as a worldview and a political enterprise" (Exum 1995:65). The biblical word, in other words, is not necessarily liberating to women.

As used in this article, the phrase liberating the word is applied to Matt 23 , a chapter where Jesus is portrayed as condemning the teachers of the law in harshest terms. Warren Carter explains and describes Matt 23 as a "very troublesome chapter," where "Jesus curses, or evokes judgment on the leaders (notable the scribes and Pharisees) ${ }^{1}$ for the societal order they administer as allies with the Jerusalem priesthood and Rome. The chapter has been falsely and hatefully read as cursing all Jews.... It reflects the pronounced post-70 hostility toward and conflict with synagogue leaders as allies of Rome's hierarchical societal order" (2007:91). It is this chapter's harsh note of condemnation that has attracted my interest, precisely because of my historical experience as an African Motswana woman, who was subjected to the same colonial Christian rhetoric. As said elsewhere:

I have related well to Matthew 23 and the "foolish Galatians" in Gal 3:1, not reading Galatians and Pharisees as static historical persons but as reference to all those who are not Christians. The rebuttal of the Pharisees in Matthew 23 has carried a painful fascination for me, for what I heard from this passage was not an old first-century story, but a familiar drama of nineteenthtwentieth century imperialist history upon non-Christian Africans (1997:11).

Unlike Carter, who reads Matt 23 as an anti-colonial rhetoric, I read it as colonizing rhetoric of suppressing the Other, since its ideology is highly dualistic and hierarchical, sanctioning the domination of the Other (Richard 1997:263-280). ${ }^{2}$ As I have argued elsewhere, while Matthew is sharply critical towards fellow Jewish groups in the post-70 CE destruction of the

1 See C. J. Roetzel,1985 for an elaborate discussion of Pharisees, their beliefs and practices. Their main pre-occupation included rites of cleanliness, interpretation of oral and written law, including the writings, wisdom and prophets.

2 See P. Richard, 263-282, elaborate description of how the ideology of binary opposition function as an instrument of domination and how they were applied by the empires in the domination of Latin America. His discussion covers a wide range of dualism such as Spanish/Indian, male female, adult/child, Father/son, Human being/Animal, soul/body, reason/passion, white/black, west/and the rest of us. 
temple, the Matthean group does not present an anti-colonial ideology towards Rome. Rather, the Matthean community competes with other Jewish groups for the attention of Rome and propounds a colonizing ideology that would later serve other empires (Dube 2000:127-144). It is one of the effects and strategies of colonialism to promote conflict and competition among the colonized, since division allows the colonizer to continue with domination (Ibid:50-51). The conflict in Matt 23, gives us a window into the splintered colonized Jewish nation, of the post Jewish-Roman war of 70 CE context, which created a power vacuum and an intense search for Jewish identity in the absence of its central symbol, the temple.

As an African Motswana woman, whose people were Christianized just over a century ago, the labelling and the condemnation of Pharisees sounds familiar and recalls similar tactics employed by missionaries on Africans. ${ }^{1}$ Missionaries unhesitatingly labelled Africans as "heathen," "savages," barbarians," illiterates," "rude"; they believed that Africans had "no religion at all" and if they perceived some religious practices, they were regarded as "entirely of the devil."2 As Muzorewa writes, "Missionaries saw the devil everywhere in Africa; they saw it as an empire of Satan" (1986:30). In their records, Africa was described as "where barbarity and cannibalism reigned undisturbed" (Oduyoye 1986:32-40). Consequently, a convert had to totally denounce his/her cultural background and adopt a new name, clothes, food, behavior, education and other new customs, most of which turned out to be more western culture than biblical Christianity (Muzorewa 1986:3). The labeling has had a lasting impact on both the converted and the unconverted. For example, in Botswana beauty is still closely associated with a light complexion, straight nose, and straight hair. The word Setswana, which means the language and culture of Botswana people, is often used with a new meaning to describe all that is negative, outdated, and archaic. Thus, one's hair can be described as "Setswana," meaning it is not straightened out with chemicals; a person can be described as "motho Setswana," meaning, one who is not civilized or backward, or one who does not make an effort to live in the European style.

1 Missionary reports and correspondence with their mother churches is full of this terminology. As used in this paper see G. H. Muzorewa, 23-34 and M. A. Oduyoye, 32-40.

2 This notion has lasted to this day, testified by the fact that in most departments and courses dealing with world religions exclude or have nothing to say about African religious traditions. 
Schooled in colonizing faith, "converts to Christianity despised their own cultures, preferring European customs. " The unconverted also began to believe in the superiority of western culture, especially because missionary preaching came at the same time as colonialism. This is attested in Words of Batswana: Letters to Mahoko a Becwana 1883-1896, which is a collection of letters written by Batswana to a London Missionary Society newspaper, Mahoko a Becwana. Under the section on cultural change where they discussed stories, legends, music, dance, funeral rites, bride price, sorghum beer, and agricultural and initiation rites, it is clear that these European groomed/educated Batswana, while putting up a vibrant resistance on most subjects, had also been colonially crafted (Mgadla \& Volz 2006:122-231). For example, Tshikedi Masegidi writing about the Setswana initiation of teenagers into adulthood on Aug. 30, 1891 says:

Doesn't it seem like people are more afraid of light than darkness? John says that the light shines in the darkness, but the darkness does not overcome it (John 1:5). This practice of initiation causes me pain. I hear children who had been taught in school have gone back to the vomit. They now tumble in the mud...This practice of initiation is still hurting me, and even today I dislike initiation rites with all my heart. I say God should strengthen the heart of the government to stop initiation rites immediately (Mgadla \& Volz 2006:230-1).

It has been argued that missionary activities were the worst form of colonialism because the former aimed at changing the minds of the colonized and shaping them according to the European thought. This process taught Africans to hate and despise themselves, because African cultures supposedly stood for all that is uncivilized and devilish. ${ }^{2}$ It is therefore notable that in the above quote, Masegidi, as a Motswana Christian convert, equates Setswana initiation schools with "vomit" and the act of tumbling in the mud. Using a biblical text, he equates Setswana initiation schools with "darkness." If one considers that initiation schools were the space

1 Ibid, 33, it is my belief that the notion has got imprisoned in most African thinking, crippling their own creativity and the potential of developing things that are relevant to their own cultural context. Instead Africa has become content to be on the receiving end of everything that is western, an attitude which endorses that the western things are superior.

2 Bishop D. Tutu in his paper, "Black Theology and African Theology: Soul mates or Antagonists," 46-58, argues that the denunciation of African personhood was the worst form of colonialization than foreign governments since it created low self-esteem amongst Africans. 
where Batswana children were formally instructed about Setswana cultures and their roles in the society as they become adults, the vomit and darkness labels then speak volumes. Studies on contemporary Pentecostal movements suggest that colonial Christian rhetoric of categorizing African cultures negatively and the internalization of negativity persists today. In his study of African Charismatics: Current Developments Within Indigenous Pentecostalism in Ghana, Kwabena Asamoah-Gyadu finds that:

Following the born-again experience, Ghanaian neo-Pentecostals generally come to view non-Christian religions as demonic. The attitude of CMs to non-Christian faiths and other religious traditions is a virtual extension of the attitude to African traditional religions. They are all considered instruments of Satan in blinding people from the truth about God's revelation in Christ... Christian exclusivism is used here to refer to the claim that Jesus is God's final revelation and that salvation is not available in anyone else (2005:144).

This approach of labeling and condemnation was not only applied to Africans. For example, in 1869 when the Church Missionary Society summarized their experience with various people they said:

We have gone around the world, we have seen the proud Brahman, the fanatical Mussulman, the self-satisfied Buddhist, the superstitious barbarian of Africa or the South Seas who seeks to appease the evil spirits; the highly educated Hindu and the ignorant black fellow of Australia; and we have found in two very deep senses there is no difference. All alike belong to the sinful and ruined family of man." 1

The colonial Christian missionary approach was characterized by condemnation of all that was unfamiliar and a celebration of European culture above all others. Kwok Pui Lan, a Chinese theologian, assessing this approach amongst her people, argues that labeling other cultures as "heathen" through the employment of the Bible became a, "western construction superimposed on other cultures, to show that western culture is the norm and superior" (1989:27). On these grounds, she finds a link between colonization and missionary activities of colonial times as tools of dominance. My argument, however, is that there was more to it than just the superiority of western culture amongst colonial missionaries. In short, it is my thesis that the missionary ideology of condemning the Other was also a scripturally informed strategy.

1 See M. A. Oduyoye, 33. It is notable that this condemnation is accompanied by the celebration of western culture as civilized and almost identifies it with Christianity. 
Drawing from my experience as a Motswana African woman and from the attestation of worldwide colonial missionary and contemporary Pentecostal archives in general, I question the legitimacy of condemning the Other. Why has the church and its servants on several occasions of history managed to live and participate with ease alongside such evils as slavery, colonialism, sexism, homophobia, anti-Semitism, and HIV\&AIDS stigma among many other oppressions? For colonial history, the belief in the superiority of western culture and lack of adequate training of colonial missionaries have been identified as some of the major causes behind the missionary approach. ${ }^{1}$ But these do not explain everything. The question still remains: why has the Bible lent itself to such interpretations and activities? Is it possible to view some of these major weaknesses of Christian witness to be inherent within its authoritative book? If so, how should one arrest the repetition of such tragic interpretations? With these questions and experiences, I will turn to Mathew 23 in an attempt to assess the forces at play in this passage. My attempt to re-read and arrest the ideology of the passage will be through interrogating and exposing the ideology propounded by the passage and the implication for Christian encounter with the Other. Lastly, I hope to suggest a possible re-reading of the passage, by falsifying some of its claims and through offering a counter scripture $^{2}$ that is, reading another scripture to counteract the ideology Matt 23. The passage of Matt 5:43-44, on loving one's enemies, shall be used for a counter reading.

\section{An African Feminist Liberationist Approach: A Definition}

The feminist perspective in my approach seeks to acknowledge the experience of being a woman, and of many other women theologians, which shall be brought to have a bearing on the passage under scrutiny. Female gender ushers another encounter with the ambiguous role of biblical tradition,

1 The attitude of sending inadequately trained missionaries was because some societies believed that 'men not fitted for English ordination might yet prove good missionaries to savages, rude and illiterate" See M. A. Oduyoye, 32 this attitude in itself tells tales of what the colonizing to the so-called mother churches thought of the nations they evangelized.

2 Feminist strategies of reading the oppressive passages are various. They include critiquing androcentric biblical texts, their interpretations and translations; recovering female images of God, reconstruction of the history of Israel and early Christian beginnings; marking some passages as dangerous and beyond re-reading and sometimes using to counter-passages or interpretations to counter passages that legitimate oppression. See J. C. Anderson, 1992:106-112. 
which over the centuries has lent itself to the oppression of women in the name of God (Ringe 1992:1-9). Yet, female gender encounters further oppression in colonially contested contexts that breed nativist or fundamentalist discourses. Nativist discourse is the strategy of the colonized as they turn to stringent keeping of their cultures as a form of resistance against the foreign invasion (Dube 2000:111-112). Fundamentalism, which characterizes resistance against contemporary globalization, is described as "modern political movements which use religion as a basis for their attempt to win or consolidate power and extend social control" (Sahgal \& Yuval-Davis 2003:43). In both cases women in colonized or affected areas become the site of the struggle for power, as the local/national patriarchal regimes resist foreign invasion, through cultural or religious observance. Hence Sahgal and Yuval-Davis point out that "fundamentalism can align itself with different political trends in countries. It can appear as a form of orthodoxy-a maintenance of traditional values - or as a revivalist radical phenomenon dismissing impure and corrupt forms of religion 'to return to original source" (46). In both these definitions, one can map and understand the $1^{\text {st }}$ century Jewish sects (Roetzel 1985:1-23).

While feminism has been understood as a political movement of women and men that seeks the human rights of the former, there are many forms and practices of feminisms across the globe. Speaking of feminist biblical critics, Anderson says they all "witness to the different forms and degrees of oppression in patriarchal religious institutions, the academy, and the society" (1992:105). "Feminist," in this article, is thus understood in a broad way; ${ }^{1}$ that is, it is concerned with the impact of the oppressive patriarchal and colonial perspectives that affect relationships in the earth community as a whole. This broad feminist approach includes paying attention to the social categories of race, class, ethnicity, dis/ability, sexual orientation, colonialism, globalization, militarism, and environmental degradation.

This broad understanding of feminism is adopted for two reasons. First, because, feminism recognizes that unless all forms of oppression are identified and arrested, oppression against women will remain vibrant in social and cultural systems and practices. Second, this broad definition of feminism as liberation of all is a reflection of historical journeys that women of various cultures have experienced in the struggles for liberation

1 Although most of the time the word feminist is merely understood to advocacy for women liberation, feminist literature indicate a wide approach that embraces all humanity and seeks to promote theories that will enable all to relate without exacting oppression and violence. This is attested by wide subjects covered by feminists such as ecology, militarism and promotion of peace movement, especially the work of R. R. Reuther. Even radical ones like Daly, their literature dream of full humanity for all. 
and national development strategies that are often male-centered while claiming to be liberative and inclusive (Dube 2000:111-115). That is, more often than not, liberation movements exclude/ed gender justice, leading feminist movements to develop one of the most comprehensive frameworks of liberation, which often seeks not to condone any form of oppression. Consequently, feminism today represents one of the most socially conscious and comprehensive liberation discourses. A comprehensive feminist liberation paradigm is particularly poignant for me as a Twothirds World woman because it addresses a number of oppressive forces confronting women of Two-Thirds World.

Feminist biblical critics have agreed that patriarchal culture underlines and permeates all of our biblical traditions, manifesting itself in the exaltation of androcentric perspectives and suppression of female presence or history (Exum 1995:65-70). Consequently, early biblical feminists tended to aim at re-interpreting those passages that are overtly sexist, highlighting the liberating passages and traditions, sometimes exposing irredeemably oppressive texts without attempting to re-read them (Collins 1985; Russsell 1985; Anderson 1992:105-110). Passages that do not directly refer to or feature women have not been adequately addressed. ${ }^{1}$ For example, within Matt 23, both feminist commentators of the Gospel of Matthew focused on Matt 23:34-38, which uses female imagery (Levine 1992:260; Wainwright 1995:657). The latest feminist theories call for practices that are more inclusive and liberative in the sense that they underline the interconnection of gender oppression with various other social categories such as race, ethnicity, class, colonialism, militarism, globalization, hence seek to understand liberative hermeneutics as the attempt to address all forms of oppression within the text and society (O'Brien Wicker et. al 2005; Schroer \& Bietenhard 2003).

The introduction has already indicated what constitutes my critical interpretation; namely, the background of being a black African woman, whose experience of biblical texts is intertwined with colonialism. This becomes the background which frames the questions that I bring to Matt 23. They are shaped by my historical and contemporary experience as an African, a woman, and a postcolonial subject. These are categories that expose me to multiple oppressions; that is, oppression on the basis of race, gender,

1 This is attested by the fact that feminist biblical scholars have hardly gone into criticizing individual books as a whole and there is hardly any, if there is one, feminist commentary on any biblical books, save those in the two edited volumes of feminist commentaries, which pretty much focused on passages that overtly deal with or feature women. 
class, colonialism, globalization, among many other factors. By virtue of being an African, my major concern and questions are closely related to the time and the way Christianity was introduced to my world; that is, in a colonial context and colonizing manner. The history of modern colonialism forms a major background to my reading of the gospel. My struggle is to understand the reasons why 'the gospel' comes as condemnation and as a helpmate of the oppressive powers of colonization. I seek to understand if it is yet another indication that the Bible is not a neutral book. If it is something inherent in the scriptures, the question is how to read in a way that arrests the colonial and colonizing ideology. With this background, my analysis of Matt 23 may be regarded as a feminist liberative approach, since feminism aims at building a holistic world by addressing all forms of oppression.

By using the phrase 'liberating the word,' in my title, this paper suggests that the supposed authority and goodness of the scripture cannot be taken for granted. Its capacity to liberate becomes the work of the reader to refuse to embrace whatever oppressive ideology that the scripture propounds and promotes. As Edward Said points out, "texts are fundamentally facts of power, not democratic exchange" (1983:45). Consequently, "the critic is responsible to a degree for articulating those voices dominated, displaced or silenced by the textuality of texts" (53).

\section{Analysis of the Text: A Social Historical Assessment}

Matt 23 is a unique creation of the author of the Gospel of Matthew, since it does not appear in its current form either in Mark or (apparently) in the Q-source, the two major sources for the author. As in the Sermon on the Mount, the author has employed various independent traditions with different settings and audience to create a coherent unit of speech with a certain thematic message. ${ }^{1}$ This unit of speech may be regarded as a rhetorical unit aimed at persuading the intended listeners or readers to adopt a certain understanding and perspective as well as reject others. Assum-

1 Matthew has taken Mark 12:36-38 to form Matthew 23:6-7a, Taken Matthew 20:20-28// (Mark 10:35-45) to create the "woes" from the Q-Source (Luke 11:37-53) and made other independent additions which added force of this point such as "blind guides," "hypocrites" and also his own conclusion. 
ing that this is a classical rhetorical unit, the passage shall now be dissected to identify various aspects that constitute it. ${ }^{1}$ This attempt is undertaken in order to identify Matt 23's intention as well as its author's way of bringing across the point.

\section{Matt 23: The Denunciation of Teachers of Law and the Pharisees}

- Speech Setting: Synagogue, crowds and disciples (v. 1)

- Introduction: Verses 1-12 covers negative and positive aspects of the thesis and specifies the reasons

- Thesis (Positive): The teachers of the law and Pharisees sit on the chair of Moses, so you must obey and do everything they tell you (vv. 1-3a)

- Thesis (Negative): But do not practice what they do (v. 3b)

- Reason: For they do not practice what they preach (v. 3c)

- Narration: (An elaboration of the practices of the teachers of the law and the Pharisees (vv. 4-7). They tie heavy burdens on people which they do not even try to lift (v. 4). They love high places and titles of honor (vv. 6-7)

- Exhortation: On the contrary they (the addressees) must not adopt titles of honor but must be servants and humble (vv. 8-12)

- Argument: An elaboration of the first thesis that lists seven "woes" unto the teachers of the law and the Pharisees to emphasize why their practices should not be adopted. This forms the major part of the argument. Each "woe" is a condemnation followed by a supportive point or example displaying the evil attributes of the accused (vv. 13-32). In some of the woes, analogies have been used to strengthen the points (vv. 23-28)

- Conclusion: Judgment upon the accused pronounced, "how will you escape being condemned to hell...so upon you will come the blood of all the righteous that has been shed on earth...all this will come upon this generation" (vv. 3-36)

Although I am assuming that the standard unit of a classical rhetor can be discerned B. L Mack, 1990, 93-102, has observed that Christian writers diverted from the standard norm; adding more analogies, with little or no historical examples to cite, with authority being frequently centralized on Christ, often highly polemical and addressed to two audiences at the same time. These observations apply to Matthew 23. 
- Pathos/Affection: “Jerusalem, Jerusalem...how often I have longed to gather your children together, as a hen gathers her chicks under her wings, but you were not willing? Look your house is left desolate" (vv. 37-39)

- Citation: "You will not see me again until you say blessed is he who comes in the name of the Lord" (v. 39; Psa. 118:26). ${ }^{1}$

\section{The Audience of Matt 23}

The audience of Mathew 23 and the place of women demands attention. The above analysis indicates the speech was directed to the disciples and the crowds (v. 1) which would include both men and women of the Matthean community. However, this audience is maintained only in the first 12 verses of the chapter. From the beginning of the first woe (v. 13) to the end of the speech and chapter (v. 39) there is a change of focus and audience. Jesus lays attack on the scribes and the Pharisees (who would be largely Jewish males of middle to upper class, since Jewish women were excluded from learning and teaching the law (Roetzel 1985:28). The speech begins to address teachers of law directly: "woe to you," as if they are present and listening to him. ${ }^{2}$ The speech shifts to address "this generation" (v. 36) then "Jerusalem" (v. 37) and "to your children who have been left desolate" (v. 38). Her house has been left desolate and she will not escape judgment. With this note, Jesus ends his condemnation and leaves the temple, for the very last time, predicting its destruction (24:12). Yet the Matthean writer, whose date of authorship is generally placed between 85-90 CE (Riches 2007:1-8), captures the past rather than the future: Jerusalem, the seat of religious leaders, had already been destroyed by Rome in the 66-70 CE Roman-Jewish war. ${ }^{3}$ Both the Matthean community and the teachers of law were colonized by the Roman Empire, and

1 See B. L. Mack, 1990, 47-48. The rhetorical structure used to analyze this passage follows the standard form of the classical judicial speech unit which was used to accommodate other types of the speeches. Mack warns that the pattern was never followed rigidly.

2 Luke's woes were directly addressed to the Pharisees and the teachers of the law in their presence. Thus one may surmise that by maintaining the direct person pronoun, Matt may have been keeping the original form of these woes, most probably because they served his own purposes.

3 It is Matthew's intention to show even though Jesus was sent to the lost sheep of Israel, 15:24 they rejected him, 21:43-45, 27:23-25 and ultimately the Gospel was sent to the nations, 28:19-20. 
their conflict is related to the destruction of the temple, the identity crisis and the struggle for power it created.

The first audience, that is, the crowds or disciples, seem to disappear or get pushed aside as Jesus begins to address the scribes and the Pharisees. It has been recognized that this passage serves as a climax of the conflicts that Jesus constantly has with the religious leaders, which eventually culminates in his death (Kingsbury 1986:116). Simultaneously, most scholars agree that this passage is pedagogical; that is, it is a teaching to the community of Matthew, who are being persuaded to adopt certain attitudes and practices as well as being dissuaded from other practices. ${ }^{1}$ As such, while the audience seems to shift, the discourse remains directed to the Matthean community (the disciples and crowds), painting the teachers of law negatively, to persuade the community to distance themselves from the scribes and the Pharisees.

The manner of persuasion and dissuasion uses a dualistic and hierarchical framework. The latter propounds an ideology of suppression and domination of the Other. Its strategy is unacceptable as well as dangerous for the world, if readers/believers continue to practice the same type of rhetoric in their communities. ${ }^{2}$ That is, while historically the victims of this rhetoric were Pharisees, in colonial times it was the colonized; in the Pentecostal age it is still the Other, who is non-Christian; and in gender relations the women are always the victims of this ideology, which will continue to function as a tool of suppression and domination, wherever differences are encountered for suppression. But the substance of my stand towards the ideology of Matt 23 needs to be backed up by an analysis of the historical-social dynamics that prevailed in the Matthean community, which finally led to the rhetoric of the woes and judgment on the scribes and Pharisees, then the leaders of Israel.

1 D. E. Garland, $40 \& 62-3$, he regards inclusion of crowds as a deliberate move to warn them against their misleading leaders and to give them a chance to choice correctly. Ultimately it is shown that they sided with their leaders against Jesus, 27:23-26.

2 See Kingsbury 1986:115. His analysis of the story of Matthew shows that Matthew story world is dualistic, squarely build on those who think the things of God and those who think the human things. He shows that Matthew has categorized the religious leaders as a flat character, all of them thinking the human things. In Matthew 23, this major fault of the author says they do everything for men to see, v. 5. Kingsbury points out that "the picture the reader gets of the religious leaders in Matthew story is not historically objective but wholly negative and polemical." 


\section{Matt 23: A Social-Historical Reconstruction}

At this point, my aim is to attempt to reconstruct from the passage, and other supporting evidence, what is going on in the world of Matt 23. The most obvious fact is conflict between the Matthean community, the scribes and Pharisees. In verse 1 the author enjoins his audience to "obey them" and "do everything" that the Pharisees tell them. The reason for obedience is provided: because the latter "sit in Moses' seat" (v. 3). This is the only positive aspect that the author attributes to them. The acknowledgment reflects the position of authority held by Pharisees and scribes, which Matthew's community must observe. This is imperative to Matthew's community, who viewed the law as valid (5:17-19).

Other verses, such as vv. 4-7 and 13, also indicate that the Pharisees and the scribes held significant authority, for they could supposedly put burdens on other people's shoulders, be offered honourable seats in banquets and synagogues, be called rabbi and greeted in the public, and they could, alleges the narrator, actually shut the kingdom of heaven in people's faces. All these attest that they must have held very influential positions in the society, to the extent that even Matthew's community had no choice but to acknowledge their role and the validity of what they say (vv. 2-3). Simultaneously, the passage indicates that the Matthean community had also suffered at the hands of Pharisees. Verse 34, which reads, "Behold I am sending you prophets and wise men and teachers. Some of them you will kill and crucify; others you will flog in your synagogues and pursue from town to town," indicates conflict that actually extended to persecution. Most scholars agree that this verse is anachronistic, projecting what the missionary activities of the Matthean community had come up against or even what was still persisting back into the lifetime and prophecies of Jesus (Mackenzie 1968:103).

The passage suggests that the Matthean community had to acknowledge the influence of their counterparts and to live with the unpleasant power struggle. Indeed, the first chapters of the gospel of Matthew indicate that there is competition between his community and the teachers of the law. Matt 5:20 says, "Unless your righteousness surpasses that of scribes and the Pharisees, you will certainly not enter the kingdom of heaven." This verse suggests that the Matthean community found the scribes and Pharisees a force to be reckoned with. The Matthean community measured and saw themselves over and against the Pharisees and scribes. Also, in this verse, there is an appreciation of their strength, albeit accompanied 
by a degree of disqualification, suggesting that their holiness is not sufficient and should be surpassed. A spirit of competition is evident, but undoubtedly the Matthean community was subjected to persecution $(5: 11)$, while their rivals were in power and control (23:3).

In Matt 23, the appreciation of the Pharisees' and scribes' authority is thus accompanied by an outright condemnation. The Matthean community must take all their teaching, but must not do what they do, because they do not practice what they preach (v. 3). The basic and most consistent charge that the author lays on his antagonists is that of "hypocrisy" (vv. 35). In all the woes (vv. 13-29) the writer's main intention is to demonstrate the group's pretence, which misleads those under their leadership. Matthew labels them "blind guides" (vv. 16 \& 24); "blind Pharisees" (v. 25) and "whitewashed tombs, which look beautiful but inside are full of dead men's bones and everything unclean" (v. 27). The passage characterizes them as "full of hypocrisy and wickedness" (v. 28). Turning to direct speech the narrative asks: "You snakes! You brood of vipers! how will you escape the condemnation?" (v. 33), suggesting that their condemnation is inevitable. The use of the adjectives "blind" to disparage the teachers of law highlights that Matthean dualistic and hierarchical ideology sanctions the oppression of people with disability (Avalos, et. al. 2007), while the use of the adjective 'snakes and vipers' highlight an anthropocentric ideology (Habel 2000:45), which sanctions environmental subjugation as well. Indeed, colonizing ideologies sanction the oppression of the earth, which is often linked to the oppression of women (Lewis \& Mills 2003:613-738).

Nonetheless, even with this outright condemnation, Matt 23's argument displays inherent self-contradictions. The main accusation is that of lack of correct practice; namely, hypocrisy. Yet verses that follow eloquently attest to faith-based practice: Verse 5 indicates that Pharisees and the teachers of the law wear phylacteries and tassels-an act of keeping up with their devotion. ${ }^{1}$ Verse 15 suggests that they are capable of traveling over the land and the sea just for the sake of winning a convert. Verse 23 indicates that they have rigorous practice of tithing. Verse 25 indicates that Pharisees and scribes observe rituals and they take care of the tombs of their religious figures. Almost every verse testifies to the practical side of their religious life. It is the Matthean author who disqualifies each of their

1 If the author acknowledges that they sit in the seat of Moses, which gives them responsibility of teaching the law, the fact that they carried wide phylacteries and tassels may just have been the demands of their work than a show off. 
practices as misguided and wrong, but it certainly does not tally with his categorical declaration that "they do not practice what they preach."

Verses 8-12 are very important because the ideal is put up in order to reject religious leaders. ${ }^{1}$ Here again one encounters competition between the Matthean community and the teachers of the law. The author wants the Matthean community to distance themselves from them. The honorific titles of "rabbi," "father," and "teacher" are not to be accepted amongst them; rather, the greatest among them is to be a servant. ${ }^{2}$ The stated titles among the teachers were gender exclusive, held only by men. Although Matthew seems to be strongly advocating an egalitarian community, on the contrary, his community had scribes (13:51-52) who were "heads of the household," "prophets," "wise men," and "teachers" (23:34). They were most probably male and involved in missionary activities. It is not clear, nor is there textual evidence, if the women of Matthean community could become prophets, teachers, and respected wise persons. In fact, the gospel also ends with the eleven of the twelve male disciples being commissioned to be teachers of the word amongst nations (28:16-20). Peter, like the Pharisees of 23:13, has a massive position of power, but we do not have a female equivalent. In this gospel alone, Peter is given the keys of the kingdom of heaven and whatever he binds on earth would be bound in heaven and whatever he loses on earth would be loosed in heaven (16:19). This is a position that exalts him well above others although, like the teachers of law, he is not perfect, since immediately afterwards Jesus addresses him as "Satan" (v. 23). Matthew's denial of positions of social status within his community seems to be hypocritical and a desperate attempt to discredit the scribes and the Pharisees as well as to distance his community, as much as possible, from the teachers of law. ${ }^{3}$ It is also a reflection of a process of social formation and self-definition for a small,

1 I call it ideal because Matthew's community had several positions and it was not egalitarian as I shall show later.

2 E. S. Fiorenza, 1983, 149, celebrates the rejection of titles as total rejection of patriarchy, especially the rejection of the title "father" as representative of patriarchal institution. This interpretation overlooks the intensely dualistic and hierarchical patriarchal ideology that is at work in this passage. One cannot make some feminists reclaim of Matt 23 without sufficiently dealing with the oppressive ideology of suppression and domination.

3 This is seen as a formative period when the Christian community needed to define its distinctiveness. J. A. Overman argues that since Matthew's community had a high appreciation of the Jewish law, some of its members could have easily adopted the titles of Jewish religious leaders especially is the practiced the same functions. 
emerging group in confrontation with a bigger and stronger group. Matt 23 is a reflection of a constant conflict, competition, and a fight for power and control as well as persecution. Matthew's community is not totally independent of their rivals (vv. 2-3), although they are independent enough to define their own positions. His community suffered at the hands of their rivals $(5: 11$ and 23:34) but they are not giving up the right to define themselves.

The contradictions within the passage testify to the concrete historical situations under which the Matthean community thrived. Consequently, the post-70 CE context has been identified as the background of Matthew's gospel by Matthean scholarship (Riches 2007:1-8). The Pharisees, among other Jewish sects, had always capitalized on learning and practicing the law; hence they emerged as the most influential group after the destruction of the temple, which created a power vacuum and rendered the temple-centred priests obsolete (Roetzel 1985:24-34). All Jewish groups were under the oppressive rule of the Roman Empire. The Jewish Christians of Matthew's community who were probably, "living in close proximity to a strong Jewish community" and were themselves largely made up of a Jewish congregation and found the scribes and Pharisees to be their prime rivals in the Judaism of their times. "1 For any group to assert its legitimacy it had to prove its proper understanding of the law. Clearly, Matthew's rivals had an upper hand, since they sat on Moses' seat, to the extent that the author even encourages his community to do everything they say (23:2-3). However, the power struggle is still evident in the passage in the sense that Matthew's community has not completely accepted the authority of their rivals (23:3b). Consequently, Overman maintains that at "many points, his gospel directly addresses the struggles within his community."

Therefore, what comes to us as a biblical gospel, and authoritative scripture, is peppered by Matthew's strategies of survival. Matthew was not writing as a disinterested individual but was mostly conditioned by the prevailing power struggles in his times (Overman 1990:123). He adopts a strategy of disqualifying his rivals through a series of "woes" which denote them as hypocrites, who are full of evil yet projecting a faked holiness. The

1 See Kingsbury 1986:154. This strong appreciation of Jewish customs also attests to this fact.

2 Often the dominant classes wrote history to support the status quo, but in Matthew we have the case to the contrary, where the author writes in order to discredit the larger group. 
word "woe" could denote an exclamation or express a sorrowful expression of pity in the face of an impending doom. ${ }^{1}$ Some examples are in Matt 18:7, 24:19, 26:24. In all these cases, the woes are general and impersonal. The identity of the victim is not specified; neither is judgment passed. However, "woe" could also be used as a threat, which not only announces doom, "but consciously endorses and promotes it" (Garland 1979:73). When used in this way, it closely approximates a curse on the accused, as in the examples of Matt 23:13ff and 11:20-24. The harsh, curse form is usually direct, specifies the identity of the accused and the reasons for accusation and pronounces judgment upon them.

The context and the tone of Matt 23's woes categorize them as a condemnation or a curse upon the Pharisees and the scribes. The accused, by the end of the passage, are also projected as pronouncing curses upon themselves (27:23-25). It is my contention that this rhetoric of subjection and domination which Matthew applies to his rivals remains potent to this day, whenever and wherever the text is used by believers upon those who they regard as their rivals or enemies. Some of the consequences of these woes manifest themselves in such historical events as western Christian colonialism and the discourse of slavery, savagery, Orientalism, and the holocaust. It continues today in the Pentecostal movements, which more often than not place local cultures in the same categories applied by colonial Christianity (Asamoah-Gyadu 2005:144-147). The function and ideology of such texts remain problematic.

Kingsbury notes that the whole story of Matthew is built primarily on dualistic foundations, with two categories of people; first, those who "think the things of God" and second, those who "think the human things" (1986:115). If Kingsbury's thesis is acceptable, then it is an eloquent testimony of Matthew's dualistic ideology of suppression and domination. The group that 'think human things' are the antagonists of the Matthean group, characterized by the teachers of law. Kingsbury notes that the story is characterized by conflict between two groups and the heart of it "is the issue of authority" (Kingsbury 1986:125). Matt 23 successfully captures the ideology pervading the whole gospel.

1 See D. E. Garland, 64-82, for more elaborate meanings of the word woe in various contexts including the Hebrew Bible usage. 


\section{Liberating the Word: A Loaded Gun Can Kill}

It is evident that Matthew wrote for the survival of his group. But his strategy of survival was primarily dependent on disqualifying the other groups. His thought is largely built on dualistic and hierarchical thinking. For the Matthean writer, there cannot be various practices of faith; only the one which his community espoused. This attitude was possibly held by his rivals, who persecuted Matthew's community for their different faith interpretation (23:34), but we do not have their views, save through the Matthean story. What is undoubtedly clear in Matt 23 is a patriarchal power struggle of dualisms and hierarchical suppression of differences in a colonial context. This ideology of suppression does not celebrate differences but reduces the Other into non-human categories in order to legitimize their domination. It is a colonizing ideology, since to colonize means to take over the minds, lands, and cultures of those who are different, by denying them their sovereignty. In such frameworks, women are always the other who must be suppressed. But in colonial contexts, where the colonized are competing for power among themselves and with the colonizer, the context often becomes nativist or fundamentalist in its survival strategy, which, more often than not, sanctions further suppression of women. In the Matthean community and context, this is indicated by the author's insistence that "unless your righteousness surpasses that of scribes and Pharisees, you will certainly not enter the kingdom of heaven" (5:20). Given that Pharisees were already credited with stringent keeping of rituals and the law, ${ }^{1}$ for the Matthean community to insist on even higher standards is an attestation of a nativist or fundamentalist approach, even though these terms may not exactly fit these ancient biblical groups. Although the gospel of Matthew was conditioned by a specific historical situation, it has become a worldwide scripture, the 'authoritative word of God,' by virtue of its inclusion in the Christian canon, the Bible. Consequently, it is no longer a localized conversation of the Matthean community and the teachers of law of the first century. The Gospel of Matthew is now contained in a book called the Bible, which carries massive worldwide scriptural power among the communities that read and believe it. The context-specific strategies that sustained the first readers of Matthew may seem less obvious to a reader who is far removed from the ancient

See C. J. Roetzel, 1985:26, where it is said, "Pharisees believed the 'setting for the law observance was the field and the kitchen, the bed and the street' ...thus treating all aspects of daily life as if it were a part of the temple service. " 
historical context. Nevertheless, the ideology of suppression and domination remains alive and effective. Accordingly, evangelists, missionaries, and preachers of the word subdue the non-Christian world by totally discrediting it, as attested by narratives from modern colonialism and current Pentecostal movements. This takes the form of condemnation and negative labelling of the Other as the introduction of this paper highlights. It is a strategy that is embedded within the biblical texts themselves-and remains potent.

B. L. Mack in his book, Rhetoric and the New Testament has found the New Testament rhetorical units to be highly polemical, often addressing two audiences at the same time with the prevalence of the argument being negative contrast throughout (1990:96). Although he regards it as a "process of social definition by means of comparison and contrast with surrounding cultures of difference" (Mack 1990:96) he sees a potential danger in that such a pattern of thinking can eventually get "locked into the logic of a group's fundamental persuasions" (Mack 1990:96). He points out the danger of these patterns of persuasions because:

"The rhetorics of occasional moments in the past became by virtue of their retention and inclusion in the writings destined to become New Testament, paradigmatic discourse, mythic models of the kind of speech that is now imagined to have generated Christianity with Jesus" (Mack 1990:99).

This, Mack argues, is particularly so if it becomes "paradigmatic for christian pronouncements for those outside the border" (Mack 1990:100). To me, as an African Motswana woman, it is not only an imagined fear but a true story of the introduction of Christianity in Africa. The few missionaries proclaimed condemnation and saw evil amongst Africans as well as wrote it down for a record. This strategy applied by colonial missionaries is embedded within the Christian thought or scriptures and will always come out to serve its intended purpose, both consciously and unconsciously. It is a loaded gun that can always shoot- with deadly consequences. A condemnatory evangelism, once pronounced, remains a stigma upon those who are rejected especially in their own psyches. Moreover, women, who are already suppressed on the basis of gender, face further oppression in nativist colonial contexts of contested power. 


\section{Conclusion:}

\section{Towards a Liberating Gospel - Loving Your Enemies (Matt 5:43-44)}

In my view, the problem of colonial and colonizing interpretations does not only lie in the interpreters (although colonial and male interpreters were a definite factor in what was interpreted and how it was interpreted) or the methods of interpretation per se. Rather, the ideologies of the texts are also factors. As long as such loaded texts remain unpacked, they retain the potential to explode and kill, whenever any reader decides to pull the trigger of such a text. It, therefore, seems essential that such killer ideologies, underlining and pervading some scriptures, should always be identified and marked as dangerous by all liberation interpreters as the first step towards arresting the ideology of suppression and domination. Mack commends rhetorical criticism as one of the methods that helps us to uncover the quality of a given exchange because "it strikes the core of these reported exchanges and exposes them as inauthentic discourse" (1990:100). It is my view that the above analysis of the rhetoric of Matt 23 helps with the same, by exposing the ideology of the passage, its intention, and its embedded potential impact.

The process of liberating the word, therefore, should involve the identification of the categories of thought within which particular ideology is embedded. It should highlight the historical production and the impact of the text on history. Given the impact of these oppressive strategies of survival, they are not gospel (good news), either to the original intended audience or to the flesh and blood hearers and speakers of the same word in history and today. Christianity, unfortunately, has on several occasions applied the gospel of condemnation and thrived on this strategy to spread itself across the globe. What is encountered as different and new in the various world cultures has been categorized as dispensable-barbaric, evil savagery, devilish and superstitious material. The negative labeling is a strategy of suppression and domination--the art of legitimatizing the imposition of the so-called 'civilized,' 'developed,' 'Christian' or 'western' cultures.

How have the feminist commentators of Matthew re-read this passage? Their approach was largely informed by the early biblical feminist practice of focusing on passages that openly feature women or refer to female gender, in an attempt to reconstruct the submerged female voice. Consequently, both commentators focused on the tale end of Matt 23, verses 37 38, which reads: “Jerusalem, Jerusalem...how often I have longed to gather your children together, as a hen gathers her chicks under her 
wings, but you were not willing! Look your house is left desolate. " For A. J. Levine,

In a context of the chapter's exaggerated complaints against Pharisaic hypocrisy and elitism the feminine metaphor of gentleness and concern for children is apt. Moreover, the extended metaphor casts Jesus in the role of public mourner, a role traditionally assigned to women (cf. 28:1) and draws a connection between him and Rachel (Matt. 2:18). Both Matriarch and Messiah mourn their doomed children (1992:260).

For Elaine Wainwright,

the interpretation of Jesus and his life work in terms of the Wisdom myth are again present in the account of the Jerusalem ministry. A wisdom saying in 23:34-35 is spoken directly by Jesus: "Therefore I send you..." This is followed by the use of the female image of the hen gathering her brood under her wings (23:37). Such female imagery used in relation to Jesus is further extended if the eschatological discourse in chapter 24 is seen as Wisdom's discourse. This symbolization does not seem strong, but it is clear that it can at least begin to subvert the son Christology that dominates the narrative. Again, those half-buried clues point to a rereading of the gospel in terms of inclusive symbolism for the interpretation of Jesus, the community he gathered around him, and the mission he gave. Included within such a reading, however, must be the ethnic critique of Sophia's judgment on Israel contained in 23:36 (1995:657).

Both feminist commentators focus on the female imagery of Matt 23 in attempt to recover the submerged female voice of the biblical text. For Levine, the use of female gender (Jesus as a mother hen) is therefore welcome in this problematic chapter. Levine thus builds on the feminized image of Jesus and likens him to Rachel who mourns for her doomed children. For Wainwright, the use of female imagery recalls the Wisdom myth and "can at least begin to subvert the son Christology that dominates the narrative" and stands a chance of providing an "inclusive symbolism" for interpretation. Are these feminist re-reading liberating? Both commentators' re-reading hardly problematizes the intensely dualistic and hierarchical ideology that undergirds Matt 23. In fact, the feminized role of Jesus as mother hen who weeps for her children does not serve to soften the hard rhetoric of the passage at all. Rather, the female image and the saying serve to underline the hard-heartedness of the teachers of law (that is, the teachers of law could not even respond to the cry of their mother) and hence legitimate that "their house has been left desolate. " It seems to me that the use of a female image in Matt 23 need not be celebrated but should be interrogated for its patriarchal purposes. This is detectable 
when one applies some of Cheryl Exum's questions for reading patriarchal texts that feature women; namely, that feminist readers should ask: "What hidden gender assumptions lie behind this text?... Whose interests are served?" (1995:69-70).

Given that I find Matt 23 too oppressive for a re-reading, I suggest a strategy of using a counter text from Matt 5:43-44. The literary context of the passage is the Sermon on the (Matt 5-7:29). The audience is identified in 5:1, which reads, "When Jesus saw the crowds, he went up the mountain; and after he sat down, the disciples came to him. Then Jesus began to speak and taught them...." These crowds, and possibly disciples, would have included both men and women of the Matthean community. Notably what follows the identification of the audience are the beatitudes, beginning each of the subsequent seven verses with the phrase "blessed are" (5:3-11). The approach is a marked departure from Matt 23's approach that has a resounding hammer of seven "woe to you" phrases (vv. 13-29). One approach passes blessings, while the others pronounces curses. The Sermon on the Mount still attests that the Matthean community had undergone, or was still undergoing persecution, (5:10-11), but the approach towards their persecutors is markedly different, through its refusal to resort to the strategies of suppression and domination that characterize Matt 23. Here the community is given an injunction to be the salt of the earth (5:13-16); to keep the law (5:17-20); to control its anger (5:21-26) and love its enemies (5:43-48). The latter appears at the end of chapter 5 where the author, says, "But I say to you love your enemies and pray for those who persecute you." The verse seems to me an excellent lens for counteracting the ideology of Matt 23.

Let me underline that placing the passage within the gospel of loving your enemies (Matt. 5:43-44) is just one way of re-reading Matt 23, which I choose to use within this article. To me, the phrase "loving your enemies" unsettles the dualistic and hierarchal framework of Matt 23, thus subverting its power of suppression and domination. While Matt 23 reeked with enmity, bordering on disgust and hate, Matt. 5:43-44, discourages such an approach. Rather, one must love one's enemies. In my view, loving one's enemies is a framework that highlights and insists on difference, ambiguity, heterogeneity, multiculturalism, co-existence, and living with difference with no right to suppress, erase, hate, ridicule, or reduce difference to uniformity. Loving your enemies is the call to live and let live. Loving your enemies is the duty to recognize and maintain the humanity 
of all who are different - respecting the human rights of all. If the Matthean writer had applied the framework of 'loving your enemies' to live with prime rivals, across the entire gospel, Matt 23 would read differently and move with a different gospel ethics, different impact on history and contemporary times. The chapter would have sounded a different note of acceptance and celebration of diversity. It would be a chapter that goes to assist all relationships to celebrate rather than suppress differences based on gender, race, religious, ethnic, class, dis/ability, national and the environmental status.

'Enemies,' as used here, therefore, denote those of different gender, sexuality, class, color, age, nationality and those who hold different views, customs, values, religious practices, and faith interpretations-in the strongest sense. The act of loving an enemy is a call to accept differences and to be celebratory of that which is unfamiliar, strange, and what seems to be inauthentic under the gaze of one's own traditions. It is a call to be self-conscious, realizing that to encounter difference with a dualistic and hierarchical approach is to intentionally seek to suppress and dominate the Other. The act of loving one's enemy, therefore, is not a call for women to accept patriarchal oppression; the colonized to condone the exploitative colonial powers; people of color to accept racism, gays, and lesbians to accept homophobia or even human beings to dwell on anthropocentric perspectives that sanction the exploitation of the earth. For the framework of loving one's enemies to work best, it must govern all the involved, calling for self-consciousness of all and their terms of relating with the other, and placing a self-restraint on the enemies themselves, who must also love their enemies. The framework calls for the respect of human and environmental rights in all contexts by all. It calls for resistance of violence and domination. In short, under the framework of loving one's enemies, we do not expect women to be oppressed because of their gender difference; people of color due to race, non-Christians due to their religions, nor less aggressive nations to be subjugated by imperial powers.

Yet in so far as Christianity is concerned it has aimed in changing the whole world into its image, which is anything but loving one's enemies. Resistance which got in its way has been unhesitantly countered by means of condemnation, colonialization, and violent militarism (Rivera 1992). Consequently, historical archives suggest that we are closer to truth if we say both Matt 23 and the Christian world have been more faithful to the saying, 'Love your neighbor and hate your enemy," in so far as diversity is 
concerned. The Christian history, with its failure to love its enemies without changing them into their own likeness, has made it one of the most oppressive religious movements. ${ }^{1}$ A framework of loving one's enemies points us towards accepting the diversity of the world; celebrating the pluralistic character of our societies and acknowledging that various cultures and religious traditions of any society deserve the right to survive, to be self-re-interpretative, self-transfomative and to engage in dialogue of equals within and without cultures, than to face the imposition of completely imported religions. ${ }^{2}$ For feminist purposes, that seek the empowerment of women and all creation, the framework of loving your enemies, if properly understood and practiced, should be the gospel of liberation, both within and across cultures, religions, and identities. It should be a framework, that dispenses with dualisms and hierarchy, that more often than not, sanction the oppression of the Other.

1 The fact that most of the world evangelization was carried out by white European male at a time when western culture celebrated its superiority has contributed to low selfesteem amongst those who became victims of colonization and missionary activities.

One of the major destruction of missionary activities in Tswana Society was the demolishment of initiation schools where young boys and girls were taught values of a society. These schools marked a boundary of transition into adulthood. The missionaries denounced them as evil primarily because of lack of understanding. But their removal created a society without communal guidance to its young people especially that the church could not replace these schools of moral endorsement and training for responsibility. 


\section{References}

Asamoah-Gyadu, J. K. (2005). African Charismatics: Current Developments Within Independent Indigenous Pentecostalism in Ghana. Leiden: Brill.

Avalos, H., S. Melcher, \& J. Schipper, eds. (2007). This Abled Body: Rethinking Disabilities in Biblical Studies. Atlanta: SBL.

Carter, W. (2007). “The Gospel of Matthew,” 1-68. In F. Segovia \& R. S. Sugirtharajah, eds. A Postcolonial Commentary on the New Testament Writings. New York: T\&T. Clark

Collins, A. D. ed. (1985). Feminist Perspectives on Biblical Scholarship. Chicago; Scholars Pr.

Dube, M. W. (2000). Postcolonial Feminist Interpretation of the Bible. St Louis: Chalice Pr. (1997). Toward a Postcolonial Feminist Interpretation of the Bible, 11-26. In Semeia 78: Reading the Bible as Women Perspectives From Africa, Asia, and Latin America. Atlanta: Scholars Pr.

Exum, C. J. (1995). Feminist Criticism: Whose Interests are Served? In G. Yee, ed. Judges and Method: New Approaches in Biblical Studies. Minneapolis: Fortress Pr.

Garland, D. E. (1979). The Intention of Matthew 23. Leiden: E. J. Brill.

Kingsbury, J. D. (1986). Matthew as a Story. Philadelphia: Scholars Pr.

Kwok, P. L. (1989). Discovering the Bible in the non Biblical World, In Semeia Vol 47 ed. E. S. Fiorenza. Atlanta: Scholars Pr.

Levine, A. J. (1992). “Matthew,” 252-262 in C. A. Newsome \& Sharon Ringe, eds. The Women's Bible Commentary. Louisville: Westminster.

Lewis R. \& S. Mills, eds. Feminist Postcolonial Theory: A Reader. New York: Routledge

Mackenzie, J. L. (1968). The Gospel According to Mathew. In Jerome Biblical Commentary. New Jersey: Prentice Hall Inc.

Mack, B. L. (1990). Rhetoric and New Testament. Minneapolis: Fortress Pr.

Mack, B. L \& Robbins V. K. (1989). Patterns of Persuasion. Polebridge Pr.

Mgadla, P. \& S. C. Volz, eds. (2006). Words of Batswana: Letters to Mahoko a Becwana 1883-1896. Cape Town: Van Riebeeck Society.

Muzorewa, G. H. (1986). The Origins and the Development of African Theology. New York: Orbis Books.

O’Brien Wicker, K. Spencer-Miller \& M. W. Dube, eds. (2005). Feminist New Testament Studies: Global and Future Perspective. New York: Palgrave.

Oduyoye, M. A. (1986). Hearing and Knowing: Theological Reflections on Christianity in Africa. New York: Orbis Books.

Overman, J. A. (1990). Matthew's Gospel and the Formative Judaism: The Social World of the Matthean Community. Minneapolis: Fortress Pr.

Riches, J. \& D. C. Sim, eds. (2005). The Gospel of Matthew in Its Roman Imperial Context. New York: T \& T Clark.

Ringe, S. H. (1992). "When Women Interpret the Bible," 1-9. In C. A. Newsome \& Sharon Ringe, eds. The Women's Bible Commentary. St Louisville: Westminster

Rivera, L. N. (1992). A Violent Evangelism: The Political and Religious Conquest of the America. Louisville: John Knox Pr. 
Roetzel, C. J. (1985). The World That Shaped the New Testament. Atlanta: John Knox Pr. Russell, L. M. ed. (1985). Feminist Interpretation of the Bible. Philadelphia: Westminster Pr.

Sahgal, G. \& N. Yuval-Davis, (2003). “The Uses of Fundamentalism,” pp43-48. In R. Lewis \& S. Mills, eds. Feminist Postcolonial Theory: A Reader. New York: Routledge.

Richard, P. Hermeneutics of Liberation: A Hermeneutic of the Spirit. 263-280. In F. Segovia \& M. A. Tolbert, eds. Reading Form This Place Volume 2: Social Location and Biblical interpretation in Global Perspective. Mineapolis: Fortress Pr., 1995.

Said, E. (1983). The World, The Text, and the Critic. Cambridge: Harvard Univ. Pr. Schroer, S. \& S. Bientenhard, eds. (2003). Feminist Interpretation of the Bible and the Hermeneutics of Liberation. Sheffield: Sheffield Academic Pr.

Schüssler Fiorenza, E. (1983). In Memory of Her. New York: Crossroads.

Schüssler Fiorenza, E. ed. (1989). Interpretation for Liberation, Semeia vol 47/9. Atlanta: Scholars Pr.

Tolbert, M. A. (1999). "Reading the Bible With Authority: Feminist Interrogation of the Canon.” 141-162. In H. C. Washington, S. L. Graham \& P. Thimmes eds. Escaping Eden: New Feminist Perspective on the Bible. New York: New York Univ. Pr.

Tutu, D. (1987). “Black Theology and African Theology: Soulmates or Antagonists?” 4655. in J. Parratt., ed. African Christian Theology. London: SPCK. 


\section{Resurrection as 'Corrective' Creation}

\section{An Ecological Analysis of the Biblical Doctrines of Creation and Resurrection}

Lovemore Togarasei \& Sidney K. Berman

\section{Introduction}

Judaism, Christianity and Islam teach about the resurrection of the dead. Generally, the understanding is that at some point in future all those who have died are going to be raised either to be rewarded or to be punished. In the Christian teaching, the figure of Jesus is very central in the elucidation of this doctrine. But there are so many questions about resurrection that cannot be answered satisfactorily from the story of the resurrection of Jesus. Will the resurrected have human bodies, especially when one takes the resurrection of Jesus as an example? Will there be a continuation from the person who was to the person who will be? In other words, will it be possible to identify one's former friends, wife/wives, children, etc? Where will the resurrected go to? To some other space somewhere, or they will continue to inhabit this earth?

In this paper we do not claim to have answers to all these questions. What we intend to do is to attempt an understanding of the doctrine of resurrection by going back to the story of creation in Genesis 1 . It is our hypothesis that the resurrection belief is strongly connected to the realization that the creation, which was created good, in fact went bad, and therefore, needs to be corrected. Resurrection should therefore be understood as that attempt to correct what has gone wrong. We believe this understanding of resurrection has positive ecological implications. We, therefore, begin by looking at the original intention of God in creating the world. We follow this with a section on how creation went wrong. The third section looks at how resurrection is a correction of the creation gone wrong and finally we consider how such an analysis of the doctrines of resurrection and creation can help in addressing the current ecological problems. 


\section{And all was good}

Genesis 1 gives an account of the creation of the world. We are told that the earth and sky and all things in them were created by God. All animals and plants, seas and land features as well as other planets were created by God. From the chaos and emptiness that characterised the pre-creation period, all things were created purposefully and without fault. God's Spirit hovered over the creation project so that things would be created and set in an orderly fashion (Assohoto \& Ngewa 2006:11). Throughout the creation activities, God saw that what God had created was good (Gen 1:4, 10, $12,18,21,25)$. At the end of the chapter, the author tells us, "And God saw everything that he had made, and behold it was very good." A close look at what God had done indeed convinces us even today that this was very good. The creation was orderly, harmonious and balanced.

All ecosystems were working coherently and smoothly as intended by their creator (Conroy \& Peterson 2000:167). Among the created there was community, harmony, sharing, diversity and unity. The sun, the stars, the moon, regulated the rhythms and seasons of time. Each of the created organisms was meant to sustain the whole of creation. Human beings, animals, birds, fish and other aquatic creatures, dinosaurs and other already extinct creatures, balanced the order and sustainability of the creation. Each played its part and there was no need for fertilizers, herbicides, pesticides to control the nature. Neither was there need for greenhouses. Each creature's survival needs were naturally provided for. Assohoto \& Ngewa (2006:11) point out that God brought together all things necessary for human and animal survival before God created them. Human beings, just like animals and birds, did not have to toil for existence as all was there through divine providence. They were not afraid of wild animals, snakes or even wasps. All these were their friends and fellow creatures. There was also no rebellion against God as all his creatures were still obedient. God talked to and walked among the people. Water flowed in rivers and watered the different parts of the earth. All was indeed good.

\section{Creation goes wrong}

The Bible shows that all went wrong with the fall of humanity (Genesis 3). The fall of Adam and Eve resulted in the reversal of what God intended of creation. It brought a curse upon the whole of creation (Gen. 3:17, 18 and 21). It separated God from humanity creating a huge gap that could only be filled through intermediaries such as prophets and angels. God 
drove human beings away from his presence (Genesis 3:8). Humanity also had to toil for a living, cultivating the land or rearing animals for subsistence. The woman had to suffer in childbirth and enmity was created between human beings and some created creatures such as snakes. Humanity would not live forever as death came into the picture. Not only were they to die, but with time the life span of human beings was reduced (Genesis 5:1-32). Life was no longer as God intended it to be. Rebellion against God led to more sins like murder (Genesis 4) and prohibited intermarriages (Genesis 6:1-7). Further down biblical history, humanity's corruption became so severe that God regretted making humanity. In that instance, God promised to wipe out humanity and "animals, and creatures that move along the ground, and birds of the air" (Genesis 6:7-8). Although these stories have been interpreted by some scholars (e.g. Boadt 1984:130-132) as myths meant to explain human and cosmological conditions, they explain that God originally intended good for the creation. In fact, the whole story of the Old Testament shows how humanity went far away from God's original intention of creation. The acts of humanity also affected the rest of the creation as the whole creation was cursed because of humanity's sin.

The story of creation gone wrong has continued even in our present times and explains the current ecological crisis. Through science and technology humanity has subdued the created order often in malign ways. Humanity has overused the land, resulting in desertification in some areas. For want of development, we wantonly destroy trees and forests resulting in soil erosion. Water sources have been polluted and the majority of the world population now has no access to safe drinking water. Pollution of the water sources has also seen growth in water borne diseases. Science and technology, with their anthropocentric emphasis have seen the extinction of certain plant and animal species. The use of certain chemicals has had disastrous effects to the environment. Emission of greenhouse gases has led to climatic change, resulting in droughts and, floods due to the damage of the ozone layer. The list is long and surely there is need for a correction.

In the next section we look at resurrection as a correction of that which went wrong after the creation. We attempt an understanding of resurrection that can be useable in our context of the ecological crisis. How can an understanding of the resurrection as a correction of creation gone wrong be used to address the present ecological crisis? This is the question that we attempt to answer. 


\section{Resurrection as corrective creation}

The resurrection of Jesus is indeed the cornerstone of the Christian faith. Without it, writes Paul, "...then Christ has not been raised; if Christ has not been raised, then our preaching is in vain and your faith is in vain" (1 Cor. 15:13-14). It is also the basis upon which Christian belief in resurrection at the end of time is based. Christians believe that Jesus' resurrection was not only for him but also for them. But what does it mean to say Christ resurrected or was raised? It appears this was a hot question in first century Christianity. The evangelists and Paul, all had to address the question. Unfortunately, their answers brought more problems than they solved. The result of this, as J. D. Robinson (1998:19) correctly observes, is confusion within Christianity regarding the afterlife, and the propagation of ideas which are contradictory or illogical. This is seen, especially, in as far as the nature of the resurrected body is concerned. In the gospels Jesus' resurrected body was more human than spiritual whereas in Paul (1 Cor. 15), the resurrected body is more spiritual than physical. In the gospels Jesus rose in pain, could be touched and had visible wounds. $\mathrm{He}$ even ate fish and one would be right then to believe that the natural process of digestion took place leading him to go to the ablution to relieve himself! Although his entrance through closed doors have been interpreted as showing the spiritual nature of the body (Strauss 1973:730), generally the gospel narratives point to the resurrected body as a physical body. This is opposed to the Pauline picture of the resurrected body. For Paul, the resurrected body is qualitatively different from the normal human body. It is a celestial body as opposed to the human body which is terrestrial. Paul uses the analogy of the seed and the germinated plant to stress this qualitative difference (1 Cor. 15:42-44).

The gospel narratives would also naturally lead one to believe that resurrection will be dependent on the existence of the former body (at least its remains). It would also lead to the conclusion that the resurrected body will assume the form and nature of the old body. For instance, it would mean that those who died old will rise old, those who died crippled will rise crippled and so on and so on. It also raises questions on those who are cremated, eaten up by crocodiles, termites or whose bodies are dissolved by other natural factors. Will these people be raised since there would be no more remains of their former bodies? For this reason and following the findings of the historical-critical method (that the Pauline letters were written before the gospels), New Testament scholars now pre- 
fer to understand the resurrection from the Pauline perspective. They argue that the initial understanding of resurrection was that of a spiritual body. The idea of the empty tomb was only brought in to give a logical explanation to that which is spiritual. Since Christians were arguing that Jesus was raised, it was only logical that they claimed that his tomb was empty. "The empty tomb serves as evidence that Christ took his body with him," writes J. D. Robinson (1998:47) quoting Ladislaus Boros. Then also rose arguments that the tomb was guarded as Christians were being apologetic in the face of accusations such as that they stole the body of Christ and then claimed that he had resurrected. Thus, resurrection should be understood as Paul puts it. Paul's emphasis that Jesus was raised (egegertai) as opposed to him rising (as if it was his own initiative) underlines that the resurrection of Jesus was an act of God, a re-creation on his part as opposed to his resuscitation.

We follow the Pauline view of resurrection. Viewed this way, resurrection corrects that which went wrong after the original creation. It restores God's original intention of creation. Jesus' resurrection reflects this in a number of ways. We shall soon turn to this. The Bible also has many other texts which point to resurrection as the restoration of the original intention of God about creation in the Garden of Eden. We shall consider some such texts as Isaiah 65, Revelation 20-21 and others. But let us start with the resurrection of Jesus.

Allow us to start by recalling that for those who believed in resurrection, Jesus was the Christ, the anointed one of Israel who came to inaugurate a new era of justice and peace that Israel from the time of the fall, had failed to enjoy. This is how messianic beliefs began in Israel. Against their belief that God had created the world good, selected them as the chosen nation, they never enjoyed the good creation, neither did they ever enjoy the privilege of being the chosen ones. For those who believed the resurrection of Jesus, through it, God had begun the restoration of the world, in the words of J. M. Soskice (1997:49), "to its original created intent of wholeness and flourishing." Looking at the theologies of the New Testament, K. Nurnberger (2004:225) says Jesus as the Christ represents God's original intentions. He corrects all that led creation from the original intention of God, chief among them, sin. When God created the world, God intended to live with the people. As we have seen in the first section of this paper, God walked among the people, talked to them and guided them in their daily activities. It was the fall that led God to drive the people away from God's presence. The resurrection of the dead is going to restore this intimacy 
between God and the people. This is manifested in the person and work of Jesus, who is the first fruits of resurrection. Jesus represents what God willed humanity to be right from the beginning. After his resurrection, we are told that he is seated to the right hand of God. He now enjoys the everlasting presence of God. This is the image of the kind of relationship between God and all the people after the resurrection of the dead. The book of Isaiah sheds light on this view of a new earth, "...no more shall be heard in it the sound of weeping and the cry of distress. The wolf and the lamb shall feed together, the lion shall eat straw like the ox; and dust shall be the serpent's food" (Isaiah 65:19, 25). Another text from Isaiah foretells the restoration of life in the Garden of Eden in the age to come;

The wolf shall dwell with the lamb, and the leopard shall lie down with the kid, and the calf and the lion and the fatling together, and a little child shall lead them. The cow and the bear shall feed; their young shall lie down together; .... The suckling child shall play over the hole of the asp, and the weaned child shall put his hand on the adder's den" (Isaiah 11:6-7).

The book of Revelation (particularly chapters 20-22) is more succinct in talking of the resurrection as a correction of what went wrong at creation. It clearly shows that God will restore life on earth to his original intention at creation. In the recreated world, the devil will no longer be there. All God's people will be priests and will rule the world with God and the Lamb. God will dwell with humanity and all other creatures (Rev. 21:3). Humanity will know God face to face as they will belong to him with his name emblazoned on their foreheads (Rev. 22:4).

Resurrection also restores human life to its original intention by defeating death. Not only did sin separate humanity away from God, it also brought about death, a thing that God did not intend people to experience when God originally created them. Death was therefore a result of creation gone wrong as we have seen above. Paul describes it as the wages of sin (Rom. 3:23). Resurrection is meant to correct this as the resurrection of Jesus shows. Through his resurrection, death was conquered as J. M. Soskice (1997:49) writes, "The resurrection of Jesus, this conquest of death by the Lord's anointed, is the beginning of the restoration of the world which will bring a new heaven and a new earth. " Visions of the new earth show that there will no longer be death. The book of Revelation says death, and everything associated with it; pain, mourning, weeping and everything accursed, have no place in the new creation. M. A. Hinsdale (2000:215) has this to say about Revelation and new creation, "(Revelation) weaves together prophetic dreams of a new creation (Isaiah 65 and Ezekiel 47), a 
renewal of Jerusalem and the covenant (Zechariah 8 and Ezekiel 37) and the pilgrimage of nations to Jerusalem (Isaiah 60), together with paradise themes (Gen. 2) and wisdom texts (Psalm 46) ..." Resurrection, therefore, restores life back to God's original intention of peace and tranquility among the whole creation. Jesus, the symbol and assurance of the resurrection, in his resurrection, reconciled all things to God. As the Second Adam, his resurrection was the undoing of the wrong that Adam did or did not do (De Witt 1998:32).

\section{Ecological implications of the above analysis}

What ecological implications can be derived from the above analysis of resurrection as a correction of the first creation? There are a number of lessons that can be learnt for the good of the environment. We shall look at four such lessons. First, that this earth is eternal. One of the reasons why the Christian faith has been accused of environmental degradation is its teaching concerning another world after resurrection. If resurrection life is seen as life on another planet, this will not promote the preservation of the current world. The understanding would be that even if this world is destroyed it does not matter since it is transitory and there is another world following resurrection. Our analysis has shown that the destiny of the created order is not that of "a throw-away container which God will discard when Christ finally comes to consummate the salvation of humans" (Lucas 2005:92). Instead the resurrection and second coming of Jesus is part of a wider renewal of the whole creation through transformation. The word transformation needs to be underlined to show the continuity of this current world. For this reason S. Bouma-Prediger (2001:114) says God's future is earthy. Basing his argument on John's vision of the New Jerusalem in Revelation 21-22, he concludes that God does not give up this world that he created and covenanted. Instead he redeems it, continuously renews, renovates and reclaims it. Resurrection thus will bring an end to the distinction between heaven and earth. Life in the New Jerusalem as seen by John the Seer will literally be a heaven on earth, a restoration of life as it was in the Garden of Eden. This knowledge surely dictates that those who believe in the resurrection should take responsibility of this world as it is their and God's home forever.

The second lesson is that the final redemption and renewal of the world is not only of humans but of all the created order. In Romans 8:18-23, 
Paul says creation is groaning waiting for adoption. The resurrection of Christ especially according to Colossians 1 , is restoration and consummation of the groaning creation, "He is the image of the invisible God, the first born of all creation, for in him all things were created, in heaven and on earth, visible and invisible, whether thrones or dominions or principalities or authorities- all things were created through him and for him. He is before all things and in him all things hang together" (Colossians 1:15-17). Through his death on the cross, Christ, therefore, brought together all creation, trees, animals, humans and so on. His resurrection was a vindication of the goodness of all creation, an assurance that all creation will be transformed and renewed.

Third, resurrection prepares believers to accept death. It can hardly be disputed that much of the environmental damage is a result of humanity's attempt to produce and accumulate more. The environment is pillaged as people want to maximize production. The use of chemicals and fertilizers in agriculture, mining, overgrazing, the greenhouse gases and all other factors that have contributed to environmental degradation and climate change, are a result of human effort to produce more. It is no surprise then that the rich nations of the North are contributing more to environmental damage than the poor nations of the South. In fact, M. S. Northcott (2005:105) is right that it is the tropical zones of the South that are carrying most of the costs of the climate change. Psychologists have linked the desire to acquire more and more possessions as arising primarily from anxieties about death. "By surrounding ourselves with more and more things we hope to avoid the reality of death and gain some measure of immortality, at least, in the things that we own" (McDonagh 1990:162). But in this search for immortality humanity destroys the earth. The resurrection of Jesus is, therefore, a quick fix to this problem. Belief in the resurrection of the dead and a future life with God here on earth will not push us to seek immortality through accumulation of material possessions at the mercy of Mother Earth.

Fourth, the resurrection of Jesus marked the beginning of the restoration and renewal of the created order. It made God present permanently among believers as Jesus said after his resurrection, "and lo, I am with you always, to the close of the age" (Matt 28:19). Thus, "Talk of Jesus' resurrection simply helps us to an understanding of creation and the divine presence in creation" (O'Collins 1997:7). Believers are, therefore, already partly into the kingdom of God which is to be fully realized at the second coming of Jesus and the resurrection of all. This awareness together with 
the knowledge that this world is eternal should make believers more responsible in the upkeep of the earth as they come to know that what they do now is important for the future. Christian eschatology is, therefore, earth-keeping as it gives believers confidence that what they do today is not for naught (Bouma-Prediger 2001:126). Rossing (2000:218-219) captures this idea vividly in her interpretation of the New Jerusalem envisioned by John in Revelation;

.... Revelation's vision of the green space in the city, of a river of living water flowing from God through the centre of our cities, can be a vision of eschatological renewal. New Jerusalem is a vision for the future. It is a vision that we can glimpse even now; in the river flowing through the heart of Boston from the heart of God; in a tree nursery tended by low income gardeners in the heart of Baltimore; in the tree-planting eucharist liturgies of Christian churches in Zimbabwe, in the work of community building, justice seeking, bread breaking, nation healing. In every tree, every river, every city, we can glimpse God's holy city dawning in our midst...

Lastly, the resurrection of Jesus gives believers hope that God is able to bring the dead back to existence. Thus, "Belief in the resurrection helps Christians overcome denial and despair on an issue such as climate change" (McFague 2000:42). Ezekiel's vision of dry bones, like the resurrection of Christ, also points to God's ability to use nature to bring about that which is already dead. In this vision God used two creatures; the human being and wind, to make a new creation (McFague 2000:43). Creation is, therefore, not a lost cause. Working together with human beings, God is able to bring back to life that which humanity has destroyed. Bouma-Prediger (2001:126) says, in small ways human beings are already working on the restoration and renewal of creation through such efforts as recycling, composting and cycling to work. There is more that human beings can do with confidence that God can give life to what is dead.

\section{Conclusion}

This paper analysed the doctrine of the resurrection of the dead as a corrective of creation gone wrong. It considered the resurrection as an attempt to renew creation to its original condition, and even better. The earth was created good but through human sin, went bad, with serious negative ecological consequences. Thus, firstly this paper discussed how all things started as very good in Genesis 1 . The environment, animal and plant life were functioning properly as intended by God. Secondly, the paper then discussed how things went wrong primarily because of human 
exploitation of the rest of creation in its quest for technological advancement and domination. Thirdly, the paper explored how Jesus' rising from the dead guarantees the restoration of the human body and creation back to their qualities of eternity and functional goodness. It discussed the positive ecological implications of the doctrine of the resurrection on creation so as to discover how the doctrines of resurrection and creation can help in addressing the current ecological problems.

\section{References}

Assohoto, B. \& S. Ngewa, 2006. 'Genesis,' in T. Adeyemo (Ed.), The African Bible Commentary, Nairobi: WordAlive, 9-84.

Boadt, L. 1984. Reading the Old Testament: an introduction, New York: Paulist Pr.

Bouma-Prediger, S. 2001. For the Beauty of the Earth: a Christian vision for creation care, Grand Rapids: Baker Academic.

De Witt, C. B. 1998. Caring for the Creation: Responsible Stewardship of God's Handiwork, Grand Rapids: Baker Books.

Hinsdale, M. A. 2000. 'Response to Catherine Keller,' in D. T. Hessel \& R. R. Reuther (Eds.), Christianity and Ecology, Cambridge, MA: Harvard Univ. Pr., 199-204.

Lucas, E. 2005. 'The New Testament Teaching on the Environment,' in The John Ray Initiative, A Christian Approach to the Environment, London: JRI, 73-96.

McDonagh, S. 1990. The Greening of the Church, Maryknoll: Orbis Books.

McFague, S. 2000. 'An Ecological Christology: Does Christianity Have It?' in D. T.

Hessel \& R. R. Reuther (Eds.), Christianity \& Ecology, Cambridge, MA: HUP, 29-46.

Northcott, M. S. 1996. The Environment and Christian Ethics, Cambridge: CUP.

Nurnberger, K. 2004. Biblical Theology in Outline: The Vitality of the Word of God,

Pietermaritzburg: Cluster.

O'Collins, G. 1997. 'The Resurrection: The State of the Questions,' in S. T. Davis, D.

Kendall \& G. O'Collins (eds.), The Resurrection, Oxford: Oxford Univ. Pr., 5-28.

Robinson, J. D. 1998. Life After Death? Christian Interpretation of Personal Eschatology,

New York: Peter Lang.

Rossing, B. R. 2000. 'River of Life in God's New Jerusalem: An Eschatological Vision for

Earth's Future,' in D. T. Hessel \& R. R. Reuther (Eds.), Christianity and Ecology,

Cambridge, MA: Harvard Univ. Pr., 205-226.

Strauss, D. F. 1973. The Life of Jesus Critically Examined, London: SCM Pr.

Soskice, J. M. 1997. 'Resurrection and the New Jerusalem,' in S. T. Davis, D. Kendall \&

G. O'Collins (eds.), The Resurrection, Oxford: Oxford Univ. Pr., 41-58. 


\section{Biblical Texts, Ecology, and Sustainable Development An African Eco-theological Discourse}

Francis Machingura Q Ishanesu Gusha

\section{Introduction}

Religious texts are important for believers and this is true of the Christian faith where the Bible is taken as an inspired and holy word of God. The challenge for biblical scholars, theologians, environmentalists, ecologists and biblical readers would be the use of morally challenging biblical examples in the proclamation of the kingdom. Texts that sound environmentally unfriendly, for example, Genesis 1:28 (where God instructed His created beings to subdue and have dominion on the earth), Mark 5:1-20 (where the healing makes the herd of pigs be driven into the sea) and Jesus cursing a fig tree. These are typical examples of morally difficult texts on the relation between the kingdom of God and the environment. The following questions have been raised: What is the morality of Jesus' actions in cursing the tree? Do biophobic biblical texts have an impact on Christians' interactions with their environment? Is sustainable development possible in a context of biophobic tendencies? How best can such texts be interpreted in a context where there is an environmental crisis characterized by deforestation, contaminated waters, polluted air and rampant poaching? Are the texts sensitive and friendly to the environment? How would African Christians morally regard and interpret such actions on the environment? Traditional culture sanctions peoples' behaviour and interaction with their environment. As a result, fruit trees are highly regarded amongst Africans. Any behaviour that destroys nature is not encouraged. It is, therefore, the task of this paper to discuss the miracle of the cursing of the fig tree in Matt 21:18-22 in the light of sustainable development and environmental theology. Further, how would a Zimbabwean Christian sustainably read Matt 21:18-22 for development? 


\section{Biophobia: The Inception Discourses}

The early usage of the word, 'biophobia' was mainly associated with feminist philosopher Mary Daly. She was a champion for the defence of women and animal rights. Biophobia is defined as 'an aversion to nature'. For Orr (2004:187), biophobia ranges from discomfort with natural places to active scorn of whatever is not man-made, managed, or air-conditioned. Biophobia encompasses the killing of things that we perceive as being a threat to us, whether that threat is real or not is something else. It is a condition of not seeing the beauty, integrity and harmony of creation. It is that state of lacking friendliness to our environment. How can someone make it a hobby of shooting birds or animals or cutting of trees? Lee (1996:21) proposes four factors as main causes of biophobia and these are:semantic factors, lack of training in biology, exclusive focus on humans and moral/political factors. The four factors negatively contribute to the biophobic tendencies in people. However, Mann (2012) identifies the rise of technology and the subsequent decline in agrarian activities as some of the causes of the increase in biophobia; for example, the coming of the industrial revolution led people to abandon the hunter-gatherer lifestyle and further alienated them from nature. People failed to see the beauty in natural forests but in concrete forests (mega city structures). As a result, biophobic tendencies come as a condition of unreasonable dislike of nature. How does ATR guard against biophobic actions? How can biophobic biblical texts be read and interpreted for sustainable development? Such questions help to address challenges faced today in creating a balanced eco-system and sustainable development.

\section{Eco-theology}

Macquarrie (2009) listed six formative factors of theology as: experience, revelation, scripture, tradition, culture, and reason. In history, new theologies have been born as a result of challenges that people face and ecotheology is not spared from this phenomenon. The rise of eco-theology is mainly associated with the prominent names of theologians such as: Pierre Teilhard de Chardin, Alfred North Whitehead, John Cobb Jr., Jürgen Moltmann, Rosemary Radford Ruether, Catherine Keller, and Sallie McFague. Eco-theological discourses have influenced religious institutions to come up with courses that touch on ecological issues. Churches 
have not been left behind. For example, the fifth mark of the mission ${ }^{1}$ of the Anglican Church worldwide reads, "to strive to safeguard the integrity of creation, and sustain and renew the life of the earth" (www.anglicancommunion.org/identity/marks-of-mission.aspx). The Anglican Diocese of Harare in an attempt to implement this fifth mark, appointed the environmental chaplain responsible for running the diocese's environmental desk. The Anglican Diocese of Cape Town also established an environmental ministry with a full-time priest being in charge of it. A worldwide network of Anglican bishops known as eco-bishops or green bishops has been formed. In Zimbabwe, several denominations are theologically engaged in environmental issues in one way or another. The Living Waters Bible Seminary of Apostolic Faith Mission in Zimbabwe (AFM) through its former principal, Lovejoy Chabata, introduced environmental courses in the theological curricula of the training college. All these efforts are a result of what the Christian communities feel to be an urgent need in addressing the environmental crises in Zimbabwe hence the eco-theological discourse.

Sarah Speight (2013:4) feels that eco-theology is a form of constructive theology that focuses on the inter-relationships of religion and nature, particularly in light of environmental concerns. Eco-theology is the opposite of biophobia. Eco-theology emerges out of a quest for the survival of the environment against global warming, earthquakes, volcanoes and landslides. Millions of people are dying every year as a result of natural disasters. Questions are being asked such as: what has gone wrong with the environment? Who is to blame for these catastrophes that affect the sustainable development of any nation? For Christians, is God behind these disasters? For African traditionalists, the environmental challenges are a result of the ancestral spirits' anger. The list is inexhaustible. It was within this framework that Celia Deane-Drummond (2008:XII) postulated that, eco-theology seeks to uncover the theological basis for a proper relationship between God, humanity, and the cosmos.

1 The Five Marks of Mission for the Anglican Church are an important statement on mission which expresses the Anglican Communion's common commitment to, and understanding of, God's holistic/integral mission. And the five marks are; (1) To proclaim the Good News of the Kingdom; (2) To teach, baptize and nurture new believers; (3) To respond to human need by loving service; (4) To transform unjust structures of society, to challenge violence of every kind and pursue peace and reconciliation; (5) To strive to safeguard the integrity of creation, and sustain and renew the life of the earth (www.anglicancommunion.org/identity/marks-of-mission.aspx). 
Eco-theology developed out of the concerns over the decline of the environment in the last decades. Of late, religious organizations, politicians, religious scholars and theologians have taken over the subject of environment. The Bible as the sacred book for Christians is being used as the basis for eco-theology by different churches. This explains why we chose Matt 21:12-46 in our environmental discourse. However, not every Christian embraces eco-theology as one of the priorities of the church's ministry. The biophobic texts are commonly cited in the Zimbabwe public sphere whenever one is talking about the power of miracles. This is despite the fact that, Zimbabweans just like most Africans are socialized in ATR that is generally eco-friendly. Therefore, what has gone wrong? Can't ATR teachings on environment help Zimbabweans develop hermeneutics of environment when reading biophobic biblical texts such as Matt 21:1246 and Mark 5:21-43 on the withering of the fig tree thereby contributing to sustainable development?

\section{Sustainable Development and Environment}

There is no universally agreed definition of these two concepts. Mohammad Kamral Ahsan (2012:43) argues that "the concept of 'sustainability' is used frequently in diverse ways in everyday discourse." However, this does not mean that there is no general consensus among scholars. The proponents of economic and social development as well as environmentalists assert that 'sustainability' is an essential factor in development plans or policies, which are expected to have the capacity of continuing into the future, and also have the capacity to serve a great many purposes in the future (Ahsan 2012:45). Nigel Dower (1992:112) argues that: a form of development worth sustaining will, at the very least, not only protect the future, but also be:

(a) Just in terms of present social structures and practices of society

(b) Non-damaging to the natural environment

(c) Non-damaging to people in other countries

(d) Fair in relation to the like aspirations of other countries.

Sustainability in summary, therefore, includes the following elements: continuity into the future, justice, mindfulness of other countries, and preservation of the environment. It is, therefore, impossible to talk of sustainable development in the context of biophobic tendencies.

The concept 'development' is also not easy to define, just like the concept 'sustainability'. Reed (1985:21) sarcastically argues that "development is a 
very general concept; ask any three experts to say what they mean by 'development' and the likelihood is that you would be given three different answers." There is no universally agreed definition of the term development. This is the reason why Gasper (2004:27) argues that "development is a term ubiquitous in daily language. It can refer to the emergence or elaboration or evolution or improvement of almost anything." Michael Edwards (1999:4) adds that, the major universal objectives of the concept development are: to be free from poverty and violence and the servitude these bring in their wake, to be loved and enjoy a sense of belonging, to feel more in control and less vulnerable to vagaries of unaccountable power, and to be subjects of their own destiny rather than objects of intentions of others. Sustainable development, therefore, entails a combination of plans and policies that foster a sense of belonging, free from poverty and violence, control and be subjects of our destiny while enhancing continuity into the future and not jeopardizing the aspirations of our neighbors. Is sustainable development possible without taking seriously the importance of the environment? How can sustainable development be realized against biophobic texts commonly used by Christians?

\section{Matt 21:12-46: Environment and Sustainable Development}

According to Matthew, soon after Jesus' arrival in Jerusalem he proceeded to cleanse the temple. So, in verses $12-17$, Jesus is cleansing the temple and healing the visually impaired and the lame. Then he goes to Bethany for a night's rest. The following day he comes back to Jerusalem in the morning and while on the way, He curses the fig tree (18-22). In verses 23-46 he is back to the temple where he is being interrogated by the chief priests who are questioning the authority of his actions.

Matthew adds the word 'early' ( $\pi \rho \omega i)$ to justify why Jesus was hungry. Jesus might have missed two meals on the previous day as he had a long procession to Jerusalem (triumphal entry) and the cleansing of the temple. These two events might have caused him to miss one or two meals. Jesus started his day early, therefore, he might have missed his morning breakfast meal. The subject of Jesus being hungry is contained in both parallel passages. Hagner (1995:605) argues that, "this provides the occasion for Jesus' approach to the fig tree." Hunger is used as a trigger to the biophobic miracle. The phrase can be translated as, "as he returned to the city" and this seems to suggest that the miracle happened very close to the city of Jerusalem. Why closer to Jerusalem? For Matthew if the miracle 
has to do with the impending fall of Jerusalem then it must happen closer to the city's entrance. The dried-up tree then served as a constant reminder of the curse of the city because she (Jerusalem) denied the messiah. This is supported by Davies \& Allison (1997:148) when they argued that, Jerusalem or the temple hierarchy is symbolically punished in the fig tree for the messiah's rejection.

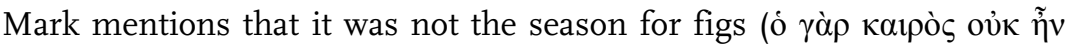

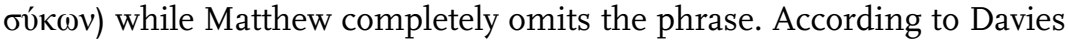
\& Allison (1997:147), this phrase vexed interpreters since Origen because it seems to make Jesus' search irrational; how could he expect to find figs out of season? Jesus' attitude and behaviour are presented in Mark as reckless to the environment and sustainable development. In that sense Matthew's omission becomes reasonable. The phrase provokes many questions, for example, how would Jesus detect the barrenness of the tree when it was not the season of the fruit? Is it justifiable environmentally to curse the tree for not producing fruits out of season? Will that attitude towards the environment be helpful in sustainable development? The two texts in Matthew and Mark are agreed that, the miracle resulted in the fig tree withering. It seems as if from a source critical perspective, Matthew relied on Mark for this story, but altered the material to suit his theological position.

This miracle is interpreted in different ways by different theologians. It can be classified as a prophetic act of power hence a semeion (sign) in the Johannine sense (Davies \& Allison 1997:148). The nature miracles like this one were occasions for the demonstration of power by Jesus. Such occasions are meant to intensify the faith of the followers. It is through such miracles that the followers of Jesus would see the divine nature of Jesus. Matthew's use of the Greek word, $\pi \rho \omega \grave{~ / ~ p r o i ̈ ~(e a r l y) ~ s u g g e s t s ~ a n ~}$ early start by Jesus. Nolland (2003:850) argues that, the Jewish daily meal patterns seem sometimes to have involved three and sometimes only two meals. According to Graig, S Keener (2014:98), by this time of the year fig trees near the Mt of Olives would have leaves, but only green fruit with an unpleasant taste appeared this early. Edible figs appeared around early June. Often the green fruit would fall off, so that only leaves remained. These early, green and edible fruit buds are known to contemporary Palestinian Arabs as taqsh (Keener 2014:98). The fig tree, unlike other fruit trees, bears fruit more than once a year (Keener 2014:98). In times of drought people would eat these green fruits regardless of the unpleasant taste hence contributing to sustaining life and development in the face of 
drought. The tag of it being barren is also justified though not yet the time of figs because green figs would be expected to be seen in the tree or on the ground. Therefore, Mark presents Jesus as not unreasonable when he looked for the figs to eat from the fig tree since it was expected to have the green fruit. The question is; if that was the case why would Matthew omit that statement? The question remains unanswered.

Most interpreters have seen the fig tree as symbolic of Israel; hence regard the cursing as a symbol of God's judgment on fruitless Judaism or the Jewish leadership (Keck 1995:407). The setting of the story between the temple events in the Matthean account suggests the same connection of judgement on Temple Judaism. The withering of the fig tree, therefore, has some apocalyptic message of judgment that will find its fulfilment in the pending destruction of the city of Jerusalem and its temple. The literal interpretation of biblical texts has resulted in some believers trying to imitate such behaviour against nature. And such behaviour is not good for sustainable development.

Leander E Keck (1995:408) argues that, 'Matthew never uses the word 'fig tree' literally, but only in the ethical sense.' Viviano (1990:664) adds that, a barren fig tree is a symbol of blighted promise failure. Daniel J Harrington, Watson E Mills, and Richard interpret the miracle as the prediction of the fall of Jerusalem and the destruction of the temple around AD 70 (Harrington 1989). All these interpretations hold one thing in common, that is, the judgement of Israel. The usage of the words faith ( $\pi i \sigma \tau \imath v)$, believe $(\pi 1 \sigma \tau \varepsilon v 0 v \tau \varepsilon \varsigma)$, and prayer ( $\pi \rho \circ \sigma \varepsilon v \chi \tilde{\eta})$ in verses $21-22$ seem to suggest that the key message of the Jesus' miraculous act was to teach on faith and prayer. Jesus is teaching on the power that is based on prayer offered to God in faith. This interpretation is further supported by Daniel J Harrington (1989:297) that both Mark and Matthew understood the withering of the fig tree as an event which served as the occasion for the teachings on the power of prayer. However, why would teaching on prayer use negative examples that lead to a negative attitude towards the environment and unsustainable development?

The cursing of the fig tree by Jesus as portrayed by Matthew would lead people to practice their faith negatively on the environment through the theology of imitation. The negative use of the faith and authority can be disastrous to the environment and sustainable development. Therefore, these texts have nothing to do with Eco-theology. They should not be taken as a prescription of how people should relate to the environment. This is not the first instance where Jesus teaches about the kingdom of God using 
negative examples. The parable of the Shrewd Manager in Luke 16:1-13, is a typical example of a text where Jesus used a negative example to teach positive things about the kingdom of God. Therefore, in such texts, the reader should not focus on the negative example, but on the positive message or imagery that is being taught by the text. In this miracle, therefore, the focus should be on the power of the word of Jesus rather than on the act of the withering of the tree.

The reference to the lifting and casting of mountains into the sea should not be understood in terms of biophobic language, but the reader should realize that here Jesus is using metaphoric language. Jesus is, therefore, not encouraging people to demonstrate their faith by damaging nature. This statement is not a prescription on how people should treat the environment, but metaphorically it is a statement that demonstrates that with faith in God the impossible can be done. It will be catastrophic to interpret metaphoric language literally. However, this metaphor has been understood by some scholars, for example, John Nolland (2003:854) in terms of liberation from bondage. The mountain here represents bondage not the physical mountain hence removing it is like opening an escape route from bondage. Nolland argues that, the reason for the removal of the mountain is to open up an escape route from Jerusalem under attack. We have realized that, Zimbabwean Christians usually cite such texts in cases where they want to emphasize the results of faith. Unfortunately, they do not weigh on the implications of their statements of faith.

Questions still abound as to why cursing the tree instead of asking it to produce fruits? Why haphazardly moving nature as a way of showing one's faith? Whenever Jesus encountered a sick or demon possessed person, Jesus would simply heal or exorcise the person concerned. Why not healing the barren tree if barrenness is taken as sickness? With the cursing of the fig tree, scholars like Harrington (1998:297) accuse Jesus of destroying property and his behaviour as reckless and irrational. Hare (1993:243) argues that, it is particularly scandalous to modern Christians because the reported incident appears to be an act of unjustified petulance on Jesus' part. It is difficult to reconcile the Jesus of the Sermon on the Mount with the Jesus who cursed the fig tree. What can eco-theologians learn from this text when it comes to sustainable development? This text cannot be taken as prescriptive to environmental ethics and sustainable development.

The reason why this text has been chosen is to demonstrate how to deal with such difficult texts, especially from an environmental perspective. 
The reader should be aware that interpreting such texts literally can lead to misperceptions about Jesus' attitude towards the environment. The eco theologian should also be careful not to formulate an eco-theology discourse on such controversial texts. The appropriation of such texts should be focusing on the divine nature of Jesus who had power over nature and human beings cannot emulate such miracles since they do not have the same authority over nature. One, therefore, should read this text not with the intentions of formulating an environmental theology out of it, but with the mind of understanding the divine qualities of Jesus. Our argument is that this text should not be listed under Eco-theology texts but under the texts to be watchful of. It is a text not to be used on the discourse on sustainable development. We would like to term this text, 'a sustainable development quanta cura.' Quanta cura was Pope Pius IX's syllabus of errors. Such texts, therefore, would constitute the eco-theology syllabus of errors texts. This is not to undermine their canonical status or doubt their authority or inspiration, but their usage should be on the issues to do with the power of prayer and faith. The argument here is that such texts should be forbidden in eco theological discourse. Therefore, the limitation of the text to certain areas should not be taken as challenging its authority.

As African eco theologians, how should we read such texts? How can seemingly biophobic texts be interpreted amongst Africans and Zimbabweans especially in the context of sustainable development? The worldview of Africans and their interaction with the environment is built through taboos. Jesus' behaviour or actions on the fig tree would have militated against the Zimbabwean Shona taboos on people towards the environment. This text poses some challenges to the African view of environment and especially those African eco-theologians who seek to understand biblical view on environment from an African perspective. In such contexts, where a text seems to be biophobic in nature, the African theologian should therefore consult our African culture as a source of theology. What is the African view on the environment, particularly trees?

\section{The African View on Trees}

The major source of African views on trees are the taboos. Taboos are moral codes of a given society. For Munamato Chemhuru and Dennis 
Masaka (2010:121), taboos form an integral part and parcel of the Zimbabwean Shona morality. Taboos among the Shona people ${ }^{1}$ are found in all areas of individual and communal ethical conducts, for example, the regulation of natural resources. The taboos play significant roles in promoting sustainable use and conservation of various natural resources, such as water sources, vegetation, and animals. For the Shona people, environmental taboos have a pivotal moral role towards the ontological wellbeing of both the individual person and the environment (Chemhuru \& Masaka 2010:121). ATR does not have an anthropocentric (human-centered) view of nature as shown in the selected biophobic text in Matthew. One can rightly argue that in ATR, there is promotion of sustainable development that greens the environment. The preservation of nature through taboos help to preserve natural resources for the future generations. In the Shona cosmology, the natural vegetation and wildlife are used, instrumentally to fulfill the needs of humanity. Natural vegetation has a significant value to the spirituality of Africans (Chemhuru \& Masaka 2010:128). We have selected Matt 21:12-46 because of its popularity amongst Zimbabweans on issues of faith and trust in God. However, in most cases they do not weigh or realize the implication of the text on the environment where gospels are popularly evoked in the Zimbabwean public sphere.

Trees are significant in ATR for several reasons such as: religious (Spiritual) and medicinal, sources of energy, building materials, tools, furniture, and food. Trees are highly regarded amongst Africans, especially the Shona people. Among the Shona taboos, it is believed that, cutting a muhacha (the Hissing) tree causes drought (Chemhuru \& Masaka 2010:129). The concept 'development' also involves alleviation of poverty. Preservation of such fruit trees curbs hunger not only for this generation but also for the future ones as part of sustainable development. The taboo helps preserve such trees as rainmaking ceremonies ${ }^{2}$ are performed under the Muhacha tree. The tree is considered sacred and holds a similar position like that of Temples in Judaism, Churches in Christianity, and Mosques

1 The Shona people are the largest ethnic group in Zimbabwe. However, the term 'Shona' represents a family of five-related dialects which are; Ndau, Manyika, Zezuru, Korekore, and Karanga. See Mazarire 2009.

2 The elders observed the rain-making ceremony to ask for rain from the ancestors. For seven days; all the female elders who no longer slept with men, prepared beer for the ceremony. At dawn, people gathered around the sacred muchakata tree. A fence made of poles and bark was erected around the tree and pots of beer were placed at its base. For further reading on the ceremony please consult: Murimbika 2006. 
in Islam. The fig tree cursed by Jesus would also fall under such trees considered important by virtue of producing fruits. In ATR, all big trees let alone fruit trees are considered sacred and not to be tampered with whether they bear fruits or not. Augustine Mukoro (2012; 1) argues that, big trees belong to the ancestral spirits believed to dwell in tree branches. They are venerated for being abodes of ancestral spirits. It is a taboo to cut or defile forests in ATR.

In Muzarabani (Northern part of Zimbabwe) among the Korekore people, there are large tracts of thick forests that are believed to be resting places of mhondoro spirits (lion spirits). It is a taboo to cut such trees or say bad things let alone see trees dying or being recklessly cut or seeing somebody using mysterious powers to destroy trees. In Muzarabani, it's a punishable offense to cut trees such as the sacred baobab tree (Мuиүu). Among the sacred trees are: the baobab, tamarind, fig trees, and marula trees which are believed to protect human beings from evil forces. Crispen Dirwai (2007:61) argues that, in the Shona and Ndebele world views ${ }^{1}$ of Zimbabwe the Muchecheni/ Umphafa/ Umlahla bantu/Ziziphus macronota tree is believed to drive away witches. There is a belief that after burying someone, witches come at night to open the fresh grave and take away the corpse. To scare away witches, the branch of the thorny tree/Muchecheni is put on top of the grave. As a result, most trees get preserved and protected against deforestation. One of the major challenges that is being created by development projects globally is deforestation. Such developmental projects do not take into consideration the plight of the future generations. This is against the tenets of sustainable development where the future is of great importance.

Trees and shrubs also play significant roles in the healing of the sick, for example, mental sickness. For the Shona, leaves, roots, and barks are used for healing people and animals. Shoko (2007:504) compiled a list of trees and shrubs and the sickness they treat. The healing can be both spiritual and physical. The list of the trees and their medicinal value is too long to be exhausted in any paper or book. What is interesting is that, almost every tree has some healing effects. The Shona people value nature and would find Jesus' action on that fig tree difficult to understand as it does

1 The Ndebele people are considered the second largest ethnic group in Zimbabwe. They occupy the southern part of the country. Historically they migrated from South Africa under King Mzilikazi during the Mfecane. Cf. Mlambo 2009. 
not sustain the lives of future generations. Cutting trees entails jeopardizing the health of the future generation as trees are an important source of medicine.

Chemhuru \& Masaka (2010:129) argue that, indigenous fruit trees like the Muzhanje (Wild loquat), Mutamba (Guazuma ulmifolia), Mutohwe (Snot apple), and Munhengeni (Sourplum) are not used for firewood because they produce bad fire. Taboos are meant to protect these trees from firewood seekers. Nutritionally, some indigenous trees produce fruits that contain healthy food nutrients. Nyanga (etal) (2013:168) adds that, the masau (Ziziphus mauritiana) fruit is richer than apples in protein, phosphorus, calcium, and vitamin C. They contain more phosphorus, iron, Vitamin $\mathrm{C}$ and carbohydrates than oranges. Indigenous fruits are there to benefit both animals and human beings hence commercializing them is prohibited. For Munyaradzi Mawere \& Tapuwa R Mubaya (2015:16), one of the most common ways in which many Zimbabwean societies coped with drought and famine was the gathering of wild fruits, namely the muchakata (Parinari curatellifolia Planch), Muzhanje (Wild loquat), and Mutukutu (Camel-foot). Ironically, indigenous trees just like the Israelite fig tree bear much fruit during the drought years, thereby sustaining the lives of birds, animals and people. Therefore, they have always been referred to as, famine fruits, because they give communities a lifeline during the times of adversity (Mawere \& Mubaya 2015:16). In ATR, fruit trees belong to the community. Strangers on a journey can help themselves with some fruits though harvesting them is prohibited. The taboos on fruit trees are silent on barren ones. The Shona people find it ironical for a passerby behaving the way Jesus did when he cursed that fig tree. The curse shortened the lifespan of a tree which had no fruits out of season. The curse by Jesus gives the assumption that all barren trees do not deserve to live. Yet the barren ones are still useful for the community. They are not only there to bear fruits.

Chiefs in ATR are considered custodians of religious values. The traditional or justice courts are normally carried under a huge tree. Chiefs as custodians of land are the ones responsible for the preservation of the natural resources. Chiefs regulate the usage of these natural resources hence it is not permissible to cut trees haphazardly. Cutting a sacred tree attracts a huge fine and a lesser one for ordinary trees. For example, in Muzarabani, it is an offense to harvest masau (Ziziphus mauritiana) fruits for commercial purposes or disturbing the peace of the tree. The biophobic 
reportage in Matthew would have put Jesus in trouble with the Shona traditional authorities in Zimbabwe. Jesus' action in Matt 21:18-22, would have been found unacceptable in ATR. There is no problem with looking for fruits as a hungry man as this is acceptable in ATR. ATR is hospitable to the strangers. However, Jesus' action of cursing a fig tree is unacceptable in ATR. It does not matter whether the action depicted the miraculous hand of God or not, or whether it is meant to convey a message or not. Even chiefs and other sacred practitioners do not have that freedom of destroying nature. In ATR, Jesus would have been considered biophobic hence susceptible to a heavy punishment. The only situation when the destruction of a big tree is acceptable is when one hangs himself on it. This is the only time when the tree is considered cursed. The chief or headman orders the cutting and burning of that tree and no one is allowed to use it for firewood.

If this miracle was to be performed in contemporary Zimbabwe, the Acts of Parliament would have still found Jesus wanting. Issues of the environment are provided for by the country's constitution under the Environmental Management Act (EMA) Chapter 20:27. This Act is broad and has many other sub-Acts and trees are covered under the Forestry Act 19:05. The EMA 20:27 was enacted with the purpose of:

Sustainable management of natural resources and protection of the environment; the prevention of pollution and environmental degradation; the preparation of a National Environmental Plan and other plans for the management and protection of the environment; the establishment of the Environmental Management Agency (EMA) and an Environmental Fun; to amend references to intensive conservation areas and committees and associated matters in various acts (EMA Act 20:27:5).

EMA, therefore, is a government parastatal that oversees the implementation of this act and other sub-acts for specific environmental portfolios such as trees, water, and minerals. The management of trees, therefore, is the task of the Forestry Commission that eventually reports to EMA. For the terms and reference of the Forestry Commission one then should consult the Forestry Act 19:05. According to the Act, the word tree means, 'the whole or any part of any tree as ordinarily understood, or of any shrub, seedling, transplant, sapling, reshoot, under-bush, under-growth and regrowth' (Forestry Act 19:05:4). It is a crime under section 78 for any individual to, "cut, fell, injure, or destroy, collects, takes or remove any tree, timber or other forest produce" (Forestry Act 19:05:31). Any natural or artificial feature along the highway belongs to the state and this applies to 
the trees as well. Any damage to the trees along the highways is then considered a crime to be punishable under EMA Act 20:27. So if Jesus' had performed this miracle along the highways of Zimbabwe, He would have been convicted of the crime of violating Forestry Act 19:05. Therefore, the miracles of Jesus that touch on the environment have to be understood in their context if they are ever going to contribute towards the preservation of the environment. In the African cultural context, the biophobic texts do not make any sense if taken and understood in their literal form as they will not help us and future generations on how some biblical texts have been read to promote sustainable development and the environment.

\section{Biophobic Tendencies and Sustainable Development}

According to Benjamin K Pachauri (2008:17), "it is now becoming increasingly apparent that the global community over several decades has pursued a path of development which is clearly not sustainable. " How sustainable are Pachauri's sentiments? The current popular discourse on global warming is a clear testimony to Pachauri's sentiments. For anthropocentric reasons, people have sacrificed nature, trees in particular, for the sake of development. Just like Jesus, as narrated by gospel evangelists, who cursed the tree for the reasons of not meeting his personal needs, people are also destroying nature for self-aggrandizement. For example, the construction of the Long Cheng Plaza shopping mall and amusement park in gazetted wetlands in the outskirts of Harare in 2013 generated much controversy between government and EMA (Mathuthu 2013). Important functions of wetlands such as, feeding downstream waters, trapping floodwaters, recharging groundwater supplies, removing pollution, and providing fish and wildlife habitat were all ignored in favour of the $\$ 200$ million investment on the mall by the Chinese firm. The other example is the story of sand poaching in areas such as Epworth, Seke, Dzivarasekwa Extension and Chitungwiza. Tons of sand are illegally dug every day for construction purposes. Such activities have created gullies which have become breeding sites for mosquitos and, therefore, a health hazard to the local communities. As people celebrate 'development' through construction of houses, children are at the risk of drowning especially during the rainy season (Kafe 2018). Such development policies do not promote sustainability because of their disregard of the plight of the future generations. A literal interpretation of biophobic texts such as 
Matt 21 promotes such selfish and uncaring attitude towards the environment and future. A deep reflection on the plight of the future generations would help to read such biophobic texts with a liberal mind. Therefore, biophobic tendencies are an antithesis for sustainable development.

\section{Conclusion}

Matt 21:18-22 has several significances to different people. From an African religio-cultural perspective the text has some negative connotations of being biophobic. For the environmentalists, Matt 21:18-22 also carries some negative connotations since every tree whether barren or not plays a significant role in biodiversity. Such biblical texts cannot help in fostering sustainable development. The paper therefore recommends that biophobic texts should not be taken as manual for environmental ethics. The text must never be understood literally but should be interpreted in light of its theological context and significance. The actions of Jesus must be understood parabolically. What matters for Christians in this text are not the details of the story but its context, theological/ spiritual significance in relation to the teachings on the Kingdom of God theme. However, Christians have to be wary of the biblical texts that portray negatively or lead to the ill-treatment of the environment. Biblical texts that lead to negative attitudes toward the environment must be re-read, re-interpreted, and read in the light of other texts that talk positively about the environment. Few texts that are negative on the environment should not be taken as constituting the entire biblical theology on environment. Biblical interpreters should, therefore, consult other positive texts on the same subject and reach balanced positions on the biblical view on environment. Our African Traditional Religion should also be seriously considered as a source of environmental theology for African biblical scholars particularly those areas that are compromising the tenets of Christian theology. A combination of ATR and Biblical theology makes a better environmental theology.

\section{References}

Ahsan, Mohammad, K. 2012. “Sustainable Development and Environmentalism. An Ethical Framework for Policy and Decision Making in Developing Countries, With Special Reference to Bangladesh", Doctorate Thesis (Cardiff Univ.)

Brown, Jeannine K. 2007. Introducing Biblical Hermeneutics: Scripture as Communication (Michigan, IL: Baker Academic). 
Chemhuru, Munamato. Masaka, Dennis. 2010. 'Taboos as Sources of Shona People’s Environmental Ethics', Journal of Sustainable Development in Africa 12. 7: 121-133.

Davies, Dale, W. D. Allison, C. Jr. 1997. The Gospel According to Matthew (Edinburg: T\&T Clark).

Deane-Drummond, Celia. 2008. Eco-Theology (London: DL \& T).

Dirwai, Crispen. 2007. 'Sustainable Environmental Management: An Ethno-Based Approach: The Case of Totems, Spirostachys Africana and Acacia Nigrescens in Conserving Zimbabwean Fauna and Flora', Journal of Sustainable Development in Africa 9, 4: 48-80.

Environmental Management Act 20:27

Dower, Nigel. 1992. "Sustainability and the Right to Development", in International Justice o the Third World, ed. by Attfield, R \& Wilkins, B (London: Routledge) 93-116.

Edwards, Michael. 1999. Future Positive: International Co-operation in the 21st Century (London: Earth Scan).

Farmer, William R 1976. The Synoptic Problem: A Critical Analysis (Dillsboro: WNC Pr.). Forestry Act 19: 05.

Gasper, D. 2004. The Ethics of Development (Edinburg: Edinburg Univ. Pr.)

Hagner, Donald A. 1995. Word Biblical Commentary Vol 33b Matthew: 14-28 (Dallas:

Word Books Publisher).

Hare, Douglas R. A. 1993. Interpretation. A Bible Commentary for Teaching and Preaching: Matthew (Louisville: John Knox Pr.).

Harrington, Daniel J. 1991. The Gospel of Matthew (Minnesota: The Liturgical Pr.). Harrington, Daniel J, 1989. 'Matthew”, in D. Bergant \& R. J Karris (eds.) The Collegeville Bible Commentary (Minnesota: The Liturgical Pr.): 861-902.

Kafe, Emmanuel. 2018. 'Sand Poaching endangering lives, agric', in The Sunday Mail $(18 / 02 / 2018)$

Keck, Leander, E (etal), The New Interpreter's Bible Vol VIII (Nashville: Abingdon Pr., 1995).

Keener, Graig S. 2014. The IVP Bible Background Commentary: New Testament (Downers: Intervarsity Pr.).

Lee, Ellis. 1996. 'A Discipline in Peril: Sociology's Future Hinges on Caring its Biophobia', American Sociologist 27. 2: 21-41.

Macquarrie, John. 2009. Principles of Christian Theology (London: SCM Pr.).

Mann, Justin. 2012. 'Biophobia and Biophilia' in: www.academia.edu.5488553/. Assessed, 10/03/2016.

Mathuthu, Mthulisi. 2013. 'Chinese Mall opens despite warnings from Environmentalists', Nehanda Radio (18/12/2013)

Mawere, Munyaradzi. Mubaya, Tapuwa, 2015. 'Indigenous Mechanisms for Disaster Reduction: How the Shona of Zimbabwe Managed Drought and Famine', in M. Mawere \& S. Awuah-Nyamekye (eds.) Harnessing Cultural Capital for Sustainability. A PanAfricanist Perspective (Bamenda: LSPCIG):1-31. 
Mazarire, Chikozho, G. 2009. 'Reflections on Pre-Colonial Zimbabwe 850-1880s', in B. Raftopoulos \& A. Mlambo (eds.) Becoming Zimbabwe: A History from Pre-Colonial Period to 2008 (Harare: Weaver Pr.): 1-38.

Mbiti, John S. 2015. Introduction to African Religion (Long Grove: Waveland Pr., $2^{\text {nd }}$ edn.)

Mlambo, B. R. A. S. 'The Hard Road to Becoming National', in B. Raftopoulos \& A. Mlambo (eds.) Becoming Zimbabwe: A History from Pre-Colonial Period to 2008 (Harare: Weaver Pr.): i-xx.

Mukoro, Augustine. 22/02/2012. 'Zimbabwe, Muhacha Most Venerated Tree', Financial Gazette (Harare)

Murimbika, McEdward. 2006. Sacred Powers and Rituals of Transformation: An Ethno archaeological Study of Rainmaking Rituals and Agricultural Productivity During the Evolution of the Mapungubwe State, AD 1000 To AD 1300. Unpubl. thesis, Univ. of the Witwatersrand, Johannesburg,

Nickerson, Brian J. 1994 'The Environmental Laws of Zimbabwe: A Unique Approach to Management of the Environment', Boston College, Third World Law Journal 14. 2: $189-230$.

Nolland, John. 2003. The Gospel of Matthew. A Commentary on the Greek Text, (Michigan: WB Eerdmans)

Nyanga, Loveness K. Gadaga, Tendekayi H. Nout, Martinus J. R. Teun, Eddy J. S. 2013. 'Nutritive value of masau fruits from Zambezi Valley in Zimbabwe', Food Chemistry138: 168-172.

Orr, David W. 2004. 'Love it or Lose it: The Coming Biophilia Revolution', in D. W. Orr (ed.) Earth in Mind: On Education, Environment, Land and the Human Prospect (Washington: Islands Pr.). 186-213.

Pachauri, Rajendra, k. 2018. 'Battling Climate Change by Promoting Environmentally Sustainable Development', in Achieving Sustainable Development and Promoting Development Cooperation-Dialogues at the ECOSOC (New York: UN). 17-22.

Reed, A. 1985. Inequality and Development (London: Bell \& Hyman) Shoko, Tabona. 2007. 'Karanga Traditional Medicine and Healing', African Journal of Traditional, Complementary, and Alternative Medicines 4. 4: 501-509.

Speight, Sarah. 2013. Learning for Sustainability (Nottingham: Univ. of Nottingham). Viviano, Benedict T. 1990. 'The Gospel According to Matthew', in R. E Brown, J. A Fitzmyer \& R. E Murphy (eds.) The New Jerome Biblical Commentary (New Jersey: Prentice Hall): 630-674. 


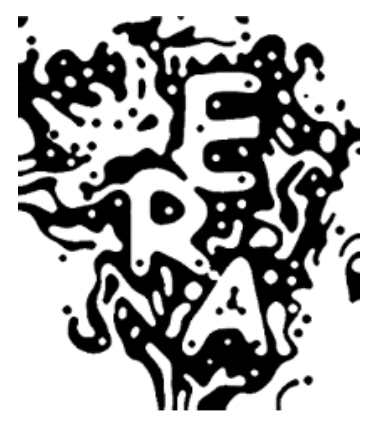




\title{
The Bible, Sexuality Challenges and the Development Agenda
}

\author{
Zimbabwe's Tertiary Institutions in Focus
}

\author{
Canisius Mwandayi
}

\section{Introduction}

Since the establishment of learning centres by missionaries during the colonial era (Zvobgo 1996), the word of God has been read and preached ceaselessly to both students and staff. In spite of all these efforts, sexuality challenges in these learning centres and particularly tertiary institutions has remained a hidden transcript that some students not only acquire but often carry along with, as they leave tertiary life into the job market and often impacting negatively on a country's developmental efforts as many often succumb to sexually transmitted illnesses, including HIV \& AIDS. What happens at colleges and universities defies the common missionary expectation that one becomes better the more he/she is preached to or reads the Bible.

To unmask the complexities around sexuality challenges, I shall first provide the method and procedure adopted in the paper, move on to provide a general understanding of sexuality challenges, look at transactional sex in tertiary institutions, discuss the implications of sexual challenges to the development agenda of a nation and lastly emphasize on the need for an educator to understand all these dynamics for the good of the students, as well as the common good of the nation.

\section{Method}

Using a canonical approach to the Biblical texts as well as the systems perspective, it is the interest of this chapter to explore the phenomenon of sexuality challenges at some length. As opposed to a diachronic approach whereby one looks at the development of the text over time (historical criticism), the canonical approach takes a synchronic approach whereby one looks at the Biblical texts as they exist at one point in time (Pereira 2015). The canonical approach is particularly interested in the meaning of texts 
within their canonical context as finished works and historical criticism is not rejected but is given a subordinate status. As for the systems perspective, Leischow \& Miltein (2006) defines it as a paradigm or perspective involving a focus on the whole picture and not just a single element, awareness of the wider context, an appreciation for interactions among different components, and trans-disciplinary thinking (as cited in Kumanyika et al 2010).

While the common approach has been to condemn transactional sex in tertiary institutions as contrary to Biblical injunctions and label those found in the habit of practising it as incorrigible and leading sinful lives, this paper argues for the need to learn from God who is not only patient with individuals facing challenges but loves them, waiting for their return to him. This chapter advocates a holistic approach to the matter given that the issue is complicated and there is rarely a sole cause to this problem nor a quick solution to it. Faced with this situation, therefore, systems thinking helps to tackle this complex problem by stepping back and looking at all the factors which contribute to prostitution in tertiary institutions and just as importantly, the relationship between these factors.

\section{Procedure}

The nature of this study called for a desktop survey using internet resources focusing on transactional sex in tertiary institutions not only in Zimbabwe but in other contexts as well. Despite its own weaknesses, electronic media has become one of the dominant sources about social life happening anywhere in the world.

\section{Definition of terms}

\section{Transactional sex}

The term transactional sex appears quite elusive when it comes to defining it as interpretations of the term often tend to be culturally determined and construed. In Soweto and Hammanskraal in South Africa, a Zulu word ukuphanda (loosely meaning to get money) is used in reference to informal transactional sex, while in Lesotho transactional sex relationships are referred to as bonyatsi, which is a socially acceptable extramarital relationship of a long-term nature in which men provide material and 
non-monetary assistance (Formson \& Hilhorst 2016). As a working definition for this paper, I shall adopt a widely accepted understanding of transactional sex as an engagement in sex in exchange for cash, goods, services, commodities, or privileges in order to meet the needs and wants of the parties involved (Chatterji et al. 2005; Dunkle et al. 2004).

Given that there are a number of grey areas bordering the terms transactional sex and prostitution, I shall at times use them interchangeably. This does not mean the two in the strict sense should be taken as one and the same as the exchange of gifts for sex in transactional sex is part of a broader set of obligations that might not involve a predetermined payment as in prostitution. While in everyday transactional sex relationships, exchange is not necessarily a straightforward cash transaction or simply sex pursued on a professional basis, it is not that different from prostitution in that in praxis both involve the use of one's body in exchange for something.

\section{What is deviance?}

As to the exact meaning of deviance, one is also faced with the reality that there is no unanimous definition among social scientists as to what it really means (Charles 2002). The cause of this lack of unanimity is that social scientists use different approaches in trying to analyse what may be termed acceptable standards of conduct in a given society or group. A follow up to the various approaches used by social scientists in trying to determine what the acceptable standards are, however, lies beyond the scope of this paper. In simpler terms, deviance is any behaviour that violates social order and norms. It is usually of sufficient severity to warrant disapproval from the majority of society. It can be criminal or non-criminal. People who are considered deviant normally engage in such activities as alcoholism, excessive gambling, being nude in public places, stealing, lying, prostitution and purchasing the services of prostitutes. People who engage in deviant behaviour are referred to as deviants. The concept of deviance is very complex because norms vary considerably across groups, times and places. This means that what one group considers deviant could be regarded as acceptable by the other and vice- versa. It is deviant behaviour to greet someone with a kiss in some parts of Africa, yet in other places a kiss is a sign of respect and showing love in public.

A general working definition that this chapter will use is that deviance refers to "some behaviour that is inconsistent with standards of acceptable conduct prevailing in a given social group [...]" (Charles 2002, \1). Such a 
definition is related to the one provided by Erickson when he said that deviance can be defined as "conduct which is generally thought to require the attention of social control agencies, that is, conduct about which something should be done" (Erikson cited in Rainwater 1960:18). What both definitions show is that deviance is not an aspect that can be said to be part and parcel of certain forms of behaviours but is rather something which is labelled upon these forms by the society or group of persons who directly or indirectly witness such behaviour.

In studying social deviance, therefore, while the individual involved in deviance should not be left out, the most critical element in such a study should be the society or social audience for it is this audience which determines whether an action is deviant or not. It is on this basis that this chapter intends to focus on educators in the tertiary education system.

\section{Understanding sexuality challenges and deviance}

The rationale for good understanding of social deviance by the educator is linked to the expected role which should be played by the tertiary educator. A look at education history shows that conventional pedagogic approaches have had the tendency of positioning the teacher as the designer of every aspect of the learning, including what will be learned, when and how (Hart et al. (2004); Field, (2006) cited in Vigurs, (2012). While such a teacher-centred approach suited so well to those old days, given the fact that there were less technological advances, it, however, had a dark side to it. It created a dependency syndrome of the learner on the teacher. A learner, in other words, was subjected to a passive and submissive role (Tett, (2010) cited in Vigurs 2012).

The past decades have witnessed a gradual shift from this position as most educators are advocating student-oriented approaches. Due to this shift of goal posts, the role of the educator is no longer defined in terms of just being a 'listen to me' or 'the sage on the stage' kind of role but is now explained as that of trying to enable students to create and manage their own education. Instead, however, of such developments resulting in the role of the educator being reduced to that of being just a 'guide by the side,' the role of the educator has increasingly become so diversified also. Stephen Downes (2010) defines the role of the educator as that of being able to 'model and demonstrate.' For him, students need prototypes on which to model their work as this is premised on the fact that we almost all begin by copying successful practice, and then begin to modify that 
practice to satisfy our own particular circumstances and needs. Apart from the need to be able to model and demonstrate, student-oriented approaches demand that the educator assumes the role of being a facilitator, a moderator, a mentor, and a coordinator.

To explain just briefly on each of these: a facilitating role entails the capacity to direct the learning process or discussion forward, but within a broad range of parameters that will stress clarity, order, inclusiveness, and good judgment. The facilitator's task, in other words, is to keep things on track and within reason, gently nudging things forward, but without typically imposing his or her opinion or agenda onto the outcome. As for moderation, this is related to facilitation but is a separate skill which involves encouragement, governing and pruning. The moderator is more concerned about decorum, good behaviour and rules. The art of mentoring, as noted by Stephen Downes (2010:37), is "multi-faceted, ranging from sharp critic to enthusiastic coach, but outweighing these is the personal dimension, the presence of the entire personality rather than some domain or discipline." Last but not least, the role of being a coordinator in a class encompasses organizing schedules, setting expectations, managing logistics, following up and solving problems.

The above-mentioned roles put the educator in a better position to understand his/her students quite well. He/she is able to tell who among his students abides by the set rules of the institution as well as those who fail to live according to the given rules. A good understanding of the nature of the students he/she would be dealing with helps the educator to achieve the desired learning goals of the modules he/she teaches as well as those goals set by the institution in line with the national agenda.

In any given learning environment, there are always bound to be some students who portray some behaviour that is inconsistent with the prevailing standards of acceptable conduct. Chief among the factors leading to students behaving so differently is the fact that students come from diverse backgrounds and the educator needs to be cognisant of that. Due to this diversity in terms of background, some students may portray deviant behaviour simply because they are seeking attention, or it may simply be a way of trying to avoid work. Robertson (1996) was thus right when he suggested that when considering the causes of misbehaviour, it is useful to identify what the motive for the (student) pupil might be (Robertson cited in Kyriacou 1997). What it means then is that these students deserve more attention; they need to be helped navigate their schooling instead of being shoved aside. Failure to handle their situation properly or diagnose 
the cause of the deviant behaviour may negatively impact on the whole programme being taught or even derail the national developmental agenda itself.

\section{Causes of Sexuality Challenges and Deviance}

There are a number of theories that try to explain the causes of deviance in general that have been forwarded by researchers. Some of the common theories are: the differential association theory; the anomie theory; the control theory; the labelling theory and others.

\section{The differential association theory}

As noted by Harcourt (2016), it is Edwin Sutherland who coined the phrase 'differential association' to address the issue of how people learn deviance. According to the proponents of the differential association theory, people learn their norms from various socializing agents like, for example: teachers, church members, friends, co-workers, the media, family members and many other socializing groups they interact with. It is these particular social groups which provide norms of conformity as well as those of deviance, thus heavily influencing how an individual may look at the world including how he/she may react. Thus, for the proponents of this theory, the environment in which one finds him/herself has a lot of influence on how an individual may learn a deviant behaviour. Briefly put then, the theory says that an individual learns deviant behaviour just like any other behaviours from his/her association with others especially intimate social groups.

\section{The anomie theory}

Robert Merton (cited in Harcourt 2016) is known to have used the term 'anomie' to describe the experience or reaction that arises when an individual realises an obstacle in his pursuit of a socially accepted goal. When an individual is faced with such a scenario, he/she may employ deviant behaviours or to attain his goals, retaliate against society to attain his/her goals or simply to make a point. Along with other theories, the anomie theory also adds to our understanding of the many forms of deviance. 


\section{The control theory}

According to the proponents of this theory, there are various restraints that control people from engaging in deviant behaviours. There are what they would term as internal controls, such as conscience, values, integrity, morality, and the desire to be a "good person"; and outer controls, such as police, family, friends, and religious authorities (Reckless \& Hirschi cited in Harcourt 2016). Since the key to developing self-control is proper socialization, especially early in childhood, children who lack this self-control may grow up to commit crimes and other deviant behaviours.

\section{The labelling theory}

Labelling theory emphasizes on the role that attitudes and reactions of others have in the development of deviance. Proponents of this theory hold that behaviours are deviant only when society labels them as deviant (Harcourt 2016). Their argument is that it is conforming members of society, who interpret certain behaviours as deviant and then attach this label to individuals. Powerful and influential members of the society such as politicians, judges, police officers, medical doctors, and so many others are said to impose the most significant labels. The aspect of being labelled, however, as a drug addict, alcoholic, criminal, delinquent, prostitute, sex offender and psychiatric patient to mention but a few, is known to have far-reaching consequences as those labelled may end up rejecting themselves leading to suicidal cases or they may even act more deviantly as a result of the label.

\section{Prostitution in Tertiary Institutions}

Prostitution is a phenomenon that falls under the general category of sexual deviance. Ritzer (2007) defines sexual deviance as "behaviours that involve individuals seeking erotic gratification through means that are considered odd, different, or unacceptable to either most or influential persons in one's community." Prostitution as such is defined by Jenkins (2016) as "the practice of engaging in relatively indiscriminate sexual activity, in general with someone who is not a spouse or a friend, in exchange for immediate payment in money or other valuables." In terms of the actual persons, prostitutes may be either male or female or transgender and it may entail heterosexual or homosexual activity. The 
term prostitution is now widely frowned upon with commercial sex work becoming a more acceptable description.

What often leads tertiary students into acts of transactional sex varies from individual to individual as well as from one campus to the other such that there is no way one can say this particular theory or reason answers why all such acts are becoming more rampant in tertiary institutions. A desktop research of some online articles has a lot to reveal. According to one post entitled: Prostitution on the increase at Universities and Colleges, Students open up (2009), a number of students did participate in a live talk show on a radio programme hosted by Sithandekile Simango and revealed why they were engaging in prostitution. From the live talk one could conclude that sex is increasingly being taken by students as a medium of exchange for one to get a good pass mark, to get a decent meal, free rides to school and free accommodation. For example, one female student called and openly confessed:

I bed my lecturers so that I get good grades, bed a sugar daddy outside college in order to get money for food and rent, then I bed the Kombi driver in order to get free rides to school and sometimes even have sex with the landlord in case I fail or delay to meet rent dues and lastly bed a hard working guy from class so that I get help when doing assignments since there is no time to concentrate on school work given the number of guys I have to attend to (female student cited in Zaniest 2009).

While such a disclosure looks to be something which was made up, it captures at least some of the reasons why students end up opting for transactional sex during their years at college. Male students who participated in the programme admitted that they were in no better position than their female counterparts for they alleged that they were being preyed on also by some men within and outside the colleges for homosexual sex for precisely the same reasons as their female mates. In some cases, also, male students testified that they were being used by both their female counterparts and the male "hunters" to arrange dating chances at an agreed commission.

In the same article, the author acknowledges that it is not a hidden secret that students in Zimbabwean colleges and varsities struggle to survive as the government is hardly doing anything to cater for their welfare. Due to limited accommodation at most institutions, students are forced to seek expensive alternative lodgings. A study, for example, conducted by Mwandayi in 2013 revealed that, students in Senga and Nehosho, loca- 
tions in Gweru city, were being made to occupy a small room in disproportion to their bigger numbers. Rooms which under normal circumstances would accommodate at most two to three people were made to accommodate five to seven students and each was required to fork out amounts ranging from US\$ 50.00-\$70.00 and this had to be paid right on time otherwise the student risked being chucked out (Mwandayi 2014). It is such distressing situations which drain their purses and make life extremely difficult that often force students to seek alternative means of survival.

A growing literature concerning transactional sex among university students in Zimbabwe positions sexual exchange practices clearly within a 'sex-for-consumption' framework (Mitchell 2011). A 2014 publication by the Financial Gazette, 'STIs rife in Tertiary Colleges,' for example, reveals that university and college students are engaging in the oldest profession of hawking sex to augment their meagre income. A number of students, it appears are entrapped into commercial sex not so much out of desire as such but because of need. Many of those who have entered the profession may identify with the voice of an interviewee with the pseudonymous name Malinda Ayatola, who is quoted saying: "No one is born a prostitute. It is the circumstances that some of us come across that force us to do whatever it takes to put food and school fees on the table," (Ayatola cited in Financial Gazette 2014).

Sympathizing with the predicament that most students face when they come to college, another publication by a local newspaper NewsDay titled: 'Female Students Dice with Death for Survival'(2012), underscores the fact that most of the girls, who end up engaging in transactional sex relationships, "would have left their parents' homes as God-fearing and sexually-righteous individuals, but they are quickly exposed to this unsavoury behaviour upon getting into college."

In a report published by UNESCO, 'Young People Today, Time to Act Now' (2013), it was noted that poverty was one of the leading drivers in transactional sex, especially with the rise in school fees for most higher tertiary education institutions. Most students were found to sell sex because they need money. Living in poverty leads to increased stress and anxiety. This in turn affects physical and mental health and limits personal choice. The report gives credence to the fact that if there is lack of adequate financial resources for basic needs, the chances of transactional and intergenerational sex become higher and this will see young students engaging with much older partners known as 'sugar daddies' and 'jelly mammas.' As 
noted in the report, transactional relationships (for money, gifts such as school provisions or shelter and protection) are common and they disempower the receiving partner, usually girls or young women. The greater the economic gift or transfer, the less likely it is for safe sex to be practised (UNESCO 2013). Similar sentiments were expressed by Leclerc- Madlala who noted that against considerable material gain as well as psycho-social and emotional benefits, ' any perceived risk of HIV is often pushed aside in an effort to add meaning to difficult and uncertain lives and to create at least the illusion of romance` (as cited in West \& Haddad 2016).

While poverty was noted as one of the leading drivers to transactional sex, other researchers have gone a step further to point at the mere need by some students to lead a visible and flashy life while on campus. Tsitsi Masvawure in her publication, “'I just need to be flashy on campus': female students and transactional sex at a university in Zimbabwe" (2010), for example, sees peer groups which place a high value on materialism and 'visible' success as key players that motivate female students to engage in transactional sex. She argues that young women's 'visual' success is measured through a number of ways including owning fashionable clothes, the latest mobile phones and hairdos, eating takeaway food, and receiving lifts in expensive cars. For her, it is through owning the latest 'luxury' items, sporting the latest hairdo and consuming high-priced food that female university students are able to 'visibly' position themselves on campus as cultured, successful, mature, desirable and modern subjects distinctly different from their peers (Masvawure cited in Mitchell 2011). Since young women consider prestige as the most important thing, they consider it not bad to peddle their bodies in exchange for the gifts that make them see themselves as miles ahead of others.

Such a phenomenon observed by Masvawure is not a unique feature of Zimbabwean tertiary institutions but is found also in other tertiary institutions outside the country, if not the world over. During their study on mixed sexual relationships, Silberschmidt \& Rasch (cited in Shumba et al 2011) found that Gauteng university women students exchanged sex for account payments and fashionable clothing, access to commodities that conferred a certain status and represented a sophisticated lifestyle. Such a trend is also found to be common not only in universities in Africa but the world over. From the USA to the UK, writes Maya (2015) 'sugar daddies' and 'sugar babies' are becoming a reasonable option for young women who are not only sexually curious, but also seeking to fund ridiculously high educational costs with money from rich men who are eager 
to generously pay for 'companionship.' At the back of her mind, as observed by Almon Shumba et al (2011), the female student does not see herself as a victim of sex with older males or even young mates who have resources but rather sees herself as a consumerist entrepreneur who gives sex in exchange for gifts and other 'modernist' items. She sees herself as an active agent and entrepreneur who deliberately exploits the partner(s) in the relationship.

\section{Implications of sexuality challenges and deviance to the development agenda}

The Roman philosopher and theologian of the late Roman / early medieval period, Augustine is inter-alia known for his warning advice, "Remove prostitution from human affairs and you will destroy everything with lust" (cited in Alvarez 2015). Augustine was of the opinion that it was better for a man to have non-procreative sex with a common woman than with his wife because at least he would not be corrupting an innocent woman. Augustine's views led not only to the recognition of prostitution as a necessary evil by the medieval society since it was a means to curb men's lust, but it also led to the legalisation of prostitution in much of western Europe. Municipal officials permitted prostitution to function within the city walls so long as it was regulated and was a source of revenue to the state coffers (Hammer cited in Alvarez 2015). From this historical angle one cannot dismiss the fact that prostitution in a way contributed to the development agenda not only by helping society move on through averting potential problems but also through contributing to the state's fiscus.

Since those medieval days up to the present-day prostitution whether officially recognised or not has continued to contribute in some way to the development agenda. A number of women in the profession have been able not only to bring food on the tables of their families but also send their children to school from monies cashed through prostitution. As with young ladies in tertiary institutions, some who engage in transactional sex have been able to clear their accommodation bills while on campus, pay their tuition fees and even assist their financially struggling siblings back home. When positively looked at, one cannot dismiss the fact that all these endeavours have something to add towards the achievement of at least two of the key targets of the millennium developmental goals namely: to eradicate extreme poverty and hunger and to achieve universal primary education. 
While for countries with struggling economies entrepreneurial skills are the way to go and that a consumerist entrepreneur who gives sex in exchange for gifts and other 'modernist' items somehow makes some contribution to the development agenda of a nation, there are some pitfalls associated with transactional sex, especially, when it involves young ladies in tertiary institutions. Tertiary institutions are supposed to be the producers of skilled human resources, which is critical for development to happen. However, if the product in the making engages in risky sexual behaviour it spells nothing other than disaster not only for the individual but also to the very fabric of the nation itself. HIV \& AIDS and complex sexually transmitted ailments know of no boundaries and when these are compounded by other complications associated with early sexual life before marriage, the nation falls short of skilled labour hence its development is curtailed. A report given by the Centre for Strategic and International Studies, shows that Southern Africa is in serious developmental challenges as HIV \& AIDS is the leading cause of death and disease among women of reproductive age, thus, it is tearing into the promising human resource. The report shows that young women aged between 15 and 24 are at particular risk and their infection rate is three times higher than that of males of their age (Fleischman 2010). The problem lies in the fact that young women tend to prefer sex relationships with men who are much older than their age. This finds echo in the research by Gerald West and Beverly Haddad (2016) who argue that research of the past decade has consistently shown that age-disparate relationships increase the rate of HIV infections, especially, among young women.

\section{Finding God in campus life}

Reading and listening to talks about campus sex life tempts one to quickly conclude that God dwells not in tertiary institutions for what goes on there appears directly opposed to God's dictates. While the temptation to talk about the absence of God in tertiary life is very high given the high levels of sexual immorality that characterises such a life, the sombre atmosphere and chorus of praise and worship that marks the evenings of most tertiary institutions sends a different signal which appears to confirm God's presence in the midst of such a life. Though God's word is clear in such texts like 1 Cor. 6:9,18; 2 Cor. 12:21; Eph. 5:3; Heb. 13:4; Mt. 5:28; Mk. 7:22-23; Prov. 1:15-19 that God approves not of sexual immorality, there is need to admit that God dwells with people in all their situations, no matter how 
sinful they are. This finds echo in Jer. 14:9 who says: "You are in our midst, O LORD, and we are called by Your name. Do not forsake us." God's call to repentance is stronger the more one drifts away from God and is patient enough waiting for one's return as well exemplified in the case of the prodigal son (Lk. 15:11-32).

Looking at campus life in view of the word of God, one finds both a circumvention as well as efforts to assent to God's will. It is a circumvention in the sense that some students, despite being praise worshippers themselves who almost daily hear and at times preach to others God's prohibitions, continue to indulge in transactional sex. While circumventing God's word is in itself bad and sinful, the very effort, however, they show in coming before his presence needs to be acknowledged as assenting to God's will. In Isaiah, God invites people to repentance and promises total cleansing of their filthiness. Through Isaiah the prophet God says: "Come now, let us set things right, though your sins be like scarlet, they may become white as snow; though they be crimson red, they may become white as wool" (Isaiah 1:18). It is from reading such passages as these in Isaiah and 1 John that one can come to a glimpse that God loves and understands deviants better than we do as humans and this we have to learn. Such passages like Isaiah 1:18 and 1 John 1:18 demonstrate that the Bible can actually be used as a positive resource in equipping young people to face the challenge of their own human weakness and move forward in the confidence that God still loves them and need not despair. They can also help interpret such passages to their own peers and in so doing influence social change in the context of HIV \& AIDS vulnerability. With the support they would derive from such passages, many would appreciate that being infected does not mean the end of the road and such a positive mind is critical for the development agenda.

\section{Understanding Sexuality Challenges and Deviance}

A good understanding of sexual deviance among students by the educator provides also a platform to provide some corrective measures. The ability to single out sexual deviants and understanding their behaviour will enable the educator to handle their case professionally. Students, as noted earlier on, come from various backgrounds and there is no way in which an educator can help them unless he/she understands the cause of their deviant behaviour. Some grow up without parental guidance and hence they just grow up thinking that whatever they decide for themselves is fine 
as long as it suits their ego. Even if they were to fail to turn up for a lecture or hand in an assignment on time, they do not feel any qualms about it for in their years of growing up no one was there to either say this is right or this is wrong. A good understanding of the nature of such students would enable the educator to provide that missing guidance in the student's life. Through counselling, the educator may thus assume the role of a parent in the student's life and help him/her navigate well his/her schooling. In dealing with deviant students it is important to let them know that the educator cares really for them and would try every means to help them.

As reflected in the foregoing articles covering transactional sex in tertiary institutions, some students may engage in transactional sex not out of will as such but due to circumstances. After listening to such students, one may actually end up sympathizing with the student. Some may be coming from a single-parent-headed family and the mother or father might not be working and the student would have to work for her own fees by crossing the border to South Africa and Botswana, buying clothes for re-sale here in Zimbabwe. It is only through that way that one can pay her fees. Some forms of sexual deviance among students, therefore, are not done on purpose. When the student, therefore, portrays a deviant behaviour towards the educator she may not mean to disrespect the teacher as such, but it may simply be his/her way of responding to things and an educator needs to understand this.

Apart from other factors like social background, it may simply be due to the developmental stage at which the student is still at. Since human development is one of the biggest contributing factors to human behavior, it is crucial for the educator to have a thorough understanding of that development for that “can be used to gear the teacher's lesson plans in order to maximize the success of students in both the academic and the social realms of their lives. This understanding can also be used to minimize problems in the classroom" (Vercillo 2012:1)

The human tendency is often to condemn what society regards as deviant behaviour and with students, this is often seen by the negative coverage in the media if a student/s happen to be caught in a sex scandal. Not only is the image of that student tarnished, the institution that the student belongs to is not spared as well. This often leads to a stigma that is attached to particular institutions of learning. Such a stigma may at times affect not only the learning process but also the delivery processes of a lecturer 
if he/she does not get to understand the nature of students he/she would be dealing with.

It is not only the educator who is provided with the platform to come up with corrective measures by an awareness of the students' deviant behaviour, the responsible authorities of the tertiary institution are given also an opportunity to create an enabling environment for such a class of people. Usually the goal of an institution is to enable all, without discrimination, who pass through it, to get the necessary skills they would need in their future as actors in the development agenda. As students leave university or any tertiary institution, they consciously or unconsciously carry with them the name of their university/institution wherever they go hence, it is important for the university/institution to ensure that it produces good, marketable products who will continue to market its name. Knowing thus the various manifestations of deviance among students will enable the school authorities to put in place measures that will benefit not only the deviant students themselves but also the institution itself. Failure to create an enabling environment spells disaster not only for the institution but also puts the development agenda of a country at risk.

Apart from enabling the school authorities to create an enabling learning environment for the type of students under discussion, deviance, even though it is often a shunned phenomenon, can actually positively contribute towards the institution in that it unites the teaching staff to come up with ways of reacting to that social ill. A student who usually fails to submit coursework in one subject area may be in the habit of doing the same in other subject areas. In such scenarios there is often success when lecturers team up together and find ways of helping the student conform to stipulated rules and regulations. Emile Durkheim was thus right when he averred that deviance clarifies norms and increases conformity, strengthens social bonds among the people reacting to the deviant, and can help lead to positive social change (Durkheim cited in Barkan 2011:9).

The need to have a good understanding of social deviance among students is also a great asset to the educator in that it enables one to stick to the objective goals of the institution which are tied to national goals. Lack of this understanding may result in the educator giving up his/her duties as an educator or taking measures which would not only endanger the education of the students themselves but also run counter to the goals set by the institution itself and the nation at large. Educators who do not understand social deviance among students may often find that they are frustrated in their working lives. A good understanding of social deviance thus 
prepares an educator to be always ready to handle any form of deviant behaviour that may be displayed by those under his/her instruction without causing unnecessary commotion in the learning process.

\section{Conclusion}

To sum up, the foregoing discussion has demonstrated that it is indeed key that the educator has a good understanding of sexuality challenges and social deviance among his students for it is only by understanding such behaviour that he/she can find a way to help them and develop a more harmonious relationship with them. Being an educationist is a multifaceted profession which does not just consist in delivering lectures to students but involves also the aspect of offering a rich, unique and enabling learning environment to every student who passes through the educator's hands so that the student would later be an asset to the development of the country. Singling out prostitution in tertiary institutions, the paper has argued that some students may engage in acts of prostitution not out of will as such but due to various circumstances. Some may be coming from single-parent-headed families and the mother or father might not be working and the student would have to work for her own fees by engaging in transactional sex. It is only through that way that one can pay her fees. Some forms of sexual deviance among students, therefore, are not done as ends but as means. When a student portrays a deviant behaviour towards the educator, he/she may not mean to disrespect the teacher as such, but it may simply be his/her way of responding to things and an educator needs to understand this. In dealing, therefore, with such students it is important for the educator to let them know that he/she really cares for them and would try every means to help them. The love and patience God should be a constant reminder to educators that they need to follow that way as well in dealing with young people since the whole teaching profession itself is not just a career to earn monies but a call they received to be carried out conscientiously in continuity of God's work. If an educator can bring them to a position where they can at least distinguish what is good or bad and apologize whenever they have done something wrong, then he/she would have moved a great mile in trying to help the students. 


\section{References}

Alvarez S. (2015). Prostitution in the Medieval City, The Medieval Magazine, http://www.medievalists.net/2015/07/prostitution-in-the-medieval-city/

Charles, R. (2002). Encyclopaedia of Crime and Justice. Retrieved from

http://www.encyclopedia.com/topic/Deviance. aspx.

Chatterii, M., Murray, N., London, D. \& Anglewicz, P. (2005). 'The factors influencing transactional sex among young men and women in 12 sub-Saharan African countries', Biodemography and Social Biology 52(1-2): 56-72.

Barkan, S. E. (2011). Sociology: Understanding and Changing the Social World. Brief Edition. Retrieved from http://catalog. flatworldknowledge.com/bookhub/reader/4306?e=barkbrief.

Downes S. (2010). The Role of the Educator. Retrieved from www.huffingtonpost.com/stephen-downes/the-role-of-the-educator_b_790937.

Dunkle et. al. (2004). 'Transactional sex among women in Soweto, South Africa: prevalence, risk factors and association with HIV infection', Social Science Q Medicine 59: 1581-1592.

Female Students Dice with Death for Survival. (2012, Jan. 19). NewsDay, Retrieved from www.newsday.co.zw/2012/01/19/2012-01-19-female-students-dice-with-death-forsurvival.

Fleischman J. (2010). Linkages between Gender, AIDS and Development: Implication for US Policy, A report of the CSIS Global Health Policy Centre, file:///E:/Linkages\%20btw\%20Gender\%20AIDS\%20\&\%20Development.pdf

FormsonC \& HilhorstD. (2016), The many faces of transactional sex: Women's agency, livelihoods and risk factors in humanitarian contexts: A Literature Review, Working Paper 41, file:///E:/transactional\%20sex\%20in\%20Southern\%20Africa.pdf

Kyriacou, C. (1997). Effective Teaching in Schools: Theory and Practice, London: Nelson Thornes.

Kumanyika, S. K., Parker, L., \& Sim, L. J. (eds) 2010, Bridging the Evidence Gap in Obesity Prevention: A Framework to Inform Decision Making,

The National Academic Pr., https://www.nap.edu/read/12847/chapter/6.

Harcourt H. M. (2016). Theories of Deviance. CliffsNotes. Retrieved from www.cliffsnotes.com/study-guides/sociology/deviance-crime-and-socialcontrol/theories-of-deviance.

Jenkins P. J. (2016). Prostitution. Encyclopaedia Britannica. Retrieved from https://www.britannica.com/topic/prostitution.

Masvawure T. (2010) 'I just need to be flashy on campus': female students and transactional sex at a university in Zimbabwe, Culture, Health \& Sexuality, An International Journal for Research, Intervention and Care, Volume 12, 2010 - Issue 8, https://www.tandfonline.com/doi/abs/10. 1080/13691050903471441

Maya M. (2015, July 8). I Had Sex With A Sugar Daddy to Help Pay My Tuition, And Here's Why I Wouldn't Do it Again. Retrieved from

https://www.bustle.com/articles/91812-i-had-sex-with-a-sugar-daddy-to-help-paymy-tuition-and-heres-why-i. 
Mitchell E. (2011, Aug. 16). Towards an Understanding of Transactional Sex and HIV Risk Among Female University Students in Fiji. In Intersections: Gender and Sexuality in Asia and the Pacific. Issue 26. Retrieved from http://intersections. anu. edu. au/issue26/mitchell.htm

Mwandayi C. (2014). Leviticus 19:33-34 -the forgotten injunction. A case study of 'alien' students in Senga and Nehosho suburbs of Gweru, Zimbabwe. In L. Togarasei, M. Gunda \& J. Kügler (Eds.), Bible and Children, Bamberg: Univ. Bamberg Pr.

Pereira G. C. (2015). An evaluation of the canonical approach: Is it adequate for the task of Old Testament theology in Christian hermeneutic endeavour? Scriptura Vol. 114, http://www.scielo.org.za/scielo.php?script=sci_arttext\&pid=S2305445X2015000100030.

Rainwater L. (Ed.), (1974). Social Problems and Public Policy: Deviance and Liberty, Chicago: Aldine Publ. Company.

Ritzer G. (Ed.), (2007). Blackwell Encyclopaedia of Sociology. Retrieved from www.blackwellreference.com/public/tocnode?id=g9781405124331_chunk_g978140 512433125_ss1-91.

STIs rife in Tertiary Colleges. (2014, March 13). The Financial Gazette. Retrieved from http://www.financialgazette.co.zw/stis-rife-in-tertiary-colleges/

Shumba A., Mapfumo J., Chademana J. (2011). The Prevalence of Concurrent Sexual Partnerships among Students in Institutions of Higher Education in Zimbabwe. Retrieved from http://www.krepublishers.com/02-Journals/JHE/JHE-34-0-000-11Web/JHE-34-1-000-11-Abst-PDF/JHE-34-1-053-11-2170-Shumba-A/JHE-34-1-05311-2170-Shumba-A-Tt.pdf.

UNESCO (2013). Young People Today, Time to Act Now, UNESCO, Paris. http://unesdoc. unesco.org/images/0022/002234/223447e.pdf

Vigurs K. (2012). The role of the teacher in higher education: exploring a learnercentred approach to teaching and learning with non-traditional HE students. Retrieved from http://www.academia.edu/1071588/.

Vercillo K. (2012, Oct. 31). Why It is Important for Teachers to Understand Child Development Stages. Retrieved from

https://hubpages.com/education/WhyTeachersMustUnderstandChildDevelopmen.

West G. O. \& Haddad B. G. (2016). Boaz as 'Sugar Daddy': Re-Reading Ruth in the Context of HIV, Journal of Theology for Southern Africa 155, Special Issue, 137-156.

Zaniest Z. (2009, March 9). Prostitution on the increase at Universities and Colleges, Students open up. Retrieved from http://iharare.co.zw/prostitution-on-the-increaseat-universities-and-colleges-students-open-up.

Zvobgo C. J. M. (1996), A History of Christian missions in Zimbabwe, 1980 - 1939, Gweru: Mambo Pr. 


\section{Notes on Authors and Editors}

ATIEMO Abamfo Ofori (PhD) is a Senior Lecturer in the Department for the Study of Religions, University of Ghana, Legon. He is a Historian of Religion and specializes in the History of Religion in West Africa. His current research interests include African Hindus in Ghana; Religion and Development; and Myth and nation Building. Among his publications are: "In Need of New Lens: An African Christian Scholar's Religious Critique of Western European Attitudes toward Religion and Development in Africa". Religion and Theology 24 (2017) 250 - 273; "Returning to our Spiritual Roots': African Hindus in Ghana Negotiating Religious Space and Identity." Journal of Religion in Africa 47 (2017) 405-437; "Hinduism, African Hindus and Neo-Hinduism: between Nomenclature and Authenticity". Philosophy and the Life-world, Vol. 18: (2016) 5-17; and Religion and the Inculturation of Human Rights in Ghana. London/New York: Bloomsbury (2013).

E-mail:abamfoatiemo@gmail.com

AWUAH-NYAMEKYE Samuel (Prof) is Associate Professor of Religion and Environment in the Department of Religion and Human Values at the University of Cape Coast in Ghana. His research interests are Religion and Environment, Environmental Ethics, Religion and Development, Religion and Politics, Religion and Women and Religion and gender issues. His publications include, "Climate change and indigenous Akan religio-cultural practices: Lessons for policy-makers and implementers in environmental conservation in Ghana". Worldviews Global Religions, Culture and Ecology 23 (1): 2019: 59-86; "The religion-humanity nexus: The Ghanaian situation”. In: Ezra Chitando \& Joram, Tarusarira (eds.), Religion and Human Security in Africa, Routledge, 2019: 48-62; Managing the Environmental Crisis in Ghana: The Role of African Traditional Religion and Culture with Special reference to Berekum Traditional Area. Cambridge Scholars Publ. Ltd, 2014; Religion and development: African Traditional Religion's perspective, Journal Religious Studies and Theology, 31(1), 2012: 75-90. awuah.nyamekye2ucc.edu.gh /

E-mail: kwasi.nysamekye@yahoo.com

BERMAN Sidney K. (Rev Dr) is currently pastoring a branch of Africa Evangelical Church in Gaborone, Botswana. He holds a PhD in Old Testament Interpretation. Dr. Berman has worked as a postdoctoral fellow at North West University and as a lecturer at the University of Botswana where he taught Old Testament studies and Hebrew language. He has published a book, articles and book chapters in the areas of Old Testament, the books of Ruth and Hosea, Bible translation studies and contemporary hermeneutics. E-mail: sydneybrmn@yahoo.co.uk

CHIMUKA Tarisayi A. (PhD) is a lecturer at the National University of Lesotho. His research interests are in History of Philosophy, Logic, Critical Thinking, African Philosophy and Epistemology. His latest publications include, "Interrogating the Death Penalty Discourse and its Hidden Dynamics in an African Context", in Fainos Mangena, Jonathan Chimakonam (Eds.), The Death Penalty from an African Perspective: Views from Zimbabwean and Nigerian Philosophers, Vernon Pr. (2018): 
167-188 - "The Conundrum of Disability and African Solutions in Education", BOLESWA - Journal of Theology, Religion and Philosophy, 4. 3, (2017): 35-50. - "The Threat of Gullibility: Faith and Christian Behaviour in Southern Africa”, Oral History Journal of South Africa, 5. 1(2017): 1-15. E-mail: chimtandy@gmail.com

CHITA Chita Joseph (MEd-RS) is a Lecturer at the University of Zambia, Lusaka, Zambia. His research interest is in Religion and Education, and some of his publications include: "Pentecostalising the Voice in Zambian Charismatic Church History: Men of God's Expression of Spiritual Identities, 1990 to Present.” Studia Historiae Ecclesiasticae 44. 3 (2018): 1-13. - "The Church's Social Responsibility in Zambia: The Catholic Response to the 2016 Prejudiced Attacks on 'Others'." Alternation - Interdisciplinary Journal for the Study of the Arts and Humanities in Southern Africa 19. (2017): 132-156. - “Trailing a Missionary Teacher's Position and Contributions in Zambian Religious Education." Religion Q Education 44. 1 (2017): 22-38. - "Navigating through institutional identity in the context of a transformed United Church of Zambia University College in Zambia” HTS Teologiese Studies/ HTS Theological Studies 73.3 (2017): 1-8. E-mail: chonochitajoseph@gmail.com

CHITANDO Ezra (Prof Dr) is a Professor in History and Phenomenology of Religion at the University of Zimbabwe and Theology Consultant/Southern Africa Regional Coordinator of the World Council of Churches Ecumenical HIV \& AIDS Initiatives and Advocacy. His research interests include method and theory in the study of religion, as well as religion and: gender, politics, security, climate change, development and leadership. With Joram Tarusarira, he has edited the volume, Religion and Human Security in Africa (2019). E-mail: chitsa21@yahoo.com

DUBE Musa W. (Prof Dr), a Humboldtian awardee (2011) and a biblical scholar, is based at the University of Botswana. She studied the New Testament in the University of Durham (UK, 1990) and the University of Vanderbilt (USA 1997). Her research interests include: gender, postcolonial, translation and HIV \& AIDS studies. She is currently a research fellow at the Department of Biblical and Ancient Studies, UNISA. E-mail: dubemw@mopipi.ub.bw

GATHOGO Julius (PhD) is a Senior Lecturer, Kenyatta University, in the Department of Philosophy and Religious Studies, School of Humanities and Social Sciences. He is widely published with over 80 refereed journals, 20 book chapters and 20 individually authored books. He is also a research fellow at UNISA, and an Academic Preceptor/Distinguished Professor at St. Alcuin, Minnesota, USA. E-mail: jumgathogo@gmail.com

GUNDA Masiiwa Ragies (Prof Dr) is an Old Testament scholar and founding co-editor of the BiAS book series. Alexander von Humboldt Foundation repeatedly granted him research stays at University of Bamberg. He is currently PSI Guest Professor at the University of Bamberg (2019-2021). His research interests are on the intersection of the Bible and Justice for the marginalized peoples of the world. His research focuses much on the multiple key populations on the African continent. 
Gunda is a Consultant on Religion, Gender and Sexuality in Africa. Among his recent publications is a monograph, At the Crossroads: A Call for Christians to Act in Faith for an Alternative Zimbabwe (BiAS 21, 2018).

E-mail: mrgunda75@gmail.com

GUSHA Ishanesu Sextus (Rev Dr) is a lecturer at the University of Zimbabwe's Department of Religious Studies, Classics, and Philosophy. He is a lecturer of New Testament studies having graduated with; PhD (University of Pretoria), MTS (Nashotah House-Wisconsin, USA), MRS, BA Hons, Diploma in Religious Studies (University of Zimbabwe), and Diploma in Pastoral Studies (Bishop Gaul College). He is passionate about Peace Building and Reconciliation, especially from the Interfaith Dialogue perspective. His research interests are; biblical theology, conflict resolution, peace building, dialogue facilitation, identity, and environment.

HARON Muhammed (Prof Dr) is attached to the University of Botswana's Theology \& Religious Studies Department where he is Professor of Religious Studies. Haron was formerly associated with the University of the Western Cape where he taught Arabic Studies and at the University of Cape Town where he taught Islamic Studies. Currently, Haron is an Associate Researcher at the University of Stellenbosch; he was formerly attached, in the same capacity, to the Universities of Johannesburg and Pretoria respectively. During 2018 (April-May) he was a visiting International Relations' Professor at Rhodes University; and prior to this he was also a visiting lecturer at UKM (1993/1994), Rhodes (2008), and Stellenbosch (2008). He co-edited Proceedings of the 2016 Islamic Civilization in Southern Africa Congress (Istanbul 2018/9 [in Pr.]). E-mail: haronm@mopipi.ub.bw

JOHN Sokfa F. (PhD) is a postdoctoral research fellow at the University of KwaZuluNatal. His current research is on the articulation of religious worldviews with civil rights in South African digital cultures. His areas of specialization and research interests are ethnic and religious conflicts in Africa, digital humanities and cultures, algorithms and datafication in religion and humanities.

E-mail:sokfa.john@gmail.com

KAUNDA Chammah J. (Prof Dr) is Professor in World Christianity in College of Theology/ United Graduate School of Theology, Yonsei University. Kaunda has authored more than 70 peer reviewed journal articles and book chapters, published both locally and internationally within World Christianity, African Theologies, African Pentecostalism, African Religions, Ecumenical Theology and Missiology. His recent book: "The Nation that Fears God Prospers": Zambian Pentecostalism and Politics (Fortress, 2018). E-mail: pastorchammah@gmai.com

KAUNDA Mutale Mulenga (PhD) is a Post Doctoral Research Fellow at the University of KwaZulu-Natal, as well as a writing mentor to graduate students in the Gender, Religion and Health programme at UKZN. Her research focus is on the intersections of gender, sexuality, religion, culture and women's work in Africa. The most recent article is co-published with Chammah J. Kaunda "Infunkutu (Sexual Dance) 
and Bemba Women's Sexual Agency," Journal of Theology for Southern Africa, 155 (July 2016 Special Issue: Sexuality in Africa): 159-175.

KILONZO Susan Mbula (PhD) is a Senior Lecturer at Maseno University, Kenya. Her doctorate and Master's degrees are in sociology of religion. She also holds eleven postgraduate certificates from professional development trainings in gender studies, peace \& conflict studies, research methods, political economy analysis, policy engaged research, case writing \& teaching, among others. Susan has held research fellowship positions at: The Open University, Milton Keynes, UK; New Europe College, Bucharest; University for Peace (UPEACE), among others. Through these fellowships and other researches, Susan has over fifty publications - journal articles, book chapters, books and research reports. The latest publications appear in Routledge Taylor \& Francis Group (Global Africa, 2018), IDS-UK Bulletin (2017); Journal of Public Affairs Education (2016); Journal for the Study of Religions in Africa and its Diaspora (2015); and, African Conflict \& Peacebuilding Review ACPR (2015). She is a member of different professional bodies and journal editorial boards. She has also accumulated a wealth of experience in mixed method research, an area she has trained for research organizations at professional development level.

KIRIAGHE Uzziah Maate (Rev. Canon Dr.) is a Priest in the Anglican Church of Uganda and a Senior Lecturer in the Department of Development Studies at Uganda Christian University, based at the main campus in Mukono. He holds a Bachelor's degrees in Social Work and Social Administration (Makerere University); Bachelor of Divinity (ATIEA); Master of Theology in Theology and Development (Edinburgh University); Master of Arts and PhD in Community Economic Development (Southern New Hampshire University - USA). He has wide experience in planning, management and implementation of community-based development initiatives under the Church. His academic specialty is in Governance and Development. He is passionate about holistic development as the mandate of the Christian Church in service to communities.

KÜGLER Joachim (Dr. theol. habil.) is a Professor for New Testament Studies at OttoFriedrich-University Bamberg (Germany) since 2008. Before that he was Pro $\neg$ fessor at Bayreuth University (1999-2008). He is one of the founding editors of "Bible in Africa Studies" (BiAS) series and of the sub-series ERA. His research focusses on the Gospel of John but comprises also religio-historical contexts of the NT, and biblical gender studies. E-mail: joachim.kuegler@uni-bamberg.de

MACHINGURA Francis (Prof Dr) is the Chairperson and an Associate Professor (Biblical Studies) at the University of Zimbabwe, Curriculum and Arts Education Department, Faculty of Education. He is a specialist in Biblical Studies. His areas of special interest are on the: Interaction of the Bible and Gender, Politics, Health, Inclusivity, Sexuality, Music and Pentecostal Christianity in Africa. He has published books, articles and chapters. E-mail: fmachingura@yahoo.com 
MASEKO Lindiwe $P$. is a graduate from Midlands State University holding a Bachelor of Arts in Theology and Religious Studies Honors Degree. She is currently studying her postgraduate degree in Gender and Religion in the school of Religion, Philosophy and Classics, at the University of KwaZulu Natal in South Africa. Her areas of interest are Religion and Gender, Peace and Justice, Human security and $\mathrm{Hu}$ man Rights. E-mail: lindyprincessmaseko@gmail.com

MASENO Loreen (PhD) is a Senior Lecturer at the Department of Religion, Theology and Philosophy, Maseno University, Kenya. She is also a Research Fellow, Department of Biblical and Ancient Studies, University of South Africa. Her research interests include, Gender and Religion, Securitization, Feminist Ecology, Religion and Development. Recently a Humboldt Fellow, she is co-editor of The Bible and Sociological Contours: Some African Perspectives: Festschrift for Professor Halvor Moxnes (New York: Peter Lang, 2018) and author of, among others, "Framing Freedom of Religion or Belief for Countering Violent Extremism in Kenya: The Equivalency Framework of the Evangelical Alliance of Kenya. " The Review of Faith \& International Affairs. (2018). Vol. 16, No. 4, 75-87 and “'The Glory Is Here'! Faith Brands and Rituals of Self-Affirmation for Social Responsibility in Kenya”. Alternation Journal (2017). Vol. 19: 252-267. E-mail: loreenmas@gmail.com

MUNHENZVA Petronella is a postgraduate student and a Graduate Teaching Assistant in the Department of Economic History at the University of Zimbabwe. She is a researcher with a keen interest in colonial and post-colonial state policies. Her primary research interest is the role of the state in land distribution and land conflicts. She has explored and written about the Zimbabwe 2000 Fast Track Land Reform, analysing the dynamic farmer-miner relationships revolving around tenancy, land ownership and distribution in the light of inconsistent state policies.

E-mail: pettymunhenzva@gmail.com

MOTSWAPONG Elizabeth $P$. (PhD) is a Senior Lecturer in the Department of Theology and Religious Studies at the University of Botswana, Gaborone, Botswana. Her research fields are: Indian Religions with a Concentration in Hindu Studies, HIV \& AIDS, Gender in Comparative Religions and Queer Studies. Her publications include, "A Little Baby is on the Way: Botho/Ubuntu and Community Building in Gaborone Baby Showers. " Gender Studies (GS) Vol. 14/1 (2018): 83-94. "Understanding Draupadi as a Model of Gender and Resistance," Stellenbosch Theology Journal, Vol 3, No 2, (2017): 477-492. "Zero Stigma, Zero Discrimination and Zero Infection: A Farfetched Dream for Botswana.” Alternation Journal, Vol. 23,2 (2016): 105-119. “Sita's Story as a Text of Terror: A Motswana Woman's Impressions”, in Unravelling and Reweaving Sacred Canon in Africana Womanhood eds. Rossetta Ross \& R. S. Amenga- Etego, 153-166 (NY: Lexington Books, 2015) and "Lesbians and Gays in Botswana: Surviving Behind the Mask", 336-340, in Queering Paradigms ed. Burkhard Scherer (Frankfurt/M: Peter Lang, 2009).

E-mail: motswaponge@mopipi.ub.bw 
MWALE Nelly (MEd-RS) is a lecturer at the University of Zambia, Lusaka, Zambia. Her research fields are religion and education, church history and African Indigenous Religions. Her publications include, "125 Years of Catholicism in Zambia: The History and Mission of the Church in the Provision of University Education" Oral History Journal of South Africa 6. 1. (2018): 1-16. - "Liturgy and Identity in Zambian Traditional Ceremonies in the $21^{\text {st }}$ Century," in: Liturgy and Identity: African ReligioCultural and Ecumenical Perspectives. Ed. by R. Hewitt \& L. C. Siwila (2018), 135151. - "Trailing a Missionary Teacher's Position and Contributions to Zambian Religious Education.” Religion and Education Journal 44. 1(2017): 22-38 (with Chita, J). - "Religious pluralism and Disability in Zambia: Approaches and Healing in Selected Pentecostal Churches." Studia Historiae Ecclesiasticae 42. 2 (2016): 53-71. - "Religion and Development in Zambia: The Role of the Roman Catholic Church in Political Development, 1890-1964." Interdisciplinary Journal for the Study of the Arts and Humanities in Southern Africa (Alternation), 1 (2013): 110-33.

E-mail:nelmwa@gmail.com

MWANDAYI Canisius (PhD) is currently a senior lecturer in the Department of Religious Studies at Midlands State University, Zvishavane. His research interests include: Inculturation, Cultural Hermeneutics \& Old Testament Interpretation. His publications include: 'The silent 'machoman' in the house: the case of women in Biblical and African societies, in 'Rethinking Women Empowerment in post-independent Zimbabwe in LASU Journal of Religions and Peace Studies (JOREPS) 2018; 'Towards a Reform of the Christian Understanding of Shona Traditional Marriages in Light of Ancient Israelite Marriages. 'Studia Historiae Ecclesiasticae, 2017; 'Biblical perspectives on health and well-being Navigating Shona traditional ways of healing and well-being' in H. Moyo \& B. Okyere-Manu (eds), Intersecting African Indigenous Knowledge Systems and Western Knowledge Systems: Moral Convergence and Divergence, Cluster Publications, 2018; 'A forgiven Sinner? Robert Mugabe and the strained Catholic relations, in Mawere, Duri (eds) The End of An Era? Robert Mugabe and a Conflicting Legacy, 2018. E-mail: canisiusm@gmail.com

NDZOVU Hassan J. (PhD) is a Senior Lecturer of Religious Studies at Moi University, Kenya. His research interests focus on Islam in sub-Saharan Africa, revolving around religion and politics and religious based conflict. His publications include, Muslims in Kenyan Politics: Political Involvement, Marginalization and Minority Status. Evanston: Northwestern University Pr., (2014). "The Status of those with Non-Normative Sexual Identities in African Muslim Communities", in The Global Encyclopedia of Lesbian, Gay, Bisexual, Transgender and Queer (LGBTQ) History. Ed. by Howard Chiang et al (2019), 851-856. "Kenya's Jihadi Clerics: Formulation of a 'Liberation Theology' and the Challenges to Secular Power" Journal for Muslim Minority Affairs. 38.3 (2018): 1-12. E-mail: ndzovuhassan@hotmail.com

NYAHUMA Blessing is a PhD-candidate (New Testament Studies) with the University of Bamberg (Funded through DAAD scholarship) He Holds a BA from Solusi University, BA Hons, and MA from the University of Zimbabwe. He is an ordained 
pastor in the Seventh-day Adventist Church. His research interests include, Religion and Development, Gender Studies, Socio-historical exegesis and Apocalypticism. E-mail: psnyahuma@gmail.com

NYAWO Sonene $(\mathrm{PhD})$ is a Senior Lecturer in the Department of Theology and Religious Studies at the University of Eswatini (UNESWA), Eswatini. Her research fields are gender and religion, and African culture. Her publications include; "Socio-cultural religious reflections on women fertility and their implications in the context of HIV \& AIDS in Swaziland," BOLESWA Journal of Theology, Religion and Philosophy, (2018): 101-112; "Christians' cut: popular religion and the global health campaign for medical male circumcision in Swaziland," Culture, Health a Sexuality, Taylor \& Francis, (2017): 844-558; "Are Prayers a Panacea for Climate Uncertainties? An African Traditional Perspective from Swaziland," The Ecumenical Review "Praying for Rain? African Perspectives on Religion and Climate Change" (2017); "Reflections on women's political participation and representation in the post constitutional era (2005-2015)," UNISWA Research Journal, Volume 28, (2015): 1-13; 'Having No Child is Like Having No Home': Exploring the Notion of 'Complete Personhood' in Selected Swazi Women's Narratives on Fertility," Journal of Gender and Religion in Africa Vol. 21 No. 1. (2015): 127-151 and Religious Education Learners Books (4 series). Matsapha: Macmillan Swaziland National Publ. Company (2017). E-mail: snyawo@uniswa.sz

OMONA Andrew David (PhD) is a Senior Lecturer and Head of Department at Uganda Christian University, a National Coordinator for Religious Leaders' Justice and Peace Network, a Researcher, Transitional Justice Fellow and a Trainer of Trainers in Peace-building and Conflict Resolution in the East and Greater Horn of Africa. He holds a PhD in Political Studies/International Relations and Diplomacy, MA International Relations and Diplomacy, MA Theology, BA with Education, and several specialized Diplomas and Certificates. He has done extensive research on conflicts in Africa, the Great Lakes Region and Uganda in particular. His current research interest is in Transitional Justice, Peace-building and Conflict Resolution, and Ethics. He has done collaborative research with people from across the world and still looks forward to getting researchers to collaborate with in his areas of expertise. E-mail:adomona3@gmail.com

SIWILA Lilian C. (Prof Dr) is an Associate Professor of Theology in the School of Religion, Philosophy and Classics at the University of KwaZulu-Natal, South Africa. She is an active member of the Circle of Concerned African Women Theologians. She has published widely in the areas of Gender and Culture, African Feminism and Ecclesiology, Sexual and reproductive health and its interface with Religion and women, Social and economic trends in contemporary theologies, Gender and Liturgy, as well as Religion, sacred spaces and ecology. One of her latest publications is: Siwila LC and Hewitt R. (eds.), 2018. Liturgy and Identity: African Religiocultural and ecumenical perspective. Pietermaritzburg: Cluster Publication. E-mail: siwilach15@gmail.com 
TARINGA Beatrice (PhD) holds a doctorate in Education from the University of Zimbabwe. She is a senior lecturer in Research and Contemporaray Subjects at Belvedere Technical Teachers' College, Harare in Zimbabwe. Her research interests are on Gender Representation in ChiShona Literature Texts, as well as Curriculum Issues in Education, Gender and Education, Culture and Education, Developments in African Languages, Socio-Linguistics, Education and Development and Language Education. She has published in the area of Gender and Education.

E-mail: taringabeatrice@gmail.com

TARINGA Nisbert Taisekwa (Prof Dr), a Fulbright scholar, was an Associate Professor of Religious Studies at the University of Zimbabwe. He held a PhD in Religious Studies (University of Zimbabwe), MA in Intercultural Theology (Radboud University, The Netherlands) and MA in Religious Studies (University of Zimbabwe). He was a member of the American Academy of Religion, Bayreuth Academy of Advanced African Studies (Germany), Communities Engaging with Difference and Religion, African Consortium for Law and Religion Studies and the African Association for the Study of Religion. He has published a book, Towards and African-Christian Environmental Ethic (UBP 2014) and many book chapters and journal articles on religions and contemporary issues such as ecology, development, gender, HIV \& AIDS, sexuality, animals in religions, religions and reconciliation, peace and conflict resolution, and human rights.

TOGARASEI Lovemore (Prof Dr) is a Professor of Theology and Religious Studies at the University of Botswana where he teaches courses in Biblical Studies. His research interests lie in the area of the Bible and African Christianity, especially Pentecostal Christianity. He has published widely, addressing such issues as the gospel of prosperity, leadership, health, politics and popular culture. Among his latest publications is an edited volume, Aspects of Pentecostal Christianity in Zimbabwe (2018). E-mail: ltogarasei@yahoo.com 


\section{The BiAS book series at University of Bamberg Press}

All volumes of BiAS series

are available

online

at

- http://www.uni-bamberg.de/ubp/verlagsprogramm/reihen/bible-in-africa-studies/ (informations and overview of the series)

- https://fis.uni-bamberg.de/cris/series/series00016/seriespublications.html (download of the full texts)

We will always keep you updated

if you follow us here:

- http://uni-bamberg.academia.edu/BiasSeries (information, additional texts, tables of matters, download links; pre-print versions) 


\section{Previously published volumes of the BiAS series}

1. The Bible in Context: Essay Collection / by Lovemore Togarasei, Bamberg: UBP, 2009

https://nbn-resolving.org/urn:nbn:de:bvb:473-opus-2131

2. Reign with Him for Thousand Years (Rev 20:6):

A Socio-Hermeneutical Exposition of Biblical and Contemporary Millenarian

Movements in Zimbabwe as Radical Responses to Deprivation

/ by David Bishau, Bamberg: UBP, 2010

https://nbn-resolving.org/urn:nbn:de:bvb:473-opus-2457

3. The Bible and Homosexuality in Zimbabwe:

A Socio-historical analysis of the political, cultural and Christian arguments in the homosexual public debate with special reference to the use of the Bible / by Masiiwa R. Gunda, Bamberg: UBP, 2010

https://nbn-resolving.org/urn:nbn:de:bvb:473-opus-2522

4. From Text to Practice: The role of the Bible in daily living of African people today / ed. by Joachim Kügler \& Masiiwa R. Gunda, $2^{\text {nd }}$ ed., rev. \& expanded, Bamberg: UBP, 2013

https://nbn-resolving.org/urn:nbn:de:bvb:473-opus4-20465

5. Pauvreté ou paupérisation en Afrique : une étude exegético-ethique de la pauvreté chez les Beti-Fang du Cameroun / par Jacques F. Owono,

Bamberg : UBP, 2011

https://nbn-resolving.org/urn:nbn:de:bub:473-opus-3259

6. Death and After-life Rituals in the eyes of the Shona: Dialogue with Shona

Customs with the Quest for Authentic Inculturation / by Canisius Mwandayi, Bamberg: UBP, 2011

https://nbn-resolving.org/urn:nbn:de:bvb:473-opus-3336

7. The Bible and Politics in Africa / ed. by Masiiwa R. Gunda \& Joachim Kügler, Bamberg: UBP, 2012

https://nbn-resolving.org/urn:nbn:de:bvb:473-opus4-4726

8. The Messianic Feeding of the Masses: An Analysis of John 6 in the Context of Messianic Leadership in Post-Colonial Zimbabwe / by Francis Machingura, Bamberg: UBP, 2012

https://nbn-resolving.org/urn:nbn:de:bvb:473-opus-4032 
9. HIV/AIDS and the Bible in Tanzania: A Contextual Re-reading of 2 Samuel 13:1-14:33 / by Mussa S. Muneja, Bamberg: UBP, 2012 https://nbn-resolving.org/urn:nbn:de:bvb:473-opus4-9957

10. Aluta continua biblical hermeneutics for liberation: Interpreting biblical texts on slavery for liberation of Zimbabwean underclasses / by Obvious Vengeyi, Bamberg: UBP, 2013

https://nbn-resolving.org/urn:nbn:de:bvb:473-opus4-37641

11. The Book of Ruth from a Lomwe perspective: hesed and ikharari / by Justino M. Alfredo, Bamberg: UBP, 2013 https://nbn-resolving.org/urn:nbn:de:bvb:473-opus4-50966

12. Prophets, profits and the Bible in Zimbabwe: Festschrift for Aynos M. Moyo / ed. by Ezra Chitando, Masiiwa R. Gunda \& Joachim Kügler, Bamberg: UBP, 2013

https://nbn-resolving.org/urn:nbn:de:bvb:473-opus4-55996

13. Towards an African-Christian Environmental Ethic / by Nisbert T. Taringa, Bamberg: UBP, 2014

https://nbn-resolving.org/urn:nbn:de:bvb:473-opus4-64812

14. Beyond Making Money: The Prophetic Songs of Paul Dzampah from Ghana; Edition, Introduction, and Annotations / by Joachim Kügler, Bamberg: UBP, 2014 https://nbn-resolving.org/urn:nbn:de:bvb:473-opus4-101753

15. Multiplying in the Spirit: African Initiated Churches in Zimbabwe / ed. by Ezra Chitando, Masiiwa R. Gunda \& Joachim Kügler, Bamberg: UBP, 2014 https://nbn-resolving.org/urn:nbn:de:bvb:473-opus4-105096

16. Analysing the Frames of a Bible: The Case of the Setswana Translations of the Book of Ruth / by Sidney K. Berman, Bamberg: UBP, 2014 https://nbn-resolving.org/urn:nbn:de:bvb:473-opus4-250198

17. The Bible and Children in Africa

/ Lovemore Togarasei \& Joachim Kügler (eds.), Bamberg: UBP, 2014 https://nbn-resolving.org/urn:nbn:de:bvb:473-opus4-252876

18. On the Public Role of the Bible in Zimbabwe: Unpacking Banana's "re-writing" call for a socially and contextually relevant Biblical Studies / by Masiiwa R. Gunda, Bamberg: UBP, 2015 https://nbn-resolving.org/urn:nbn:de:bvb:473-opus4-255608 
19. Offering the Gospel ADAPANON: An interpretation and application of 1 Corinthians 9:18 / by Johannes M. Wessels / Ed. \& provided with a foreword by Joachim Kügler, Bamberg: UBP, 2015 https://nbn-resolving.org/urn:nbn:de:bvb:473-opus4-264687

20. The Bible and Violence in Africa: Papers presented at the BiAS meeting 2014 in Windhoek (Namibia), with some additional contributions / Johannes Hunter \& Joachim Kügler (eds.), Bamberg: UBP, 2016 https://nbn-resolving.org/urn:nbn:de:bvb:473-opus4-461656

21. At the Crossroads: $A$ Call to Christians to Act in Faith for an Alternative Zimbabwe / by Masiiwa R. Gunda, Bamberg: UBP, 2018 https://doi.org/10.20378/irbo-53039

22. The Bible and Gender Troubles in Africa: Papers presented at the BiAS meeting 2016 in Harare (Zimbabwe) with some additional contributions / Joachim Kügler, Rosinah Gabaitse, Johanna Stiebert (eds.), Bamberg: UBP, 2019

https://doi.org/10.20378/irbo-54678

23. ERA 2 | Abundant Life and Basic Needs: African Religions as a Resource for Sustainable Development / by Bednicho Nyoni, Bamberg: UBP, 2019

https://doi.org/10.20378/irbo-54768

24. ERA 3 | African Pentecostalism, the Bible, and Cultural Resilience: The Case of the ZAOGA / by Kudzai Biri, Bamberg: UBP, 2020

http://dx.doi.org/10.20378/irb-47003 


\section{University \\ of Bamberg \\ Press}

What is development? Who defines that one community/ country is "developed", while another community/ country is "under-developed"? What is the relationship between religion and development? Does religion contribute to development or underdevelopment in Africa? These and related questions elicit quite charged reactions in African studies, development studies, political science and related fields. Africa's own history, including the memory of marginalisation, slavery and exploitation by global powers ensures that virtually every discussion on development is characterised by a lot of emotions and conflicting views. In this volume scholars from various African countries and many different religions and denominations contribute to this debate.

The editors and authors

E. CHITANDO (Zimbabwe), M. R. GUNDA (Zimbabwe/ Germany), L. TOGARASEI (Botswana), J. KÜGLER (Germany), A. O. ATIEMO (Ghana), S. AWUAH-NYAMEKYE (Ghana), S. K. BERMAN (Botswana), T. A. CHIMUKA (Lesotho), C. J. CHITA (Zambia), M. W. DUBE (Botswana), J. GATHOGO (Kenya), I. S. GUSHA (Zimbabwe), M. HARON (Botswana/ South Africa), S. F. JOHN (South Africa), C. J. KAUNDA (Zambia), M. M. KAUNDA (South Africa), S. M. KILONZO (Kenya), U. M. KIRIAGHE (Uganda), F. MACHINGURA (Zimbabwe), L. P. MASEKO (South Africa), L. MASENO (Kenya), P. MUNHENZVA (Zimbabwe), E. P. MOTSWAPONG (Botswana), N. MWALE (Zambia), C. MWANDAYI (Zimbabwe), H. J. NDZOVU (Kenya), B. NYAHUMA (Zimbabwe/ Germany), S. NYAWO (Swaziland), A. D. OMONA,(Uganda), L. C. SIWILA (South Africa), B. TARINGA (Zimbabwe), N. T. TARINGA (Zimbabwe).

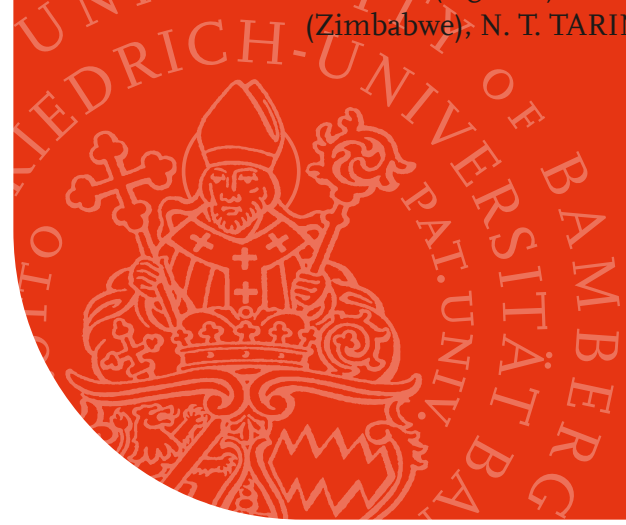

ISBN: 978-3-86309-736-3

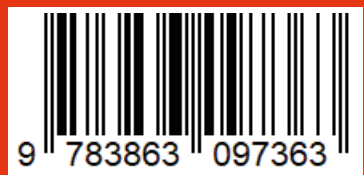

www.uni-bamberg.de/ubp 